CLAUDIO MASSUMI ODA NISHIMURA

\title{
ANÁLISE COMPARATIVA DE ALGORITMOS DE CORRELAÇÃO LOCAL BASEADOS EM INTENSIDADE LUMINOSA
}

\author{
Dissertação apresentada à Escola \\ Politécnica da Universidade de São Paulo \\ para a obtenção de Título de Mestre em \\ Engenharia
}


ANÁLISE COMPARATIVA DE ALGORITMOS DE CORRELAÇÃO LOCAL BASEADOS EM INTENSIDADE LUMINOSA

Dissertação apresentada à Escola Politécnica da Universidade de São Paulo para a obtenção de Título de Mestre em Engenharia

Área de Concentração:

Engenharia Mecânica

Orientador:

Prof. Dr. Lucas Antonio Moscato 
Este exemplar foi revisado e alterado em relação à versão original, sob responsabilidade única do autor e com a anuência de seu orientador.

São Paulo, 30 de maio de 2008.

Assinatura do autor

Assinatura do orientador

FICHA CATALOGRÁFICA

Nishimura, Claudio Massumi Oda

Análise comparativa de algoritmos de correlação local baseados em intensidade luminosa / C.M.O. Nishimura. -- ed.rev.

-- São Paulo, 2008.

$200 \mathrm{p}$.

Dissertação (Mestrado) - Escola Politécnica da Universidade de São Paulo. Departamento de Engenharia Mecatrônica e de Sistemas Mecânicos.

1.Robótica 2.Visão estéreo 3.Análise de correlação I.Universidade de São Paulo. Escola Politécnica. Departamento de Engenharia Mecatrônica e de Sistemas Mecânicos II.t. 


\section{DEDICATÓRIA}

Aos meus pais, pelo apoio constante

e incondicional, sem os quais este sonho jamais se tornaria realidade. 


\section{AGRADECIMENTOS}

Ao professor Lucas Antonio Moscato, pelo apoio ao longo do desenvolvimento deste trabalho. 


\section{RESUMO}

Este trabalho apresentou uma análise comparativa de algumas técnicas de correlações locais baseadas em intensidade luminosa, as quais são: Soma das Diferenças Absolutas, Soma dos Quadrados das Diferenças, Correlação Cruzada Normalizada, Transformada Rank e Transformada Censo. Para as comparações foram adotadas imagens estéreos disponíveis em repositórios de universidades e suas variantes com a inclusão de ruído e variação de intensidade luminosa. Após a implementação dos algoritmos escolhidos e a comparação de seus resultados, foi obtido que a Transformada Censo é um dos métodos com os piores resultados apresentando grande quantidade de correlações erradas. Foram apresentadas modificações para melhorar a performance desse método e os resultados obtidos foram melhores.

Palavras chave: Robótica. Visão estéreo. Técnicas de correlação. Transformada Censo. Transformada Modificada 


\section{ABSTRACT}

This work presents a comparative analysis of some local area intensity based correlation algorithm, which are: Sum of Absolute Differences, Sum of Squared Differences, Normalized Cross-Correlation, Rank Transform and Census Transform. For the tests stereo data sets are adopted. These data sets are available at universities websites and their variants with the inclusion of noise and variation of luminosity are created. After implementing the chosen algorithms a comparison were performed and the Census Transform was one of the methods that got the worst results showing large quantity of false correlations. On this work was presented some modifications to improve the performance of the Census Transform and the results obtained were better than the original Census Transform.

Keywords: Robotic. Stereo vision. Correlation techniques. Census Transform. Modified Transform 


\section{LISTA DE FIGURAS}

Figura 2.1: Exemplo da aplicação da Transformada Censo em uma janela ...........33

Figura 2.2: Distância "Hamming" entre dois vetores..................................... 33

Figura 3.1: Exemplo da aplicação da Transformada Modificada 1........................ 39

Figura 3.2: Exemplo da aplicação da Transformada Modificada 2 ....................... 40

Figura 3.3: Imagens do Corredor original e contaminadas com ruído de

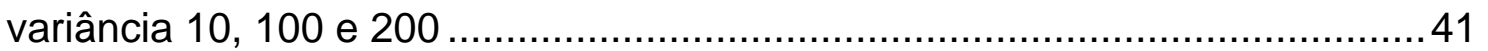

Figura 3.4: Imagens Teddy original e contaminadas com ruído de

variância 10, 100 e 200

Figura 3.5: Imagens Cones original e contaminadas com ruído de

variância 10, 100 e 200 42

Figura 3.6: Efeito da mudança do limiar na imagem original ............................. 43

Figura 3.7: Efeito da mudança do limiar na imagem com ruído de variância 10 .....44

Figura 3.8: Efeito da mudança do limiar na imagem com ruído de variância 100 ...44

Figura 3.9: Efeito da mudança do limiar na imagem com ruído de variância 200 ...45

Figura 3.10: Região escolhida para o exemplo do cálculo do limiar....................46

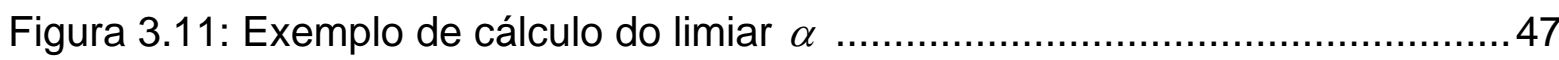

Figura 4.1: Esquema da implementação dos algoritmos..................................49

Figura 4.2: Regiões escolhidas na imagem do Corredor..................................50

Figura 4.3: Regiões escolhidas na imagem Teddy .......................................... 50

Figura 4.4: regiões escolhidas na imagem Cones........................................ 51

Figura 4.5: Imagens do corredor obtidas do repositório da Universidade de Bonn .53

Figura 4.6: Região utilizada para o cálculo do limiar na imagem do corredor .........53

Figura 4.7: Correlações erradas na imagem original do corredor........................54

Figura 4.8: Erro RMS das correlações na imagem original do corredor ..................55

Figura 4.9: Imagem esquerda com luminosidade 10\% menor ............................56

Figura 4.10: Correlações erradas na imagem do corredor com luminosidade $10 \%$ diferente .....

Figura 4.11: Erro RMS das correlações na imagem do corredor com luminosidade

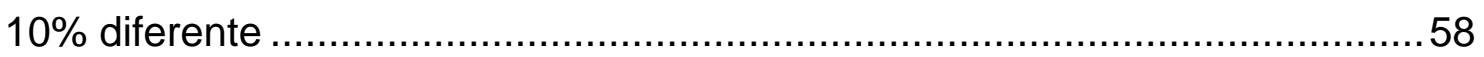

Figura 4.12: Imagem esquerda com luminosidade $20 \%$ menor .........................58 
Figura 4.13: Correlações erradas na imagem do corredor com luminosidade $20 \%$ diferente

Figura 4.14: Erro RMS das correlações na imagem do corredor com luminosidade $20 \%$ diferente 59

Figura 4.15: Imagem esquerda com luminosidade 30\% menor 60

Figura 4.16: Correlações erradas na imagem do corredor com luminosidade $30 \%$ diferente 61

Figura 4.17: Erro RMS das correlações na imagem do corredor com luminosidade $30 \%$ diferente 61

Figura 4.18: Imagens contaminadas com ruído de variância 10 62

Figura 4.19: Correlações erradas na imagem do corredor com ruído de variância 10

Figura 4.20: Erro RMS das correlações na imagem do corredor com ruído de variância 10 63

Figura 4.21: Imagens contaminadas com ruído de variância 100 64

Figura 4.22: Correlações erradas na imagem do corredor com ruído de variância 100 64

Figura 4.23: Erro RMS das correlações na imagem do corredor com ruído de variância 100 65

Figura 4.24: Imagens contaminadas com ruído de variância 200 em 50\% da imagem. 65

Figura 4.25: Correlações erradas na imagem do corredor com ruído de variância 200 e incidência 50\% 66

Figura 4.26: Erro RMS das correlações na imagem do corredor com ruído de variância 200 e incidência 50\% . 66

Figura 4.27: Imagens contaminadas com ruído de variância 200 67

Figura 4.28: Correlações erradas na imagem do corredor com ruído de variância 200 . 68

Figura 4.29: Erro RMS das correlações na imagem do corredor com ruído de variância 200 68

Figura 4.30: Imagens do Teddy obtidas do repositório de Middlebury 69

Figura 4.31: Região utilizada para o cálculo do limiar na imagem do Teddy.... 69

Figura 4.32: Correlações erradas na imagem Teddy original 70 
Figura 4.33: Erro RMS das correlações na imagem Teddy original .....................71

Figura 4.34: Imagem esquerda com luminosidade $10 \%$ menor .........................72

Figura 4.35: Correlações erradas na imagem Teddy com luminosidade 10\%

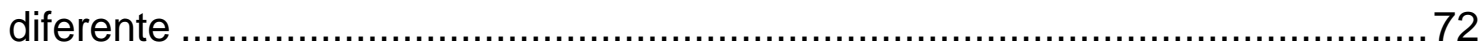

Figura 4.36: Erro RMS das correlações na imagem Teddy com luminosidade 10\% diferente

Figura 4.37: Imagem esquerda com luminosidade 20\% menor 73

Figura 4.38: Correlações erradas na imagem Teddy com luminosidade $20 \%$ diferente 74

Figura 4.39: Erro RMS das correlações na imagem Teddy com luminosidade 20\% diferente .74

Figura 4.40: Imagem esquerda com luminosidade 30\% menor 75

Figura 4.41: Correlações erradas na imagem Teddy com luminosidade 30\% diferente 76

Figura 4.42: Erro RMS das correlações na imagem Teddy com luminosidade 30\%

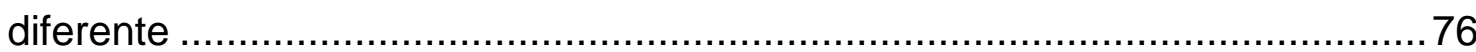

Figura 4.43: Imagens contaminadas com ruído de variância 10 ........................77

Figura 4.44: Correlações erradas na imagem do Teddy com ruído de variância 1078 Figura 4.45: Erro RMS das correlações na imagem Teddy com ruído de variância 10 78

Figura 4.46: Imagens contaminadas com ruído de variância 100 79

Figura 4.47: Correlações erradas na imagem Teddy com ruído de variância 100 .. 80 Figura 4.48: Erro RMS das correlações na imagem Teddy com ruído de variância 100 80

Figura 4.49: Imagens contaminadas com ruído de variância 200 em 50\% da imagem.

Figura 4.50: Correlações erradas na imagem Teddy com ruído de variância 200 e incidência 50\%

Figura 4.51: Erro RMS das correlações na imagem Teddy com ruído de variância 200 e incidência 50\% 82

Figura 4.52: Imagens contaminadas com ruído de variância 200 .82

Figura 4.53: Correlações erradas na imagem Teddy com ruído de variância 200 .. 83 
Figura 4.54: Erro RMS das correlações na imagem Teddy com ruído de

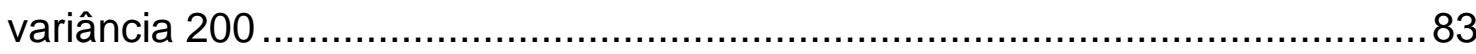

Figura 4.55: Imagens dos Cones obtida do repositório de Middlebury..................84

Figura 4.56: Região utilizada para o cálculo do limiar na imagem dos Cones ........84

Figura 4.57: Correlações erradas na imagem Cones original .............................. 85

Figura 4.58: Erro RMS das correlações na imagem Cones original ...................... 86

Figura 4.59: Imagem esquerda com luminosidade 10\% menor .......................... 86

Figura 4.60: Correlações erradas na imagem Cones com luminosidade $10 \%$

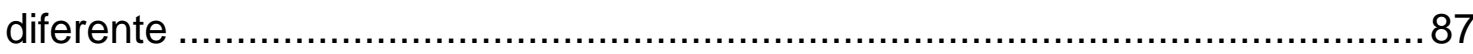

Figura 4.61: Erro RMS das correlações na imagem Cones com luminosidade 10\%

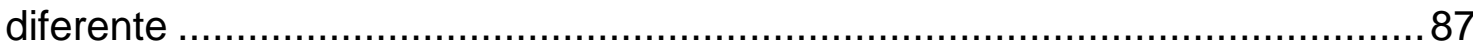

Figura 4.62: Imagem esquerda com luminosidade $20 \%$ menor .......................... 88

Figura 4.63: Correlações erradas na imagem Cones com luminosidade 20\% diferente 88

Figura 4.64: Erro RMS das correlações na imagem Cones com luminosidade 20\%

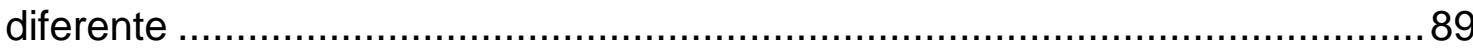

Figura 4.65: Imagem esquerda com luminosidade $30 \%$ menor ......................... 89

Figura 4.66: Correlações erradas na imagem Cones com luminosidade 30\% diferente 90

Figura 4.67: Erro RMS das correlações na imagem Cones com luminosidade $30 \%$ diferente 91

Figura 4.68: Imagens contaminadas com ruído de variância 10 91

Figura 4.69: Correlações erradas na imagem do Cones com ruído de variância 10

Figura 4.70: Erro RMS das correlações na imagem Cones com ruído de variância 10 92

Figura 4.71: Imagens contaminadas com ruído de variância 100 .93

Figura 4.72: Correlações erradas na imagem Cones com ruído de variância 100..93 Figura 4.73: Erro RMS das correlações na imagem Cones com ruído de variância 100 94

Figura 4.74: Imagens contaminadas com ruído de variância 200 em 50\% da imagem. 
Figura 4.75: Correlações erradas na imagem Cones com ruído de variância 200 e

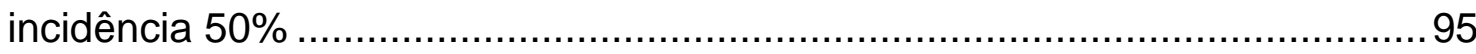

Figura 4.76: Erro RMS das correlações na imagem Cones com ruído de

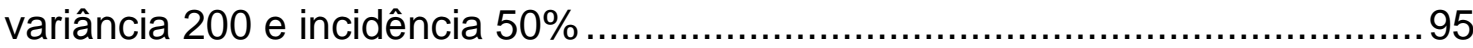

Figura 4.77: Imagens contaminadas com ruído de variância 200 ........................96

Figura 4.78: Correlações erradas na imagem Cones com ruído de variância 200.. 97

Figura 4.79: Erro RMS das correlações na imagem Cones com ruído de

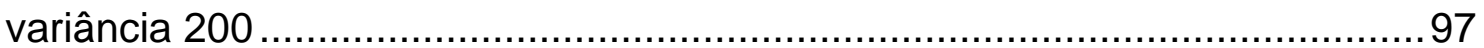

Figura 4.80: Modelo inicial implementado no simulador ................................. 98

Figura 4.81: Cálculo da disparidade equivalente à distância.............................99

Figura 4.82: Posição das câmeras no robô modelado .................................... 100

Figura 4.83: Disparidades equivalentes às distâncias................................... 100

Figura 4.84: Cena com um bloco inclinado na frente do robô ............................. 101

Figura 4.85: Mapa de disparidades obtido com o bloco inclinado ....................... 101

Figura 4.86: Cena com uma escada na frente do robô ................................. 102

Figura 4.87: Mapa de disparidades obtido com uma escada ............................102

Figura 4.88: Exemplo da imagem do simulador mostrando o robô desviando do

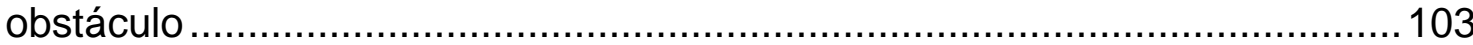

Figura 4.89: Exemplo da imagem do simulador observando o mundo com a câmera em outra posição 104

Figura B1: Execução do método Soma das Diferenças Absolutas na imagem original

Figura B2: Execução do método Soma do Quadrado das Diferenças na imagem original

Figura B3: Execução do método Correlação Cruzada Normalizada na imagem original 148

Figura B4: Execução do método Transformada Rank na imagem original............ 149

Figura B5: Execução do método Transformada Censo na imagem original.......... 149

Figura B6: Execução do método Transformada Modificada 1 na imagem original 150 Figura B7: Execução do método Transformada Modificada 2 na imagem original 150 Figura B8: Execução do método Transformada Modificada 3 na imagem original 151 Figura B9: Execução do método Transformada Modificada 4 na imagem original 151 
Figura B10: Execução do método Transformada Modificada 5 na imagem original 152

Figura B11: Execução do método Soma das Diferenças Absolutas na imagem com luminosidade $30 \%$ diferente 153

Figura B12: Execução do método Soma do Quadrado das Diferenças na imagem com luminosidade $30 \%$ diferente 154

Figura B13: Execução do método Correlação Cruzada Normalizada na imagem com luminosidade $30 \%$ diferente

Figura B14: Execução do método Transformada Rank na imagem com

luminosidade $30 \%$ diferente

Figura B15: Execução do método Transformada Censo na imagem com luminosidade $30 \%$ diferente

Figura B16: Execução do método Transformada Modificada 1 na imagem com luminosidade $30 \%$ diferente 156

Figura B17: Execução do método Transformada Modificada 2 na imagem com luminosidade $30 \%$ diferente 156

Figura B18: Execução do método Transformada Modificada 3 na imagem com luminosidade $30 \%$ diferente

Figura B19: Execução do método Transformada Modificada 4 na imagem com luminosidade $30 \%$ diferente

Figura B20: Execução do método Transformada Modificada 5 na imagem com luminosidade $30 \%$ diferente 158

Figura B21: Execução do método Soma das Diferenças Absolutas na imagem com ruído de variância 200

Figura B22: Execução do método Soma do Quadrado das Diferenças na imagem com ruído de variância 200 160

Figura B23: Execução do método Correlação Cruzada Normalizada na imagem com ruído de variância 200

Figura B24: Execução do método Transformada Rank na imagem com ruído de variância 200

Figura B25: Execução do método Transformada Censo na imagem com ruído de variância 200 
Figura B26: Execução do método Transformada Modificada 1 na imagem com ruído

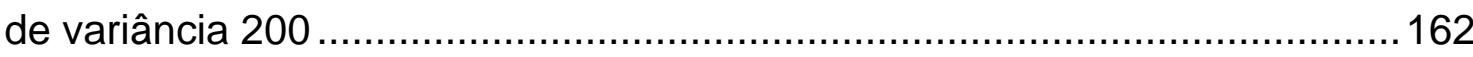

Figura B27: Execução do método Transformada Modificada 2 na imagem com ruído de variância 200

Figura B28: Execução do método Transformada Modificada 3 na imagem com ruído de variância 200

Figura B29: Execução do método Transformada Modificada 4 na imagem com ruído de variância 200 163

Figura B30: Execução do método Transformada Modificada 5 na imagem com ruído de variância 200 164

Figura B31: Execução do método Soma das Diferenças Absolutas na imagem original. 165

Figura B32: Execução do método Soma do Quadrado das Diferenças na imagem original 166

Figura B33: Execução do método Correlação Cruzada Normalizada na imagem

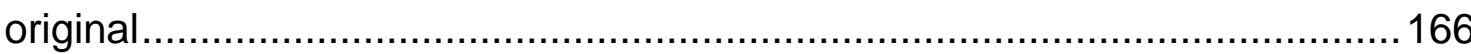

Figura B34: Execução do método Transformada Rank na imagem original.........167 Figura B35: Execução do método Transformada Censo na imagem original........167 Figura B36: Execução do método Transformada Modificada 1 na imagem original

Figura B37: Execução do método Transformada Modificada 2 na imagem original 168

Figura B38: Execução do método Transformada Modificada 3 na imagem original 169

Figura B39: Execução do método Transformada Modificada 4 na imagem original 169

Figura B40: Execução do método Transformada Modificada 5 na imagem original 170

Figura B41: Execução do método Soma das Diferenças Absolutas na imagem com luminosidade $30 \%$ diferente 171

Figura B42: Execução do método Soma do Quadrado das Diferenças na imagem com luminosidade $30 \%$ diferente 
Figura B43: Execução do método Correlação Cruzada Normalizada na imagem com luminosidade $30 \%$ diferente

Figura B44: Execução do método Transformada Rank na imagem com

luminosidade $30 \%$ diferente

Figura B45: Execução do método Transformada Censo na imagem com luminosidade $30 \%$ diferente

Figura B46: Execução do método Transformada Modificada 1 na imagem com luminosidade $30 \%$ diferente

Figura B47: Execução do método Transformada Modificada 2 na imagem com

luminosidade $30 \%$ diferente

Figura B48: Execução do método Transformada Modificada 3 na imagem com luminosidade $30 \%$ diferente 175

Figura B49: Execução do método Transformada Modificada 4 na imagem com luminosidade $30 \%$ diferente

Figura B50: Execução do método Transformada Modificada 5 na imagem com

luminosidade $30 \%$ diferente 176

Figura B51: Execução do método Soma das Diferenças Absolutas na imagem com ruído de variância 200

Figura B52: Execução do método Soma do Quadrado das Diferenças na imagem com ruído de variância 200

Figura B53: Execução do método Correlação Cruzada Normalizada na imagem com ruído de variância 200

Figura B54: Execução do método Transformada Rank na imagem com ruído de variância 200

Figura B55: Execução do método Transformada Censo na imagem com ruído de variância 200

Figura B56: Execução do método Transformada Modificada 1 na imagem com ruído de variância 200 180

Figura B57: Execução do método Transformada Modificada 2 na imagem com ruído

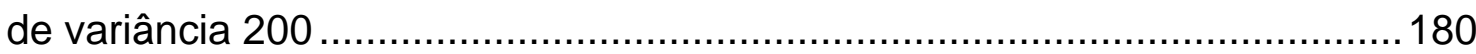

Figura B58: Execução do método Transformada Modificada 3 na imagem com ruído de variância 200 181 
Figura B59: Execução do método Transformada Modificada 4 na imagem com ruído

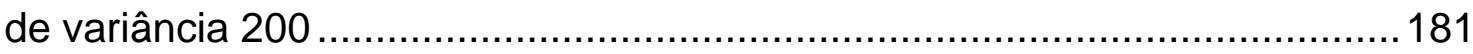

Figura B60: Execução do método Transformada Modificada 5 na imagem com ruído de variância 200

Figura B61: Execução do método Soma das Diferenças Absolutas na imagem original 183

Figura B62: Execução do método Soma do Quadrado das Diferenças na imagem original. 184

Figura B63: Execução do método Correlação Cruzada Normalizada na imagem original

Figura B64: Execução do método Transformada Rank na imagem original. 185

Figura B65: Execução do método Transformada Censo na imagem original. 185

Figura B66: Execução do método Transformada Modificada 1 na imagem original 186

Figura B67: Execução do método Transformada Modificada 2 na imagem original 186

Figura B68: Execução do método Transformada Modificada 3 na imagem original

Figura B69: Execução do método Transformada Modificada 4 na imagem original

Figura B70: Execução do método Transformada Modificada 5 na imagem original 188

Figura B71: Execução do método Soma das Diferenças Absolutas na imagem com luminosidade $30 \%$ diferente 189

Figura B72: Execução do método Soma do Quadrado das Diferenças na imagem com luminosidade $30 \%$ diferente 190

Figura B73: Execução do método Correlação Cruzada Normalizada na imagem com luminosidade $30 \%$ diferente 190

Figura B74: Execução do método Transformada Rank na imagem com luminosidade $30 \%$ diferente 191

Figura B75: Execução do método Transformada Censo na imagem com luminosidade $30 \%$ diferente 
Figura B76: Execução do método Transformada Modificada 1 na imagem com luminosidade $30 \%$ diferente 192

Figura B77: Execução do método Transformada Modificada 2 na imagem com luminosidade $30 \%$ diferente

Figura B78: Execução do método Transformada Modificada 3 na imagem com luminosidade $30 \%$ diferente

Figura B79: Execução do método Transformada Modificada 4 na imagem com luminosidade $30 \%$ diferente

Figura B80: Execução do método Transformada Modificada 5 na imagem com luminosidade $30 \%$ diferente

Figura B81: Execução do método Soma das Diferenças Absolutas na imagem com ruído de variância 200 .

Figura B82: Execução do método Soma do Quadrado das Diferenças na imagem com ruído de variância 200 196

Figura B83: Execução do método Correlação Cruzada Normalizada na imagem com ruído de variância 200

Figura B84: Execução do método Transformada Rank na imagem com ruído de variância 200

Figura B85: Execução do método Transformada Censo na imagem com ruído de variância 200

Figura B86: Execução do método Transformada Modificada 1 na imagem com ruído de variância 200 198

Figura B87: Execução do método Transformada Modificada 2 na imagem com ruído de variância 200 198

Figura B88: Execução do método Transformada Modificada 3 na imagem com ruído de variância 200 199

Figura B89: Execução do método Transformada Modificada 4 na imagem com ruído de variância 200 199

Figura B90: Execução do método Transformada Modificada 5 na imagem com ruído de variância 200 200 


\section{LISTA DE TABELAS}

Tabela 3.1: Comparação dos limiares obtidos com diferentes imagens................43

Tabela 4.1: Comparação dos limiares obtidos com regiões diferentes das imagens .51

Tabela 4.2: Tempos de execução dos métodos com as diferentes janelas utilizadas 56

Tabela 5.1: Tabela resumo das qualidades dos métodos 106 


\section{LISTA DE SÍMBOLOS}

$\alpha$

C

Corr_erradas

$d$

disp calculada

disp real

Erro_RMS

I

$I_{1}$

$\bar{I}_{1}$

$I_{2}$

$\bar{I}_{2}$

$I(x+i, y+i)$

$I(x, y)$

$i$

$j$

$\mathrm{N}$

$R$

$r(x, y)$

$T(x+i, y+j)$

$U[t]$

$x$

o limiar é um valor para a tolerância ao ruído da imagem

valor da função de correlação do algoritmo

porcentagem de correlações erradas

valor da disparidade do ponto analisado

disparidade calculada para o ponto

disparidade real do ponto

erro RMS da imagem

intensidade de um ponto da imagem da janela

intensidade de um ponto da imagem da janela alvo

valor médio da intensidade da imagem da janela alvo

intensidade de um ponto da imagem da janela busca

valor médio da intensidade da imagem da janela busca

intensidade do ponto a analisado

intensidade ponto de referência

índice para a varredura das janelas

índice para a varredura das janelas

número total de pontos da imagem

número de pontos na janela de Rank

valor resultante da transformada Rank

transformada modificada aplicada nos pontos da janela

função degrau unitário

coordenada da linha do ponto de interesse

coordenada da coluna do ponto de interesse 


\section{SUMÁRIO}

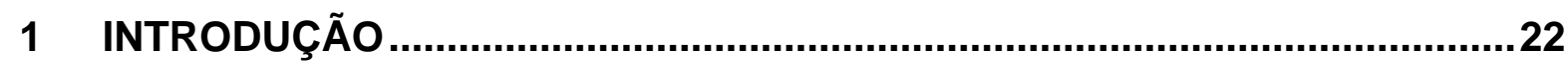

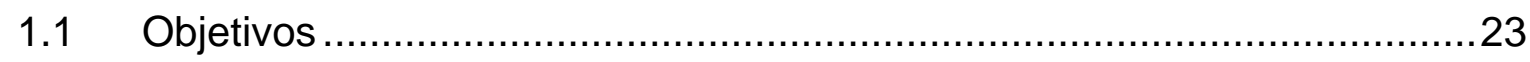

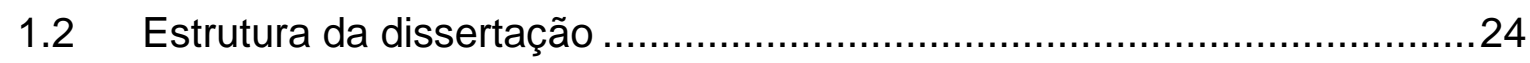

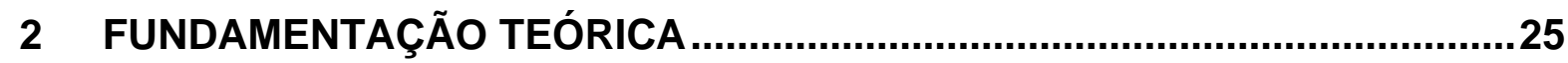

2.1 Revisão bibliográfica sobre técnicas de correspondência.......................25

2.1.1 Técnicas de correspondência locais ......................................28

2.1.1.1 Soma das Diferenças Absolutas (SAD) ..............................29

2.1.1.2 Soma dos Quadrados das Diferenças (SSD) ......................... 30

2.1.1.3 Correlação Cruzada Normalizada (Coeficiente de Correlação,

Correlação por Média Normalizada) .............................................. 31

2.1.1.4 Correspondência com a utilização da Transformada Censo

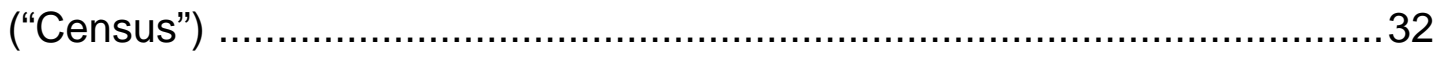

2.1.1.5 Correspondência com a utilização da Transformada Rank ........35

2.1.2 Abordagens para a comparação das técnicas de correlação .............35

3 MODIFICAÇÕES PROPOSTAS PARA A TRANSFORMADA CENSO ...........38

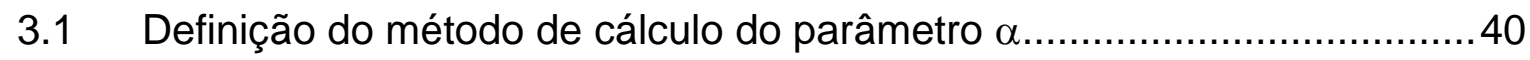

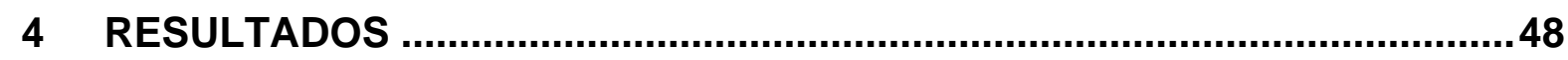

4.1 Descrição dos experimentos e da métrica de avaliação .........................48

4.2 Aplicação dos métodos na imagem do Corredor ...................................53

4.3 Aplicação dos métodos na imagem Teddy ...................................69

4.4 Aplicação dos métodos na imagem Cones ....................................... 84

4.5 Exemplo de aplicação do algoritmo de correlação................................98

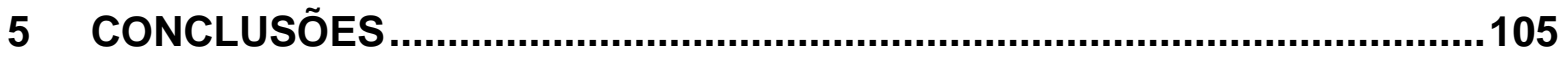

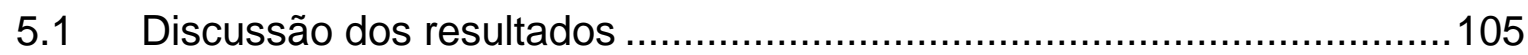

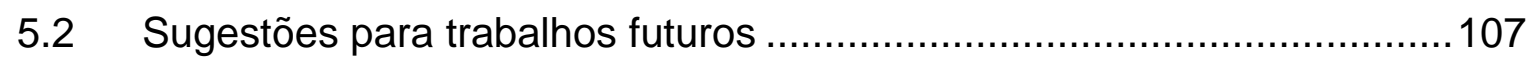

REFERÊNCIAS BIBLIOGRÁFICAS ...........................................................109

APÊNDICE A - CÓDIGO FONTE DAS ROTINAS UTILIZADAS ..........................118 


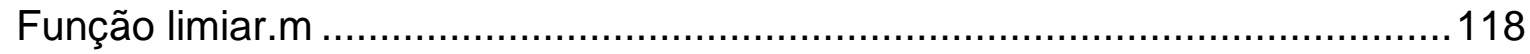

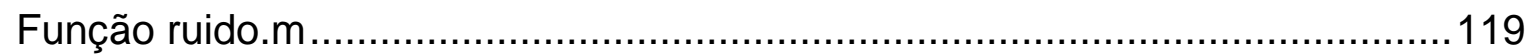

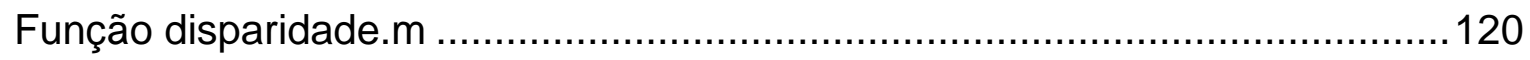

Função sad.m (Soma das Diferenças Absolutas) .............................................123

Função cor.m (Correlação Cruzada Normalizada) .........................................126

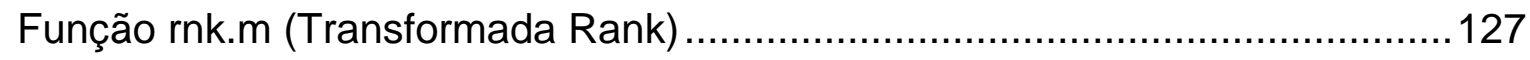

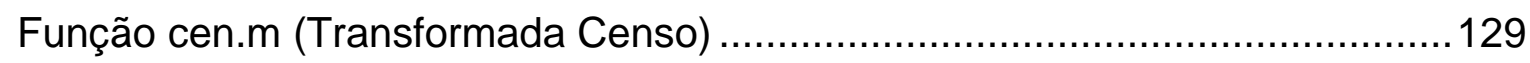

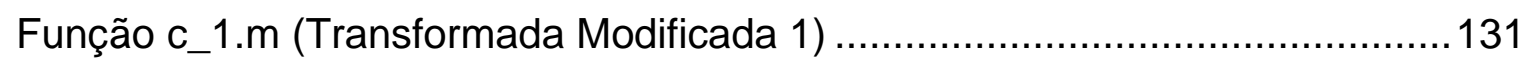

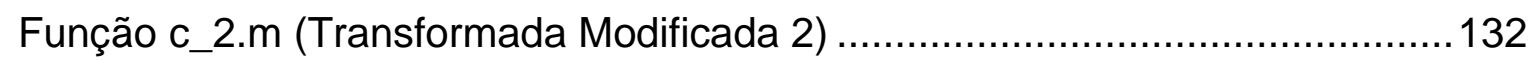

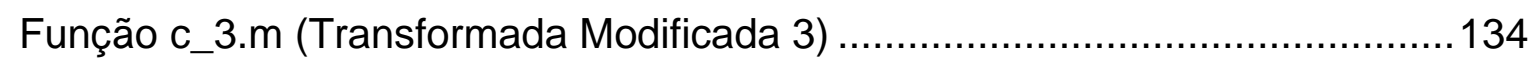

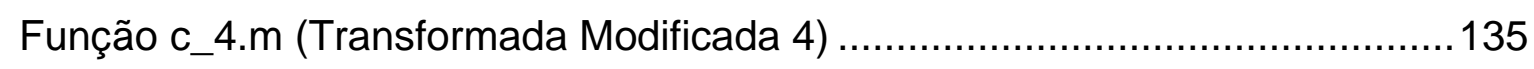

Função c_5.m (Transformada Modificada 5) …………...............................137

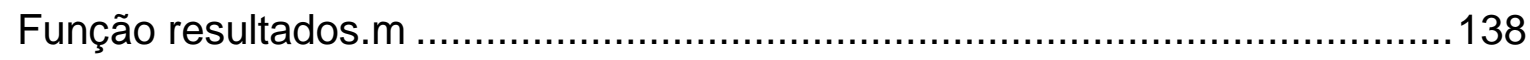

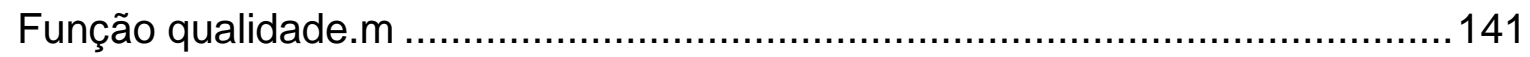

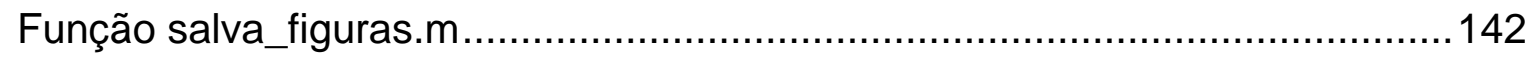

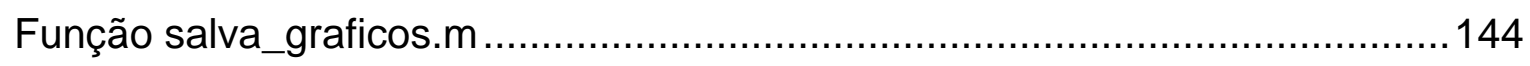

APÊNDICE B - MAPAS DE DISPARIDADES RESULTANTES DA COMPARAÇÃO

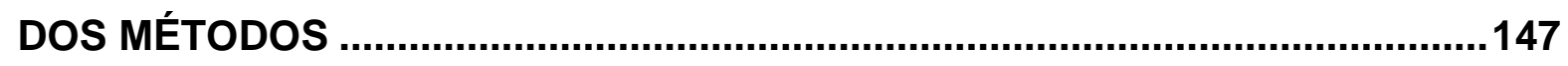

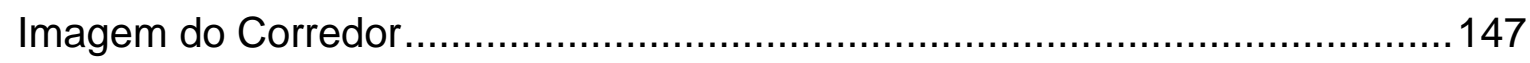

Resultados da execução dos algoritmos com a imagem original...................147

Resultados da execução dos algoritmos com a imagem esquerda com $30 \%$

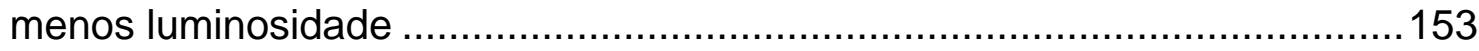

Resultados da execução dos algoritmos com a imagem contaminada por ruído

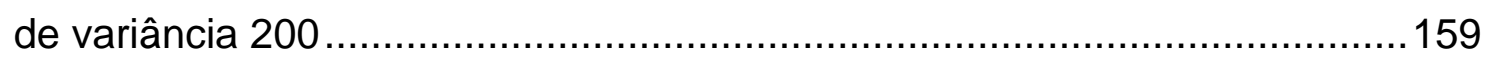

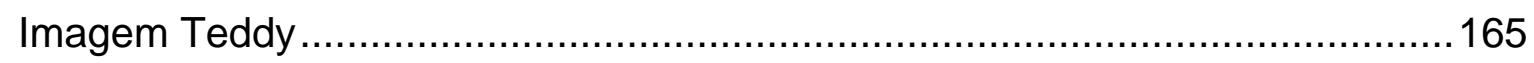

Resultados da execução dos algoritmos com a imagem original...................165

Resultados da execução dos algoritmos com a imagem esquerda com $30 \%$

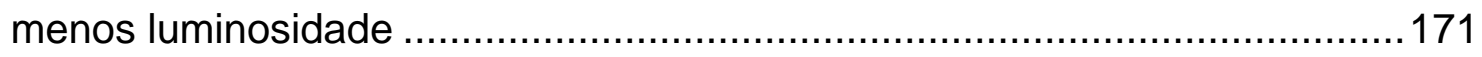

Resultados da execução dos algoritmos com a imagem contaminada por ruído

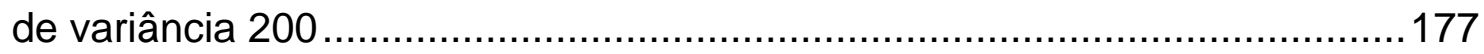

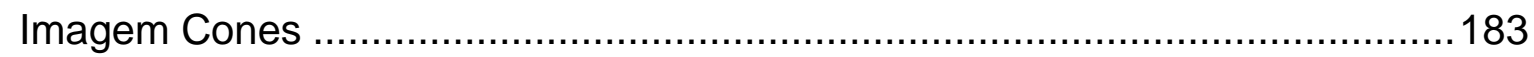

Resultados da execução dos algoritmos com a imagem original...................183 
Resultados da execução dos algoritmos com a imagem esquerda com $30 \%$

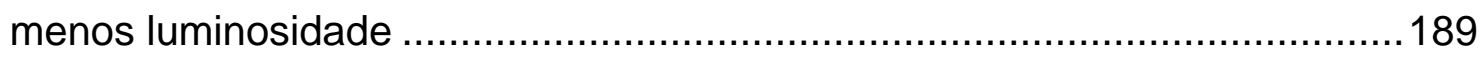
Resultados da execução dos algoritmos com a imagem contaminada por ruído

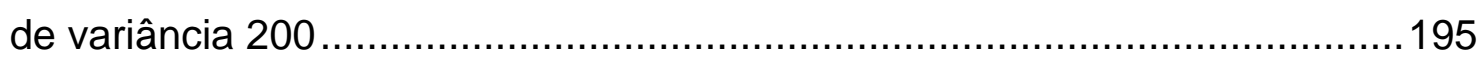




\section{INTRODUÇÃO}

A visão é um dos sentidos mais importantes do ser humano. É através dela que os homens e animais identificam indivíduos, locais, objetos, estimam distâncias e velocidades. Devido a grande quantidade de informações que é possível obter a partir deste sentido, muitos pesquisadores tentam reproduzi-lo através do uso de múltiplas câmeras. A visão estéreo é um problema fundamental no campo da visão computacional e requer o estabelecimento de correspondências entre múltiplas imagens para a obtenção de uma estimativa tridimensional. Suas aplicações são diversas, como na navegação de robôs, inspeção de peças e reconstrução de modelos tridimensionais.

Nos últimos anos um grande número de abordagens tem sido aplicadas à resolução do problema. Estas abordagens geralmente diferem umas das outras nas técnicas de correlação utilizadas, na densidade dos resultados, na acurácia das estimativas e no tempo de cálculo. Porém, a realização da correlação entre pontos de duas ou mais imagens é um problema que se mostra complexo e ainda não possui uma boa solução que possa ser aplicada em qualquer caso, apesar de esta ser uma tarefa comumente abordada na área de visão computacional e de existirem diversos algoritmos encontrados na literatura.

Atualmente, o estado da arte com relação aos algoritmos de correlação costuma utilizar uma abordagem global de forma a aperfeiçoar a estimativa inicial dos mapas de disparidade; geralmente esta estimativa inicial é obtida por algum algoritmo de correspondência local. Segundo Wang et al (2006), a abordagem global ainda possui complicações na aplicação em tempo real e os critérios de correlação puramente locais ainda continuam sendo utilizados.

Observa-se que as abordagens atuais dos métodos locais buscam aplicar restrições, pré e pós-processamentos, múltiplas janelas, janelas variáveis, entre outras técnicas para melhorar as correlações obtidas. Sendo assim, ocorre em vários casos que qualquer algoritmo de correlação local seria capaz de trabalhar conjuntamente com estas otimizações, já que estes algoritmos são apenas critérios para ponderar a comparação entre pontos e definir quais são correspondentes. 
Portanto, é de se esperar que se o algoritmo de correspondência for mais robusto a técnica em geral o será.

Para efetuar a comparação das intensidades podem ser utilizados critérios de comparação direta das intensidades, tais como a Soma das Diferenças Absolutas (Kuhl, 2005), Soma do Quadrado das Diferenças (Kuhl, 2005) ou Correlação Cruzada Normalizada (González \& Woods, 2000), ou métodos chamados de transformações não paramétricas nos quais se aplicam filtros às janelas das imagens (Transformada Rank encontrado em Banks, 1999a e Transformada Censo encontrado em Zabih et al, 1994) antes da comparação. Também existem outras abordagens não baseadas diretamente nas intensidades luminosas, mas em seu gradiente ou sua fase.

Nos resultados das comparações será possível observar que o algoritmo de correlação que obtém os piores resultados nas imagens originais e nas suas versões com ruído é a Transformada Censo (também conhecido como "Census"), portanto serão estudadas as modificações já existentes para este algoritmo e propostas novas modificações para torná-lo mais robusto e melhorar seus resultados.

\subsection{Objetivos}

Decidiu-se pesquisar e sugerir alguma forma de otimização de algum dos algoritmos de correlação comumente utilizados nas técnicas locais. Observando diversos trabalhos que abordam critérios locais de correlação decidiu-se por abordar algoritmos baseadas na intensidade luminosa, nas quais geralmente utiliza-se como critério de correlação a comparação das intensidades dos pontos de uma imagem com a outra.

Os alvos de estudo deste trabalho são a análise comparativa de algoritmos de correlação locais baseados em intensidade luminosa e a sugestão de uma modificação no algoritmo que obteve os piores resultados de forma a melhorá-lo. Neste caso, como a Transformada Censo obtém os piores resultados tanto nas imagens originais quanto nas imagens com ruído optou-se por modificá-la para que esta se torne mais robusta a ruídos. 


\subsection{Estrutura da dissertação}

No Item 2, Fundamentação Teórica, apresenta-se a visão estéreo e é citado o processo de retificação da imagem para permitir a redução da área de busca das correspondências. Em seguida realiza-se a revisão bibliográfica sobre as técnicas de correspondência e as abordagens para sua comparação.

No Item 3 apresenta-se a modificação sugerida para a Transformada Censo e descrito como obter o parâmetro de limiar a ser adotado.

No Item 4 mostram-se os resultados obtidos com todos os dez métodos analisados sendo aplicados a imagens com variação de luminosidade e ruídos.

No Item 5 realizam-se os comentários finais e as sugestões para trabalhos futuros.

Nos itens seguintes são apresentadas a bibliografia consultada e os Apêndices deste trabalho. No Apêndice A constam os códigos fontes das rotinas utilizadas e no Apêndice B os mapas de disparidades de alguns dos casos analisados. 


\section{FUNDAMENTAÇÃO TEÓRICA}

A visão estereoscópica ou estéreo é aquela que busca reproduzir a visão binocular natural para, dessa forma, conseguir reconstruir um mundo 3D obtendo-se assim medidas de profundidade. A visão estéreo é formada a partir da captura de duas imagens de uma cena a partir de posições distintas da câmera.

Então, segundo Gonçalves (2005), "a partir das diferenças de posição das projeções de objetos nas imagens, por triangulação, pode-se determinar a posição relativa. Uma vez que o sistema esteja calibrado, determina-se a qual distância outros objetos se encontram do sistema de aquisição"

A calibração da câmera pode ser realizada de diversos modos sendo a bibliografia sobre este assunto extensa e com diversas formas de equacionar o problema da calibração (Gonzalez e Woods, 2000; Holt e Netravali, 1991; Kumar e Hanson, 1994; Heikkilä e Silvén, 1997; Weng, Cohen e Herniou, 1992; Zhang, 1999).

No caso de sistemas com câmeras não calibradas, a única informação disponível para estabelecer a restrição dos emparelhamentos possíveis seria o conhecimento da geometria epipolar. Fusiello (1998 e 2000) mostra em seus trabalhos uma técnica de retificação das imagens baseada na geometria epipolar, tal técnica descreve uma maneira de re-projetar as imagens das câmeras do par estéreo de forma a ficarem colineares e paralelas.

Com o uso da retificação, um algoritmo de emparelhamento não precisa mais ficar comparando pontos e retas inclinadas na imagem. A nova configuração permite que o mesmo busque o emparelhamento apenas ao longo de linhas horizontais. Com isto, o custo computacional é reduzido em extremo.

\subsection{Revisão bibliográfica sobre técnicas de correspondência}

Dado um par de imagens sabe-se que é possível retificá-las de forma a deixar os elementos correspondentes de ambas as imagens na mesma linha de varredura reduzindo-se o espaço de busca nas imagens. O problema que as técnicas de 
correlação deverão resolver será eleger uma das imagens como referência. Nesta, escolher um ponto e buscar seu correspondente na mesma linha da outra imagem (alvo). Porém, esta tarefa possui sérios problemas os quais são: ambigüidades nas imagens, regiões com textura repetitiva, regiões sem textura e imagens com ruídos. Para a resolução destes problemas encontram-se diversas abordagens propostas e algumas serão discutidas a seguir.

Os métodos baseados nas características ("features") dos objetos das imagens primeiramente submetem separadamente as duas imagens do par estéreo, a um pré-processamento no qual serão extraídos os contornos monoculares, geralmente sendo encontrados cantos, bordas e segmentos de linha existentes nas imagens. Num segundo passo os contornos encontrados em uma das imagens são correlacionados com os da outra imagem, porém nem sempre essas correspondências estão certas, dessa forma é necessário um terceiro passo no qual as correspondências erradas são eliminadas. Como resultado estes algoritmos fornecem mapas de disparidade esparsos os quais nem sempre são suficientes para algumas aplicações. Alguns exemplos de autores que abordam este tipo de técnica são Hu (1994), Lowe (2004) e Lu (2004).

Nos casos onde é necessário obter um mapa de disparidades denso as abordagens por características já não são mais tão úteis sendo que, para isso, existem os métodos baseados em áreas. Scharstein e Szeliski (2002) em seu trabalho classificou os algoritmos estéreo densos em dois grandes grupos, os locais e globais. Porém observando-se alguns trabalhos recentes (Mattocia et al, 2007 e Hirschmüller, 2005 e 2006) é possível observar que seus autores definem uma terceira categoria de algoritmos estéreos densos, os algoritmos semi-globais.

Vários trabalhos recentes têm utilizado métodos globais para realização da correlação. Este tipo de algoritmo busca um mapa de disparidades que minimize uma função de custo global definida. Nesta abordagem costuma-se assumir que as disparidades variam suavemente nas imagens, portanto regiões ambíguas recebem o valor das disparidades propagado pelas regiões vizinhas. Os algoritmos globais costumam subdividir a imagem como sendo árvores ou utilizando o campo aleatório de Markov ("Markov random field" - MRF) e juntamente utilizam técnicas como programação dinâmica, difusão não linear, "graph cut" e "belief propagation" para realizar a otimização dos resultados. Porém mesmo nos algoritmos globais uma 
aproximação inicial da disparidade do ponto é necessária e este valor é geralmente obtido utilizando-se alguma técnica de correspondência local.

Sun et al (2005) aborda uma técnica global de correlação fazendo uma estrutura baseada em árvore e utiliza "belief propagation" em seu método global, já Veksler (2005) utiliza também uma estrutura baseada em árvore, porém conjuntamente com a programação dinâmica. No trabalho de Kim (2005) é possível observar uma outra abordagem da programação dinâmica, neste caso sendo utilizada em dois passos de otimização, primeiramente na linha de varredura e em seguida entre as linhas de varredura. Yang et al (2006a e 2006b) utiliza uma forma hierárquica do "belief propagation" e consegue implementar o algoritmo em tempo real utilizando-se a placa de vídeo para o processamento. Larsen et al (2006) realiza uma modificação na técnica de "belief propagation" de forma a trabalhar com imagens em movimento. Strecha et al (2006) utiliza a estrutura de campos aleatórios de Markov (MRF) com uma tática de maximização de expectativa. Zitnick e Kang (2007) propõem um trabalho com uma estrutura de campos aleatórios de Markov (MRF) e "belief propagation" para a aplicação em renderização baseada em imagens.

Os trabalhos que se definem como sendo algoritmos semi-globais são baseados na minimização de uma função calculada apenas em uma região da imagem. Hirschmüller (2005) apresenta um método de correlação semi-global com as correspondências realizadas pontualmente, mas baseadas em informações mútuas e na aproximação de que as disparidades possuem variações suaves. Hirschmüller (2006) mostra a aplicação do método anteriormente proposto em ambientes estruturados. Mattocia et al (2007) apresenta um algoritmo de correlação baseado na segmentação e na otimização da linha de varredura com o intuito de melhorar a detecção das bordas. Se considerado que a linha de varredura é uma região da imagem, o trabalho de Wang et al (2006) também pode ser considerado um algoritmo semi-global, porque utiliza a técnica de programação dinâmica juntamente com uma agregação adaptativa apenas na vertical, dessa forma consegue melhorar os resultados do método de programação dinâmica mantendo o algoritmo em tempo real.

As abordagens locais baseadas em área comumente utilizam correlações estatísticas das intensidades ou cores de regiões da imagem. Estas correlações podem ser diretamente baseadas nas intensidades luminosas ou pode-se utilizar uma transformação não paramétrica nas janelas, ou até mesmo partir para a análise 
da fase ou gradiente na imagem. Algumas destas abordagens serão discutidas no item subseqüente por serem o objeto deste trabalho.

\subsubsection{Técnicas de correspondência locais}

Dentre os tipos de correlação local a correspondência por fase é a que trata a imagem de forma diferente não a utilizando no domínio da intensidade, mas transformando-a através da aplicação da transformada de Fourier ou o filtro de Gabor para o domínio da freqüência (Fleet et al, 1991). Estando no domínio da freqüência o método consegue correlacionar as regiões das imagens a partir da diferença de fase.

Segundo Fleet et al, 1991 este método sofre com problemas de ambigüidade para disparidades maiores que meio comprimento de onda para cada lado do ponto, porque a fase é periódica com período $2 \pi$.

Já as correlações realizadas diretamente por intensidade luminosa ou aquelas que utilizam alguma transformada não paramétrica são técnicas nas quais em torno de cada ponto analisado é gerada uma janela e nesta é suposto que todos os pontos sejam pertencentes à mesma profundidade, portanto possui uma dificuldade inerente nas regiões de descontinuidades nas profundidades.

Em seus casos mais simples, seus algoritmos supõem que um objeto possui a mesma intensidade luminosa em ambas as imagens, portanto são susceptíveis às variações de luminosidade entre as imagens e à distorções radiométricas, nas quais os tons de cinza em uma imagem diferem dos tons de cinza na outra imagem. Para resolver este problema pode-se executar um pré-processamento na imagem de forma a equalizar as luminosidades de ambas as vistas, porém também existem algoritmos que são capazes de contornar estes problemas utilizando-se de uma abordagem baseada na comparação das intensidades subtraídas da média da intensidade das janelas ou aplicando as transformadas não paramétricas às janelas nas imagens, como é possível observar em França et al (2005).

Em muitos trabalhos encontram-se maneiras de otimizar a correlação dos métodos locais sendo que no geral é comum encontrar pré-processamentos tal como a equalização do brilho das imagens, pós-processamentos para a aceitação 
das disparidades, janelas adaptativas, múltiplas janelas e restrições. Alguns exemplos de trabalhos recentes podem ser citados.

Por exemplo, França (2005), mostra seu algoritmo de múltiplas janelas para a obtenção de uma correlação mais robusta. Wang et al (2006) realiza uma comparação de várias otimizações que podem ser realizadas nas janelas de busca e compara seus resultados. Zhao et al (2006a, 2006b, 2007) em seus trabalhos apresenta uma nova abordagem de obtenção da janela de busca de forma a melhorar a correlação nos contornos dos objetos, sendo que em um deles o autor parte para um passo de otimização global das disparidades por programação dinâmica. Outro autor, Lei et al (2006) também utiliza a combinação de um método local de correspondência com a programação dinâmica. Klaus (2006) utiliza uma tática de segmentação por cores conjuntamente com uma técnica de correspondência auto adaptativa. Gehirig e Franke (2007) propõe uma restrição gravitacional que auxilia na redução de falsas disparidades e um algoritmo de suavização das disparidades obtidas. Tombardi et al (2007) mostra uma abordagem com janela adaptativa baseada em segmentação para melhorar a correspondência em regiões com pouca textura e em contornos. Yang et al (2007) apresenta uma técnica de pós-processamento que permite o refinamento de resolução "sub-pixel" no mapa de disparidades. Yoon et al (2007) propõe um novo critério de medição de similaridade para ajudar a melhorar os resultados dos métodos locais em caso de ambigüidade.

Algumas técnicas de correlação foram escolhidas para a comparação por serem citadas e utilizadas em vários trabalhos, elas serão abordadas nos sub-itens a seguir.

\subsubsection{Soma das Diferenças Absolutas (SAD)}

É um algoritmo de correspondência que computa a diferença de todos os pontos da janela definida e em seguida soma o módulo de todos os resultados dessas diferenças. O valor mínimo desta função denota qual das janelas melhor se correlacionou. A disparidade é então calculada como a diferença horizontal entre as coordenadas dos pontos. 
Este é um critério bem comum e utilizado para casos onde o tempo de processamento é critico segundo França (2003), e é expresso pela equação 2.1.

$$
C(x, y, d)=\sum_{i} \sum_{j}\left|I_{1}(x+i, y+j)-I_{2}(x+d+i, y+j)\right|
$$

Onde:

$C$ é o valor da função de correlação do algoritmo

$d$ é o valor da disparidade do ponto analisado

$i$ e $j$ são os índices para a varredura das janelas

$I_{1}$ é a intensidade de um ponto da imagem da janela alvo

$I_{2}$ é a intensidade de um ponto da imagem da janela busca

$x$ e $y$ são as coordenadas, linha e coluna, do ponto de interesse

Pode-se observar aplicações recentes do algoritmo SAD nos trabalhos de Jacobi et al (2006) no qual o autor implementa o algoritmo em uma FPGA para obter processamento em tempo real. Em Zhao et al (2006a, 2006b e 2007) é abordado um método de múltiplas janelas para a melhoria da correlação do algoritmo SAD na região de bordas. Ambrosh et al (2007) implementou o algoritmo SAD em hardware para a obtenção de até 425 quadros por segundo em imagens de $320 \times 240$ pontos.

\subsubsection{Soma dos Quadrados das Diferenças (SSD)}

É outro critério de correspondência clássico e é bem similar ao SAD segundo Kuhl, 2005. Neste critério o algoritmo de correspondência computa a diferença de todos os pontos da janela definida e em seguida soma o quadrado de todos os resultados dessas diferenças. Como no SAD, o valor mínimo desta função denota qual das janelas melhor se correlacionou e a disparidade é então calculada como a diferença horizontal entre as coordenadas dos pontos. O método é expresso pela equação 2.2. 


$$
C(x, y, d)=\sum_{i} \sum_{j}\left(I_{1}(x+i, y+j)-I_{2}(x+d+i, y+j)\right)^{2}
$$

Onde:

$C$ é o valor da função de correlação do algoritmo

$d$ é o valor da disparidade do ponto analisado

$i$ e $j$ são os índices para a varredura das janelas

$I_{1}$ é a intensidade de um ponto da imagem da janela alvo

$I_{2}$ é a intensidade de um ponto da imagem da janela busca

$x$ e $y$ são as coordenadas, linha e coluna, do ponto de interesse

\subsubsection{Correlação Cruzada Normalizada (Coeficiente de Correlação, Correlação por Média Normalizada)}

Este critério foi escolhido para fazer parte da comparação por ter sido mencionado em diversas fontes tais como em Koyama e Hasegawa (2002), González \& Woods (2000), França (2005), Mordohai e Medioni (2006), Brockers et al (2005) e também porque segundo Faugeras et al (1993a) é considerado um algoritmo que obtém bons resultados sendo insensível às variações de tons de cinza. No caso do trabalho de Brockers (2005) o autor utiliza o método como critério de correlação, porém seu foco é a apresentação de um método global de relaxação de custo que auxilia na eliminação de ambigüidades.

Este critério utiliza-se da subtração da média da intensidade das janelas e dessa forma consegue não ser tão influenciado pela variação na luminosidade do ambiente (equação 2.3). Outro fator interessante neste critério é que ele é normalizado entre -1 e 1, de forma que uma imagem perfeitamente correlacionada resultará em um valor 1 da função de correlação. 


$$
C(x, y, d)=\frac{\sum_{x} \sum_{y}\left(\left(I_{1}(x+i, y+j)-\bar{I}_{1}(x, y)\right) \cdot\left(I_{2}(x+d+i, y+j)-\bar{I}_{2}(x+d, y)\right)\right)}{\sqrt{\sum_{x} \sum_{y}\left(I_{1}(x+i, y+j)-\bar{I}_{1}(x, y)\right)^{2} \cdot \sum_{x} \sum_{y}\left(I_{2}(x+d+i, y+j)-\bar{I}_{2}(x+d, y)\right)^{2}}}
$$

Onde:

$C$ é o valor da função de correlação do algoritmo

$d$ é o valor da disparidade do ponto analisado

$i$ e $j$ são os índices para a varredura das janelas

$I_{1}$ é a intensidade de um ponto da imagem da janela alvo

$I_{2}$ é a intensidade de um ponto da imagem da janela busca

$\bar{I}_{1}$ é o valor médio da intensidade da imagem da janela alvo

$\bar{I}_{2}$ é o valor médio da intensidade da imagem da janela busca

$x$ e $y$ são as coordenadas, linha e coluna, do ponto de interesse

\subsubsection{Correspondência com a utilização da Transformada Censo ("Census")}

Esse método de correlação tem por base a utilização da Transformada Censo (Zabih et al, 1994) na imagem para a realização do remapeamento dos pontos da imagem em uma seqüência de bits.

Para esta Transformada dada uma janela centrada em $(x, y)$, varre-se os pontos da janela comparando-se suas intensidades com a do ponto na posição $(x, y)$. Caso a intensidade seja maior que a da referência atribui-se o valor "1" ao bit correspondente na seqüência, caso contrário atribui-se "0" (Figura 2.1). 


\begin{tabular}{|c|c|c|}
\hline 181 & 182 & 181 \\
\hline 183 & 180 & 170 \\
\hline 179 & $175(x, y)$ & 167 \\
\hline 177 & 157 & 157 \\
\hline 158 & 155 & 158 \\
\hline
\end{tabular}

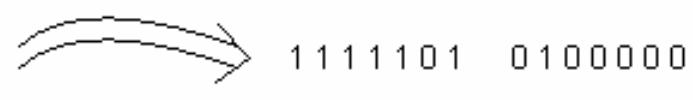

Figura 2.1: Exemplo da aplicação da Transformada Censo em uma janela

Onde:

$x$ e $y$ são as coordenadas, linha e coluna, do ponto de interesse

Após realizada a transformada, a semelhança é comparada através da utilização da distância de "Hamming" entre as seqüências de bits (Figura 2.2), sendo que quanto menor o valor maior será a correlação entre as seqüências.

\begin{tabular}{|c|c|c|c|c|c|c|c|c|c|c|}
\hline 1 & 0 & 1 & 1 & 1 & 0 & 0 & 1 & 1 & 0 & $=>$ primeiro vetor \\
\hline 1 & 0 & 0 & 1 & 0 & 0 & 1 & 0 & 0 & 0 & $=>$ segundo vetor \\
\hline 0 & 0 & 1 & 0 & 1 & 0 & 1 & 1 & 1 & 0 & => distância de "Hamming" \\
\hline
\end{tabular}

Figura 2.2: Distância "Hamming" entre dois vetores

Foi realizado também um levantamento das publicações que utilizaram a Transformada Censo e também das que propuseram modificações para a mesma.

Qiu et al (1998) aplicou a correlação utilizando imagens coloridas para a extração de bordas de objetos móveis. Neste trabalho os autores sugerem que a Transformada Censo seja aplicada separadamente a cada canal de cor, para em seguida somar o resultado da distância de "Hamming" dos canais.

Woodfill et al (1999) implementou o algoritmo Censo em uma FPGA. Neste mesmo ano Gautama et al faz um estudo comparativo entre os algoritmos de correlação Censo, Censo modificado e a correlação por média normalizada. A modificação sugerida para a Transformada Censo é a utilização do valor da intensidade média da janela para a comparação com os pontos vizinhos, em vez da utilização do valor do ponto central. Esta modificação da Transformada Censo também será utilizada na comparação dos algoritmos de correlação. 
Yamada et al (2000) desenvolveu um sistema de cálculo de disparidades utilizando-se de três câmeras e para tal os autores utilizam a Transformada Censo como algoritmo de correlação.

Smeraldi (2002) compara em um trabalho de detecção de padrões as Transformadas Censo, Rank, Rank binário, Wavelets e Ranklets.

Kuhn et al (2003) implementa em hardware algoritmos de correlação baseados na Transformada Censo e na Soma dos Quadrados das Diferenças e compara os resultados de ambos.

Em 2004, Fröba et al utiliza a Transformada Censo com uma modificação para a detecção de padrões. Neste trabalho o autor descreve que se o valor da intensidade média da janela for utilizada como o valor de comparação com os pontos vizinhos consegue-se distinguir uma maior variedade de padrões. Esta modificação é a mesma proposta por Gautama (1999), mas com uma aplicação diferente.

Woodfill et al (2004) mostra a implementação do algoritmo Censo para obtenção de mapas de disparidades em alta velocidade (200 quadros por segundo com imagens de 512 x 480 pontos).

Kuhl (2005) diz em seu trabalho que implementou uma modificação na Transformada Censo, porém não deixa claro que tipo de modificação foi realizada, sendo apenas comentado que a janela de varredura da imagem foi aumentada.

Naoulou et al (2006) mostra uma arquitetura implementada em FPGA para a correlação de imagens utilizando a Transformada Censo. Neste mesmo ano Just et al mostrou um trabalho de reconhecimento de padrões utilizando a Transformada Censo modificada. A modificação mostrada era manter a imagem na forma matricial em vez de transformá-la em vetor.

Em 2007 Murphy et al implementou um sistema de visão estéreo de baixo custo implementado em FPGA, que utiliza a Transformada Censo em seu algoritmo de correlação. 


\subsubsection{Correspondência com a utilização da Transformada Rank}

Esse método de correlação tem por base a utilização da Transformada RANK (Banks, 1999a, 1999b e 2001) na imagem para a realização do remapeamento dos pontos da imagem.

Esta transformada segue a seguinte função:

$$
\begin{aligned}
& r(x, y)=R-\sum_{i} \sum_{j} U[I(x+i, y+j)-I(x, y)] \\
& U[t]= \begin{cases}1, & t \geq 0 \\
0, & t<0\end{cases}
\end{aligned}
$$

Onde:

$R$ é o número de pontos na janela de Rank

$r(x, y)$ é o valor resultante da transformada Rank

$i$ e $j$ são os índices para a varredura das janelas

$I$ é a intensidade de um ponto da imagem da janela

$x$ e $y$ são as coordenadas, linha e coluna, do ponto de interesse

$U[t]$ é a função degrau unitário

Para esta transformada varre-se os pontos da imagem toda com uma janela de i linhas por $\mathrm{j}$ colunas aplicando a equação 2.4 , dessa forma temos uma nova imagem alterada pela Transformada de Rank.

Após obter as imagens transformadas pode-se utilizar o método SAD ou SSD para realizar a correlação entre as imagens.

\subsubsection{Abordagens para a comparação das técnicas de correlação}

Com relação às abordagens para a comparação dos algoritmos de correlação existentes pode-se observar que Scharstein e Szeliski (2002) fizeram um extenso 
trabalho de implementação e comparação de métodos de correspondência já publicados implementando-os conforme propostos pelos seus autores. Observa-se que Scharstein e Szeliski (2002) implementam tanto técnicas locais quanto globais, incluindo as otimizações locais (janelas móveis, múltiplas janelas, "winner take all", restrição de unicidade, entre outros), globais (programação dinâmica, "simulated annealing", "scanline optimization", "graph cut", entre outros) e refinamento das disparidades em nível de "sub-pixel". A métrica utilizada para a comparação dos algoritmos, segundo os autores, é semelhante à de estudos anteriormente publicados. As imagens utilizadas no trabalho são de repositórios e possuem o mapa de disparidade real.

Kuhl (2005) apresenta um trabalho de comparação dos algoritmos de correlação Soma das Diferenças Absolutas, Soma dos Quadrados das Diferenças, Transformada Censo e Transformada Censo Modificado. Neste trabalho a autora utiliza a imagem do repositório de Tsukuba e faz a comparação dos algoritmos pelos tempos de execução e pela qualidade visual dos mapas de disparidades.

Wang et al (2006) mostra um trabalho que compara os métodos Soma das Diferenças Absolutas, Soma das Diferenças Absolutas Truncada e "sampling insensitive matching criterion" aplicados conjuntamente com métodos de otimização e refinamento dos resultados tais como janelas móveis, "oriented-rod", "boundaryguided" e pesos adaptativos. Como métrica para a comparação o autor utiliza a porcentagem de erros e o tempo de execução.

Yoon et al (2006) apresenta um trabalho mais focado na comparação dos métodos de otimização da janela (janelas adaptativas, janelas variáveis, janelas móveis, entre outros) e avalia os métodos com a porcentagem de erros apresentados.

Yoon et al (2007) apresenta um método de medição de similaridade para ajudar a melhorar os resultados dos métodos locais em caso de ambigüidade e faz a comparação deste método com os métodos de otimização janelas adaptativas, segmentação, "belief propagation", entre outros. Neste trabalho o autor escolhe quatro imagens de repositórios e compara os algoritmos utilizando a porcentagem de erros.

Com relação às abordagens para a comparação dos algoritmos de correlação existentes pode-se perceber que normalmente os autores comparam os métodos de correspondência em seu todo incluindo as otimizações e pós-processamentos. 
Sendo que apenas Kuhl (2005) fez uma comparação dos resultados puros dos algoritmos de correlação, ou seja, fez a comparação sem a utilização de métodos de otimização e refinamento dos resultados. Porém neste trabalho a autora elaborou apenas um comparativo visual dos resultados dando mais ênfase nos tempos de processamento. Este é um dos motivos da opção pelo desenvolvimento de um trabalho comparando-se os algoritmos de correlação sem a aplicação de otimizações e pós-processamentos.

No trabalho de Scharstein e Szeliski (2002) observa-se que os autores escrevem que existem algoritmos de correlação que são insensíveis às variações de luminosidade e também dizem que tem algoritmos que resolvem facilmente as disparidades de imagens sem ruído, mas tem dificuldades com a versão com ruído das imagens. Porém, não fazem uma comparação dos algoritmos nestas situações que geram dificuldades.

França et al (2005) diz, ao descrever o equacionamento do método Soma das Diferenças Absolutas, que este não normaliza as intensidades das janelas e, portanto é sensível à variação de luminosidade, porém não faz nenhuma comparação da performance do algoritmo com imagens com este tipo de distorção.

A partir das abordagens vistas para a comparação de métodos de correspondência optou-se por elaborar o comparativo dos algoritmos de correlação com imagens de repositórios e também utilizar versões dessas imagens com diferenças de luminosidade e ruído, para verificar a robustez dos algoritmos a estes tipos de distorções. 


\section{MODIFICAÇÕES PROPOSTAS PARA A TRANSFORMADA CENSO}

Pensando-se em uma maneira de melhorar o resultado do método Censo que foi o que apresentou os piores resultados quando da presença de ruídos nas imagens foi possível perceber que este era susceptível aos ruídos porque sempre toma como base a intensidade de um ponto para aplicar a transformada. Então, caso o ponto em questão seja justamente o ponto com ruído, a qualidade da correlação ficará bem prejudicada.'

Após alguns testes foi possível tentar modificar a Transformada Censo adicionando-se mais um nível de valor "-1", de forma a tornar o nível "0" em um patamar neutro que não contribua, nem atrapalhe a correlação. Sendo assim com a modificação teríamos a equação 3.1:

$$
T(x+i, y+i)=\left\{\begin{aligned}
1, & I(x+i, y+i)>I(x, y)+\alpha \\
0, & I(x, y)-\alpha \leq I(x+i, y+i) \leq I(x, y)+\alpha \\
-1, & I(x+i, y+i)<I(x, y)-\alpha
\end{aligned}\right.
$$

Onde:

$\alpha$ será chamado de limiar e é um valor para a tolerância ao ruído da imagem $I(x+i, y+i)$ é a intensidade do ponto analisado

$I(x, y)$ é a intensidade ponto de referência

$i$ e $j$ são os índices para a varredura das janelas

$x$ e $y$ são as coordenadas, linha e coluna, do ponto de interesse

$T(x+i, y+j)$ é a equação da transformada modificada aplicada nos pontos da janela

Em uma abordagem inicial, ao realizar esta transformada para as janelas de alvo e busca, observa-se não ser mais possível utilizar a distância de "Hamming" de forma eficiente na comparação entre as janelas. Tal fato ocorre porque esta métrica fornece apenas um resultado binário dizendo se o bit analisado é igual ou não. Sendo assim, torna-se interessante adotar a comparação entre as janelas da mesma 
forma como o Soma das Diferenças Absolutas faz com as intensidades das imagens, apenas subtraindo-se uma janela da outra, porque este modo de comparação entre as janelas consegue fornecer um resultado com mais graduações que auxiliam na diferenciação de janelas diferentes.

Aproveitando a impossibilidade da utilização da distância de "Hamming", decidiuse por implementar esta alteração na Transformada Censo de duas formas. Em uma primeira abordagem a ser chamada de Transformada Modificada 1, a modificação será aplicada da mesma forma que o Censo é aplicado, ou seja, em cada janela alvo e busca gerada na varredura das imagens, conforme exemplificado na Figura 3.1.

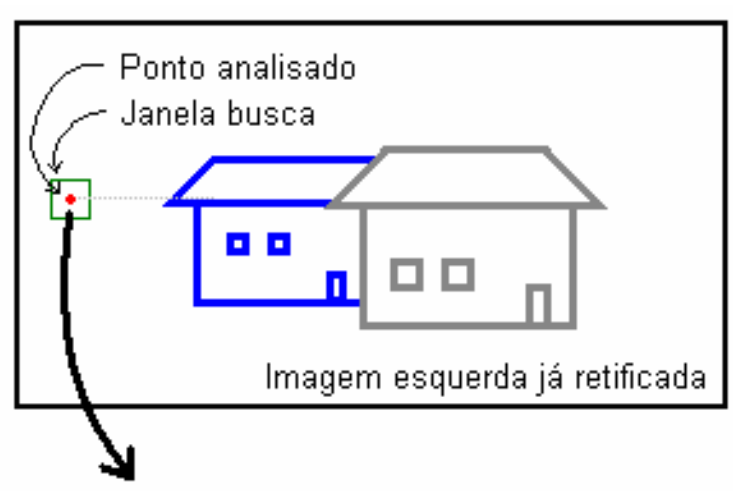

Aplicaçẫo da Transformada Modificada 1 na janela busca

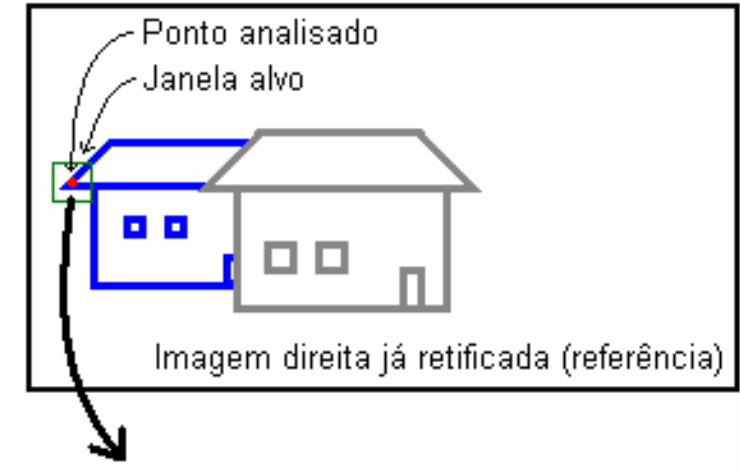

Aplicaçâo da Transformada

Modificada 1 na janela alvo

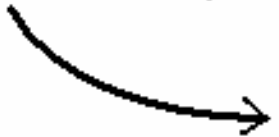

Correlaçâo das janelas após a transformada

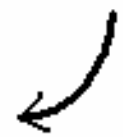

Figura 3.1: Exemplo da aplicação da Transformada Modificada 1

Já na segunda abordagem definida como Transformada Modificada 2, foi realizada uma outra abordagem modificando-se o modo de aplicação da transformada. Tal modificação resulta em um menor o tempo de processamento da correlação. Nela, aplica-se a transformada antecipadamente nas imagens esquerda e direita inteiras gerando-se novas imagens transformadas. Para isto é realizada uma varredura das imagens com uma janela de tamanho a ser definido pelo usuário. De posse destas novas imagens pode-se realizar a correlação pelo método Soma das Diferenças Absolutas ou outro método de correlação a ser escolhido pelo usuário. Um exemplo da aplicação desta transformada está na Figura 3.2. 


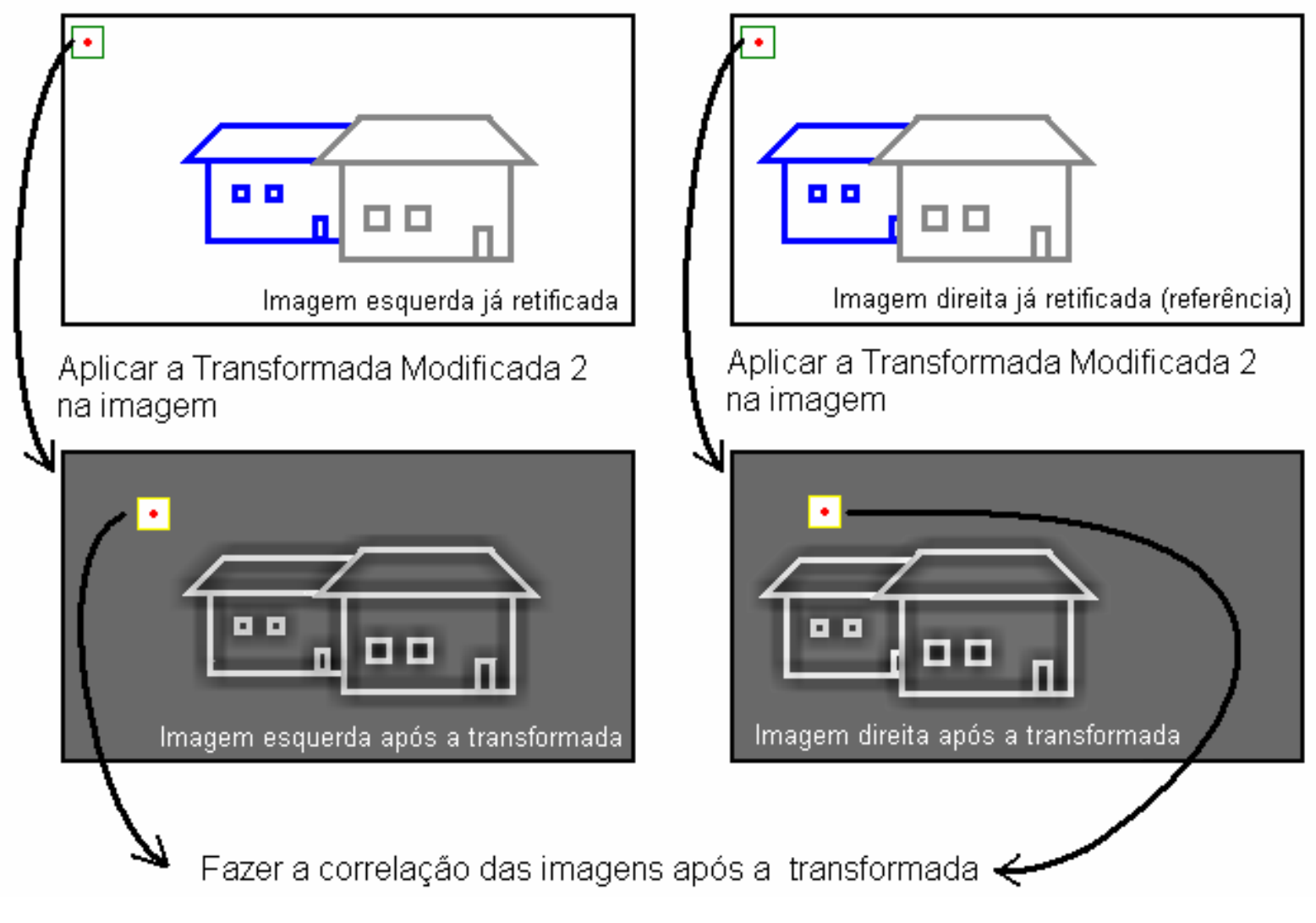

Figura 3.2: Exemplo da aplicação da Transformada Modificada 2

Para efeito de comparação dos resultados será implementada também a modificação mostrada por Gautama (1999), sendo esta chamada de Transformada Modificada 3. Nesta modificação os valores serão comparados com as médias de cada janela.

As variantes 4 e 5 da Transformada Modificada são testes com a utilização da média da intensidade da janela (Gautama, 1999) aplicada na transformada sugerida no lugar da intensidade do ponto central da janela. Sendo assim, as Transformadas Modificadas 4 e 5 são, respectivamente, as modificações 1 e 2 com a utilização da intensidade média da janela.

\subsection{Definição do método de cálculo do parâmetro $\alpha$}

Após o levantamento de mapas de disparidade com os diversos valores para o parâmetro $\alpha$ em diversas imagens diferentes. Procedeu-se uma comparação dos 
valores de limiar dos casos com os melhores resultados usando vários parâmetros das imagens tais como histograma, intensidade média, variância e desvio padrão de forma a tentar encontrar alguma relação entre esses valores e o valor do $\alpha$ a ser adotado.

Muitos testes foram realizados com as Transformadas Modificadas 1 e 2, sendo que as transformadas Modificadas 4 e 5 não foram utilizadas nesta fase porque estas transformadas foram definidas apenas na fase de comparação dos algoritmos como sendo variantes das Transformadas Modificadas 1 e 2.

Nos testes observou-se que, em geral, os valores de $\alpha$ que resultam em bons resultados se assemelham muito aos valores obtidos do dobro do desvio padrão da matriz de diferenças de intensidades entre o ponto e seu sucessor. Isto quando aplicado em uma região da imagem que deveria possuir intensidade constante ou no máximo com variação suave de intensidades (preferencialmente em regiões de textura uniforme). Por exemplo, tomando-se as imagens do Corredor (Universidade de Bonn, 2005), Teddy (Middlebury, 2007) e Cones (Middlebury, 2007) das Figuras 3.3 a 3.5 (obtidas de repositórios) e calculando o limiar conforme descrito anteriormente, obtém-se em média os valores da Tabela 3.1.
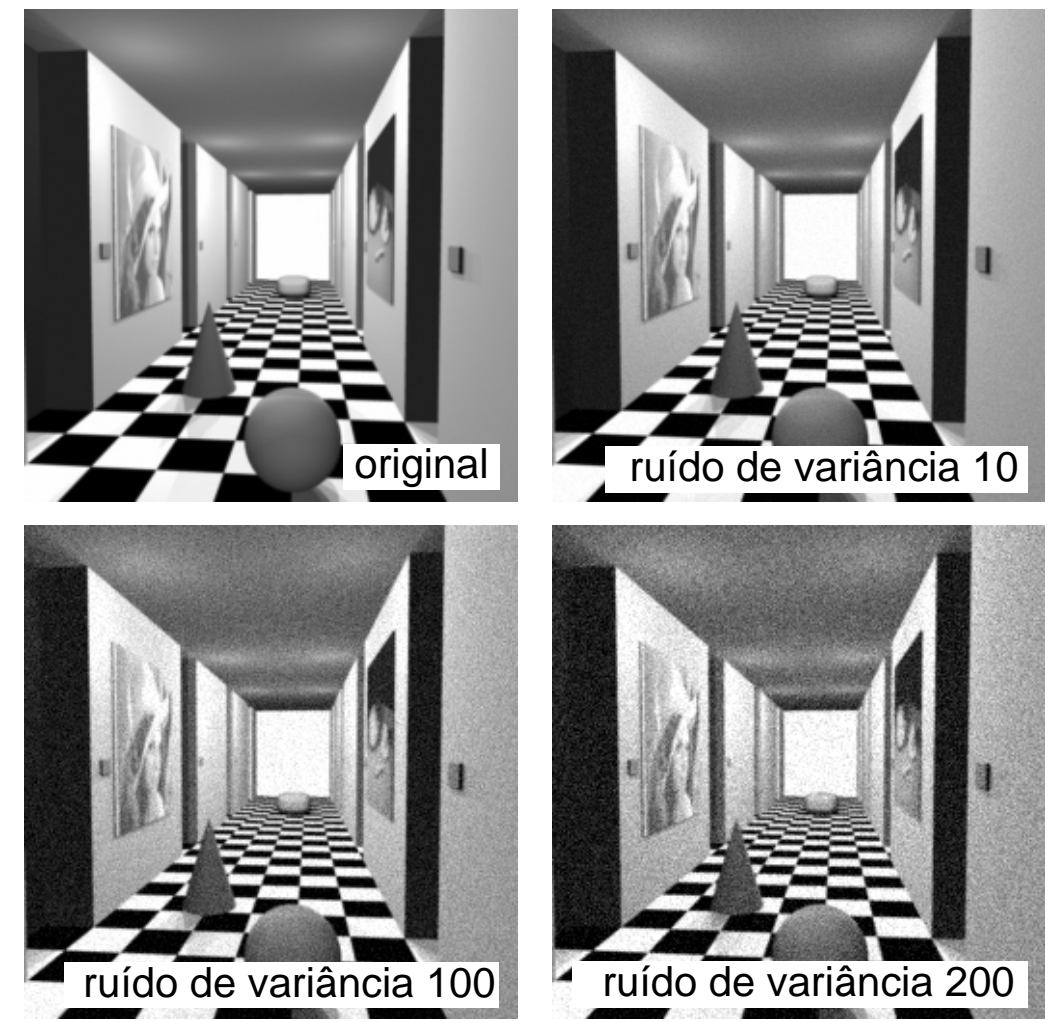

Figura 3.3: Imagens do Corredor original e contaminadas com ruído de variância 10, 100 e 200 

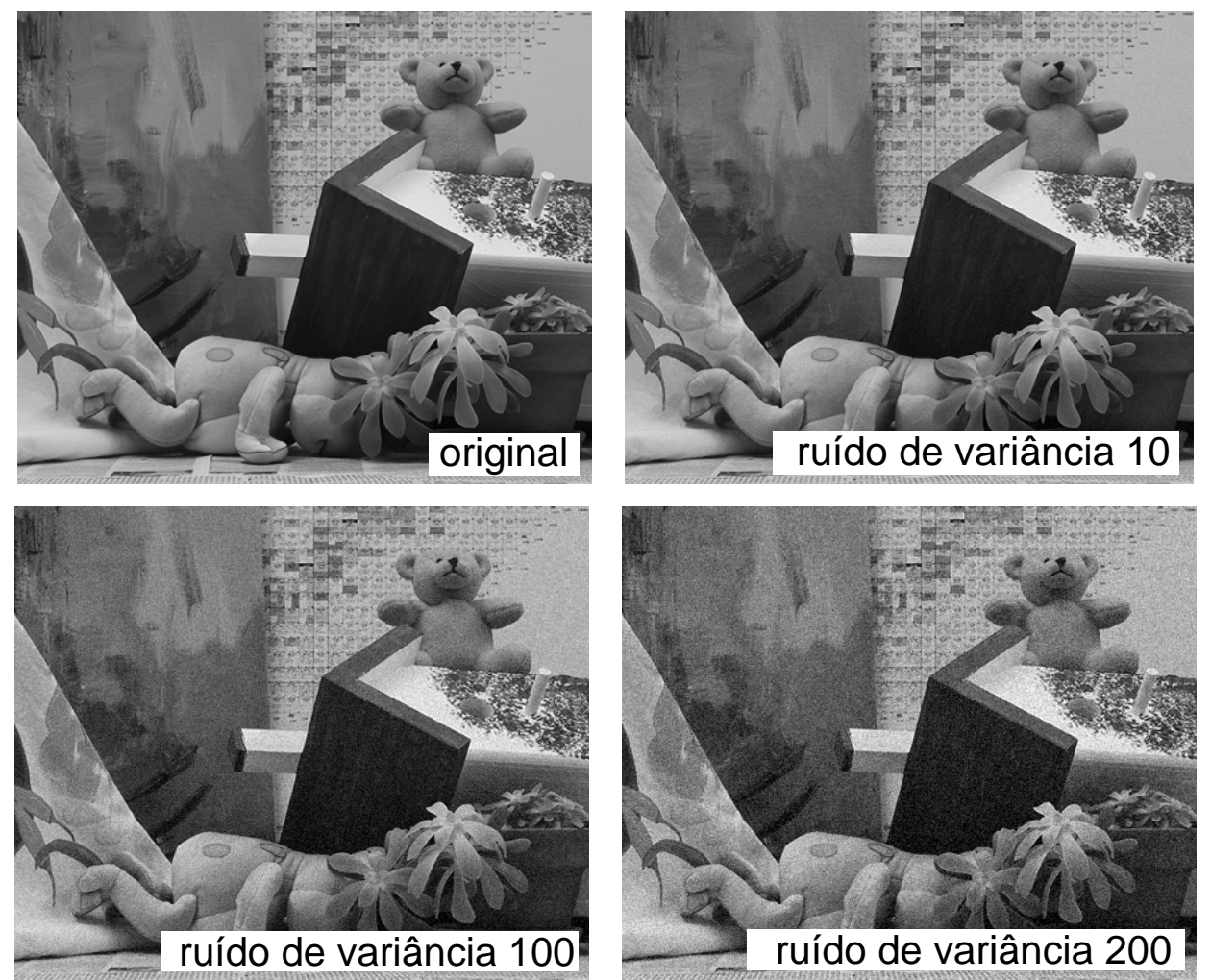

Figura 3.4: Imagens Teddy original e contaminadas com ruído de variância 10, 100 e 200
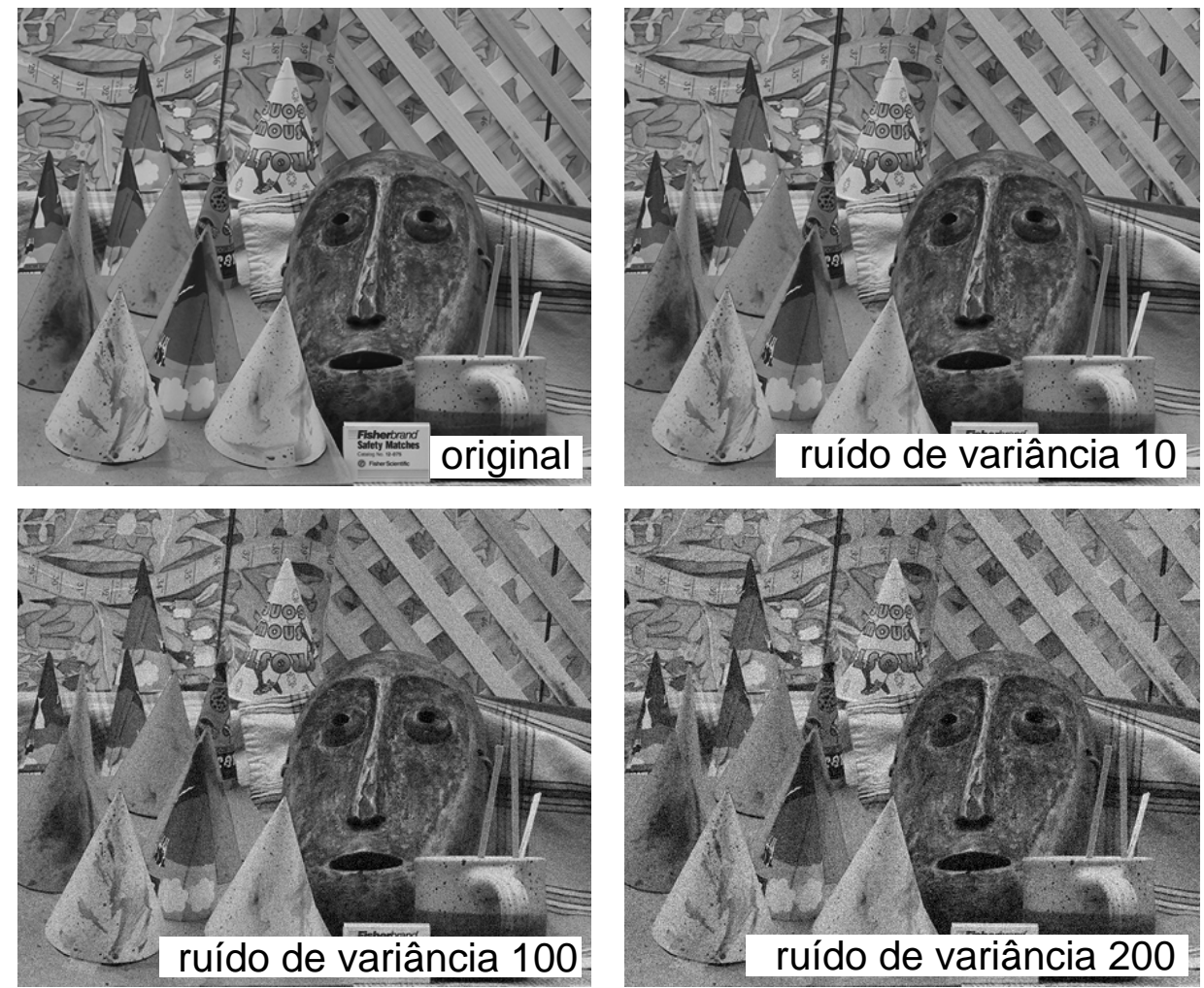

Figura 3.5: Imagens Cones original e contaminadas com ruído de variância 10, 100 e 200 


\begin{tabular}{|c|c|c|c|}
\hline \multirow{2}{*}{$\begin{array}{c}\text { Média do limiar } \alpha \\
\text { calculado }\end{array}$} & $\begin{array}{c}\text { Imagem do } \\
\text { Corredor }\end{array}$ & $\begin{array}{c}\text { Imagem } \\
\text { Teddy }\end{array}$ & $\begin{array}{c}\text { Imagem } \\
\text { Cones }\end{array}$ \\
\cline { 2 - 4 } [pontos] & [pontos] & [pontos] \\
\hline Original & 3 & 2 & 2 \\
\hline $\begin{array}{c}\text { Com ruído de } \\
\text { variância 10 }\end{array}$ & 5 & 6 & 5 \\
\hline $\begin{array}{c}\text { Com ruído de } \\
\text { variância 100 }\end{array}$ & 12 & 12 & 12 \\
\hline $\begin{array}{c}\text { Com ruído de } \\
\text { variância 200 }\end{array}$ & 14 & 13 & 14 \\
\hline
\end{tabular}

Tabela 3.1: Comparação dos limiares obtidos com diferentes imagens

Ao executar as Transformadas Modificadas 1 e 2 com a modificação proposta e com janela de 15 x 15 apenas variando-se o limiar, obtém-se os gráficos de influência do limiar conforme mostrado nas Figuras 3.6 a 3.9. Nestes gráficos o valor médio do limiar obtido está destacado.

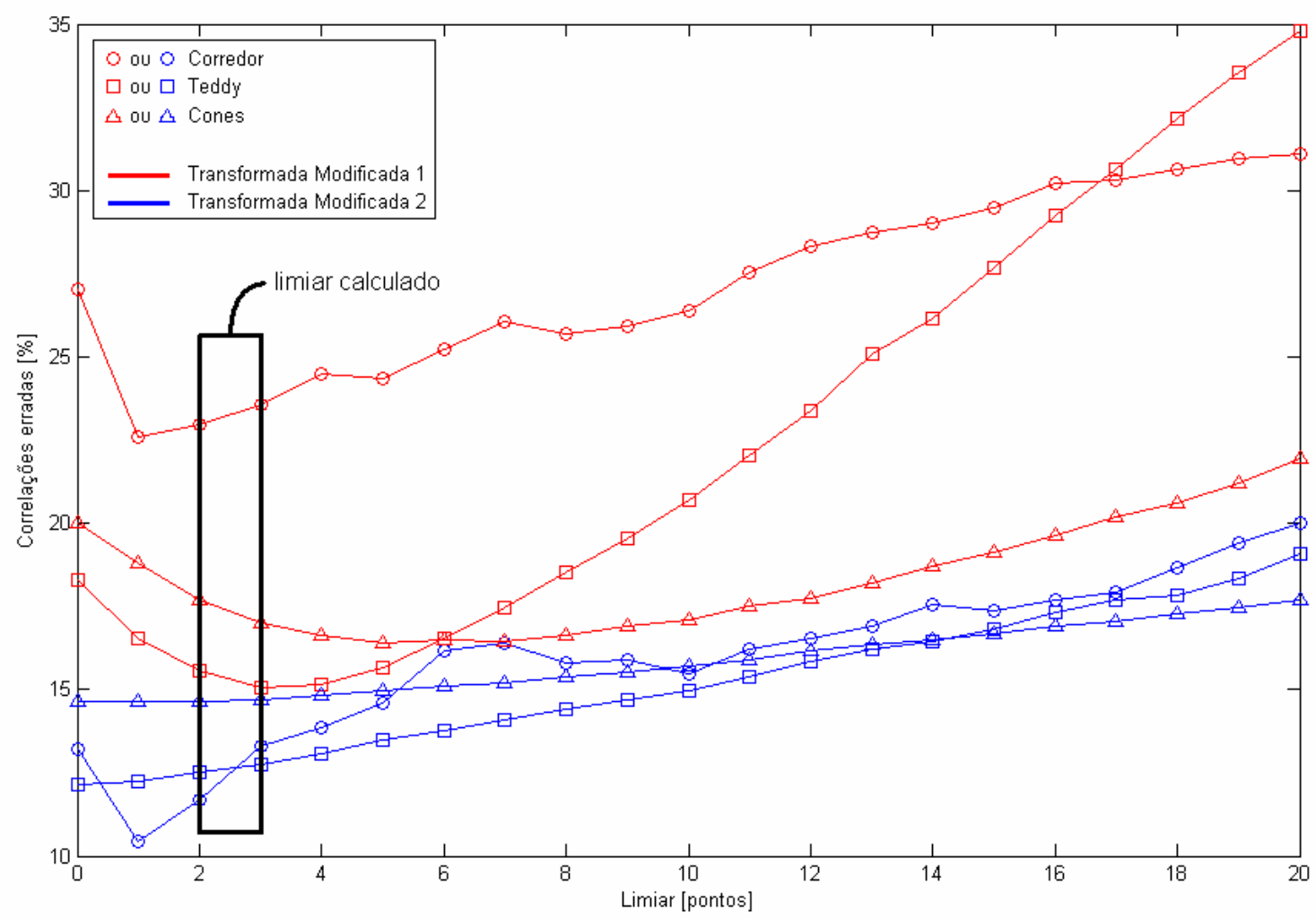

Figura 3.6: Efeito da mudança do limiar na imagem original 


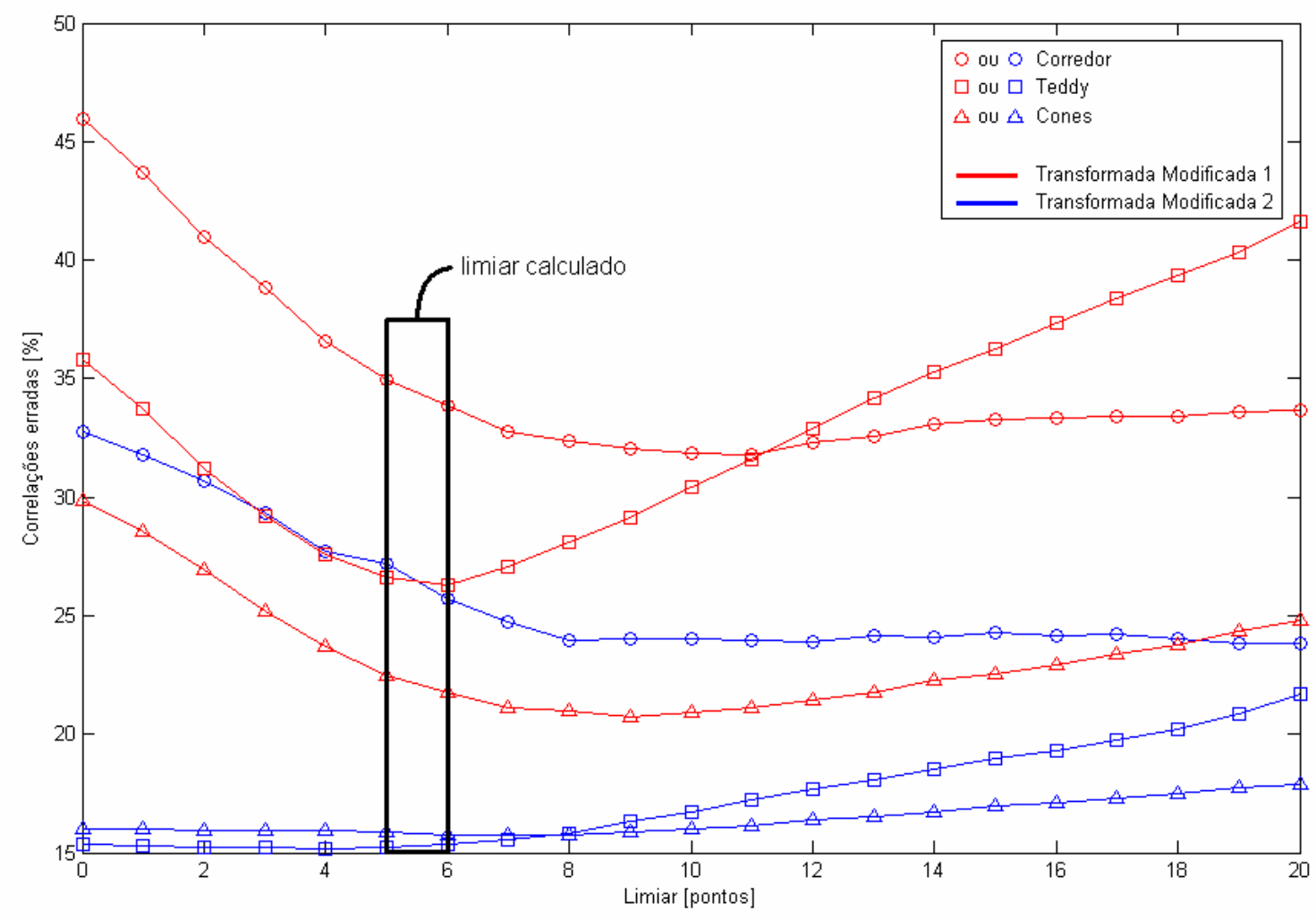

Figura 3.7: Efeito da mudança do limiar na imagem com ruído de variância 10

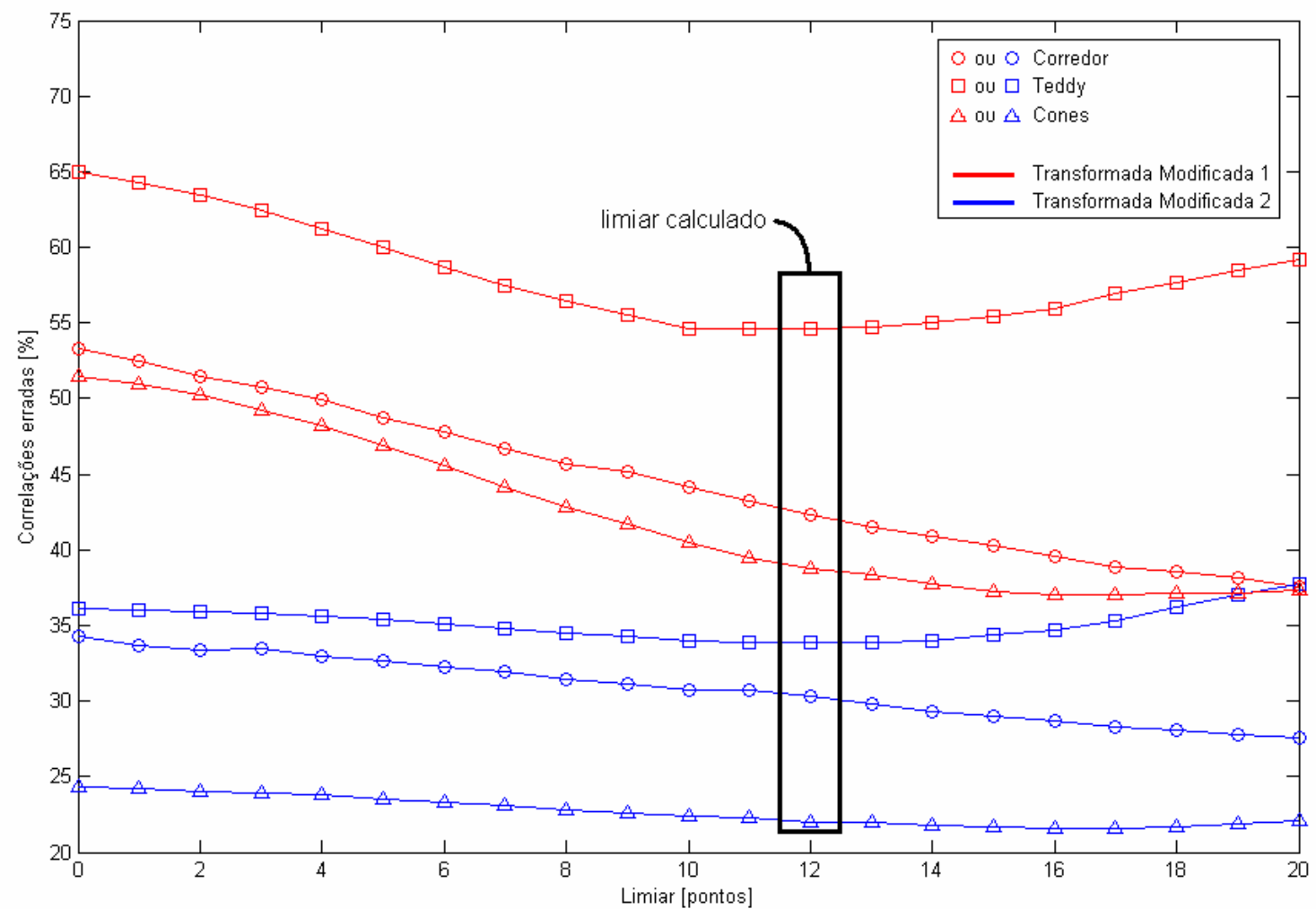

Figura 3.8: Efeito da mudança do limiar na imagem com ruído de variância 100 


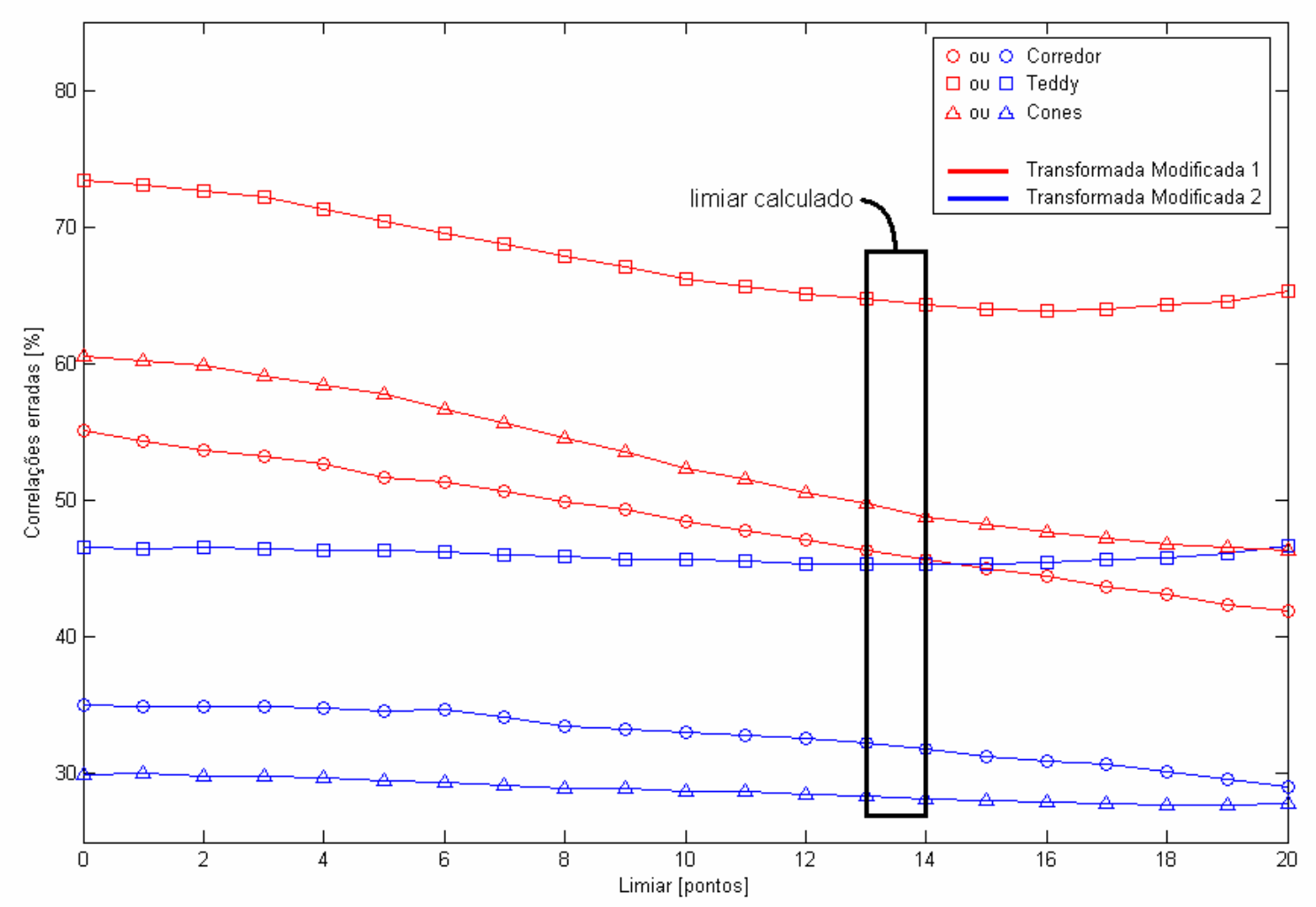

Figura 3.9: Efeito da mudança do limiar na imagem com ruído de variância 200

Como é possível observar nas Figuras 3.6 a 3.9 os valores de $\alpha$ calculados conforme proposto resultam em valores próximos dos melhores casos de limiar, oferecendo uma incidência de correlações erradas próximas do mínimo possível de se obter variando apenas o limiar. Portanto, o parâmetro $\alpha$ pode ser definido pela equação 3.2:

$$
\alpha=2 \cdot \begin{gathered}
\text { média do desvio } \\
\text { padrão das linhas }
\end{gathered}\left(\begin{array}{c}
\text { matriz de diferenças entre as colunas, calculada em } \\
\text { uma região da imagem com variação suave de intensidade }
\end{array}\right)
$$

Onde:

$\alpha$ será chamado de limiar e é um valor para a tolerância ao ruído da imagem

Como o valor de $\alpha$ é definido em pontos, este deve ser arredondado para o inteiro mais próximo quando da utilização em algum dos métodos.

Um exemplo do cálculo do valor do limiar para uma imagem será mostrado adotando a região destacada na Figura 3.10. Observa-se que região escolhida é 
pequena apenas para facilitar a representação da matriz da intensidade dos pontos no exemplo, pois o tamanho da região escolhida influencia pouco no resultado final desde que escolhida uma região variação suave de intensidade.

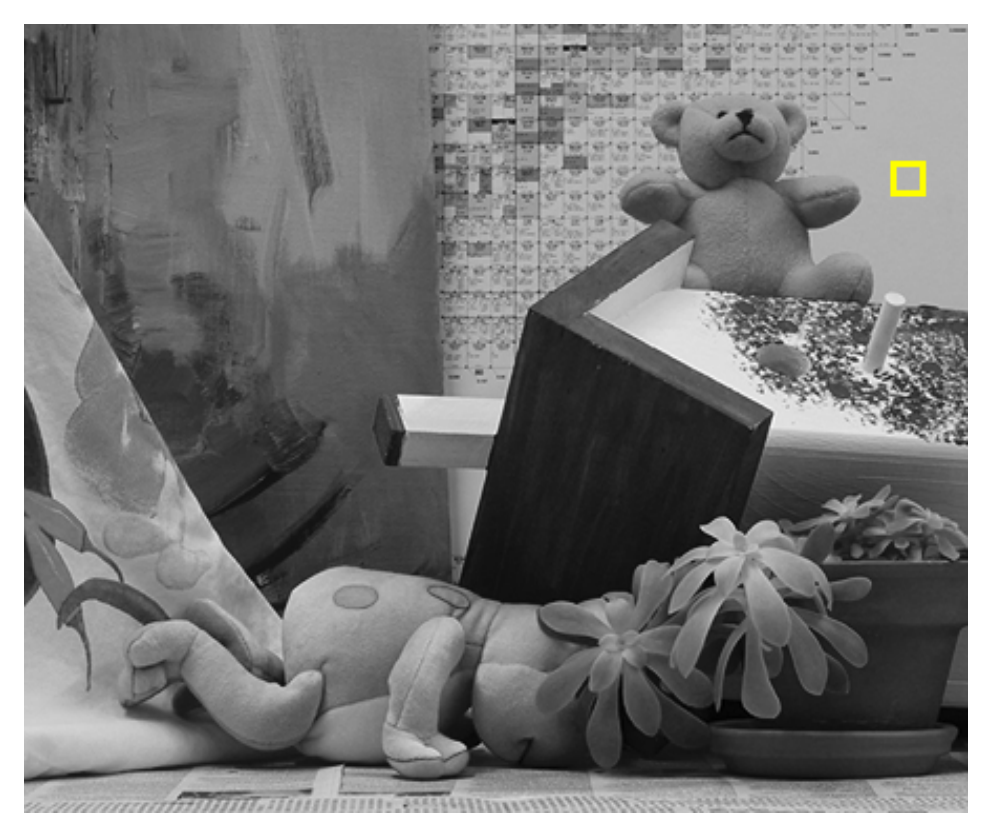

Figura 3.10: Região escolhida para o exemplo do cálculo do limiar

A região destacada na Figura 3.10 possui as intensidades luminosas mostradas na primeira matriz da Figura 3.11. O primeiro passo a ser feito é a subtração de uma coluna pela outra, em seguida obtém-se o desvio padrão das linhas da nova matriz obtida após a subtração. O passo final é a obtenção da média do desvio padrão das linhas e multiplicá-lo por 2 para se obter a estimativa do $\alpha$ a ser utilizado. 


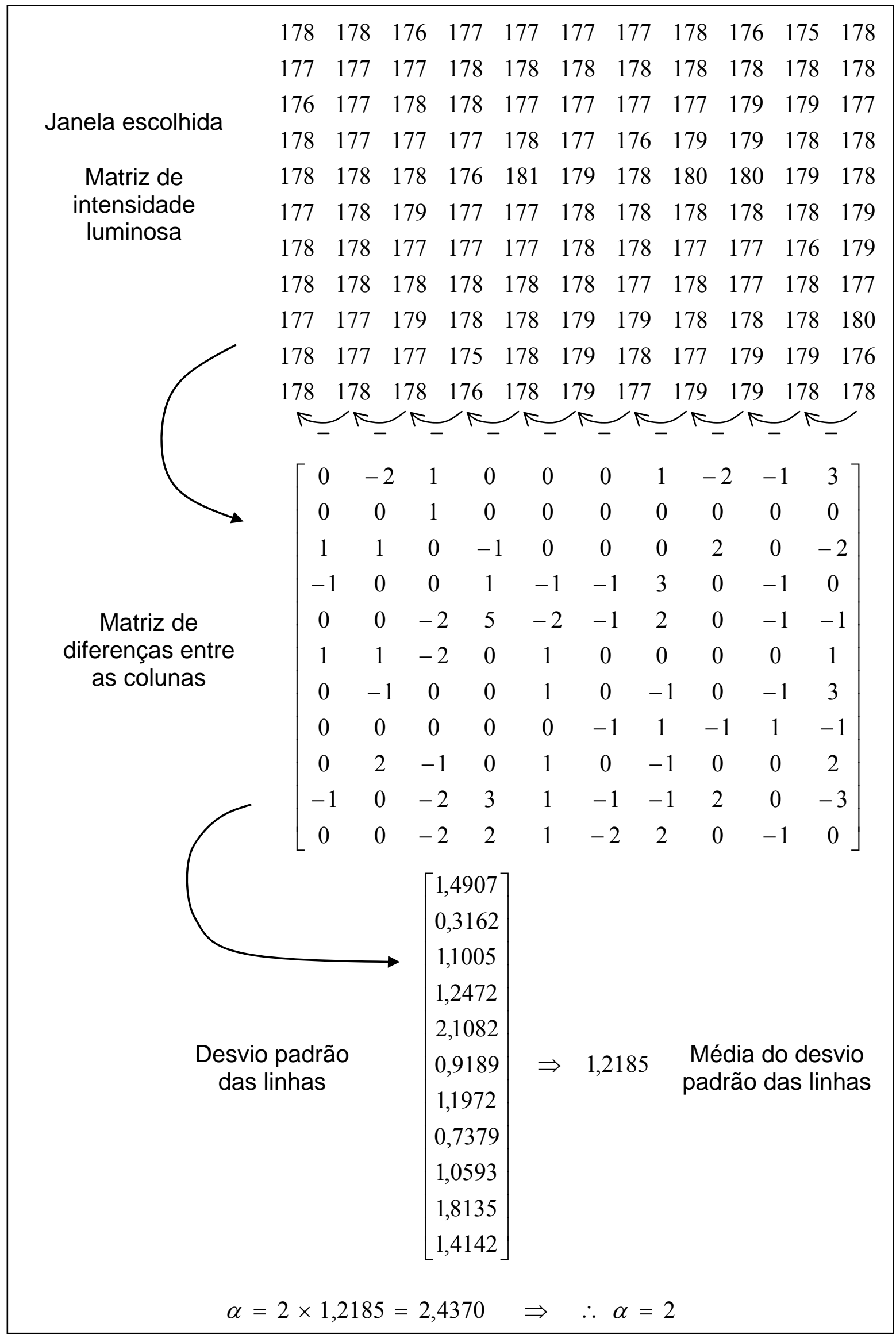

Figura 3.11: Exemplo de cálculo do limiar $\alpha$ 


\section{RESULTADOS}

\subsection{Descrição dos experimentos e da métrica de avaliação}

Como este trabalho busca comparar apenas os algoritmos de correspondência verificando sua eficiência em algumas situações e propor uma alteração no método da Transformada Censo, será adotada uma implementação simples dos algoritmos sem a utilização de pós-processamentos, restrições ou janelas adaptativas que possam mascarar os resultados obtidos pelos métodos. Apenas será considerado que as imagens já estão retificadas para a redução do espaço de busca.

Em linhas gerais a implementação adotada para os algoritmos do trabalho será:

Primeiramente, escolhe-se um ponto de interesse na primeira imagem, em seguida define-se uma janela de interesse ao redor desse ponto escolhido, comumente chamada de janela alvo ou referência.

Define-se na segunda imagem uma janela contendo o alvo a ser localizado, esta é a chamada janela de busca.

$\mathrm{Na}$ etapa final realiza-se a pesquisa na janela de busca movendo-se uma janela de dimensões iguais à janela alvo e comparando-a com a janela alvo, o ponto correspondente é o que produzir o máximo (ou mínimo dependendo da função de correlação) valor na função de correlação. O modo de realizar essa comparação muda de algoritmo para algoritmo, porque em cada um existe uma função distinta para tentativa quantificação da semelhança das janelas.

Já tendo encontrados os pontos correspondentes, a disparidade do ponto entre uma imagem e a outra será a diferença das coordenadas do ponto na imagem esquerda e na direita (em pontos). Neste caso a diferença ocorrerá apenas na coordenada $\mathrm{x}$, porque as linhas já estão correspondentes devido à retificação realizada anteriormente.

Para a comparação da performance dos algoritmos de correlação analisados, foi realizada uma implementação dos métodos sem aplicar técnicas de correção e aperfeiçoamento dos mapas de disparidades calculados. Portanto, não serão 
aplicadas táticas como a restrição de variação suave das disparidades, nem os métodos WTA ("Winner Take All") e a verificação das disparidades com as correlações esquerda-direita e direita-esquerda (respectivamente janelas de busca e alvo).

$\mathrm{Na}$ implementação adotada utilizaram-se janelas fixas definidas pelo usuário no momento da chamada da função e a disparidade máxima a ser buscada também é fornecida neste momento. Na implementação dos algoritmos definiu-se que a imagem direita será a imagem de referência (alvo) e a imagem esquerda a de busca conforme esquematizado na Figura 4.1. Então, para cada ponto na imagem de referência a imagem de busca será varrida partindo-se de um ponto na mesma posição até uma disparidade máxima a ser verificada.
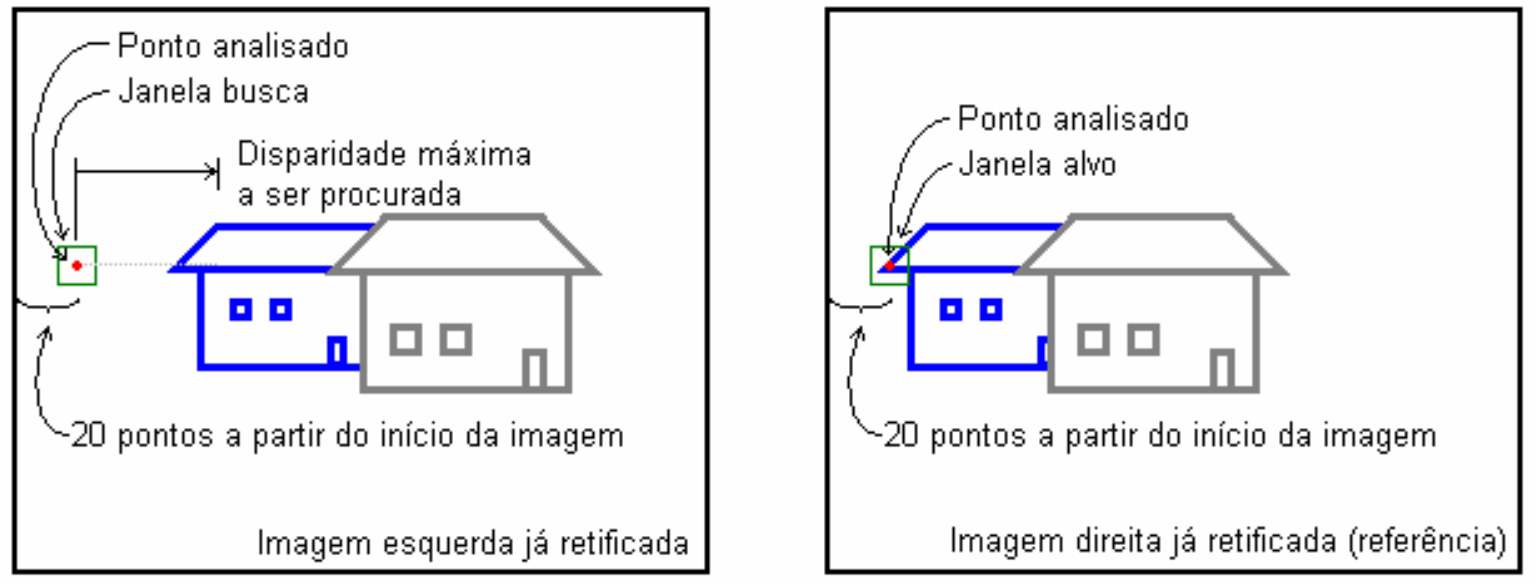

Figura 4.1: Esquema da implementação dos algoritmos

Ao todo serão comparados 10 algoritmos diferentes sendo que 5 são comuns e bastante utilizados, uma modificação do algoritmo Censo proposta por Gautama (1999) à bastante tempo e quatro variantes diferentes da modificação propostas no trabalho. Todos os códigos fontes das implementações encontram-se no Apêndice A.

No caso da modificação proposta para a Transformada Censo é necessário mais um parâmetro chamado limiar. O valor do limiar adotado para as imagens foi definido para cada imagem adotando-se uma pequena área em uma região da imagem que possua uma textura uniforme e calculado conforme descrito no item 3 equação 3.2. A função chamada limiar.m (Apêndice A) implementa o cálculo do limiar na imagem fornecida. 
A Tabela 4.1 mostra que a escolha da região na imagem, desde que a mesma possua textura uniforme, possui pouca influência no valor do limiar. Para o cálculo dos valores obtidos na tabela utilizaram-se janelas escolhidas nas imagens contaminadas com ruído de variância 100. As Figuras 4.2 a 4.4 mostram as regiões utilizadas para os cálculos dos valores mostrados na Tabela 4.1.

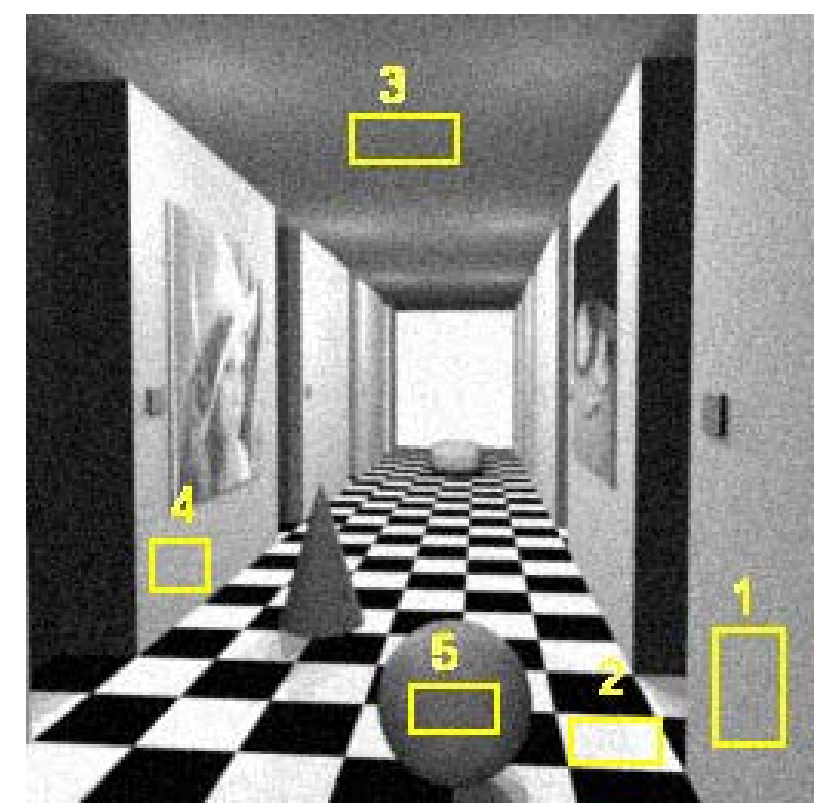

Figura 4.2: Regiões escolhidas na imagem do Corredor

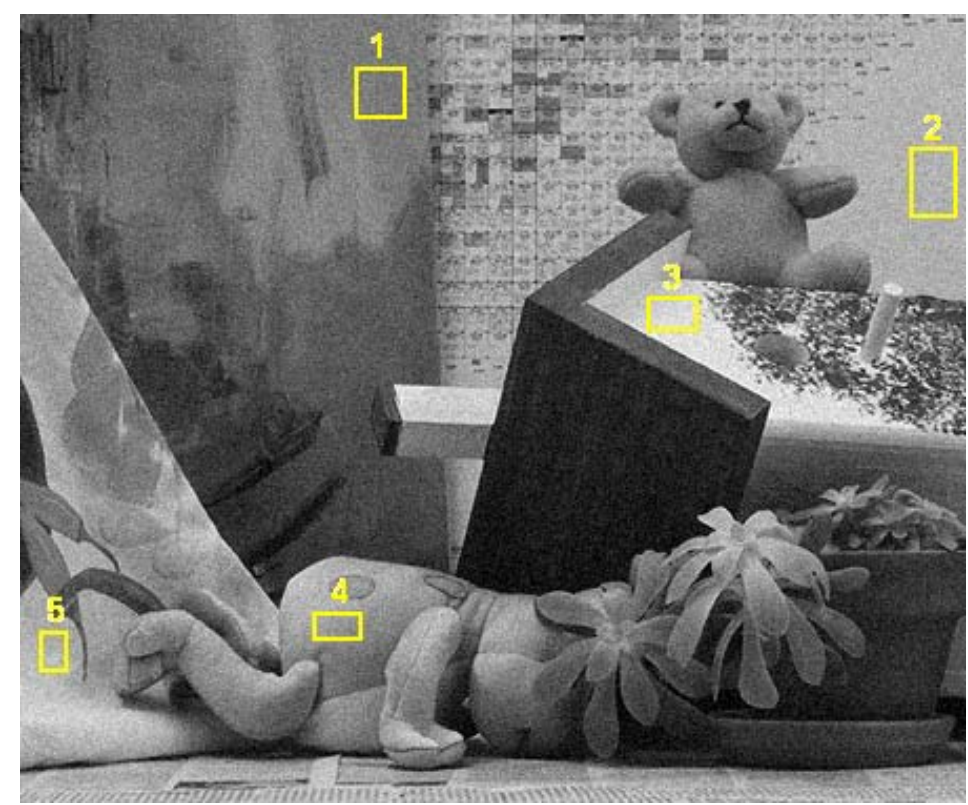

Figura 4.3: Regiões escolhidas na imagem Teddy 


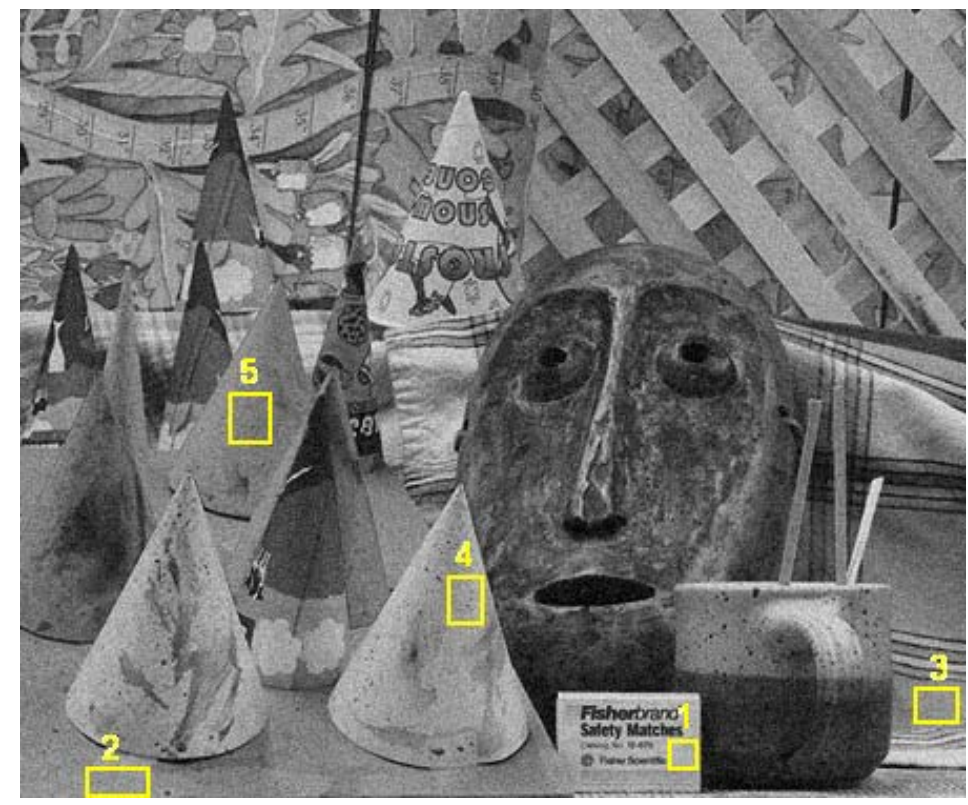

Figura 4.4: regiões escolhidas na imagem Cones

\begin{tabular}{|c|c|c|c|c|c|c|}
\hline \multirow{2}{*}{$\begin{array}{c}\text { Áreas } \\
\text { escolhidas }\end{array}$} & $\mathbf{1}$ & $\mathbf{2}$ & $\mathbf{3}$ & $\mathbf{4}$ & $\mathbf{5}$ & Média \\
\cline { 2 - 7 } & [pontos] & [pontos] & [pontos] & [pontos] & [pontos] & [pontos] \\
\hline Corredor & 11,7 & 11,2 & 11,7 & 11,5 & 11,6 & 11,5 \\
\hline Cones & 12,2 & 12,3 & 11,3 & 12,8 & 12,9 & 12,3 \\
\hline Teddy & 11,4 & 11,7 & 11,4 & 12,2 & 11,8 & 11,7 \\
\hline
\end{tabular}

Tabela 4.1: Comparação dos limiares obtidos com regiões diferentes das imagens

O ruído foi introduzido nas imagens com uma função escrita em Matlab para ser possível controlar sua variância e incidência. A função que insere o ruído na imagem encontra-se no Apêndice A e chama-se ruido.m. O ruído especificado foi inserido em ambas a imagens. O ruído tem por objetivo tentar simular alguma interferência na transmissão ou captura da imagem ou a granulação gerada na imagem pelo uso de sensibilidade ISO muito elevada.

A variação de luminosidade foi introduzida nas imagens com o auxílio de um programa editor de imagens. A imagem escolhida para o escurecimento foi a imagem esquerda, sendo a direita mantida com sua luminosidade original. A mudança de luminosidade em apenas uma imagem tem por objetivo simular as diferenças inerentes às duas câmeras utilizadas. 
A avaliação dos resultados será realizada comparando-se os mapas de disparidades calculados com o mapa de disparidade verdadeiro disponível nos repositórios de onde as imagens foram obtidas. Serão exibidos os valores das correlações erradas em forma percentual (Equação 4.1). O limite utilizado para aceitar a disparidade calculada como correta será de \pm 1 ponto, da mesma forma como adotado em Scharstein e Szeliski (2002).

$$
\text { Corr_erradas }=\frac{1}{\mathrm{~N}} \cdot \sum_{(\mathrm{x}, \mathrm{y})}\left(\left|\operatorname{disp}_{\text {calculada }}(\mathrm{x}, \mathrm{y})-\operatorname{disp} \mathrm{real}_{\text {real }}(\mathrm{x}, \mathrm{y})\right|>1\right) \cdot 100
$$

Onde:

Corr_erradas corresponde a porcentagem de correlações erradas

disp calculada corresponde à disparidade calculada para o ponto

disp real corresponde à disparidade real do ponto

$\mathrm{N}$ é o número total de pontos da imagem

$x$ e $y$ são as coordenadas, linha e coluna, do ponto de interesse

Observa-se que neste trabalho a incidência de correlações erradas será vista como um todo, não se separando as regiões com oclusões e nem as regiões de bordas.

Será apresentado também o erro RMS ("Root Mean Squared") entre o mapa de disparidades calculado e o real. Este erro será calculado conforme mostrado na equação 4.2 .

$$
\text { Erro_RMS }=\left(\frac{1}{\mathrm{~N}} \cdot \sum_{(\mathrm{x}, \mathrm{y})}\left|\operatorname{disp}_{\text {calculada }}(\mathrm{x}, \mathrm{y})-\operatorname{disp}_{\text {real }}(\mathrm{x}, \mathrm{y})\right|^{2}\right)^{\frac{1}{2}}
$$

Onde:

Erro_RMS corresponde ao erro RMS da imagem

disp calculada corresponde à disparidade calculada para o ponto

disp real corresponde à disparidade real do ponto

$\mathrm{N}$ é o número total de pontos da imagem

$x$ e $y$ são as coordenadas, linha e coluna, do ponto de interesse 


\subsection{Aplicação dos métodos na imagem do Corredor}

Esta imagem foi obtida no repositório da Universidade de Bonn (2005), sendo um exemplo de imagem sintética simples com várias regiões praticamente sem textura. As imagens esquerda, direita e o mapa de disparidades verdadeiro da imagem direita são mostrados na Figura 4.5.
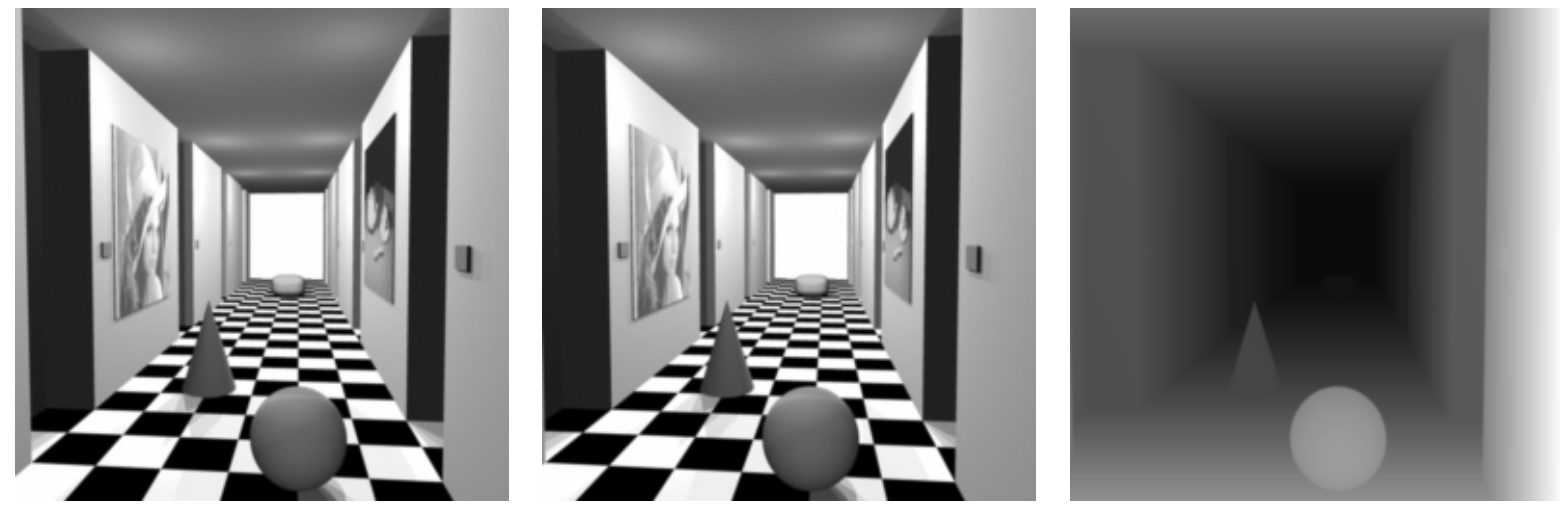

Figura 4.5: Imagens do corredor obtidas do repositório da Universidade de Bonn

Em um primeiro teste foram calculados os mapas de disparidades com as imagens originais com todos os métodos e comparados os resultados.

Para a aplicação dos métodos com a Transformada Modificada 1, 2, 4 e 5 calculou-se o valor do limiar adotando-se como referência a região destacada na Figura 4.6, visto que já foi mostrada a pouca influencia da região escolhida no valor obtido para o limiar.

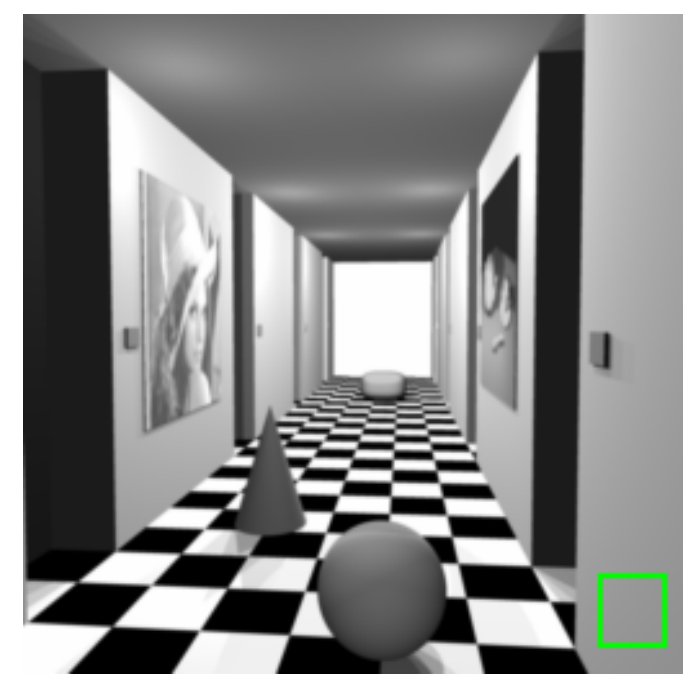

Figura 4.6: Região utilizada para o cálculo do limiar na imagem do corredor 
O limiar obtido na imagem original e nas imagens com luminosidade modificada é de 3 pontos, mostrando que a mudança da luminosidade não interfere no valor do limiar.

Nas Figuras 4.7 e 4.8, observa-se que o método que fornece mais correlações erradas é o que utiliza a Transformada Censo. Os métodos com as Transformadas Modificadas 1, 3 (proposto por Gautama, 1999) e 4 (junção da modificação realizada em 1 com a realizada em 3) os quais utilizam a implementação comum da Transformada Censo e aplicam a transformada em cada janela analisada apresentam resultados apenas um pouco melhores que os da Transformada Censo.

Já as Transformadas Modificadas 2 e 5 (junção das modificações de 2 e 3) conseguem uma grande melhora nos resultados das disparidades, conseguindo performance semelhante aos dos métodos Soma das Diferenças Absolutas e Soma dos Quadrados das Diferenças em alguns casos de janelas de busca.

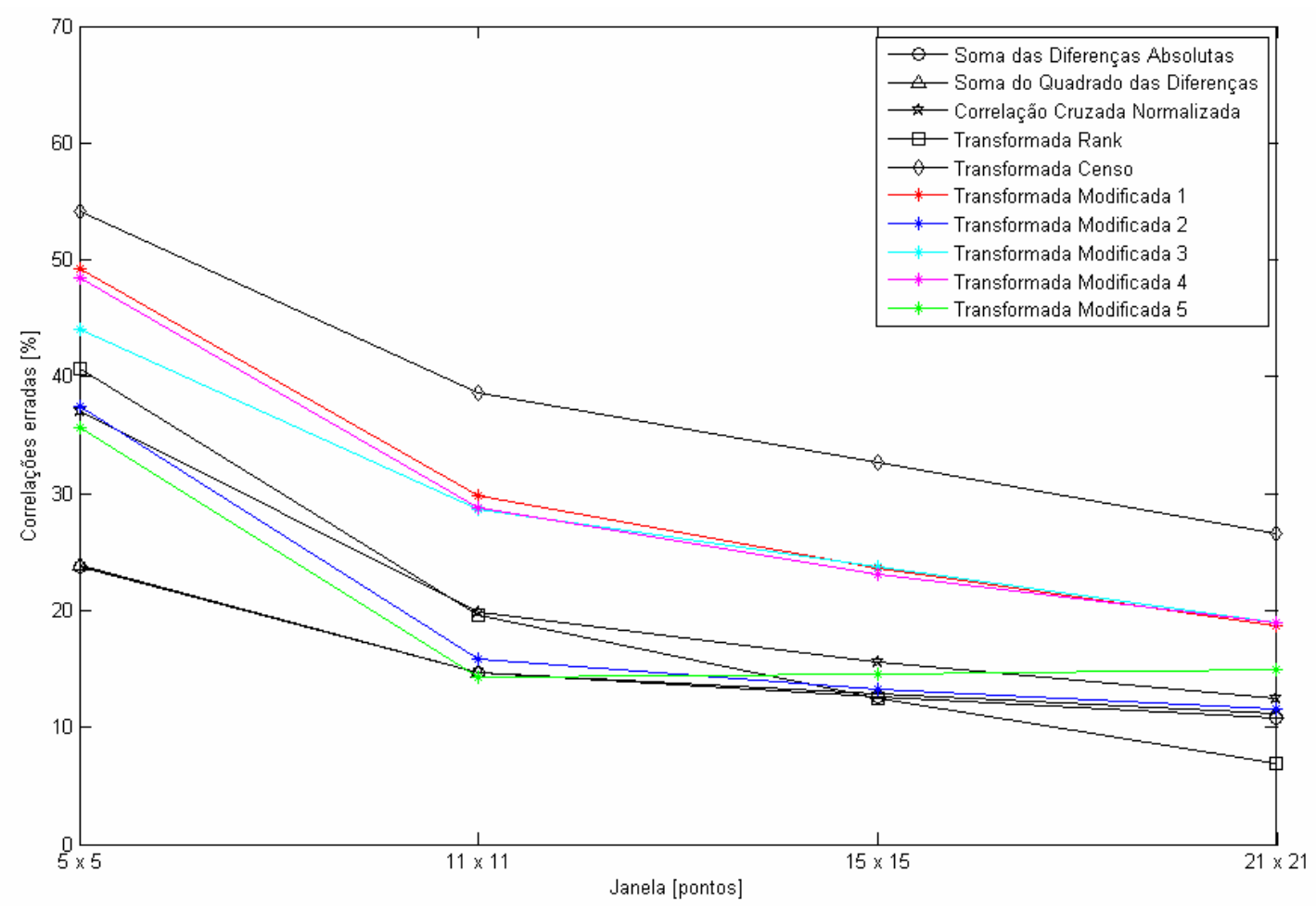

Figura 4.7: Correlações erradas na imagem original do corredor 


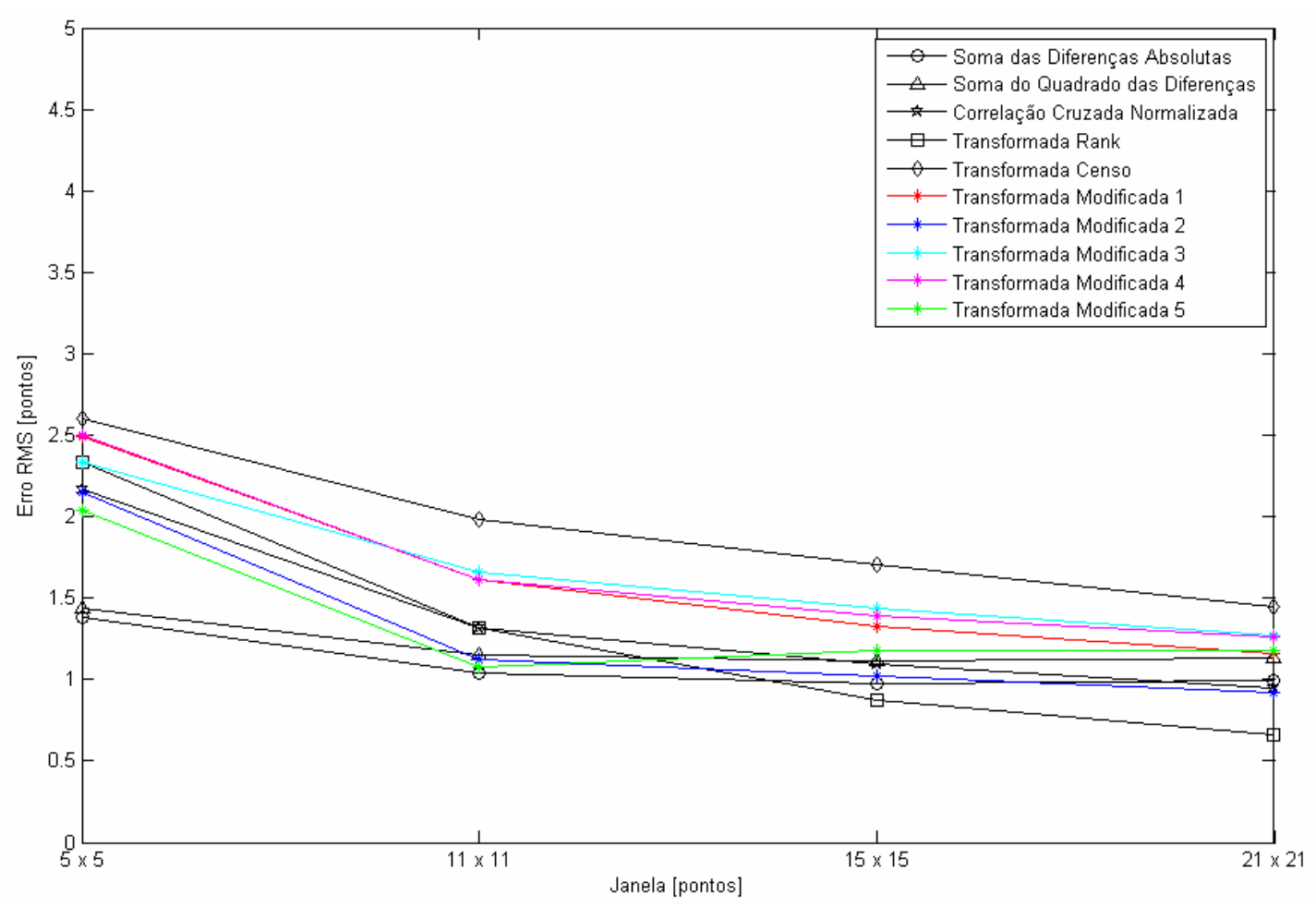

Figura 4.8: Erro RMS das correlações na imagem original do corredor

Com relação ao tempo de execução, observa-se que conforme há o aumento da janela as Transformadas Modificadas 1, 5 e 2 apresentam melhorias nos tempos de execução comparando-se com a Transformada Censo (Tabela 4.2). Observa-se também que a Correlação Cruzada Normalizada, a Transformada Modificada 3 e a Transformada Modificada 4 são os métodos com os piores tempos de execução. Os tempos mostrados na tabela 4.2 são de experimentos executados em um computador Core 2 Duo E6300 com 1 GB de memória DDR2 667.

Os mapas de disparidades resultantes da execução dos algoritmos nas imagens originais estão disponíveis no Apêndice B nas Figuras B1 a B10. Neles é possível observar como os mapas de disparidade se apresentam conforme o tamanho da janela é modificado nos diversos métodos analisados. Nos mapas mostrados no Apêndice B é adotada uma apresentação em tons de cinza, no qual tons claros indicam objetos próximos e tons escuros objetos distantes. 


\begin{tabular}{|c|c|c|c|c|}
\hline \multirow{2}{*}{ Janela } & $\mathbf{5} \mathbf{x} \mathbf{5}$ & $\mathbf{1 1} \mathbf{x} \mathbf{1 1}$ & $\mathbf{1 5} \mathbf{x} \mathbf{1 5}$ & $\mathbf{2 1} \mathbf{x} \mathbf{2 1}$ \\
\cline { 2 - 5 } & {$[\mathbf{s}]$} & {$[\mathbf{s}]$} & {$[\mathbf{s}]$} & {$[\mathbf{s}]$} \\
\hline Soma das Diferenças Absolutas & 5,1 & 6,8 & 7,5 & 9,7 \\
\hline Soma do Quadrado das Diferenças & 5,8 & 6,7 & 7,5 & 9,6 \\
\hline Correlação Cruzada Normalizada & 55,3 & 58,6 & 61,8 & 67,7 \\
\hline Transformada Rank & 6,6 & 7,8 & 8,9 & 11,6 \\
\hline Transformada Censo & 8,6 & 15,3 & 21,1 & 33,0 \\
\hline Transformada Modificada 1 & 12,3 & 14,8 & 17,3 & 23,3 \\
\hline Transformada Modificada 2 & 7,1 & 8,3 & 9,5 & 12,2 \\
\hline Transformada Modificada 3 & 52,3 & 54,0 & 56,3 & 61,1 \\
\hline Transformada Modificada 4 & 57,8 & 61,1 & 64,6 & 72,2 \\
\hline Transformada Modificada 5 & 12,5 & 13,8 & 15,1 & 18,1 \\
\hline \hline
\end{tabular}

Tabela 4.2: Tempos de execução dos métodos com as diferentes janelas utilizadas

Em um segundo passo, pares de imagens com luminosidades diferentes foram analisados. Optou-se por reduzir a luminosidade da imagem esquerda em 10\%, 20\% e em seguida 30\% para comparar a influência dessa variação nos resultados.

A Figura 4.9 apresenta as imagens com uma diferença de 10\% na luminosidade.
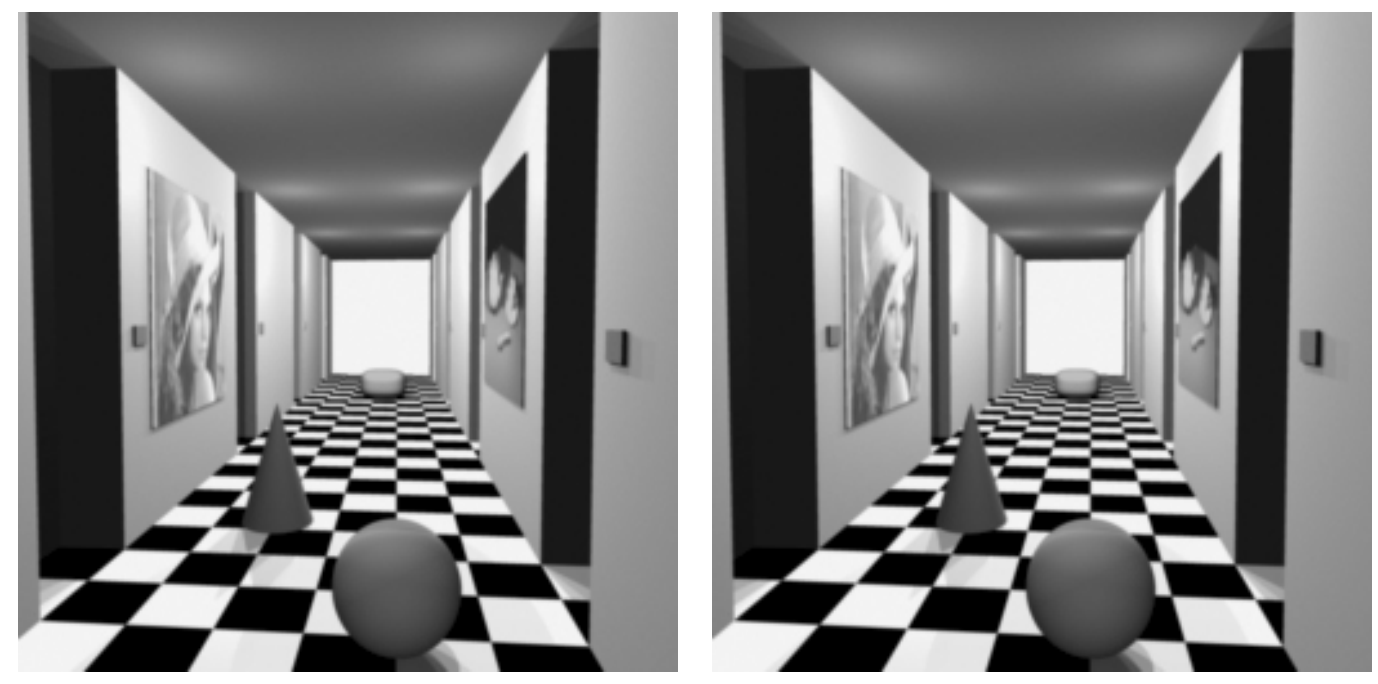

Figura 4.9: Imagem esquerda com luminosidade $10 \%$ menor

Já com apenas $10 \%$ de diferença na luminosidade entre as imagens fica visível, nos resultados mostrados nas Figuras 4.10 e 4.11, a queda da qualidade dos 
resultados dos métodos que não possuem nenhum tipo de normalização com relação a intensidade (Soma das Diferenças Absolutas e Soma do Quadrado das Diferenças).

Apenas os métodos Correlação Cruzada Normalizada e Transformada Modificada 2 conseguiram obter praticamente os mesmos resultado que os obtidos com a imagem original.

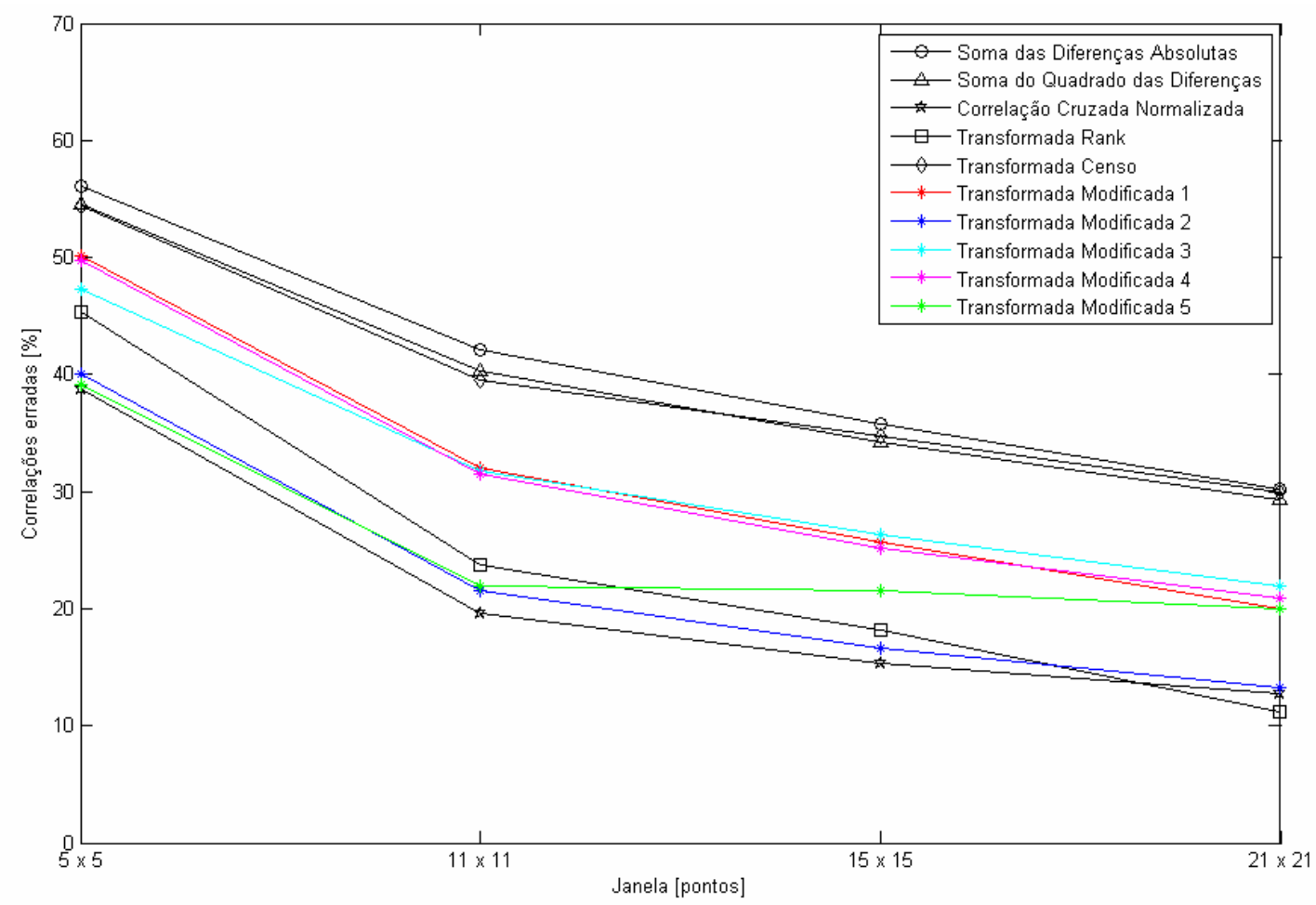

Figura 4.10: Correlações erradas na imagem do corredor com luminosidade 10\% diferente 


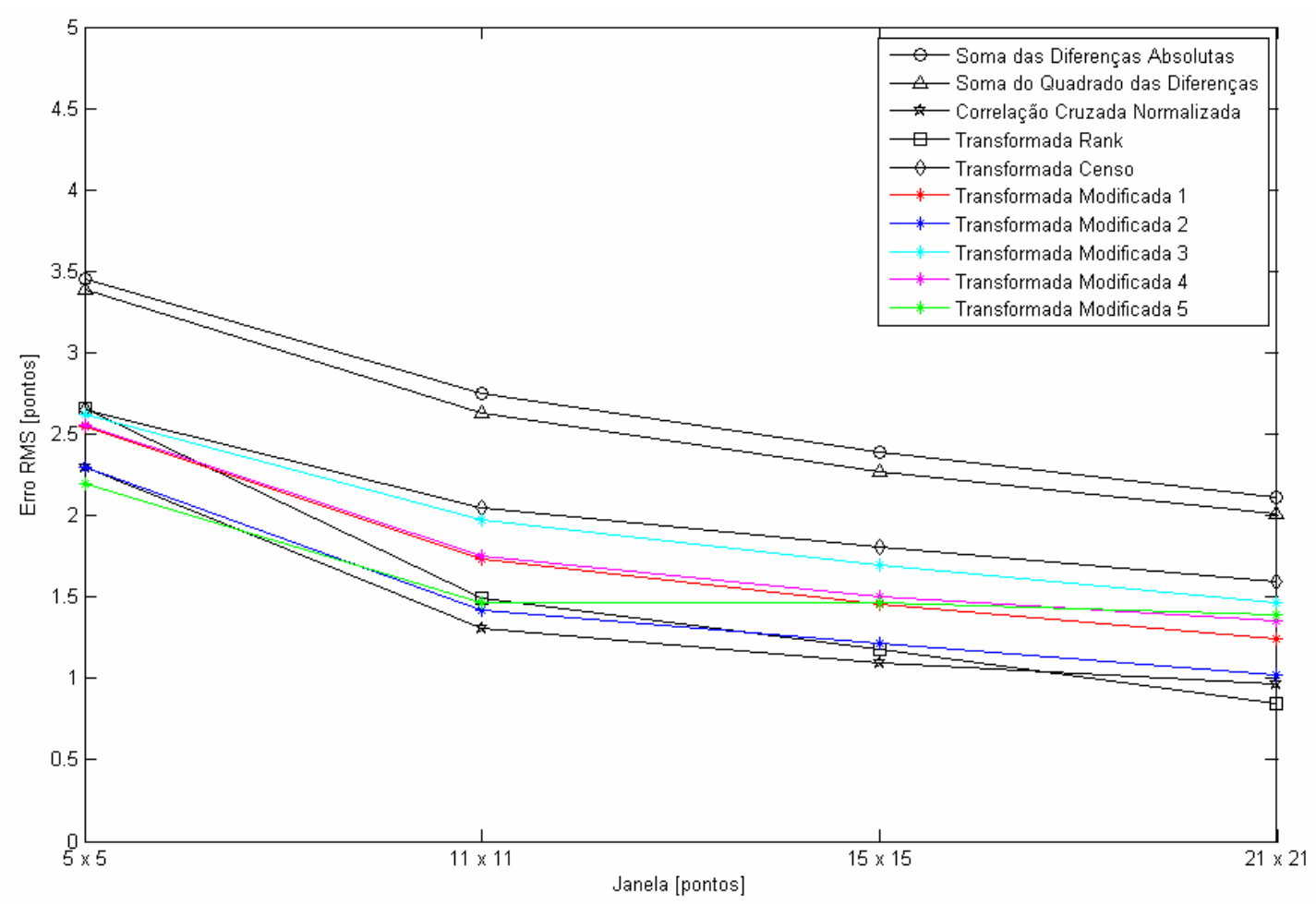

Figura 4.11: Erro RMS das correlações na imagem do corredor com luminosidade $10 \%$ diferente

A Figura 4.12 apresenta as imagens com uma diferença de 20\% na luminosidade.
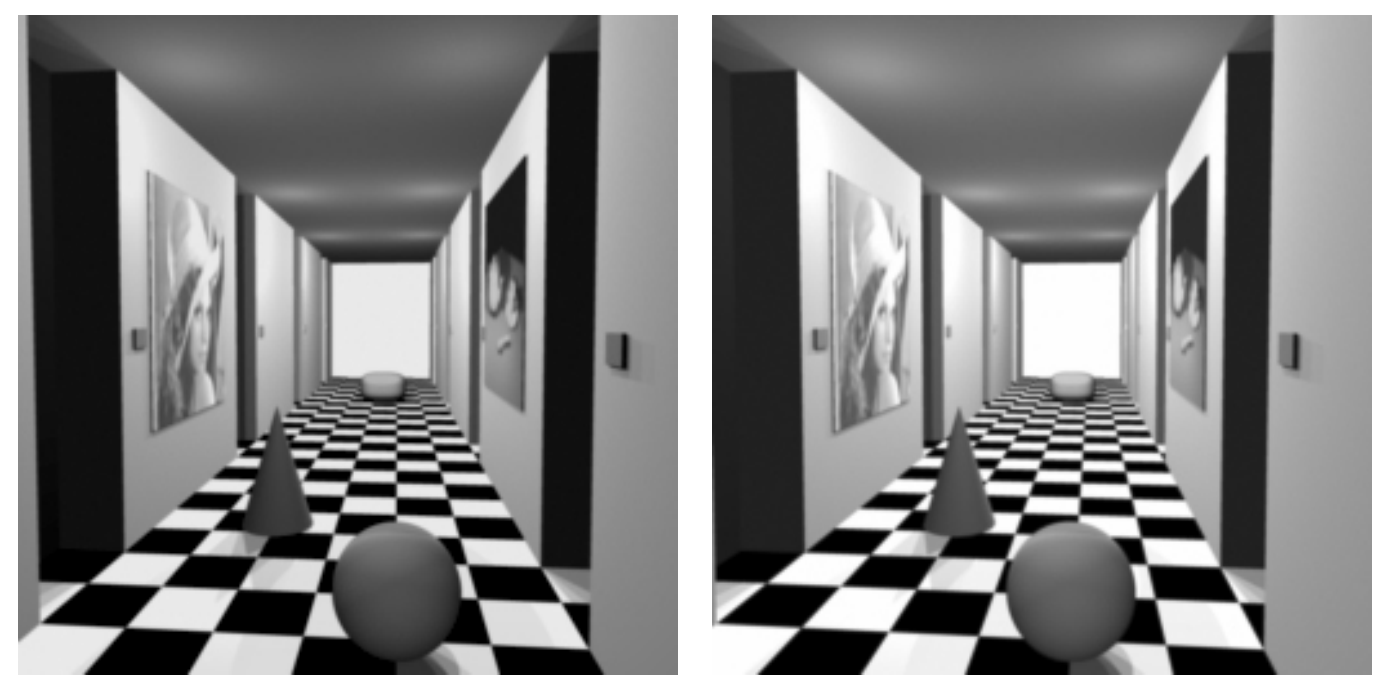

Figura 4.12: Imagem esquerda com luminosidade $20 \%$ menor

$\mathrm{Na}$ Figura 4.13 observa-se um resultado curioso, porque enquanto todos os outros métodos tiveram algum aumento nas correlações erradas apenas o método Transformada Rank voltou a obter resultados um pouco melhores que no caso da 
imagem com $10 \%$ de diferença na luminosidade. A Figura 4.14 mostra o erro RMS para os métodos quando aplicados à imagem com $10 \%$ de diferença de luminosidade.

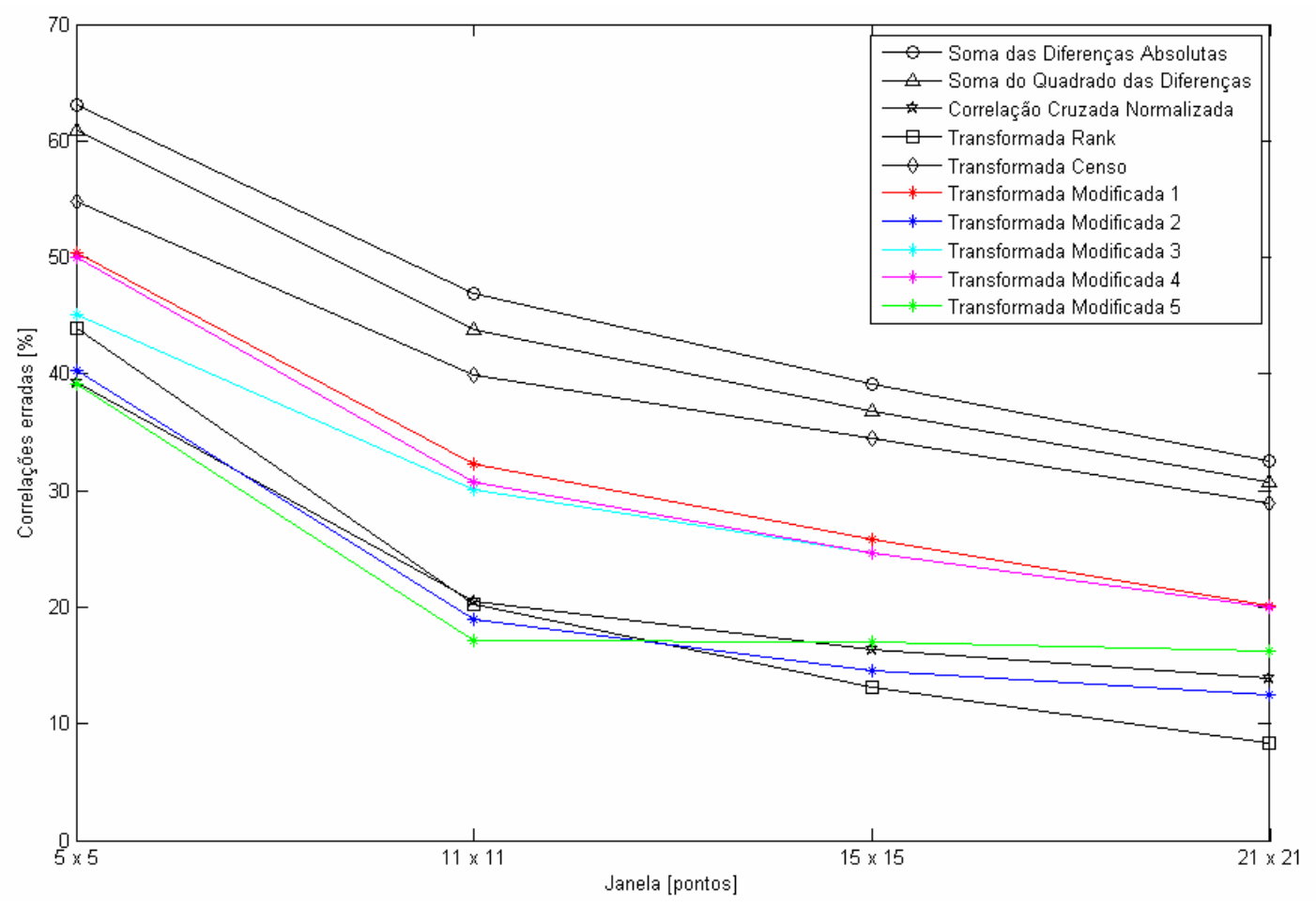

Figura 4.13: Correlações erradas na imagem do corredor com luminosidade $20 \%$ diferente

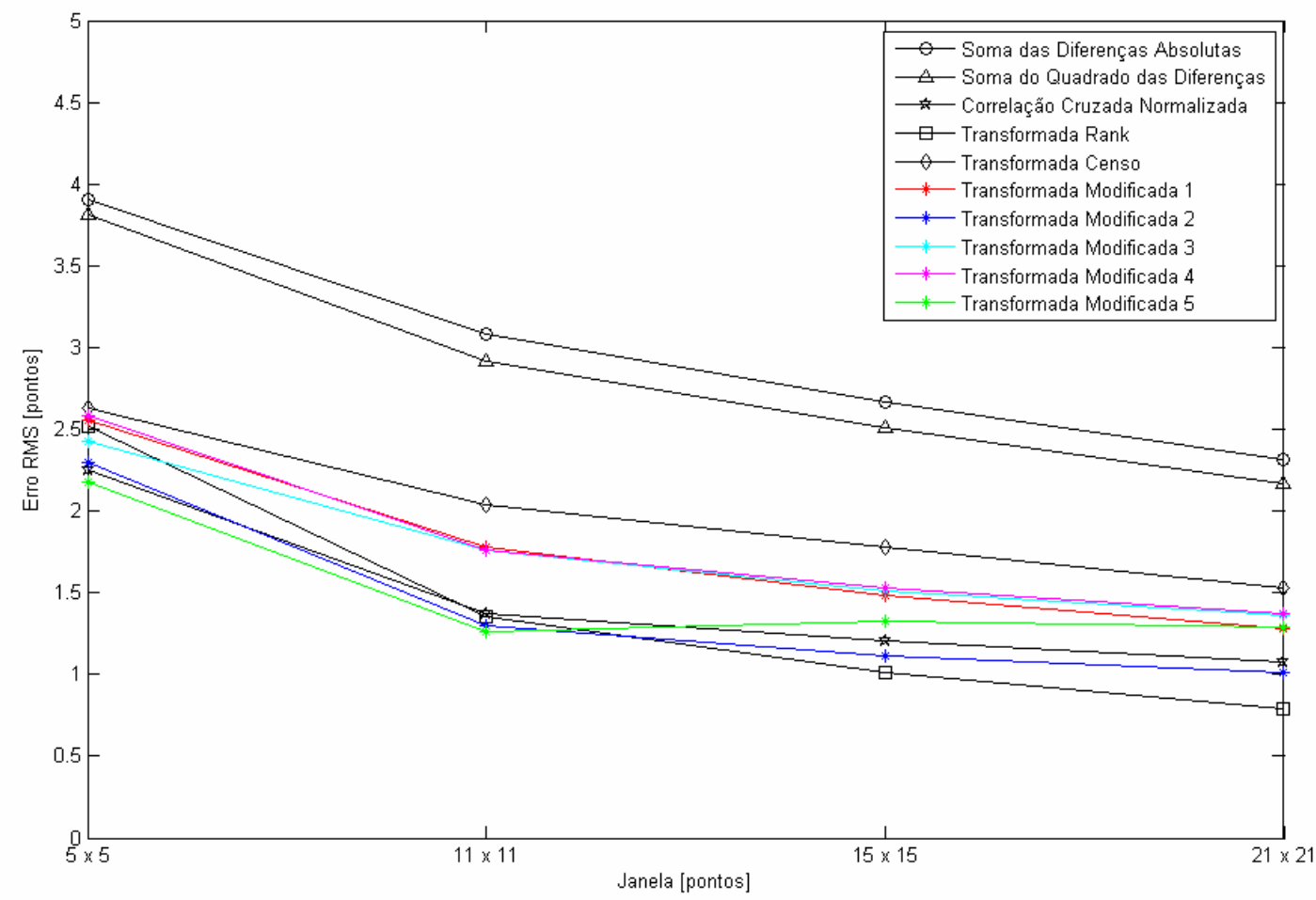

Figura 4.14: Erro RMS das correlações na imagem do corredor com luminosidade $20 \%$ diferente 
A Figura 4.15 apresenta as imagens com uma diferença de $30 \%$ na luminosidade.
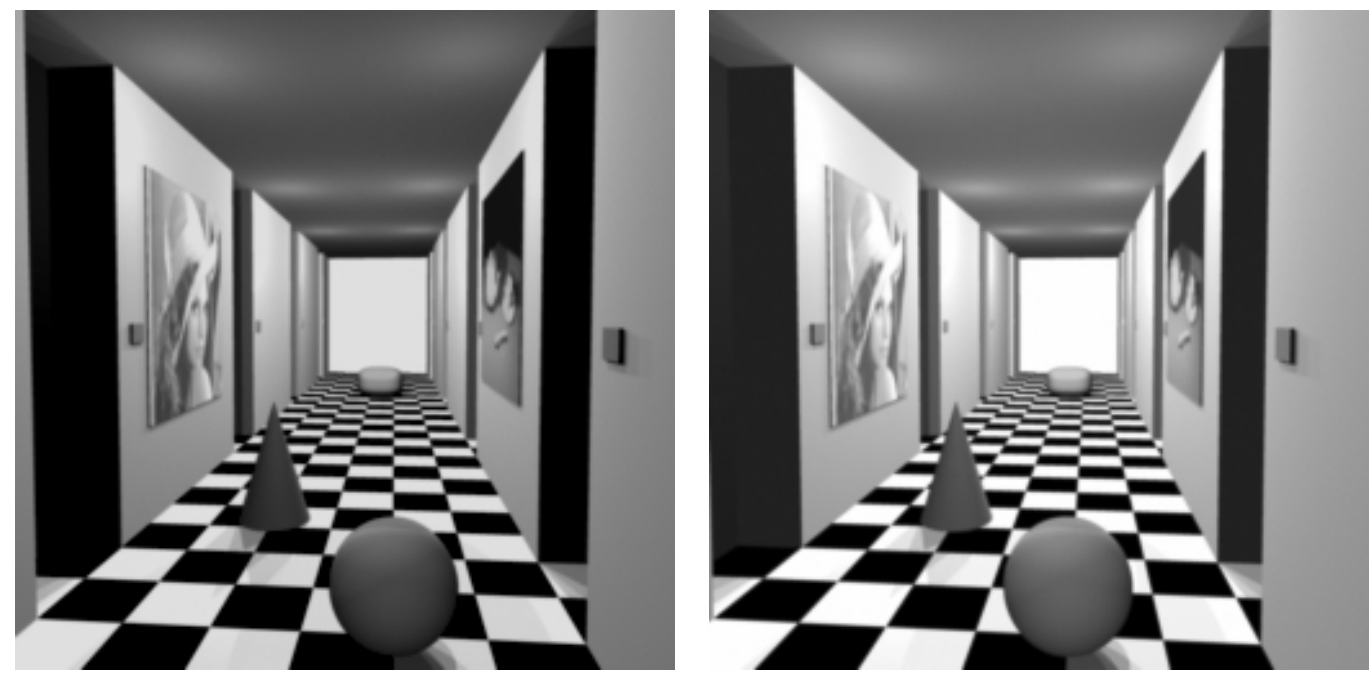

Figura 4.15: Imagem esquerda com luminosidade 30\% menor

Nas Figuras 4.16 e 4.17 é possível ver que com uma diferença de luminosidade de $30 \%$ o método Transformada Modificada 2 é o que apresentou resultados ligeiramente melhores, tanto na incidência de correlações erradas quanto no erro RMS do mapa de correlações, quando comparado aos métodos usuais que apresentam melhores resultados (Correlação Cruzada Normalizada e a Transformada Rank).

Os mapas de disparidades resultantes da execução dos algoritmos nas imagens com luminosidade $30 \%$ diferente estão disponíveis no Apêndice B nas Figuras B11 a B20. 


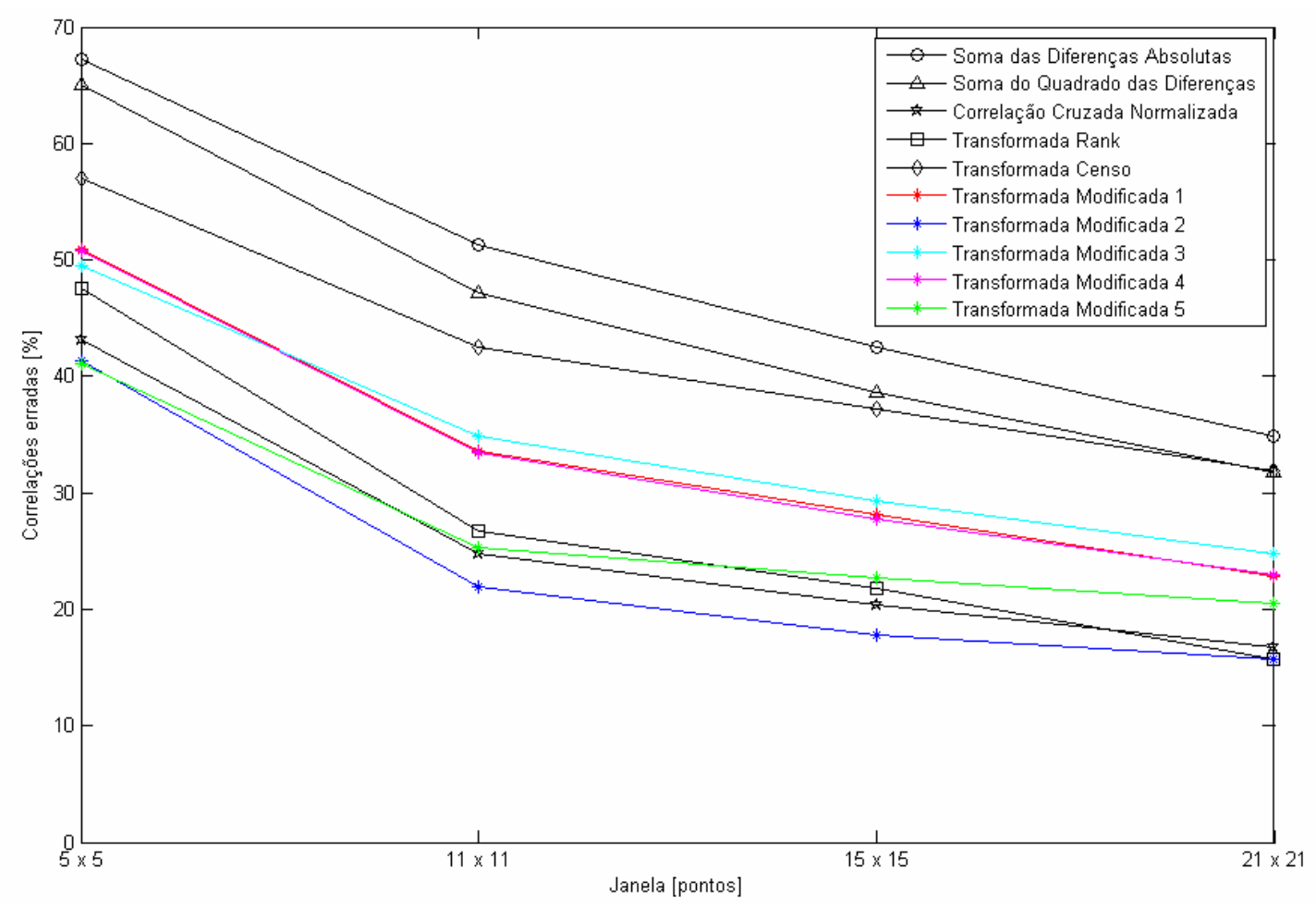

Figura 4.16: Correlações erradas na imagem do corredor com luminosidade $30 \%$ diferente

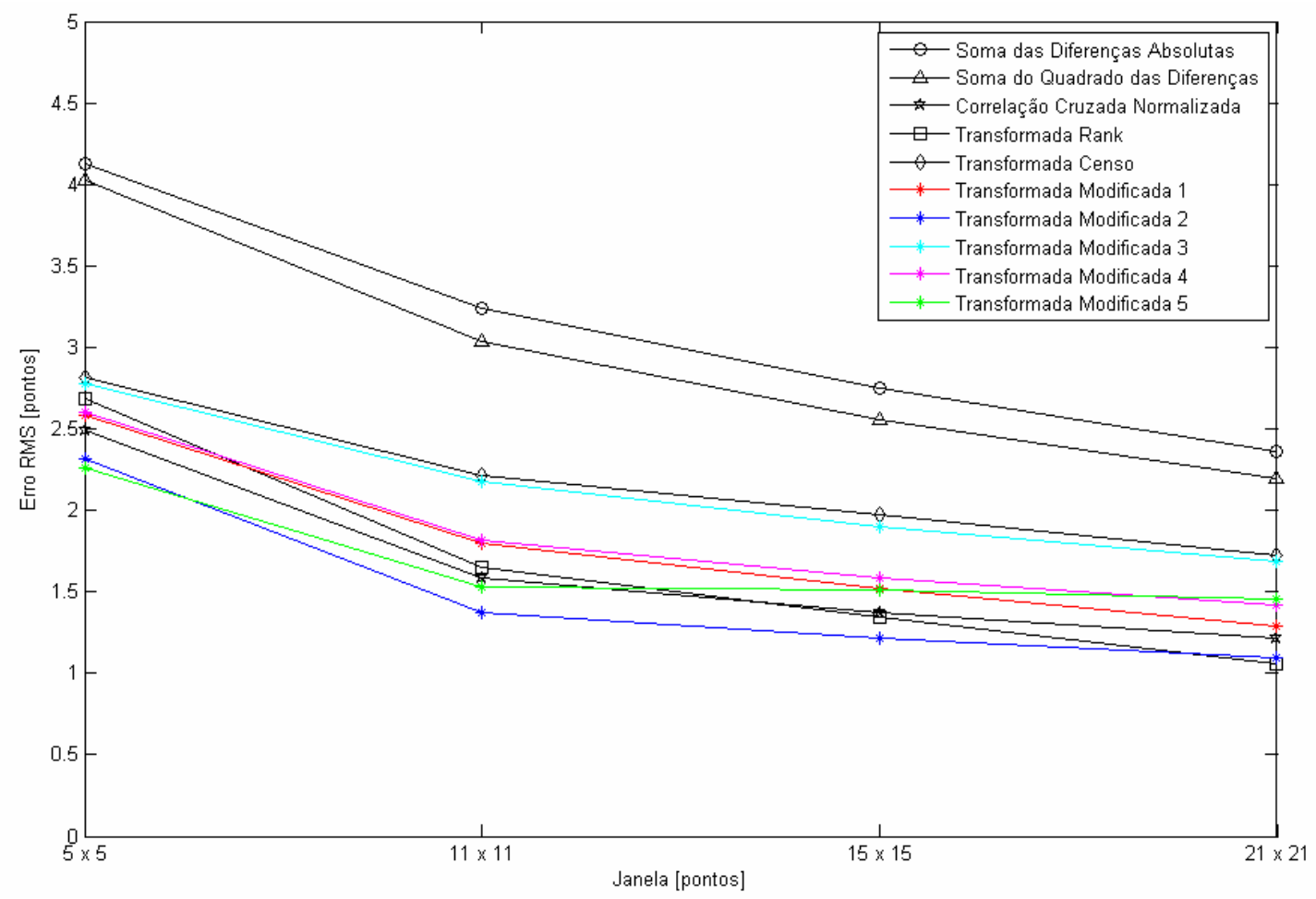

Figura 4.17: Erro RMS das correlações na imagem do corredor com luminosidade $30 \%$ diferente 
Em uma segunda etapa são comparados os resultados dos algoritmos quando executados com imagens com ruídos. Para os testes foram criadas versões das imagens originais com ruído de variância 10, 100 e 200 com incidência em todos os pontos da imagem e um caso com ruído de variância 200 com incidência em 50\% dos pontos da imagem. Conforme mencionado no Item 4.1 a rotina utilizada para a introdução do ruído nas imagens encontra-se no Apêndice $A$ com o nome ruido.m.

A Figura 4.18 mostra as imagens do corredor contaminadas com ruído de variância 10, nesta imagem foi obtido um limiar de 5 pontos.
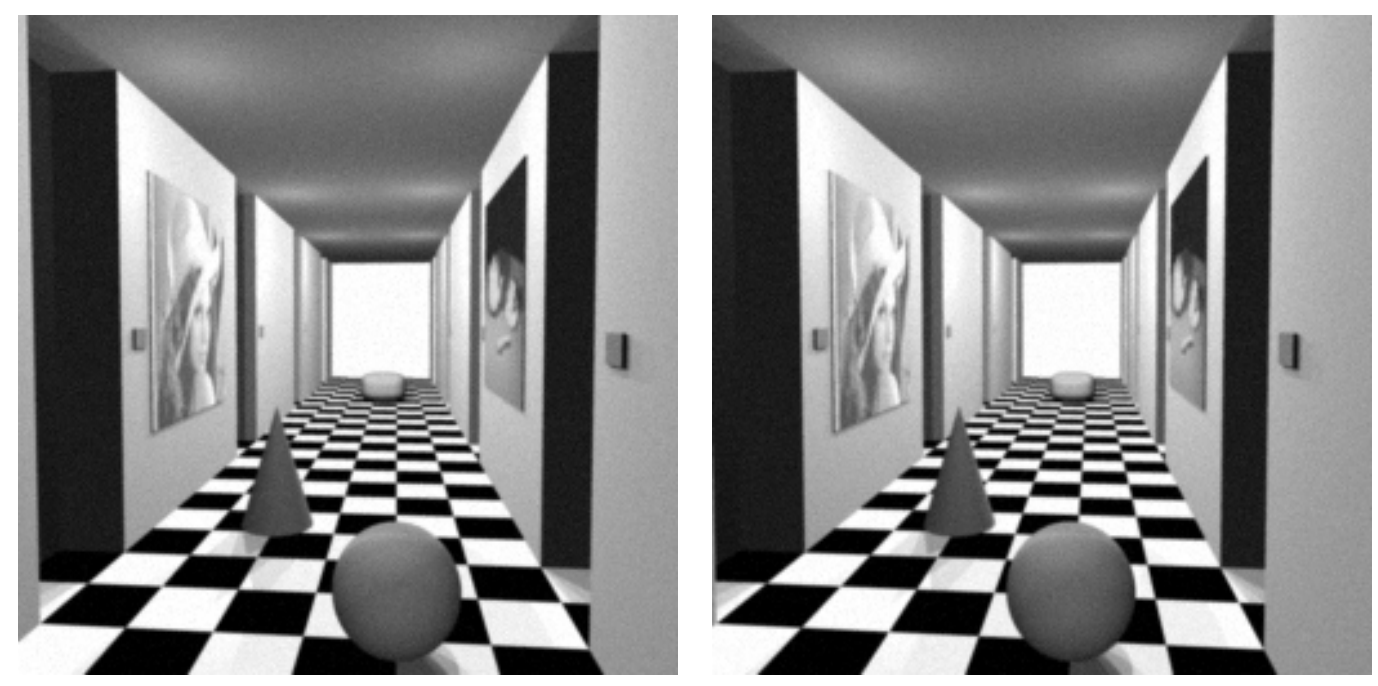

Figura 4.18: Imagens contaminadas com ruído de variância 10

Nos resultados observa-se que já com a introdução de um ruído com amplitude pequena, pouco perceptível visualmente como pode ser visto na Figura 4.18, ocorre uma grande degradação dos resultados apresentados pelos algoritmos de correlação, no geral apresentando mais de $20 \%$ de correlações erradas (Figura 4.19) e na Figura 4.20 observa-se o erro RMS dos métodos.

Observa-se que apenas a Transformada Modificada 5 consegue manter resultados próximos dos métodos Soma das Diferenças Absolutas e Soma do Quadrado das Diferenças. 


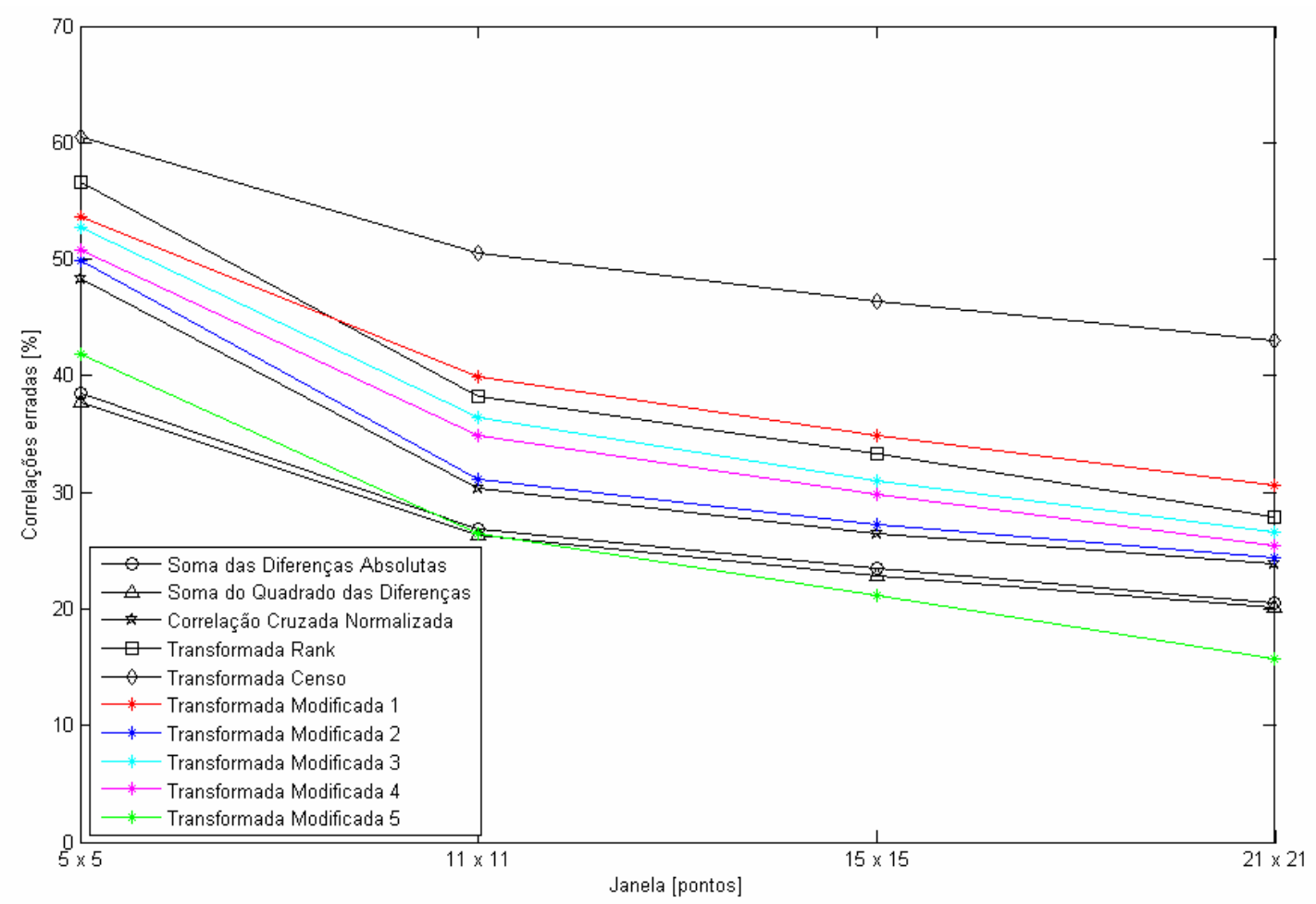

Figura 4.19: Correlações erradas na imagem do corredor com ruído de variância 10

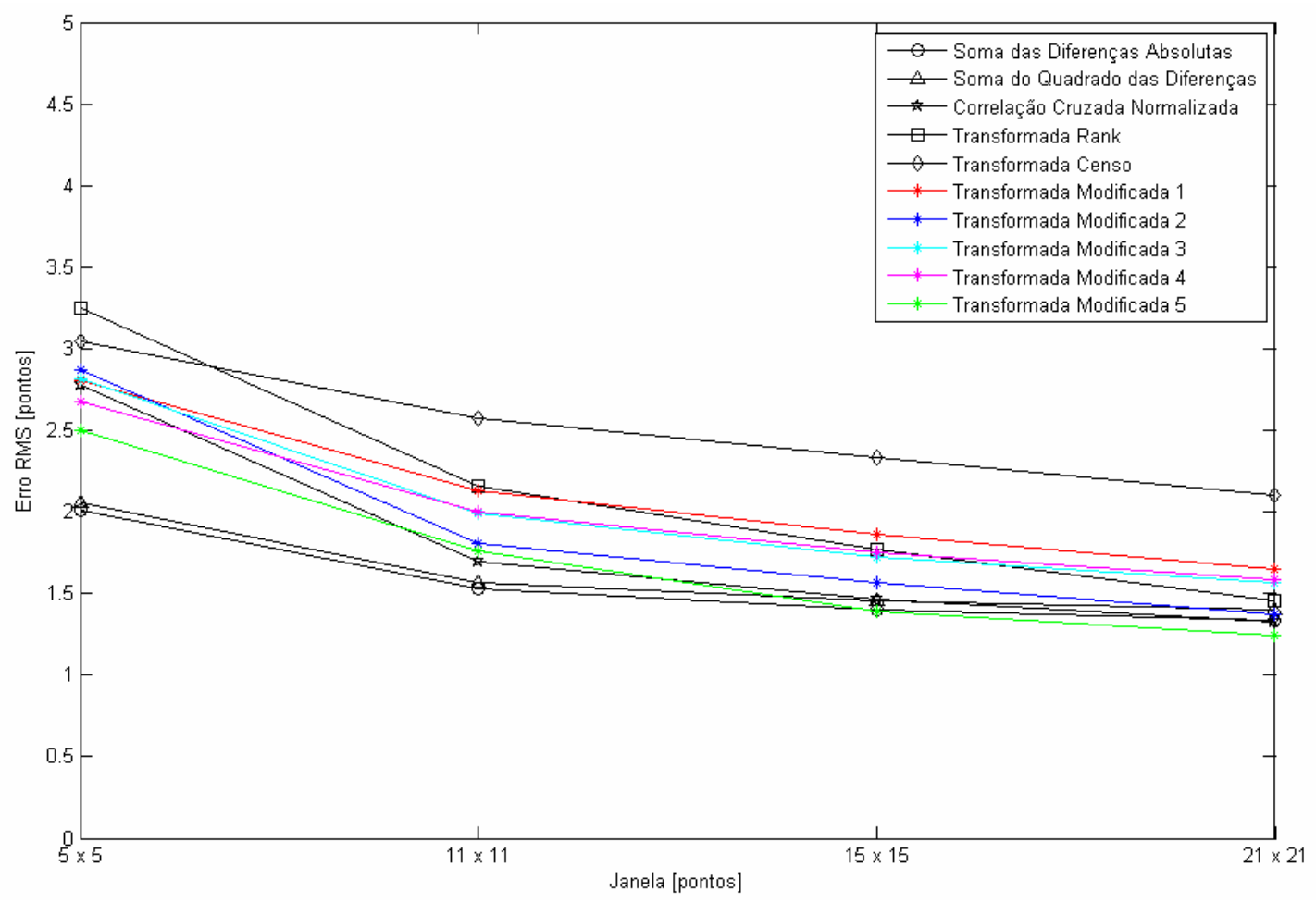

Figura 4.20: Erro RMS das correlações na imagem do corredor com ruído de variância 10

A Figura 4.21 mostra as imagens do corredor contaminadas com ruído de variância 100, nesta imagem foi obtido um limiar de 12 pontos. 

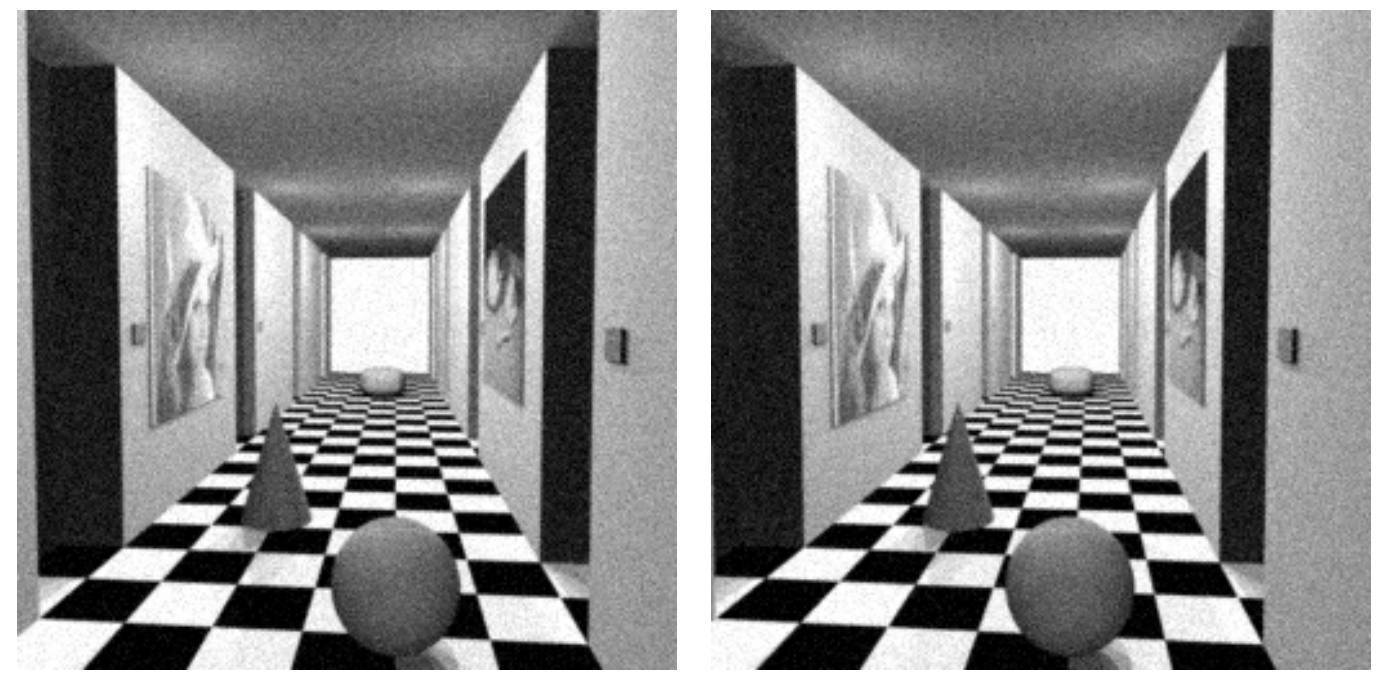

Figura 4.21: Imagens contaminadas com ruído de variância 100

Nas Figuras 4.22 e 4.23 observa-se que com as imagens de variância 100 houve um aumento das correlações erradas em todos os métodos, o que se refletiu também no erro RMS.

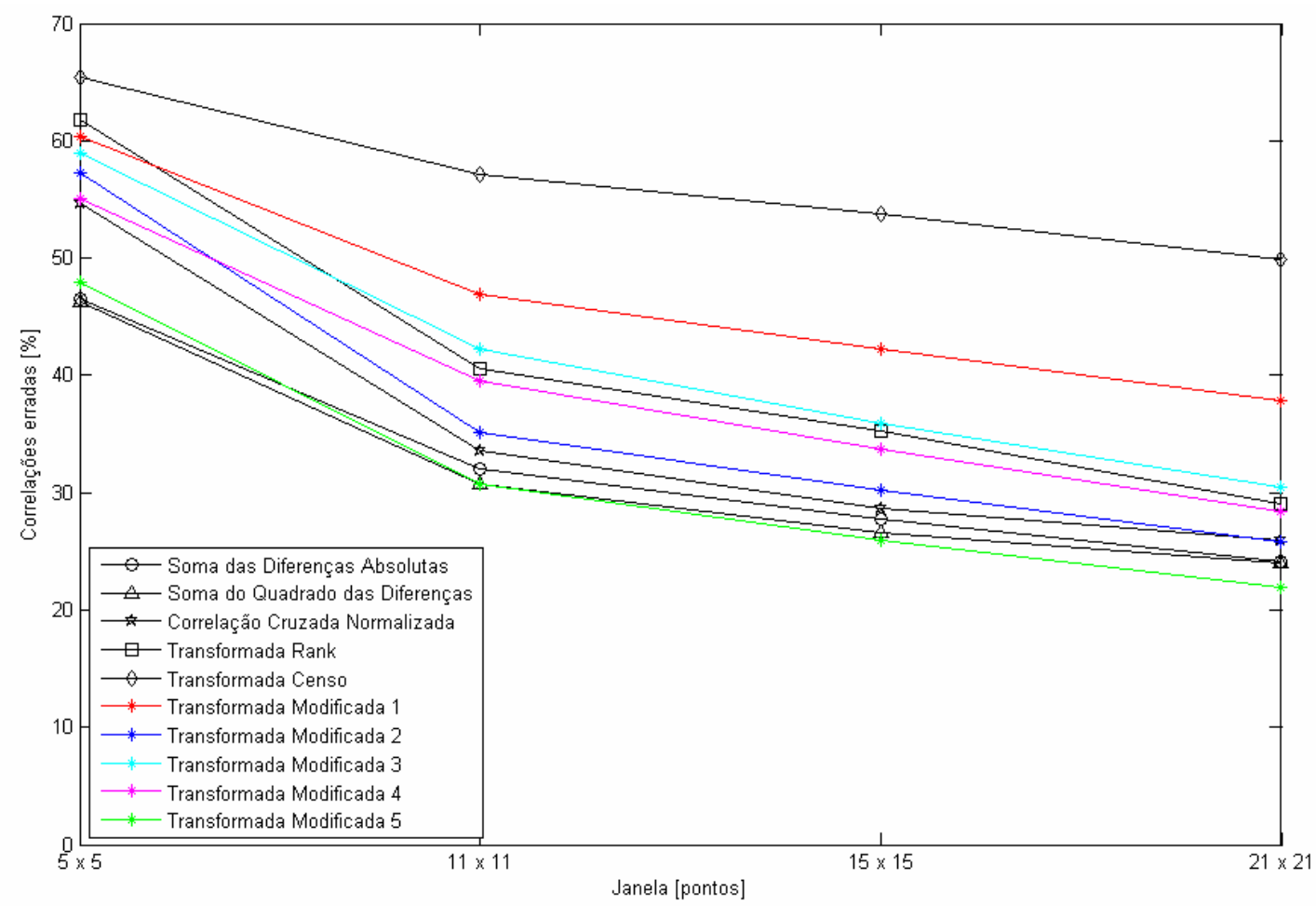

Figura 4.22: Correlações erradas na imagem do corredor com ruído de variância 100 


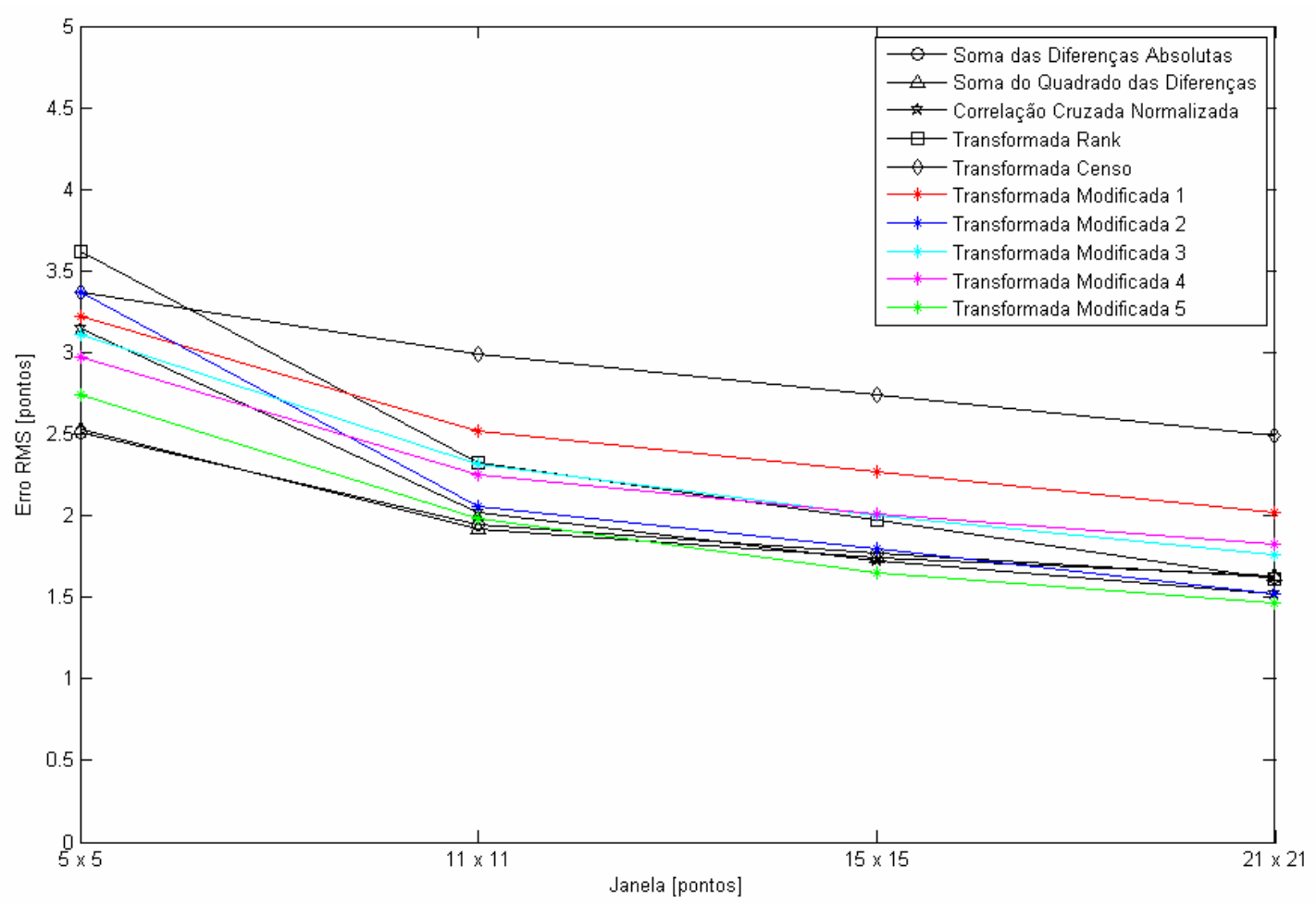

Figura 4.23: Erro RMS das correlações na imagem do corredor com ruído de variância 100

A Figura 4.24 mostra as imagens do corredor contaminadas com ruído de variância 200 e incidência em 50\% dos pontos da imagem, nesta imagem foi obtido um limiar de 11 pontos.
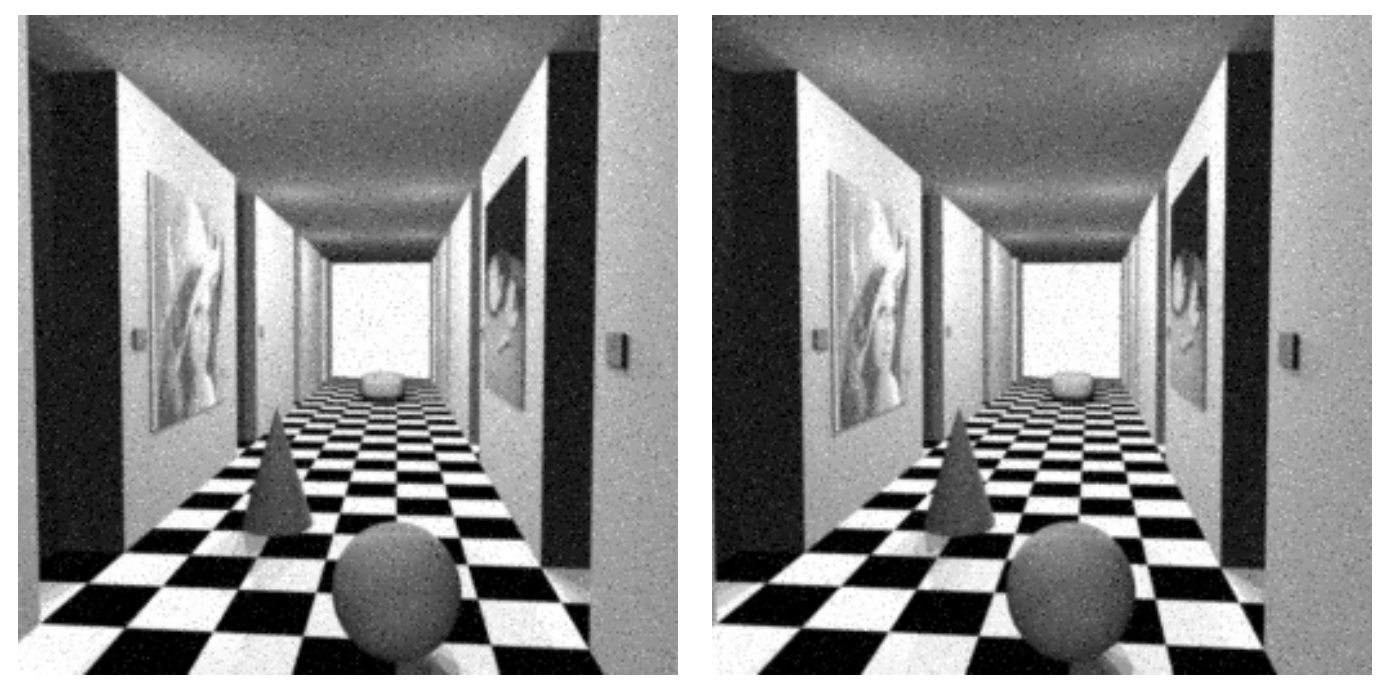

Figura 4.24: Imagens contaminadas com ruído de variância 200 em 50\% da imagem

Pelas Figuras 4.25 e 4.26 observa-se que as imagens com ruído de variância 200 e incidência em $50 \%$ da imagem tiveram resultados semelhantes aos com ruído de variância 100. 


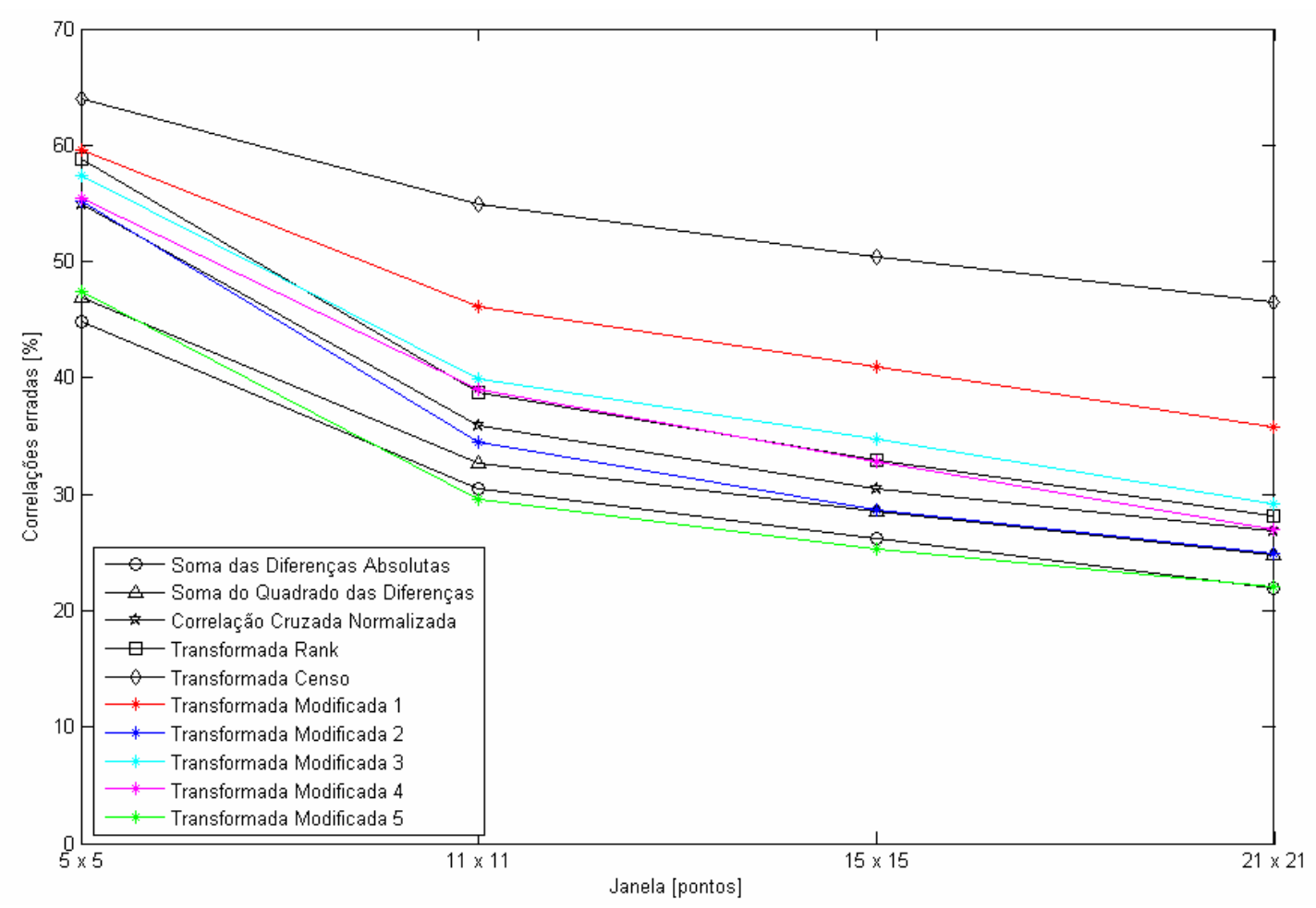

Figura 4.25: Correlações erradas na imagem do corredor com ruído de variância 200 e incidência $50 \%$

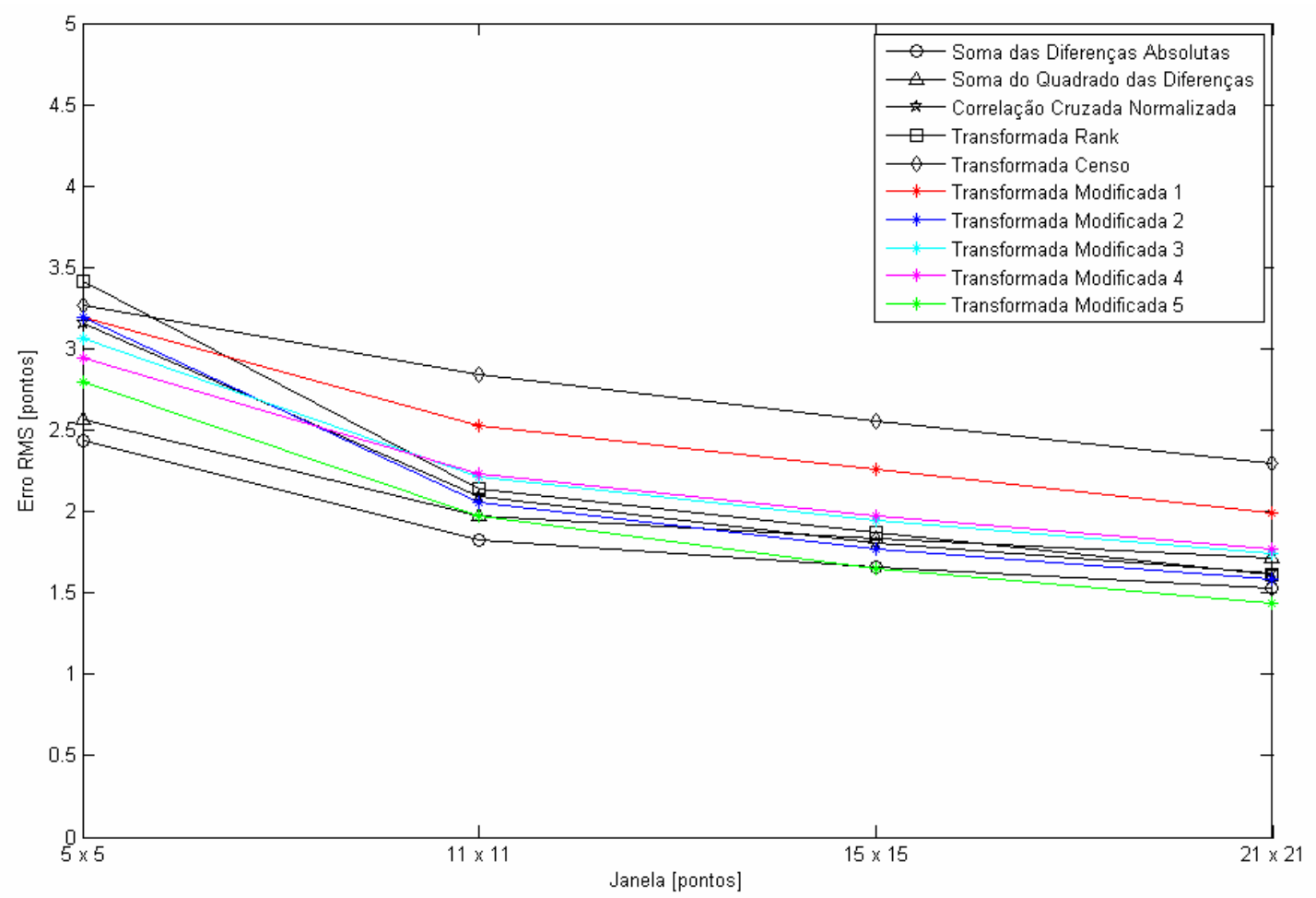

Figura 4.26: Erro RMS das correlações na imagem do corredor com ruído de variância 200 e incidência 50\% 
A Figura 4.27 mostra as imagens do corredor contaminadas com ruído de variância 200, nesta imagem foi obtido um limiar de 14 pontos.
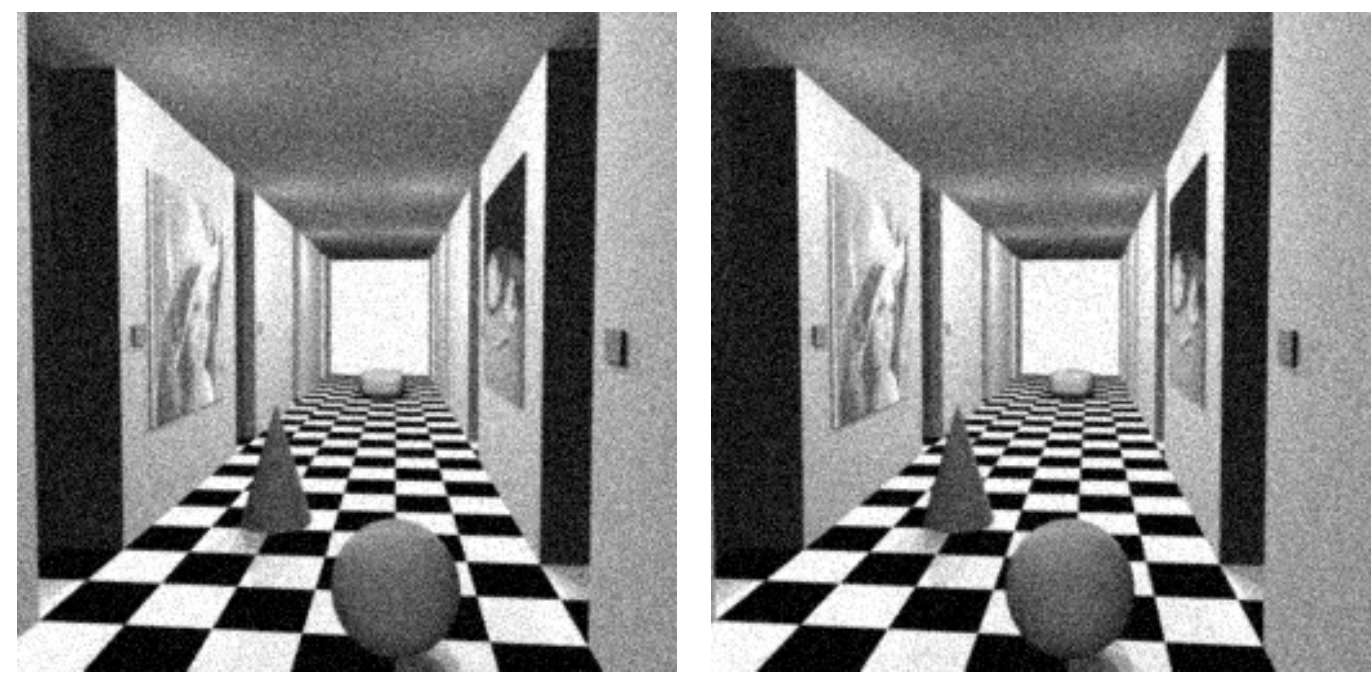

Figura 4.27: Imagens contaminadas com ruído de variância 200

Pelos resultados apresentados nas Figuras 4.28 e 4.29 observa-se que na imagem contaminada ruído de variância 200 houve uma degradação ainda maior dos mapas de correlação obtidos devido ao aumento das correlações erradas. Neste caso o método que obteve os melhores resultados foi a Transformada Modificada 5.

Os mapas de disparidades resultantes da execução dos algoritmos nas imagens com ruído de variância 200 estão disponíveis no Apêndice B nas Figuras B21 a B30. 


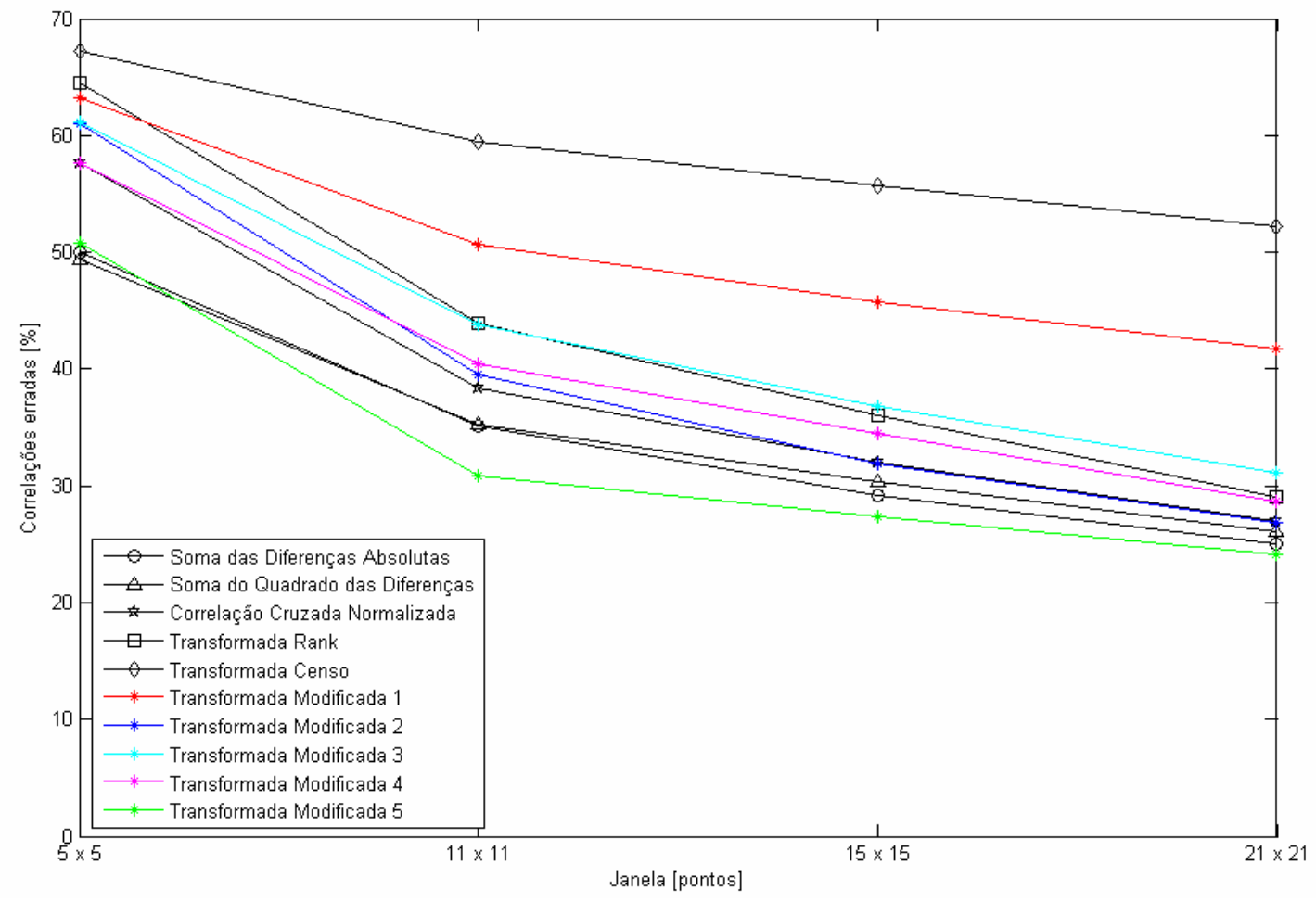

Figura 4.28: Correlações erradas na imagem do corredor com ruído de variância 200

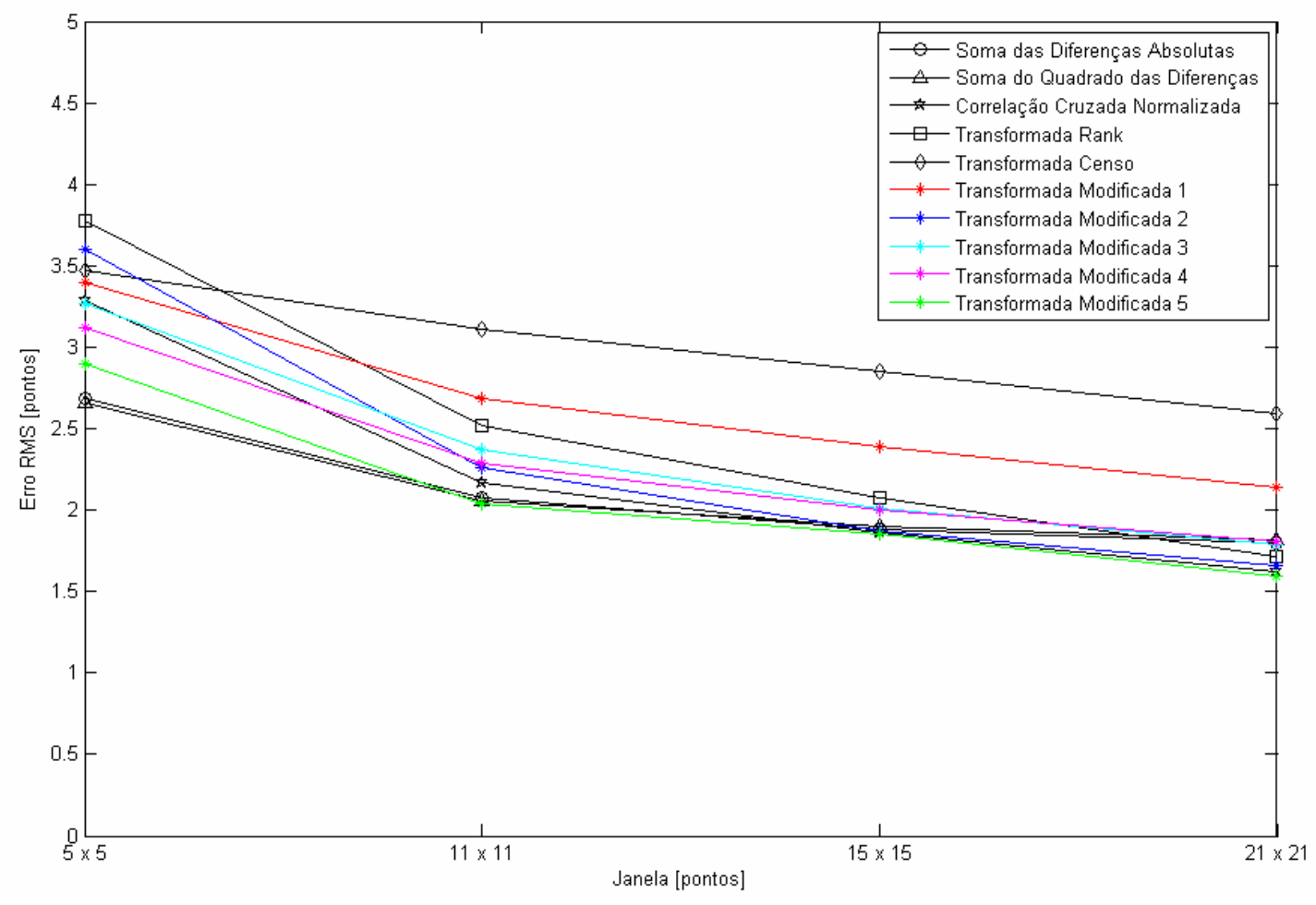

Figura 4.29: Erro RMS das correlações na imagem do corredor com ruído de variância 200 


\subsection{Aplicação dos métodos na imagem Teddy}

Esta imagem foi obtida no repositório de Middlebury (2007) e foi escolhida por possuir um bom balanceamento de regiões com pouca textura e regiões com padrão repetitivo. As imagens esquerda, direita e o mapa de disparidades verdadeiro da imagem direita são mostrados na Figura 4.30.
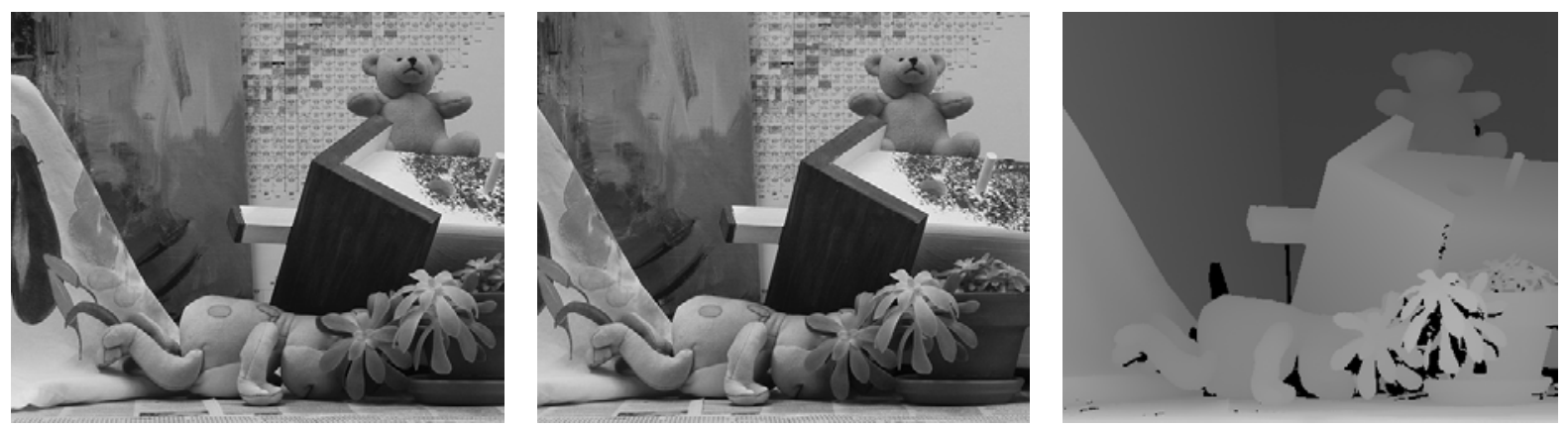

Figura 4.30: Imagens do Teddy obtidas do repositório de Middlebury

Em um primeiro teste foram calculados os mapas de disparidades com as imagens originais com todos os métodos e comparados os resultados. Para a aplicação dos métodos com a Transformada Modificada 1, 2, 4 e 5 calculou-se 0 valor do limiar adotando-se como referência a região destacada na Figura 4.31.

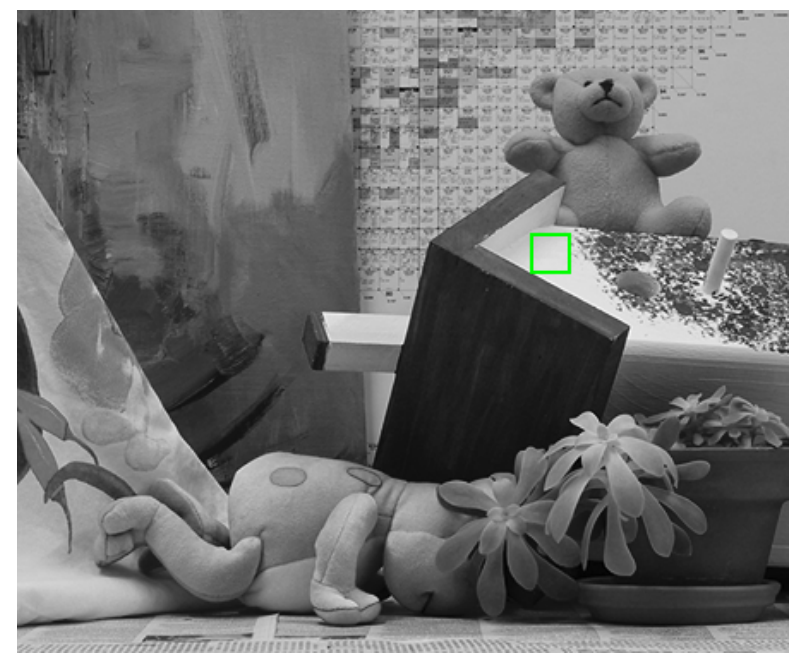

Figura 4.31: Região utilizada para o cálculo do limiar na imagem do Teddy 
O limiar obtido na imagem original e nas imagens com luminosidade modificada é de 2 pontos.

Nas Figuras 4.32 e 4.33 observa-se que com esta segunda imagem mais próxima de um ambiente real, a Transformada Modificada 5, que era a que apresentava um dos melhores resultados entre as Transformadas Modificadas, mostrou um resultado inesperado e passou a ser um dos piores métodos apresentando uma incidência de correlações erradas maior até do que a própria Transformada Censo.

Por outro lado a Transformada Modificada 2, que era a modificação com o segundo melhor resultado, foi a que apresentou os melhores resultados.

Os mapas de disparidades resultantes da execução dos algoritmos nas imagens originais estão disponíveis no Apêndice B nas Figuras B31 a B40.

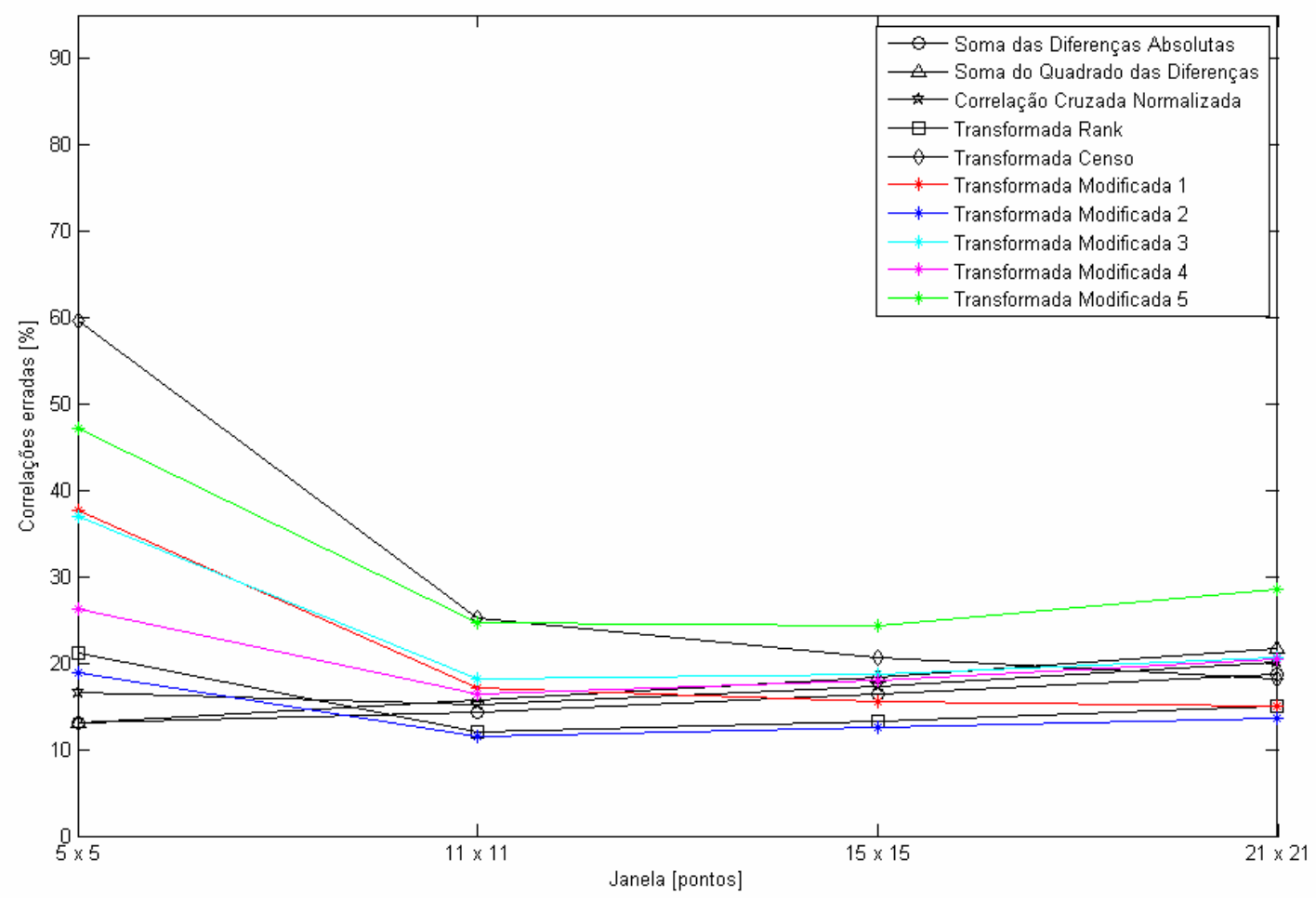

Figura 4.32: Correlações erradas na imagem Teddy original 


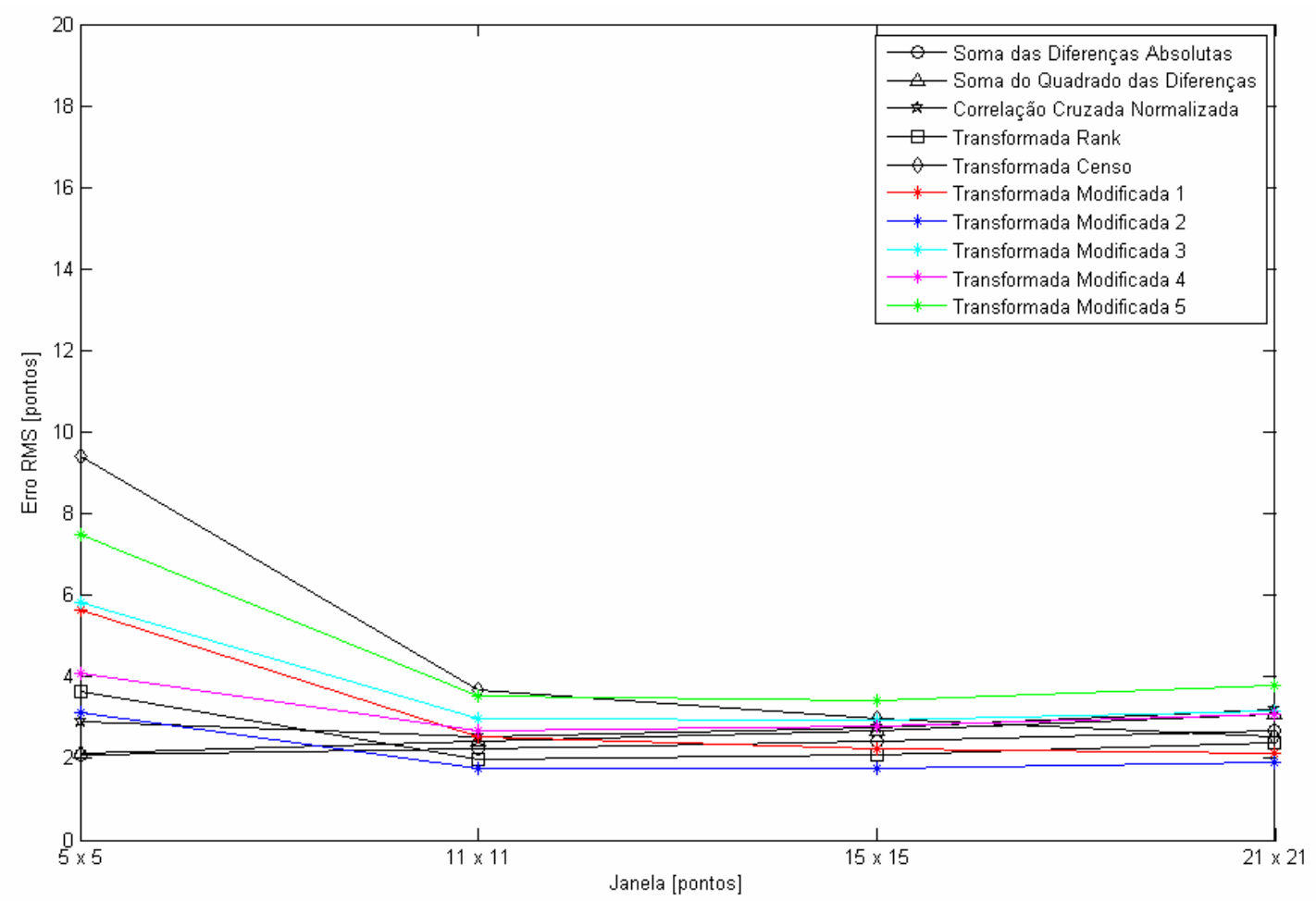

Figura 4.33: Erro RMS das correlações na imagem Teddy original

Em um segundo passo, pares de imagens com luminosidades diferentes foram analisados. Optou-se por reduzir a luminosidade da imagem esquerda em 10\%, 20\% e em seguida 30\% para comparar a influência dessa variação nos resultados.

A Figura 4.34 apresenta as imagens com uma diferença de 10\% na luminosidade. 

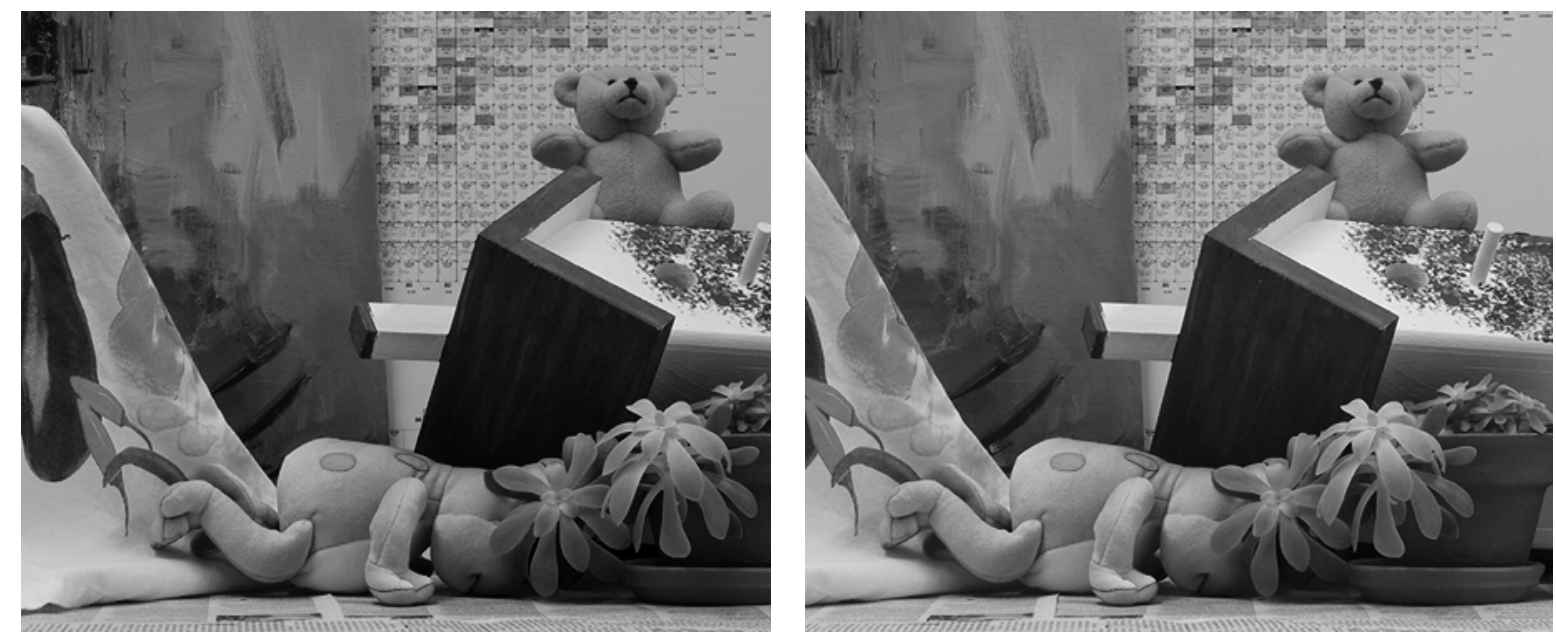

Figura 4.34: Imagem esquerda com luminosidade $10 \%$ menor

Nos resultados apresentados pelas Figuras 4.35 e 4.36 observa-se que com luminosidade 10\% menor na imagem esquerda os métodos da Transformada Rank e a Transformada Modificada 2 apresentam os melhores resultados, tanto na incidência de correlações erradas quanto no erro RMS.

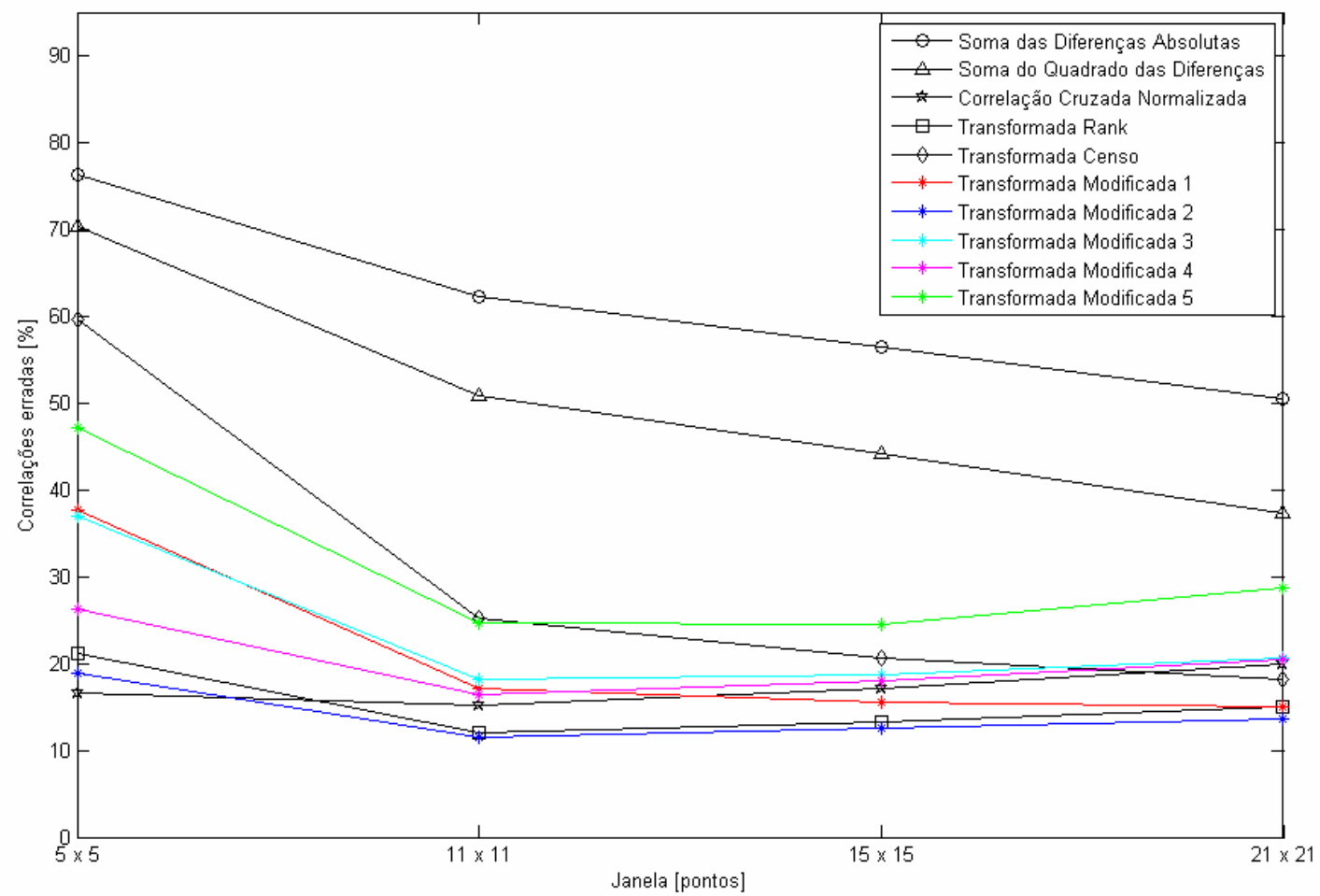

Figura 4.35: Correlações erradas na imagem Teddy com luminosidade $10 \%$ diferente 


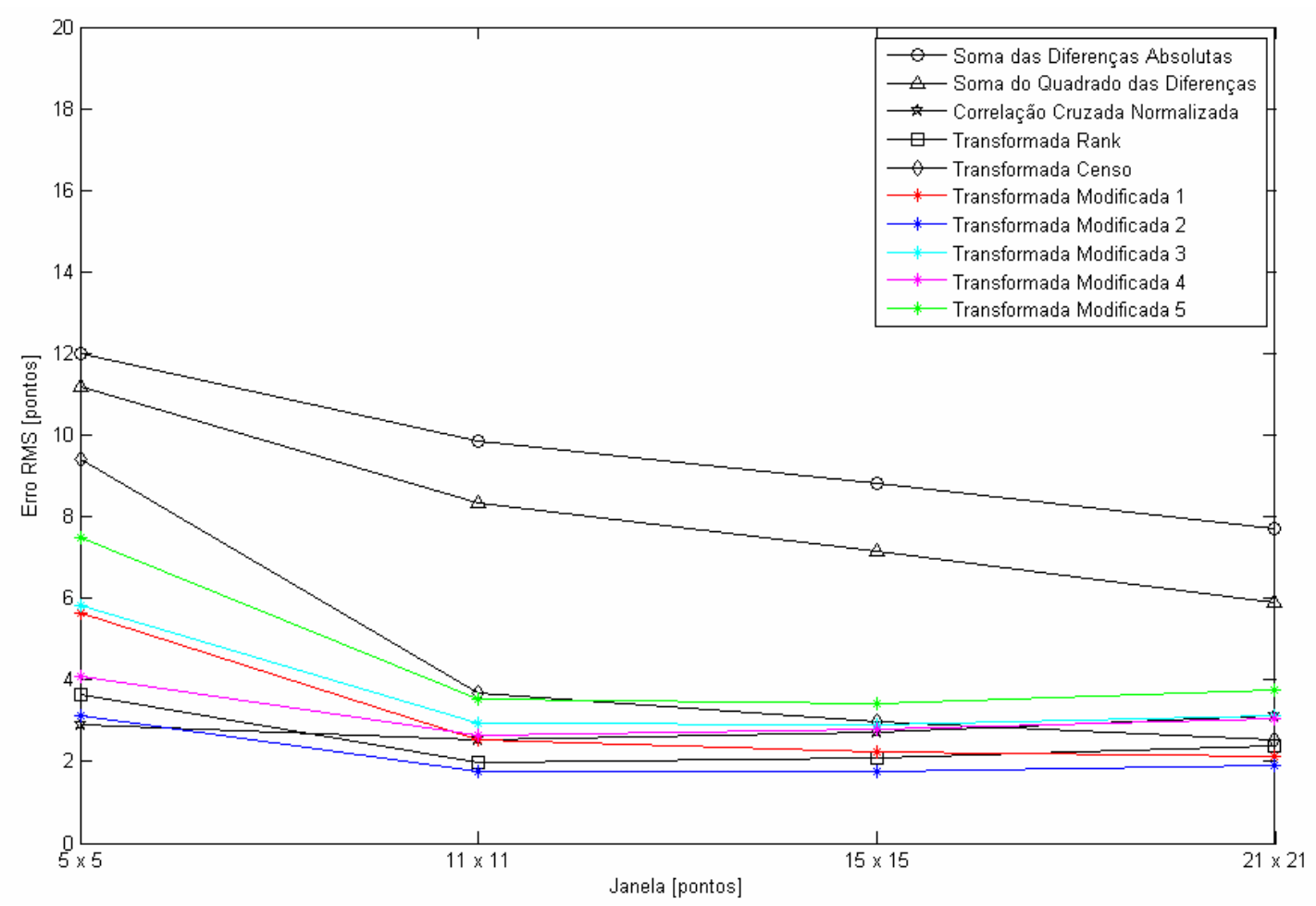

Figura 4.36: Erro RMS das correlações na imagem Teddy com luminosidade 10\% diferente

A Figura 4.37 apresenta as imagens com uma diferença de $20 \%$ na luminosidade.
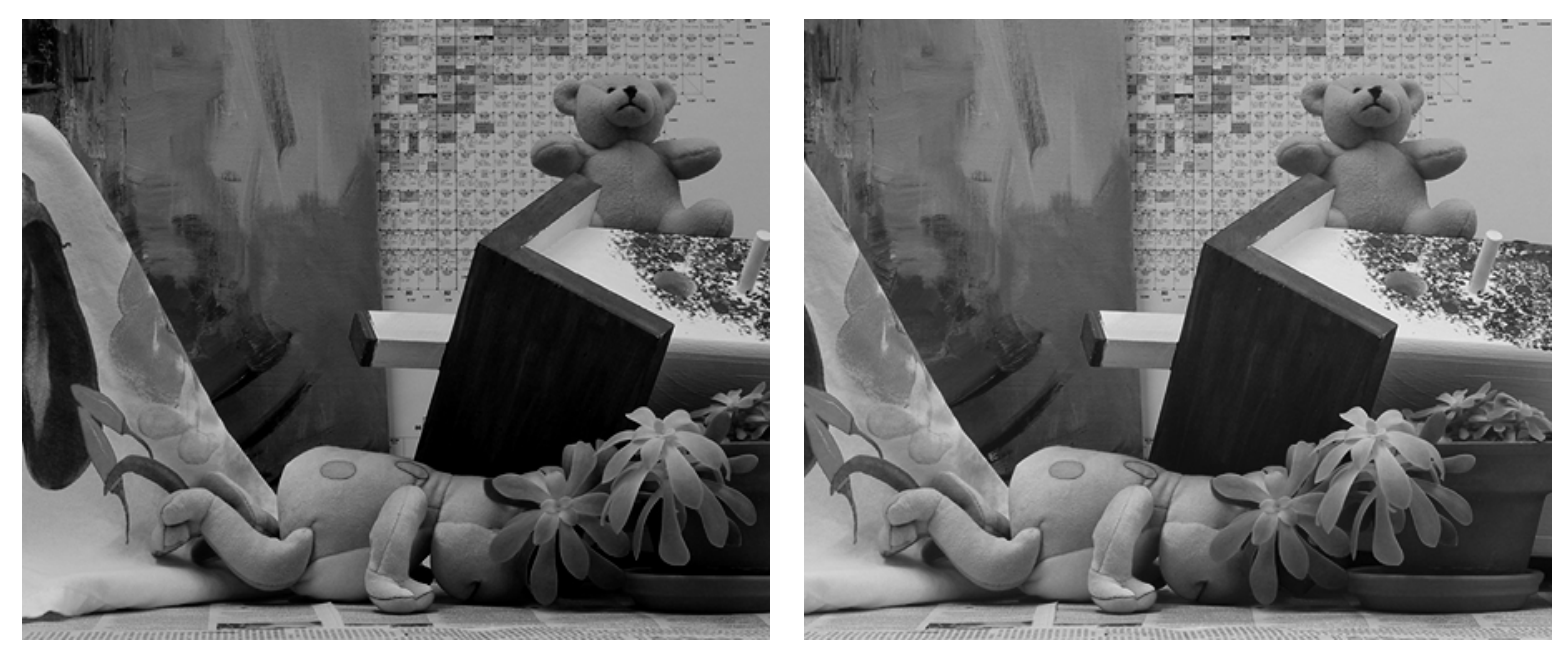

Figura 4.37: Imagem esquerda com luminosidade $20 \%$ menor

Neste caso observa-se nos resultados apresentados pelas Figuras 4.38 e 4.39 que para os métodos com as menores incidências de correlações erradas os resultados são semelhantes aos da imagem com luminosidade 10\% menor. 


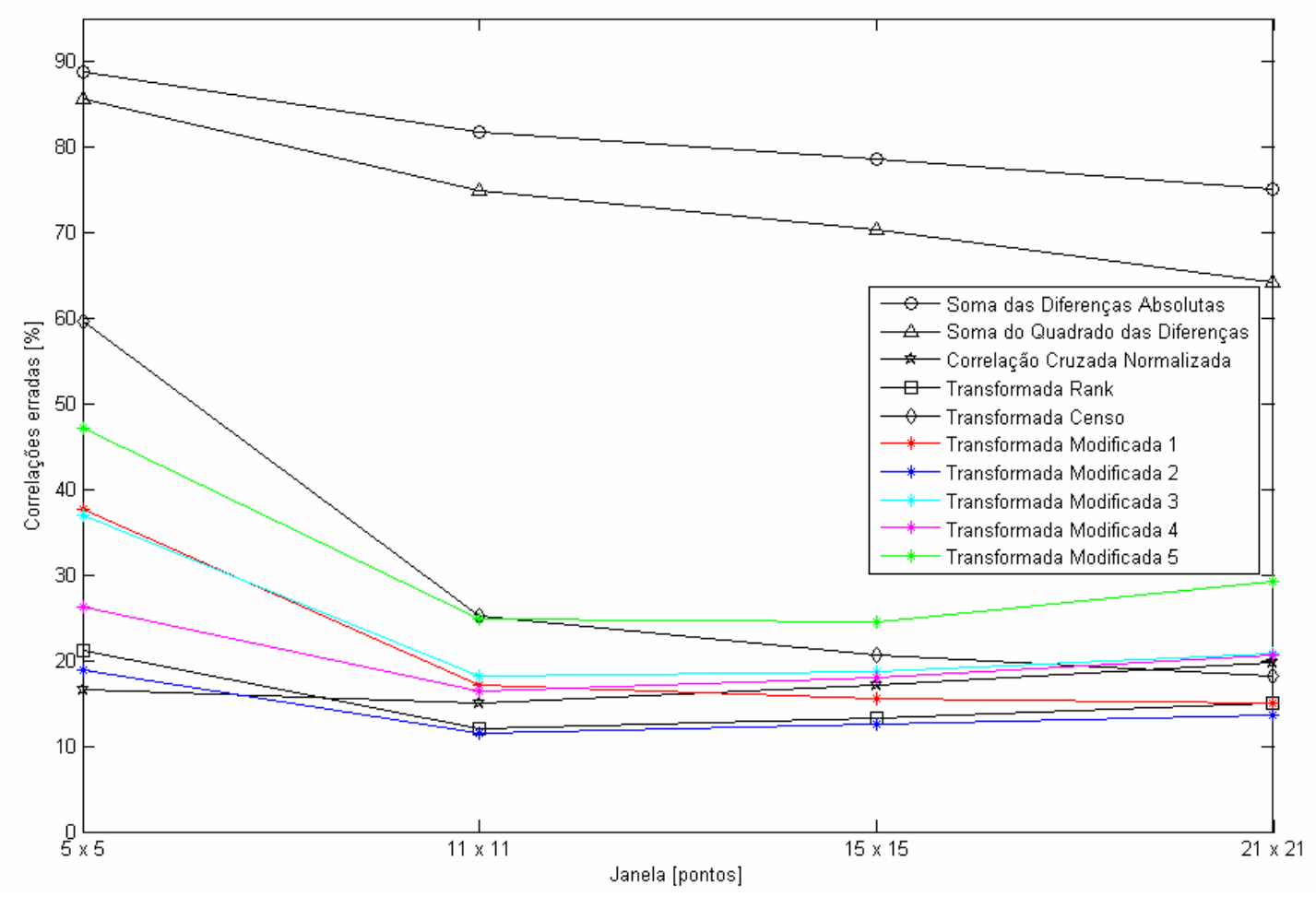

Figura 4.38: Correlações erradas na imagem Teddy com luminosidade $20 \%$ diferente

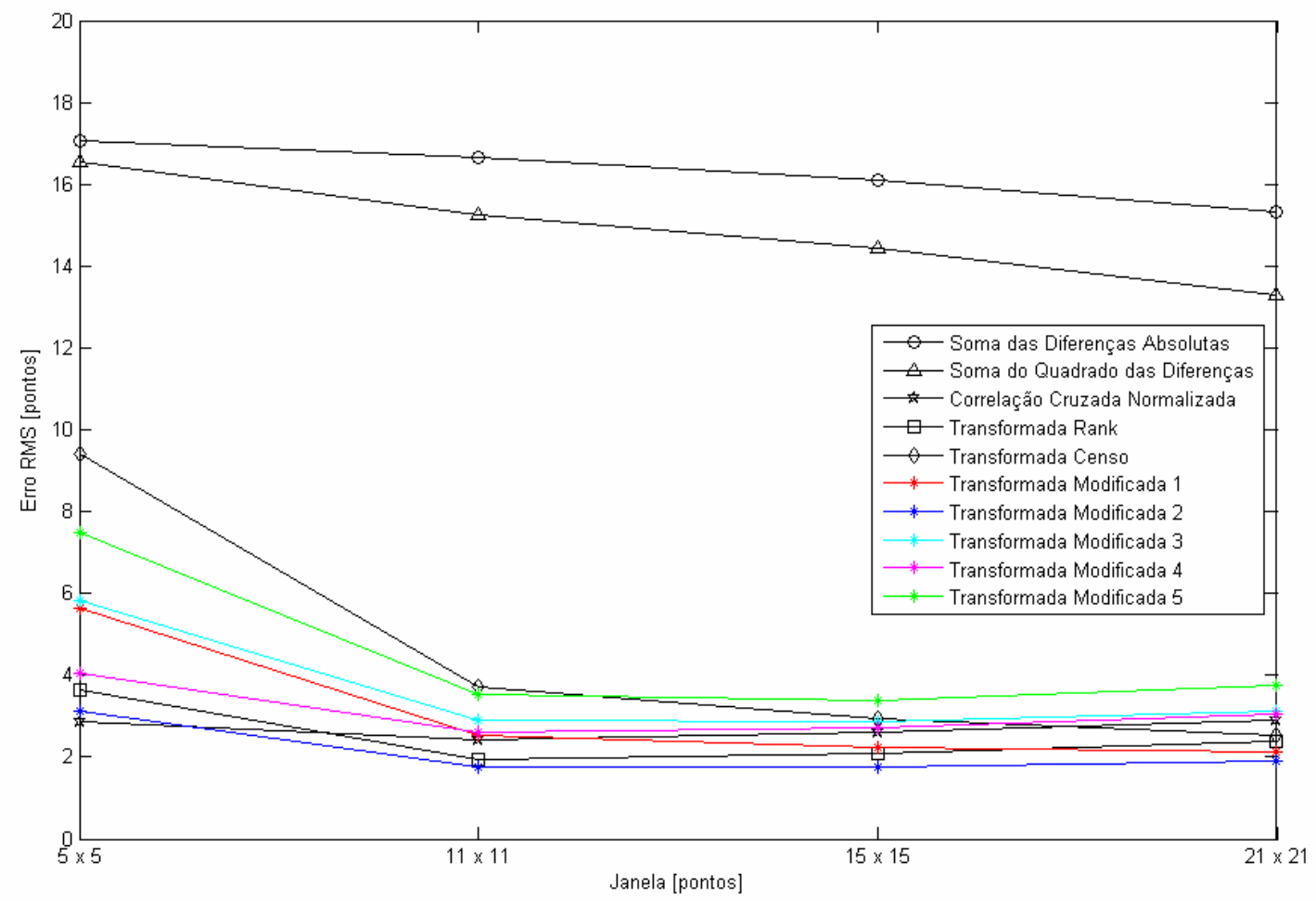

Figura 4.39: Erro RMS das correlações na imagem Teddy com luminosidade $20 \%$ diferente 
A Figura 4.40 apresenta as imagens com uma diferença de $30 \%$ na luminosidade.
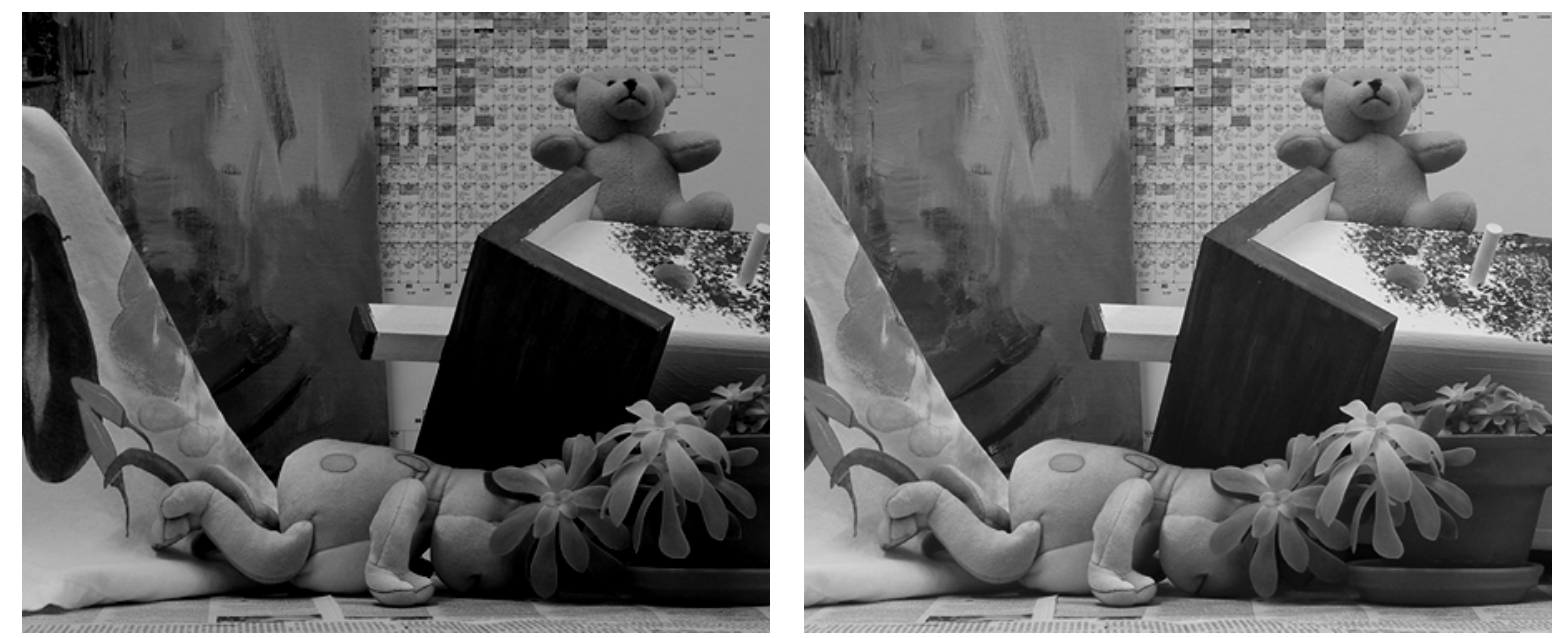

Figura 4.40: Imagem esquerda com luminosidade $30 \%$ menor

Após executados os métodos na imagem com uma diferença de luminosidade de $30 \%$ obtiveram se as Figuras 4.41 e 4.42 nas quais se pode observar que, fora os métodos Soma das Diferenças Absolutas e Soma do Quadrado das Diferenças, os resultados da quantidade de correlações erradas permaneceu praticamente inalterado com a variação da luminosidade, comportamento bem diferente do observado na imagem do corredor.

Os mapas de disparidades resultantes da execução dos algoritmos nas imagens com luminosidade $30 \%$ diferente estão disponíveis no Apêndice B nas Figuras B41 a B50. 


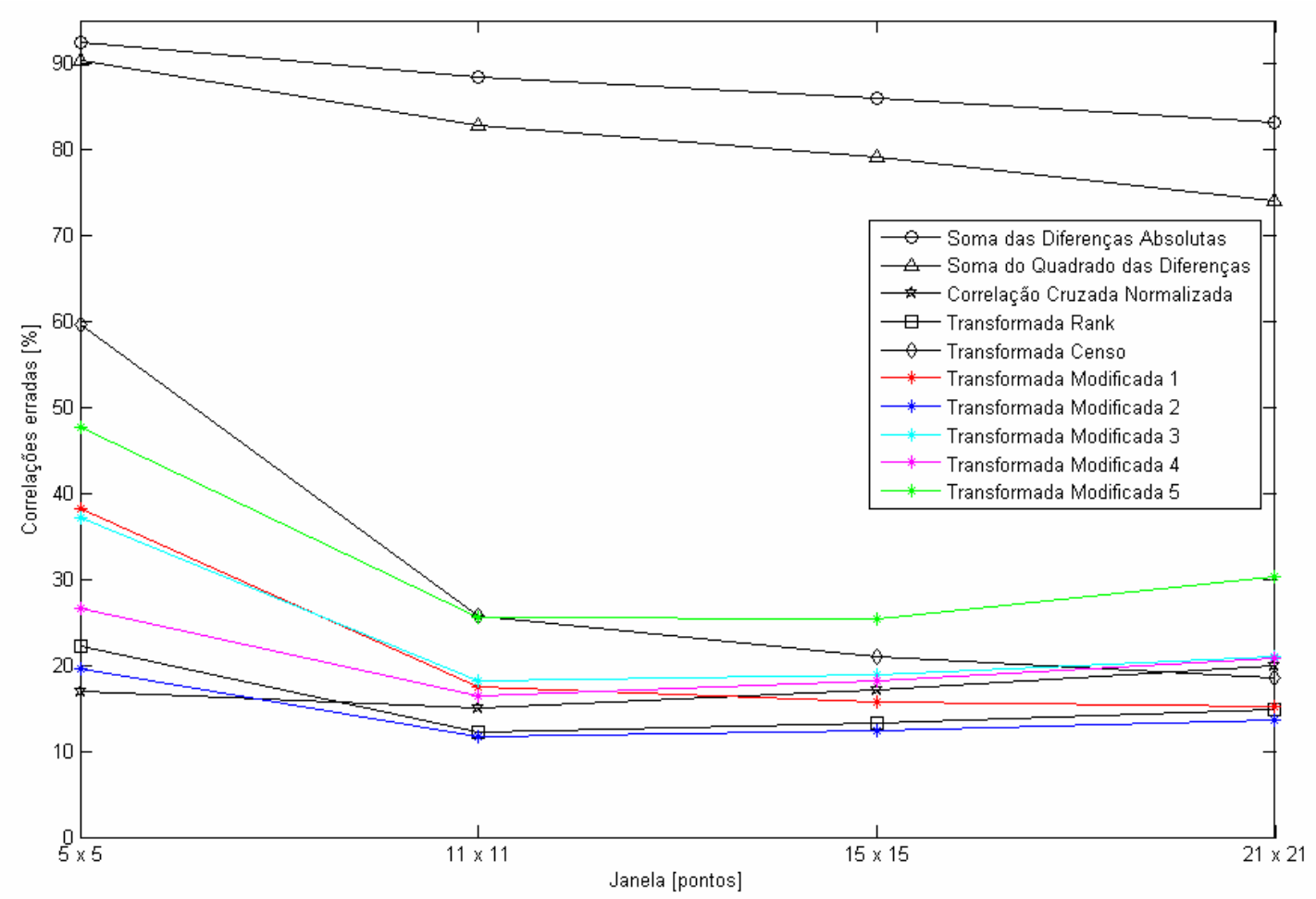

Figura 4.41: Correlações erradas na imagem Teddy com luminosidade $30 \%$ diferente

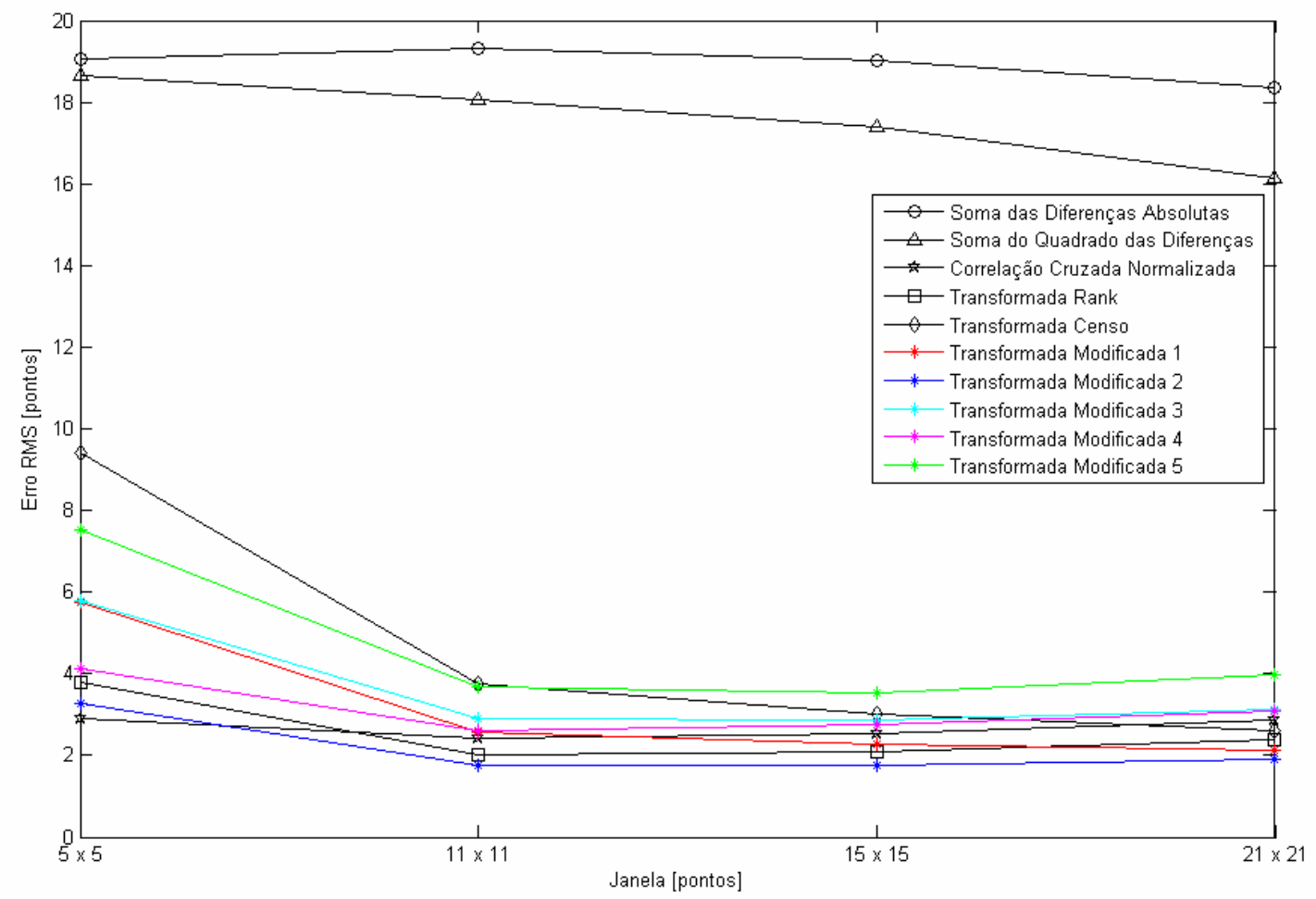

Figura 4.42: Erro RMS das correlações na imagem Teddy com luminosidade 30\% diferente 
Em uma segunda etapa são comparados os resultados dos algoritmos quando executados com imagens com ruídos. Para os testes foram criadas versões das imagens originais com ruído de variância 10, 100 e 200 com incidência em todos os pontos da imagem e um caso com ruído de variância 200 com incidência em 50\% dos pontos da imagem.

A Figura 4.43 mostra as imagens do Teddy contaminadas com ruído de variância 10, nesta imagem foi obtido um limiar de 6 pontos.
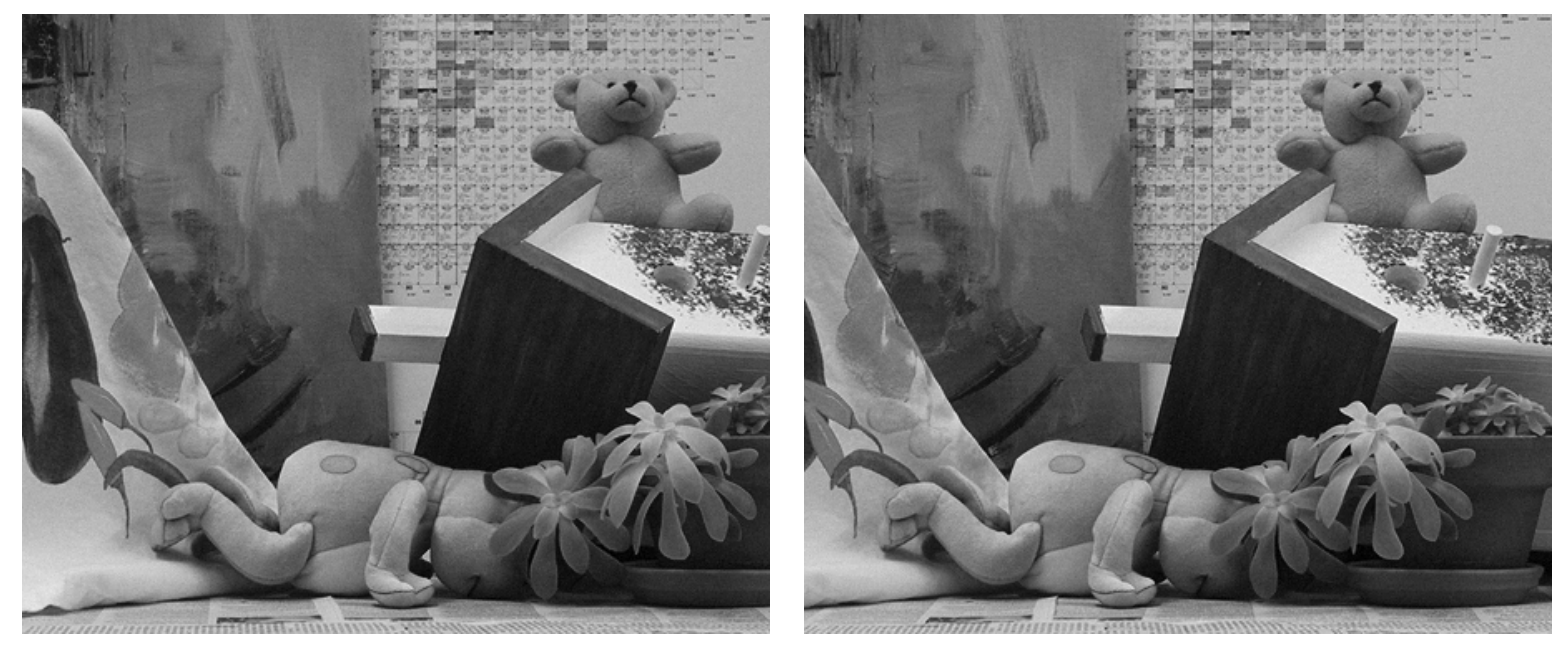

Figura 4.43: Imagens contaminadas com ruído de variância 10

Nos resultados mostrados pelas Figuras 4.44 e 4.45 observa-se que já com a introdução de um ruído com amplitude pequena houve um aumento nas correlações erradas em todos os métodos. Observa-se que a Transformada Modificada 2 consegue manter resultados próximos dos métodos Soma das Diferenças Absolutas, Soma do Quadrado das Diferenças, Correlação Cruzada Normalizada e Transformada Rank. 


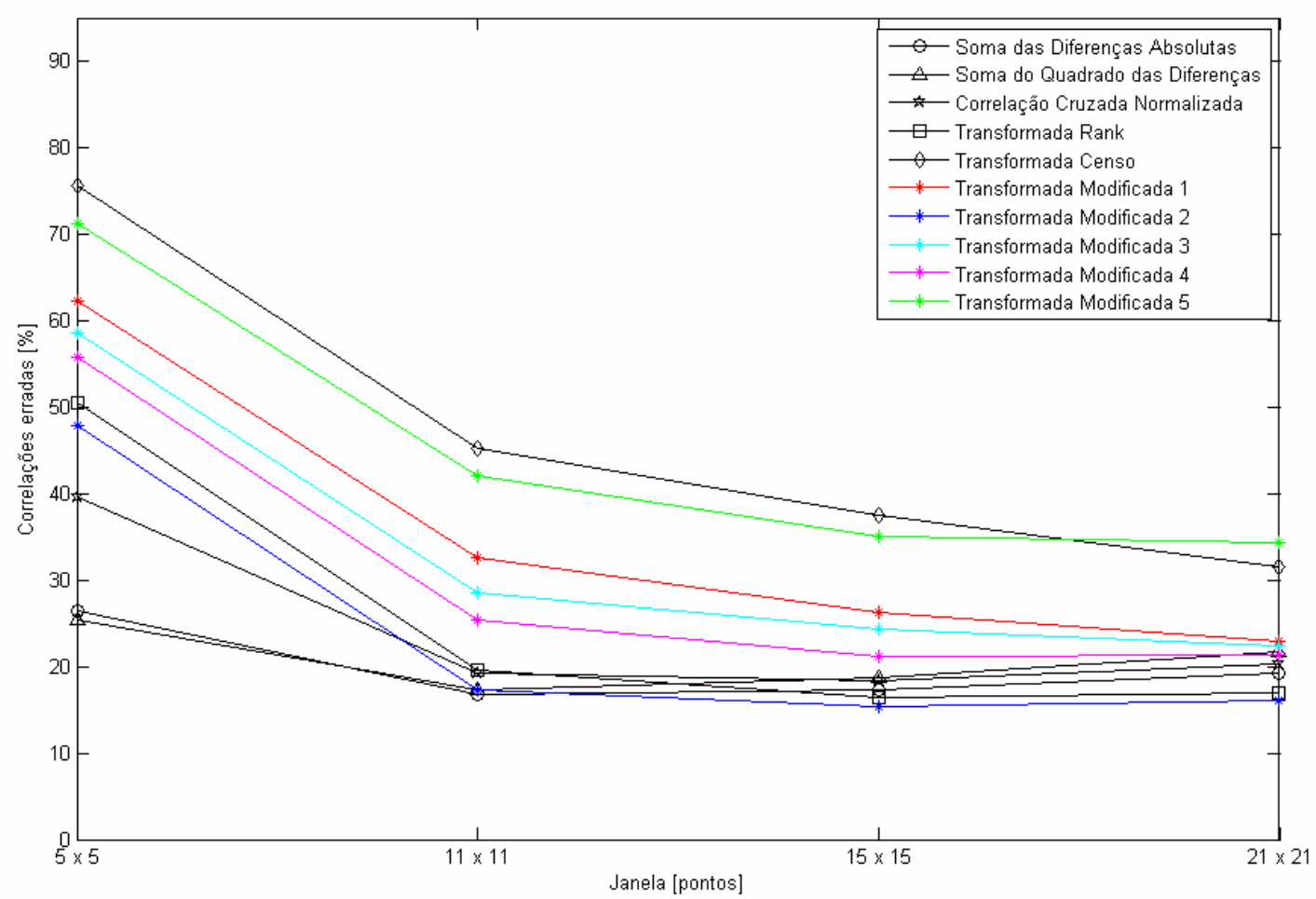

Figura 4.44: Correlações erradas na imagem do Teddy com ruído de variância 10

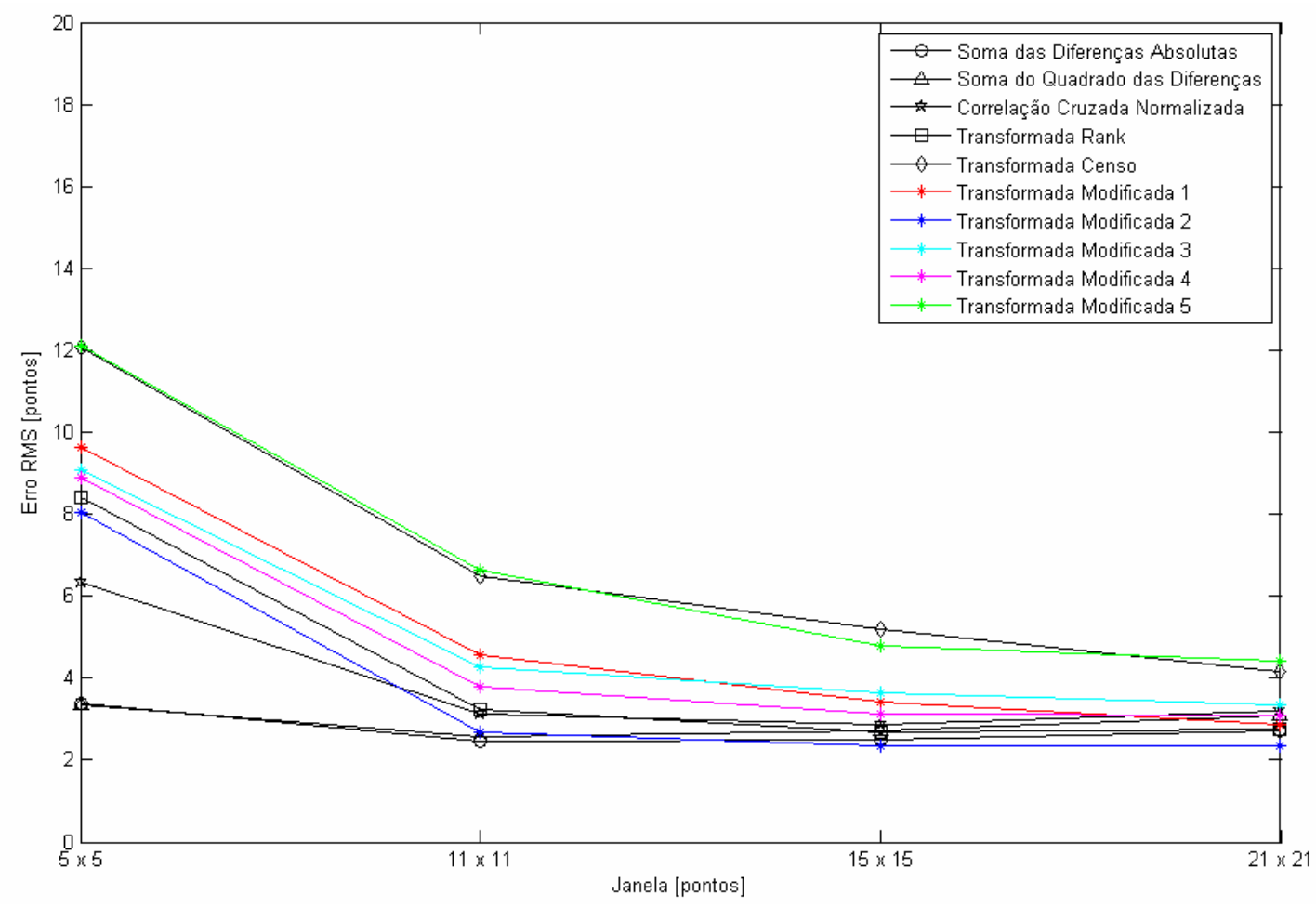

Figura 4.45: Erro RMS das correlações na imagem Teddy com ruído de variância 10 
A Figura 4.46 mostra as imagens do Teddy contaminadas com ruído de variância 100, nesta imagem foi obtido um limiar de 11 pontos. Lembra-se que neste caso o limiar utilizado é o calculado utilizando-se uma amostra semelhante a da região mostrada na Figura 4.31, não sendo utilizado o valor médio do limiar como o mostrado na Tabela 4.1.
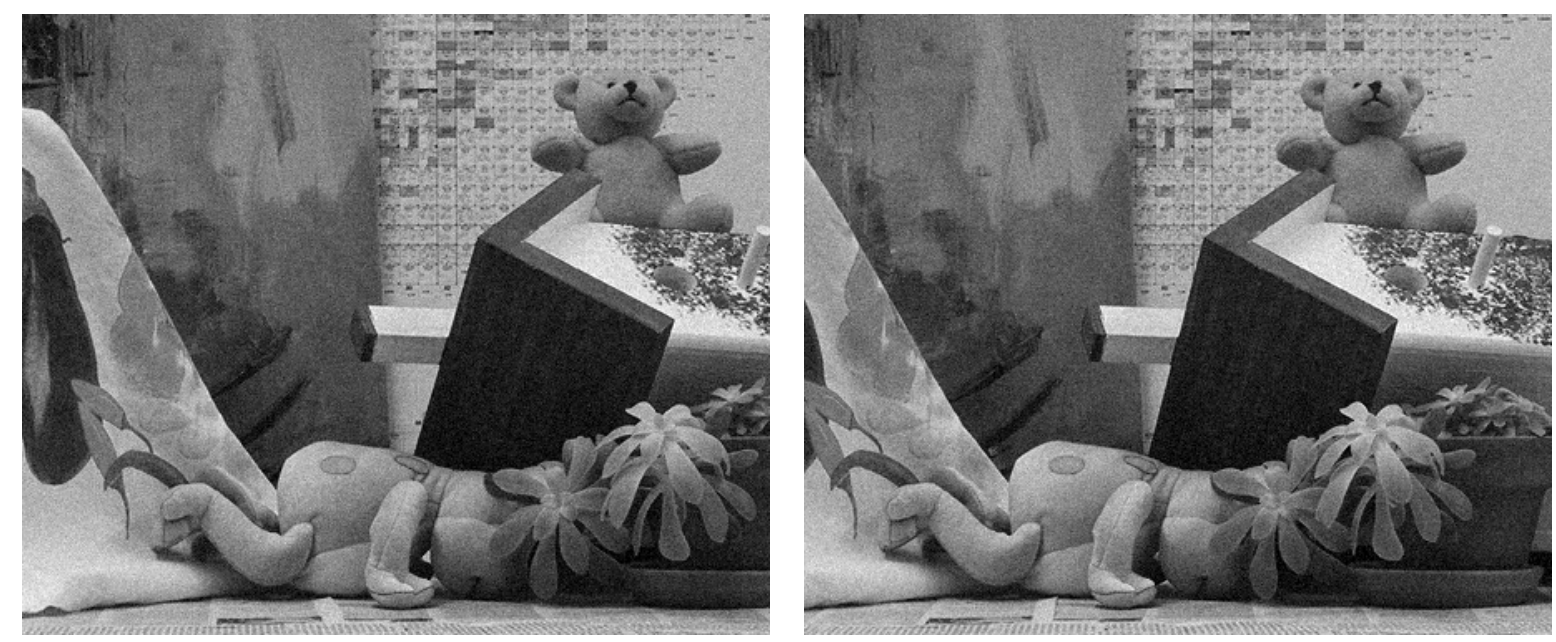

Figura 4.46: Imagens contaminadas com ruído de variância 100

Nas Figuras 4.47 e 4.48 observa-se que o aumento do ruído para variância 100 causou um grande aumento nas correlações erradas. A partir deste caso observa-se que mesmo a Transformada Modificada 2 começou a apresentar resultados piores do que os da Soma das Diferenças Absolutas e da Soma do Quadrado das Diferenças, porém com o aumento da janela observa-se que a Transformada Modificada 2 tende a atingir resultados bons. 


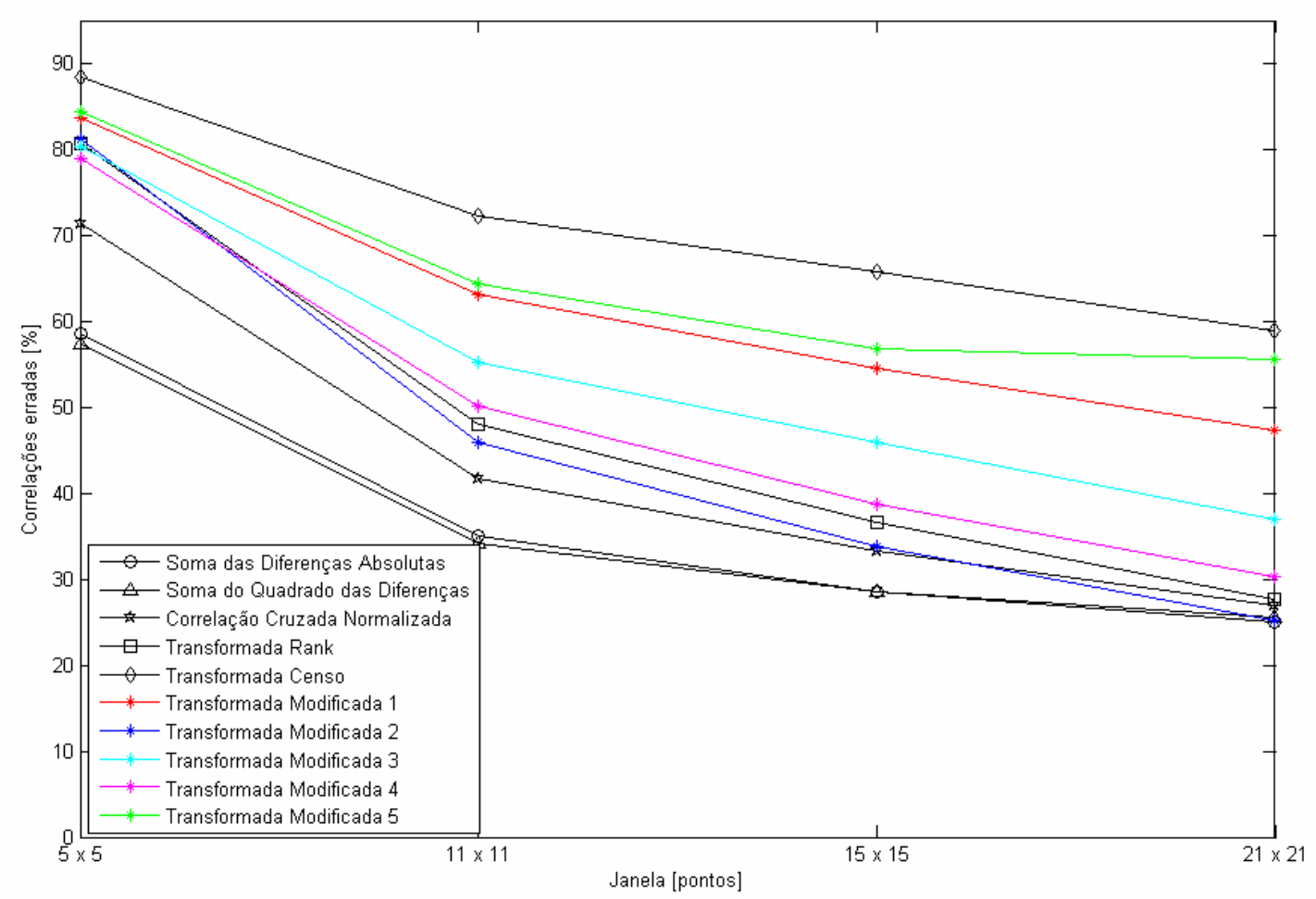

Figura 4.47: Correlações erradas na imagem Teddy com ruído de variância 100

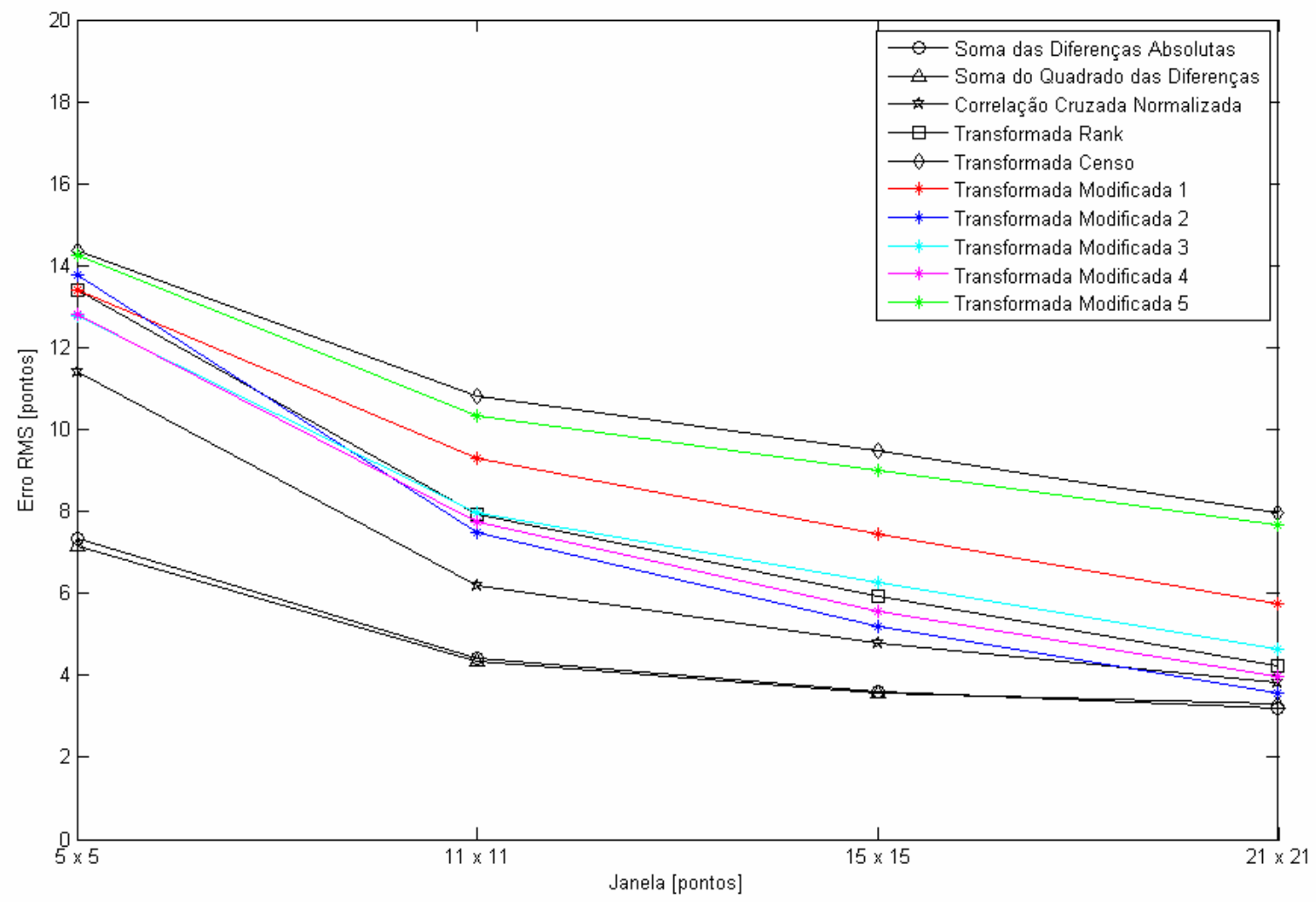

Figura 4.48: Erro RMS das correlações na imagem Teddy com ruído de variância 100 
A Figura 4.49 mostra as imagens do Teddy contaminadas com ruído de variância 200 e incidência em 50\% da imagem, nesta imagem foi obtido um limiar de 12 pontos.
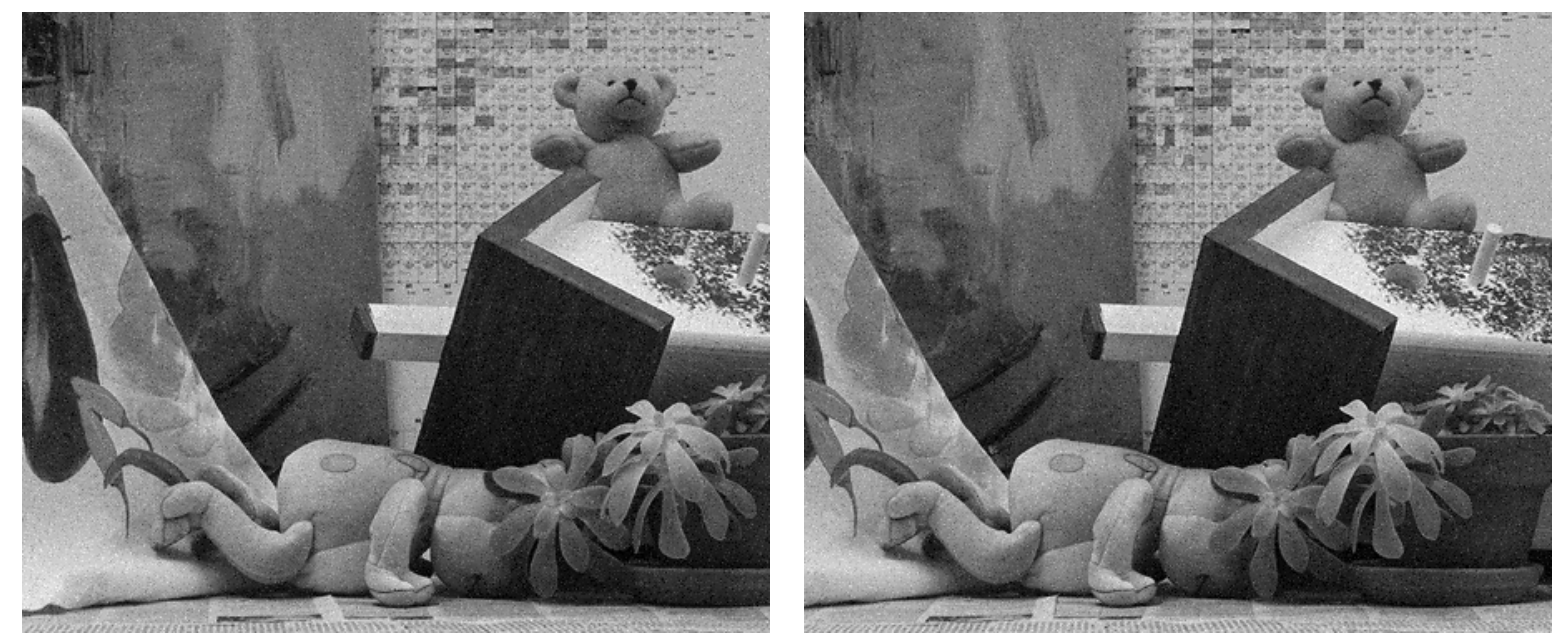

Figura 4.49: Imagens contaminadas com ruído de variância 200 em 50\% da imagem

Pelos resultados das Figuras 4.50 e 4.51 observa-se que com as imagens com ruído de variância 200 e incidência em 50\% da imagem existe uma melhora no resultado da Transformada Rank.

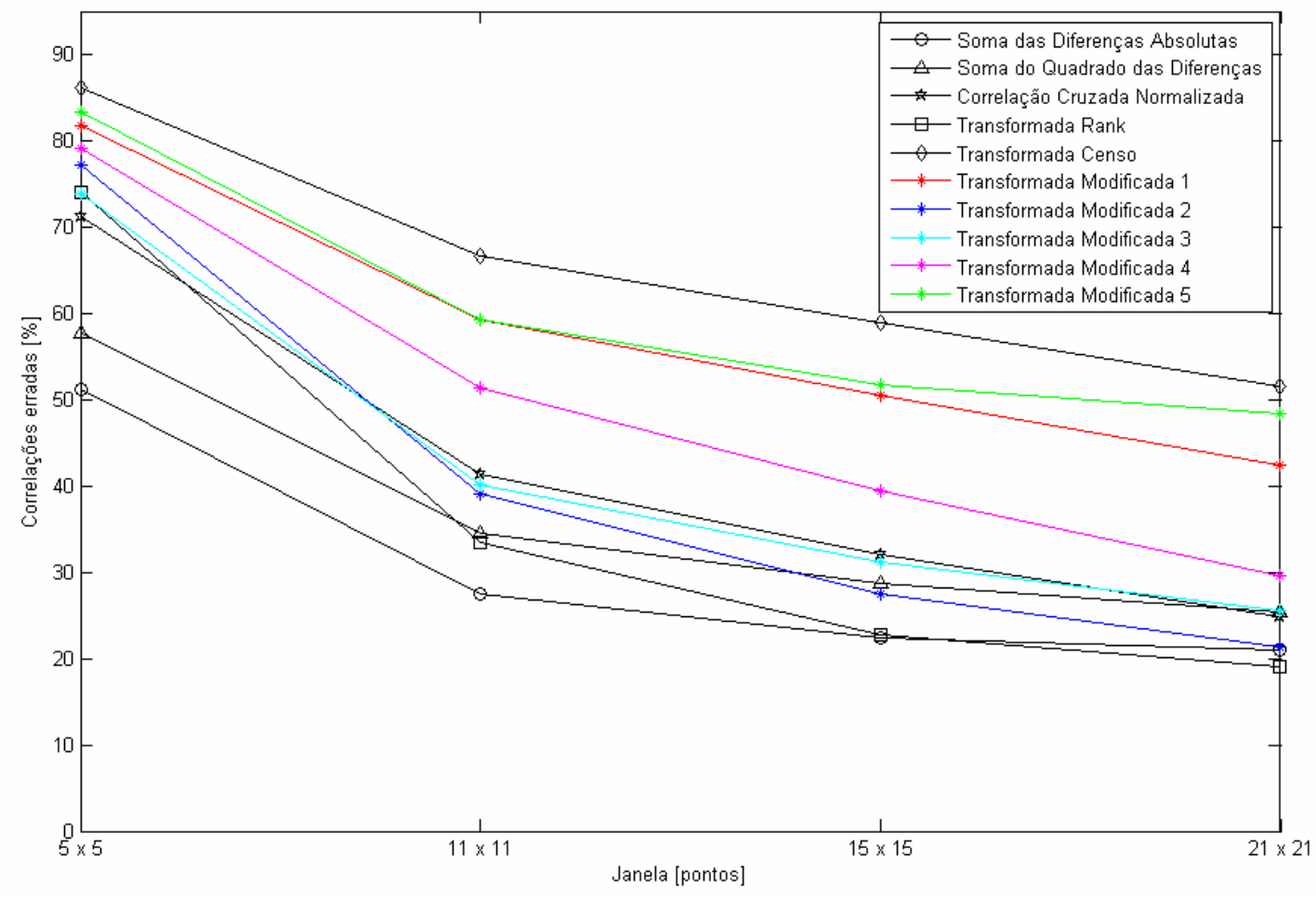

Figura 4.50: Correlações erradas na imagem Teddy com ruído de variância 200 e incidência 50\% 


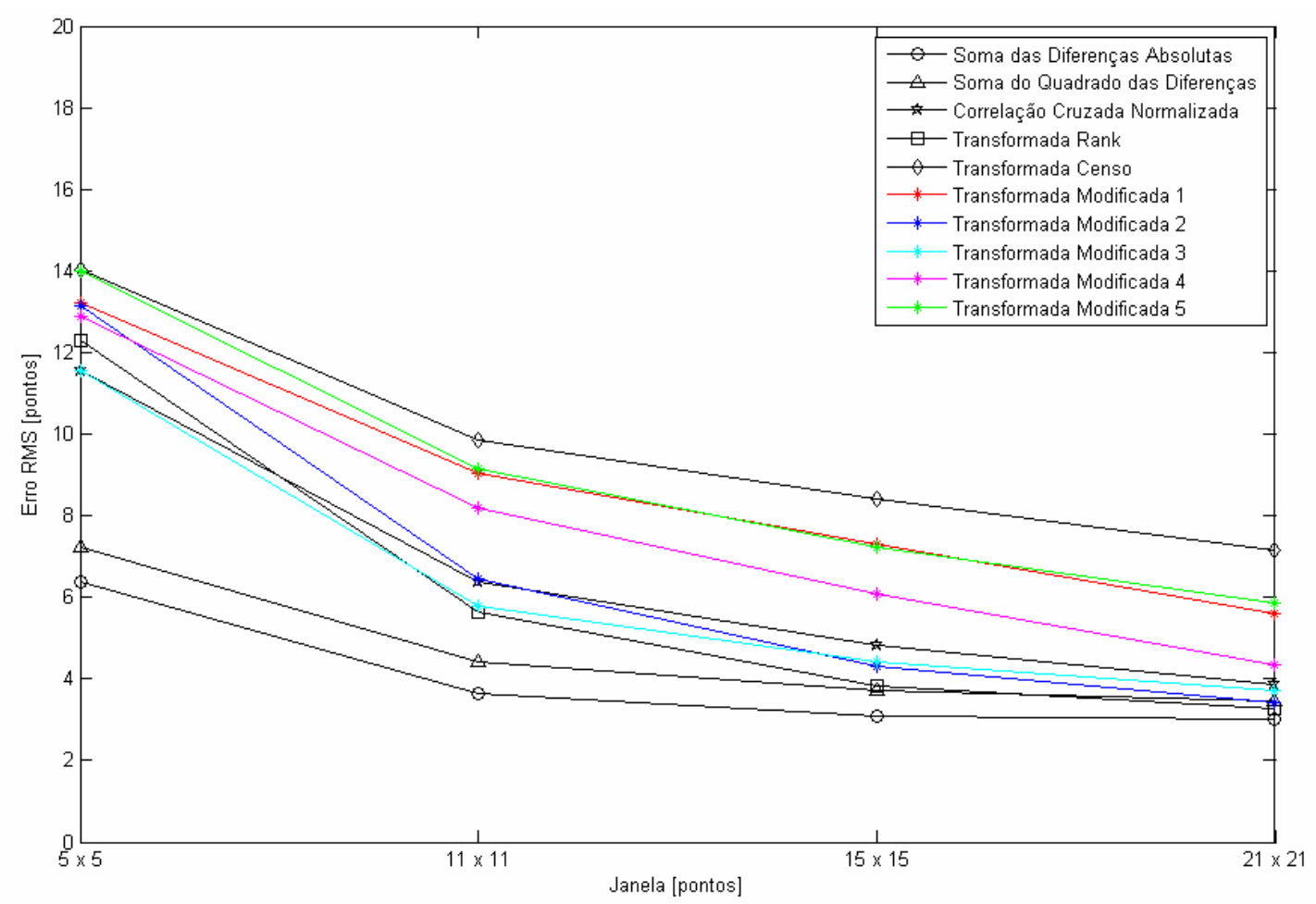

Figura 4.51: Erro RMS das correlações na imagem Teddy com ruído de variância 200 e incidência 50\%

A Figura 4.52 mostra as imagens do Teddy contaminadas com ruído de variância 200, nesta imagem foi obtido um limiar de 13 pontos.
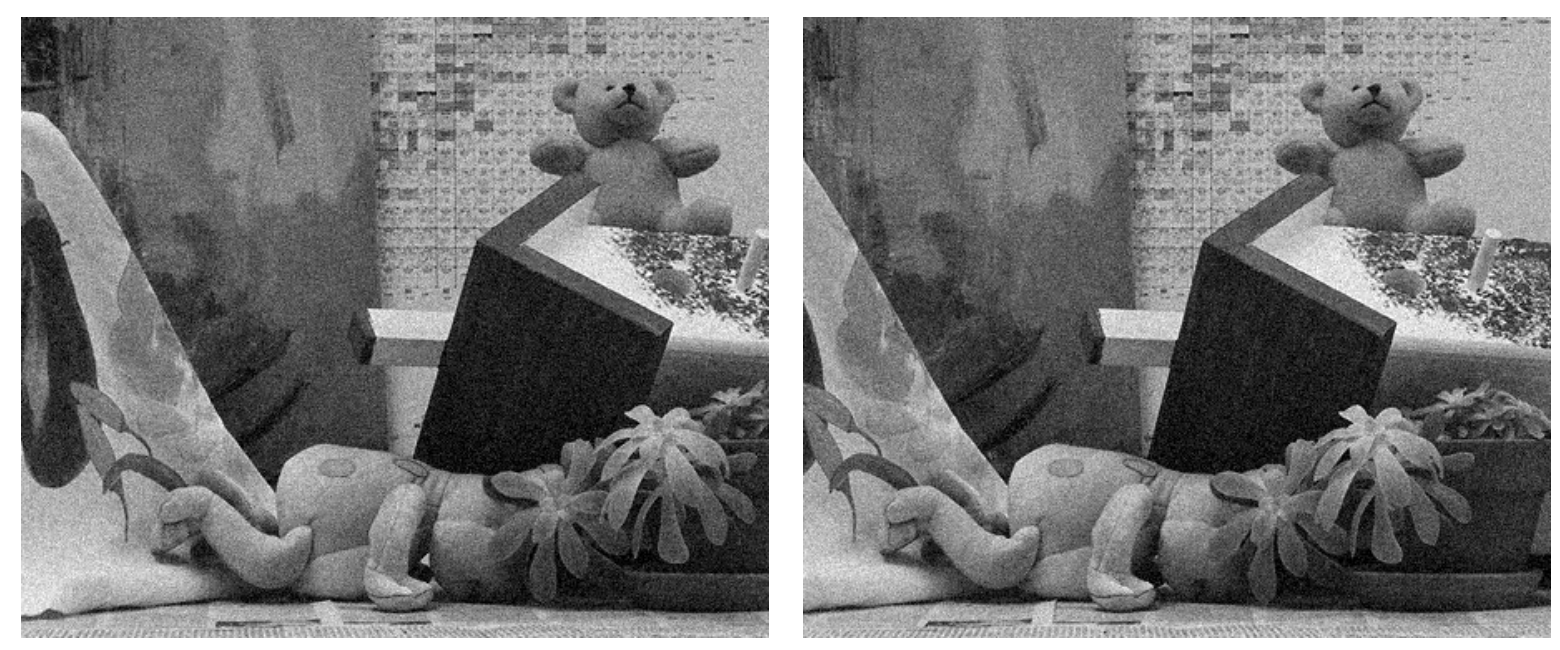

Figura 4.52: Imagens contaminadas com ruído de variância 200

Nos resultados das Figuras 4.53 e 4.54 observa-se que com a imagem contaminada ruído de variância 200 houve uma degradação ainda maior dos mapas de correlação obtidos como é possível perceber pelo aumento das correlações erradas e do erro RMS. 
Os mapas de disparidades resultantes da execução dos algoritmos nas imagens com ruído de variância 200 estão disponíveis no Apêndice B nas Figuras B51 a B60.

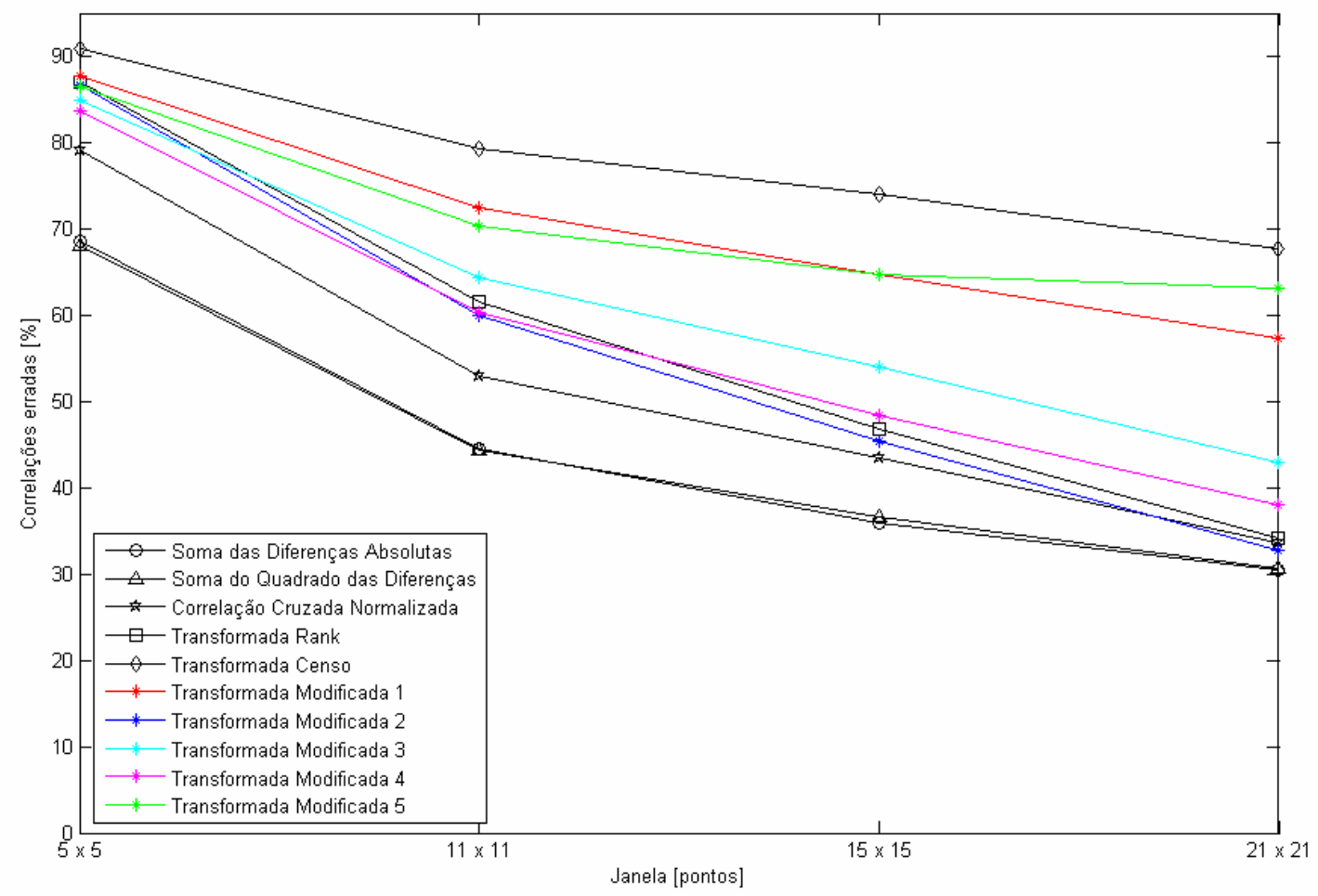

Figura 4.53: Correlações erradas na imagem Teddy com ruído de variância 200

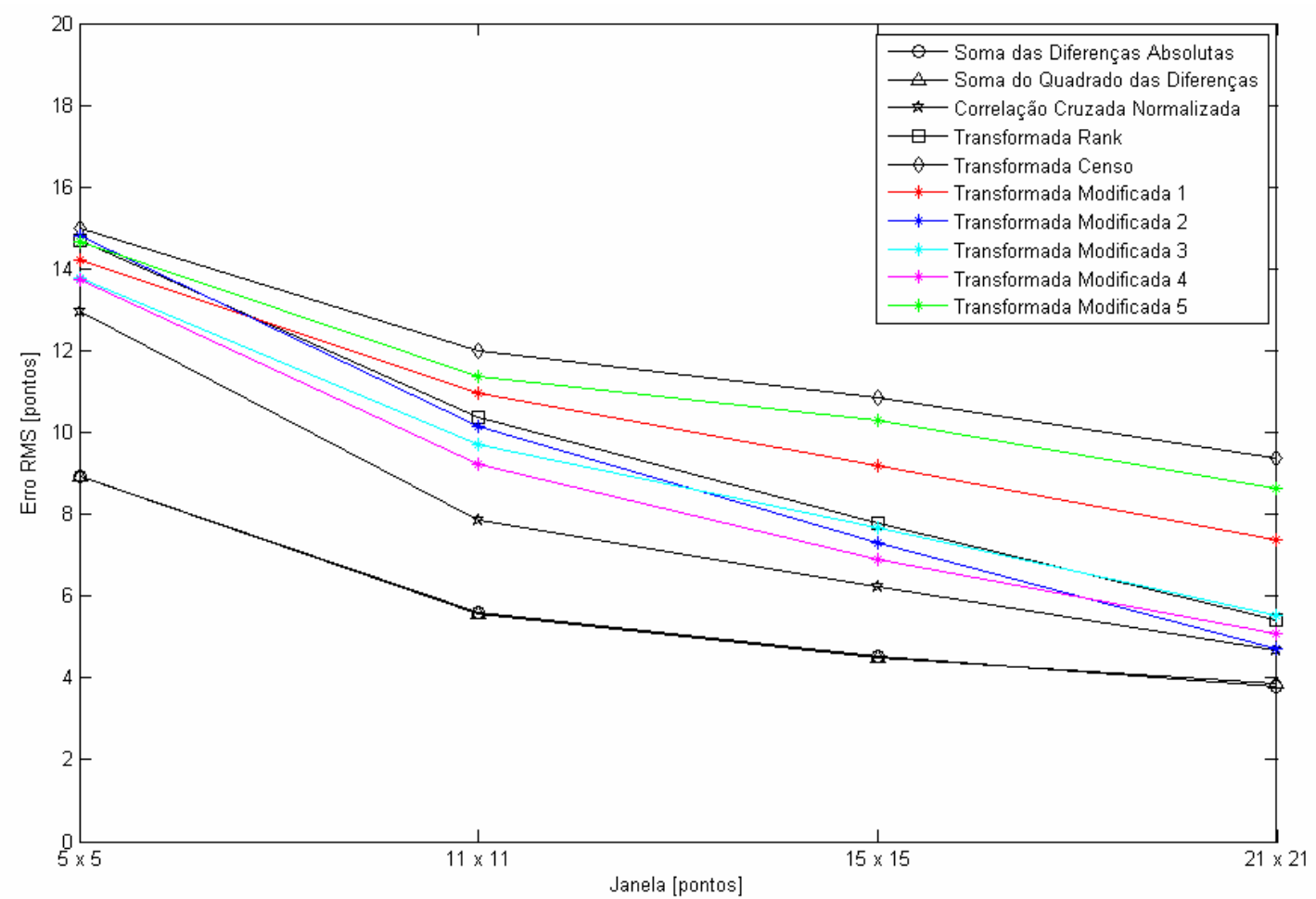

Figura 4.54: Erro RMS das correlações na imagem Teddy com ruído de variância 200 


\subsection{Aplicação dos métodos na imagem Cones}

Esta imagem foi obtida no repositório de Middlebury (2007), sendo escolhida por ser uma imagem com riqueza de detalhes e com poucas regiões sem textura. As imagens esquerda, direita e o mapa de disparidades verdadeiro da imagem direita são mostrados na Figura 4.55.
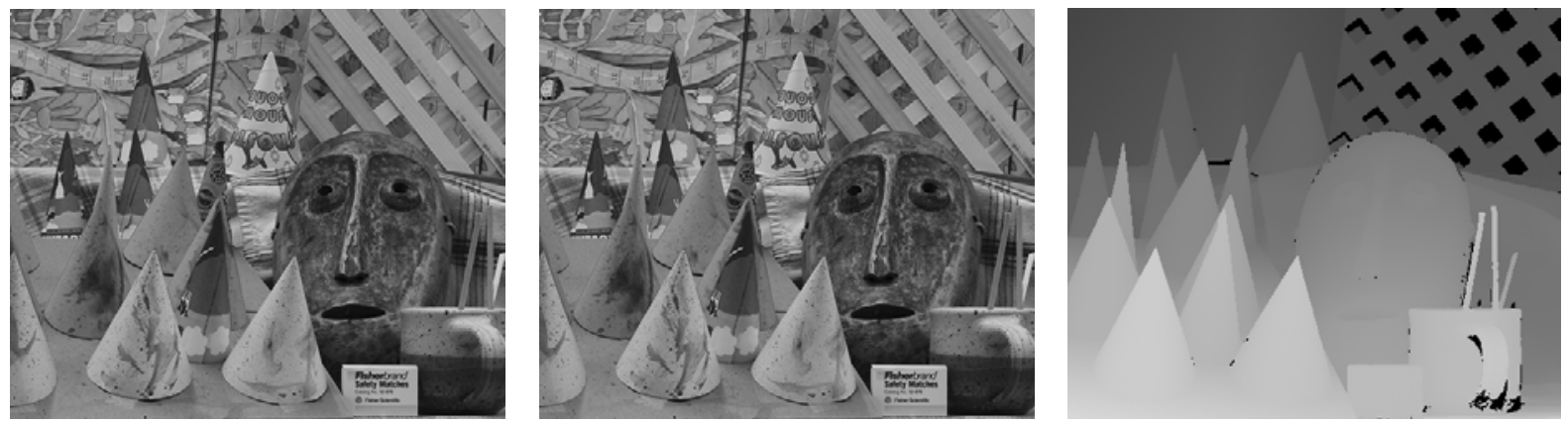

Figura 4.55: Imagens dos Cones obtida do repositório de Middlebury

Em um primeiro teste foram calculados os mapas de disparidades com as imagens originais com todos os métodos e comparados os resultados. Para a aplicação dos métodos com a Transformada Modificada 1, 2, 4 e 5 calculou-se 0 valor do limiar adotando-se como referência a região destacada na Figura 4.56.

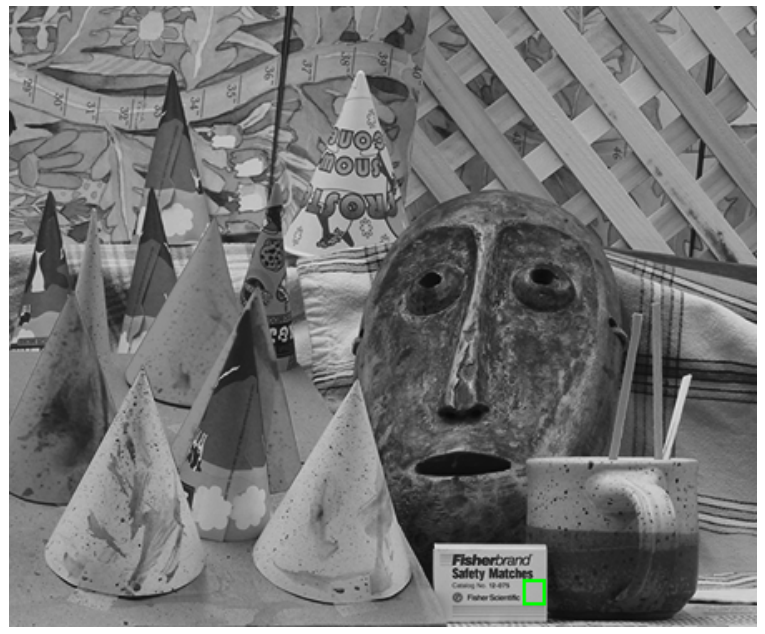

Figura 4.56: Região utilizada para o cálculo do limiar na imagem dos Cones

O limiar obtido na imagem original e nas imagens com luminosidade modificada é de 2 pontos. 
Com esta terceira imagem próxima de um ambiente real com regiões com muitos detalhes observa-se um fato interessante, os métodos Soma das Diferenças Absolutas e Soma do Quadrado das Diferenças não obtiveram resultados tão bons quanto nas imagens do Corredor e Teddy.

Nas Figuras 4.57 e 4.58 observa-se que nesta imagem dos Cones os métodos que tiveram os melhores resultados foram a Transformada Modificada 2 e a Transformada Rank. A Transformada Modificada 5 igualmente como ocorrido na imagem Teddy mostrou o pior resultado, com uma incidência de correlações erradas maior até do que a própria Transformada Censo.

Os mapas de disparidades resultantes da execução dos algoritmos nas imagens originais estão disponíveis no Apêndice B nas Figuras B61 a B70.

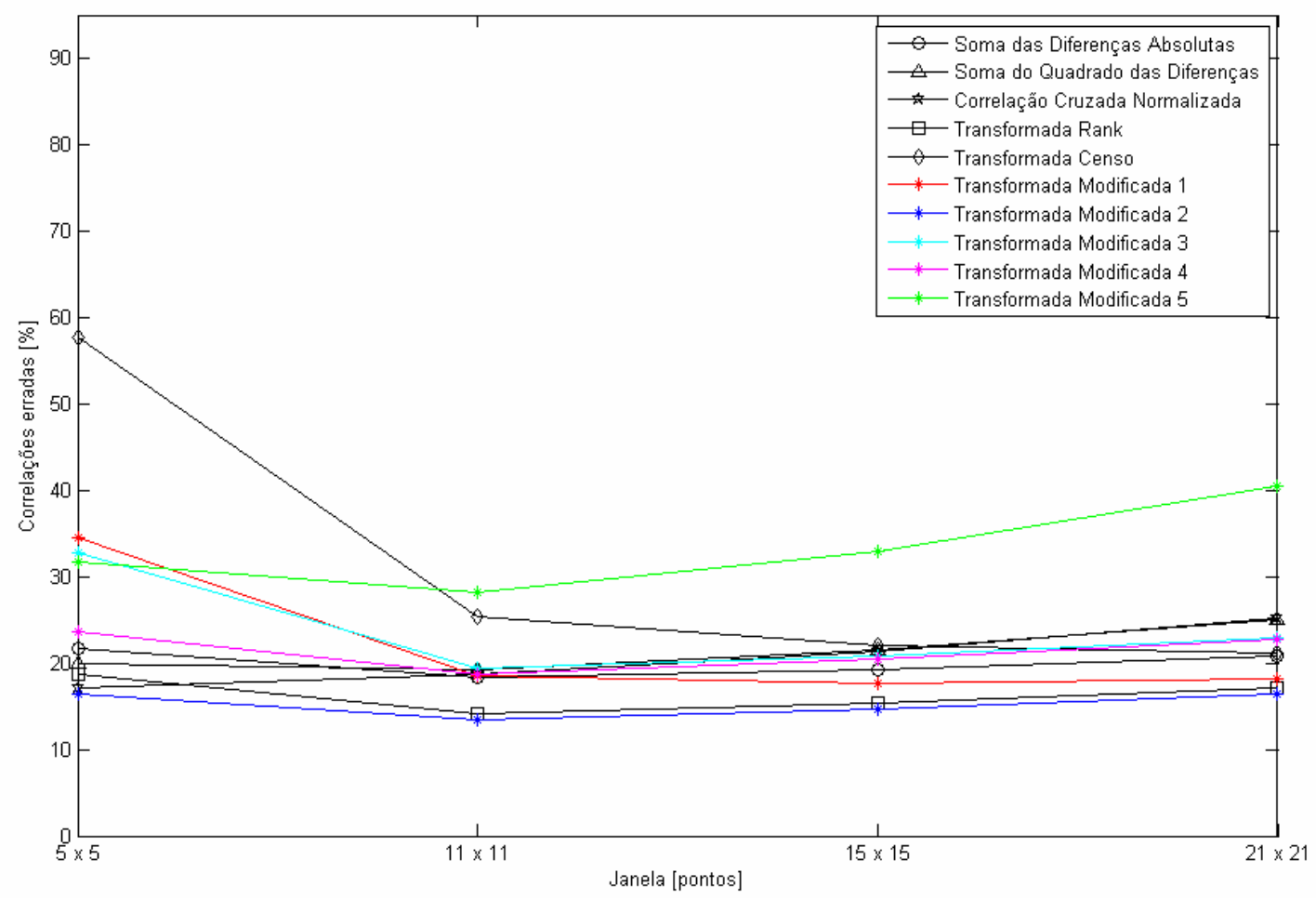

Figura 4.57: Correlações erradas na imagem Cones original 


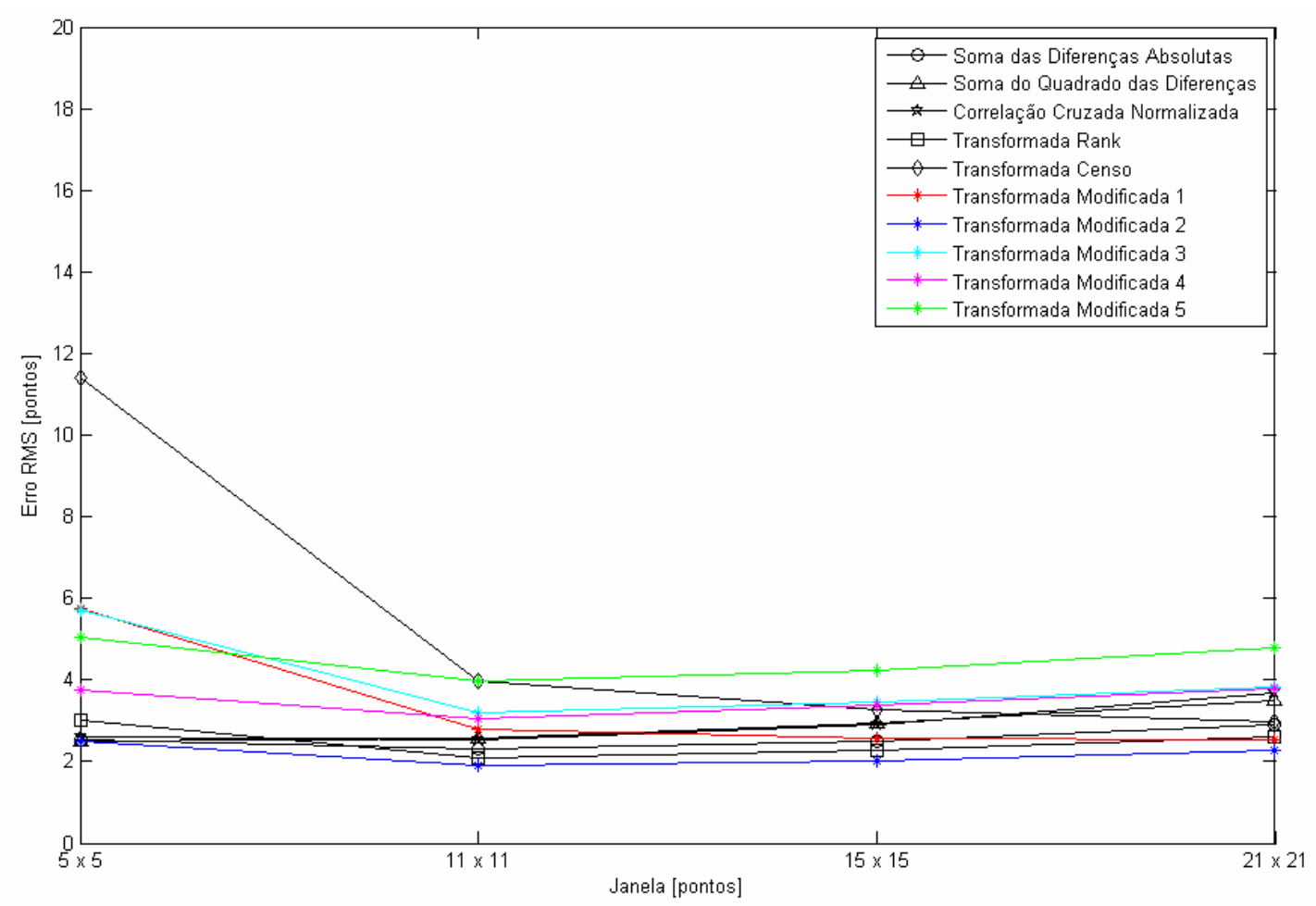

Figura 4.58: Erro RMS das correlações na imagem Cones original

Em um segundo passo, pares de imagens com luminosidades diferentes foram analisados. Optou-se por reduzir a luminosidade da imagem esquerda em 10\%, 20\% e em seguida 30\% para comparar a influência dessa variação nos resultados.

A Figura 4.59 apresenta as imagens com uma diferença de 10\% na luminosidade.
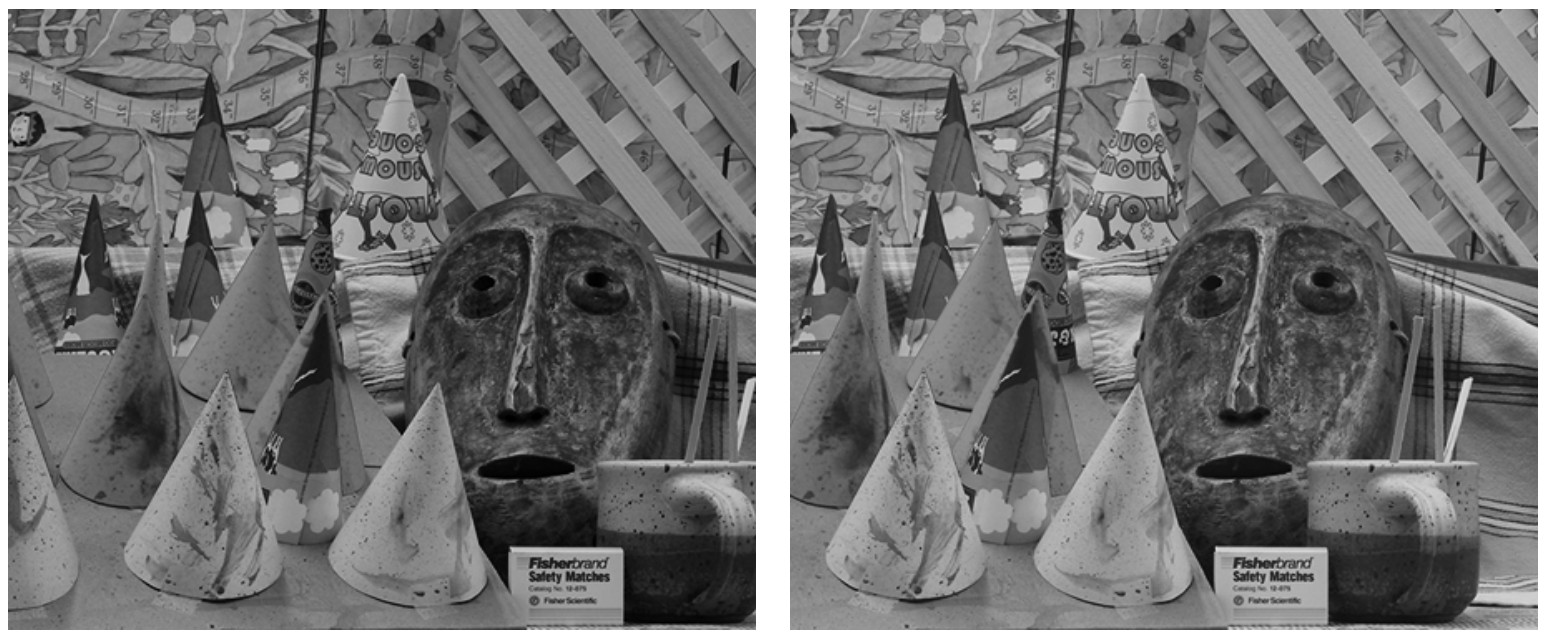

Figura 4.59: Imagem esquerda com luminosidade $10 \%$ menor 
Pelos resultados mostrados nas Figuras 4.60 e 4.61 observa-se que com luminosidade $10 \%$ menor na imagem esquerda os métodos da Transformada Rank e a Transformada Modificada 2 apresentam os melhores resultados.

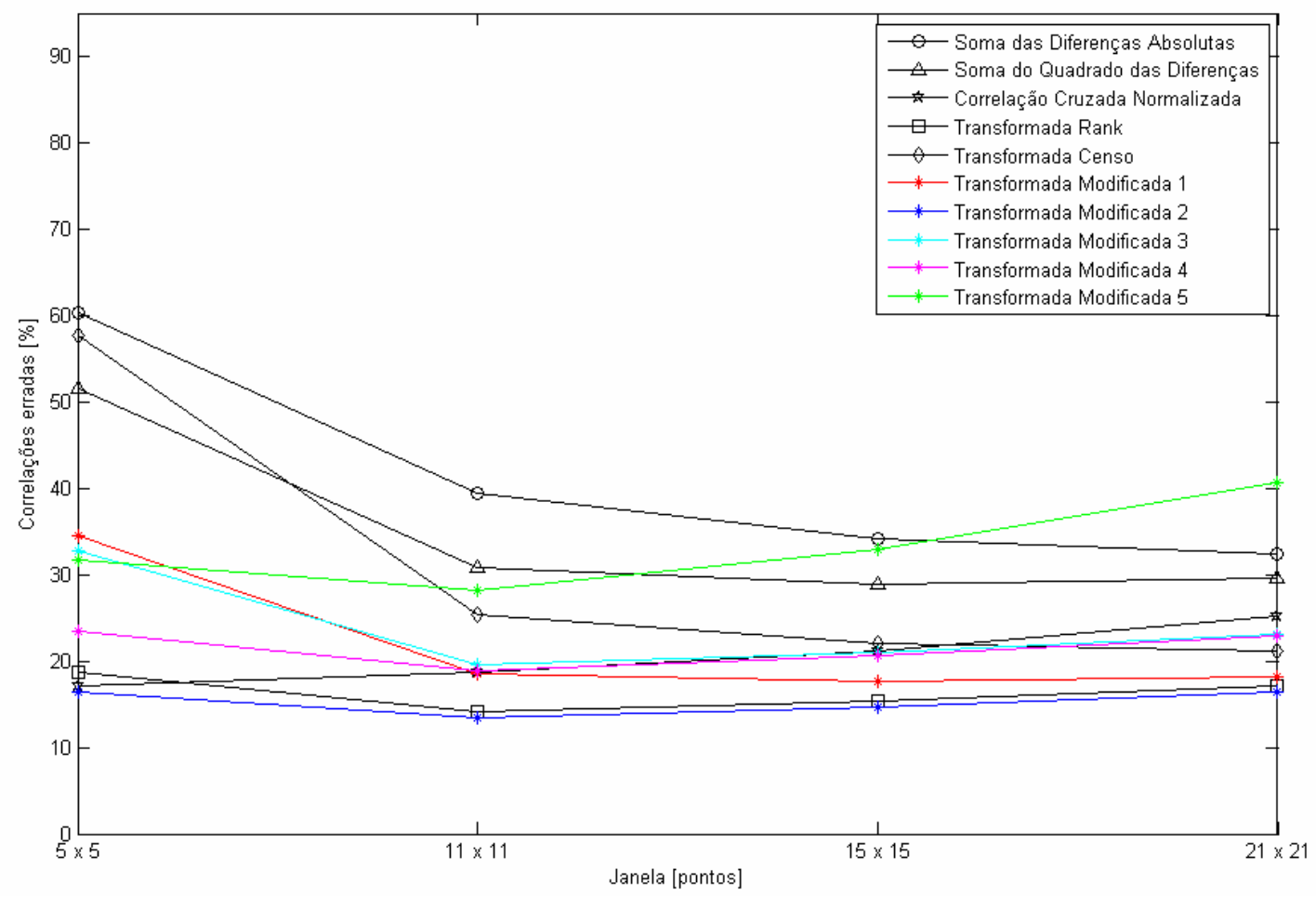

Figura 4.60: Correlações erradas na imagem Cones com luminosidade 10\% diferente

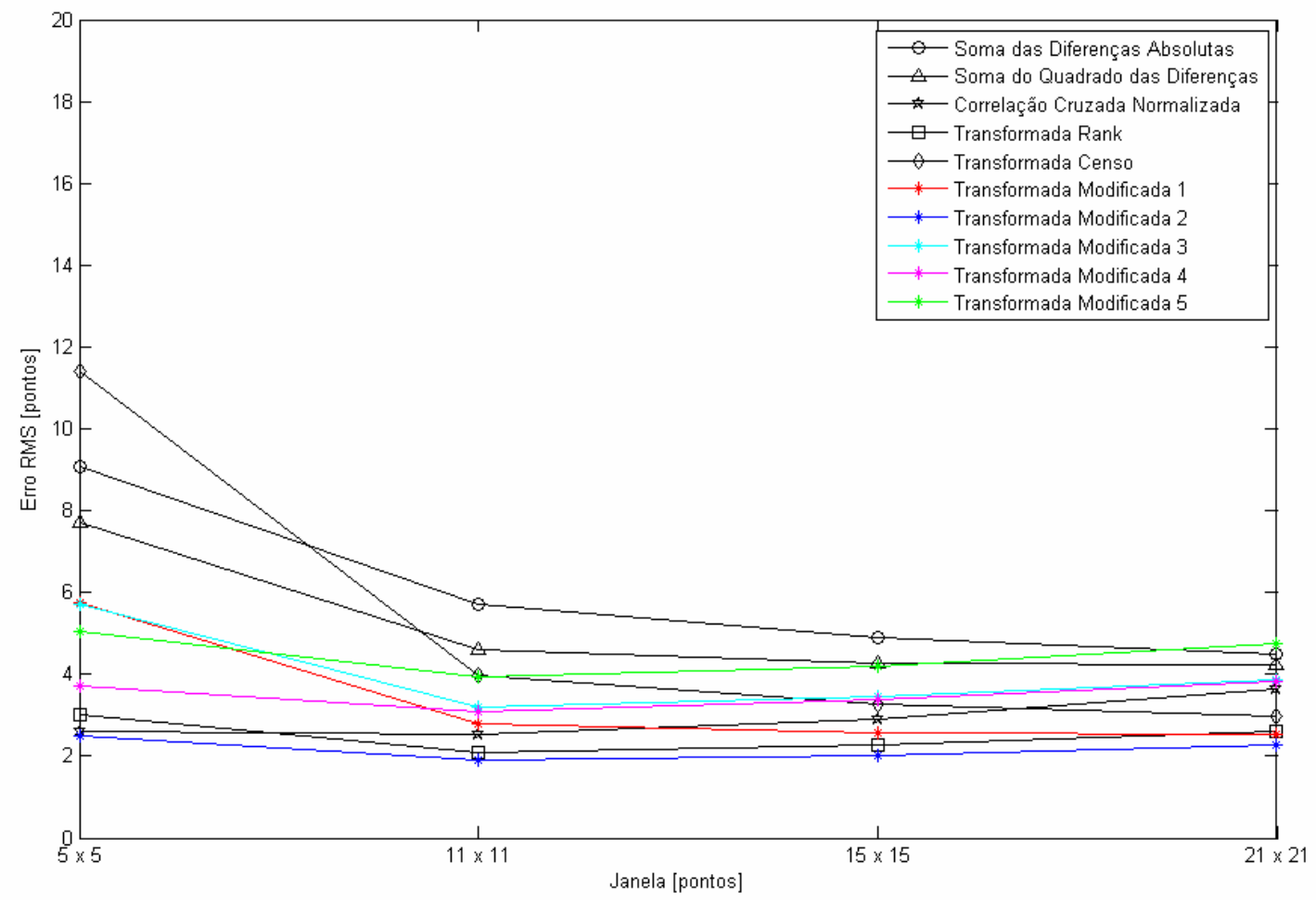

Figura 4.61: Erro RMS das correlações na imagem Cones com luminosidade $10 \%$ diferente 
A Figura 4.62 apresenta as imagens com uma diferença de $20 \%$ na luminosidade.
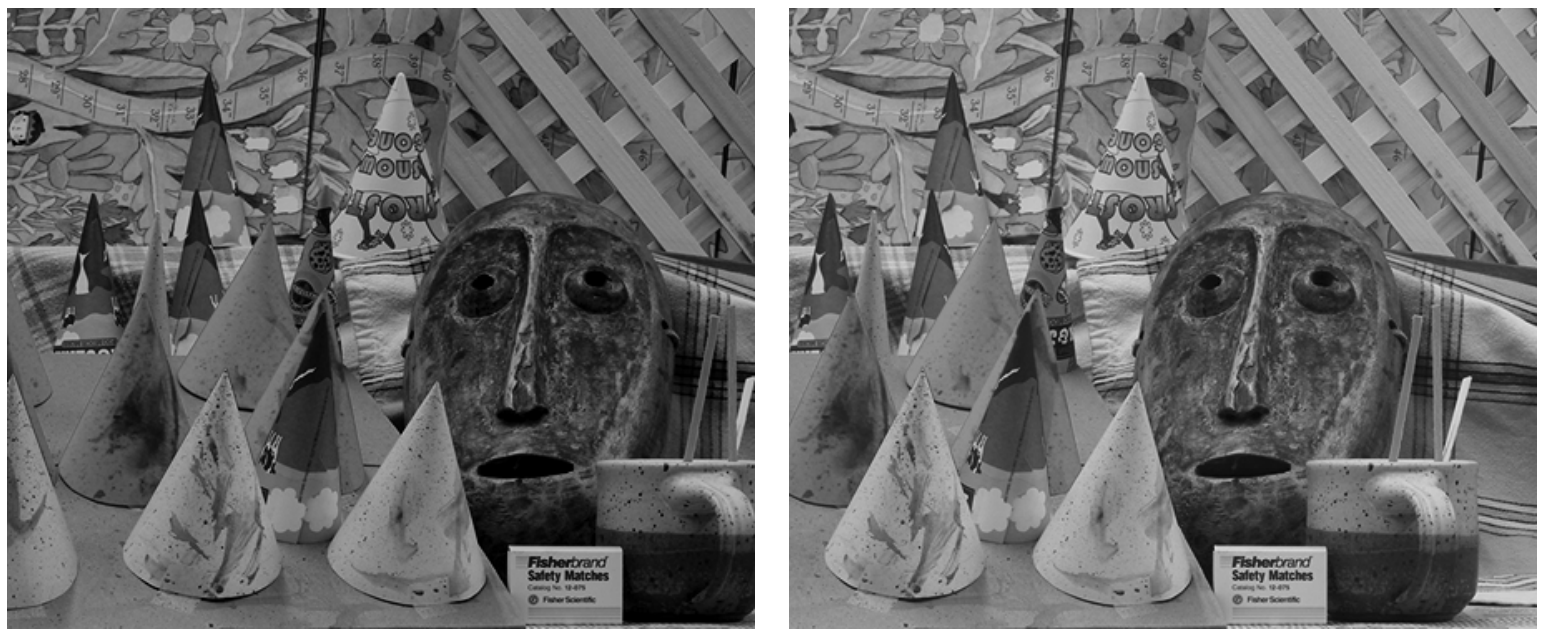

Figura 4.62: Imagem esquerda com luminosidade $20 \%$ menor

Nas Figuras 4.63 e 4.64 observa-se que após executados os métodos na imagem com uma diferença de luminosidade de $20 \%$, fora os métodos Soma das Diferenças Absolutas e Soma do Quadrado das Diferenças, os resultados da quantidade de correlações erradas permaneceu praticamente inalterado com a variação da luminosidade da mesma foram como ocorreu com a imagem Teddy.

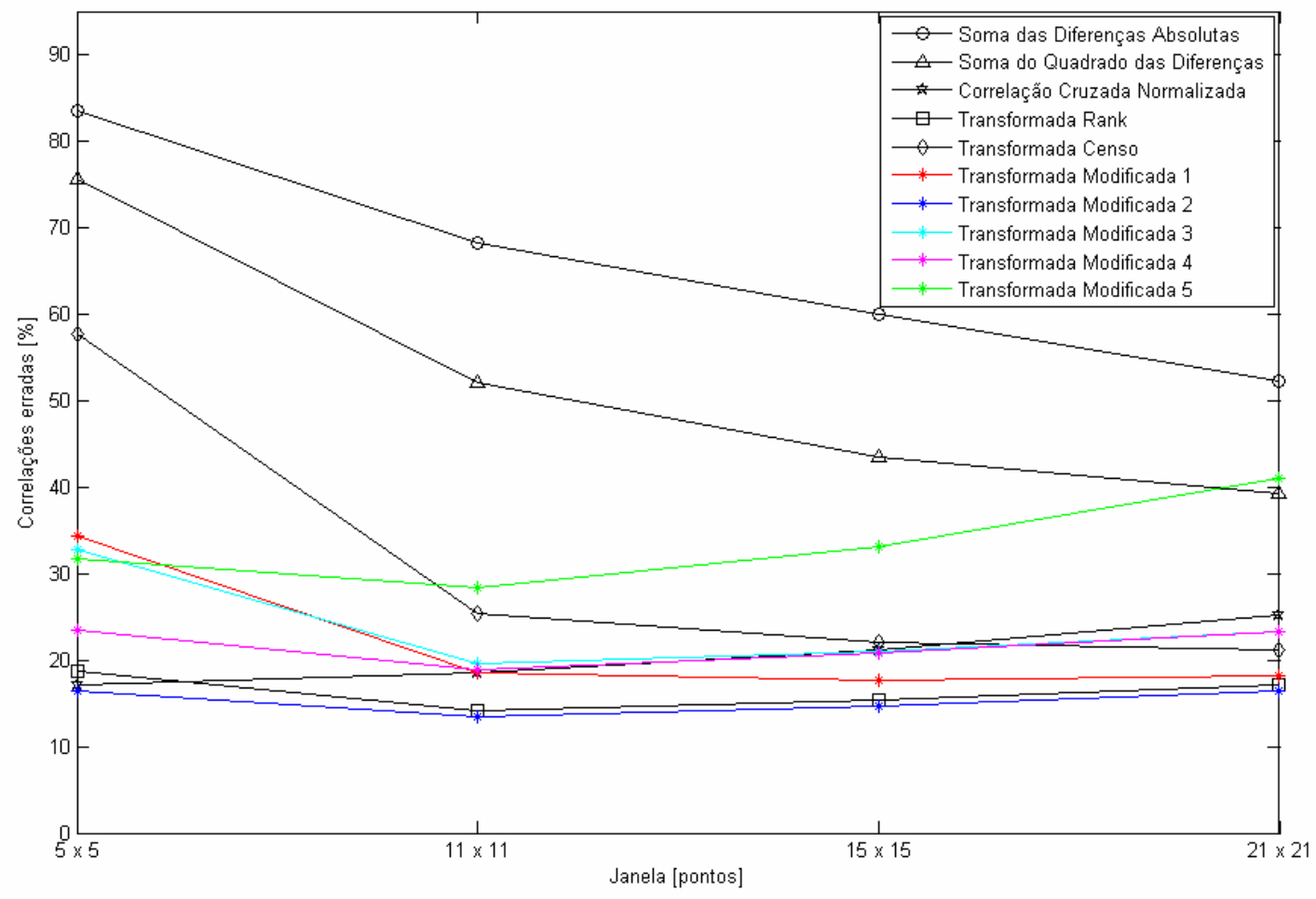

Figura 4.63: Correlações erradas na imagem Cones com luminosidade $20 \%$ diferente 


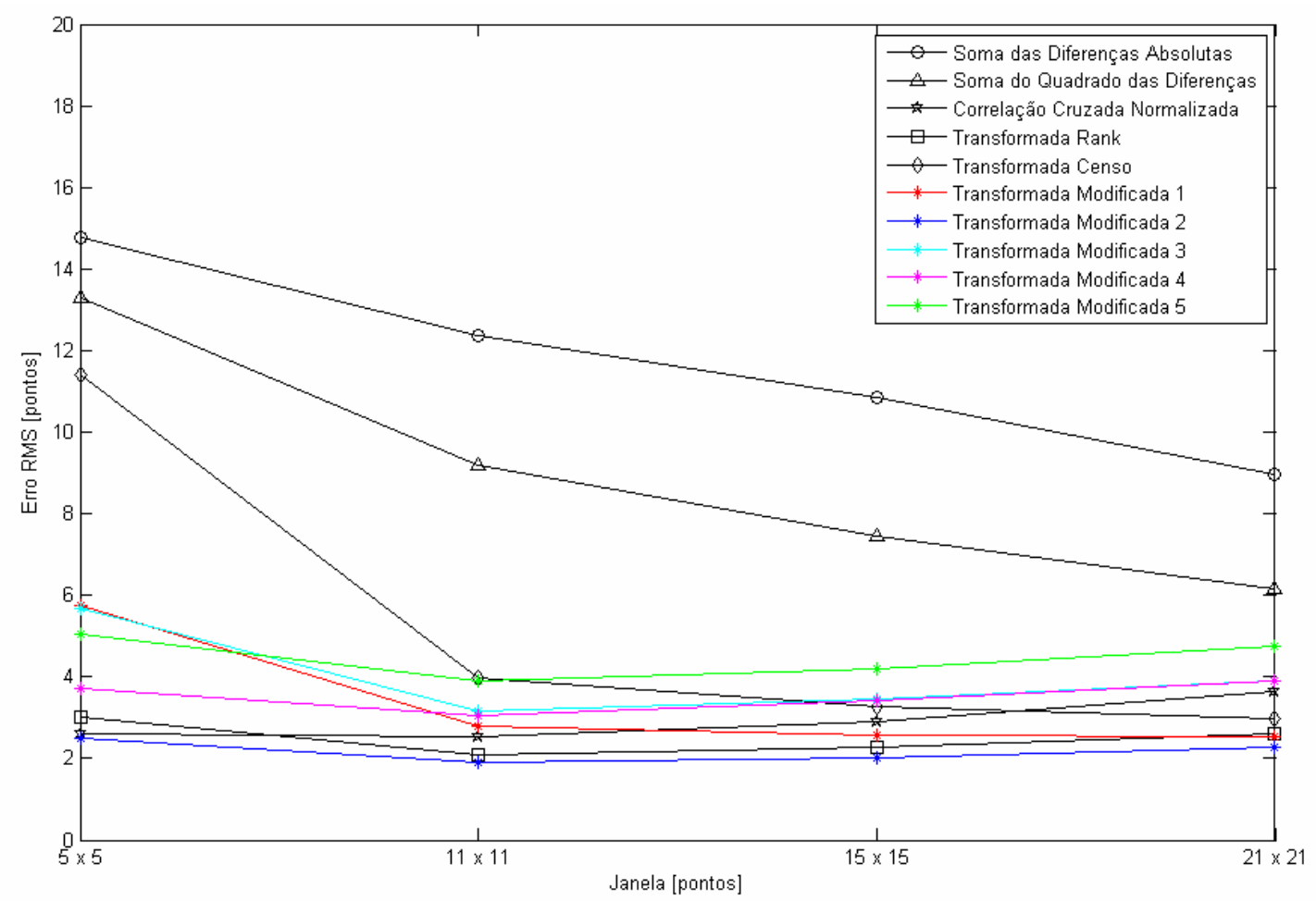

Figura 4.64: Erro RMS das correlações na imagem Cones com luminosidade $20 \%$ diferente

A Figura 4.65 apresenta as imagens com uma diferença de $30 \%$ na luminosidade.
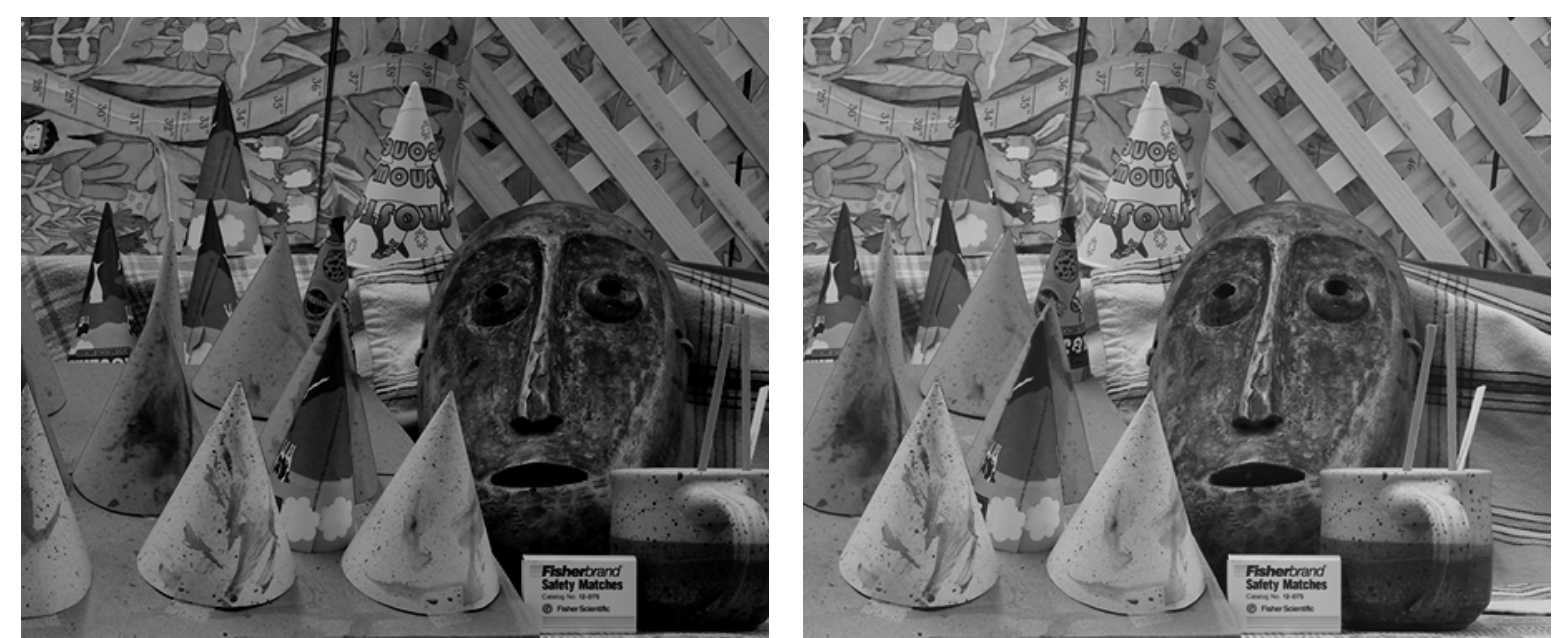

Figura 4.65: Imagem esquerda com luminosidade $30 \%$ menor

Nas Figuras 4.66 e 4.67 observa-se que após executados os métodos na imagem com uma diferença de luminosidade de 30\%, fora os métodos Soma das Diferenças Absolutas e Soma do Quadrado das Diferenças, os resultados da quantidade de 
correlações erradas permaneceram praticamente inalterados em relação às imagens com diferença de luminosidade de $20 \%$.

Os mapas de disparidades resultantes da execução dos algoritmos nas imagens com luminosidade 30\% diferente estão disponíveis no Apêndice B nas Figuras B71 a B80.

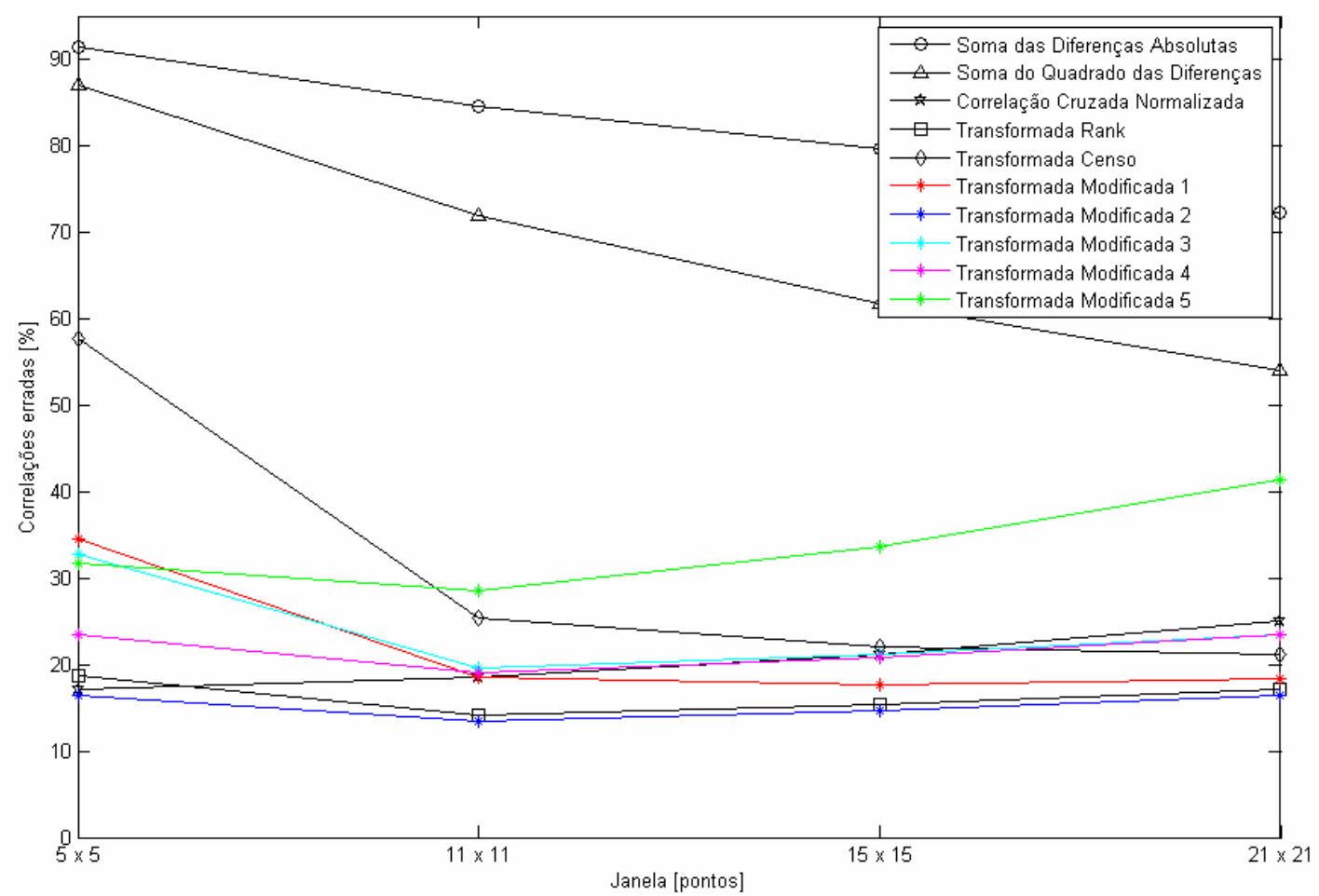

Figura 4.66: Correlações erradas na imagem Cones com luminosidade 30\% diferente 


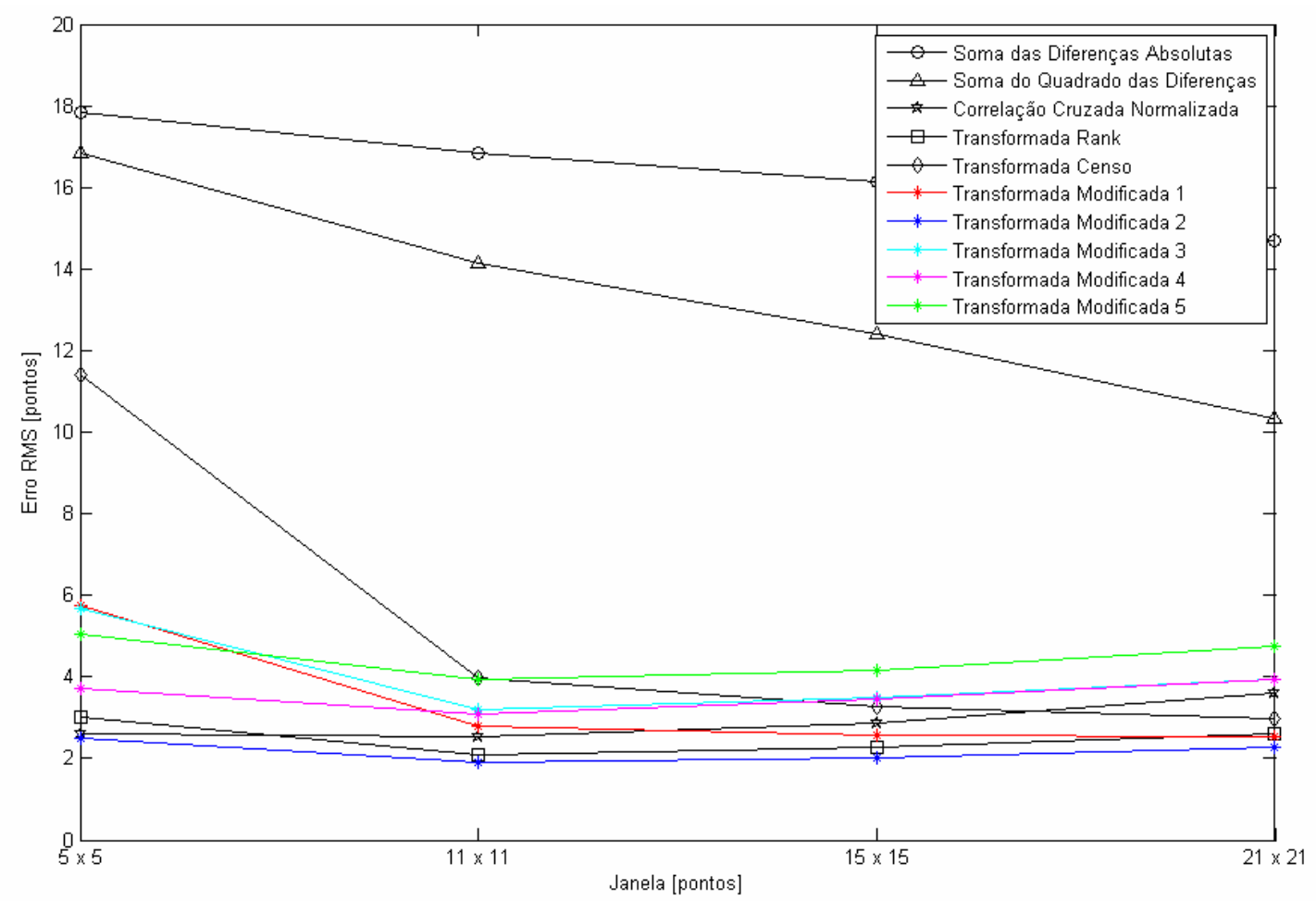

Figura 4.67: Erro RMS das correlações na imagem Cones com luminosidade $30 \%$ diferente

Na comparação dos algoritmos com as imagens com ruído foram criadas versões das imagens originais com ruído de variância 10, 100 e 200 com incidência em todos os pontos da imagem e um caso com ruído de variância 200 com incidência em 50\% dos pontos da imagem.

A Figura 4.68 mostra as imagens Cones contaminadas com ruído de variância 10, nesta imagem foi obtido um limiar de 5 pontos.
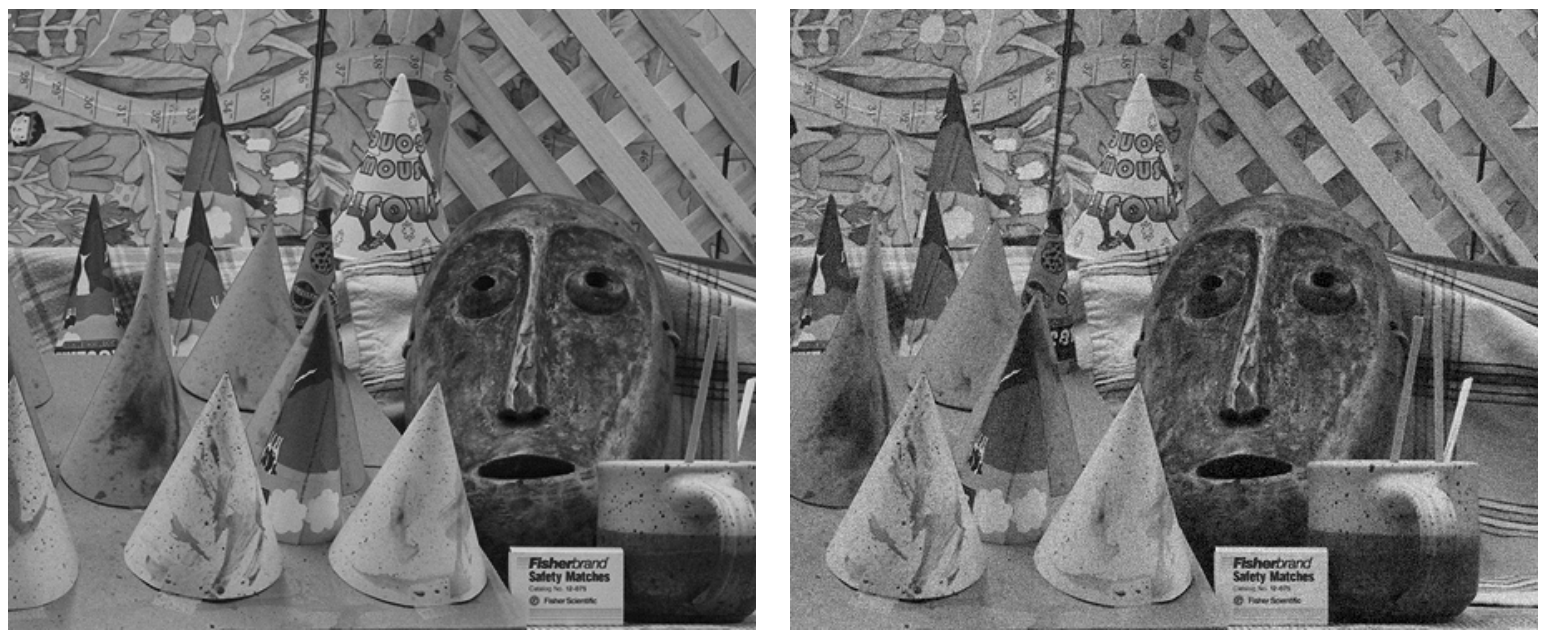

Figura 4.68: Imagens contaminadas com ruído de variância 10 
Pelas Figuras 4.69 e 4.70 observa-se que a Transformada Modificada 2 consegue manter resultados próximos da Transformada Rank, sendo um dos melhores métodos para o caso com pouco ruído.

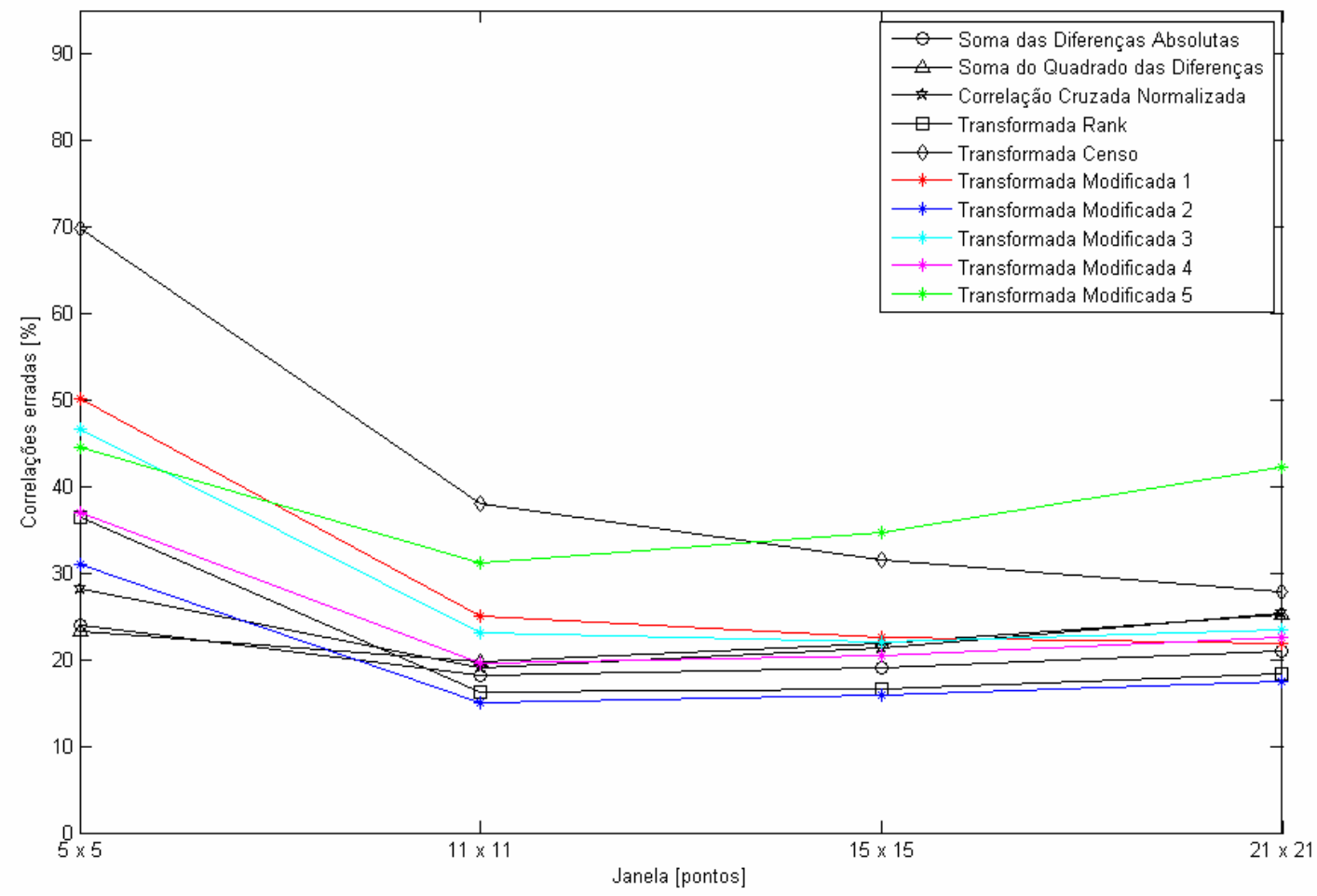

Figura 4.69: Correlações erradas na imagem do Cones com ruído de variância 10

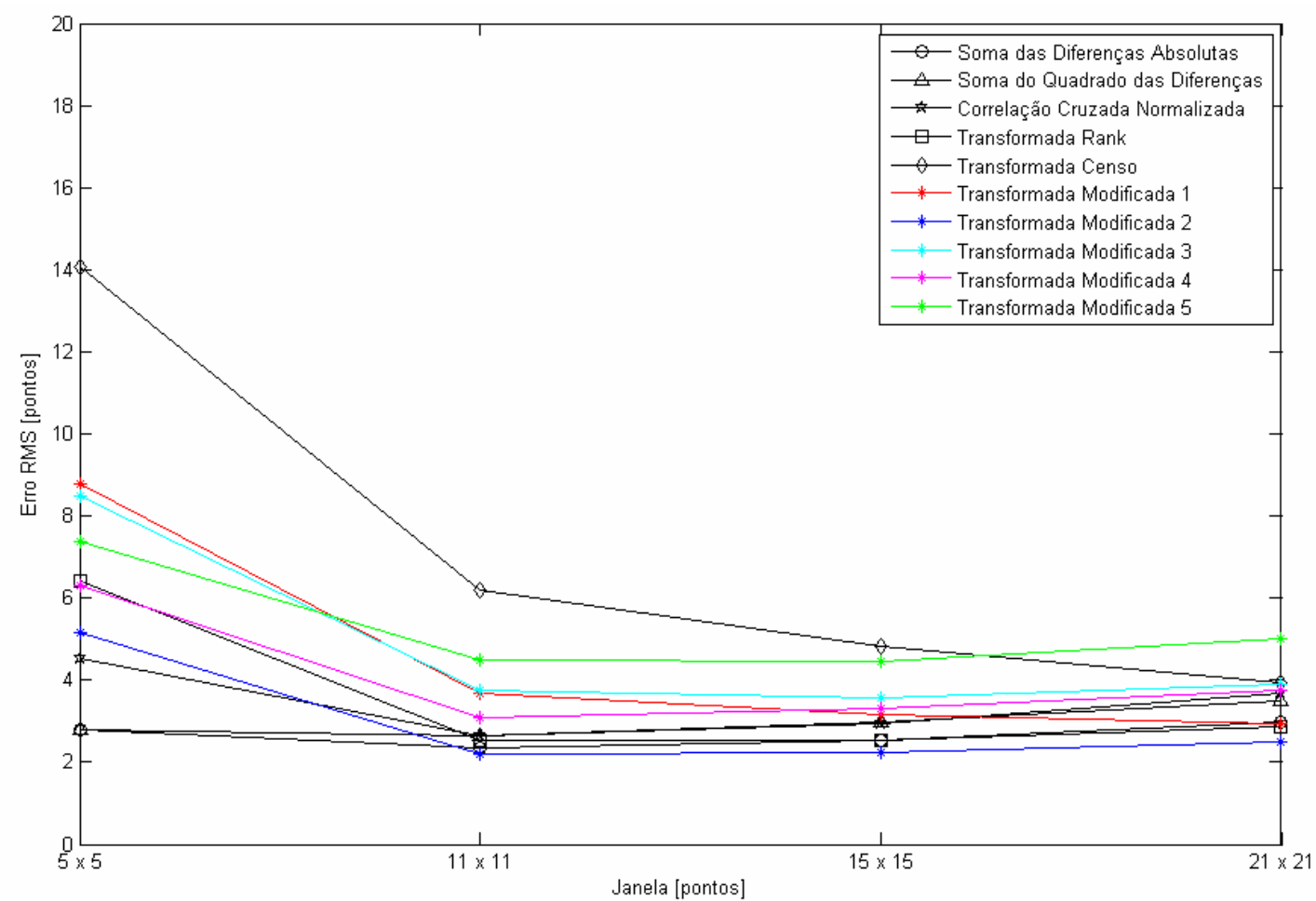

Figura 4.70: Erro RMS das correlações na imagem Cones com ruído de variância 10 
A Figura 4.71 mostra as imagens Cones contaminadas com ruído de variância 100, nesta imagem foi obtido um limiar de 12 pontos.
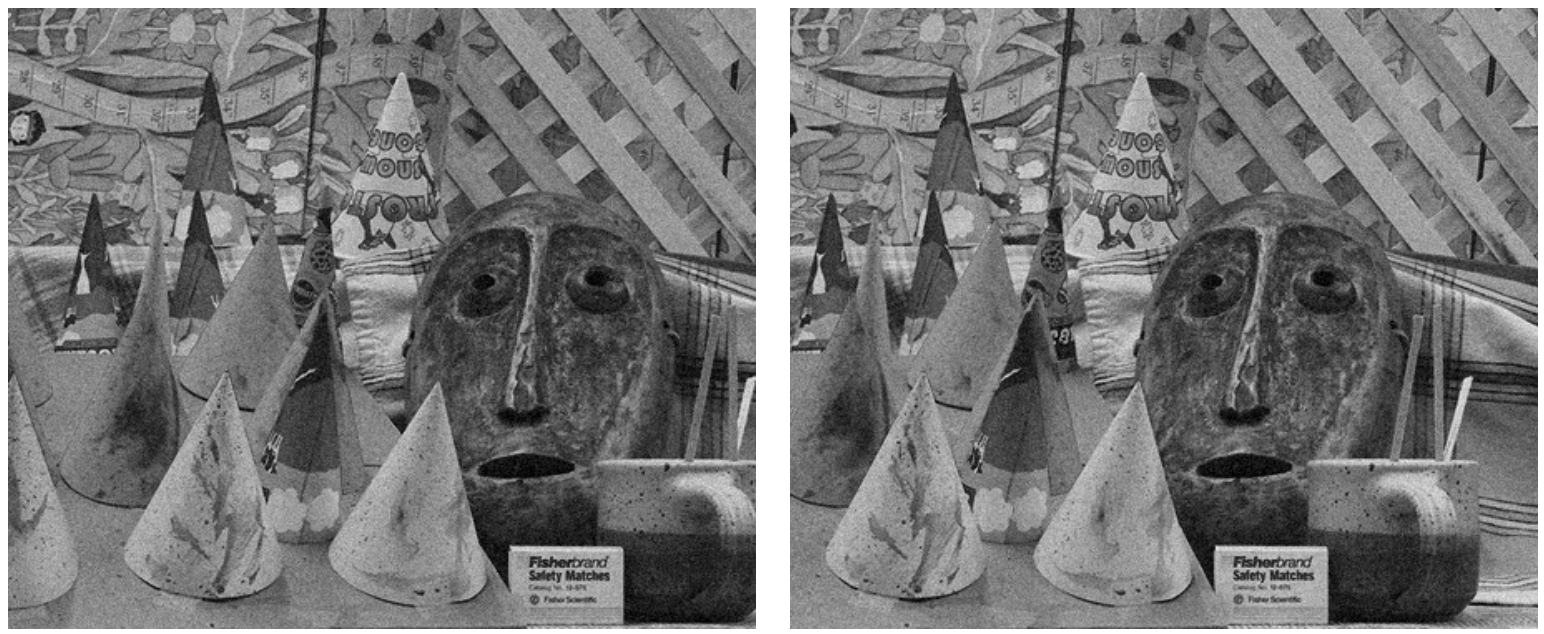

Figura 4.71: Imagens contaminadas com ruído de variância 100

Como pode ser visto nas Figuras 4.72 e 4.73 o aumento do ruído para variância 100 causou um grande aumento nas correlações erradas. Observa-se que a Transformada Modificada 2 neste caso apresenta resultados melhores que no caso da imagem Teddy, mantendo-se ainda como um dos melhores métodos.

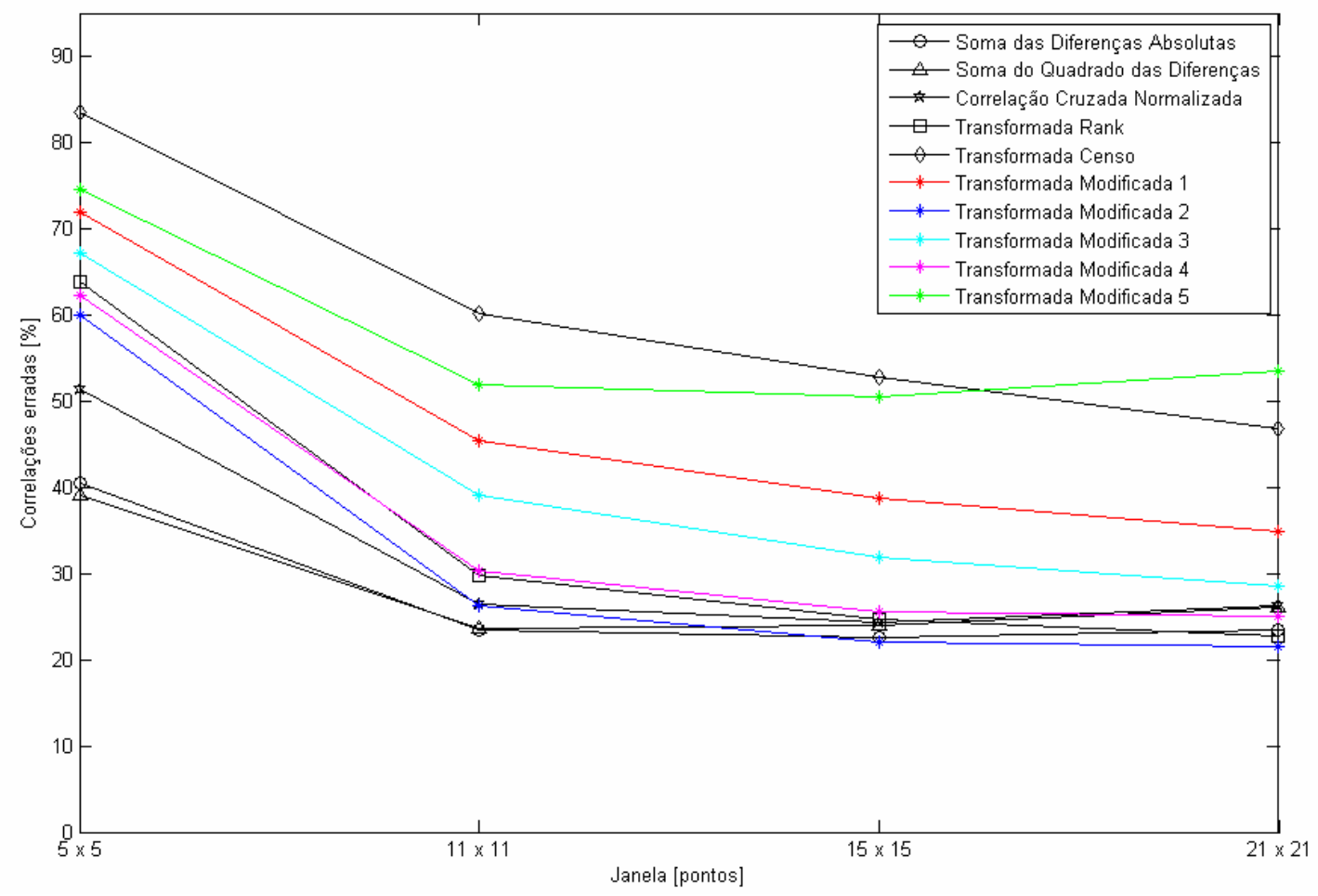

Figura 4.72: Correlações erradas na imagem Cones com ruído de variância 100 


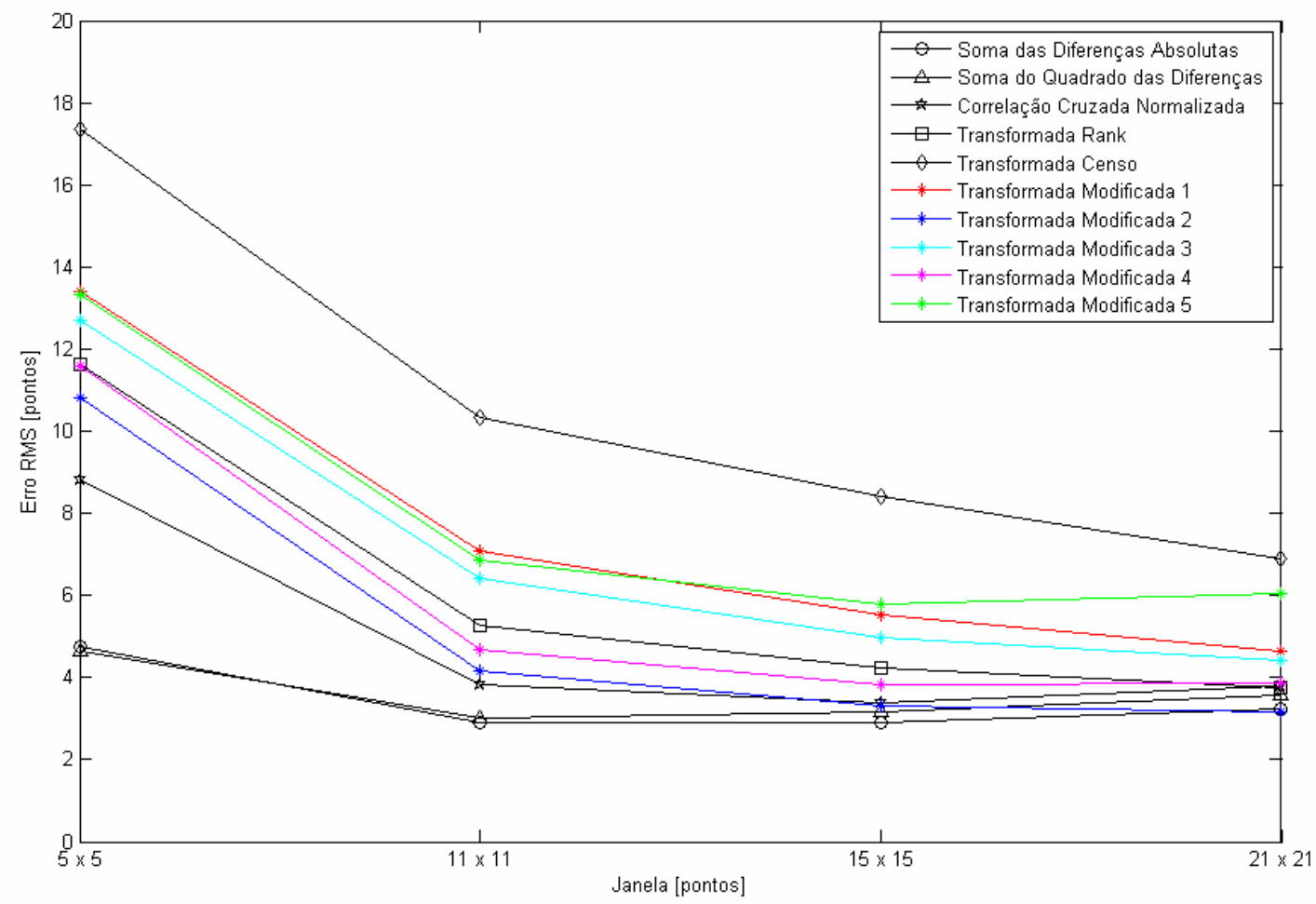

Figura 4.73: Erro RMS das correlações na imagem Cones com ruído de variância 100

A Figura 4.74 mostra as imagens Cones contaminadas com ruído de variância 200 e incidência em 50\% da imagem, nesta imagem foi obtido um limiar de 11 pontos.
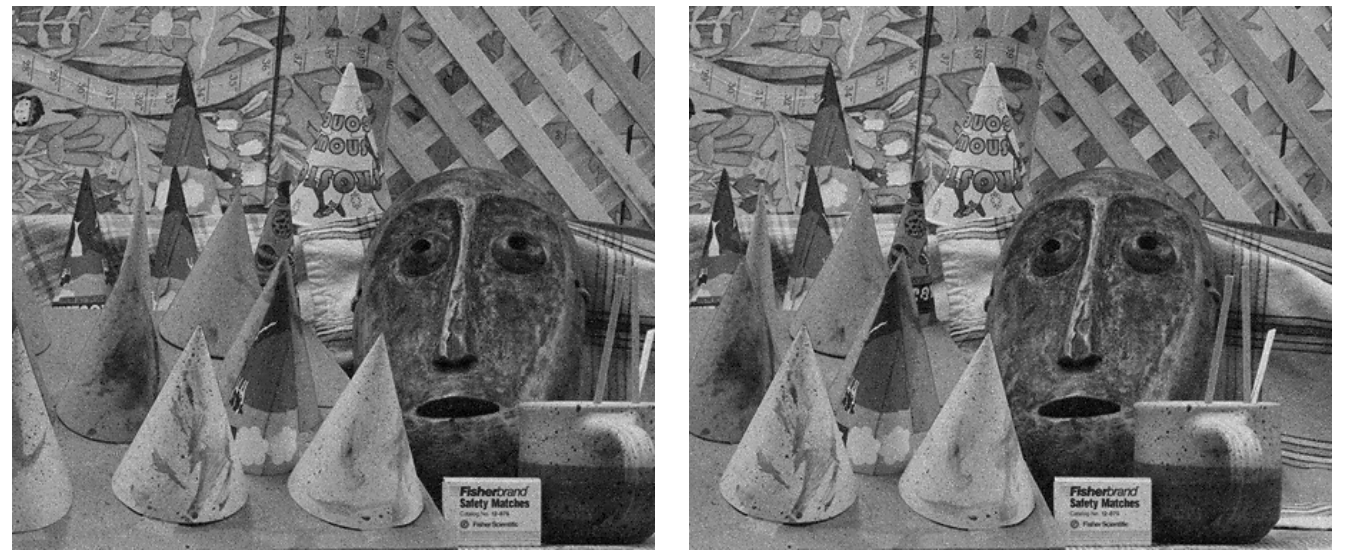

Figura 4.74: Imagens contaminadas com ruído de variância 200 em 50\% da imagem

Nas Figuras 4.75 e 4.76 observa-se que os métodos que apresentaram os melhores resultados, quando aplicados nas imagens com ruído de variância 200 e 
incidência em 50\% da imagem, foram a Transformada Modificada 2, Transformada Rank e a Soma das Diferenças Absolutas.

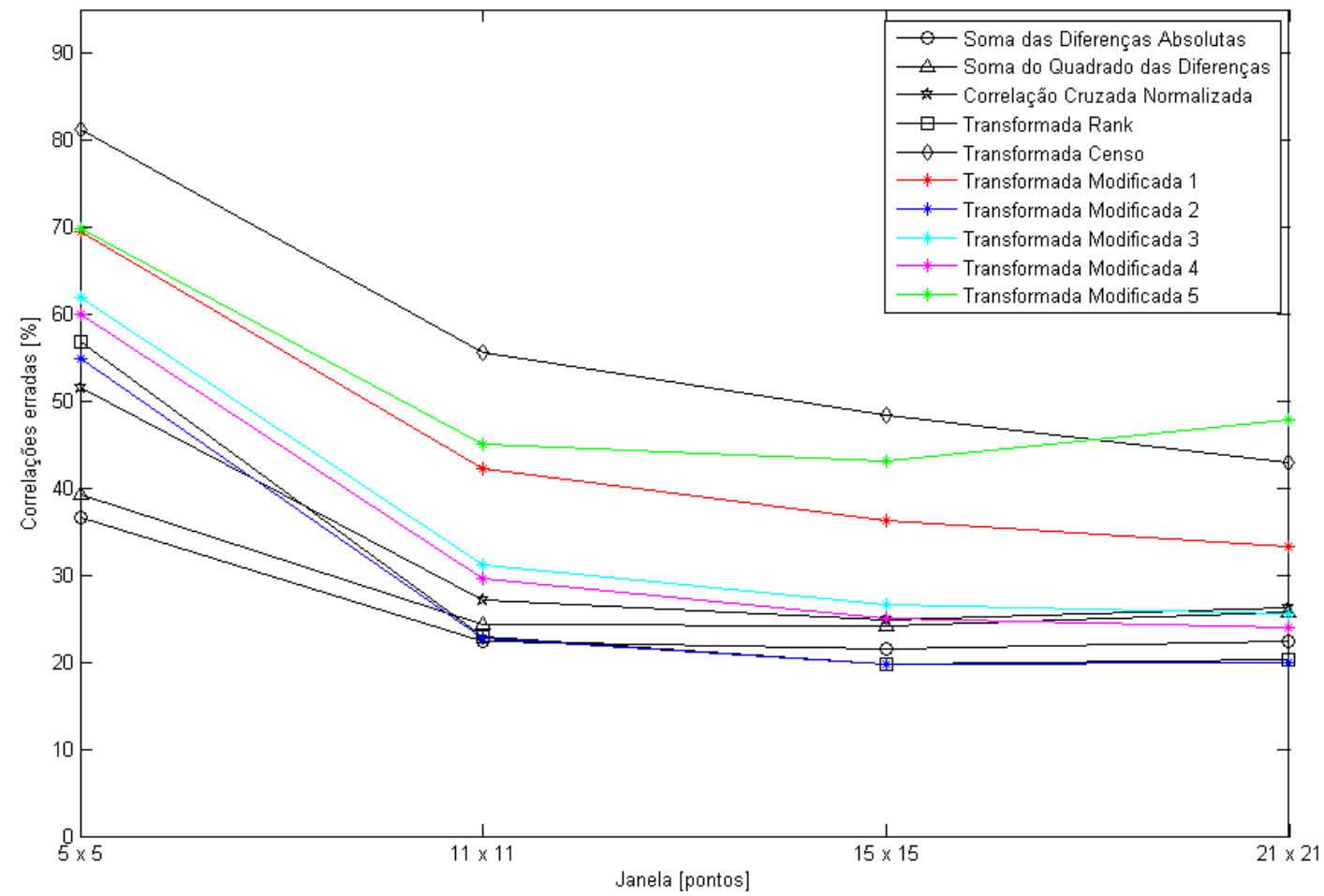

Figura 4.75: Correlações erradas na imagem Cones com ruído de variância 200 e incidência 50\%

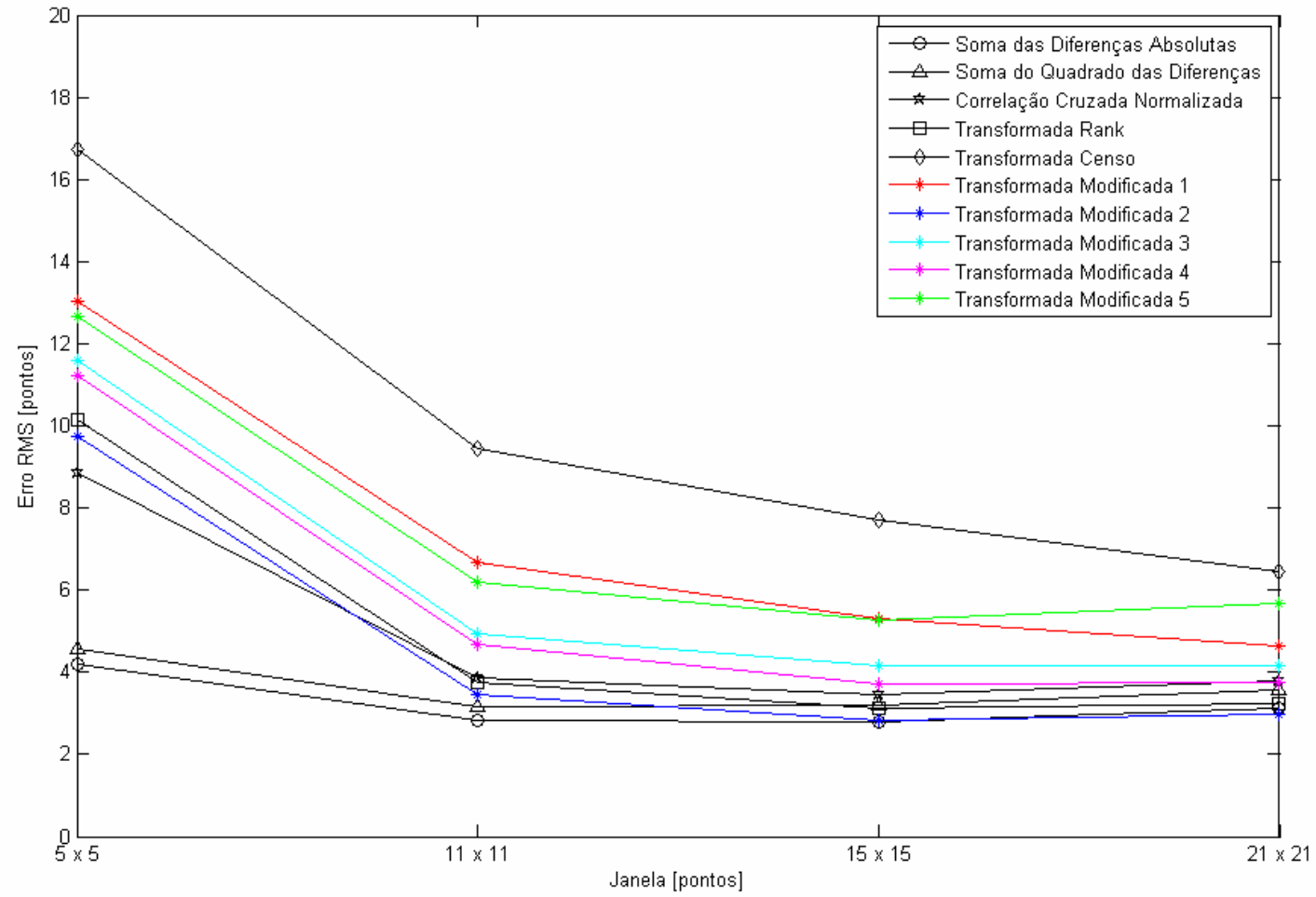

Figura 4.76: Erro RMS das correlações na imagem Cones com ruído de variância 200 e incidência $50 \%$ 
A Figura 4.77 mostra as imagens Cones contaminadas com ruído de variância 200, nesta imagem foi obtido um limiar de 14 pontos.
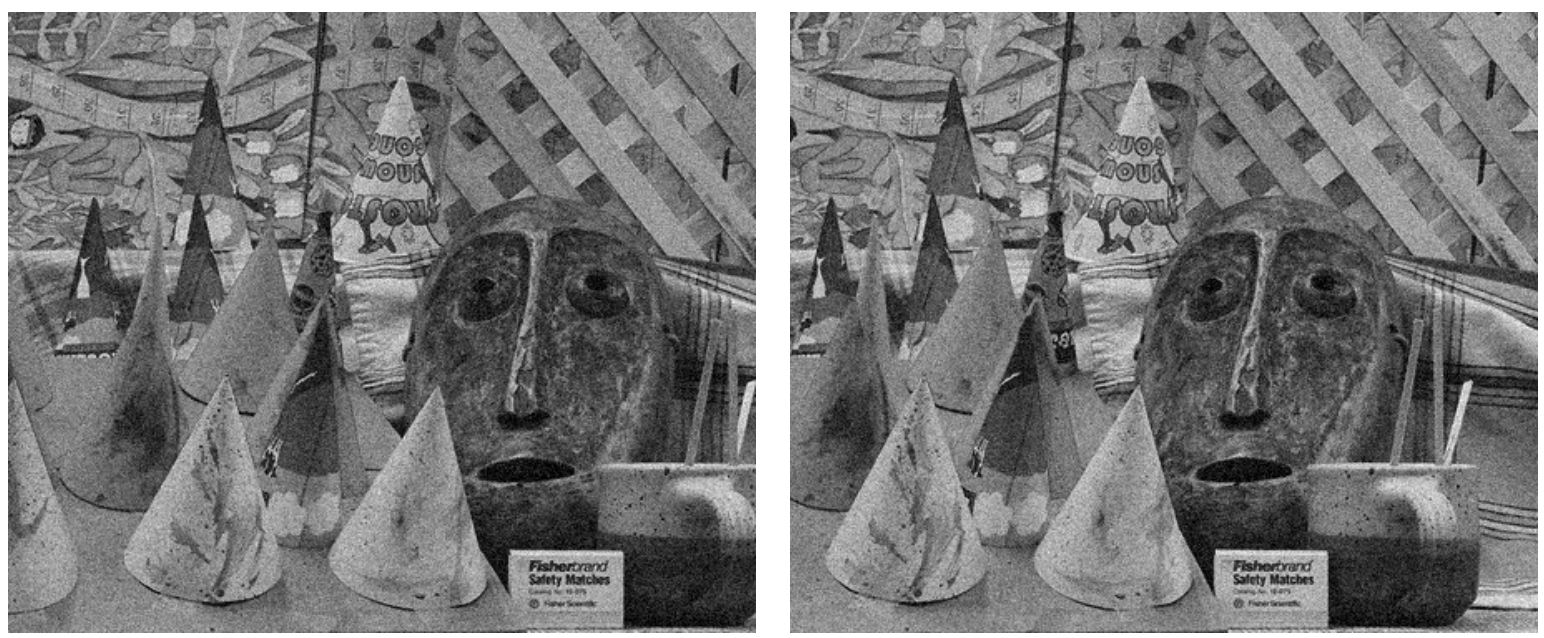

Figura 4.77: Imagens contaminadas com ruído de variância 200

Nas Figuras 4.78 e 4.79 observa-se que os métodos da Soma das Diferenças Absolutas e Soma dos Quadrados das Diferenças obtiveram os melhores resultados. A Transformada Modificada 2 mostra uma tendência de conseguir resultados semelhantes ao dos melhores métodos com a utilização de janelas grandes.

Os mapas de disparidades resultantes da execução dos algoritmos nas imagens com ruído de variância 200 estão disponíveis no Apêndice B nas Figuras B81 a B90. 


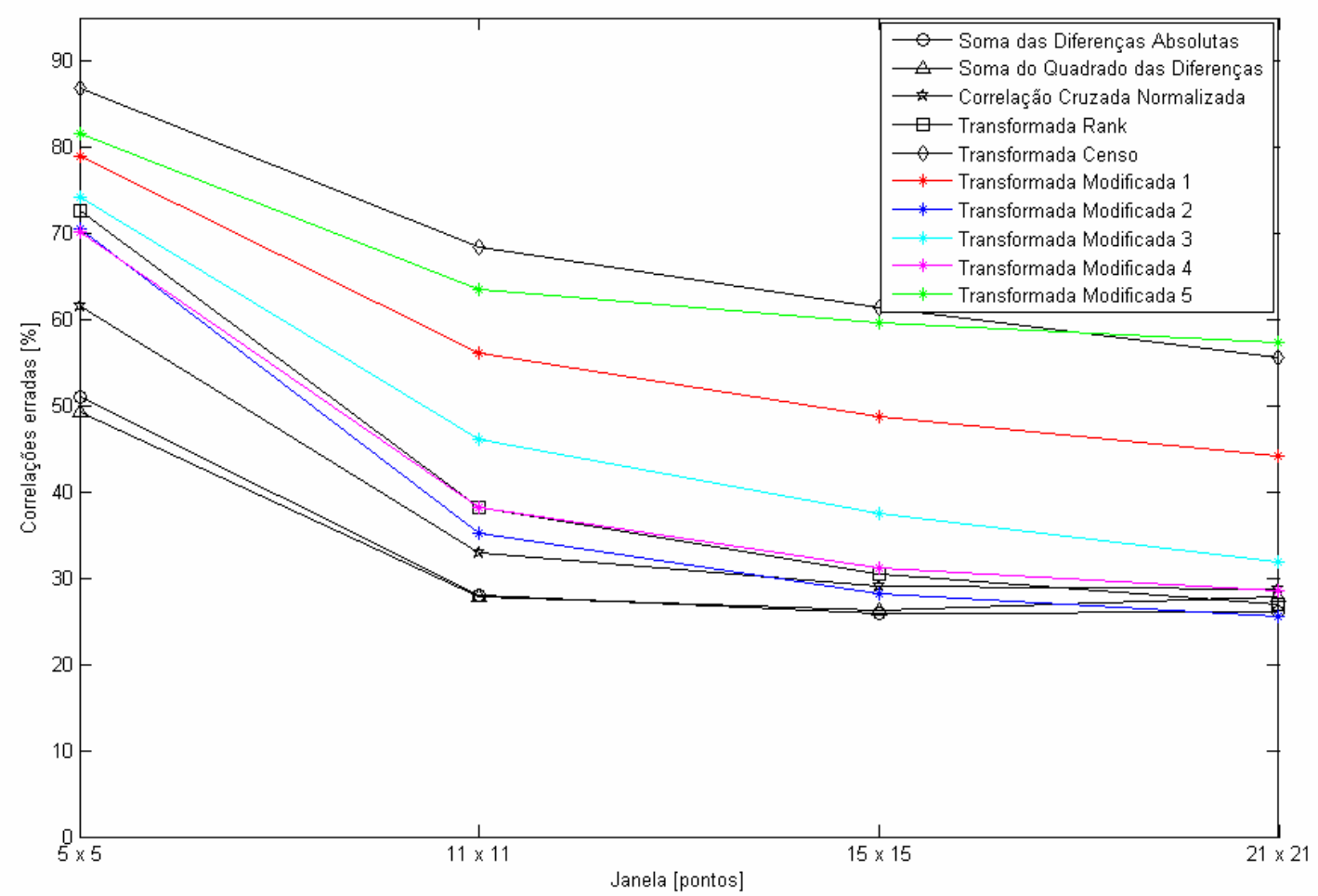

Figura 4.78: Correlações erradas na imagem Cones com ruído de variância 200

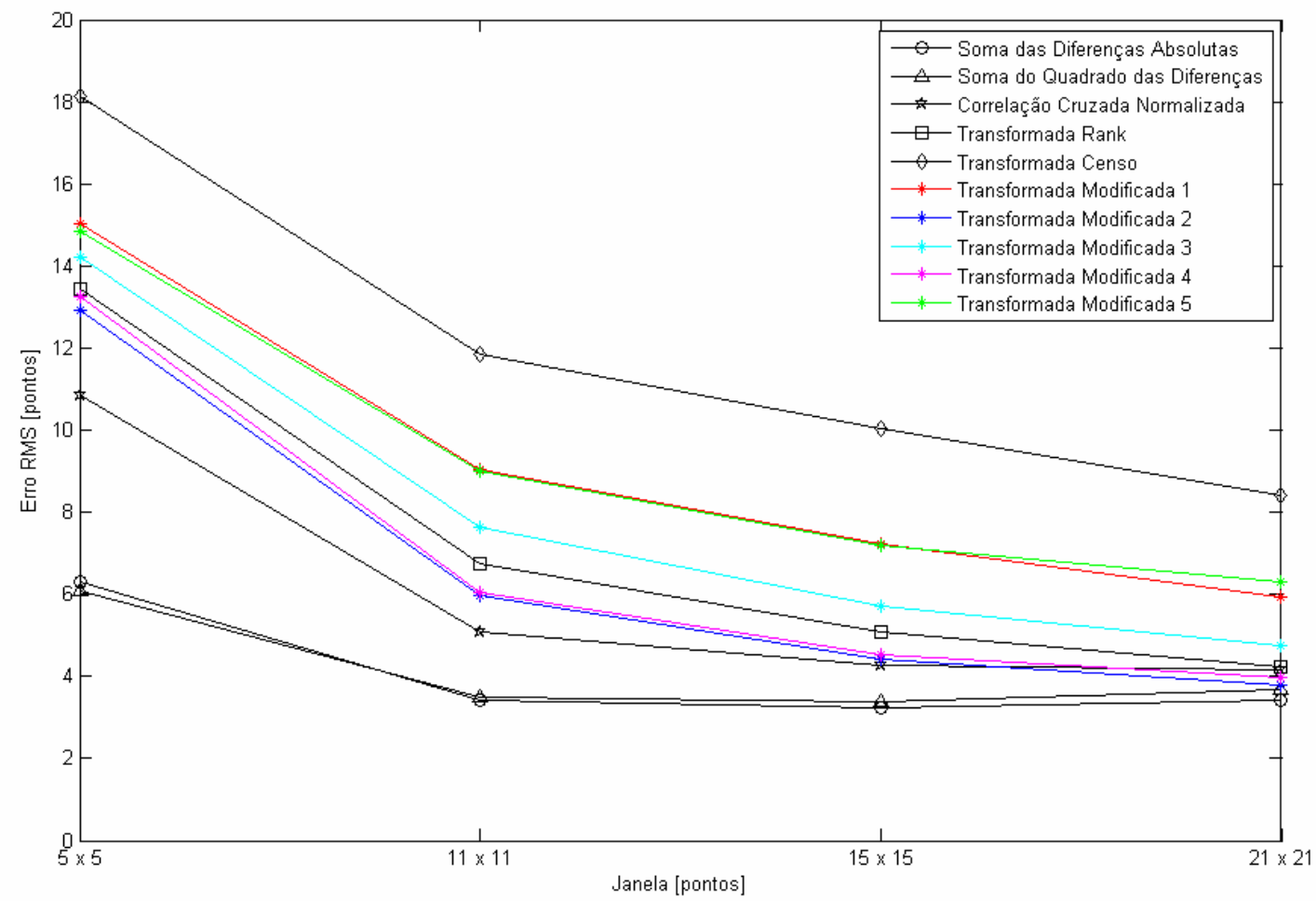

Figura 4.79: Erro RMS das correlações na imagem Cones com ruído de variância 200 


\subsection{Exemplo de aplicação do algoritmo de correlação}

Os mapas de disparidade gerados pelos algoritmos de correlação podem ter diversas aplicações, uma delas é a utilização na navegação baseada em visão. Para exemplificar esta aplicação foi escolhido um simulador chamado Webots na versão 5.4 .0 (Cyberbotics, 2007) e modelado um robô com esteiras. O robô foi equipado com duas câmeras para permitir a navegação com visão estéreo.

O ambiente modelado é uma sala quadrada de $5 \mathrm{~m}$ de lado com uma escada e alguns blocos. O robô possui aproximadamente as dimensões externas de 0,67 m de comprimento por $0,47 \mathrm{~m}$ de largura.

Para a detecção dos obstáculos com a visão foi implementado o método da Transformada Modificada 2, já que esta modificação, no geral, gerou os melhores resultados.

Como é esperado em um ambiente gerado por um simulador a imagem possui muitas regiões com pouca textura devido ao preenchimento com cores sólidas (Figura 4.80), o que dificultaria a locomoção do robô devido ao fraco desempenho dos algoritmos de correlação com regiões uniformes. Para evitar este problema decidiu-se por colocar texturas nos obstáculos.

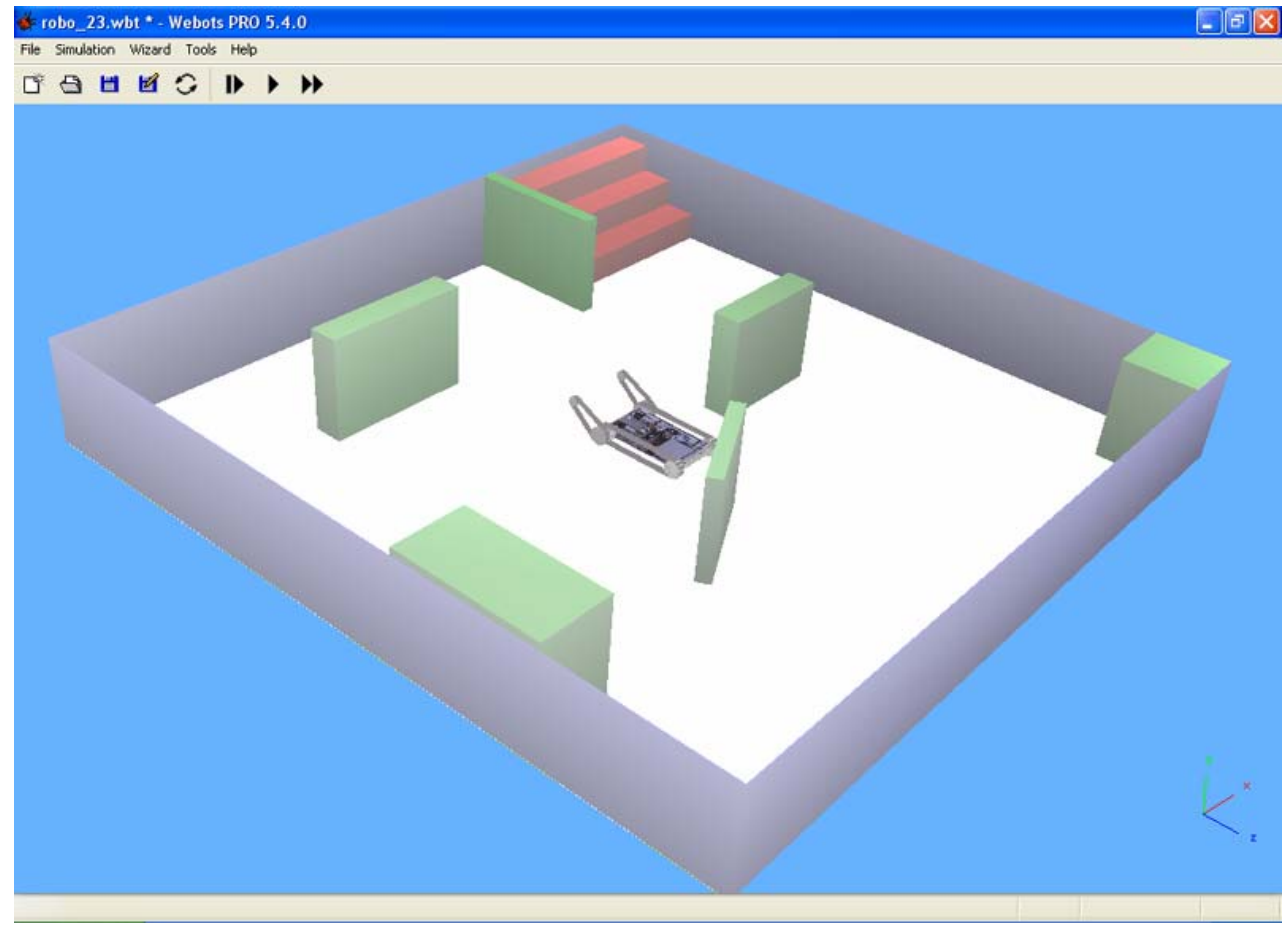

Figura 4.80: Modelo inicial implementado no simulador 
Após a definição das texturas alguns testes foram realizados para a verificação dos resultados que seriam obtidos. Para a definição da disparidade no qual o robô deve se desviar do obstáculo foi realizado um teste com um programa de controle simples. Tal programa foi desenvolvido basicamente para calcular a disparidade média no centro da imagem fazendo uma busca de até 160 pontos de disparidade. Neste teste (Figura 4.81) o robô foi mantido parado e um bloco foi movido na frente das câmeras, sendo a disparidade calculada pelo robô, anotada. As câmeras foram posicionadas a $150 \mathrm{~mm}$ de distância entre si (Figura 4.82) e a uma altura de $70 \mathrm{~mm}$ do solo.

Na Figura 4.83 é apresentada a variação da disparidade conforme a distância do objeto. Nela é possível observar que um objeto a 0,2 $\mathrm{m}$ da câmera possui uma barra de erro maior que objetos mais afastados. Pode-se notar também que conforme as distâncias crescem a disparidade tende a variar menos, portanto a resolução da estimativa de profundidade é menor com o aumento da distância.

A partir destes resultados optou-se por permitir que o robô se aproxime até em torno de 0,7 a 0,8 $\mathrm{m}$ do objeto, ou seja, quando o objeto em sua frente estiver gerando 50 pontos de disparidade o robô deverá desviar.

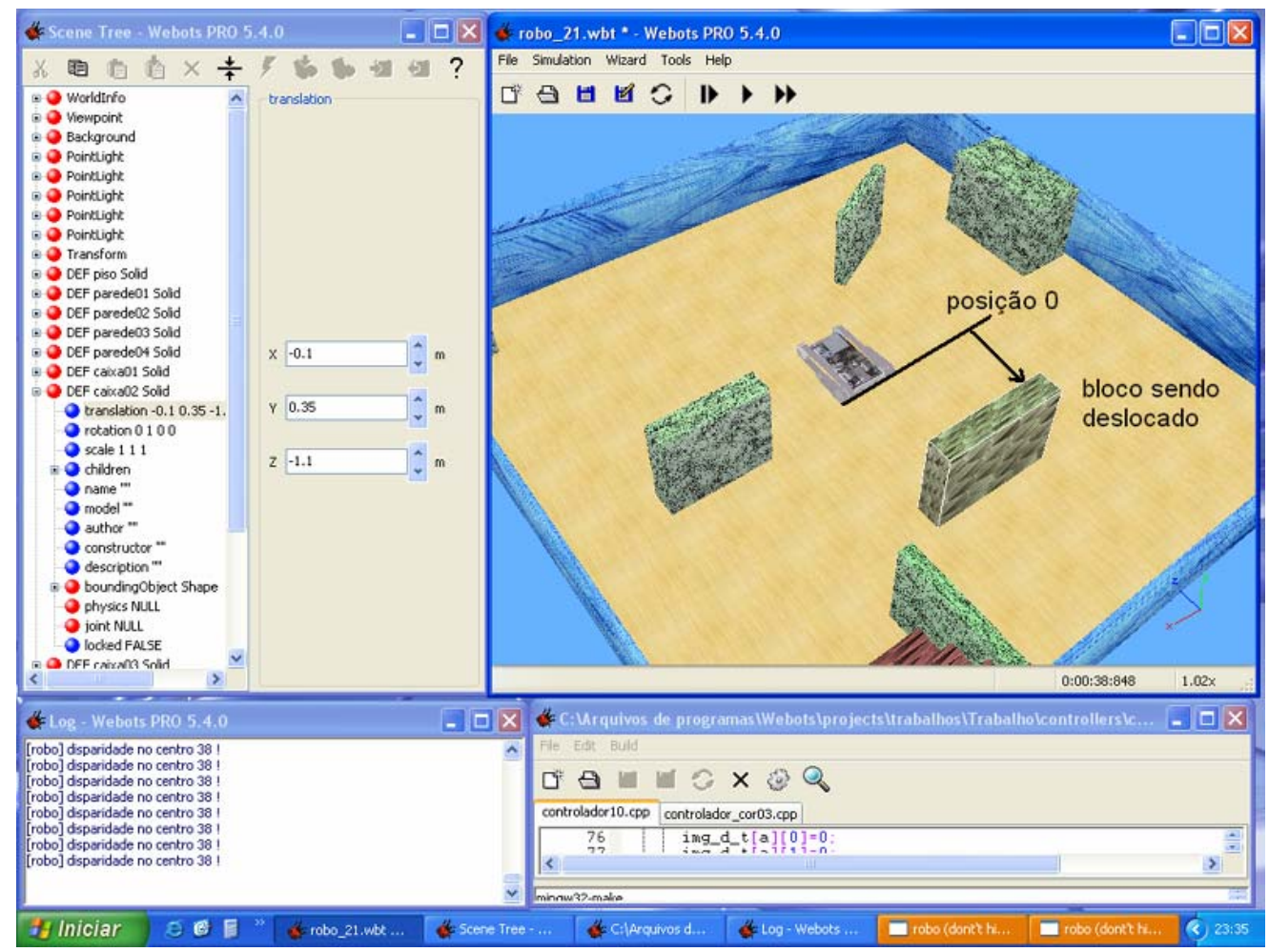

Figura 4.81: Cálculo da disparidade equivalente à distância 


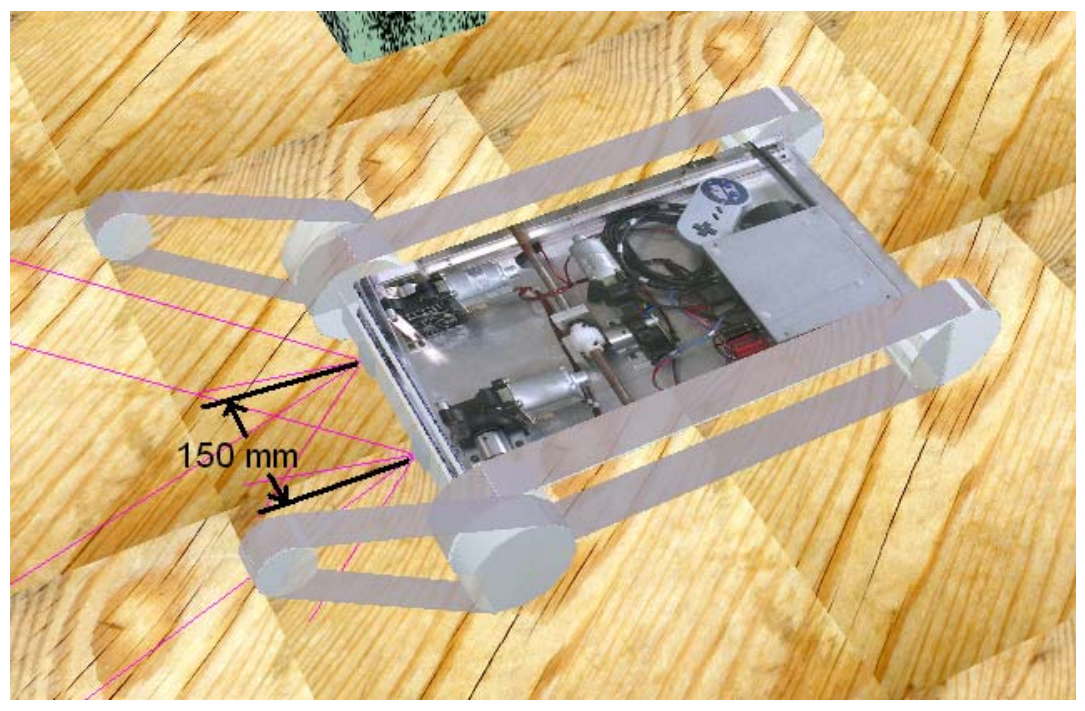

Figura 4.82: Posição das câmeras no robô modelado

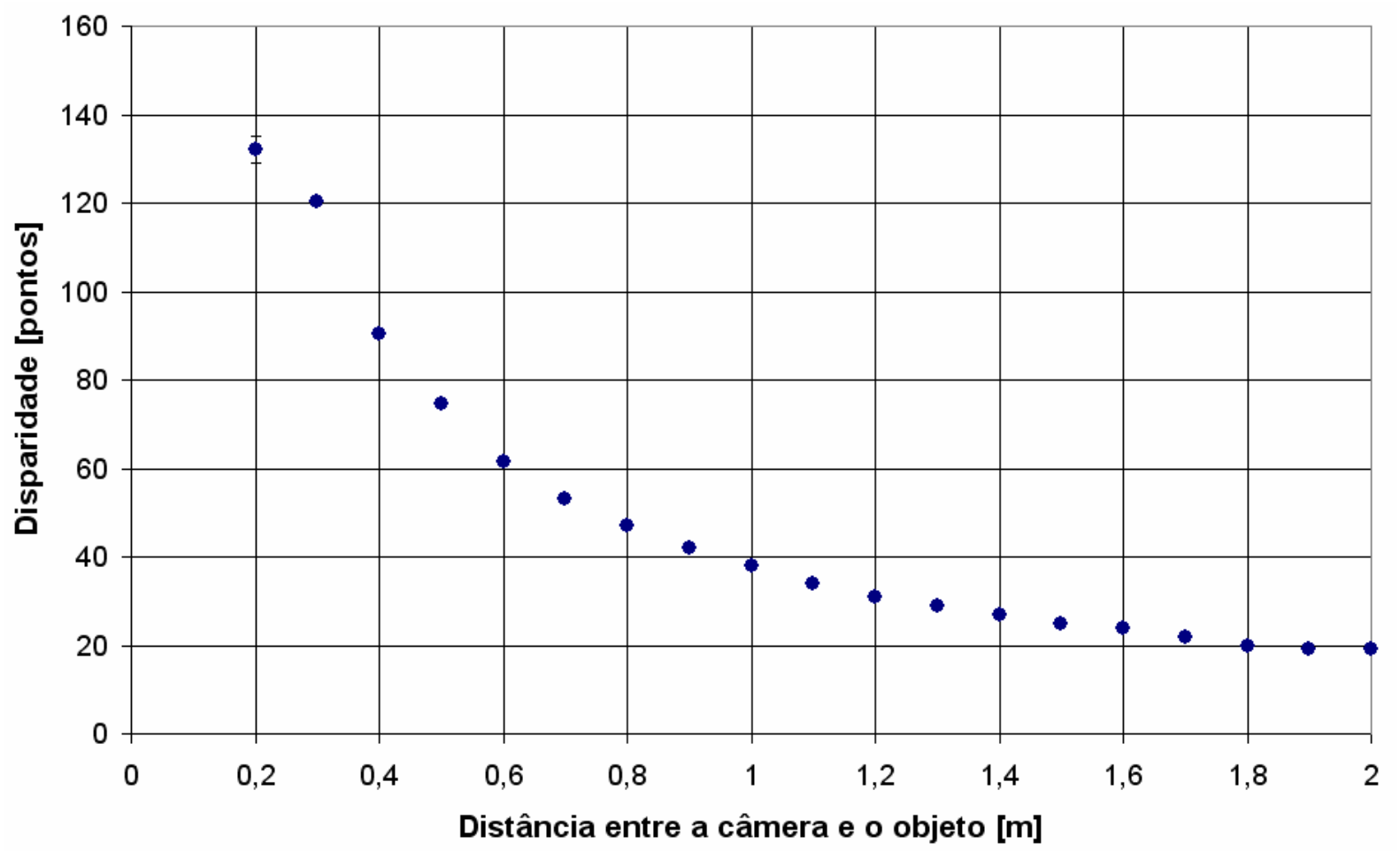

Figura 4.83: Disparidades equivalentes às distâncias

Aproveitando-se as imagens geradas com as simulações iniciais, foram capturadas algumas imagens das câmeras e gerados mapas de disparidades completos para a visualização da qualidade dos resultados obtidos. 
Na Figura 4.84 é apresentada uma cena com o robô em frente à um bloco inclinado e na Figura 4.85 observa-se que o algoritmo de correlação consegue detectar o bloco e sua inclinação, porém tem dificuldades com a detecção do chão.

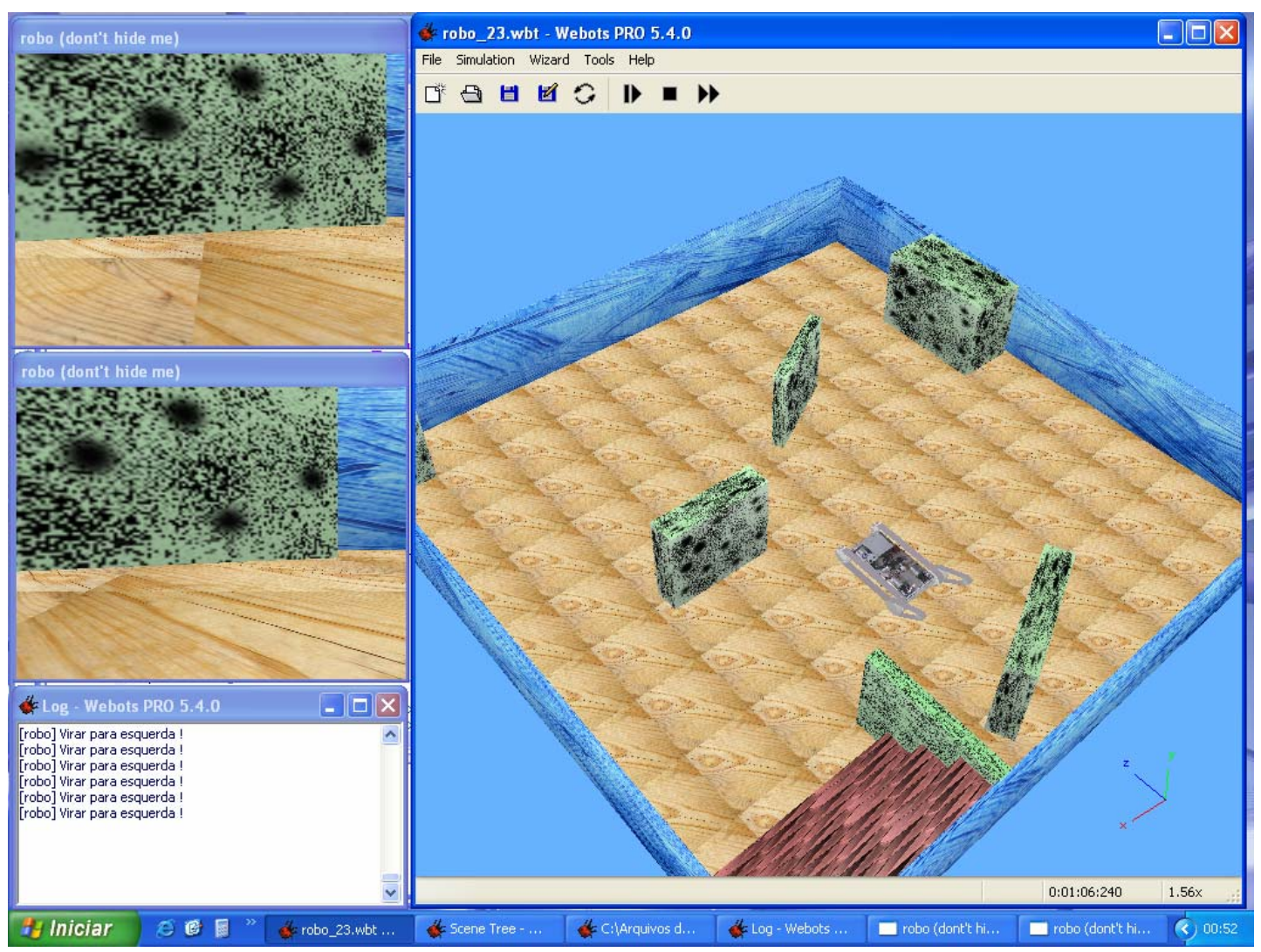

Figura 4.84: Cena com um bloco inclinado na frente do robô
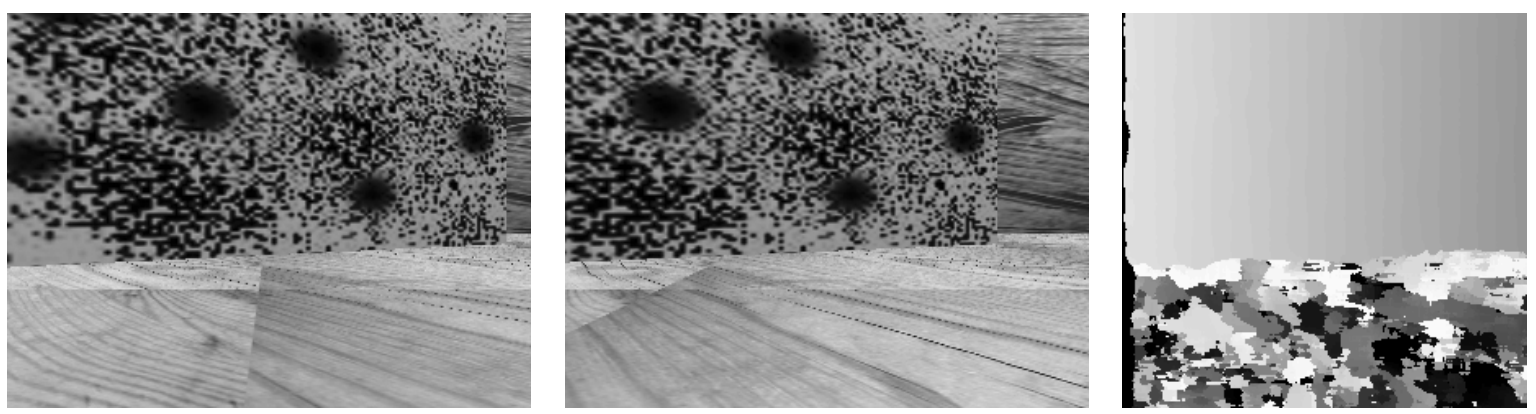

Figura 4.85: Mapa de disparidades obtido com o bloco inclinado

Na Figura 4.86 é apresentado um exemplo do robô em frente à escada e Figura 4.87 observa-se que é possível detectar claramente os diferentes níveis de disparidade referentes a cada um dos degraus. Portanto uma escada pode ser 
detectada como sendo um objeto caracterizado por faixas com níveis de disparidade decrescentes conforme a altura aumenta.

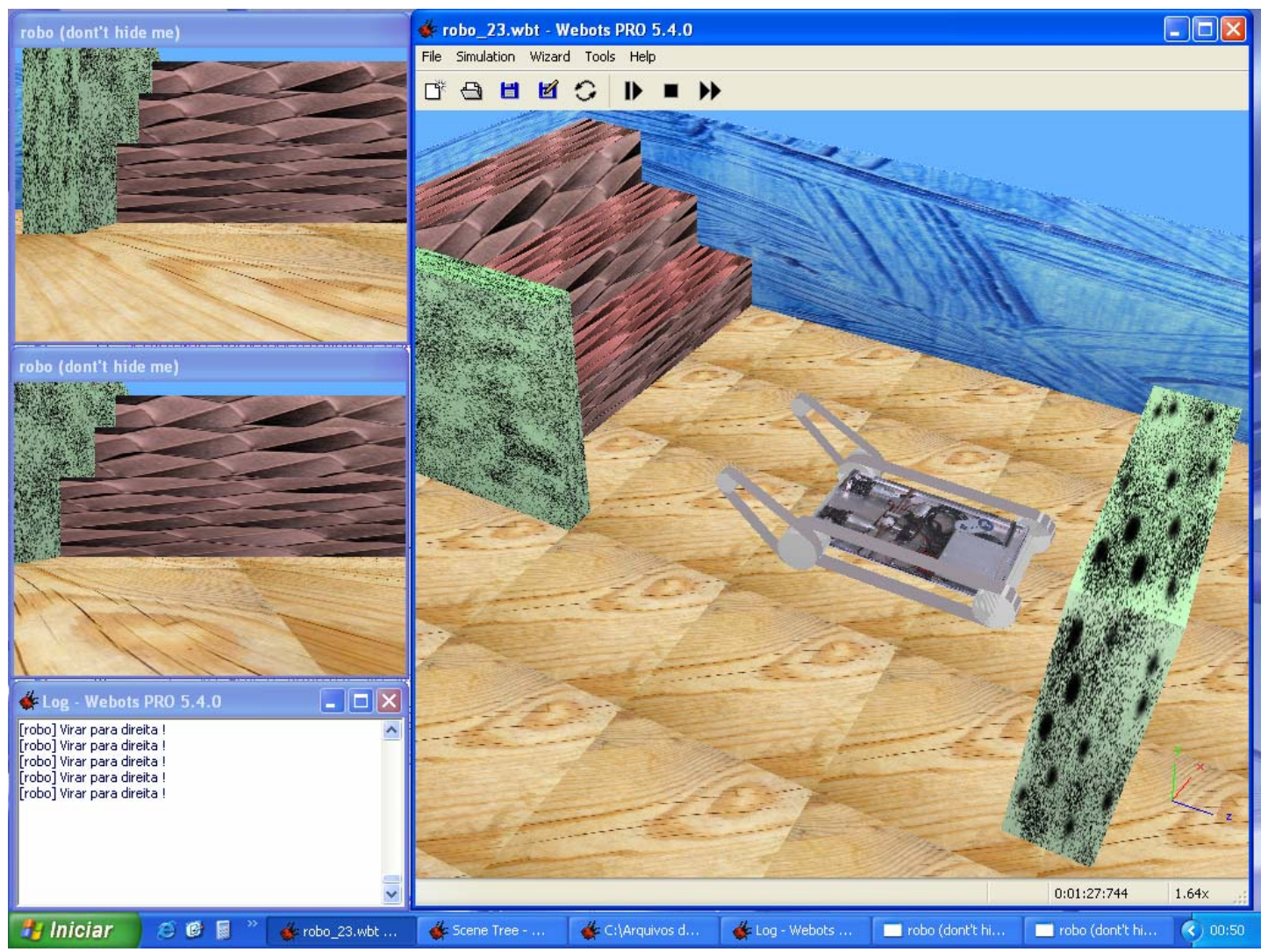

Figura 4.86: Cena com uma escada na frente do robô
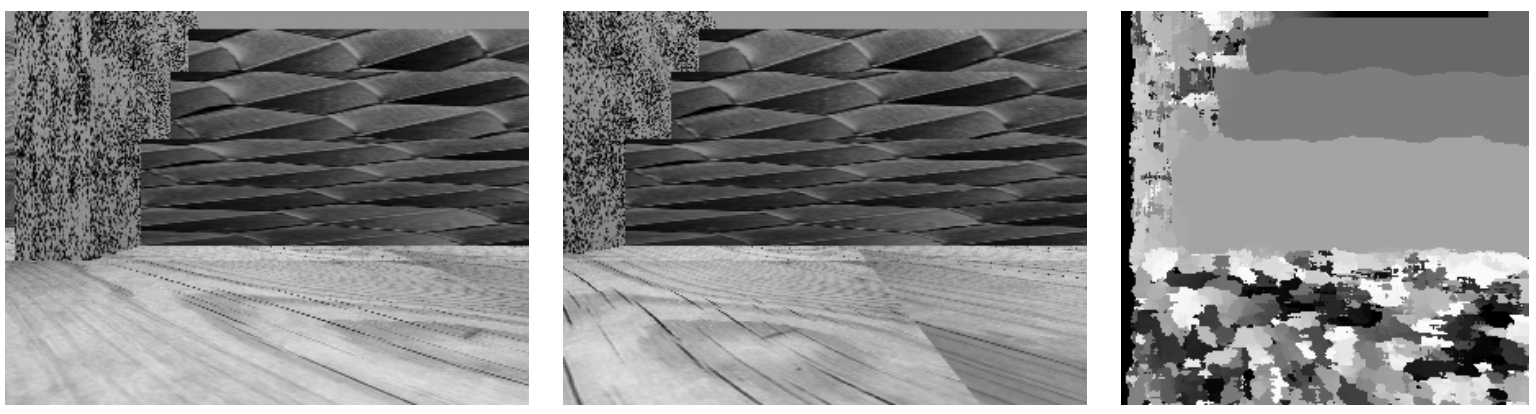

Figura 4.87: Mapa de disparidades obtido com uma escada

Ao final de vários testes com as imagens concluiu-se que é possível navegar utilizando-se o algoritmo de correlação Transformada Modificada 2. Para isto, é necessário que a detecção dos objetos seja feita em uma faixa logo acima da metade da imagem da câmera, de forma a evitar que o chão seja analisado. 
O controlador para a movimentação do robô foi implementado em C++, basicamente como um sistema de controle reativo que mantêm o robô vagando e evitando os obstáculos próximos.

Observou-se que o robô simulado (Figuras 4.88 e 4.89) consegue detectar e desviar dos obstáculos apenas navegando com as câmeras. Entretanto, ainda é necessário um refinamento maior do controlador, já que ocasionalmente o robô colide com algum obstáculo.

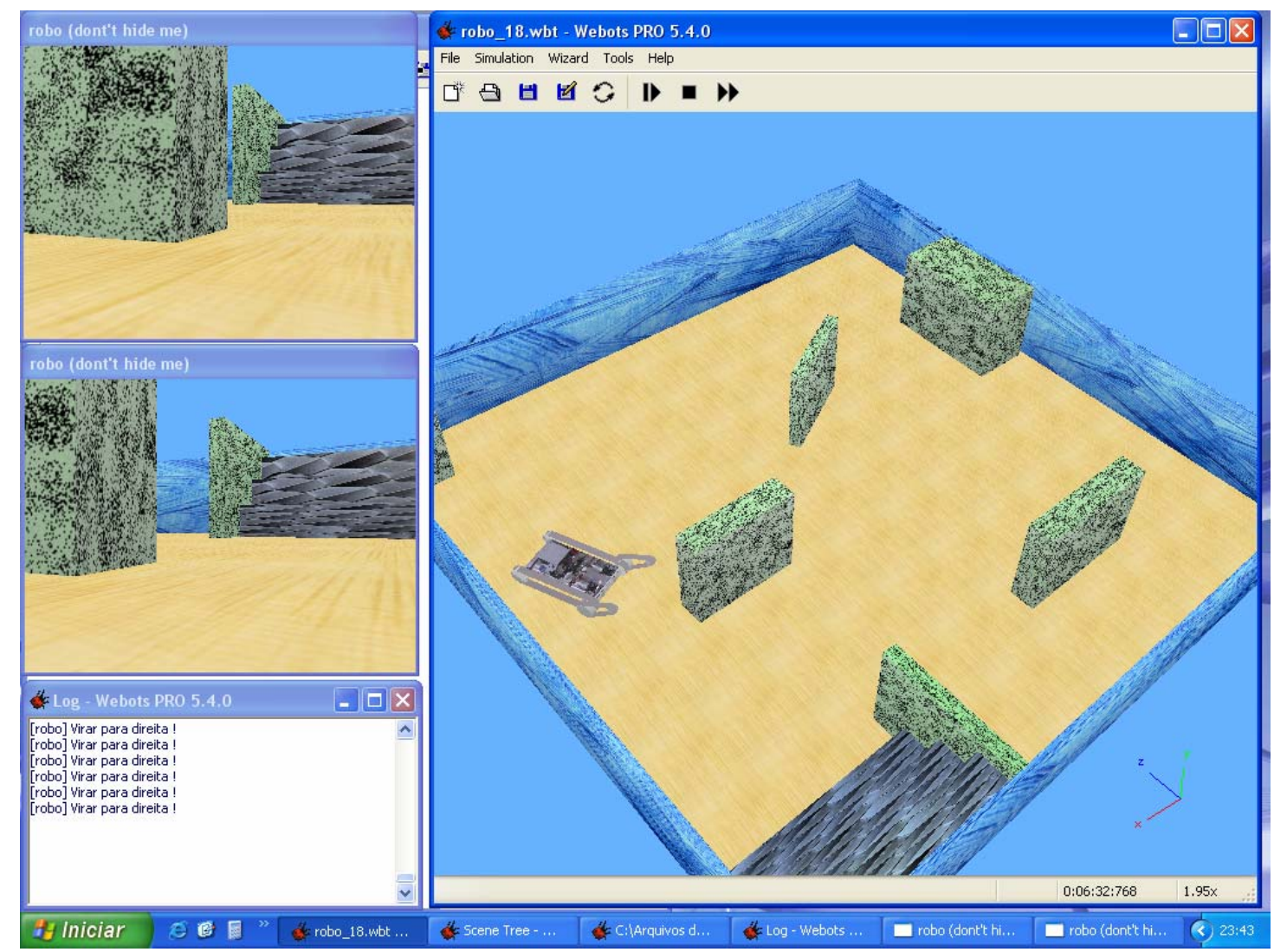

Figura 4.88: Exemplo da imagem do simulador mostrando o robô desviando do obstáculo 


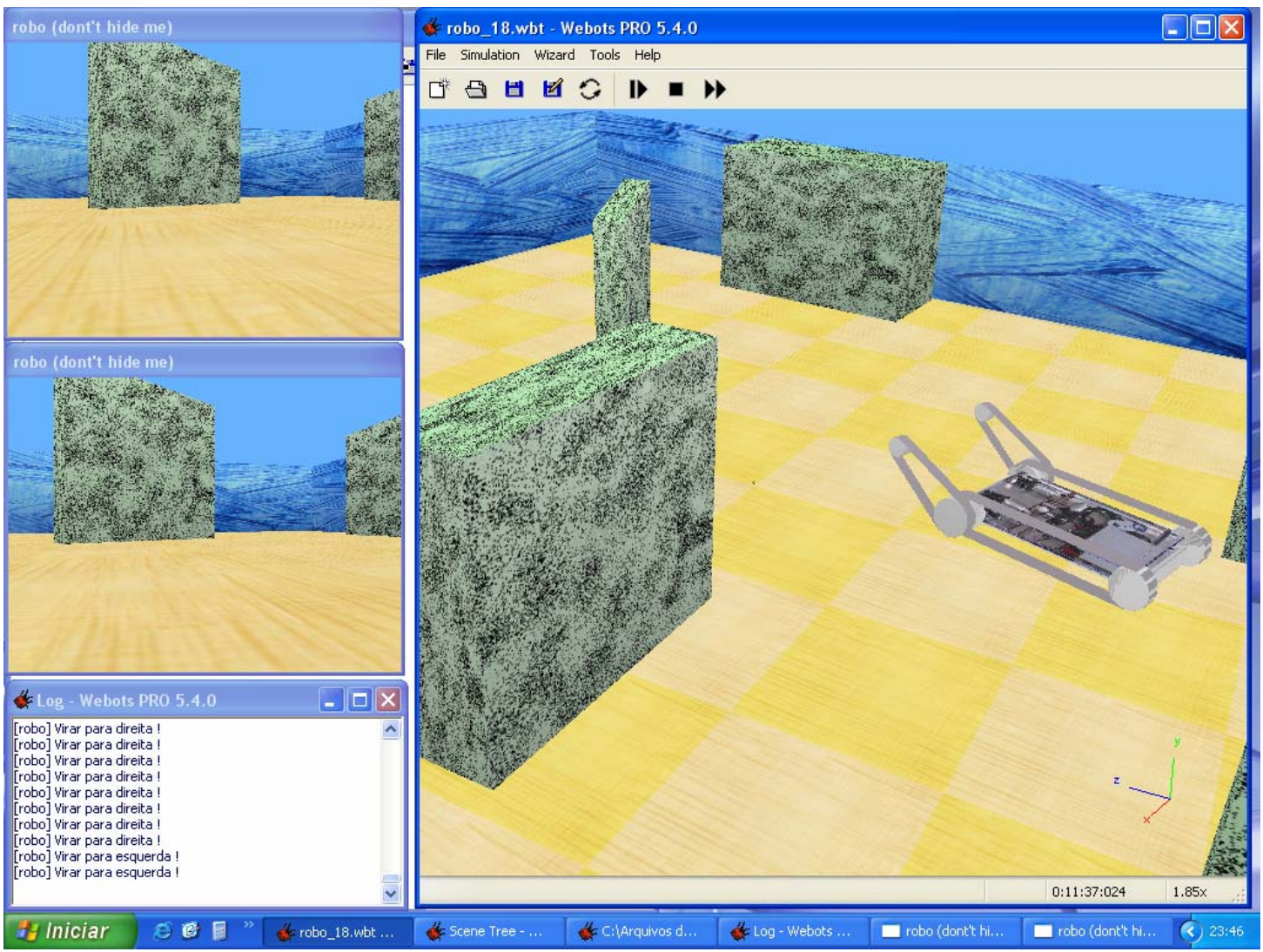

Figura 4.89: Exemplo da imagem do simulador observando o mundo com a câmera em outra posição 


\section{CONCLUSÕES}

\subsection{Discussão dos resultados}

Este trabalho abordou a comparação entre algoritmos de correlação locais e propôs modificações na Transformada Censo, por esta em geral ter obtido resultados ruins. A Tabela 5.1 mostra o resumo das qualidades dos métodos.

Os testes foram realizados com base em três imagens e suas variantes. Cada um dos pares estéreo foi escolhido por suas características singulares. A imagem do corredor por ser uma imagem perceptivelmente sintética e por apresentar várias pequenas regiões com textura uniforme. A imagem Teddy foi escolhida por ser uma imagem de aparência mais natural que possui algumas regiões com pouca textura e também regiões com um padrão repetitivo. A imagem Cones foi escolhida por sua riqueza de detalhes.

Em diversos testes realizados com as três imagens escolhidas observou-se que nem sempre um algoritmo que possui um bom resultado em uma das imagens consegue ter bons resultados nas outras imagens, como foi o caso da Transformada Modificada 5. Esta modificação apresentou resultados bons apenas na imagem do corredor em todas as suas variações, porém quando aplicada em imagens com mais detalhes mostrou-se muito ineficiente.

No geral a Transformada Modificada 2 foi a modificação que conseguiu os melhores resultados, em alguns casos apresenta uma quantidade de erros de correlação menor do que todos os outros métodos. Apesar desta modificação sempre obter resultados muito melhores do que a Transformada Censo original, por vezes conseguindo atingir a metade do número de correlações erradas em relação ao Censo, observa-se que em presença de imagens com bastante ruído de amplitude grande seu desempenho não atinge o mesmo patamar dos algoritmos Soma das Diferenças Quadráticas e Soma dos Quadrados das Diferenças. Sendo que, com janelas pequenas de $5 \times 5$ pontos, consegue se manter na média dos algoritmos e com janelas grandes, com $21 \times 21$ pontos, mostra um resultado próximo ao dos melhores métodos, como é possível observar nas Figuras 4.50 e 4.78 . 


\begin{tabular}{|c|c|c|c|c|}
\hline Método & Imagem Original & $\begin{array}{l}\text { Imagem com } \\
\text { luminosidade } \\
\text { diferente }\end{array}$ & $\begin{array}{l}\text { Imagem com } \\
\text { ruído }\end{array}$ & $\begin{array}{l}\text { Tempo de } \\
\text { execução }\end{array}$ \\
\hline $\begin{array}{c}\text { Soma das } \\
\text { Diferenças } \\
\text { Absolutas }\end{array}$ & $\begin{array}{l}\text { Muito bom com } \\
\text { imagem sintética, } \\
\text { mediano nos } \\
\text { demais casos }\end{array}$ & $\begin{array}{l}\text { Resultados } \\
\text { péssimos }\end{array}$ & $\begin{array}{l}\text { Resultados muito } \\
\text { bons }\end{array}$ & Baixo \\
\hline $\begin{array}{c}\text { Soma do } \\
\text { Quadrado } \\
\text { das } \\
\text { Diferenças }\end{array}$ & $\begin{array}{l}\text { Resultados } \\
\text { medianos com } \\
\text { imagens reais }\end{array}$ & $\begin{array}{l}\text { Resultados } \\
\text { péssimos }\end{array}$ & Resultados bons & Baixo \\
\hline $\begin{array}{l}\text { Correlação } \\
\text { Cruzada } \\
\text { Normalizada }\end{array}$ & $\begin{array}{l}\text { Resultados } \\
\text { medianos }\end{array}$ & $\begin{array}{l}\text { Resultados } \\
\text { medianos }\end{array}$ & $\begin{array}{l}\text { Resultados } \\
\text { medianos }\end{array}$ & Alto \\
\hline $\begin{array}{l}\text { Transformada } \\
\text { Rank }\end{array}$ & $\begin{array}{l}\text { Resultados muito } \\
\text { bons }\end{array}$ & $\begin{array}{l}\text { Resultados muito } \\
\text { bons }\end{array}$ & $\begin{array}{l}\text { Resultados muito } \\
\text { bons }\end{array}$ & Baixo \\
\hline $\begin{array}{l}\text { Transformada } \\
\text { Censo }\end{array}$ & Resultados ruins & Resultados ruins & Resultados ruins & Baixo \\
\hline $\begin{array}{l}\text { Transformada } \\
\text { Modificada } 1\end{array}$ & $\begin{array}{l}\text { Resultados } \\
\text { medianos }\end{array}$ & $\begin{array}{c}\text { Resultados } \\
\text { medianos }\end{array}$ & $\begin{array}{l}\text { Resultados ruins, } \\
\text { porém melhor } \\
\text { que o Censo }\end{array}$ & Baixo \\
\hline $\begin{array}{l}\text { Transformada } \\
\text { Modificada } 2\end{array}$ & $\begin{array}{l}\text { Resultados muito } \\
\text { bons }\end{array}$ & $\begin{array}{l}\text { Resultados muito } \\
\text { bons }\end{array}$ & $\begin{array}{c}\text { Resultados } \\
\text { medianos }\end{array}$ & Baixo \\
\hline $\begin{array}{l}\text { Transformada } \\
\text { Modificada } 3\end{array}$ & $\begin{array}{l}\text { Resultados } \\
\text { medianos }\end{array}$ & $\begin{array}{l}\text { Resultados } \\
\text { medianos }\end{array}$ & $\begin{array}{c}\text { Resultados } \\
\text { medianos }\end{array}$ & Alto \\
\hline $\begin{array}{l}\text { Transformada } \\
\text { Modificada } 4\end{array}$ & $\begin{array}{l}\text { Resultados } \\
\text { medianos }\end{array}$ & $\begin{array}{l}\text { Resultados } \\
\text { medianos }\end{array}$ & $\begin{array}{l}\text { Resultados } \\
\text { medianos }\end{array}$ & Alto \\
\hline $\begin{array}{l}\text { Transformada } \\
\text { Modificada } 5\end{array}$ & $\begin{array}{l}\text { Muito bom com } \\
\text { imagem sintética, } \\
\text { ruim nos demais } \\
\text { casos }\end{array}$ & $\begin{array}{l}\text { Mediano com } \\
\text { imagem sintética, } \\
\text { ruim nos demais } \\
\text { casos }\end{array}$ & $\begin{array}{c}\text { Muito bom com } \\
\text { imagem sintética, } \\
\text { ruim nos demais } \\
\text { casos }\end{array}$ & Baixo \\
\hline
\end{tabular}

Tabela 5.1: Tabela resumo das qualidades dos métodos 
Observa-se na Tabela 4.2 da seção de resultados que a Transformada Modificada 2 apresenta tempo de execução menor que o da Transformada Censo. Ficando no mesmo patamar do desempenho dos algoritmos Soma das Diferenças Quadráticas, Soma dos Quadrados das Diferenças e Transformada Rank.

As demais modificações testadas, com exceção da 5, sempre mostraram resultados melhores que a Transformada Censo original, porém apenas obtiveram performance mediana entre os algoritmos testados.

Para as simulações escolheu-se o melhor algoritmo modificado sendo este implementado no controlador. Nos resultados das simulações observa-se que a Transformada Modificada 2 mostrou-se uma opção boa, visto que permitiu que o robô simulado conseguisse navegar evitando os obstáculos, mesmo sendo implementado de forma simples sem o uso de nenhuma técnica de melhoria do mapa de disparidades.

\subsection{Sugestões para trabalhos futuros}

Na implementação atual da Transformada Modificada 2, o valor do limiar $\alpha$ a ser utilizado deve ser antecipadamente definido coletando-se amostras de imagens e efetuando o cálculo do limiar a ser utilizado. Porém, este cálculo "off-line" do limiar leva a uma falta de praticidade no caso da implementação deste algoritmo em um robô móvel, visto que estas câmeras estarão sujeitas a interferências e outros problemas, os quais podem degradar a qualidade da imagem, gerando uma modificação do valor do limiar ideal. Para resolver este problema e não precisar recalcular manualmente o limiar a cada vez que a qualidade das imagens sofre alguma alteração, é necessário estudar alguma forma de automatizar a determinação do limiar de forma a permitir a auto-adaptação do algoritmo a cada nova condição da imagem.

No controlador implementado para a navegação exclusivamente baseada em visão, enfrentaram-se problemas com o mapa de disparidades gerado pelo chão próximo ao robô. A imagem do chão, capturada a partir da posição das câmeras no robô, gerava um mapa de disparidades correto apenas em alguns poucos posicionamentos do robô, sendo que em boa parte dos casos os mapas gerados 
eram equivocados. Tal problema aparentemente estava sendo gerado pelas distorções causadas pelas diferentes perspectivas de visualização do chão.

Para a resolução deste problema é possível tentar aumentar a robustez do algoritmo às distorções nas imagens implementando-o juntamente com técnicas de otimização, tanto as locais quanto as globais. Para a verificação da melhora em seu desempenho pode-se testar a implementação do algoritmo utilizando tanto imagens geradas por um simulador quanto imagens de ambientes reais.

Depois de implementado o auto ajuste do limiar e a agregação de algum método de otimização do mapa de disparidades, pode-se aplicar este algoritmo no controlador de um robô autônomo. Para o desenvolvimento do controlador sugere-se utilizar algum programa de simulação de robôs, como por exemplo: o Webots (Cyberbotics, 2007), Player/Stage/Gazebo (Gerkey et al, 2007), Pyrobot (Blank et al, 2004) ou algum outro disponível. Em um outro passo, após a confirmação da funcionalidade do controlador, poder-se-ia implementar o controlador em um robô real para a verificação de seu comportamento ao tentar introduzir ruídos ou interferências nas imagens das câmeras e outras situações que degradem a qualidade da imagem obtida. 


\section{REFERÊNCIAS BIBLIOGRÁFICAS}

AMBROSCH, $\mathrm{K}$. et al. Hardware implementation of an SAD based stereo vision algorithm. IEEE Computer Vision and Pattern Recognition, p. 1-6, junho de 2007

BANKS, J. et al. A Constraint to Improve the Reliability of Stereo Matching Using the Rank Transform, Proceedings of the IEEE International Conference on Acoustics, Speech, and Signal Processing, Arizona, p. 3321-3324, março 1999a

BANKS, J. et al. An Extension to the Rank Constraint for Improving the Reliability of Stereo Matching Using the Rank Transform. Proceedings of the IEEE International Conference on Systems, Man, and Cybernetics, Tóquio, p. 589594, outubro $1999 b$

BANKS, J.; BENNAMOUN, M. Reliability analysis of the rank transformation for stereo matching. IEEE Transactions on System, Man, and Cybernetics, p. 870-880, dezembro 2001

BLANK, D. S.; KUMAR, D.; MEEDEN, L. e YANCO, H. Pyro: A Python-based Versatile Programming Environment for Teaching Robotics. Journal of Educational Resources in Computing (JERIC), 2004

BONN UNIVERSITY. Stereo Images with Ground Truth Disparity and Occlusion. Fornece um banco de imagens estereoscópicas artificiais. Disponível em:

<http://www-dbv.cs.uni-bonn.de/stereo_data/>. Acesso em: março de 2005

BROCKERS, R.; HUND, M.; MERTSCHING, B. Stereo vision using costrelaxation with 3D support regions. Image and Vision Computing New Zealand, Nova Zelândia, 2005

CARVALHO, P. C. et al , Fotografia 3D, disponível : <http://w3.impa.br/ /velho/>. Acesso em: março de 2005 
CYBERBOTICS Webots. Versão 5.4.0 [S.I.]: Cyberbotics, 2007. Disponível em: $<$ http://www.cyberbotics.com/products/webots/download.html>.

$<$ http://www.comsol.ch/content.php?si=317\&id=170>. Acesso em: agosto de 2007

DUDEK, G.; JENKIN, M. Computational Principles of Mobile Robotics. Cambridge University Press, Nova Yorque, 2000

EL-ETRIBY, S.; AL-HAMADI, A.; MICHAELIS, B. Dense stereo correspondence with slanted surface using phase-based algorithm. IEEE International Symposium on Industrial Electronics, p. 1807-1813, junho 2007

FAUGERAS, O.; ROBERT, L. What can two images tell us about a third one? INRIA. França, 1993a

FAUGERAS, O.; ROBERT, L. Real Time correlation based stereo: algorithm, implementations and applications. INRIA, França, 1993b

FLEET, D. J.; JEPSON, A. D.; JENKIN, M. R. M. Phase Based Disparity Measurement. Graphical Models and Image Processing: Image Understanding, Orlando, p. 198-210, março 1991

FRANÇA, J. A. Desenvolvimento de Algoritmos de Visão Estereoscópica para Aplicações em Robótica Móvel. Universidade de Santa Catatina, 2003

FRANÇA, J. A.; STEMMER, M. R.; FRANÇA, M. B. M. Algoritmo robusto para correspondência de pontos em imagens estereoscópicas na ausência de calibração. Seminário de Ciências Exatas e Tecnolágicas, Londrina, 2005

FUSIELLO, A. Tutorial on Rectification of Stereo Images. University di Udine, Itália, 1998

FUSIELLO, A.; TRUCCO, E.; VERRI, A. A compact Algorithm for rectification of stereo pairs. Machine Vision and Application, p. 16-22, 2000 
FRÖBA, B.; ERNST, A. Face Detection with the Modified Census Transform. Sixth IEEE International Conference on Automatic Face and Gesture Recognition, $p$. 17-19, maio 2004

GAUTAMA, S.; LACROIX, S.; DEVY, M. Evaluation of Stereo Matching Algorithms for Occupant Detection. Proceedings of the IEEE International Workshop on Recognition, Analysis, and Tracking of Faces and Gestures in RealTime Systems, p. 177-184, setembro 1999

GEHRIG, S.; FRANKE, U. Improving sub-pixel accuracy for long range stereo. IEEE International Conference on Computer Vision VRML workshop, p. 1-7, outubro 2007

GERKEY, B.; VAUGHAN, R. T. e HOWARD, A. The Player/Stage Project: Tools for Multi-Robot and Distributed Sensor Systems. Proceedings of the 11th International Conference on Advanced Robotics, p. 317-323, Coimbra, Portugal, junho 2003

GONÇALVES, L. M. G. Matching de Objetos em Imagens Estéreos. Universidade Federal do Rio de Janeiro, notas de aula de visão computacional, 2005

GONZALEZ, R. C.; WOODS, R. E. Processamento de Imagens Digitais. Editora Edgard Blucher Ltda, São Paulo, 2000

HEIKKILÃ, J.; SILVÉN, O. A Four-Step Camera Calibration Procedure with Implicit Image Correction. University of Oulu, Finland, 1997

HIRSCHMÜLLER, H. Accurate and efficient stereo processing by semi-global matching and mutual information. IEEE Conference on Computer Vision and Pattern Recognition, vol. 2, p. 807-814, junho 2005

HIRSCHMÜLLER, H. Stereo vision in structured environments by consistent semi-global matching. IEEE Conference on Computer Vision and Pattern Recognition, vol. 2, p. 2386-2393, 2006 
HOLT, R.; NETRAVALI, A. Camera Calibration Problem: Some New Results. CVGIP Image Understand. vol 54, nº 3, p. 368-383, Novembro 1991

HU, X.; AHUJA, N. Matching point features with ordered geometric, rigidity, and disparity constraints. IEEE Transactions on Pattern Analysis and Machine Intelligence, Whashington, vol.16, p. 1041-104, 1994

INRIA - Institut National de Recherche en Informatique et Automatique.

Stereograms of the Syntim team. O instituto INRIA disponibiliza diversas imagens estéreo calibradas. Disponível em:

<http://www-rocq.inria.fr/ tarel/syntim/paires.html>. Acesso em: março 2005

JACOBI, R.; CARDOSO, R.; BORGES, G. VoC: A Reconfigurable Matrix for Stereo Vision Processing. 20th International IEEE Parallel and Distributed Processing Symposium, p. 6, abril 2006

JENKIN, M. R. M.; JEPSON, A. D.; TSOTSOS, J. K. Techniques for disparity measurement. CVGIP: Image Understanding. vol. 53, p. 14-30, janeiro 1991

JUST, A.; RODRIGUEZ, Y.; MARCEL, S. Hand Posture Classiication and Recognition using the Modified Census Ttransformation. Proceedings of the 7th IEEE International Conference on Automatic Face and Gesture Recognition, abril 2006

KIM, J.; LEE, K. M.; CHOI, B.T.; LEE, S. U. A dense stereo matching using two pass dynamic programming with generalized ground control points. IEEE Conference on Computer Vision and Pattern Recognition, vol. 2, p. 1075-1082, 2005

KLAUS, A.; SORMANN, M.; KARNER, K. Segment-based stereo matching using belief propagation and a self-adapting dissimilarity measure. Proceedings of the 18th IEEE Conference on Computer Vision and Pattern Recognition, vol. 3, p. 15-18, 2006

KOYAMA, C. S.; HASEGAWA, J. K. Radar fotogramétrico: cálculo da velocidade de um objeto a partir de uma seqüência de imagens digitais. Revista Brasileira de Cartografia, Presidente Prudente, vol. 54, n. 1, p. 1-9, 2002 
KUHL, A. Comparison of stereo matching algorithms for mobile robots. The University of Western Australia, fevereiro 2005

KUHN, M. et al. Efficient ASIC Implementation of a Real-Time Depth Mapping Stereo Vision System. Proceedings of the 46th IEEE International Midwest Symposium on Circuits and Systems, vol. 3, p. 1478-1481, dezembro 2003

KUMAR, R.; HANSON, A. R. Robust Methods for Estimating Pose and a Sensitivity Analysis. CVGIP Image Understanding, vol. 60, $n^{0} 3$, p. 313-342, novembro 1994.

LANE, R. A.; THACKER, N. A. Tutorial: Overview of stereo Matching Research. Universidade de Manchester, Manchester, 1998

LEI, C., SELZER, J.; YANG, Y. Region-tree based stereo using dynamic programming optimization. IEEE Conference on Computer Vision and Pattern Recognition, vol. 2, p. 2378-2385, 2006

LOWE, D. G. Distinctive image features from scale-invariant keypoints. IEEE International Journal of Computer Vision, vol. 60, p. 91-110, novembro 2004

LU, X.; MANDUCHI, R. Wide Baseline feature matching using the cross-epipolar ordering constraint. IEEE Conference on Computer Vision and Pattern Recognition, vol. 1, p. 16-23, junho 2004

LARSEN, S. et al. Temporally consistent reconstruction from multiple video streams using enhanced belief propagation. IEEE International Conference on Computer Vision, Rio de Janeiro, p. 14-21, outubro 2007

MATTOCCIA, S.; TOMBARI, F.; STEFANO, L. D. Stereo vision enabling precise border localization within a scanline optimization framework. IEEE Asian Conference on Computer Vision, Tóquio, p. 18-22, novembro 2007 
MIDDLEBURY COLLEGE. Stereo Vision Research Page: Stereo data sets with ground truth. Fornece uma série de imagens estéreo, incluindo a imagem Cones e Teddy com seus mapas de disparidade esperados, este acervo disponibiliza também a imagem da Universidade de Tsukuba. Disponível em:

$<$ http://cat.middlebury.edu/stereo/data.html $>$ e

<http://cat.middlebury.edu/stereo/newdata.html>. Acesso em: junho 2007

MORDOHAI, P.; MEDIONI, G. Stereo using monocular cues within the tensor voting framework. IEEE Pattern Analysis and Machine Intelligence, vol. 28, p. 968982, junho 2006

MURPHY, C.; LINDQUIST, D.; RYNNING, A. M. Low-Cost Stereo Vision on an FPGA. 15th Annual IEEE Symposium on Field-Programmable Custom Computing Machines, p. 333-334, abril 2007

NAOULOU, A. et al. An Alternative to Sequential Architectures to Improve the Processing Time of Passive Stereovision Algorithms. IEEE International Conference on Field Programmable Logic and Applications, p. 1-4, agosto 2006

OTUYAMA, J. M. Curso de visão computacional. Universidade Federal de Santa Catarina, 1998, O site apresenta conceitos de visão estéreo. Disponível em: <http://www.inf.ufsc.br/ visao/1998/otuyama/>. Acesso em: março de 2005

QIU, L.; LI, L. Contour Extraction of Moving Objects. Proceedings of the 14th IEEE International Conference on Pattern Recognition, Whashington, vol. 2, p. 1427, 1998

SCHARSTEIN, D.; SZELISKI, R. A Taxonomy and Evaluation of Dense TwoFrame Stereo Correspondence Algorithms. International Journal of Computer Vision, vol. 47, p. 7-42, 2002

SCHARSTEIN, D.; SZELISKI, R. High-accuracy stereo depth maps using structured light. IEEE Computer Society Conference on Computer Vision and Pattern Recognition, Madison, vol. 1, p. 195-202, Junho 2003 
SMERALDI, F. Ranklets: orientation selective non-parametric features applied to face detection. Proceedings of IEEE International Conference on Pattern Recognition, Vol. 3, p. 379-382, 2002

STEFANO, L. D.; MARCHIONNI, M.; MATTOCCIA, S. Real time dense stereo on a personal computer. IEEE Computer Architectures for Machine Perception, p. 12, maio 2003

STEFANO, L. D.; MARCHIONNI, M.; MATTOCCIA, S. Fast area based stereo matching algorithm. University of Bologna, Bolonha, 2004

STRECHA, C.; FRANSENS, R.; GOOL, L. V. Combined depth and outlier estimation in multi-view stereo. IEEE Conference on Computer Vision and Pattern Recognition, vol. 2, p. 2394-2401, 2006

SUN, J.; LI, Y.; KANG, S. B.; SHUM, H. Y. Symmetric stereo matching for occlusion handling. IEEE Conference on Computer Vision and Pattern Recognition, vol. 2, p. 399-406, 2005

TOMBARI, F.; MATTOCCIA, S.; STEFANO, L. D. Segmentation-based adaptive support for accurate stereo correspondence. IEEE Pacific-Rim Symposium on Image and Video Technology, p. 427-438, 2007

VEKSLER, O. Stereo correspondence by dynamic programming on a tree. IEEE Conference on Computer Vision and Pattern Recognition, vol. 2, p. 384-390, 2005

WANG, L.; GONG, M. W.; GONG, M. L.; YANG, R. G. How far can we go with local optimization in real time stereo matching. IEEE International Symposium on 3D data processing, visualization and transmission, p. 129-136, 2006

WANG, L.; LIAO, M.; GONG, M.; YANG, R.; NISTÉR, D. High-quality real-time stereo using adaptive cost aggregation and dynamic programming. IEEE 3D Data Processing Visualization and Transmission, p. 798-805, 2006 
WENG, J.; COHEN, P. AND HERNIOU, M. Camera Calibration with Distortion Models and Accuracy Evaluation. IEEE Transactions on Pattern Analysis and Machine Intelligente, vol. 14, p. 965-980, outubro 1992

WOODFILL, J.; HERZEN, B. V. AND ZABIH, R. Frame-rate Robust Stereo on a PCI Board. Cornell University, Unpublished, 1999

WOODFILL, J. I.; GORDON, G.; BUCK, R. Tyzx DeepSea High Speed Stereo Vision System. IEEE Conference on Computer Vision and Pattern Recognition, p. 41, junho 2004

YAMADA, K. AND ICHIKAWA, T. Generation of A Disparity panorama Using a 3Camera Capturing System. IEEE International Conference on Image Processing, vol. 2, p. $772-775,2000$

YANG, Q. et al. Real-time global stereo matching using hierarchical belief propagation. British Machine Vision Conference, 2006a

YANG, Q. et al. Stereo matching with color-weighted correlation, hierarchical belief propagation and occlusion handling. IEEE Conference on Computer Vision and Pattern Recognition, vol. 2, p. 2347-2354, 2006b

YANG, Q. et al. Spatial-depth super resolution for range images. IEEE Computer Vision and Pattern Recognition, p. 1-8, junho 2007

YOON, K. J.; KWEON, L. S. Adaptive support-weight approach for correspondence search. IEEE Pattern Analysis and Machine Intelligence, vol. 28, abril 2006

YOON, K. J.; KWEON, L. S. Stereo matching with the distinctive similarity measure. IEEE International Conference on Computer Vision, Rio de Janeiro, p. 1-7, outubro 2007 
ZHANG, Z. Flexible Camera Calibration By Viewing a Plane From Unknown

Orientations. Microsoft Research, 1999, Disponível em:

<http://research.microsoft.com/ zhang>. Acesso em: maio de 2005

ZABIH, R.,; WOODFILL, J. Non-parametric Local Transforms for Computing Visual Correspondence. Third European Conference on Computer Vision, Estocolmo, vol. 2, p. 151-159, maio 1994

ZHAO, J.; KATUPITIYA, J. A fast stereo vision algorithm with improved performance at object borders. IEEE International Conference on Intelligent Robots and Systems, p. 5309-5314, outubro 2006a

ZHAO, J.; KATUPITIYA, J. A dynamic programming approach based stereo vision algorithm improving object border performance. IEEE International Conference on Intelligent Robots and Systems, p. 5315-5320, outubro 2006b

ZHAO, J.; KATUPITIYA, J. A Multi Window Stereo Vision Algorithm With Improved Performance at Objects Borders. IEEE Symposium on Computational Inteligence in Image Processing, p. 66-71, abril 2007

ZITNICK, L.; KANG, S. B. Stereo for image-based rendering using image oversegmentation. IEEE International Journal of Computer Vision, vol. 75, p. 49-65, outubro 2007 


\section{APÊNDICE A - CÓDIGO FONTE DAS ROTINAS UTILIZADAS}

\section{Função limiar.m}

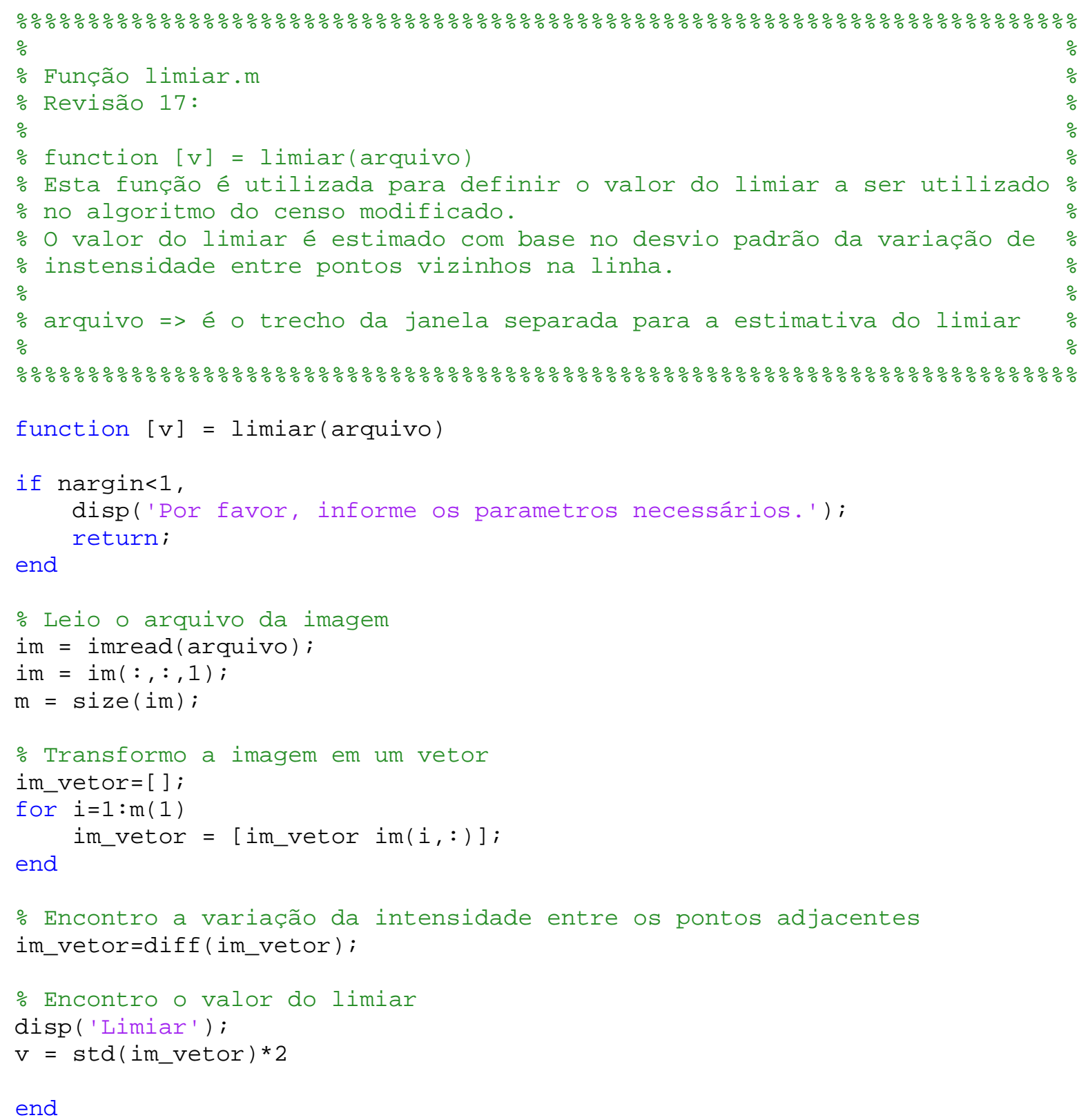




\section{Função ruido.m}

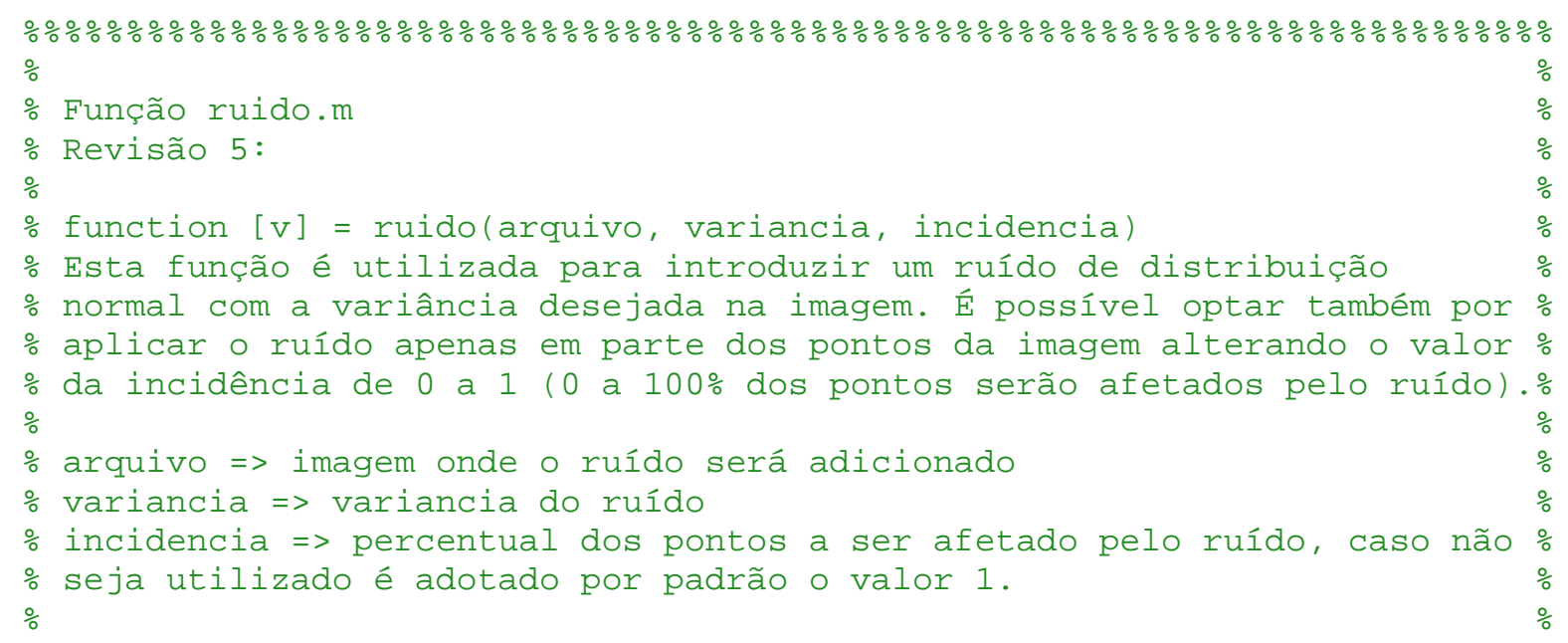

\%\%\%\%\%\%\%\%\%\%\%\%\%\%\%\%\%\%\%\%\%\%\%\%\%\%\%\%\%\%\%\%\%\%\%\%\%\%\%\%\%\%\%\%\%\%\%\%\%\%\%\%\%\%\%\%\%\%\%\%\%\%\%\%\%\%\%

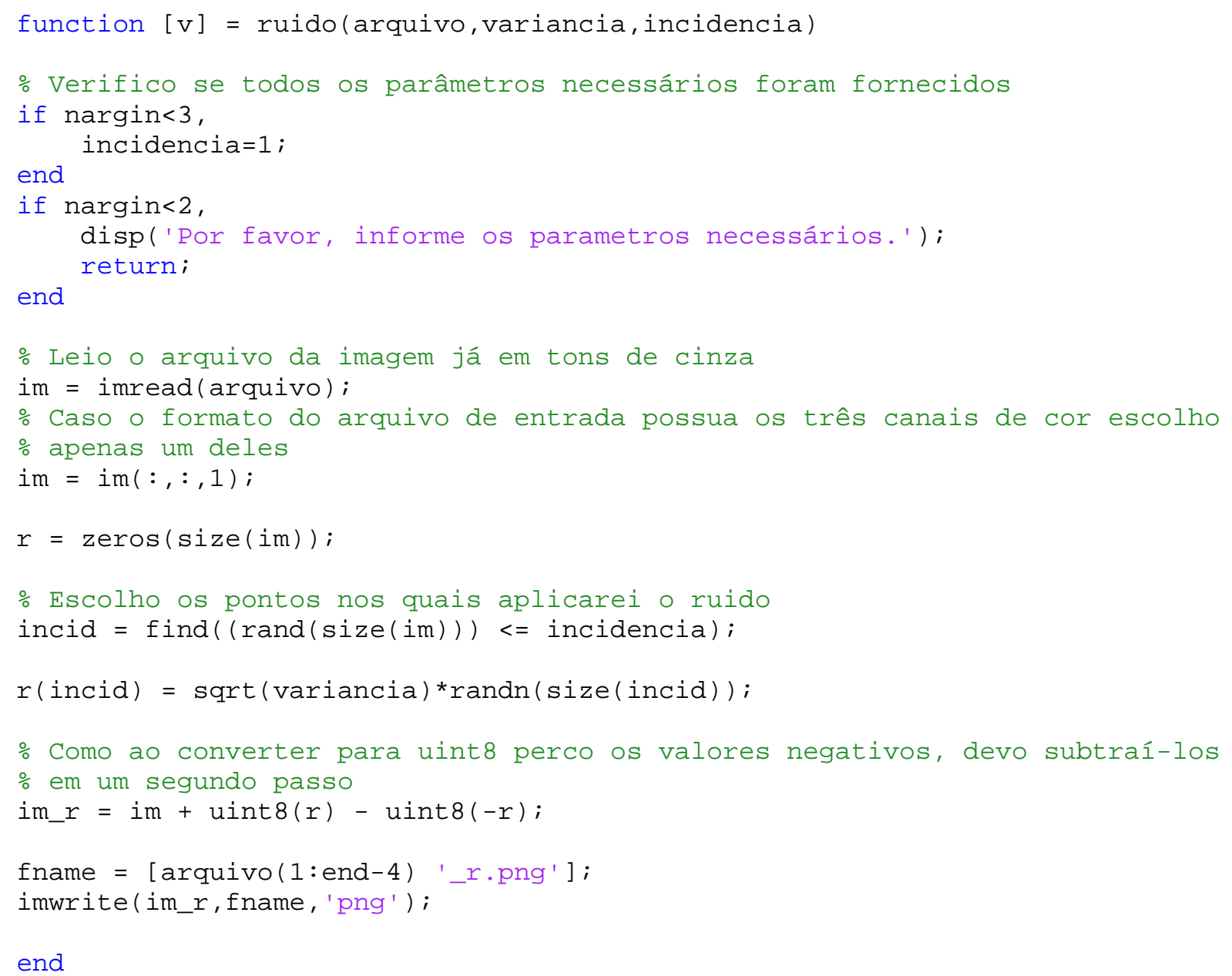


end

close all;

\% Crio os nomes dos arquivos das imagens esquerda e direita, aqui é

$\%$ definido o formato do arquivo a ser lido.

\% *1 => Caso necessário pode se utilizar: jpg, bmp, pgm, etc

fname_E=[arquivo '_e.jpg'];

fname_D=[arquivo '_d.jpg'];

\% Leio os arquivos de imagens

disp('Lendo imagens...');

im_e = imread (fname_E);

im_d = imread (fname_D);

\% Rodando a rotina de correlação, para o cálculo das disparidades disp('Calculando as disparidades...');

\% Ligando o cronômetro...

inicio=cputime;

\% Construindo o mapa de disparidades conforme o método de corrrelação

$\%$ escolhido

\% Método de correlação Soma das Diferenças Absolutas (SAD)

if metodo $==$ ' $\mathrm{sad}$ '

$\mathrm{d}=\operatorname{sad}\left(\right.$ im_e $(:,:, 1)$, im_d $(:,:, 1), \mathrm{m}, \mathrm{n}, \mathrm{disp} \_$max $)$;

eval([' save' arquivo '_sad.txt d -ascii-tabs'])

\% Método de correlação Soma do Quadrado das Diferenças (SSD)

elseif metodo $==$ ' $s s d$ '

$\mathrm{d}=\mathrm{ssd}\left(\right.$ im_e $(:,:, 1)$, im_d $\left.(:,:, 1), \mathrm{m}, \mathrm{n}, \mathrm{disp} \_m a x\right)$;

eval([' save' arquivo '_ssd.txt d -ascii-tabs'])

\% Método de correlação por média normalizada (cor)

elseif metodo $==$ 'cor'

$\mathrm{d}=\mathrm{cor}\left(\right.$ im_e $(:,:, 1), \mathrm{im} \_\mathrm{d}(:,:, 1), \mathrm{m}, \mathrm{n}, \mathrm{disp} \_$max $)$;

eval([' save' arquivo '_cor.txt d -ascii-tabs'])

\% Método de correlação baseado na transformada censo (cen)

elseif metodo $==$ 'cen'

$\mathrm{d}=$ cen $\left(i m \_e(:,:, 1)\right.$, im_d $(:,:, 1), \mathrm{m}, \mathrm{n}, \mathrm{disp} \_$max $) ;$

eval([' save' arquivo '_cen.txt d -ascii-tabs'])

\% Método de correlação baseado na transformada rank (rnk)

elseif metodo == 'rnk'

$\mathrm{d}=$ rnk $\left(i m \_e(:,:, 1)\right.$, im_d $(:,:, 1), \mathrm{m}, \mathrm{n}, \mathrm{disp} \_$max $)$;

eval([' save' arquivo '_rnk.txt d -ascii-tabs'])

\% Método de correlação baseado na transformada censo modificado 1 elseif metodo == ' $\mathrm{c} \_1$ '

$\mathrm{d}=\mathrm{c} \_1\left(\mathrm{im} \_\mathrm{e}(:, \mathrm{i}, 1), \mathrm{im} \_\mathrm{d}(:,:, 1), \mathrm{m}, \mathrm{n}, \mathrm{disp} \_m a x\right.$, limiar $)$;

eval([' save ' arquivo '_c_1.txt d -ascii -tabs'])

\% Método de correlação baseado na transformada censo modificado 2 elseif metodo $==$ ' $c$ _2'

$\mathrm{d}=\mathrm{c} \_2\left(i m \_e(:,:, 1)\right.$, im_d $(:,:, 1), \mathrm{m}, \mathrm{n}, \mathrm{disp} \_m a x$, limiar $)$;

eval([' save ' arquivo '_c_2.txt d -ascii -tabs']) 
\% Método de correlação baseado na transformada censo modificado 3 elseif metodo $==$ ' $c \_3$ '

$\mathrm{d}=\mathrm{c} \_3\left(\right.$ im_e $\left.(:,:, 1), \mathrm{im} \_\mathrm{d}(:,:, 1), \mathrm{m}, \mathrm{n}, \mathrm{disp} \_\max \right)$;

eval([' save' arquivo '_c_3.txt d -ascii-tabs'])

\% Método de correlação baseado na transformada censo modificado 4 elseif metodo == ' $c \_4$ '

$d=c \_4\left(i m \_e(:,:, 1)\right.$, im_d $(:,:, 1), m, n, d i s p \_m a x$, limiar $)$;

eval([ ' save 'arquivo '_c_4.txt d -ascii -tabs'])

\% Método de correlação baseado na transformada censo modificado 5 elseif metodo $==$ ' $c$ _5'

$\mathrm{d}=\mathrm{c} \_5\left(\right.$ im_e $(:,:, 1), \mathrm{im} \_\mathrm{d}(:,:, 1), \mathrm{m}, \mathrm{n}, \mathrm{disp} \_m a x$, limiar $)$;

eval([' save' arquivo '_c_5.txt d -ascii -tabs'])

\% Caso o método escolhido não exista o programa informa e retorna else

disp('0 método escolhido não existe.');

$d=0$;

return ;

end

\% Desligando o cronômetro ao término do cálculo das disparidades

fim=cputime ;

tempo=fim-inicio;

disp('o tempo de processamento é:');

disp(tempo);

disp(' ' );

\% Plotando as figuras com os resultados

figure(1);

imagesc(im_e);

colormap('gray');

title('Imagem esquerda');

figure(2);

imagesc(im_d);

colormap('gray');

title('Imagem direita');

figure(3);

imagesc $(d)$;

colormap ('gray');

titulo = ['Mapa de disparidades pelo método ' metodo];

title(titulo);

end 
end

\% Caso onde paro de buscar na borda da imagem

fim $=n+$ colunas;

for $v=t$ : fim

\% Defino a janela atual

busca $=\operatorname{imgE}(s-m: s+m, v-n: v+n)$;

\% Calculo do valor da correlação SAD e crio um vetor temporário

\% com os resultados da correlação de cada janela atual na

\% janela busca, para depois escolher o melhor correlacionado.

$\operatorname{result}(v-t+1)=\operatorname{sum}(\operatorname{sum}(\operatorname{abs}($ alvo-busca $))) ;$

end

\% 0 valor mínimo significa a janela mais correlacionada, portanto \% atribuo à minha matriz de disparidades a distância onde essa \% janela foi encontrada.

$[\mathrm{val}, \mathrm{col}]=\min ($ result $)$;

$\operatorname{disp}(s, t)=(\operatorname{col}-1) ;$

$\operatorname{disp}=\operatorname{disp}(m+1: \operatorname{linhas}+(m), n+1: \operatorname{colunas}+(n))$;

end

\section{Função ssd.m (Soma do Quadrado das Diferenças)}

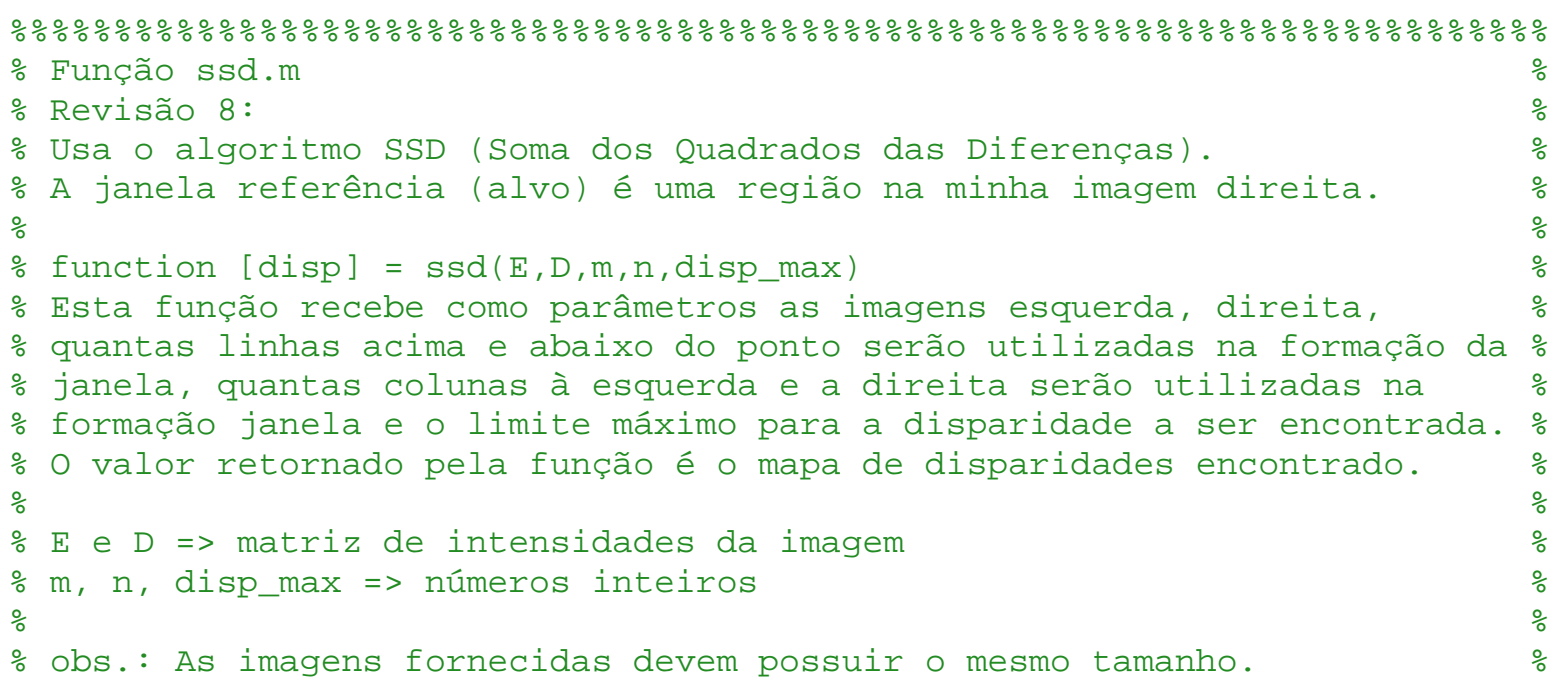
\%\%\%\%\%\%\%\%\%\%\%\%\%\%\%\%\%\%\%\%\%\%\%\%\%\%\%\%\%\%\%\%\%\%\%\%\%\%\%\%\%\%\%\%\%\%\%\%\%\%\%\%\%\%\%\%\%\%\%\%\%\%\%\%\%

function $[\mathrm{disp}]=\operatorname{ssd}\left(E, D, m, n, d i s p \_\max \right)$

\% Copiando as imagens para uma janela maior (aumentando as imagens com \% bordas $m$ e $n$ )

[linhas, colunas $]=\operatorname{size}(E)$;

imgE $=\operatorname{zeros}\left(\operatorname{linhas}+\left(2^{*} m\right), \operatorname{colunas}+\left(2^{*} n\right)\right)$; 


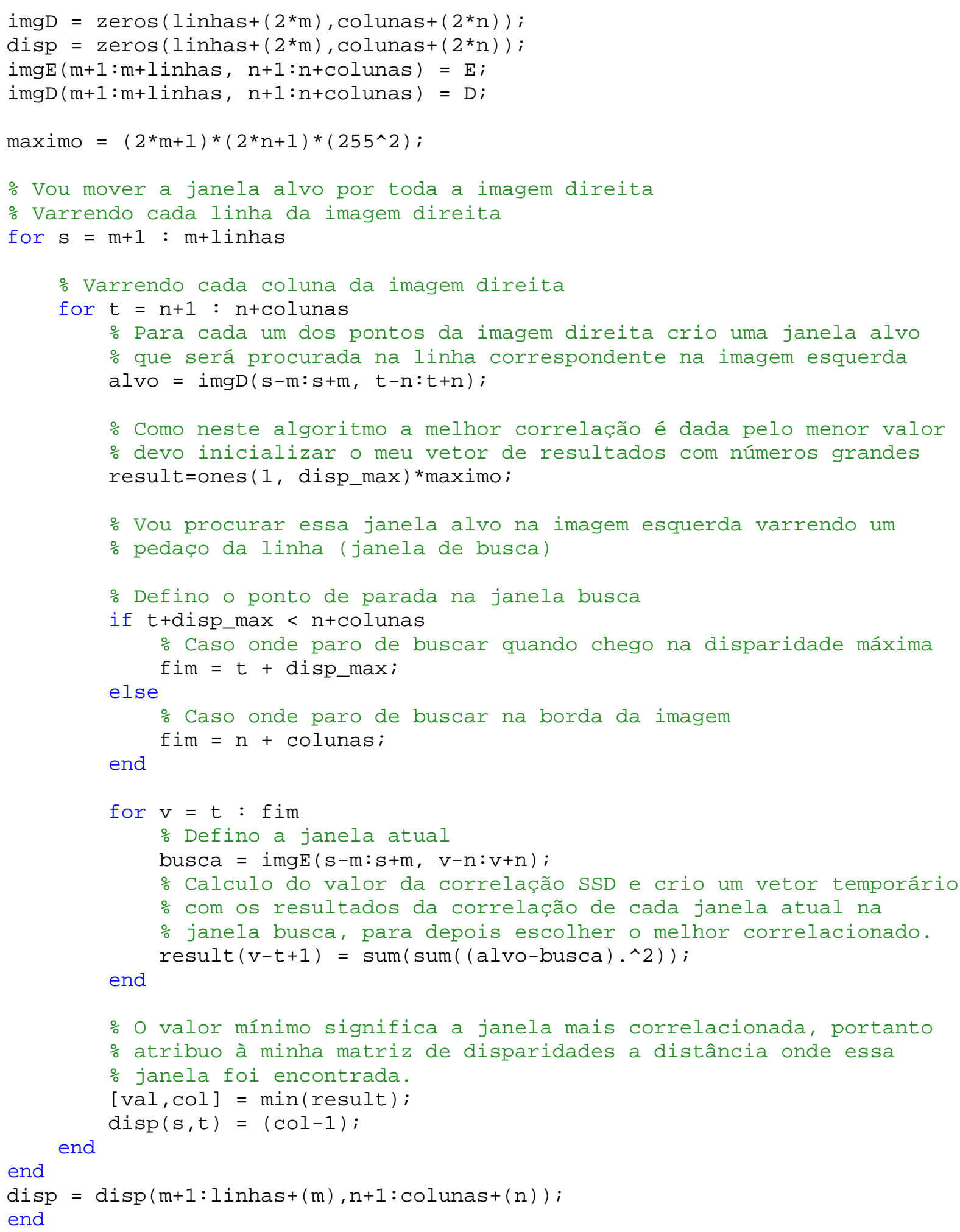




\section{Função cor.m (Correlação Cruzada Normalizada)}
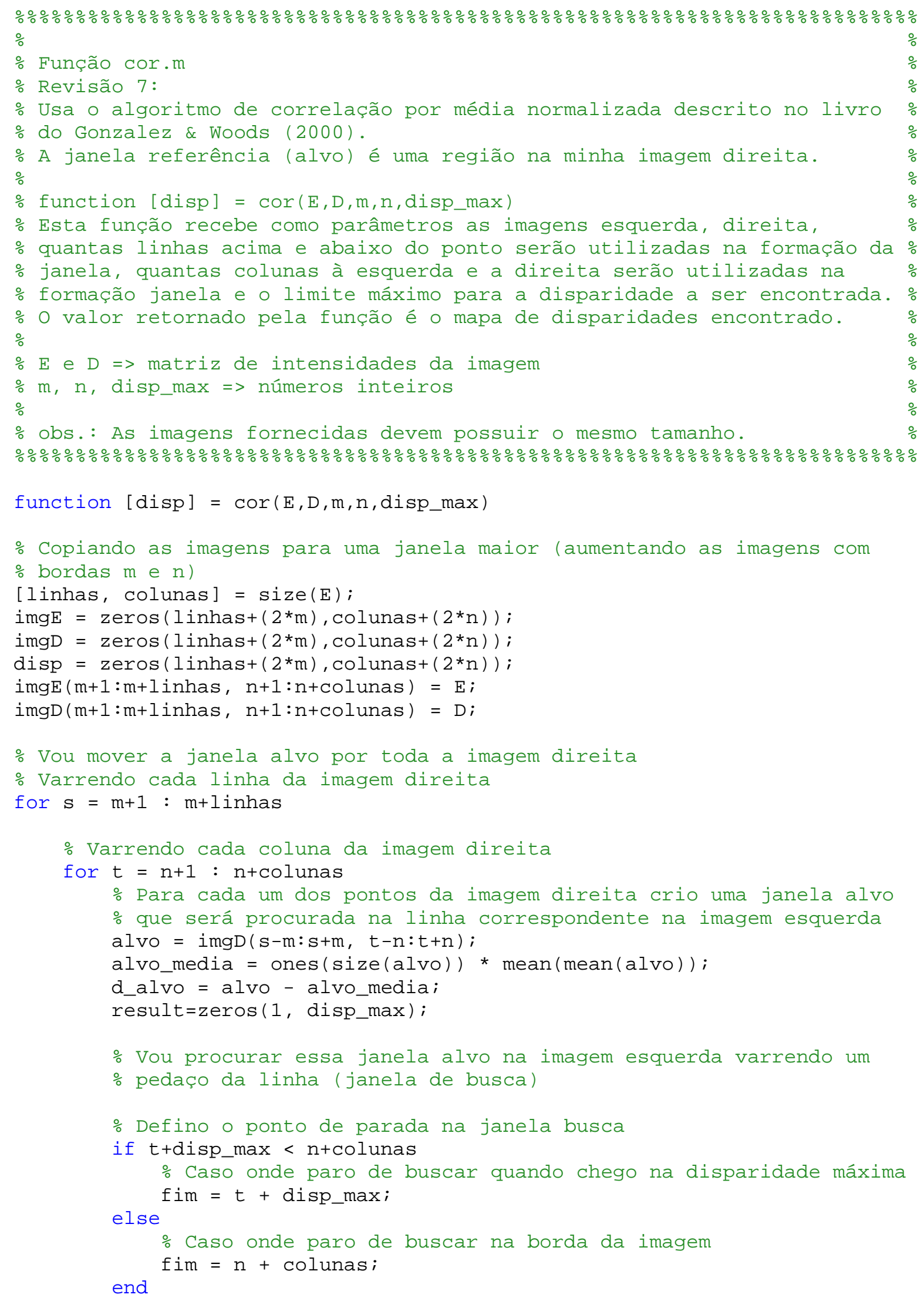
for $v=t:$ fim

$\%$ Defino a janela atual

busca $=\operatorname{imgE}(s-m: s+m, v-n: v+n)$;

busca_media $=\operatorname{ones}(\operatorname{size}($ busca $)) * \operatorname{mean}(\operatorname{mean}($ busca $))$;

d_busca = busca - busca_media;

\% Cálculo do Coeficiente de Correlação

denominador $=\operatorname{sqrt}\left(\operatorname{sum}\left(\operatorname{sum}\left(d \_a l v o . \wedge 2\right)\right){ }^{*} \operatorname{sum}\left(\operatorname{sum}\left(d \_b u s c a . \wedge 2\right)\right)\right)$; if denominador $>0$

else gama $=\operatorname{sum}\left(\operatorname{sum}\left(d \_a l v o . * d \_b u s c a\right)\right) /$ denominador ;

end

gama $=\operatorname{sum}\left(\operatorname{sum}\left(d \_a l v o . *\right.\right.$ d_busca $\left.)\right)$;

\% Crio um vetor temporário com os resultados da correlação de \% cada janela atual na janela busca, para depois escolher o $\%$ melhor correlacionado.

end

result $(v-t+1)=$ gama;

\% 0 valor máximo significa a janela mais correlacionada, portanto \% atribuo à minha matriz de disparidades a distância onde essa $\%$ janela foi encontrada.

end

$[\mathrm{val}, \mathrm{col}]=\max ($ result $)$;

end

$\operatorname{disp}(s, t)=(\operatorname{col}-1) ;$

$\operatorname{disp}=\operatorname{disp}(m+1: \operatorname{linhas}+(m), n+1: \operatorname{colunas}+(n))$;

end

\section{Função rnk.m (Transformada Rank)}

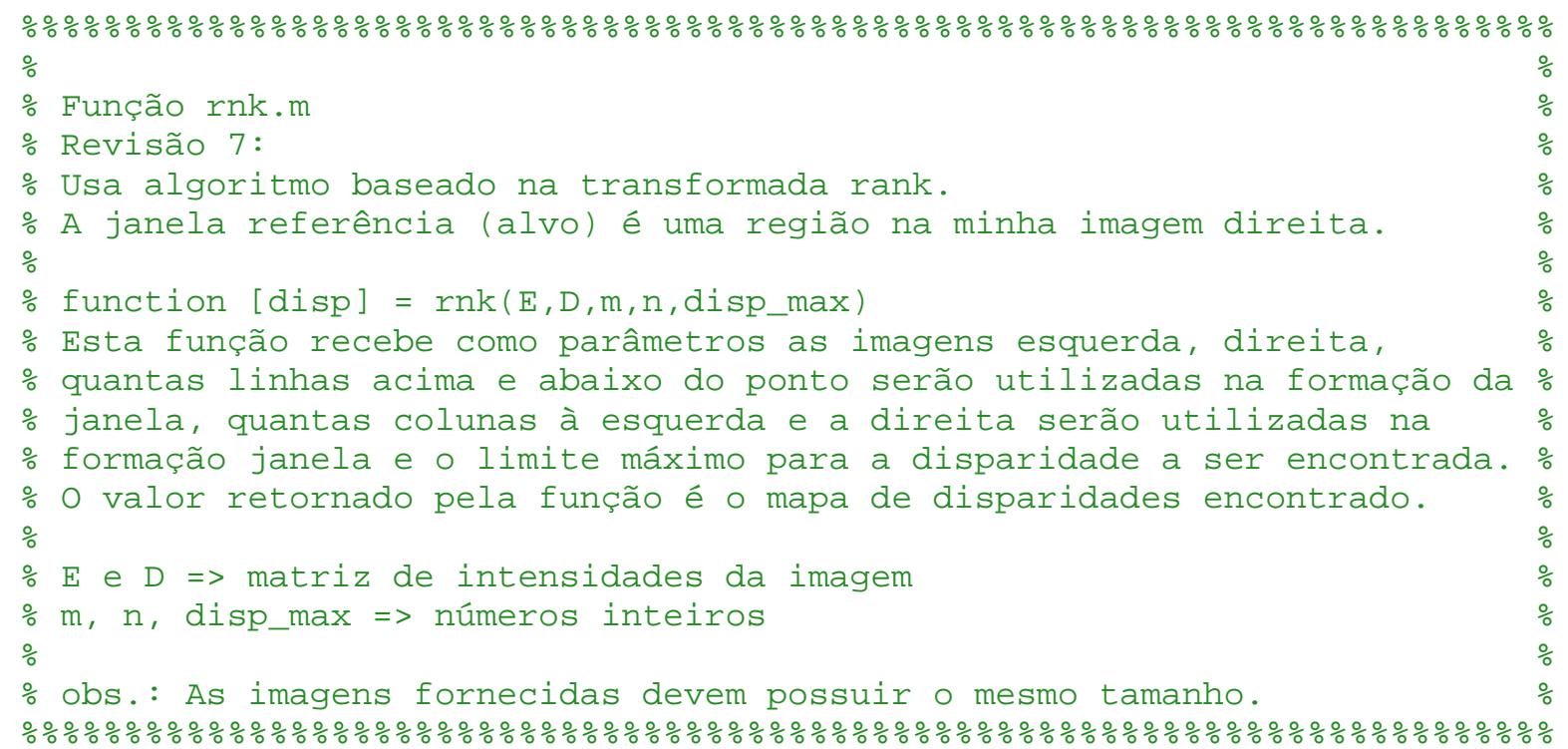




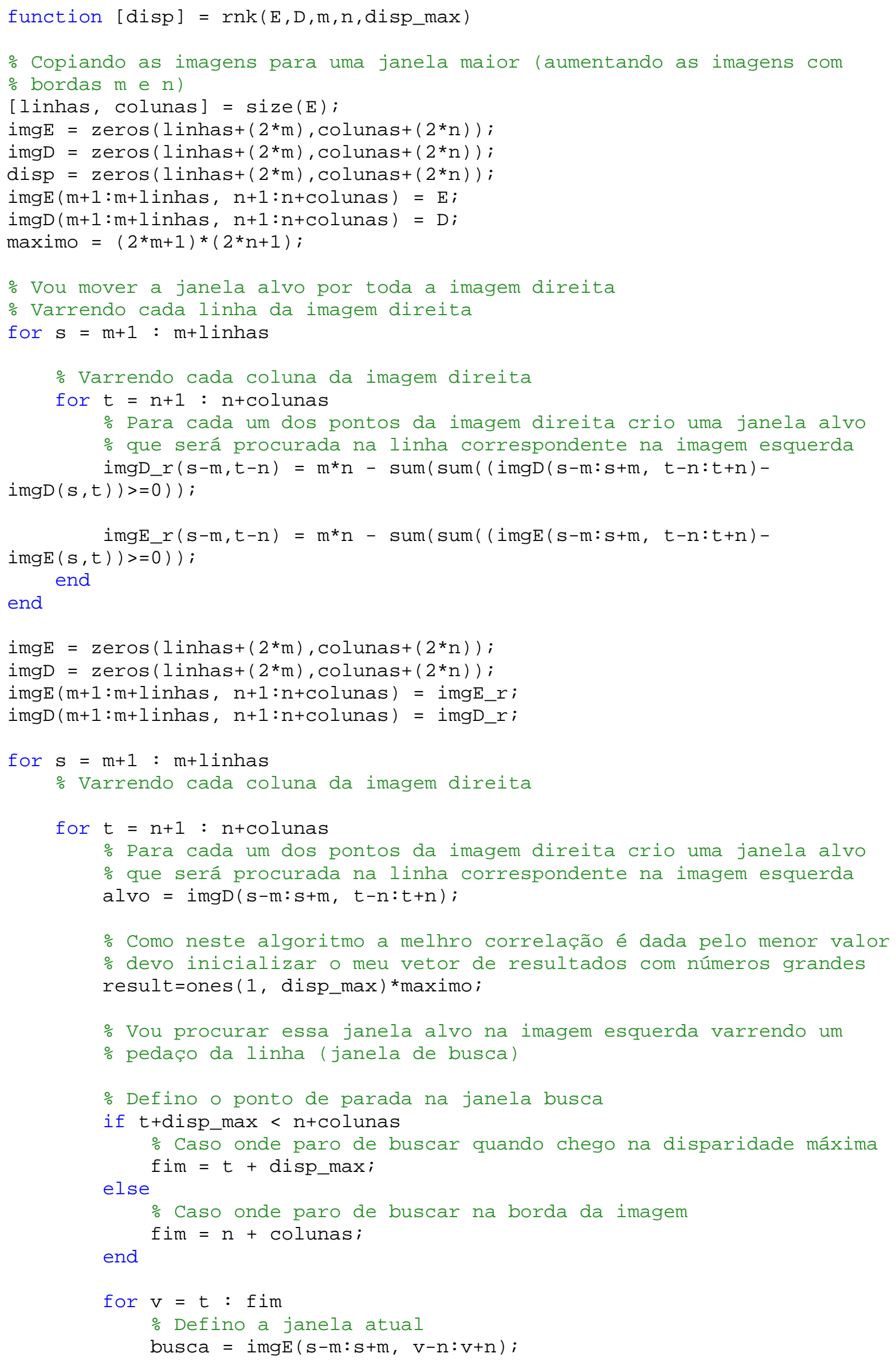


end end

\% Calculo do valor da correlação SAD e crio um vetor temporário

\% com os resultados da correlação de cada janela atual na \% janela busca, para depois escolher o melhor correlacionado. end $\operatorname{result}(v-t+1)=\operatorname{sum}(\operatorname{sum}($ abs $($ alvo-busca $))) ;$

\% 0 valor mínimo significa a janela mais correlacionada, portanto \% atribuo à minha matriz de disparidades a distância onde essa $\%$ janela foi encontrada.

$[\mathrm{val}, \mathrm{col}]=\min ($ result $)$;

$\operatorname{disp}=\operatorname{disp}(m+1:$ linhas $+(m), n+1: \operatorname{colunas}+(n))$;

end

\section{Função cen.m (Transformada Censo)}

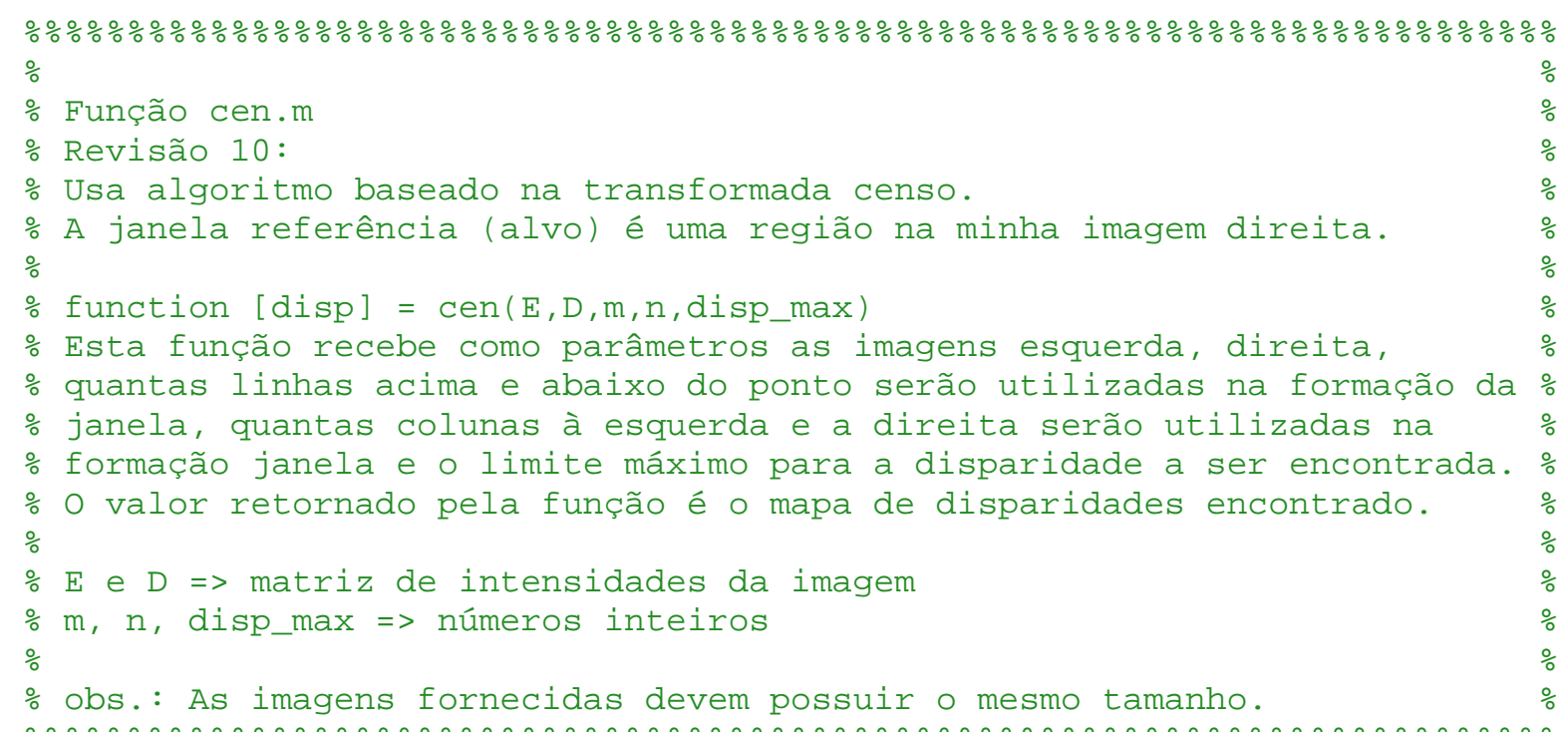

function $[$ disp $]=\operatorname{cen}\left(E, D, m, n, d i s p \_\max \right)$

\% Copiando as imagens para uma janela maior (aumentando as imagens com $\%$ bordas $m$ e $n$ )

[linhas, colunas] = size $(E)$;

imgE $=\operatorname{zeros}\left(\operatorname{linhas}+\left(2^{*} \mathrm{~m}\right), \operatorname{colunas}+\left(2^{*} \mathrm{n}\right)\right)$;

imgD $=\operatorname{zeros}\left(\right.$ linhas $\left.+(2 * m), \operatorname{colunas}+\left(2^{*} n\right)\right) ;$

disp $=\operatorname{zeros}\left(\right.$ linhas $\left.+(2 * m), \operatorname{colunas}+\left(2^{*} n\right)\right)$;

imgE $(m+1: m+1$ inhas, $n+1: n+$ colunas $)=E$;

$\operatorname{imgD}(m+1: m+1$ inhas, $n+1: n+$ colunas $)=D$;

$\operatorname{maximo}=\left(2^{*} m+1\right){ }^{*}\left(2{ }^{*} n+1\right)-1 ;$

\% Vou mover a janela alvo por toda a imagem direita

\% Varrendo cada linha da imagem direita

for $s=m+1: m+l i n h a s$ 
\% Varrendo cada coluna da imagem direita

for $t=n+1: n+c o l u n a s$

\% Para cada um dos pontos da imagem direita crio uma janela alvo \% que será procurada na linha correspondente na imagem esquerda alvo_temp $=\operatorname{imgD}(s-m: s+m, t-n: t+n)>\operatorname{imgD}(s, t)$;

$i=0$;

for $k=1: 2^{*} m+1$

for $1=1: 2 * n+1$

if $k \sim=m+1 \quad \& \& \quad l \sim=n+1$

$i=i+1$;

end

$\operatorname{alvo}(i)=a l v o \_t e m p(k, 1)$;

end

end

\% Como neste algoritmo a melhor correlação é dada pelo menor valor \% devo inicializar o meu vetor de resultados com números grandes result=ones $(1$, disp_max $){ }^{*} \operatorname{maximo\text {;}}$

\% Vou procurar essa janela alvo na imagem esquerda varrendo um \% pedaço da linha (janela de busca)

\% Defino o ponto de parada na janela busca

if $\mathrm{t}+\mathrm{disp}$ max $<\mathrm{n}+\mathrm{colunas}$

\% Caso onde paro de buscar quando chego na disparidade máxima else

fim = t + disp_max;

\% Caso onde paro de buscar na borda da imagem

end

fim $=n+$ colunas;

for $v=t:$ fim

$\%$ Defino a janela atual

busca_temp $=\operatorname{imgE}(\mathrm{s}-\mathrm{m}: \mathrm{s}+\mathrm{m}, \mathrm{v}-\mathrm{n}: \mathrm{v}+\mathrm{n})>\operatorname{imgE}(\mathrm{s}, \mathrm{v})$;

$i=0$;

for $k=1: 2^{*} m+1$

for $1=1: 2^{*} n+1$

if $k \sim=m+1 \quad \& \& \quad 1 \sim=n+1$

$i=i+1$;

end

$\operatorname{busca}(i)=$ busca_temp $(k, 1)$;

end

end

\% Calculo do valor da correlação e crio um vetor temporário

\% com os resultados da correlação de cada janela atual na

\% janela busca, para depois escolher o melhor correlacionado.

end $\operatorname{result}(v-t+1)=\operatorname{sum}($ alvo =busca $) ;$

\% 0 valor mínimo significa a janela mais correlacionada, portanto \% atribuo à minha matriz de disparidades a distância onde essa $\%$ janela foi encontrada.

$[\mathrm{val}, \mathrm{col}]=\min ($ result $)$;

$\operatorname{disp}(s, t)=(\operatorname{col}-1)$;

end

end

disp $=\operatorname{disp}(m+1:$ linhas $+(m), n+1:$ colunas $+(n))$;

end 


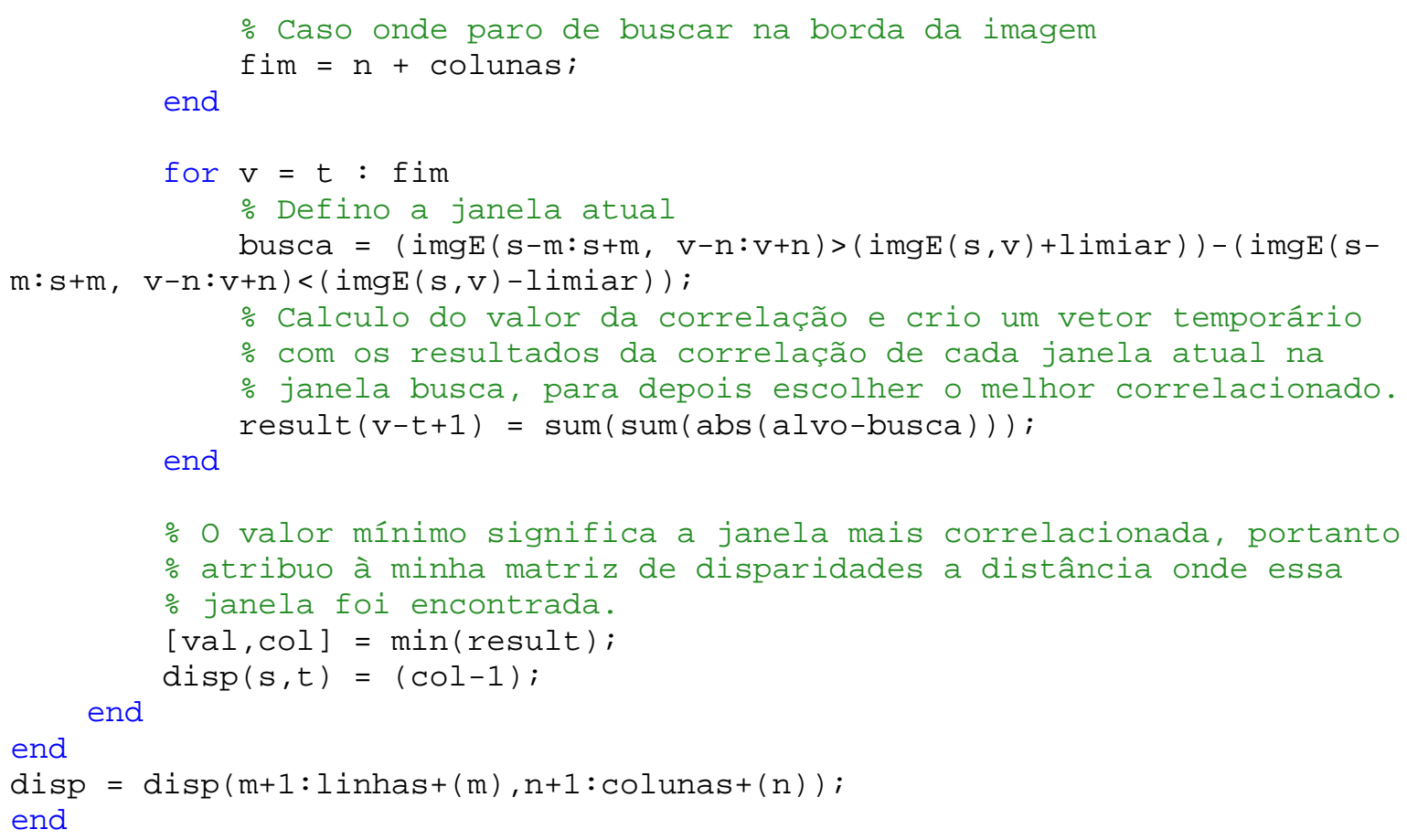

\section{Função c_2.m (Transformada Modificada 2)}

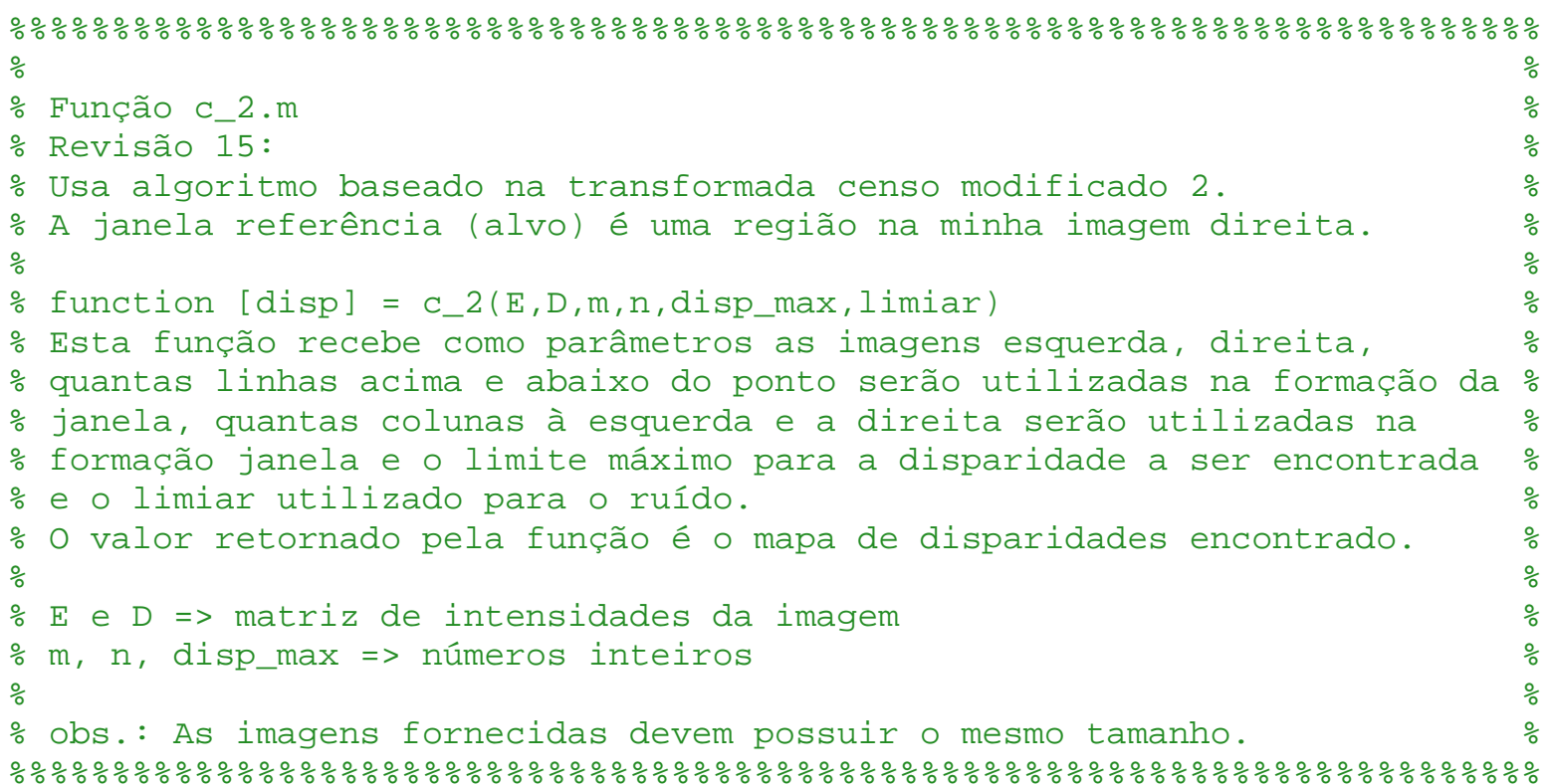

function [disp] = c_2(E,D,m, n, disp_max, limiar)

\% Copiando as imagens para uma janela maior (aumentando as imagens com $\%$ bordas $m$ e $n$ )

[linhas, colunas $]=\operatorname{size}(E)$;

imgE $=\operatorname{zeros}\left(\right.$ linhas $\left.+\left(2^{*} m\right), \operatorname{colunas}+(2 * n)\right) ;$

imgD $=\operatorname{zeros}\left(\right.$ linhas $\left.+\left(2^{*} m\right), \operatorname{colunas}+\left(2^{*} n\right)\right)$;

disp $=\operatorname{zeros}\left(\operatorname{linhas}+\left(2^{*} \mathrm{~m}\right), \operatorname{colunas}+\left(2^{*} \mathrm{n}\right)\right)$; 


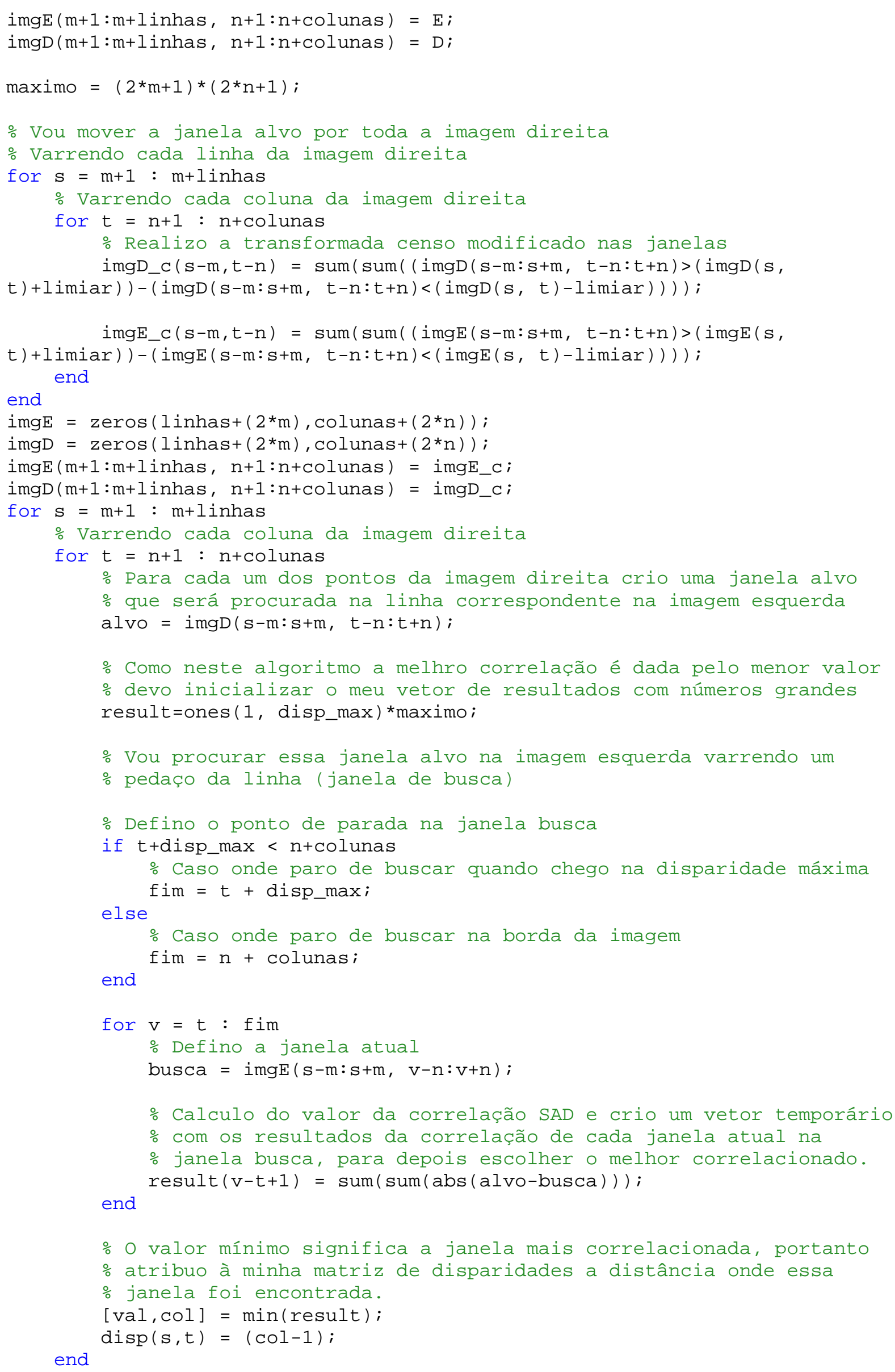


end

$\operatorname{disp}=\operatorname{disp}(m+1: \operatorname{linhas}+(m), n+1: \operatorname{colunas}+(n))$;

end

\section{Função c_3.m (Transformada Modificada 3)}

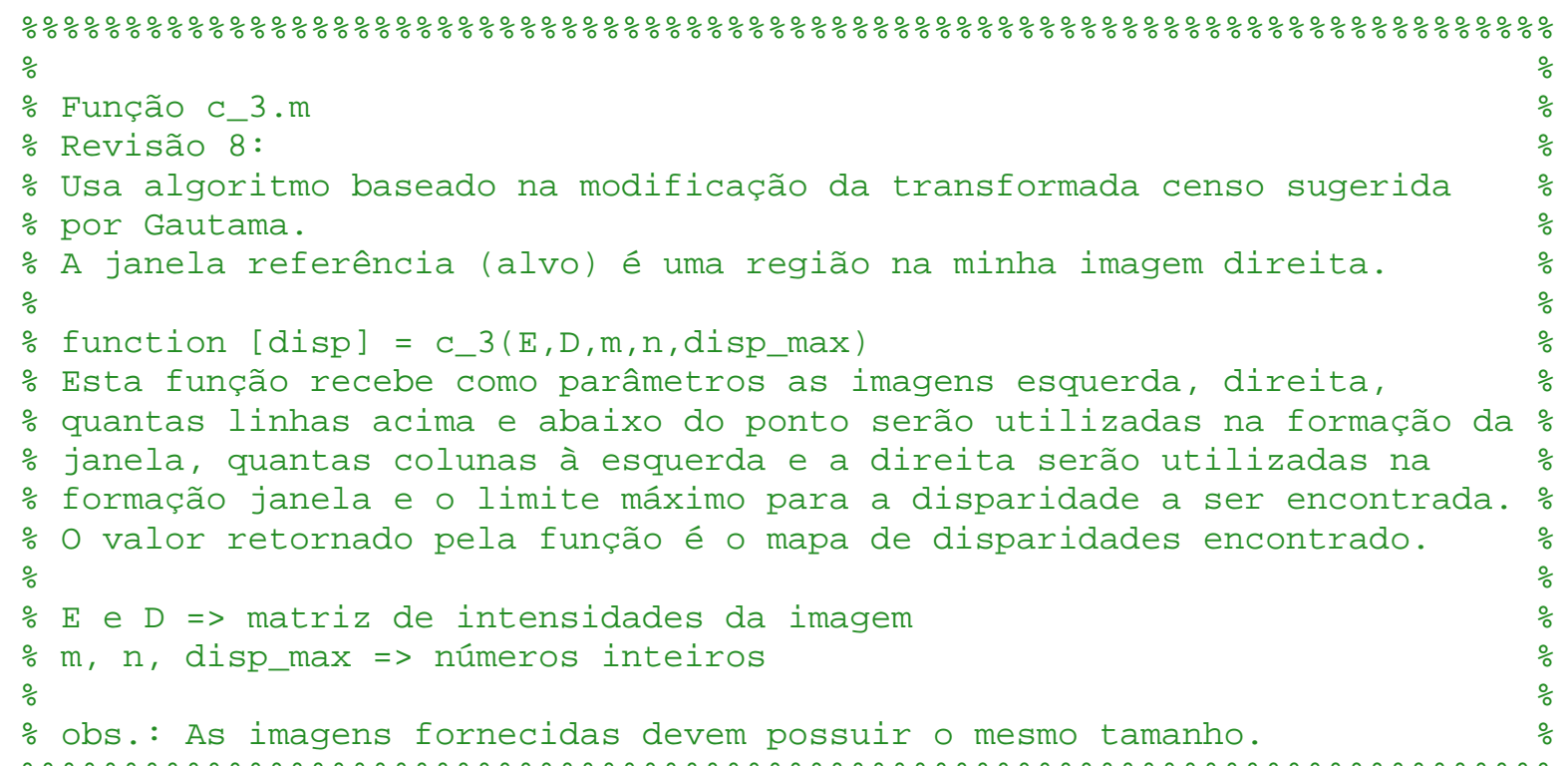

function $\left[\right.$ disp] $=c \_3\left(E, D, m, n, d i s p \_\max \right)$

\% Copiando as imagens para uma janela maior (aumentando as imagens com \% bordas $m$ e $n$ )

[linhas, colunas $]=\operatorname{size}(E)$;

imgE $=\operatorname{zeros}\left(\operatorname{linhas}+\left(2^{*} \mathrm{~m}\right), \operatorname{colunas}+\left(2^{*} \mathrm{n}\right)\right)$;

imgD $=\operatorname{zeros}\left(\right.$ linhas $\left.+\left(2^{*} m\right), \operatorname{colunas}+\left(2^{*} n\right)\right)$;

disp $=\operatorname{zeros}\left(\right.$ linhas $\left.+\left(2^{*} m\right), \operatorname{colunas}+\left(2^{*} n\right)\right)$;

imgE $(m+1: m+1$ inhas, $n+1: n+$ colunas $)=E$;

$\operatorname{imgD}(m+1: m+l$ inhas, $n+1: n+$ colunas $)=D$;

$\operatorname{maximo}=\left(2{ }^{*} m+1\right) *(2 * n+1) ;$

\% Vou mover a janela alvo por toda a imagem direita

\% Varrendo cada linha da imagem direita

for $s=m+1: m+l i n h a s$

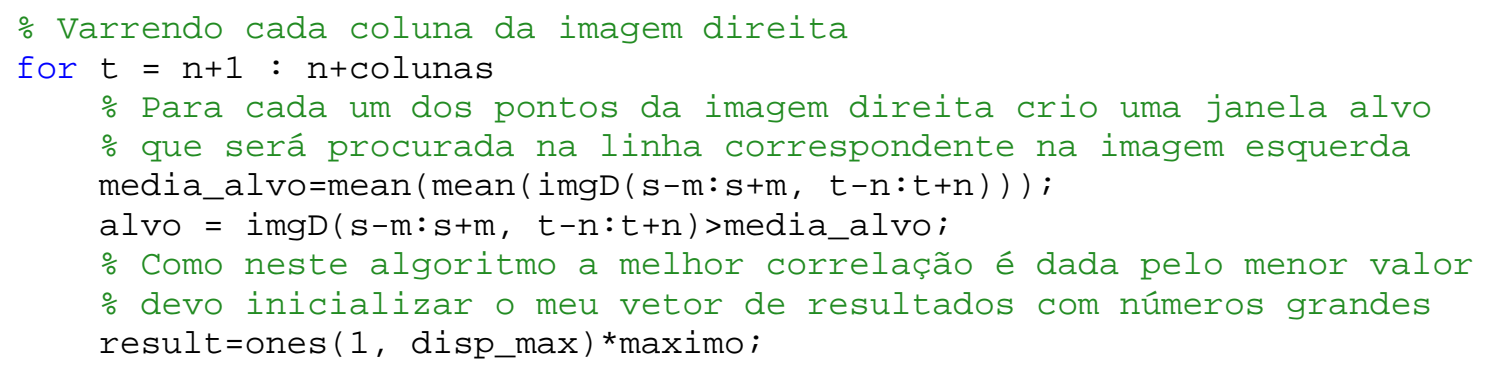


\% Vou procurar essa janela alvo na imagem esquerda varrendo um \% pedaço da linha (janela de busca)

\% Defino o ponto de parada na janela busca

if $\mathrm{t}+\mathrm{disp}$ max $<\mathrm{n}+\mathrm{colunas}$

\% Caso onde paro de buscar quando chego na disparidade máxima else

end

for $v=t$ : fim

$\%$ Defino a janela atual

media_busca=mean(mean(imgE $(s-m: s+m, v-n: v+n)))$;

busca $=\operatorname{imgE}(\mathrm{s}-\mathrm{m}: \mathrm{s}+\mathrm{m}, \mathrm{v}-\mathrm{n}: \mathrm{v}+\mathrm{n})>\operatorname{media}$ _busca;

\% Calculo do valor da correlação e crio um vetor temporário

\% com os resultados da correlação de cada janela atual na

\% janela busca, para depois escolher o melhor correlacionado. end

$\operatorname{result}(v-t+1)=\operatorname{sum}(\operatorname{sum}(\operatorname{abs}(\operatorname{alvo}=\operatorname{busca})))$;

\% 0 valor mínimo significa a janela mais correlacionada, portanto \% atribuo à minha matriz de disparidades a distância onde essa \% janela foi encontrada.

end

$[\mathrm{val}, \mathrm{col}]=\min ($ result $)$;

end

$\operatorname{disp}(s, t)=(\operatorname{col}-1) ;$

$\operatorname{disp}=\operatorname{disp}(m+1: \operatorname{linhas}+(m), n+1: \operatorname{colunas}+(n))$;

end

\section{Função c_4.m (Transformada Modificada 4)}

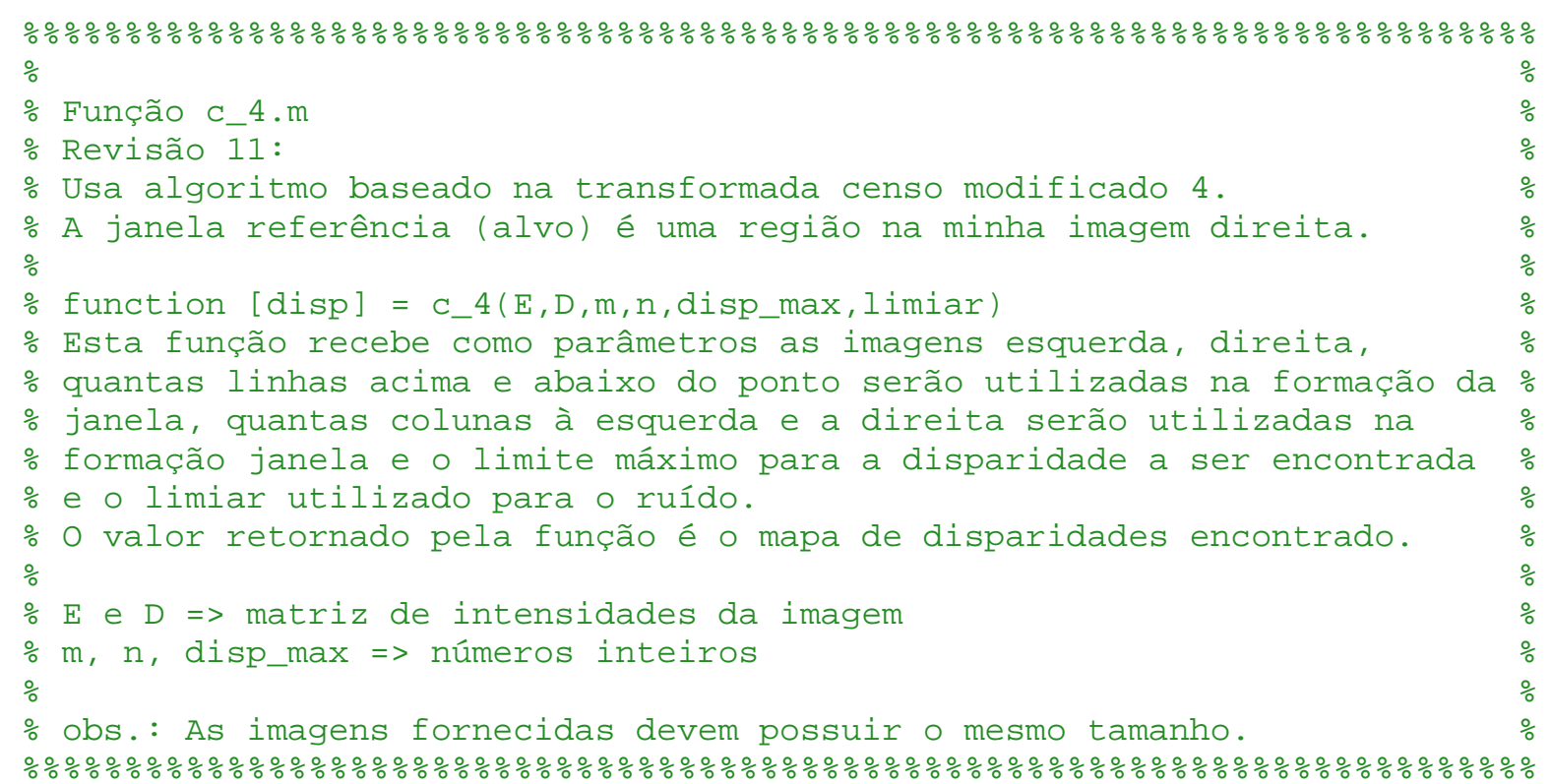




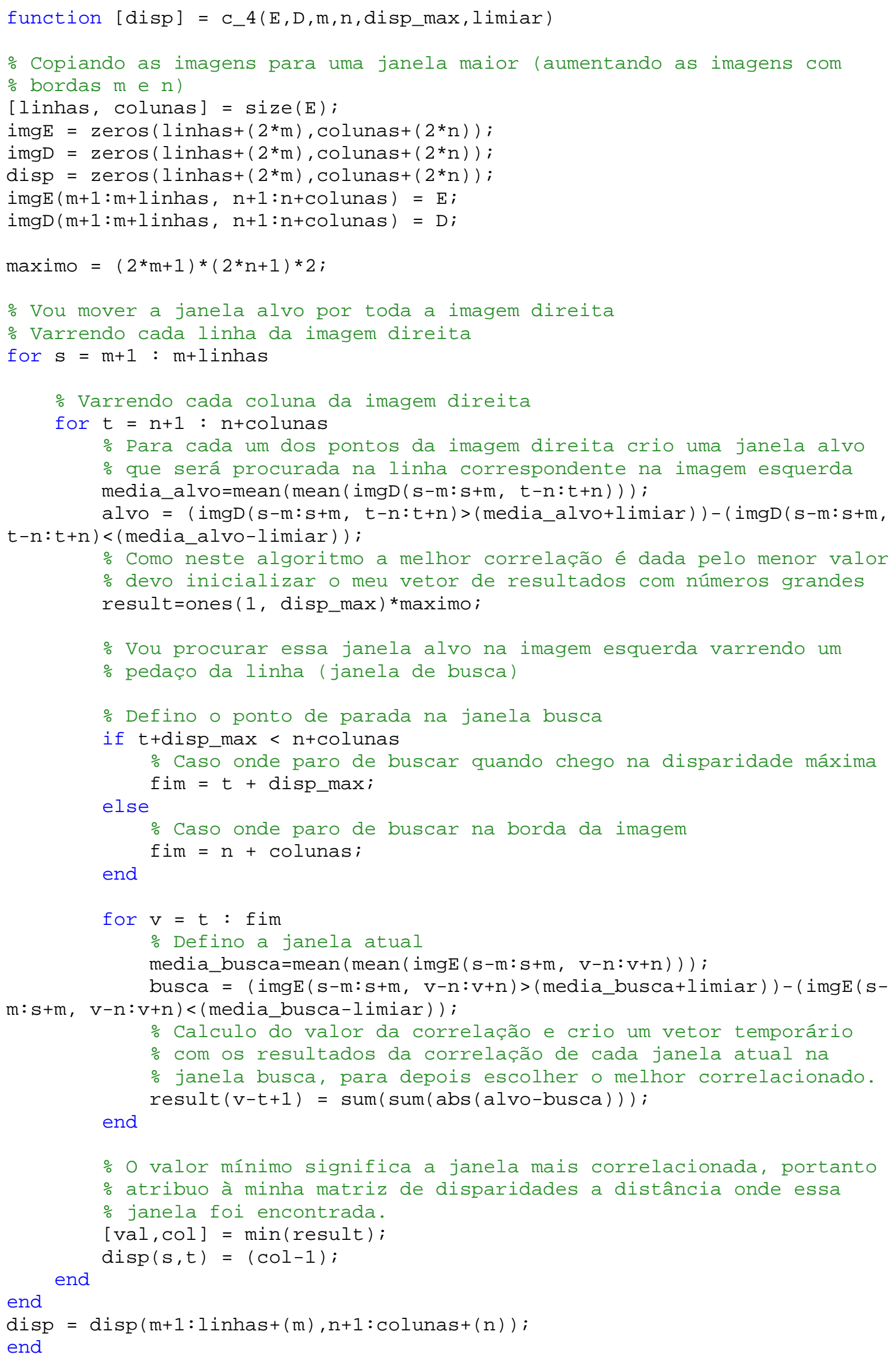




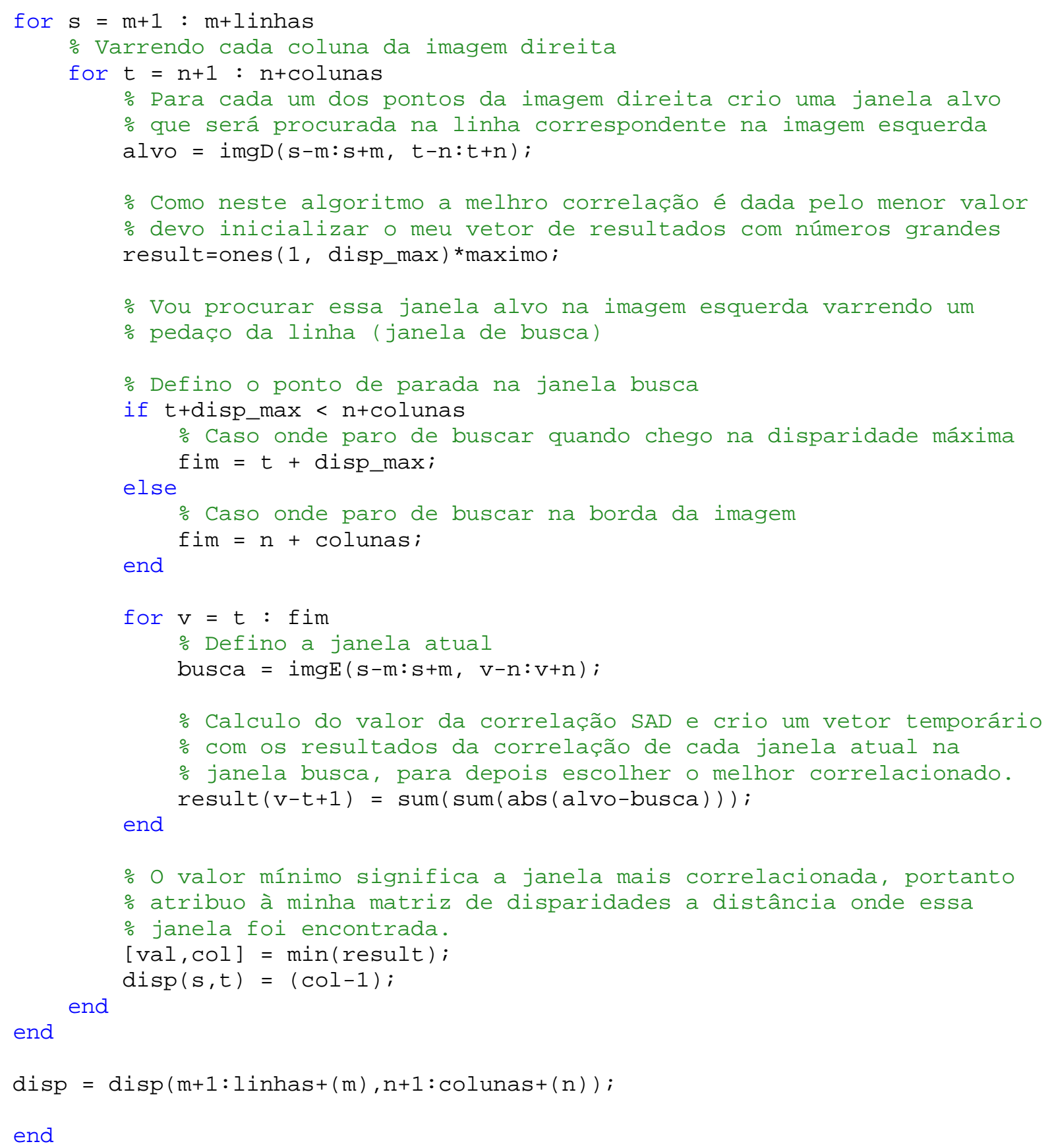

\section{Função resultados.m}

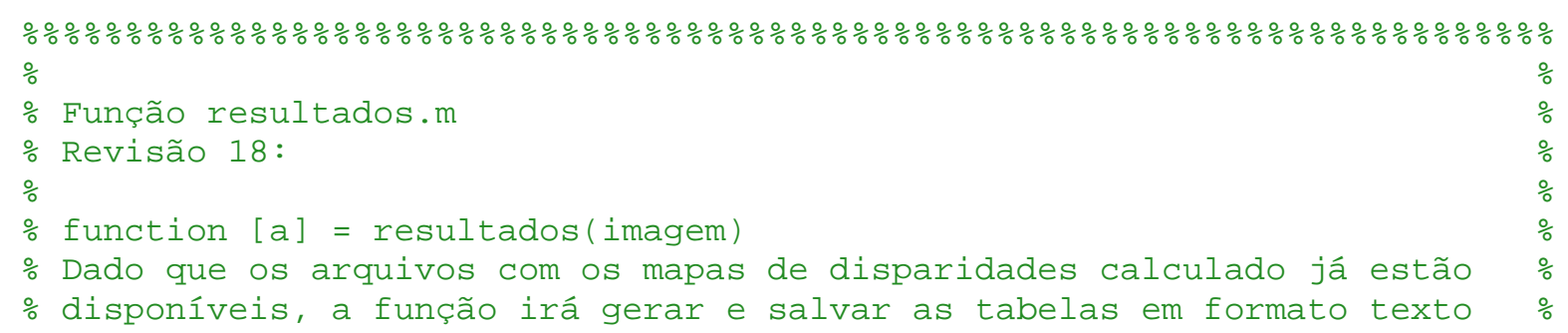




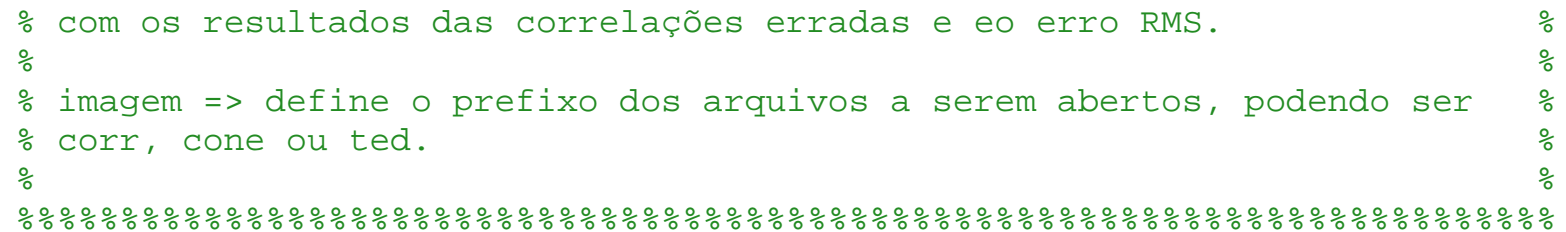

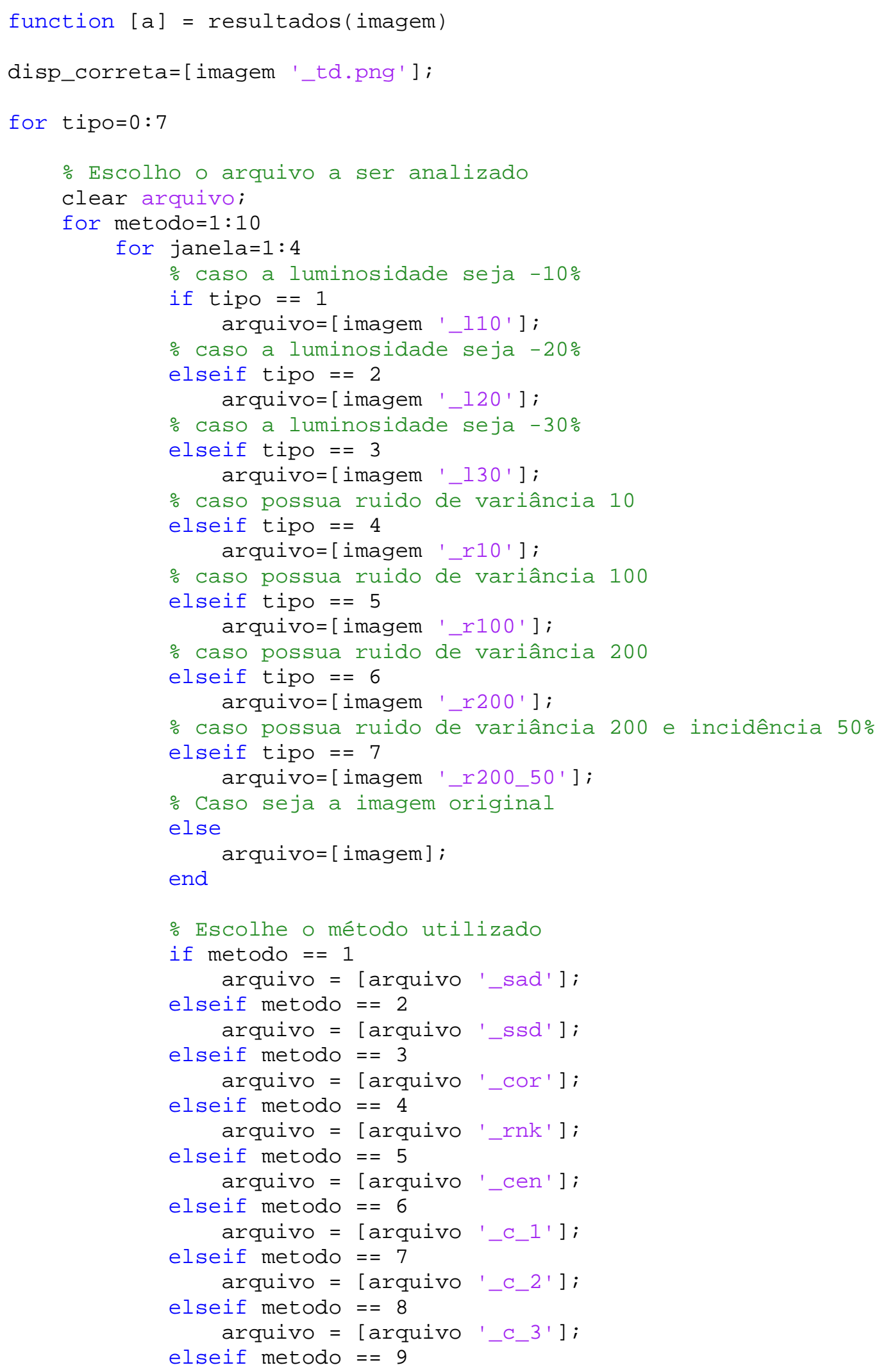




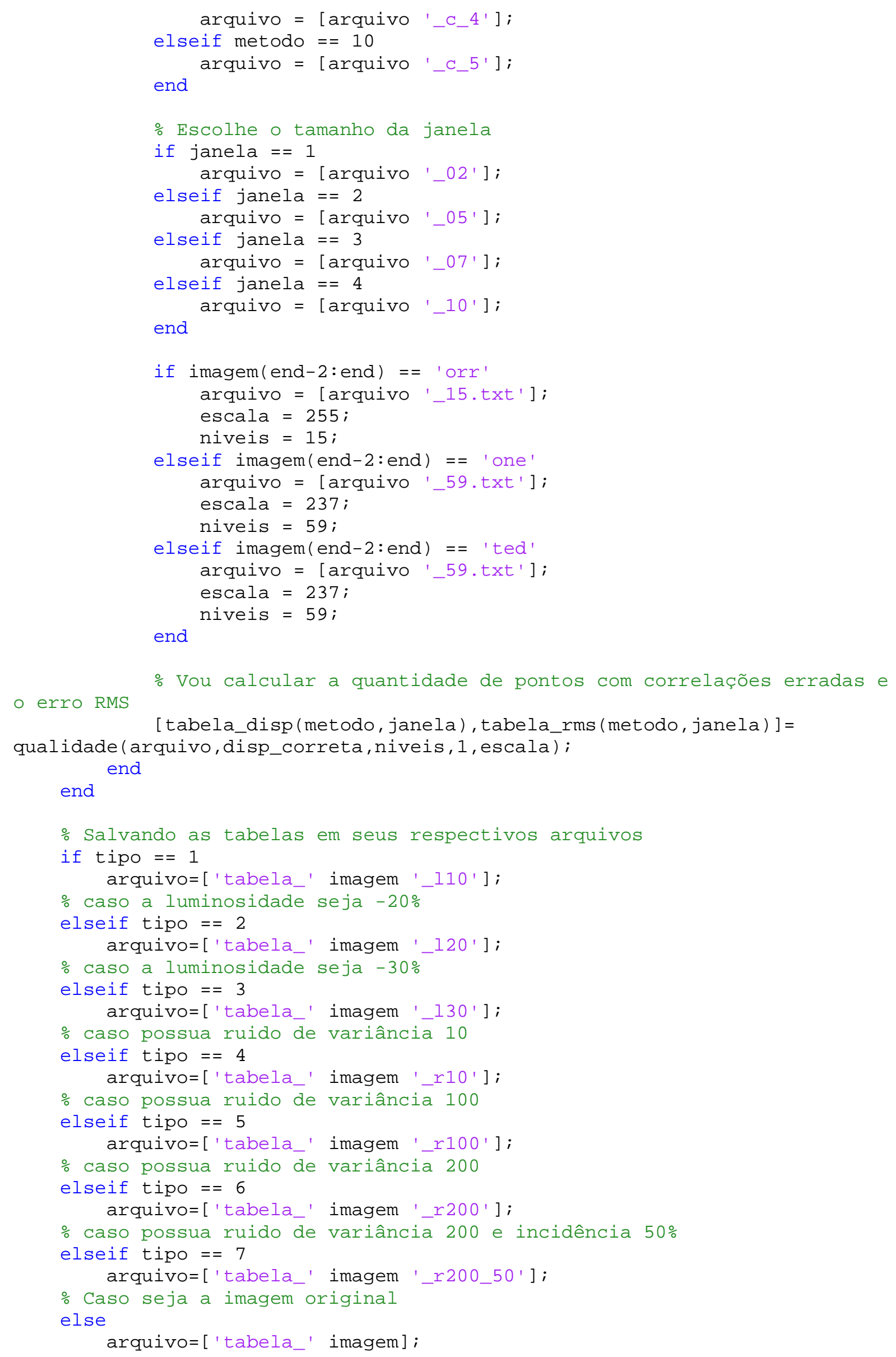


end tabs'])

eval([ ' save ' arquivo '_corr_erradas.txt tabela_disp -ascii eval([ ' save ' arquivo '_rms.txt tabela_rms -ascii -tabs'])

end

end

\section{Função qualidade.m}

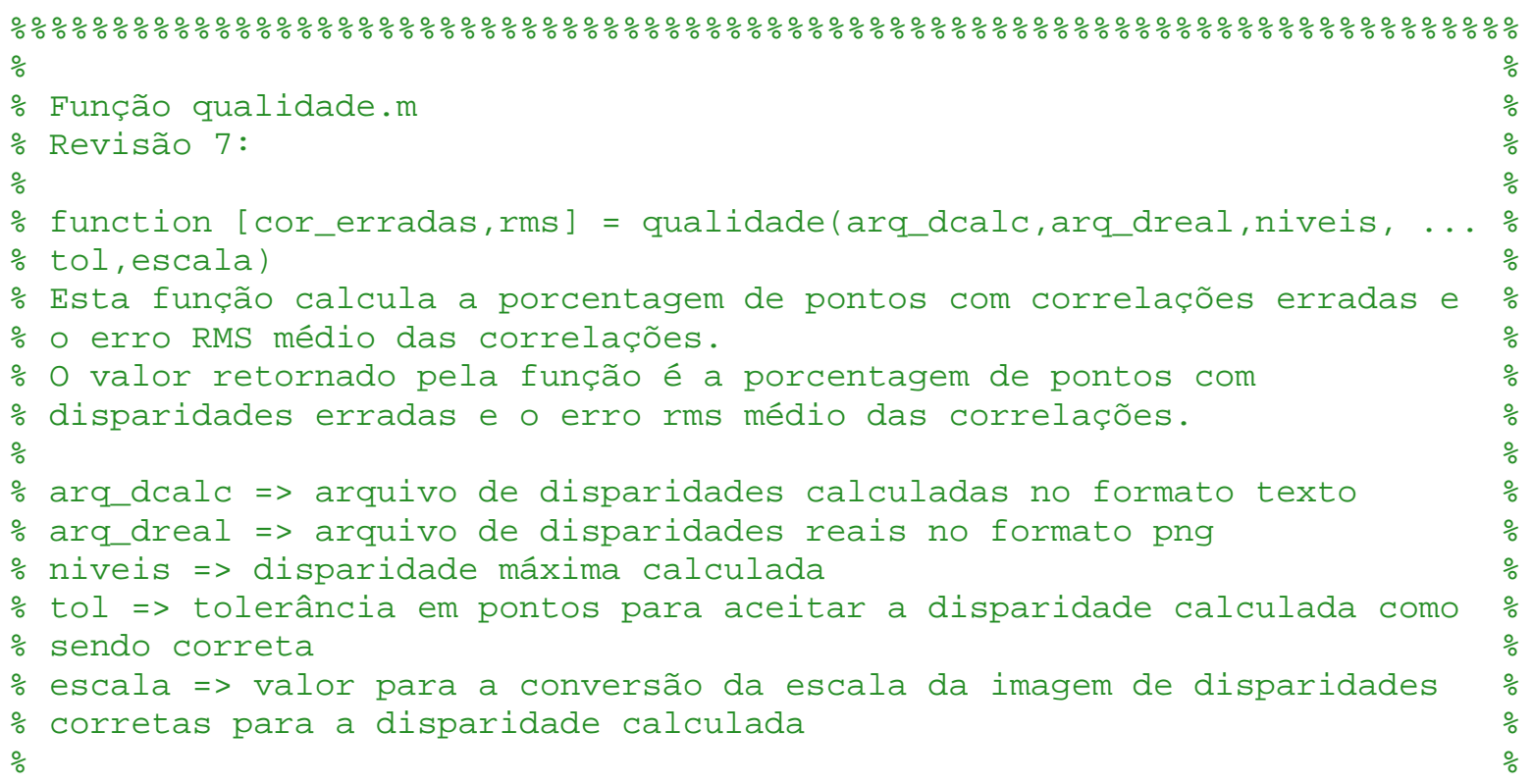

\%\%\%\%\%\%\%\%\%\%\%\%\%\%\%\%\%\%\%\%\%\%\%\%\%\%\%\%\%\%\%\%\%\%\%\%\%\%\%\%\%\%\%\%\%\%\%\%\%\%\%\%\%\%\%\%\%\%\%\%\%\%\%\%\%\%\%

function [cor_erradas, rms] =

qualidade(arq_dcalc,arq_dreal,niveis, tol, escala)

\% Para a comparação dos mapas de disparidades vou desconsiderar uma faixa

$\%$ na extremidade direita da imagem com largura de pontos igual aos niveis

$\%$ de disparidades considerado

im = imread(arq_dreal);

im $=\operatorname{double}(\operatorname{im}(:, 1:$ end-int $8($ niveis $), 1))$;

$m=\operatorname{size}(i m)$;

corr=load (arq_dcalc);

$\operatorname{corr}=\operatorname{corr}(:, 1:$ end - int8(niveis) $)$;

\% Conversão dos tons de cinza da imagem de disparidade real para a

\% escala da disparidade calculada

im2=round (im*niveis/escala);

\% Cálculo da porcentagem de pontos errados em \%

cor_erradas $=(\operatorname{sum}(\operatorname{sum}(\operatorname{abs}(\operatorname{cor} r-i m 2)>\operatorname{tol}))) /\left(m(1){ }^{*} m(2)\right) * 100$;

\% Cálculo do erro rms

$r m s=(\operatorname{sum}(\operatorname{sum}(\operatorname{sqrt}(\operatorname{double}(\operatorname{corr}-i m 2) \cdot \wedge 2) /(m(1) * m(2))))) ;$

end 


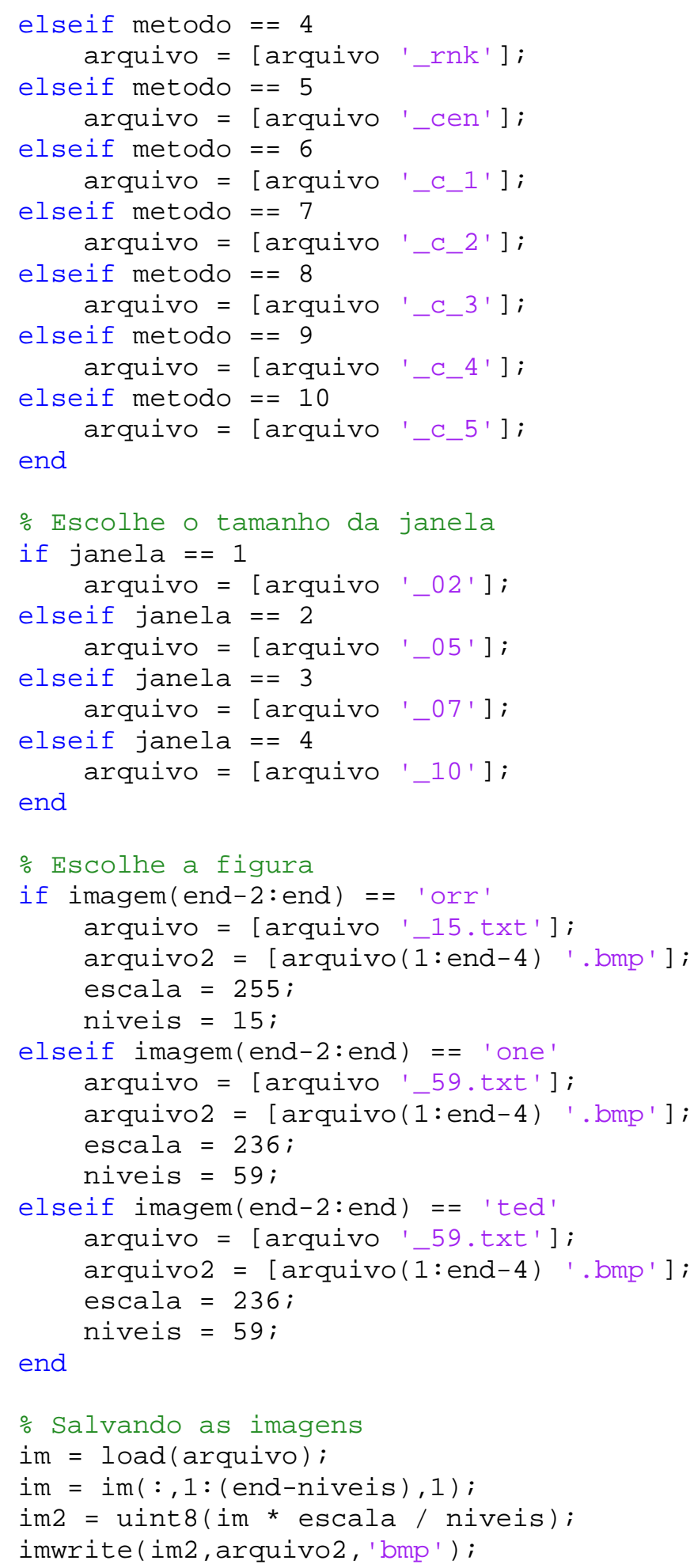

end

end 
\%\% Gerando o gráfico das correlações erradas

$\%$ SAD

plot (cor_erradas $(1,:), ' k<:$ ');

hold on;

$\%$ SSD

plot(cor_erradas(2, :), 'kx: ');

$\%$ COR

plot (cor_erradas(3,:),'k.-.');

$\%$ RNK

plot (cor_erradas (4, : ), 'kp-.' );

$\%$ CEN

plot (cor_erradas(5,:), 'kv--');

$\%$ C_1

plot(cor_erradas(6, : ), 'go-');

$\%$ C_2

plot (cor_erradas ( $7,:)$, ' $^{\wedge}$ - ' $^{\prime}$ );

\% C_3

plot (cor_erradas(8, : ), 'k*-- ');

\% C_4

plot (cor_erradas (9, : ), 'cd-' );

\% C_5

plot (cor_erradas(10, :), 'rs-' );

hold off;

xlabel( 'Janela')

ylabel('Correlações erradas [\%]')

$\operatorname{axis}([1,4,0,70])$;

set (gca, 'XTick', 1:1:4)

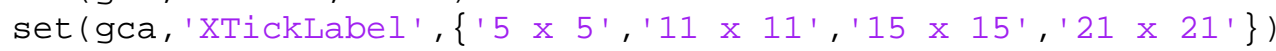

legend('Soma das Diferenças Absolutas', 'Soma do Quadrado das Diferenças',$\ldots$

'Correlação Cruzada Normalizada', 'Transformada Rank', ...

'Transformada Censo', 'Transformada Modificada 1', ...

'Transformada Modificada 2', 'Transformada Modificada 3',...

'Transformada Modificada 4','Transformada Modificada 5');

arquivo=arquivo( 1 : end -4$)$;

saveas(gcf, arquivo, 'fig')

close;

$\% \%$ Gerando o gráfico do erro rms

$\%$ SAD

$\operatorname{plot}\left(\operatorname{rms}(1,:),{ }^{\prime} k<:\right.$ ' $)$;

hold on;

$\%$ SSD

$\operatorname{plot}\left(\operatorname{rms}(2,:),{ }^{\prime} k x: '\right)$;

$\%$ COR

$\operatorname{plot}\left(\operatorname{rms}(3,:),{ }^{\prime}\right.$ k. . .' $)$;

$\%$ RNK

$\operatorname{plot}\left(\operatorname{rms}(4,:),{ }^{\prime} \mathrm{kp}-. '\right)$;

$\%$ CEN

$\operatorname{plot}\left(\operatorname{rms}(5,:),{ }^{\prime} k v--'\right)$;

$\%$ C_1

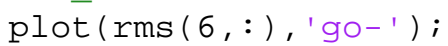

$\%$ C_2

$\operatorname{plot}\left(\operatorname{rms}(7,:), b^{\wedge}-1\right)$;

\% C_3

$\operatorname{plot}\left(\operatorname{rms}(8,:), \mathrm{k}^{*}-\mathrm{-}^{\prime}\right)$;

$\%$ C_4

$\operatorname{plot}\left(\operatorname{rms}(9,:)\right.$, ' $\left.^{\prime} \mathrm{cd}-\mathrm{-}^{\prime}\right)$;

$\%$ C_5

$\operatorname{plot}\left(r m s(10,:)\right.$, 'rs-' $\left.^{\prime}\right)$; 
hold off;

hold off;

xlabel( 'Janela')

ylabel('Erro RMS [pontos]')

axis $([1,4,0,5])$;

set (gca, 'XTick', 1:1:4)

set (gca, 'XTickLabel', \{'5 x 5', '11 x 11','15 x 15','21 x 21'\})

legend('Soma das Diferenças Absolutas', 'Soma do Quadrado das Diferenças' ${ }^{\prime}, \ldots$

'Correlação Cruzada Normalizada', 'Transformada Rank', ...

'Transformada Censo', 'Transformada Modificada 1', ...

'Transformada Modificada 2', 'Transformada Modificada 3',...

'Transformada Modificada 4','Transformada Modificada 5');

arquivo2=arquivo2( 1 : end -4$)$;

saveas(gcf, arquivo2, 'fig')

close;

end

end 


\section{APÊNDICE B - MAPAS DE DISPARIDADES RESULTANTES DA COMPARAÇÃO DOS MÉTODOS}

Nos mapas de disparidades a seguir os objetos com as maiores distâncias encontram-se representadas com tons de cinza mais escuros e o objetos mais próximos com tons de cinza mais claros.

O tamanho, em pontos, das janelas utilizadas estão indicadas no canto inferior direito de cada imagem.

Imagem do Corredor

Resultados da execução dos algoritmos com a imagem original
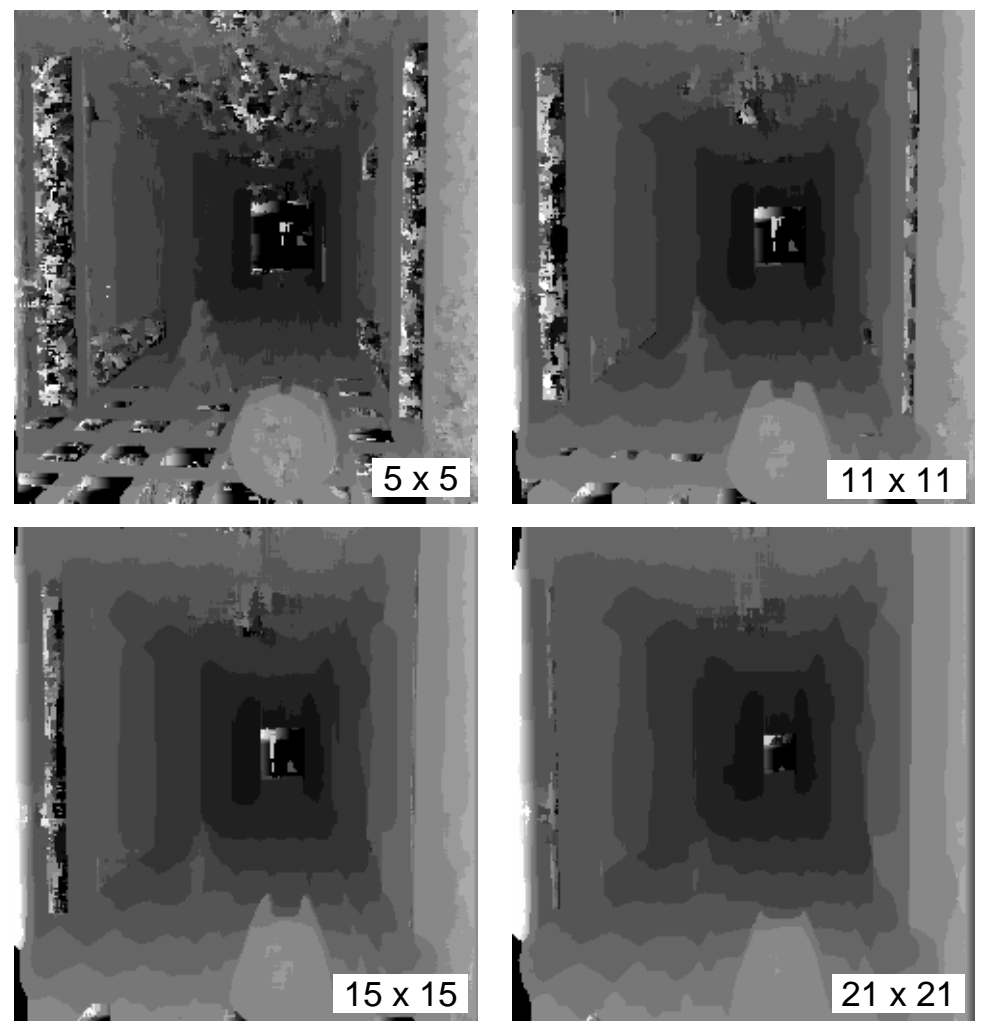

Figura B1: Execução do método Soma das Diferenças Absolutas na imagem original 

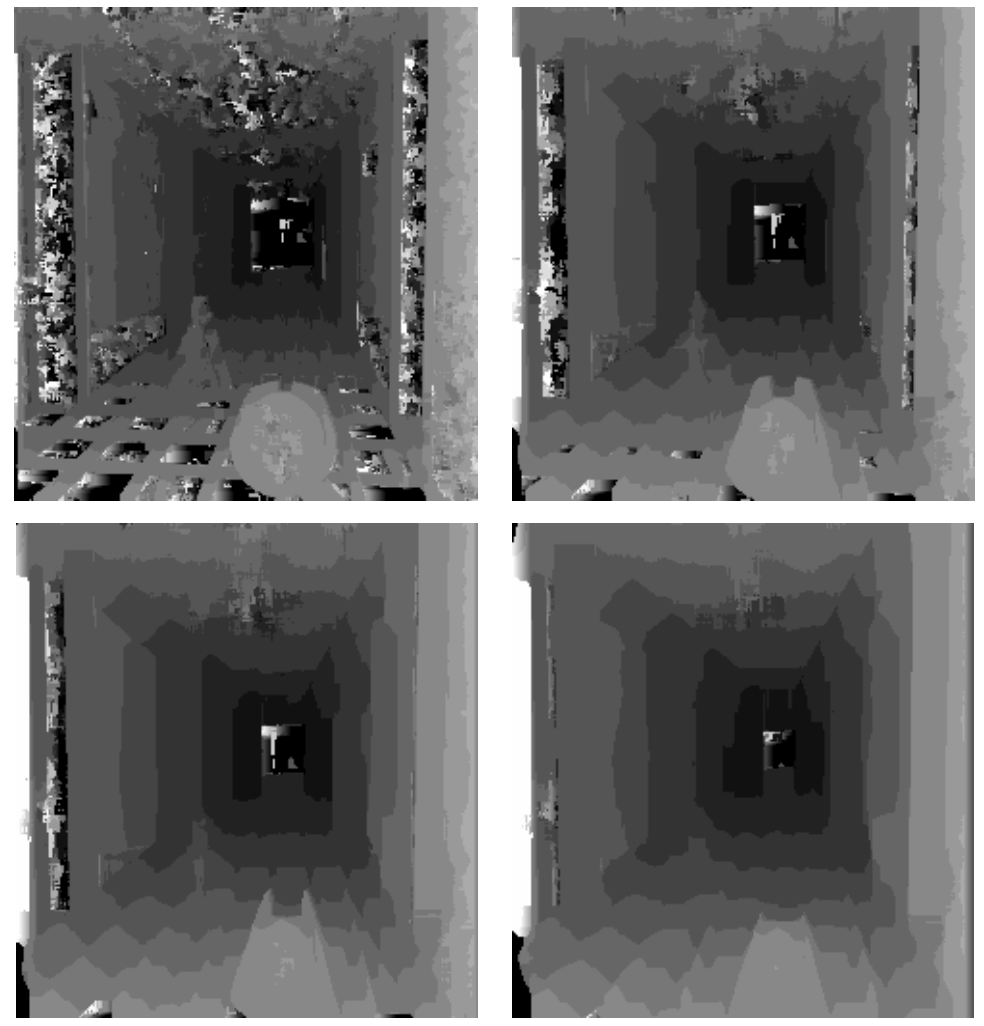

Figura B2: Execução do método Soma do Quadrado das Diferenças na imagem original
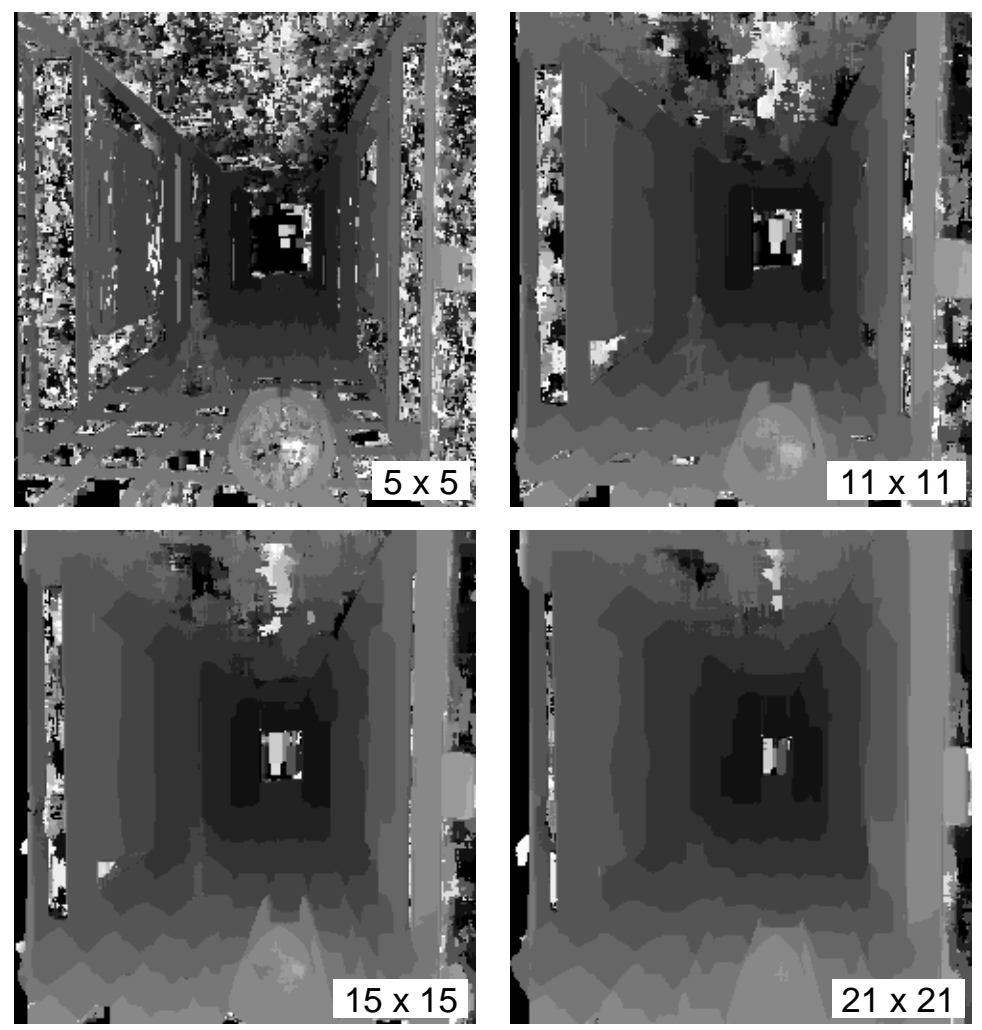

Figura B3: Execução do método Correlação Cruzada Normalizada na imagem original 

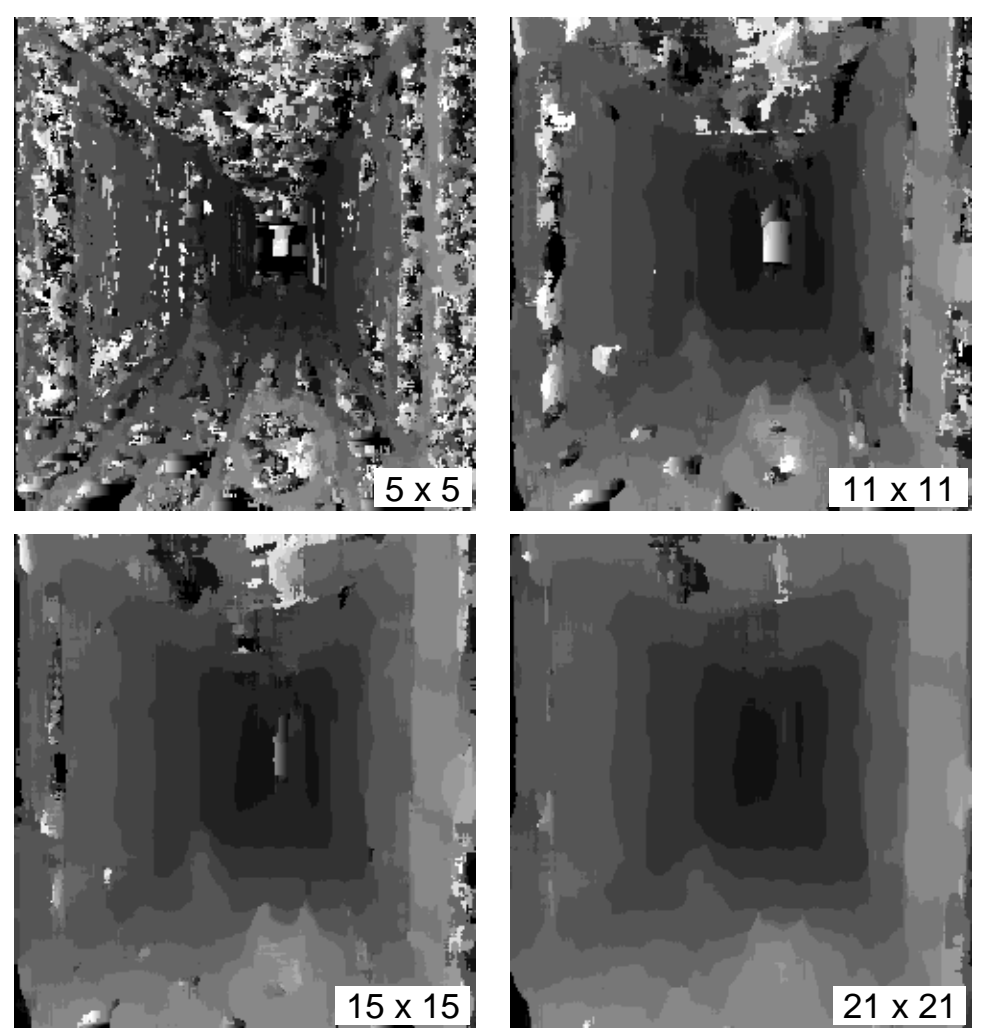

Figura B4: Execução do método Transformada Rank na imagem original
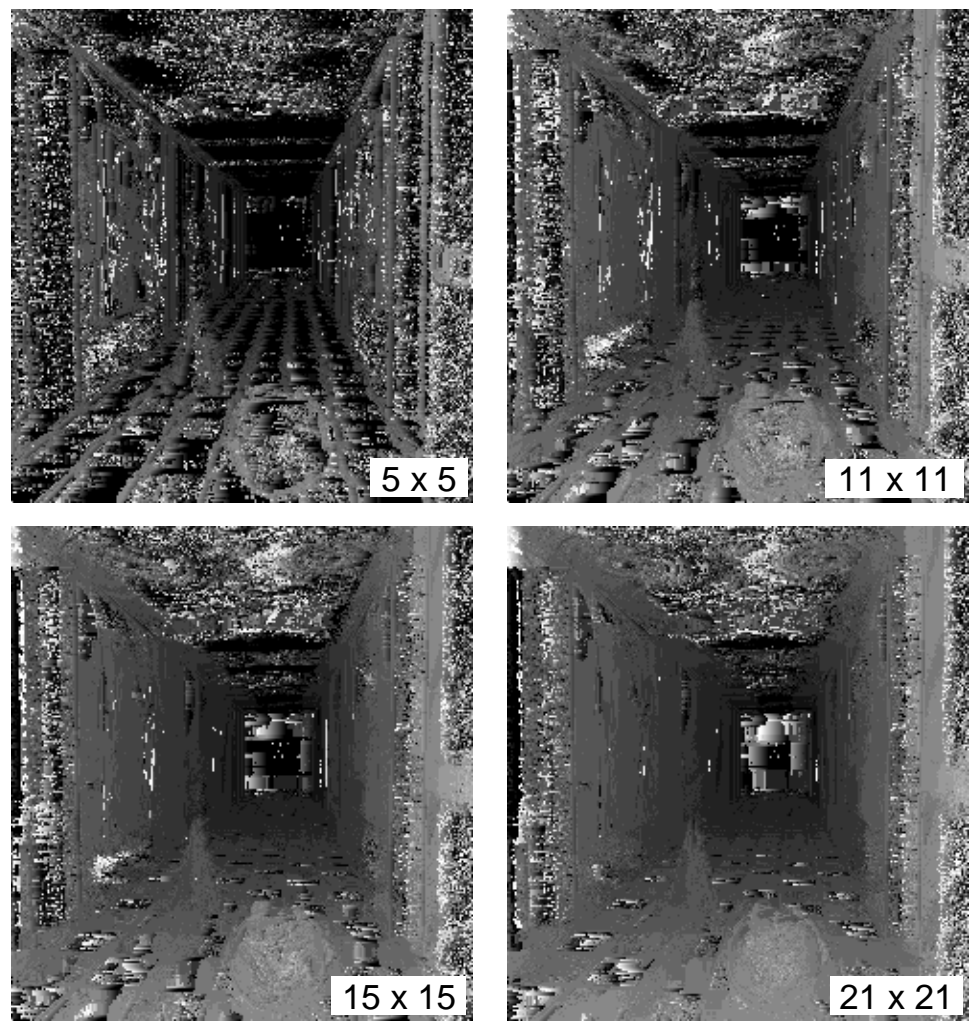

Figura B5: Execução do método Transformada Censo na imagem original 

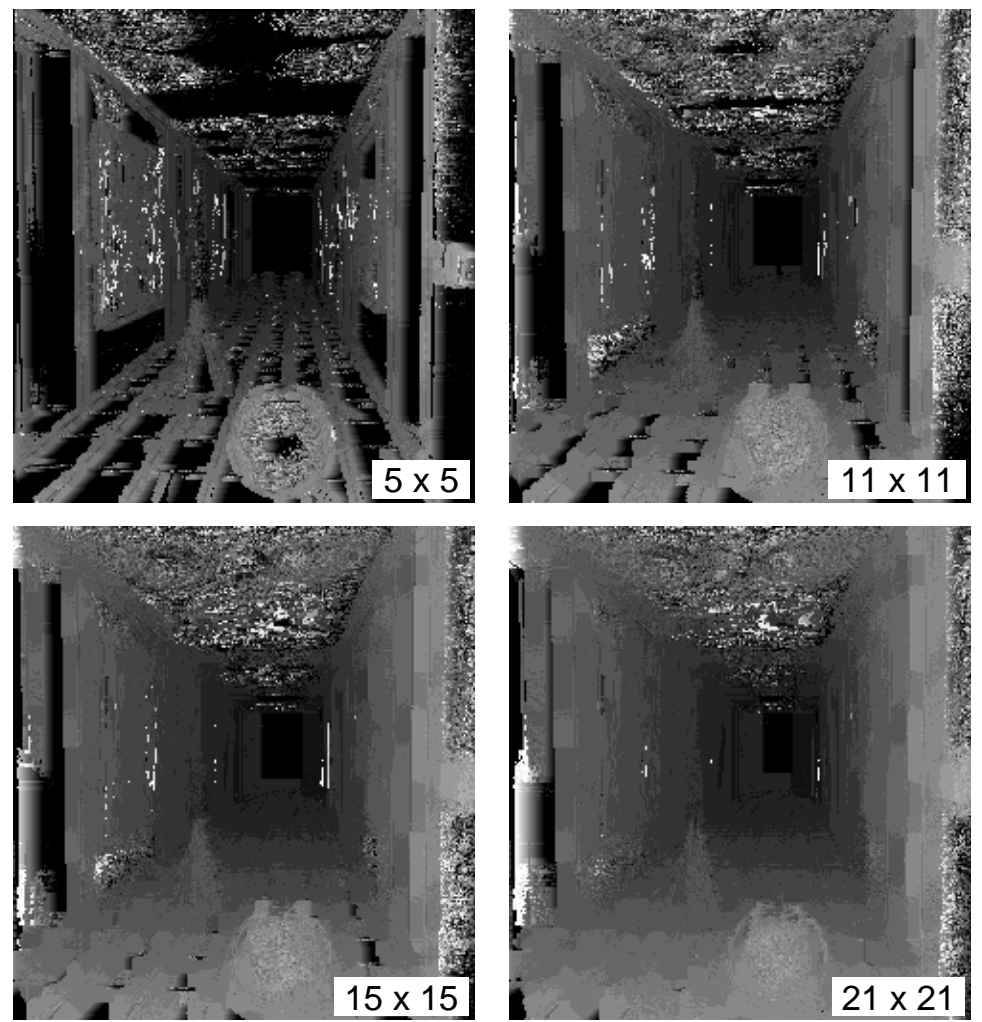

Figura B6: Execução do método Transformada Modificada 1 na imagem original
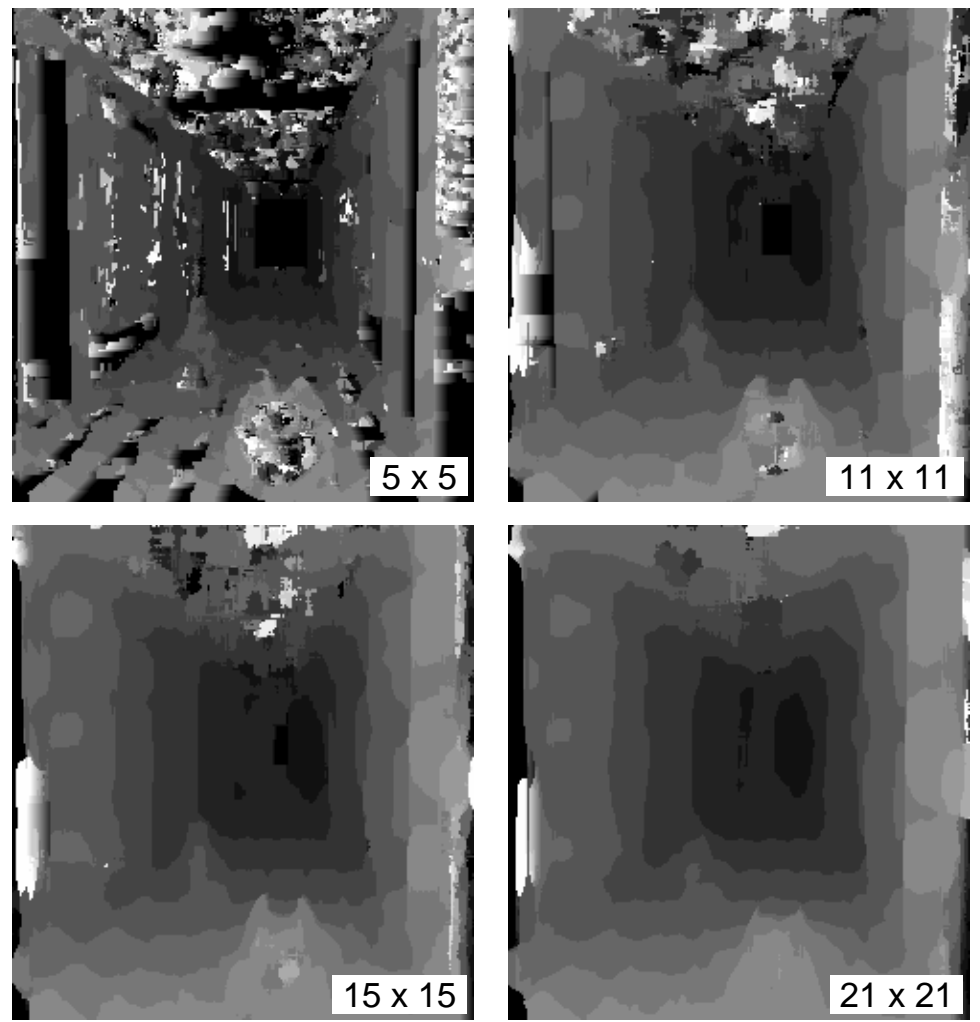

Figura B7: Execução do método Transformada Modificada 2 na imagem original 

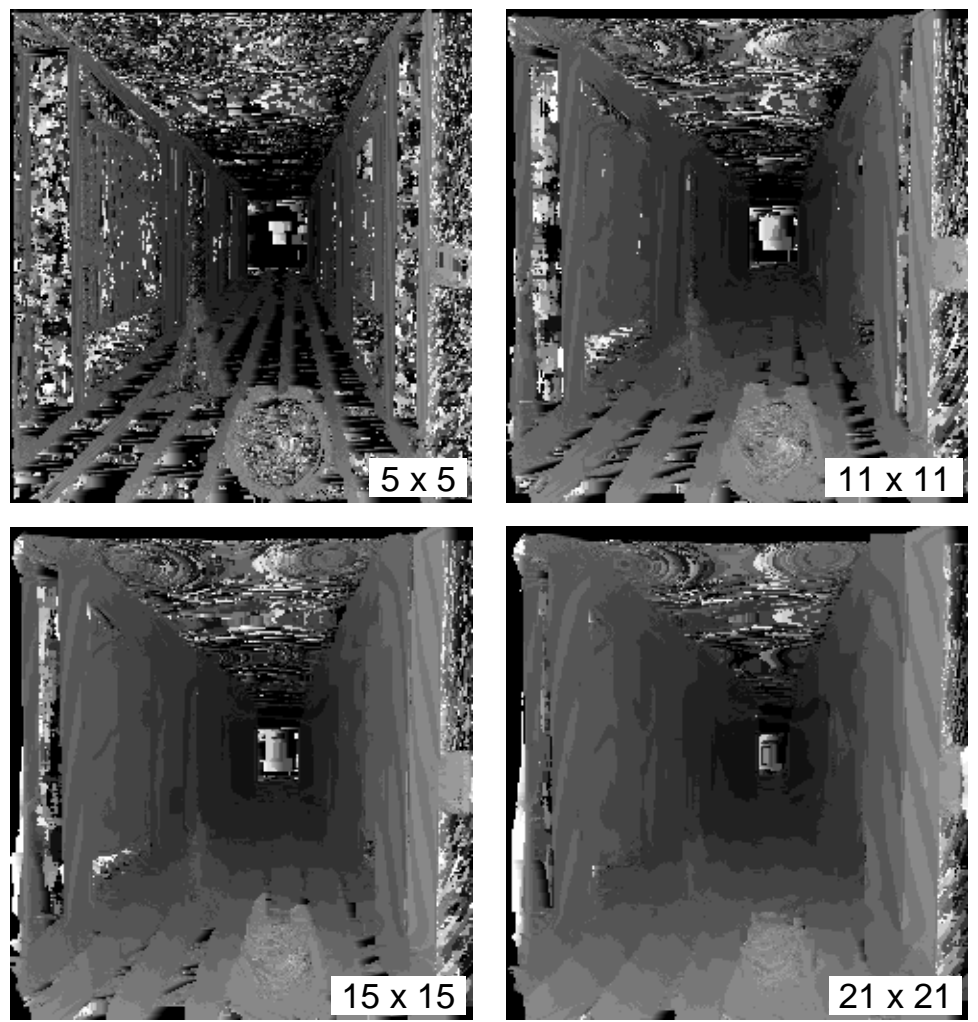

Figura B8: Execução do método Transformada Modificada 3 na imagem original
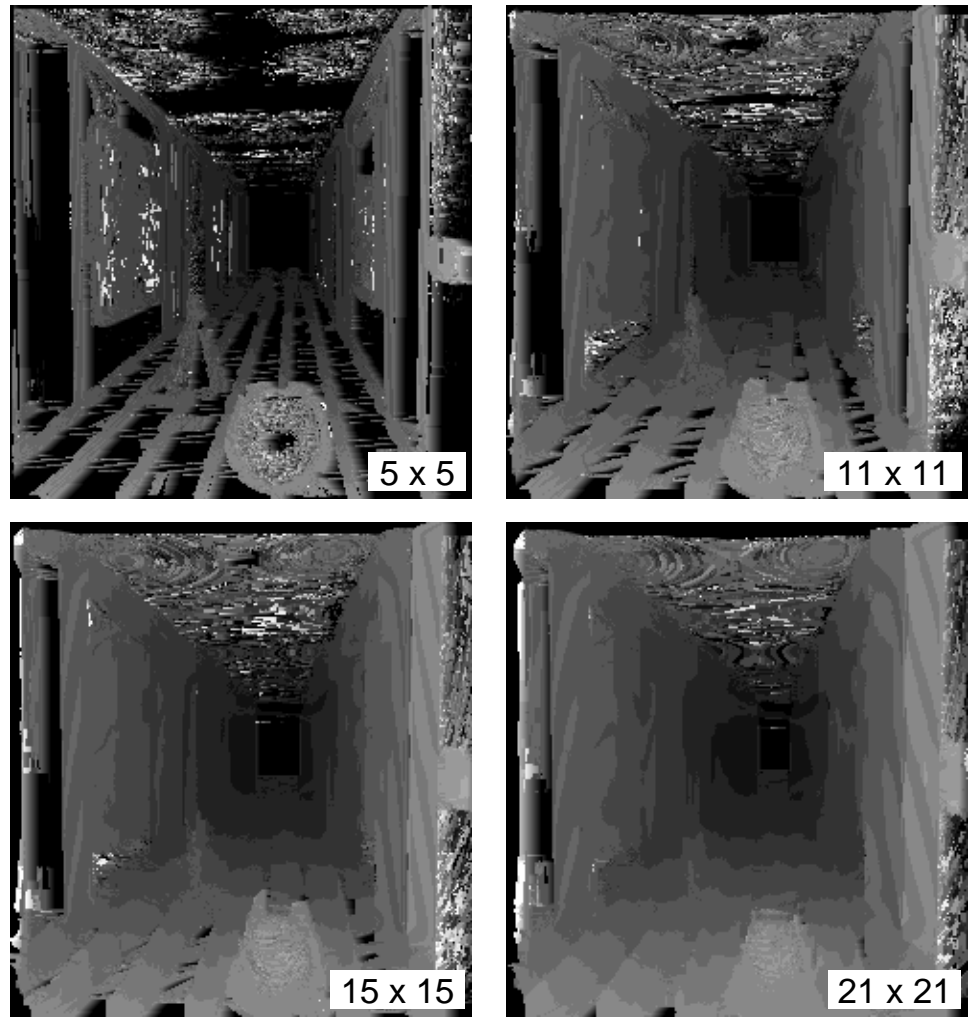

Figura B9: Execução do método Transformada Modificada 4 na imagem original 

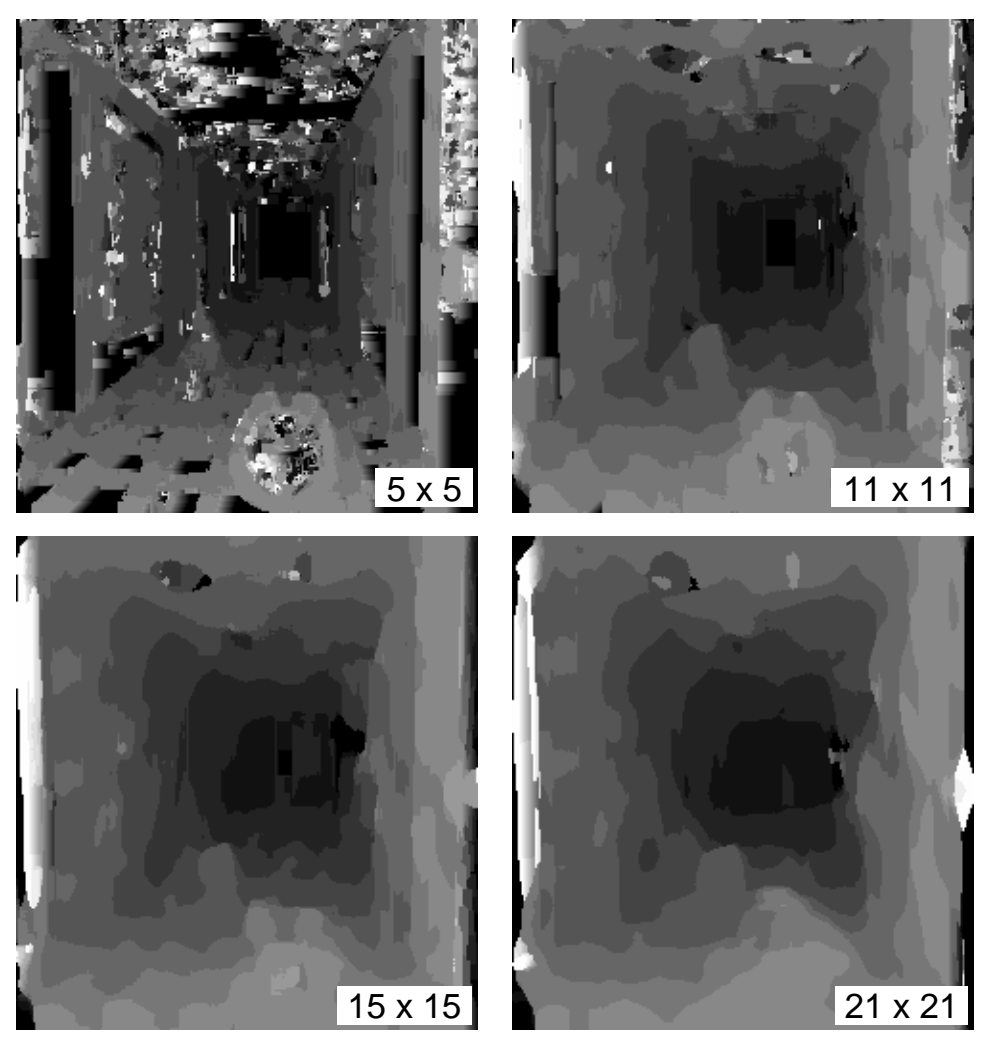

Figura B10: Execução do método Transformada Modificada 5 na imagem original 
Resultados da execução dos algoritmos com a imagem esquerda com $30 \%$ menos luminosidade

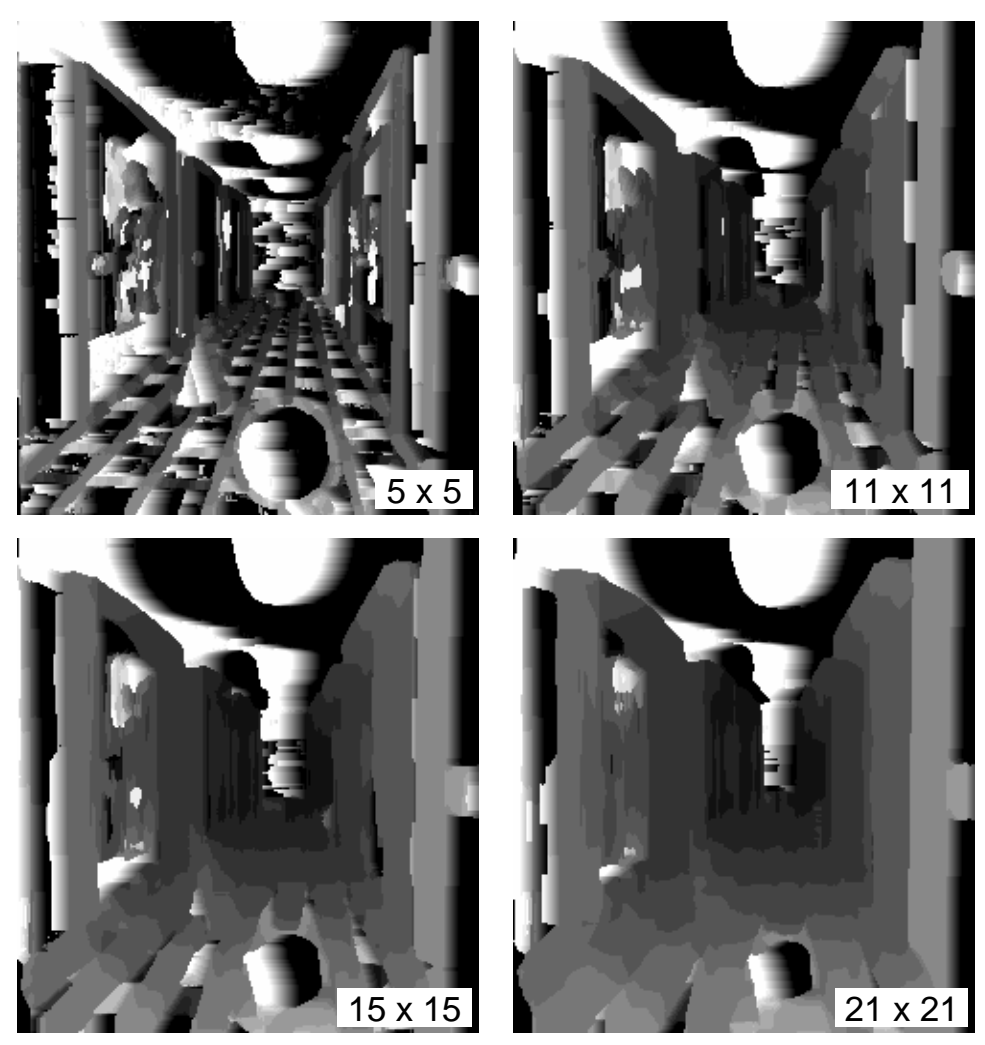

Figura B11: Execução do método Soma das Diferenças Absolutas na imagem com luminosidade $\mathbf{3 0} \%$ diferente 

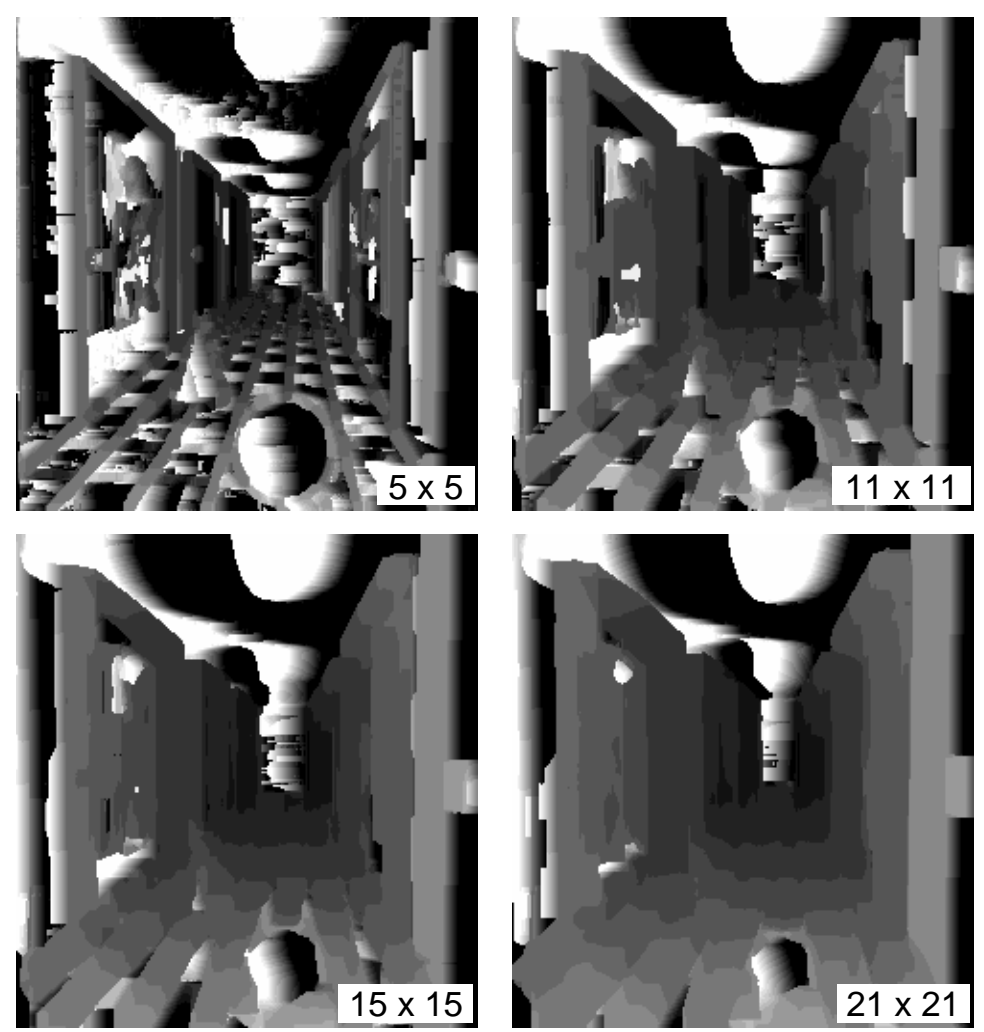

Figura B12: Execução do método Soma do Quadrado das Diferenças na imagem com luminosidade $30 \%$ diferente
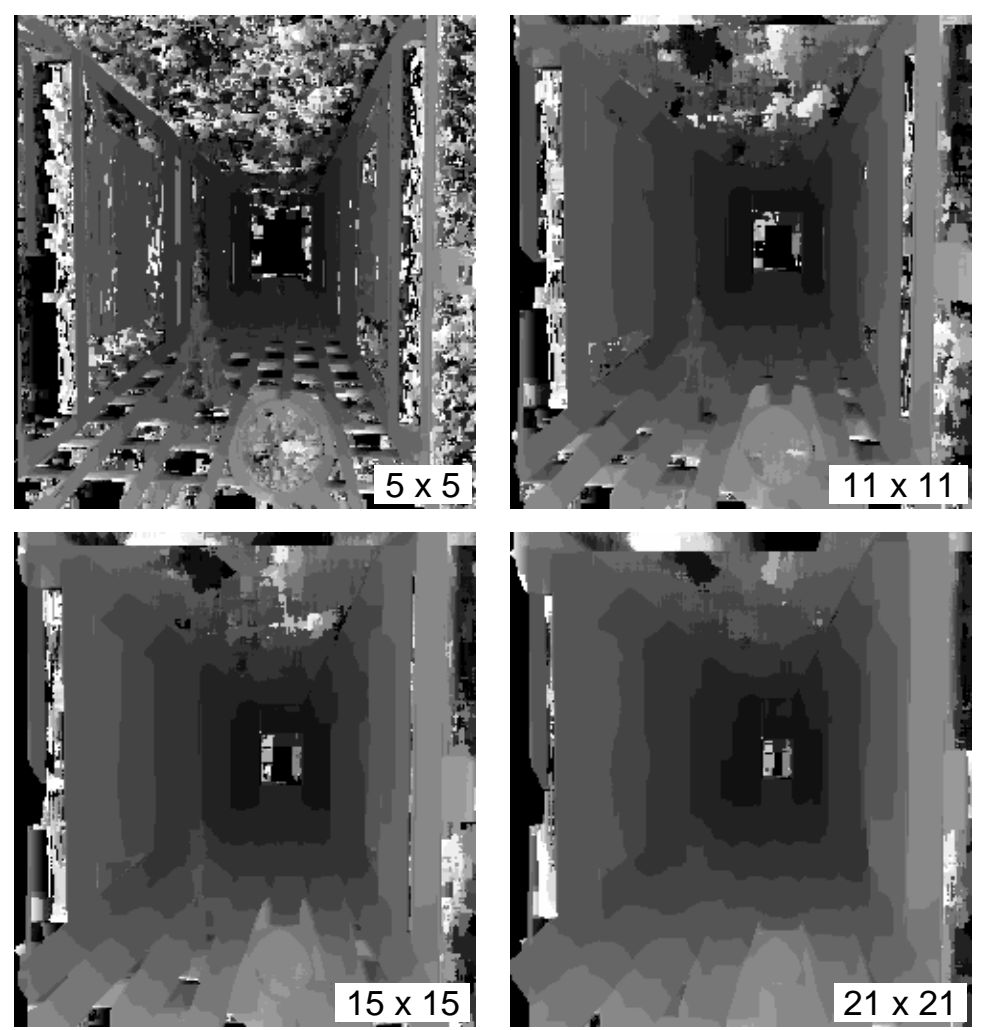

Figura B13: Execução do método Correlação Cruzada Normalizada na imagem com luminosidade $30 \%$ diferente 

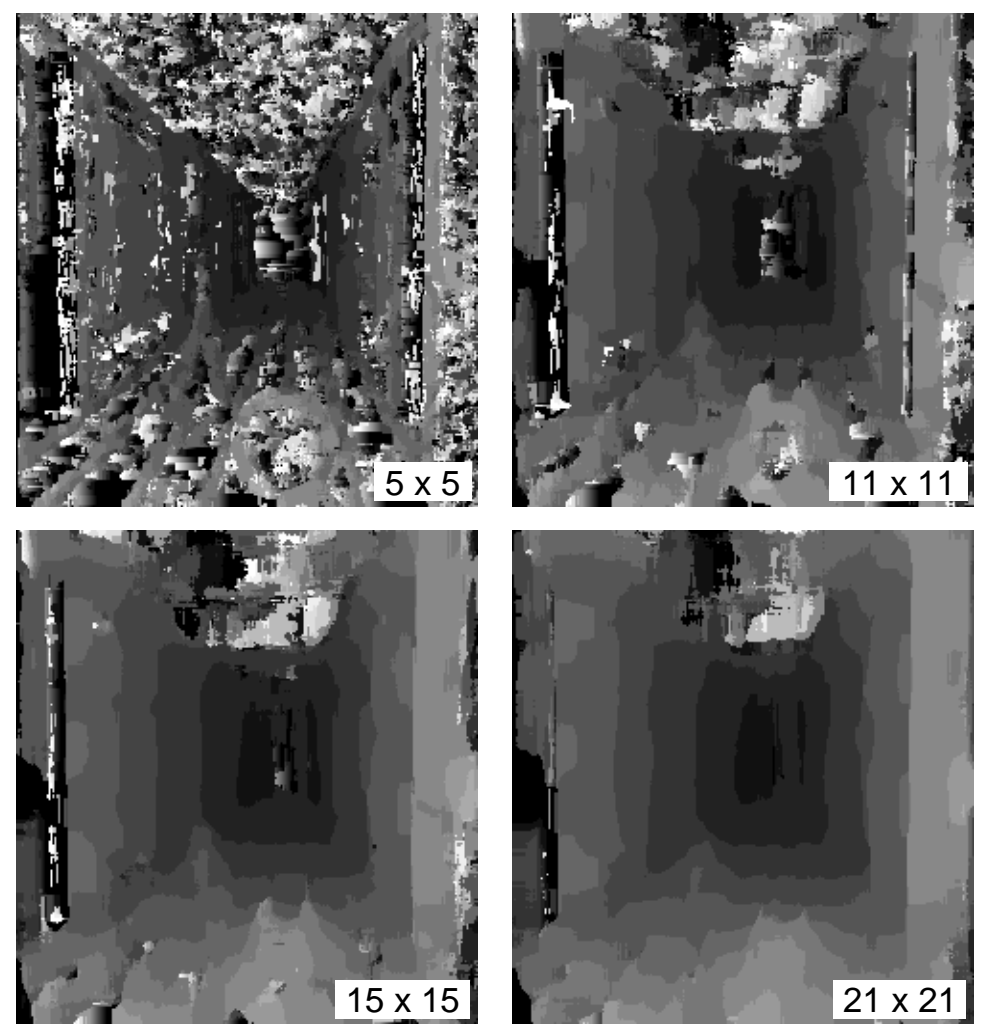

Figura B14: Execução do método Transformada Rank na imagem com luminosidade 30 \% diferente
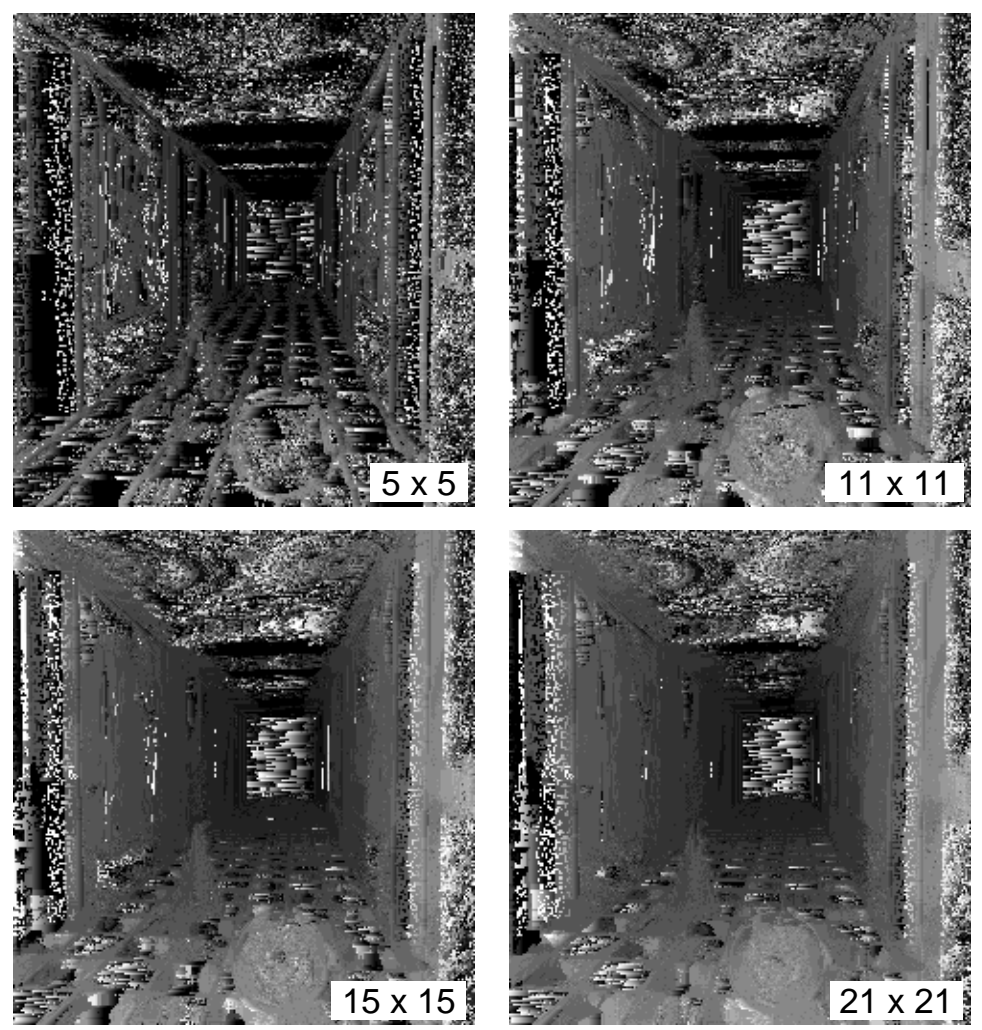

Figura B15: Execução do método Transformada Censo na imagem com luminosidade 30 \% diferente 

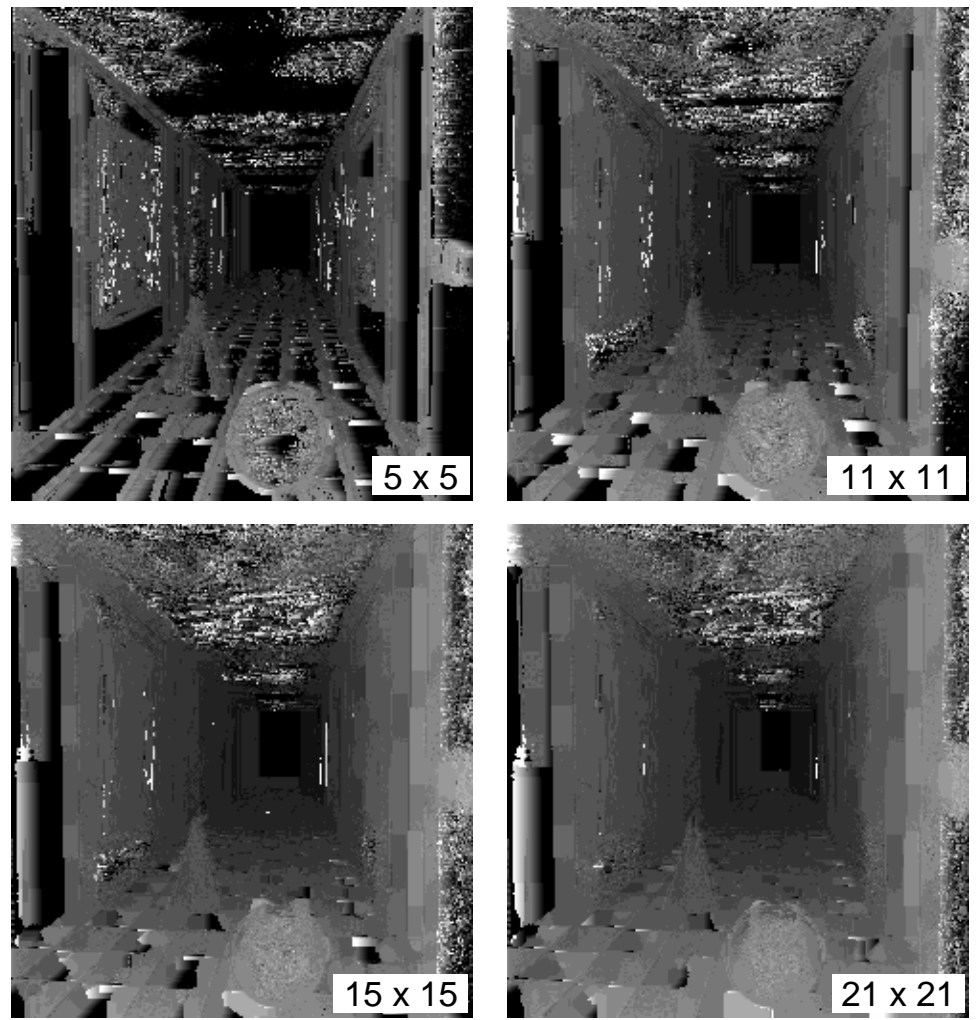

Figura B16: Execução do método Transformada Modificada 1 na imagem com luminosidade $30 \%$ diferente
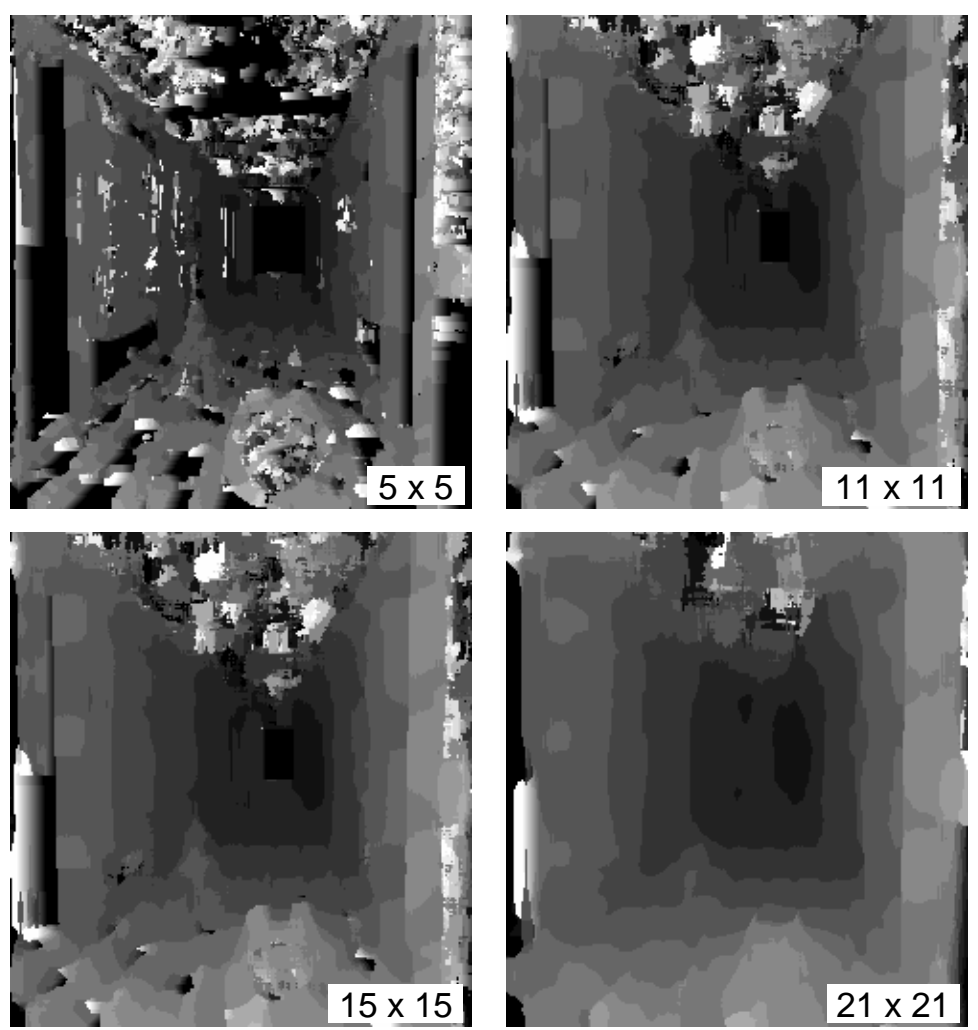

Figura B17: Execução do método Transformada Modificada 2 na imagem com luminosidade $30 \%$ diferente 

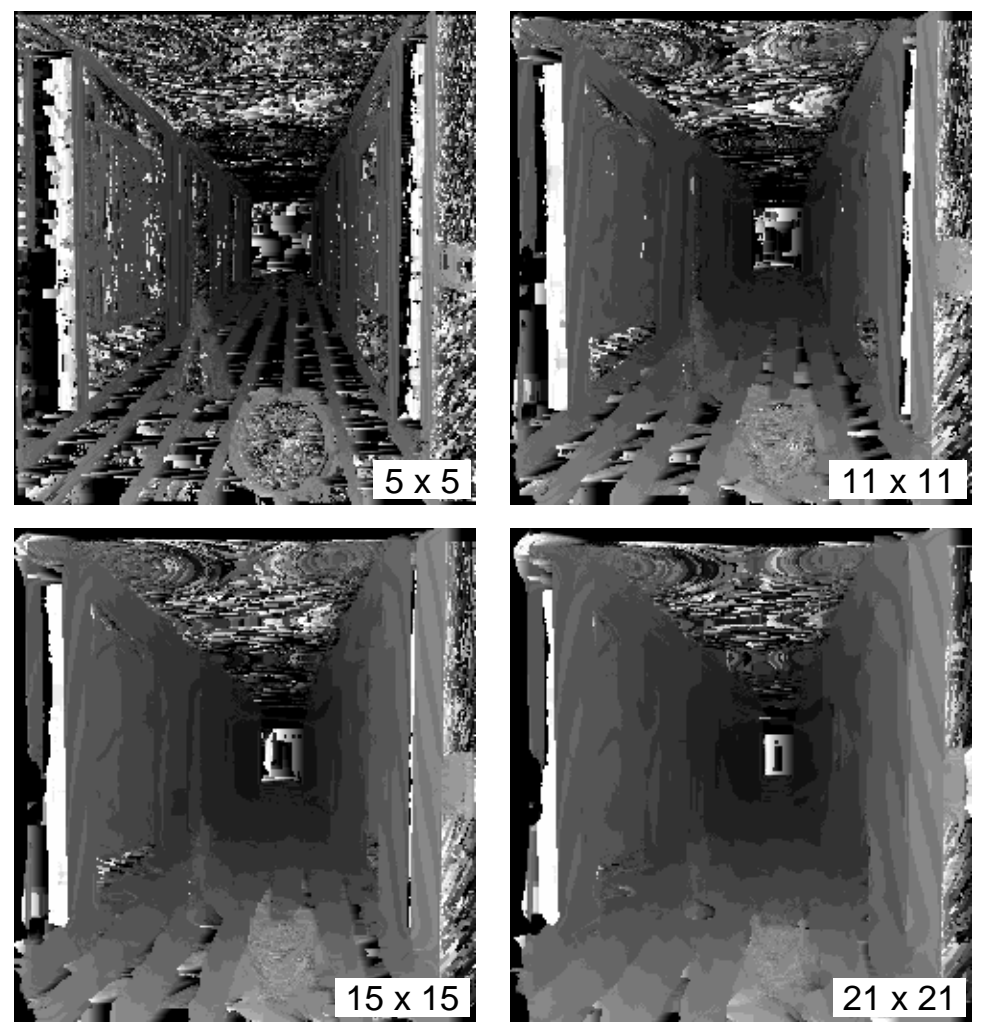

Figura B18: Execução do método Transformada Modificada 3 na imagem com luminosidade $30 \%$ diferente
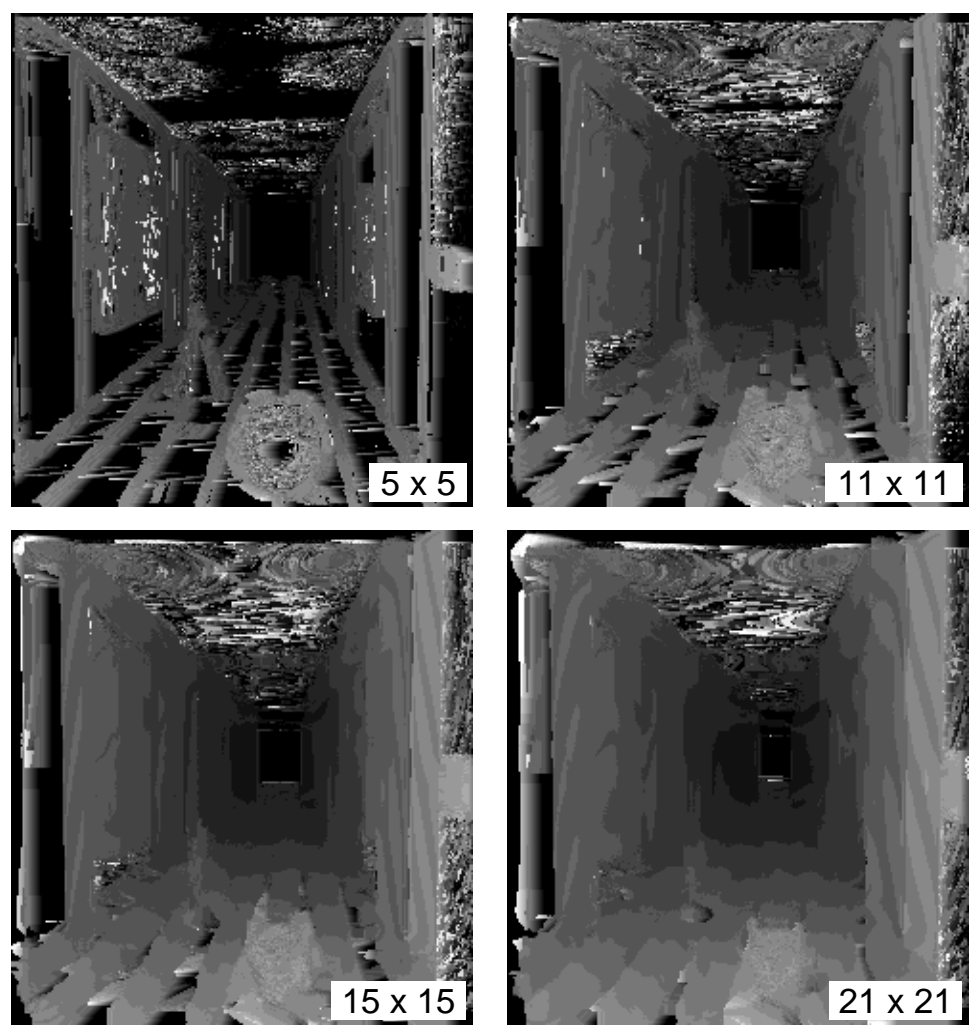

Figura B19: Execução do método Transformada Modificada 4 na imagem com luminosidade $30 \%$ diferente 

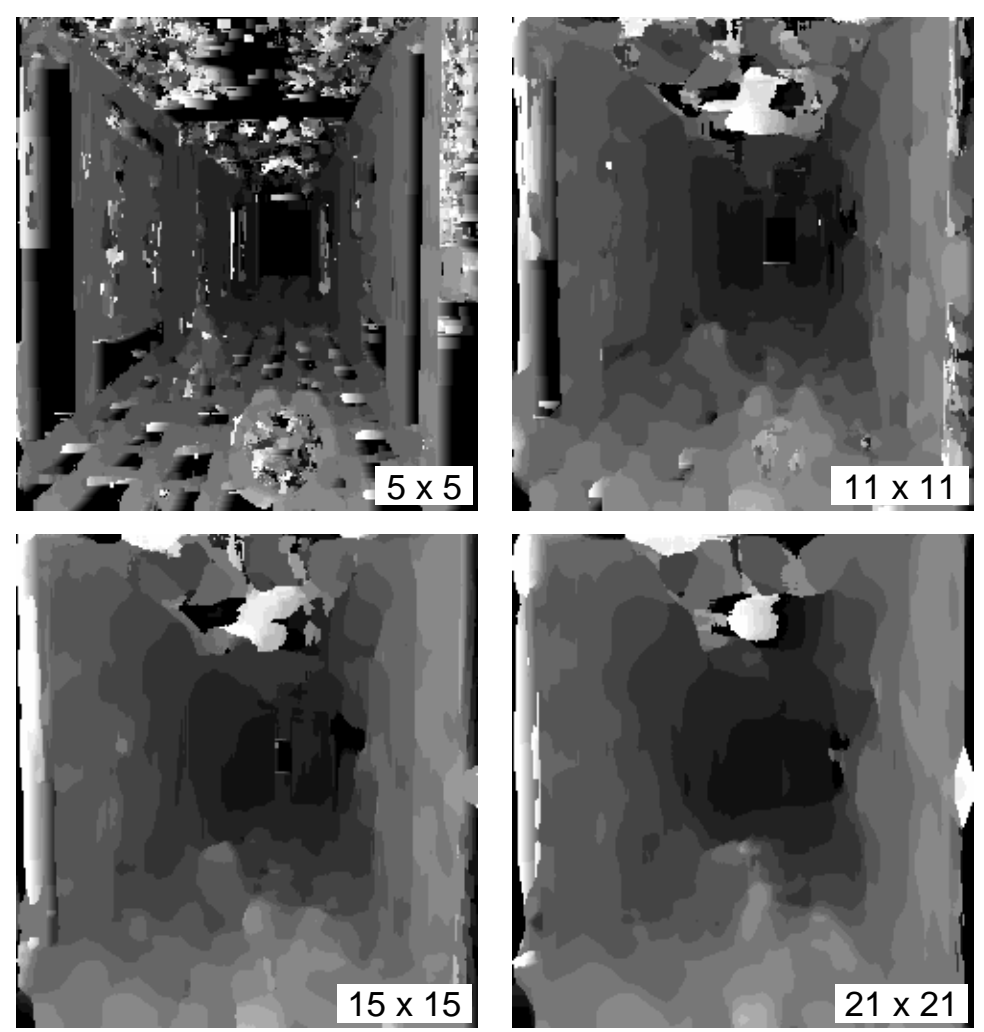

Figura B20: Execução do método Transformada Modificada 5 na imagem com luminosidade $30 \%$ diferente 
Resultados da execução dos algoritmos com a imagem contaminada por ruído de variância 200
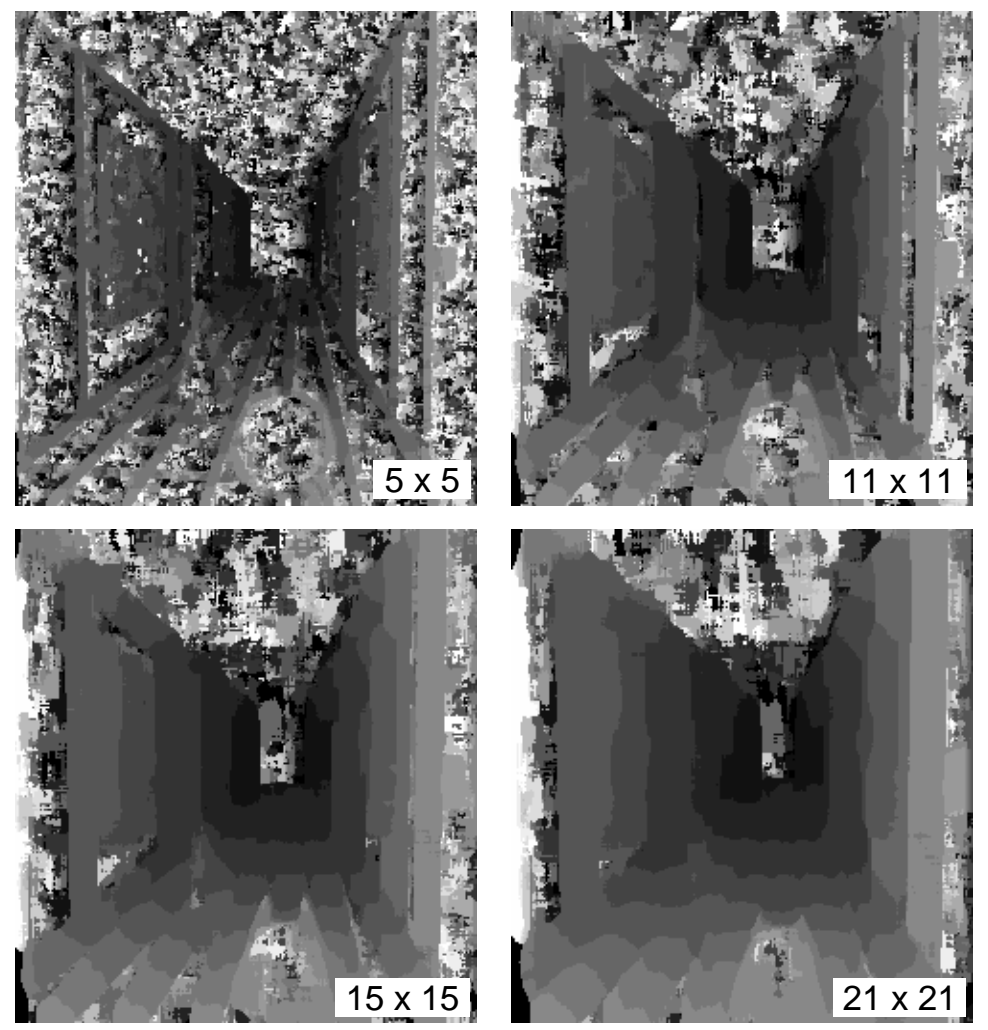

Figura B21: Execução do método Soma das Diferenças Absolutas na imagem com ruído de variância 200 

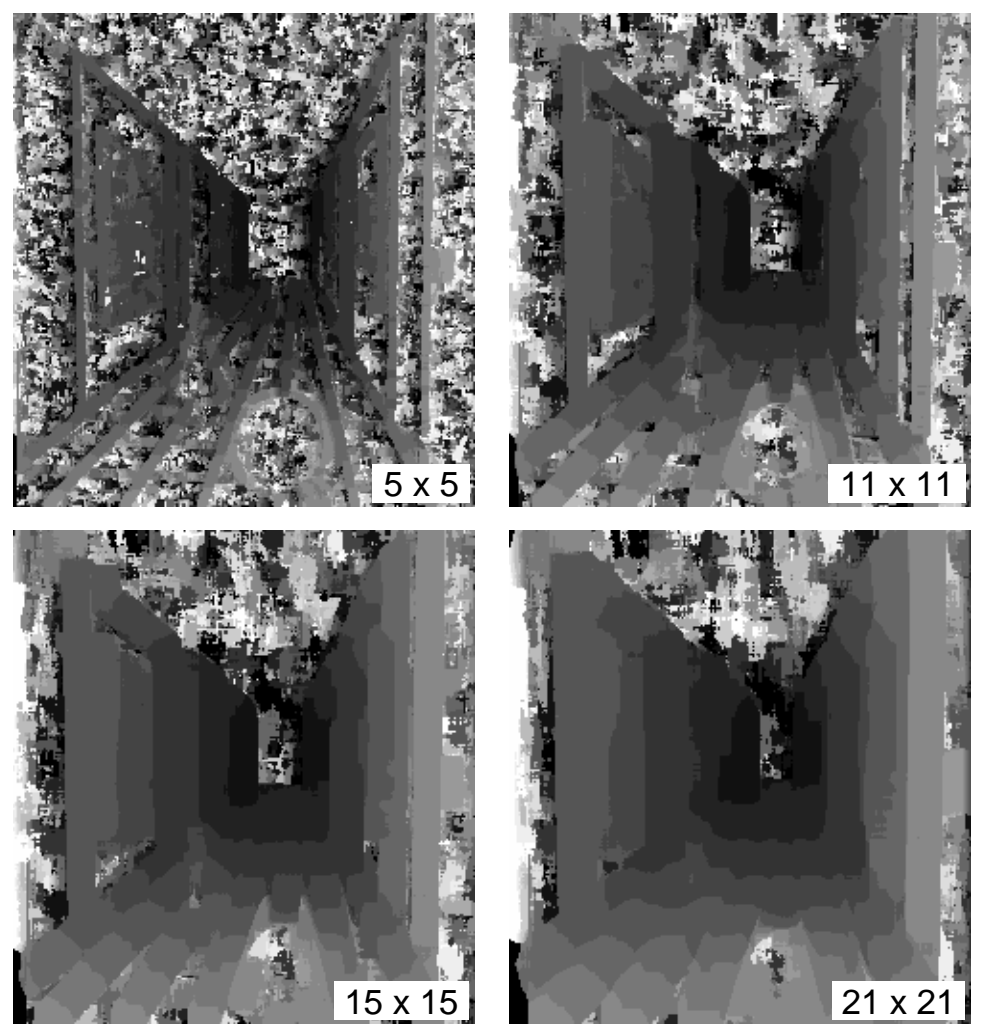

Figura B22: Execução do método Soma do Quadrado das Diferenças na imagem com ruído de variância 200
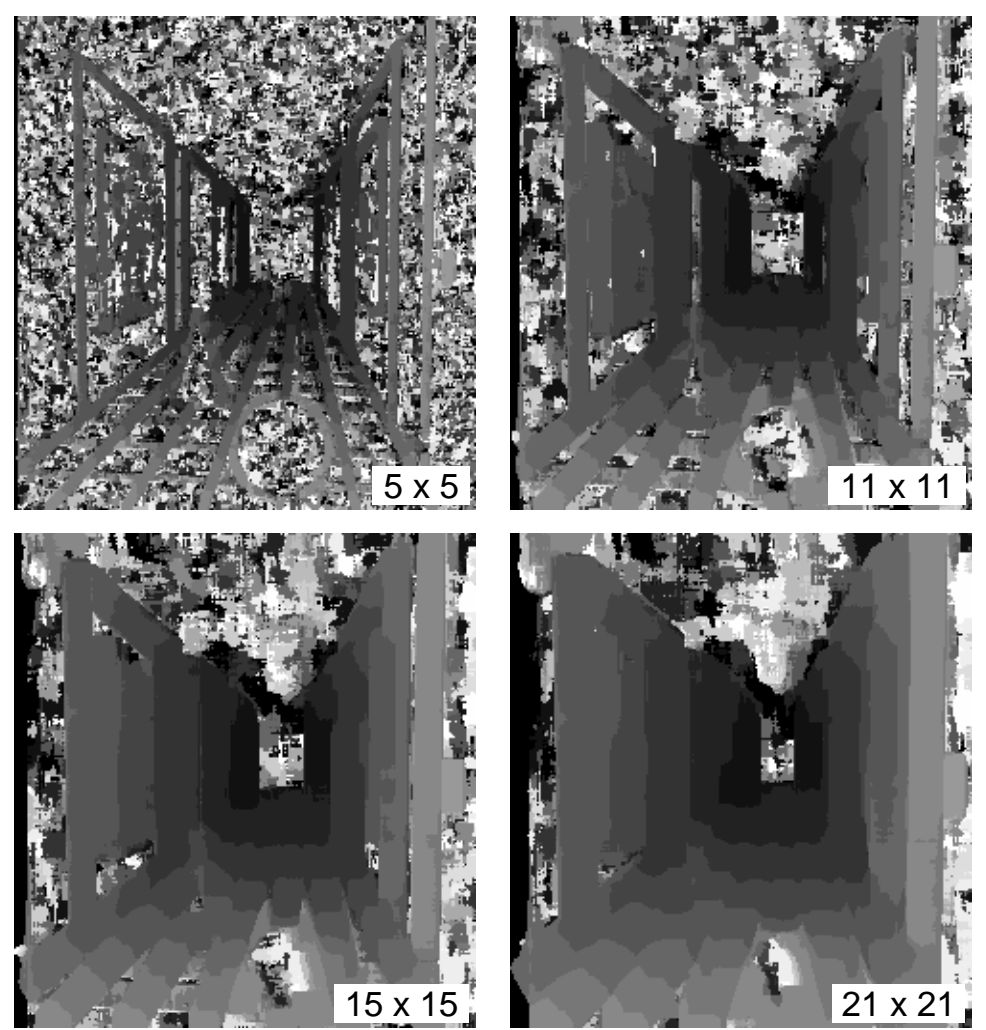

Figura B23: Execução do método Correlação Cruzada Normalizada na imagem com ruído de variância 200 

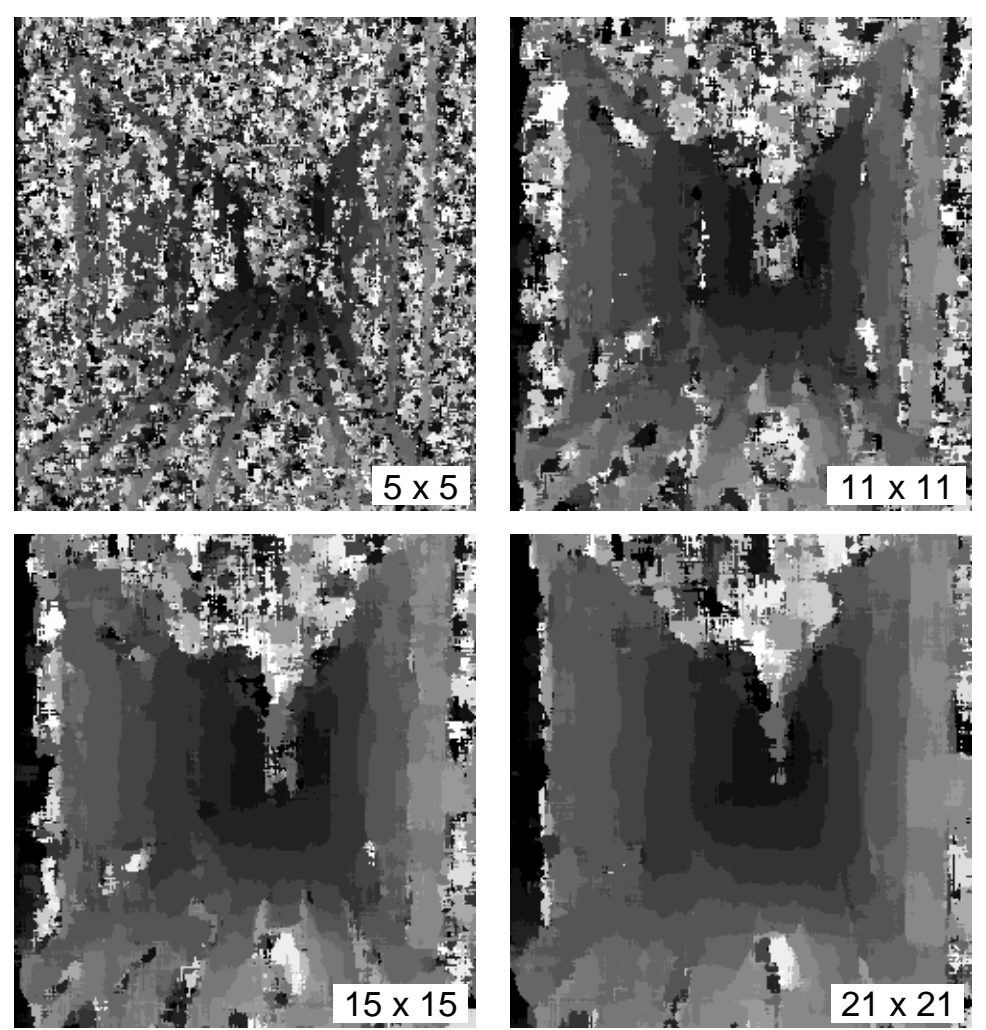

Figura B24: Execução do método Transformada Rank na imagem com ruído de variância 200
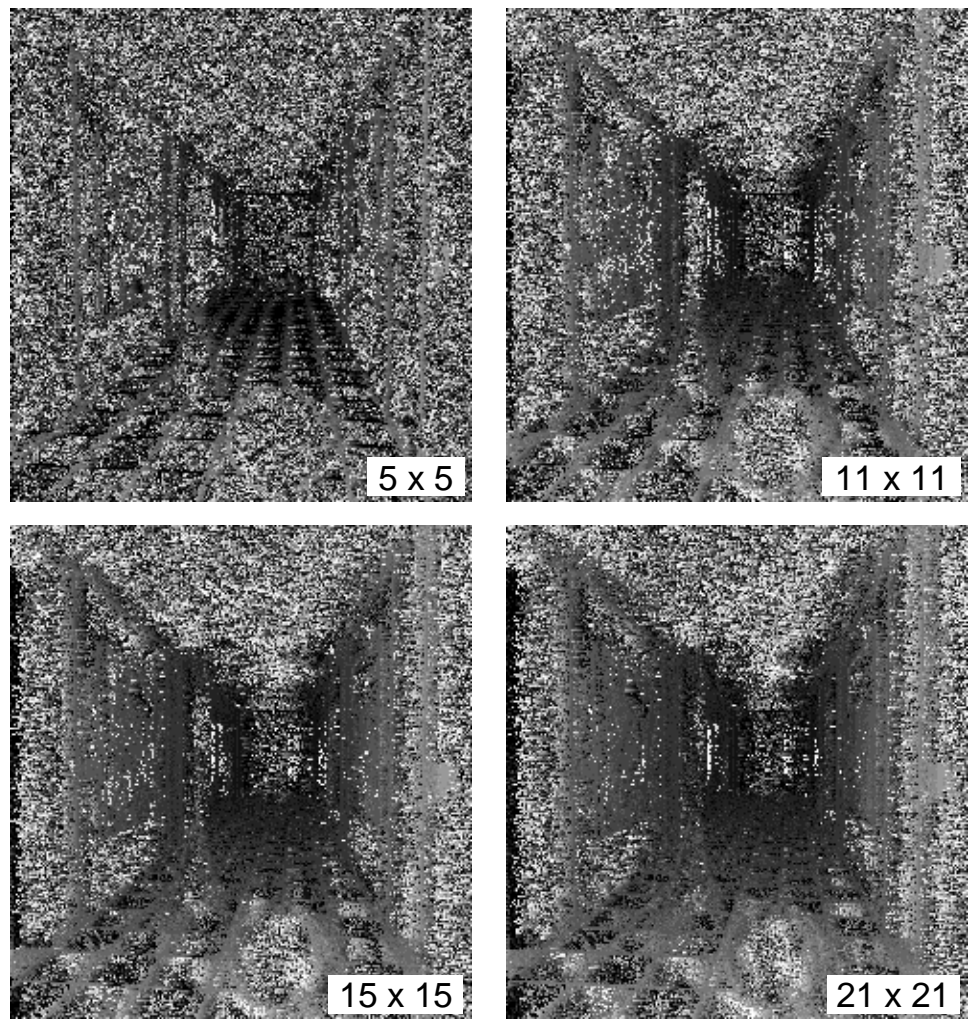

Figura B25: Execução do método Transformada Censo na imagem com ruído de variância 200 

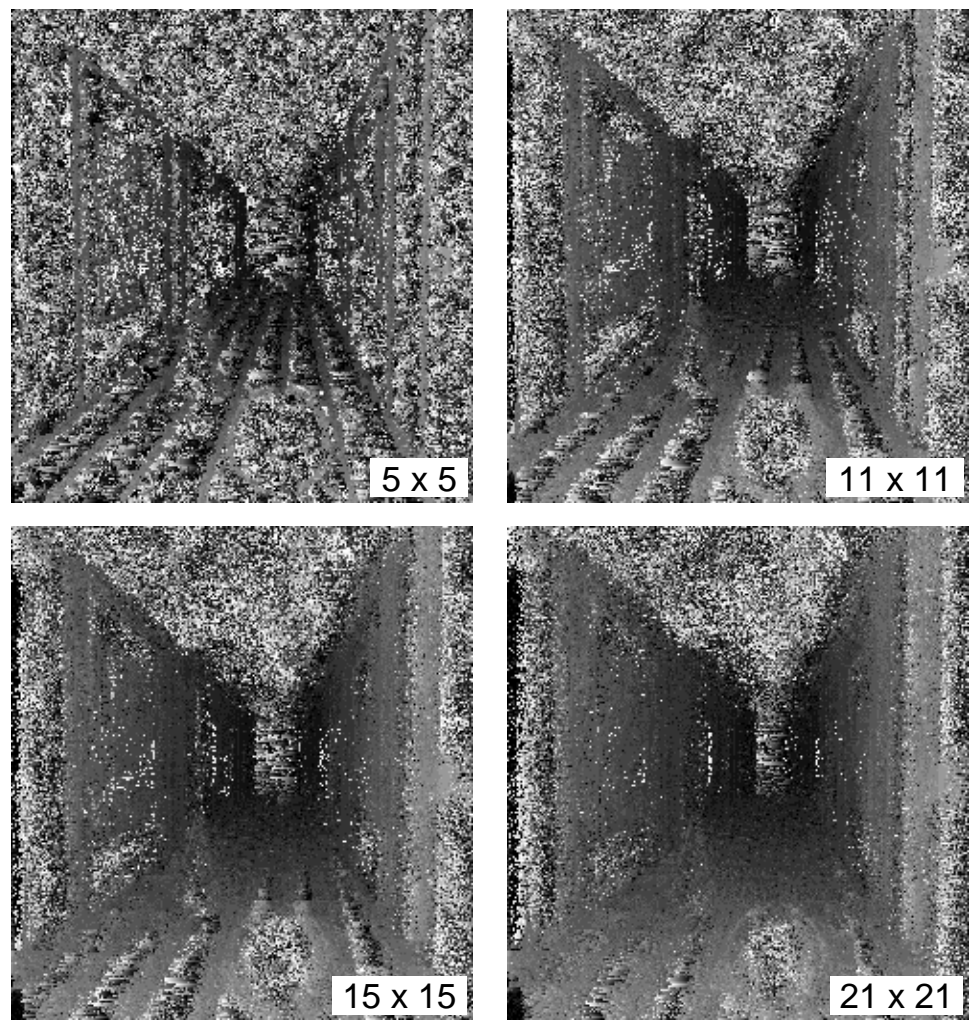

Figura B26: Execução do método Transformada Modificada 1 na imagem com ruído de variância 200
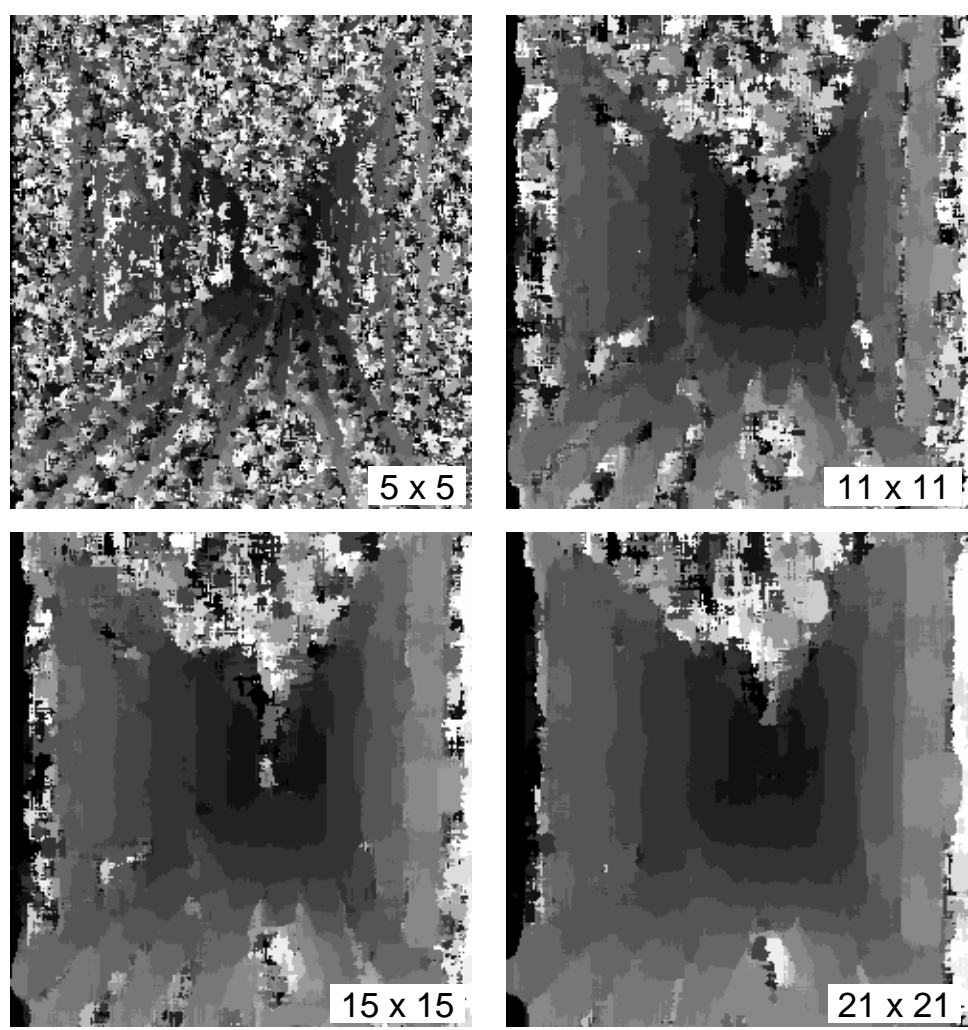

Figura B27: Execução do método Transformada Modificada 2 na imagem com ruído de variância 200 

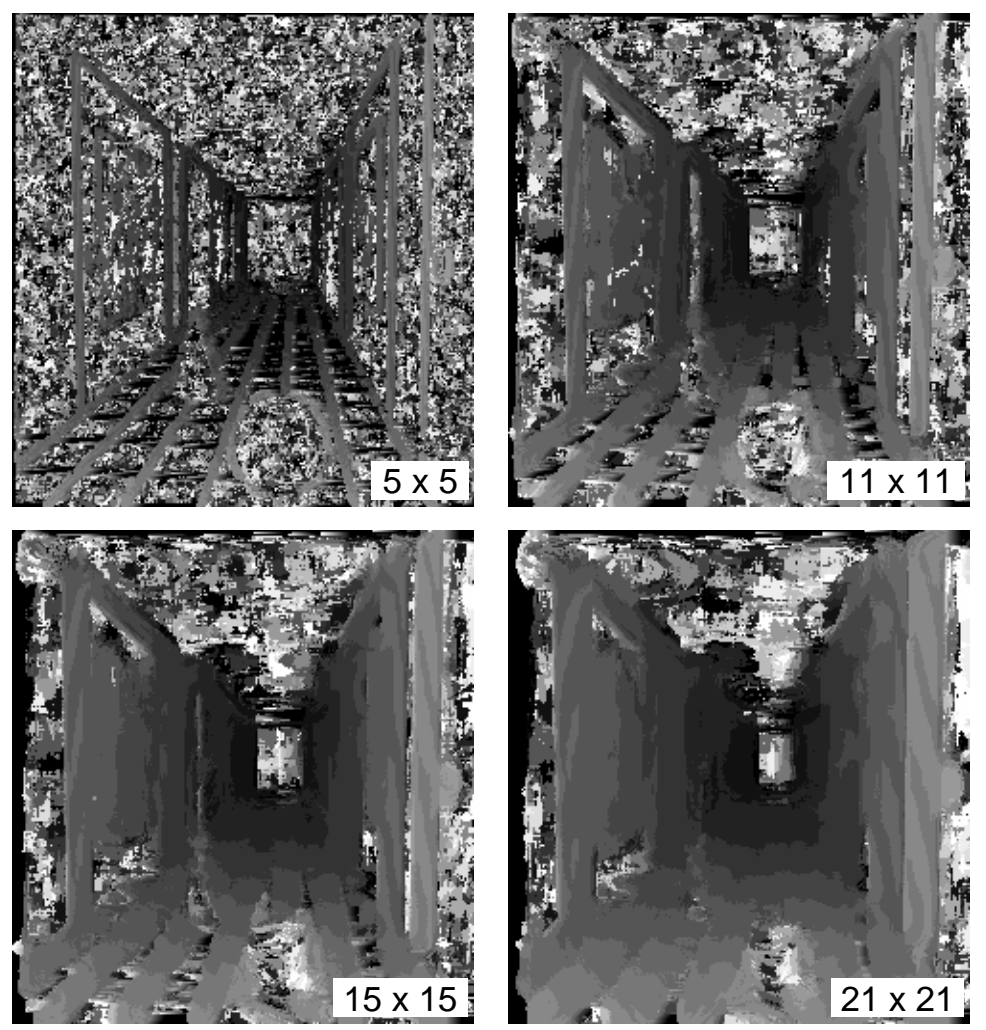

Figura B28: Execução do método Transformada Modificada 3 na imagem com ruído de variância 200
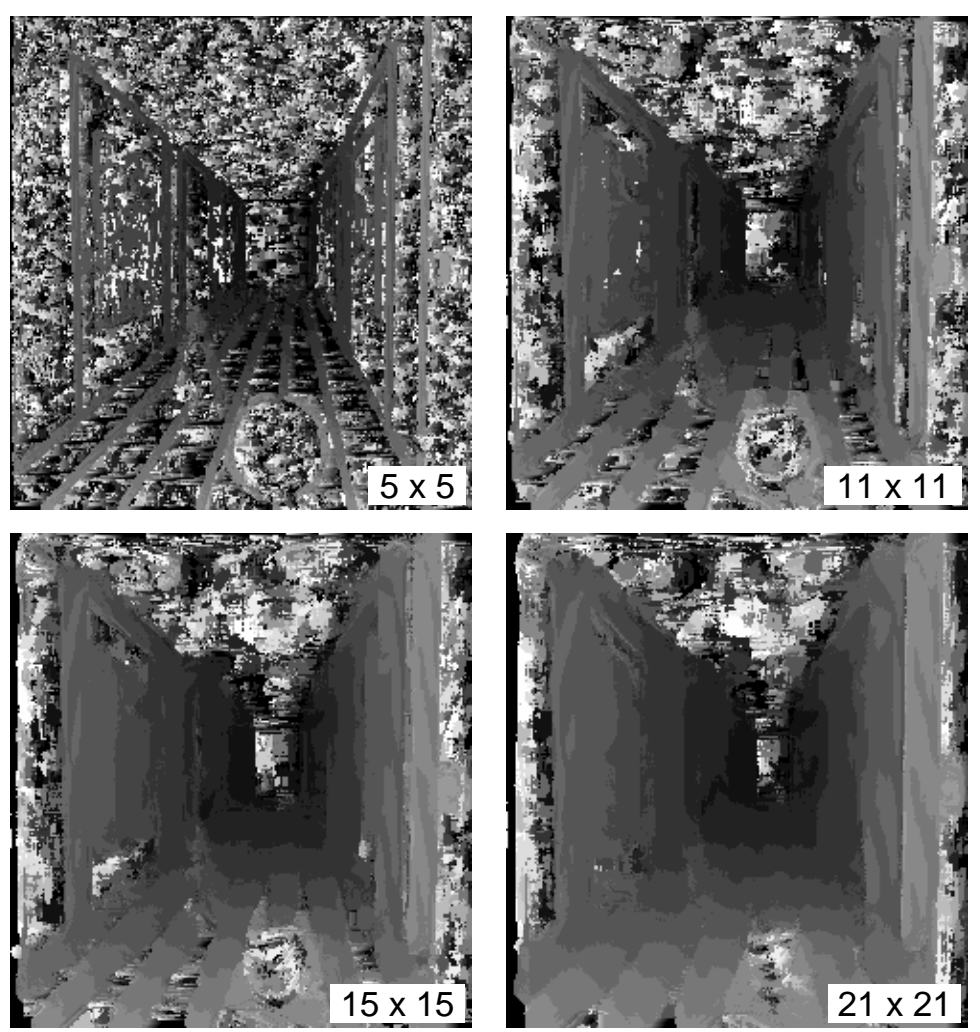

Figura B29: Execução do método Transformada Modificada 4 na imagem com ruído de variância 200 

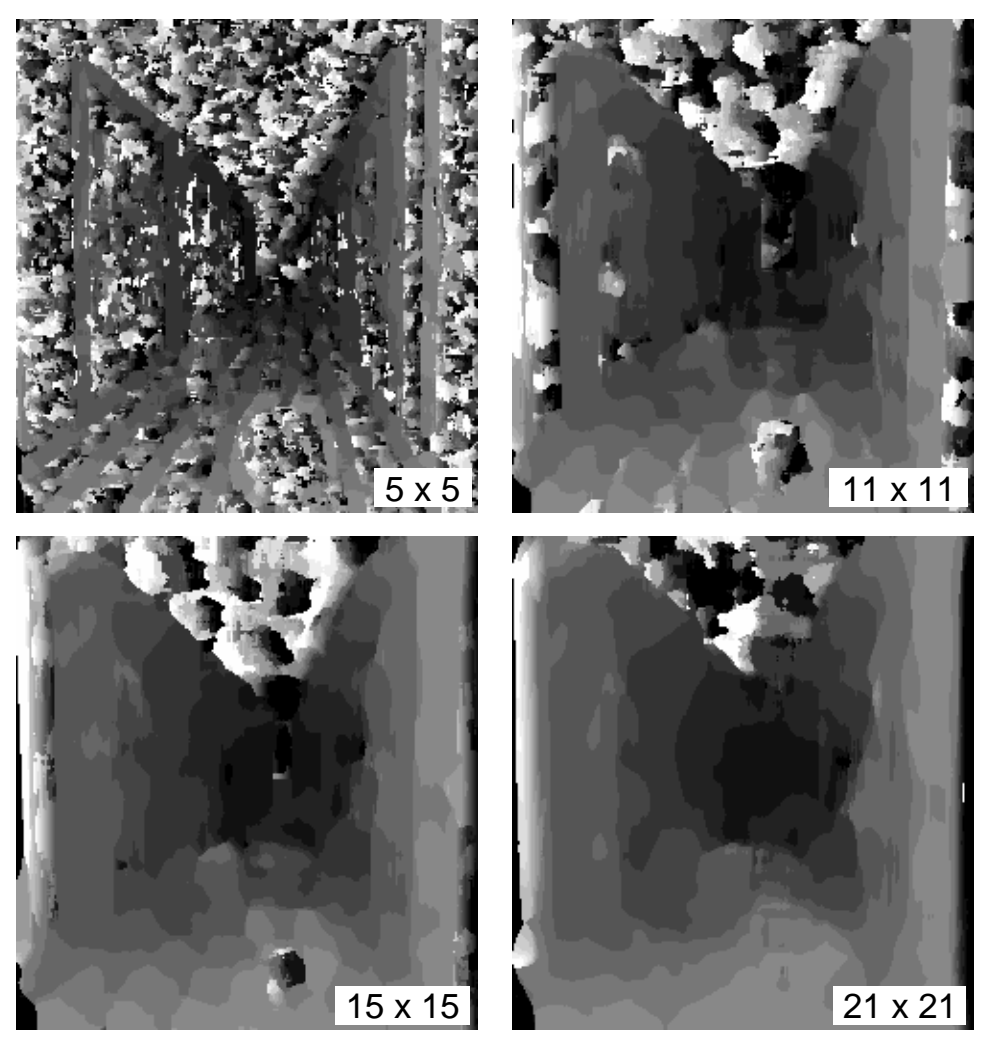

Figura B30: Execução do método Transformada Modificada 5 na imagem com ruído de variância 200 
Imagem Teddy

Resultados da execução dos algoritmos com a imagem original
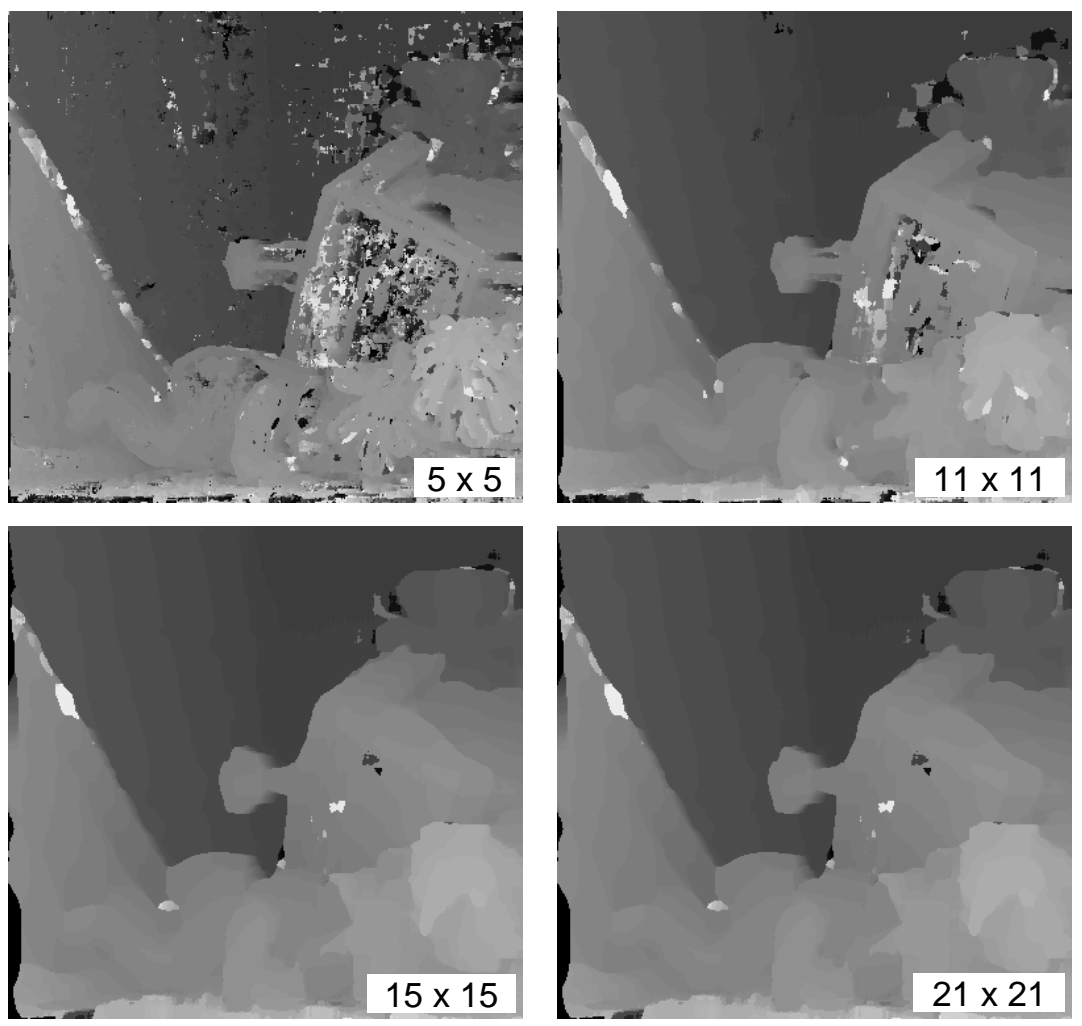

Figura B31: Execução do método Soma das Diferenças Absolutas na imagem original 

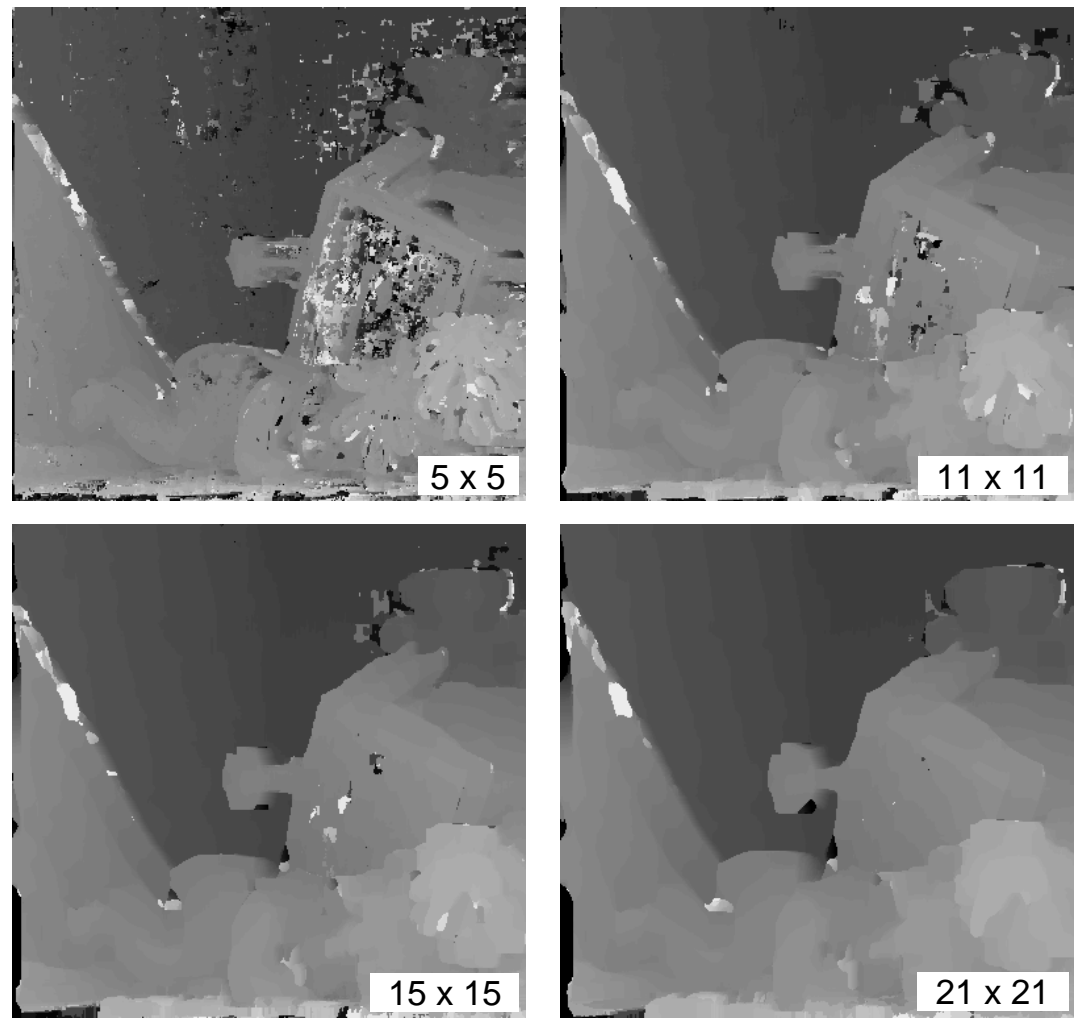

Figura B32: Execução do método Soma do Quadrado das Diferenças na imagem original
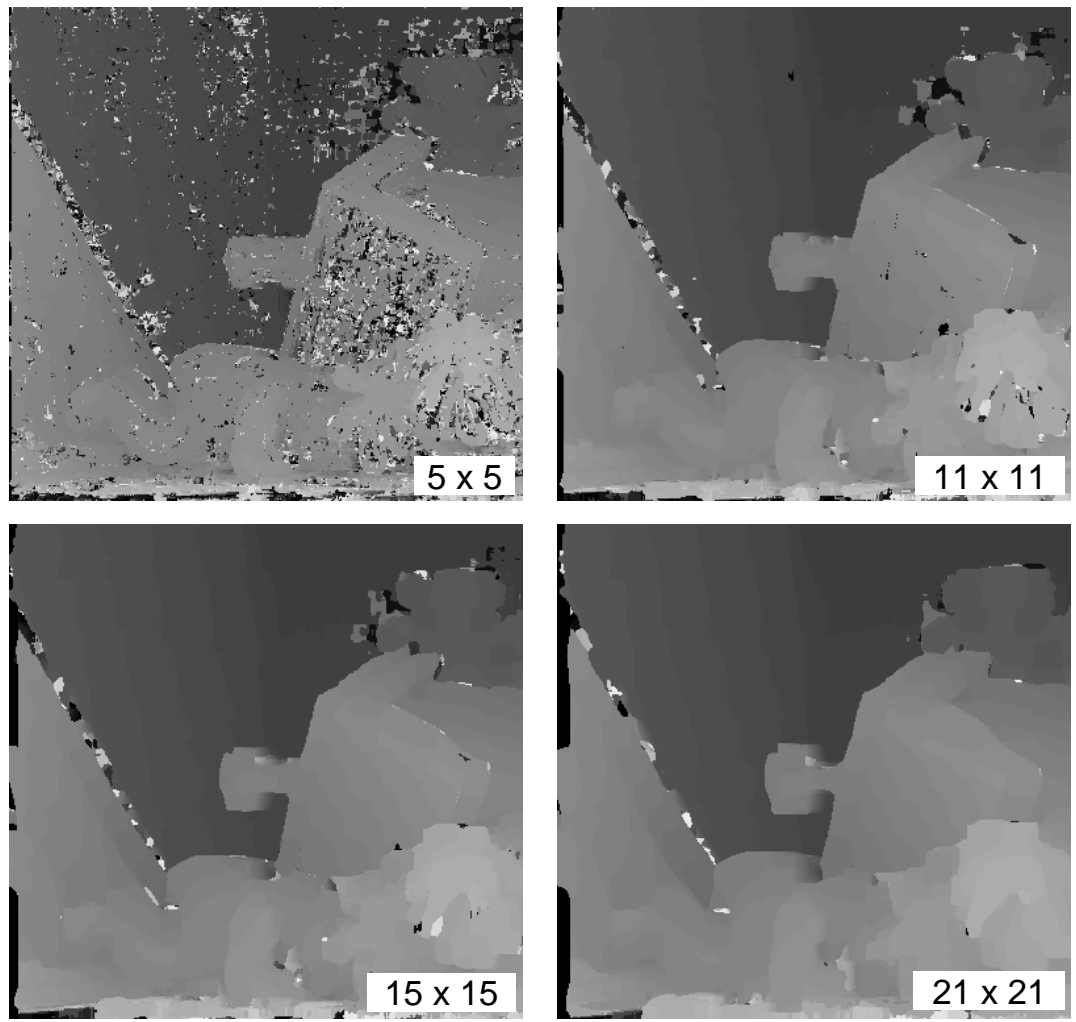

Figura B33: Execução do método Correlação Cruzada Normalizada na imagem original 

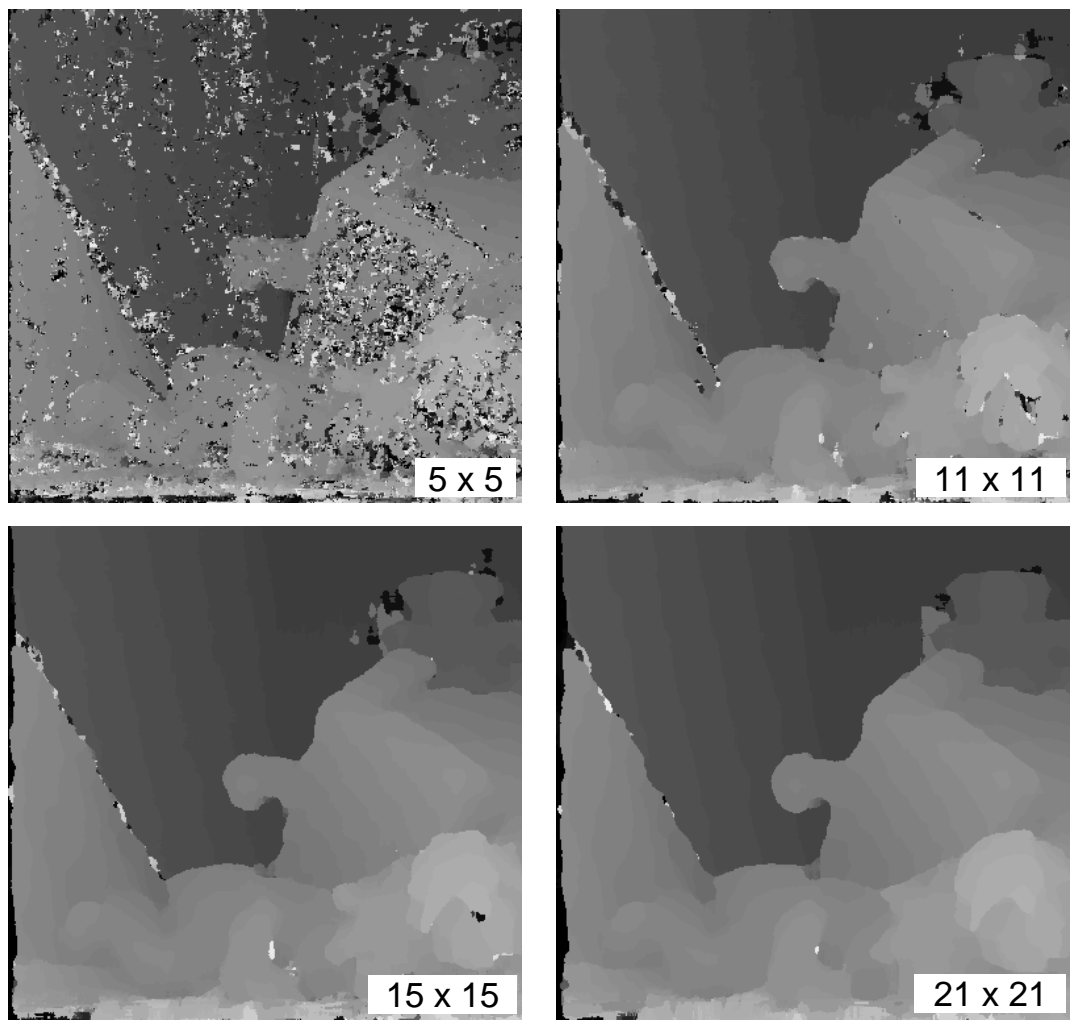

Figura B34: Execução do método Transformada Rank na imagem original
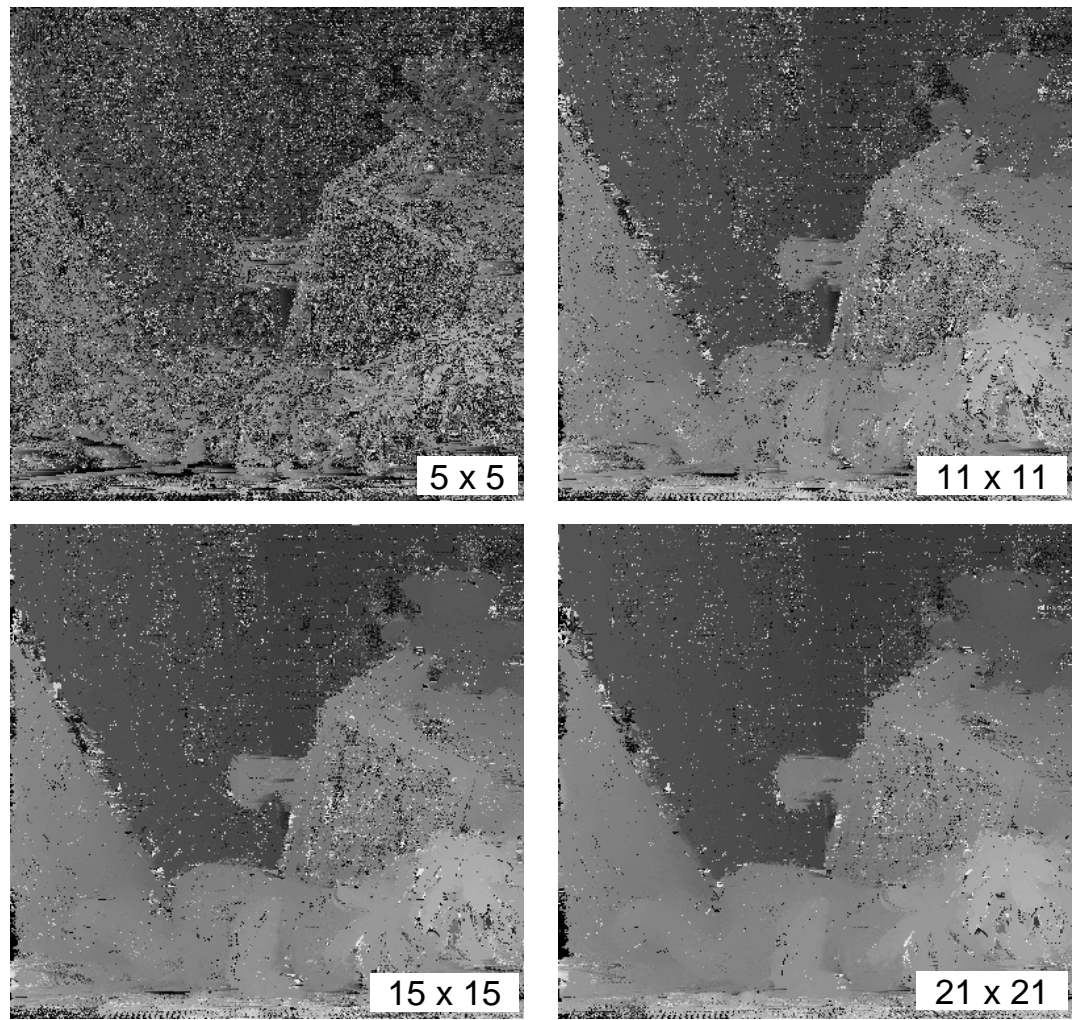

Figura B35: Execução do método Transformada Censo na imagem original 

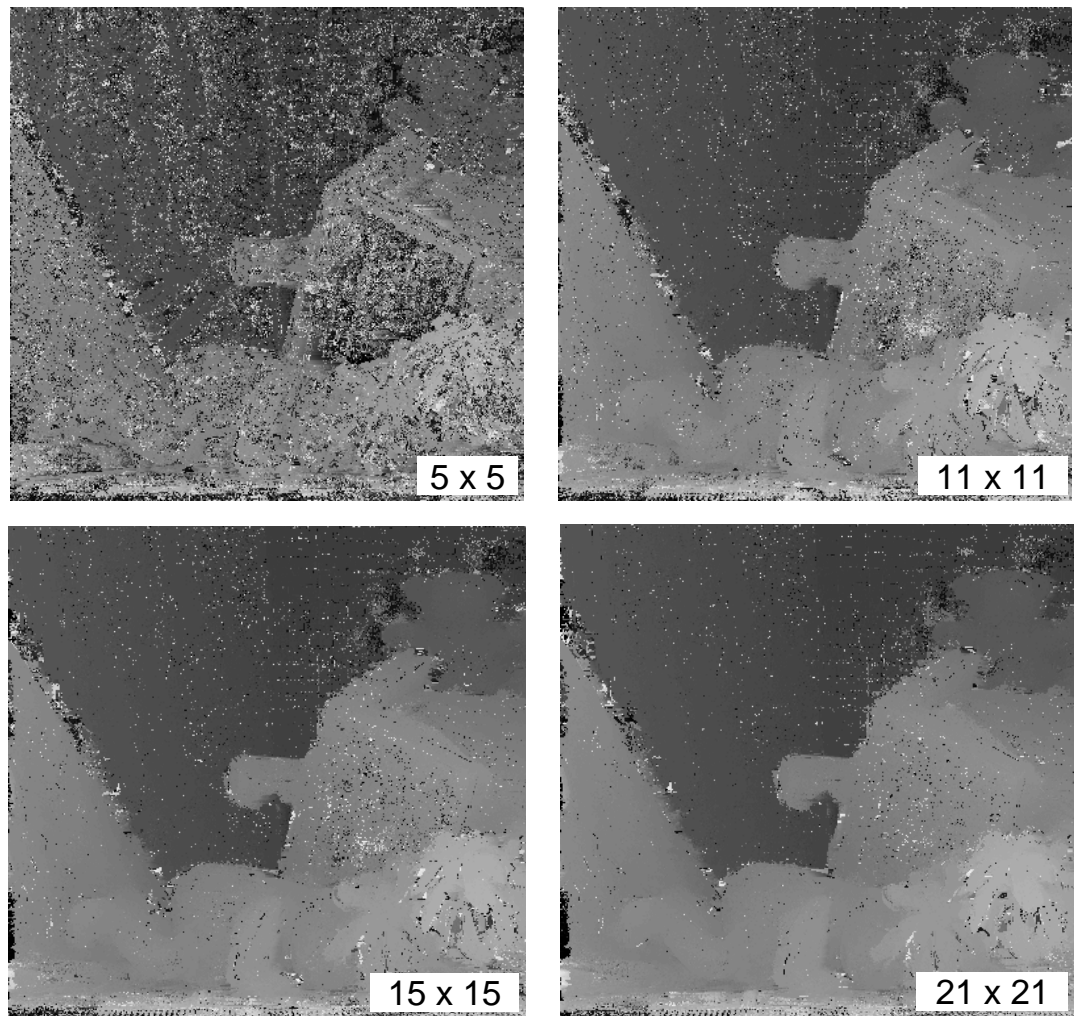

Figura B36: Execução do método Transformada Modificada 1 na imagem original
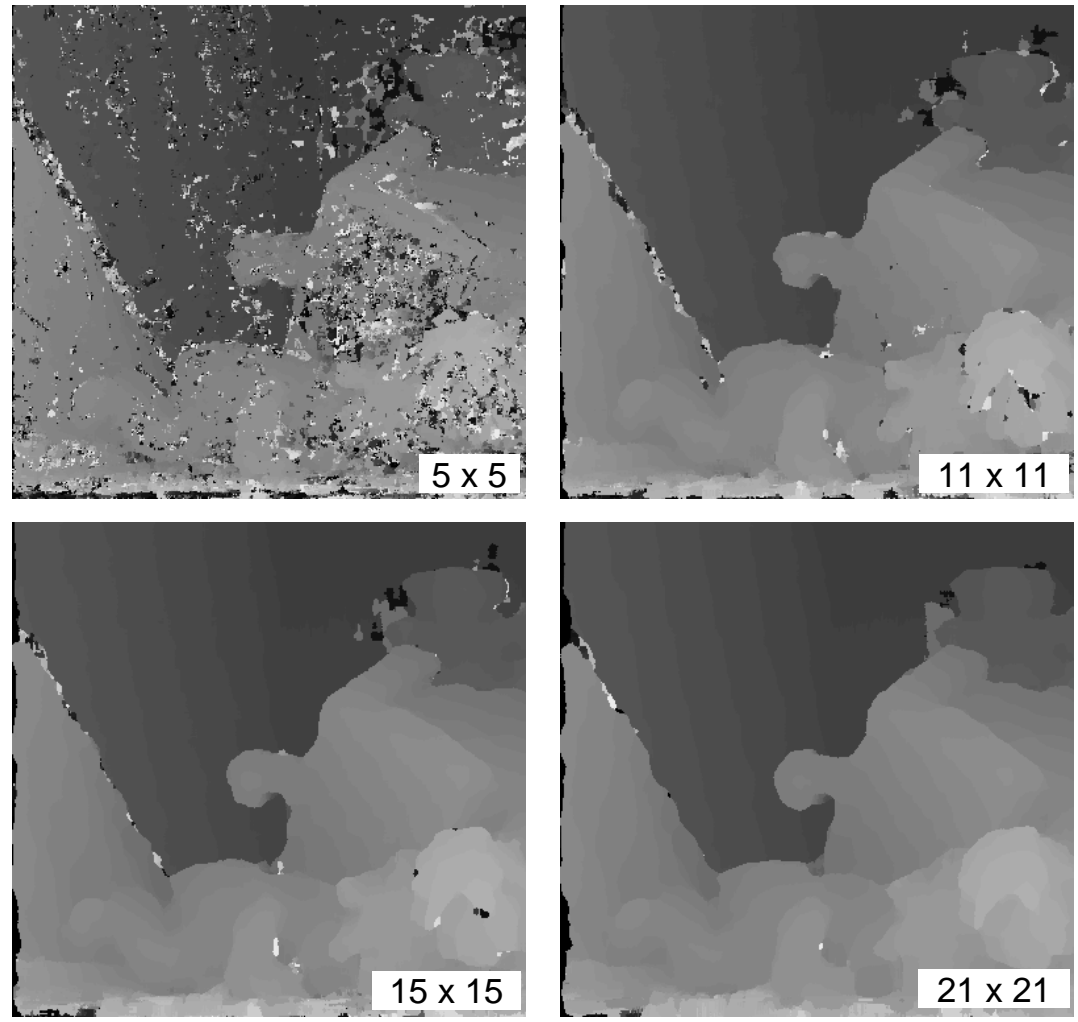

Figura B37: Execução do método Transformada Modificada 2 na imagem original 

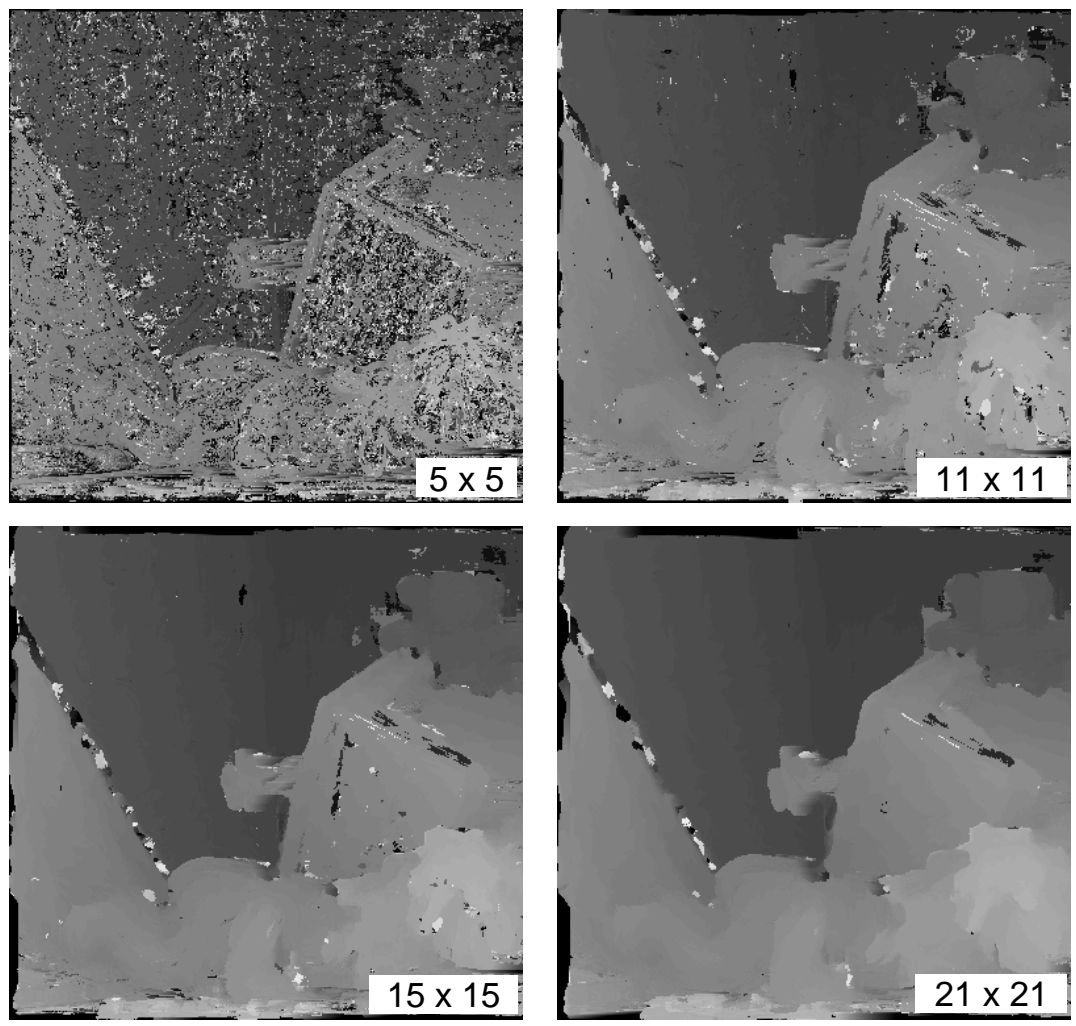

Figura B38: Execução do método Transformada Modificada 3 na imagem original
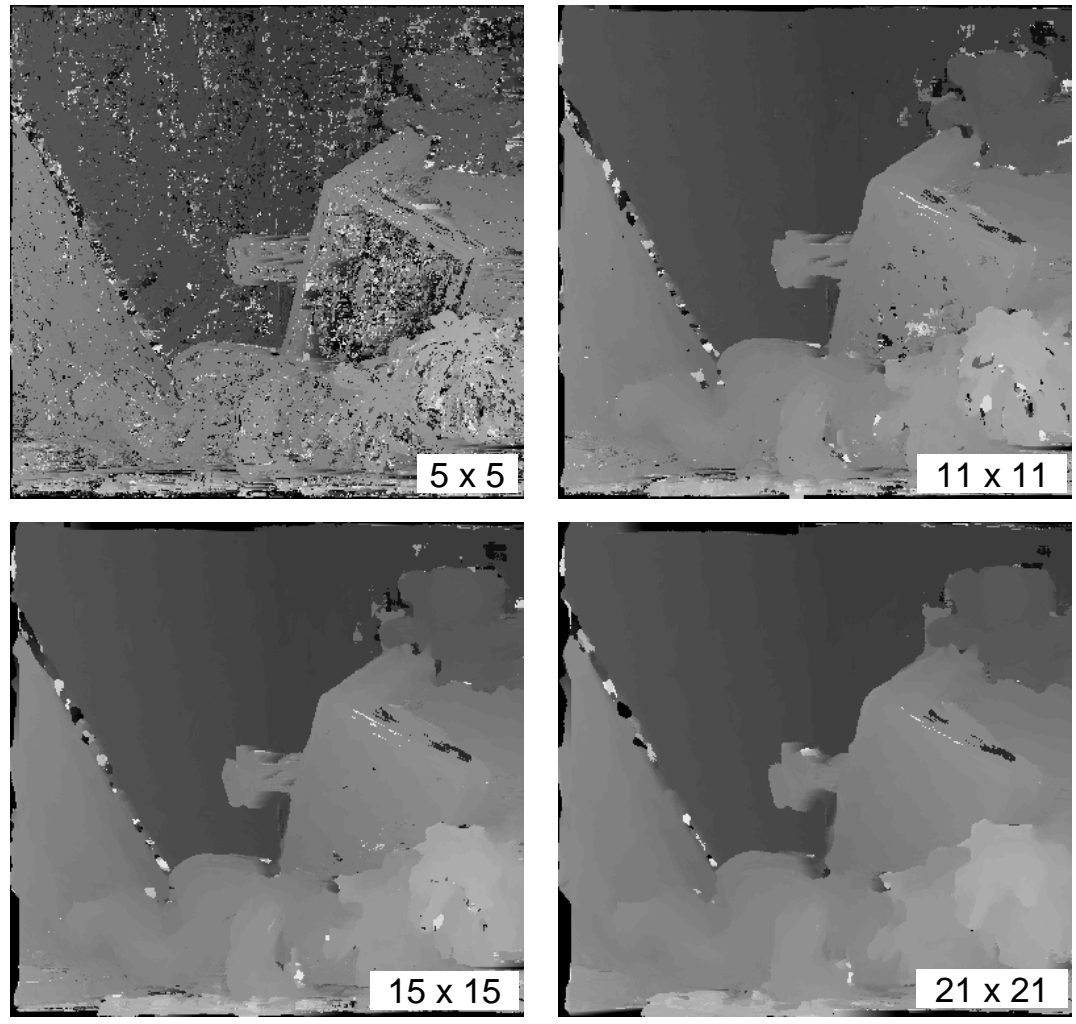

Figura B39: Execução do método Transformada Modificada 4 na imagem original 

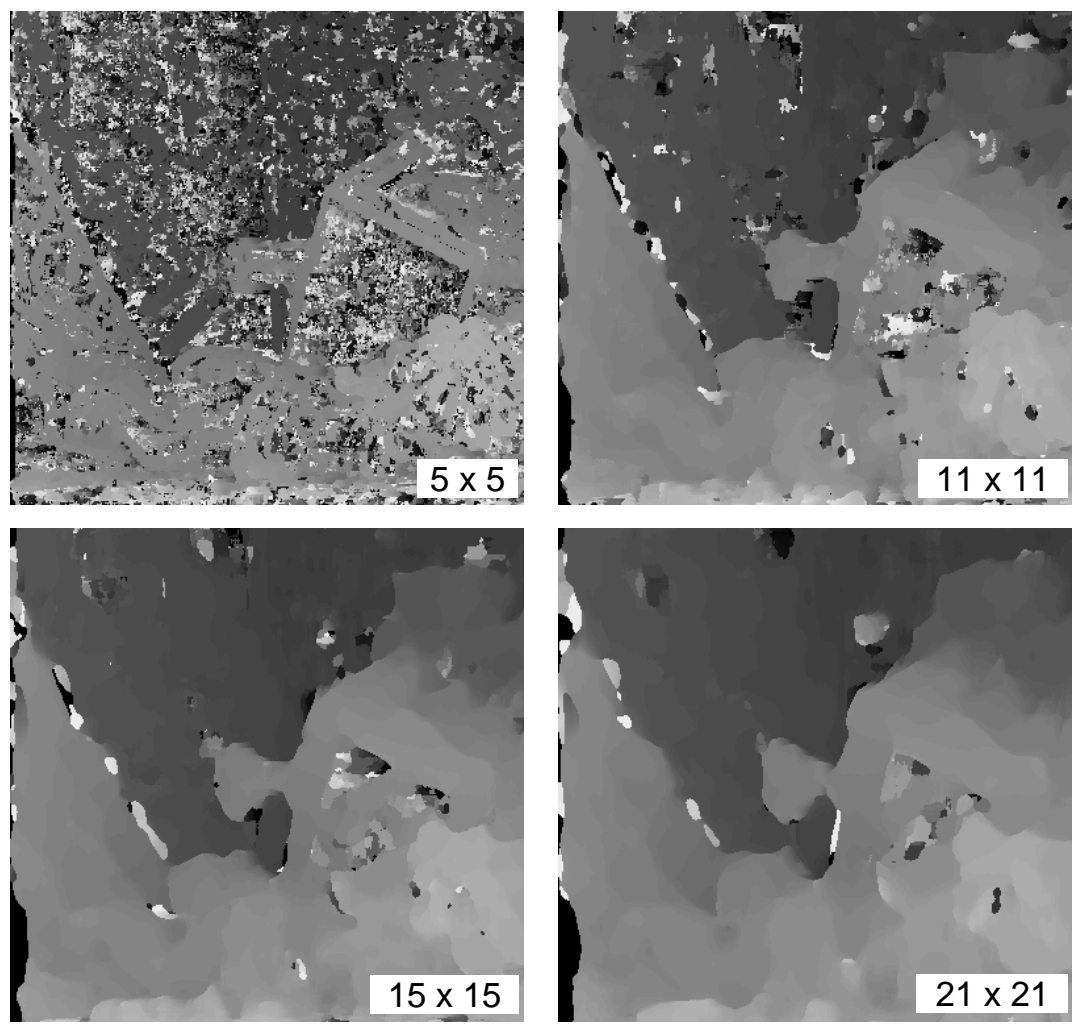

Figura B40: Execução do método Transformada Modificada 5 na imagem original 
Resultados da execução dos algoritmos com a imagem esquerda com $30 \%$ menos luminosidade
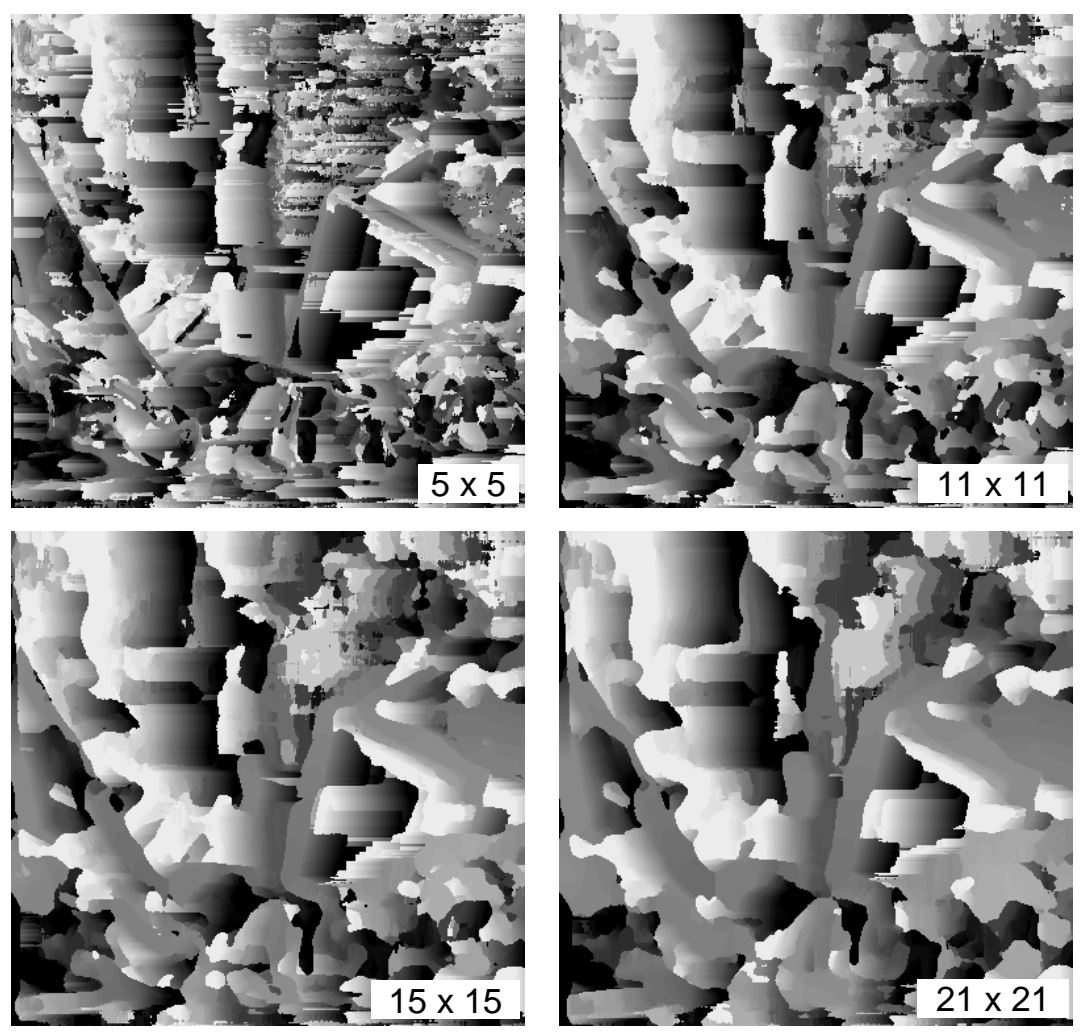

Figura B41: Execução do método Soma das Diferenças Absolutas na imagem com luminosidade $\mathbf{3 0} \%$ diferente 

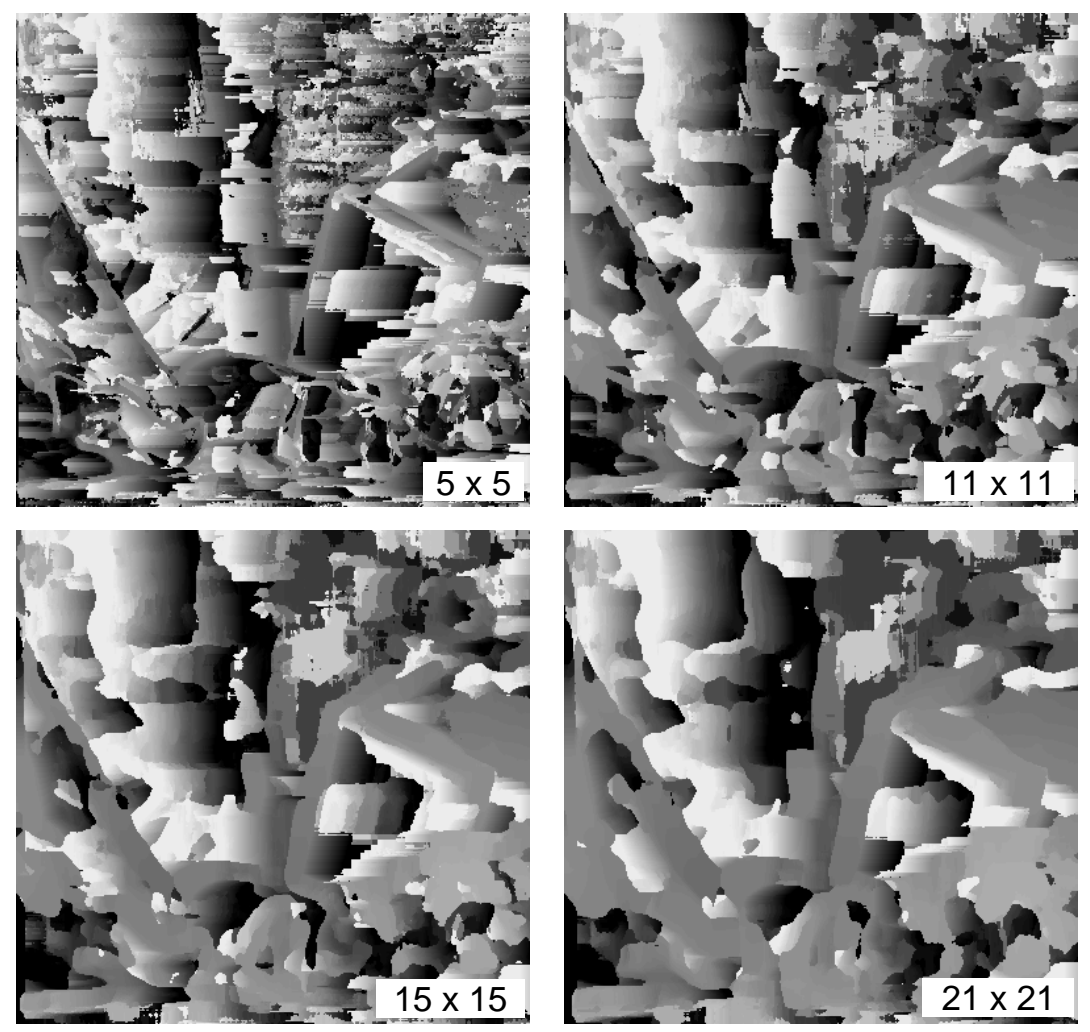

Figura B42: Execução do método Soma do Quadrado das Diferenças na imagem com luminosidade $30 \%$ diferente
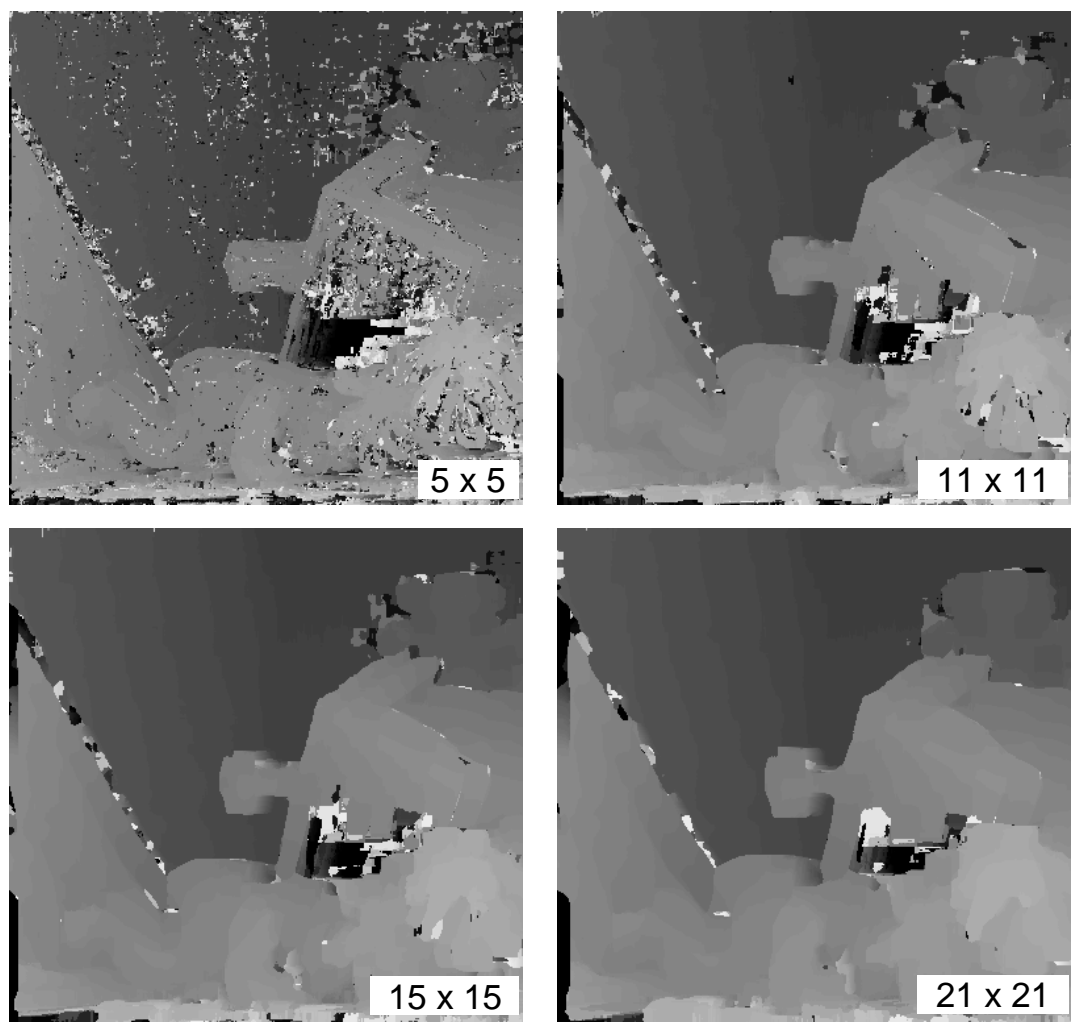

Figura B43: Execução do método Correlação Cruzada Normalizada na imagem com luminosidade $30 \%$ diferente 

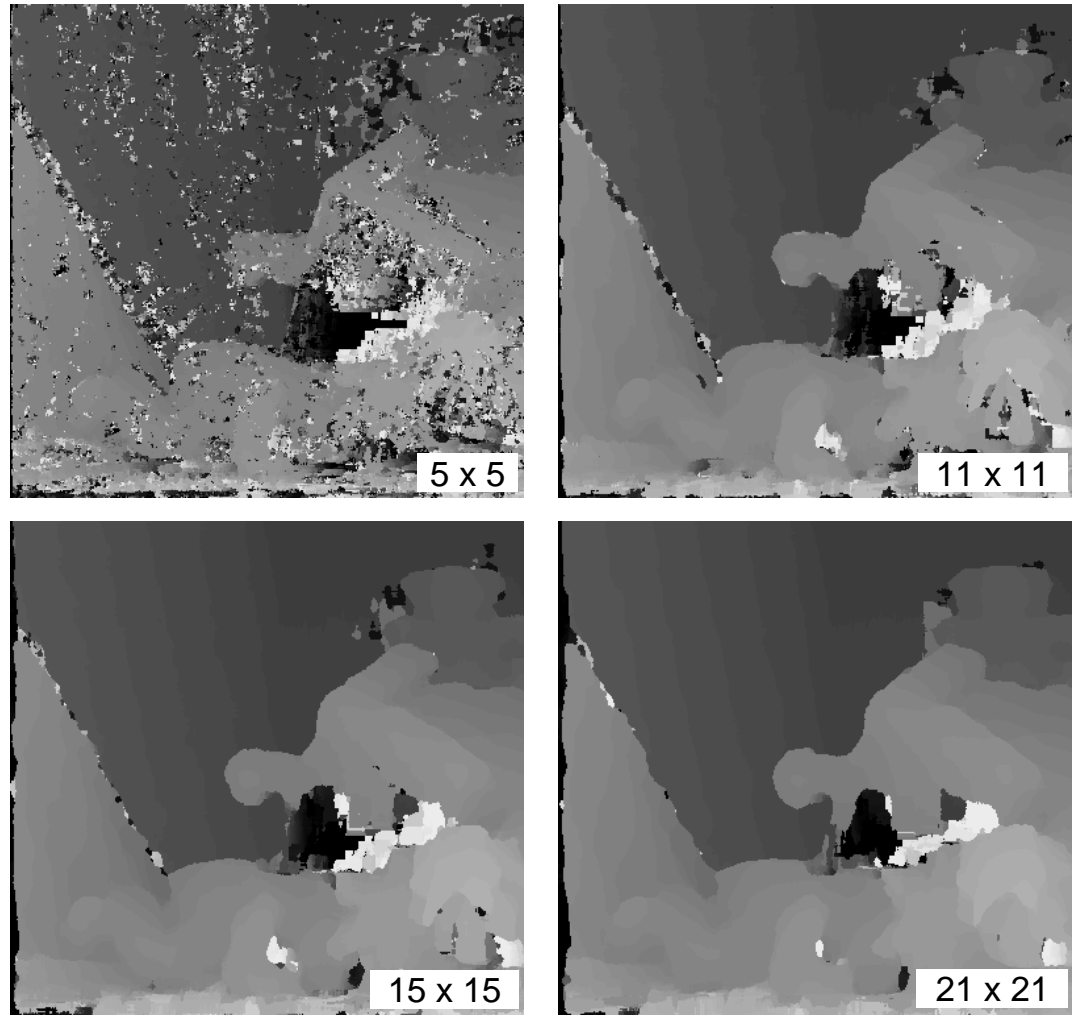

Figura B44: Execução do método Transformada Rank na imagem com luminosidade $30 \%$ diferente
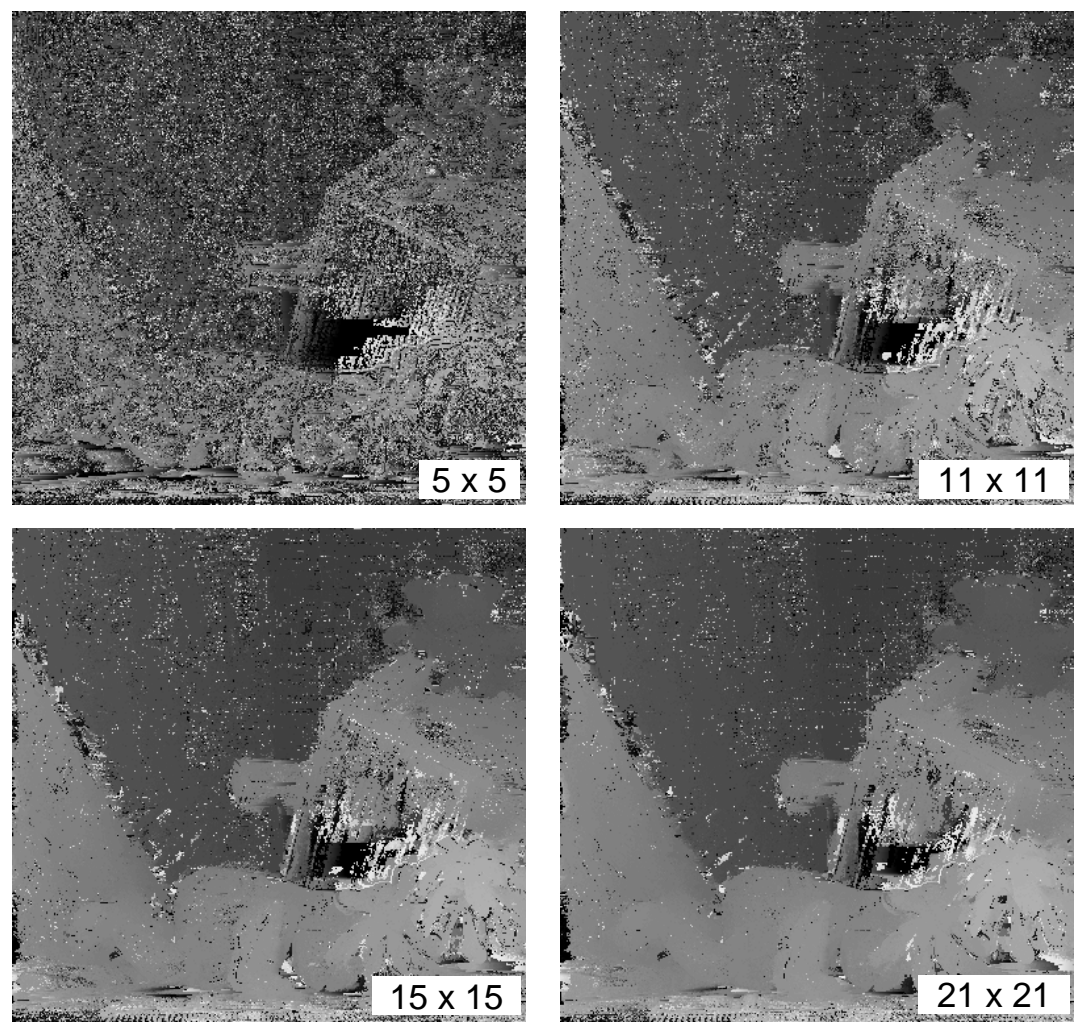

Figura B45: Execução do método Transformada Censo na imagem com luminosidade 30 \% diferente 

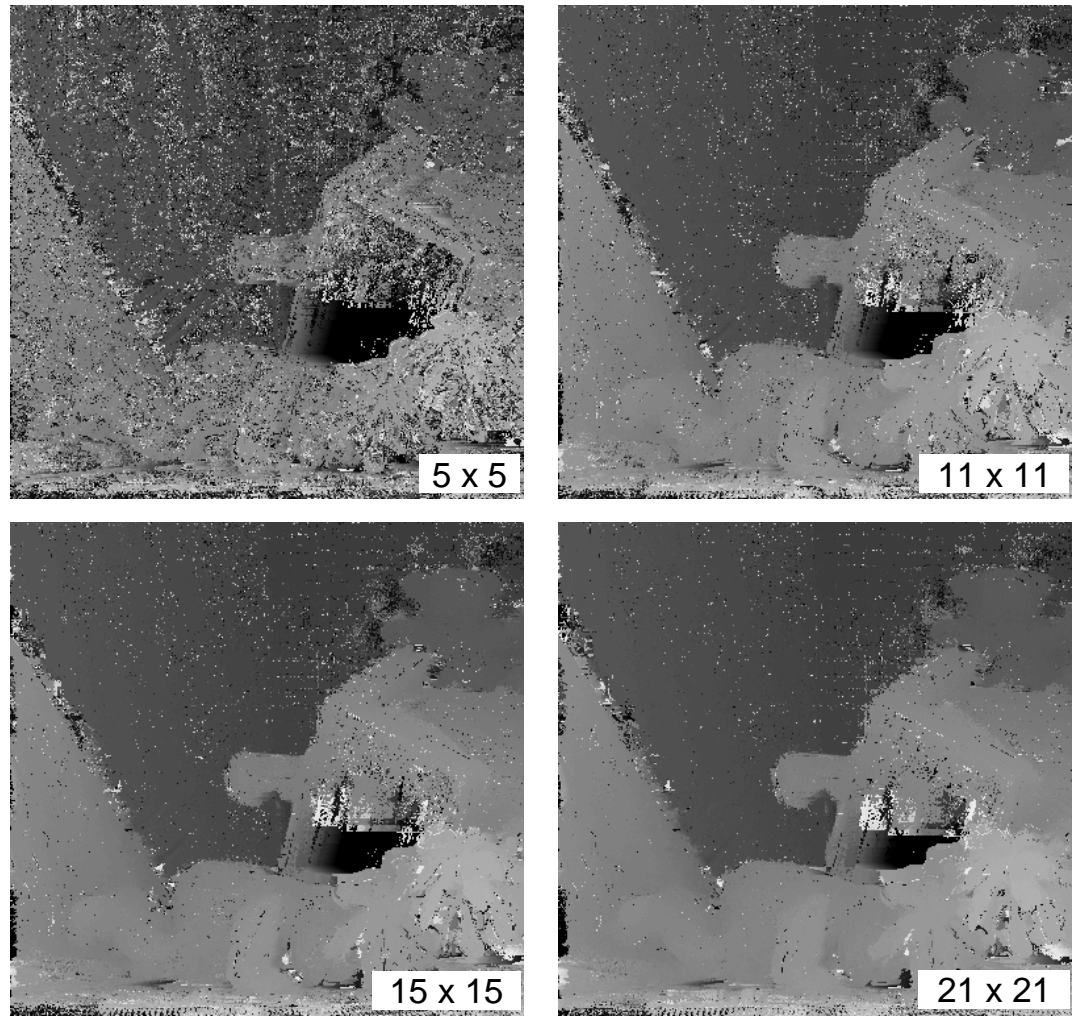

Figura B46: Execução do método Transformada Modificada 1 na imagem com luminosidade $30 \%$ diferente
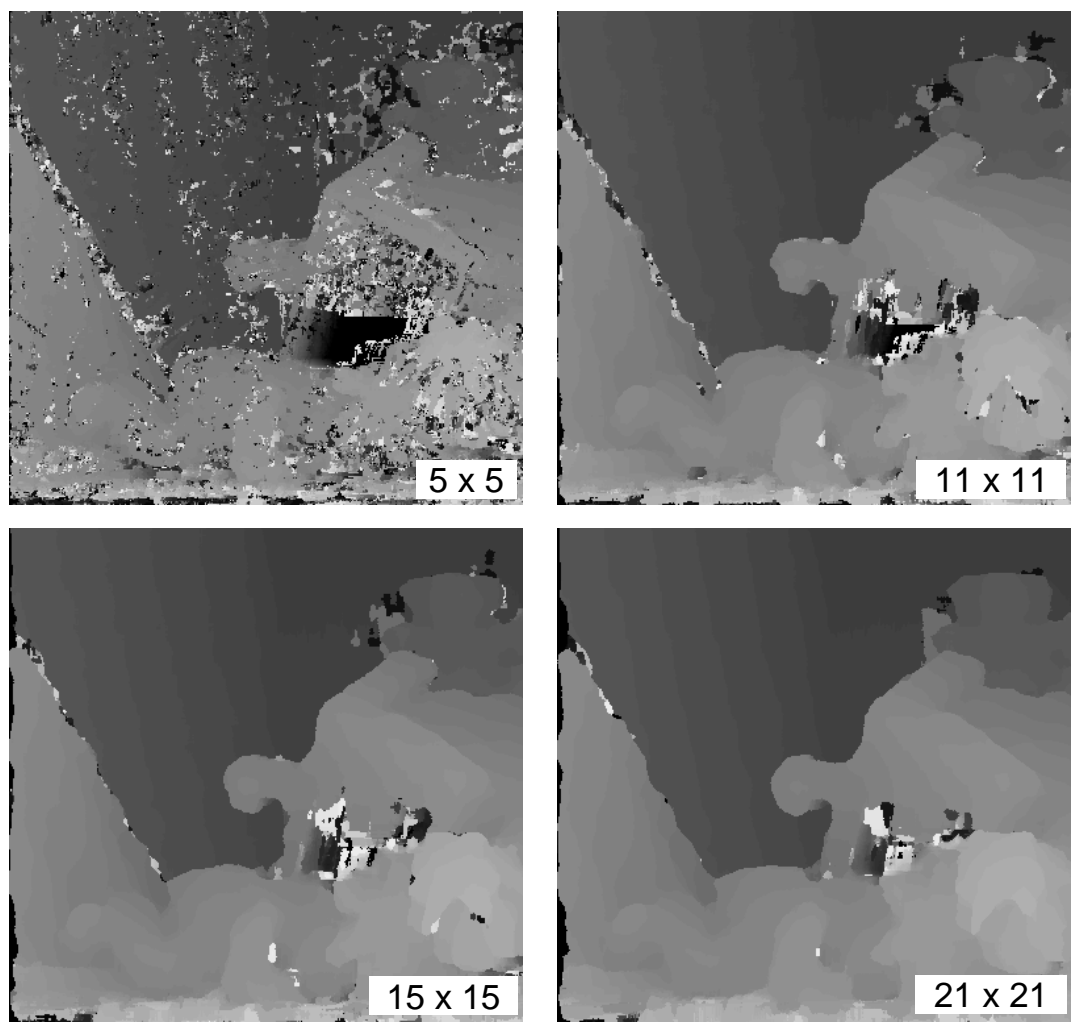

Figura B47: Execução do método Transformada Modificada 2 na imagem com luminosidade $30 \%$ diferente 

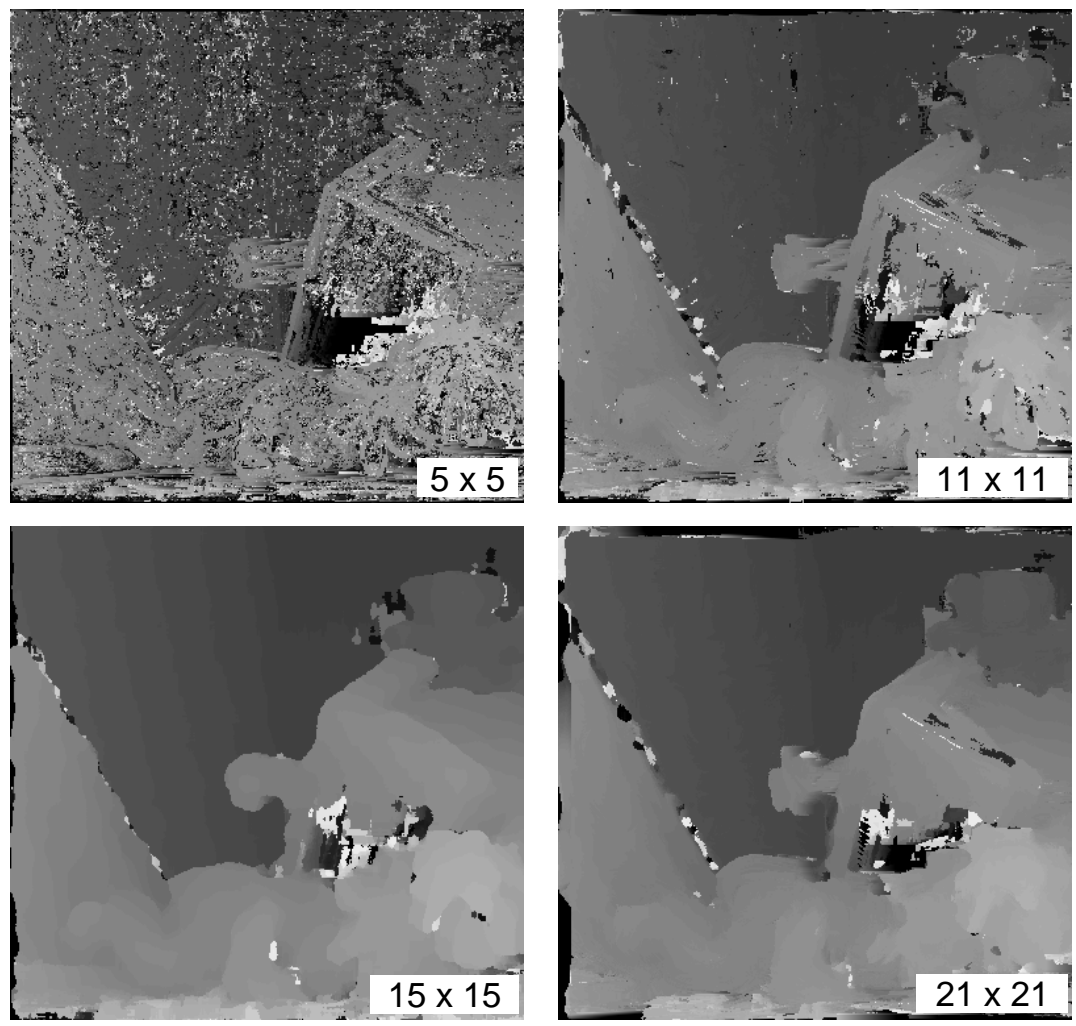

Figura B48: Execução do método Transformada Modificada 3 na imagem com luminosidade $30 \%$ diferente
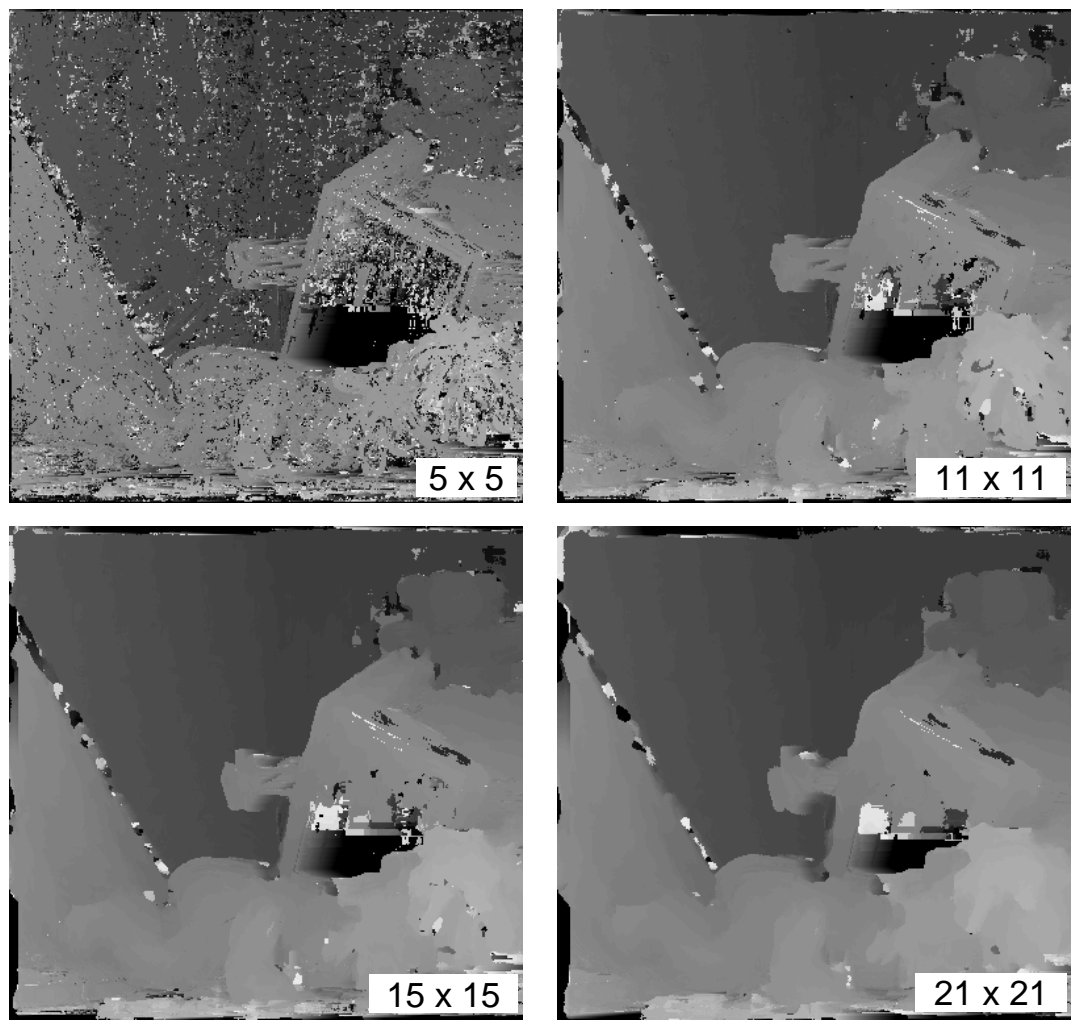

Figura B49: Execução do método Transformada Modificada 4 na imagem com luminosidade $30 \%$ diferente 

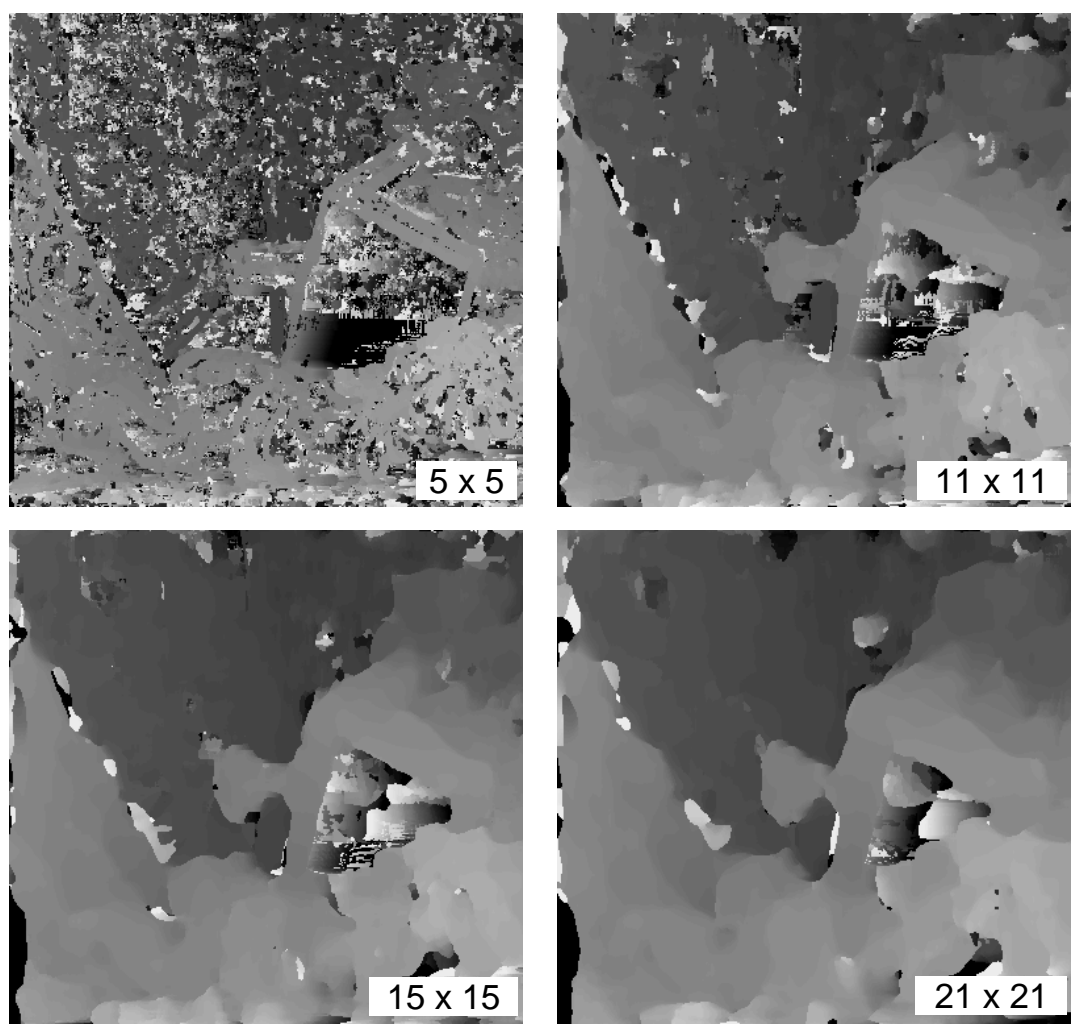

Figura B50: Execução do método Transformada Modificada 5 na imagem com luminosidade $30 \%$ diferente 
Resultados da execução dos algoritmos com a imagem contaminada por ruído de variância 200
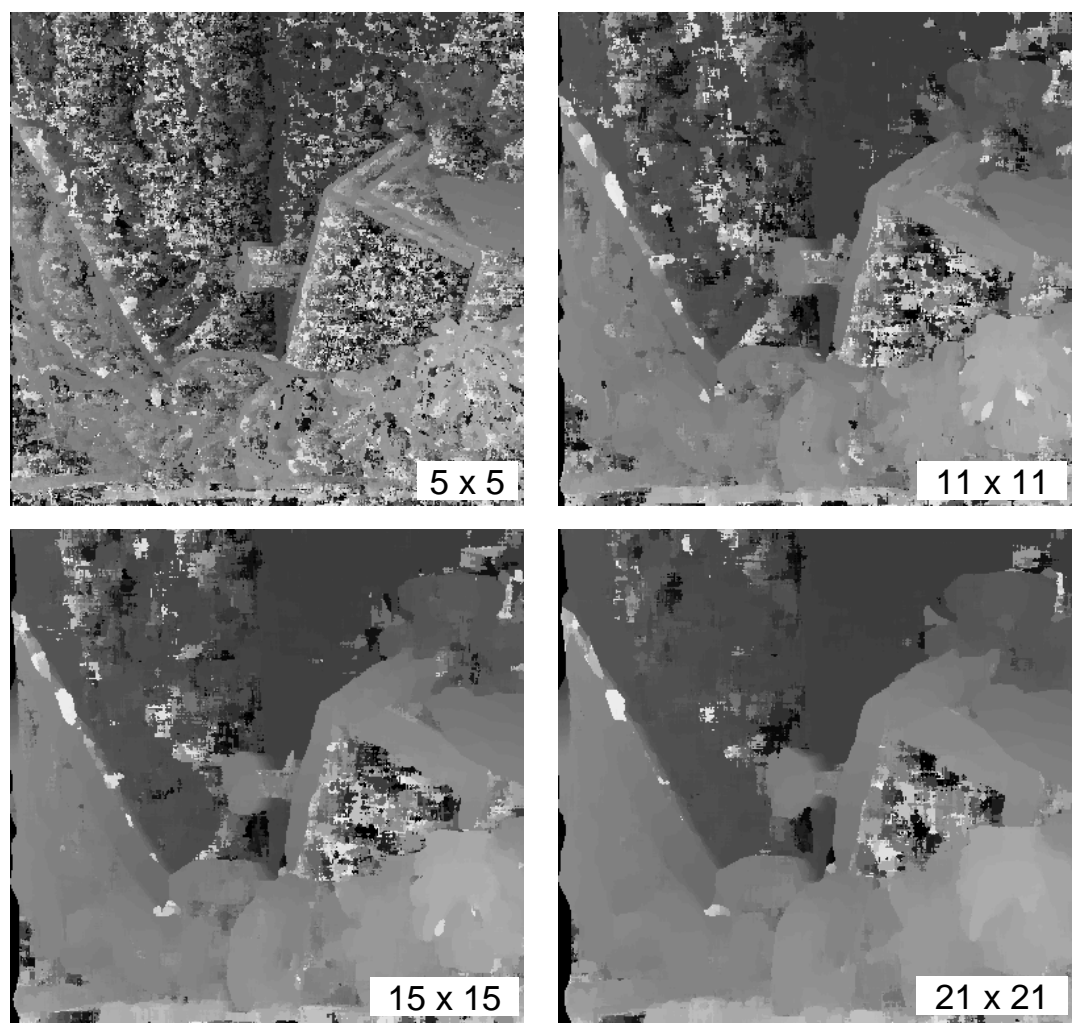

Figura B51: Execução do método Soma das Diferenças Absolutas na imagem com ruído de variância 200 

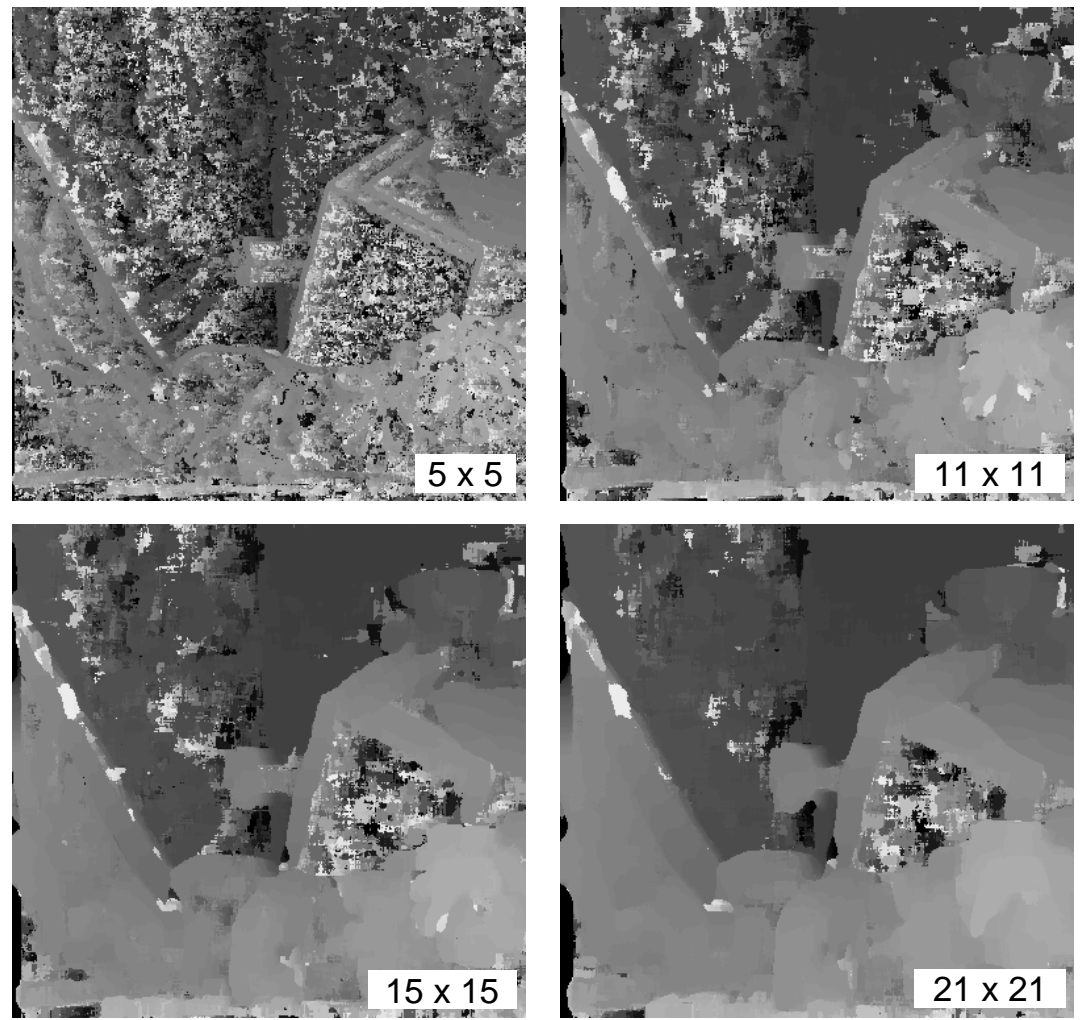

Figura B52: Execução do método Soma do Quadrado das Diferenças na imagem com ruído de variância 200
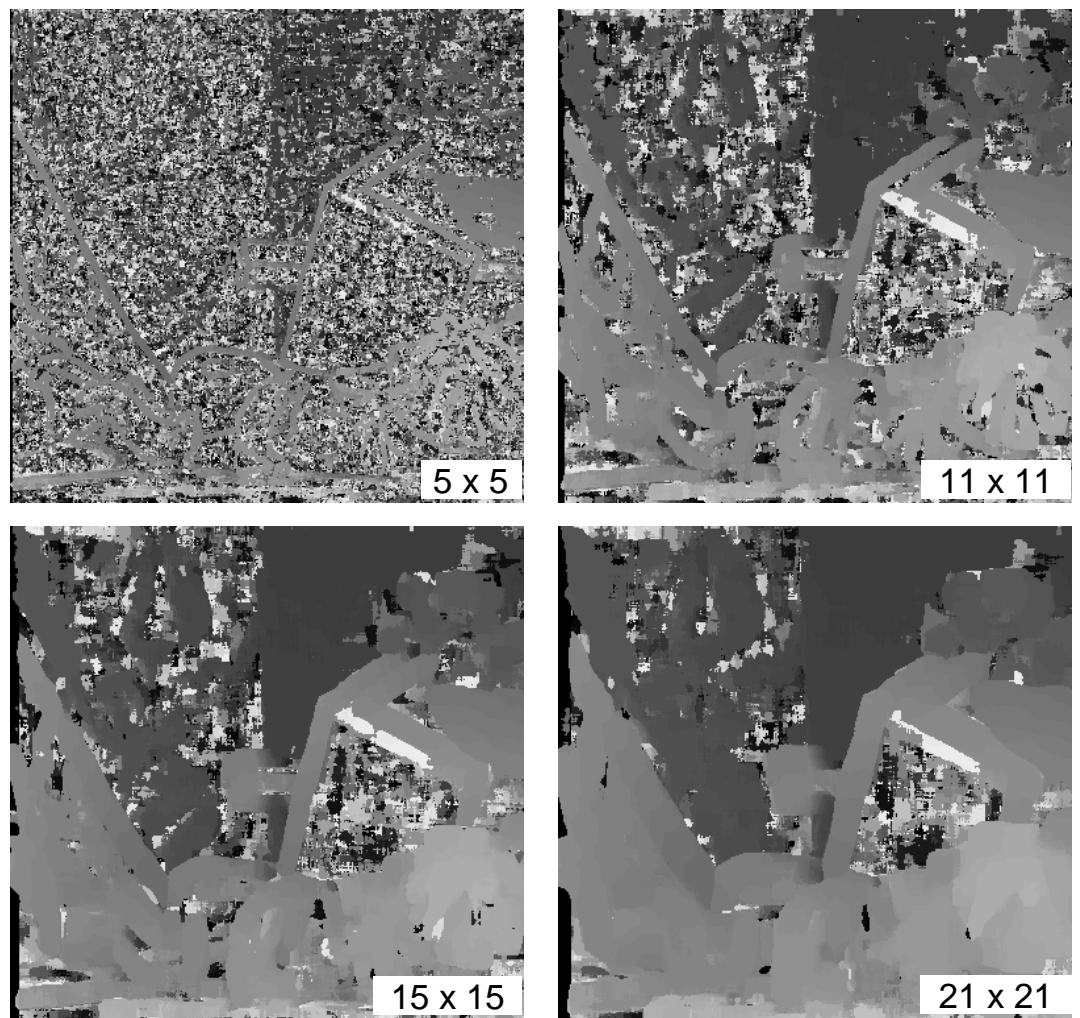

Figura B53: Execução do método Correlação Cruzada Normalizada na imagem com ruído de variância 200 

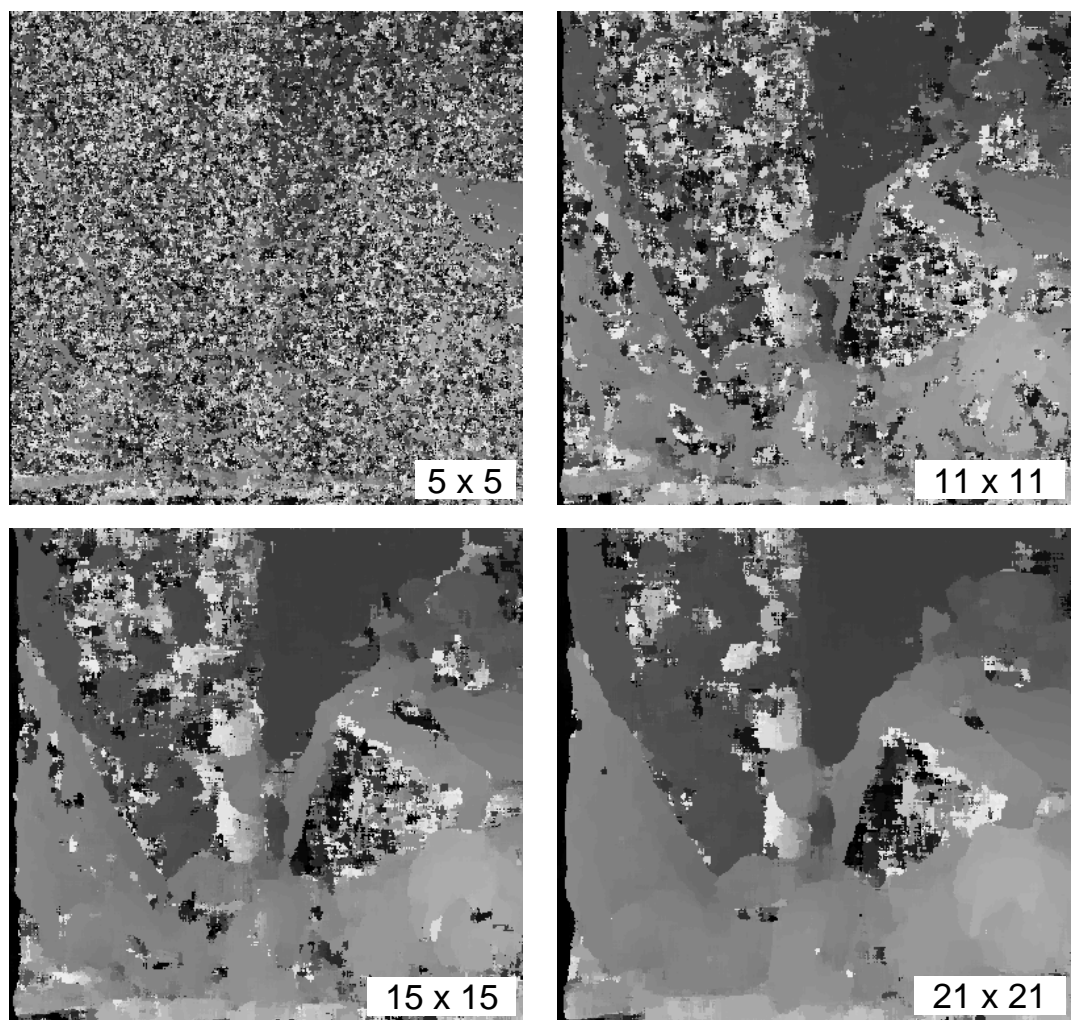

Figura B54: Execução do método Transformada Rank na imagem com ruído de variância 200
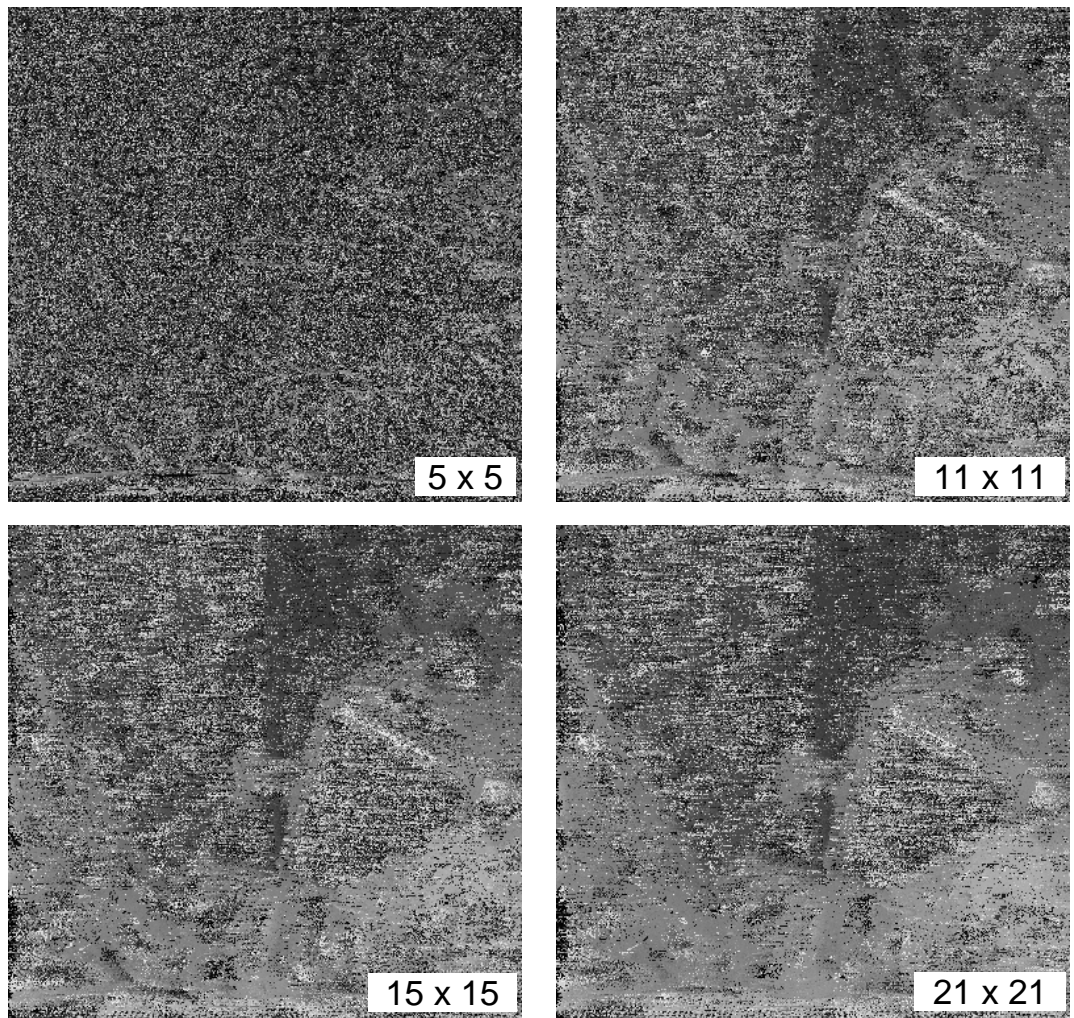

Figura B55: Execução do método Transformada Censo na imagem com ruído de variância 200 

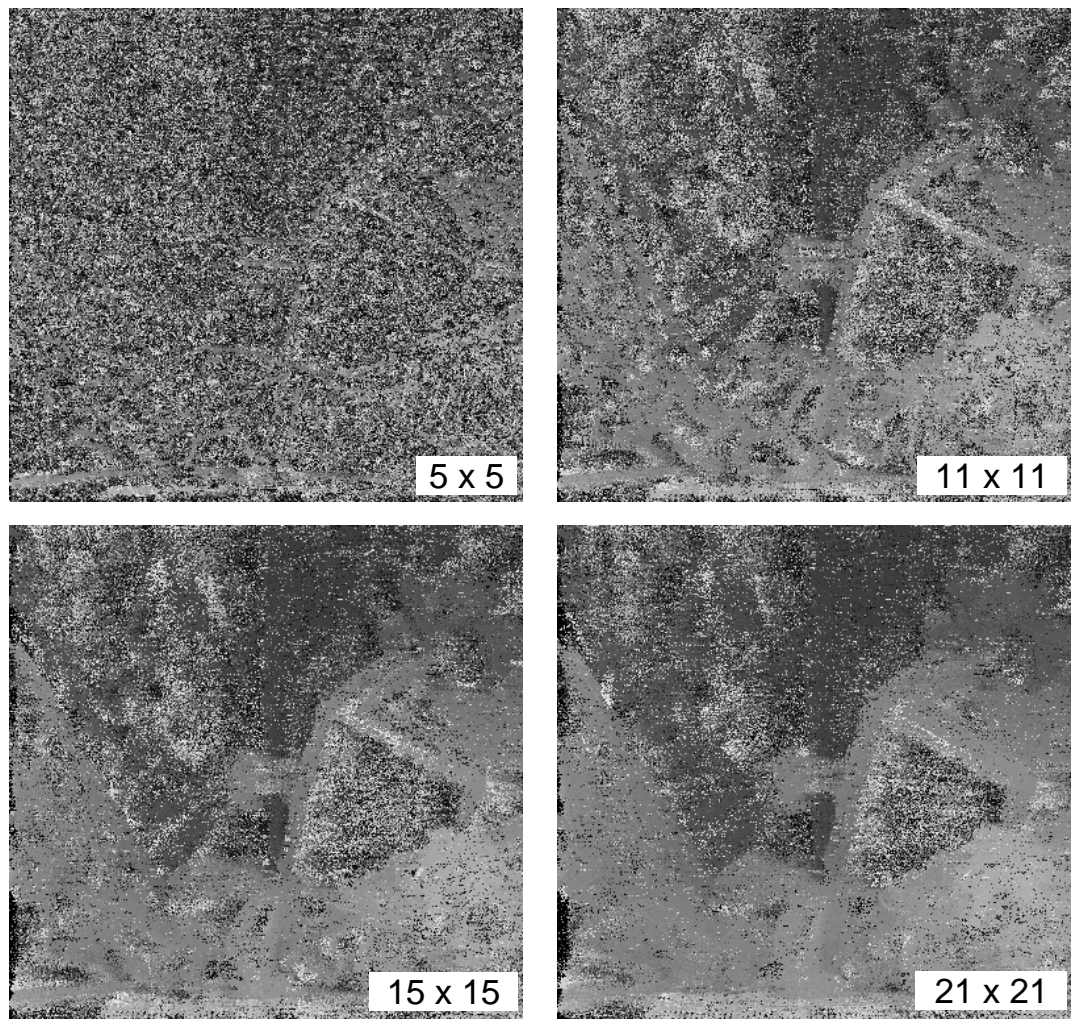

Figura B56: Execução do método Transformada Modificada 1 na imagem com ruído de variância 200
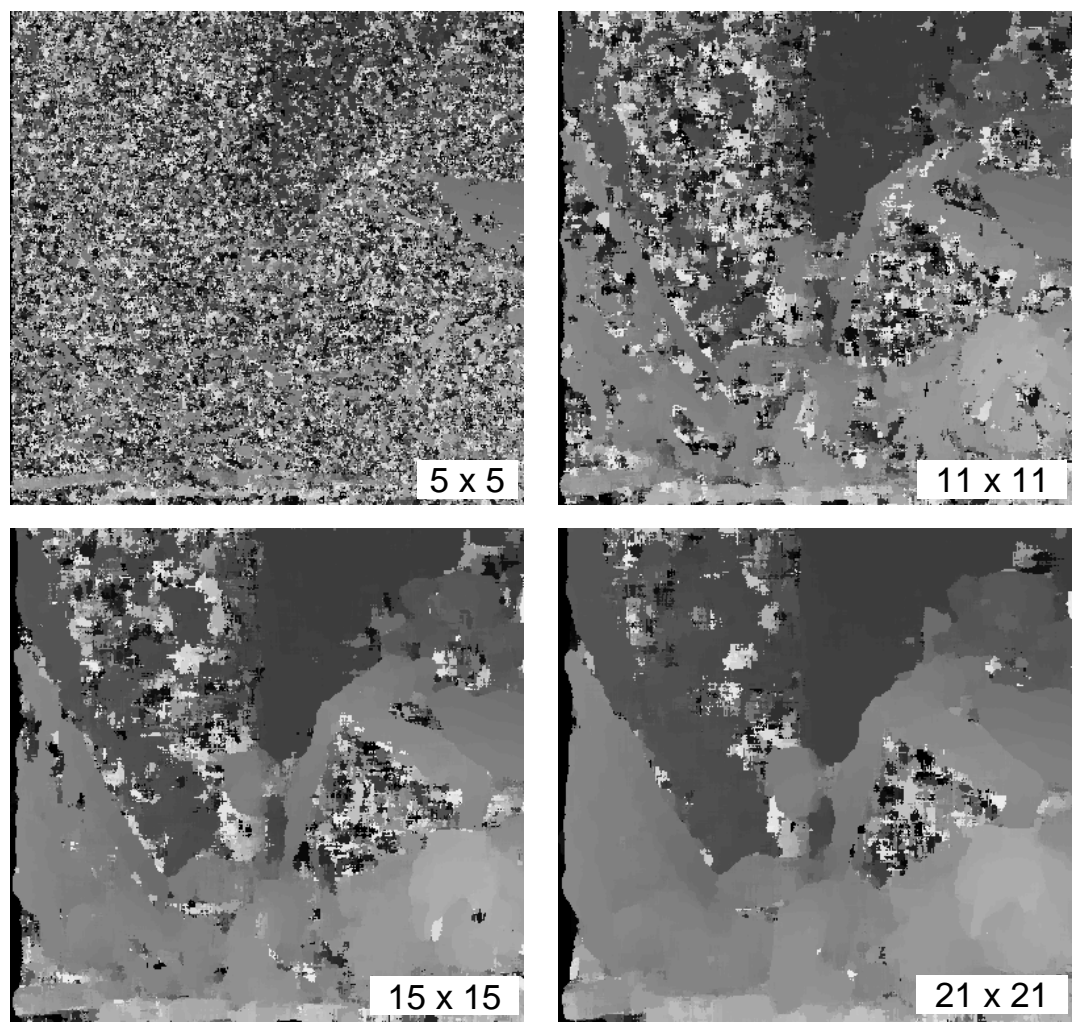

Figura B57: Execução do método Transformada Modificada 2 na imagem com ruído de variância 200 

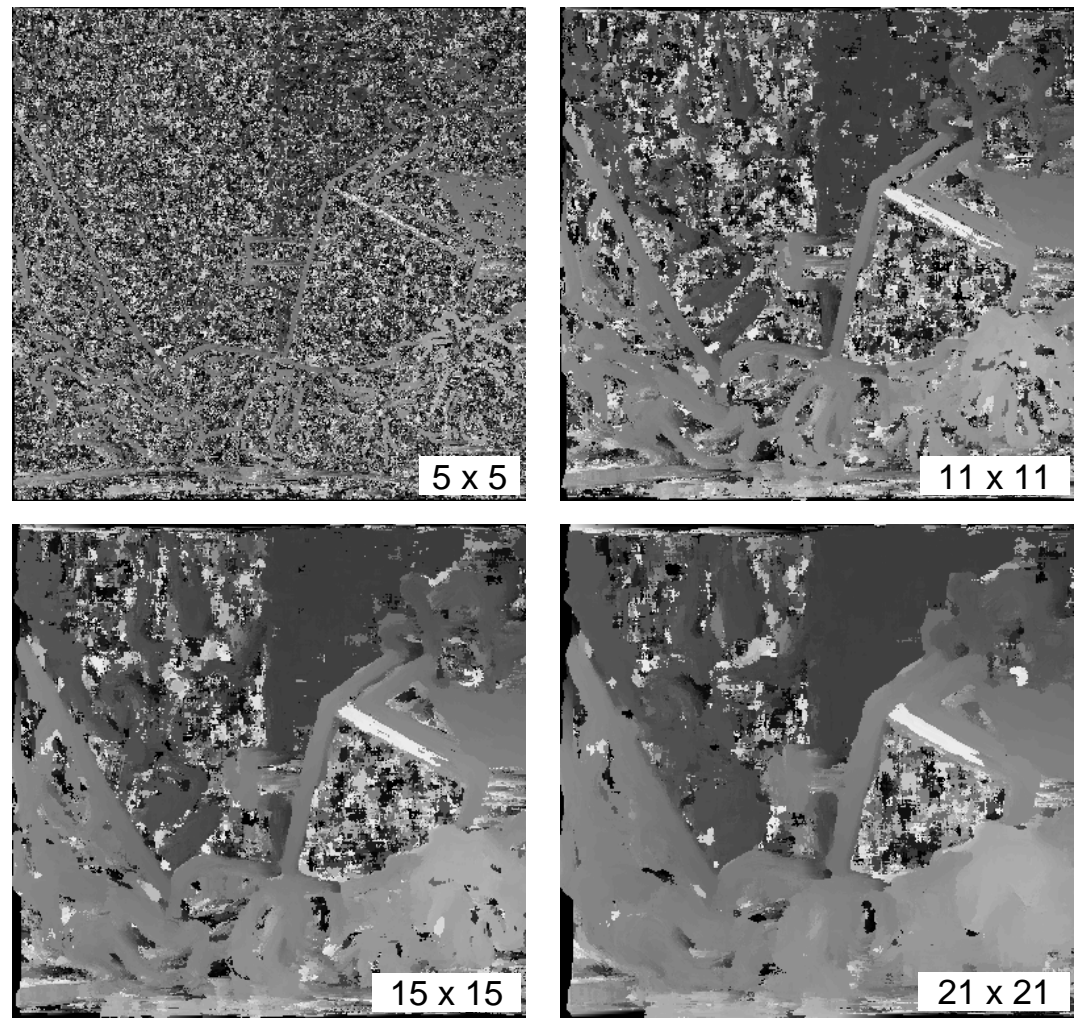

Figura B58: Execução do método Transformada Modificada 3 na imagem com ruído de variância 200
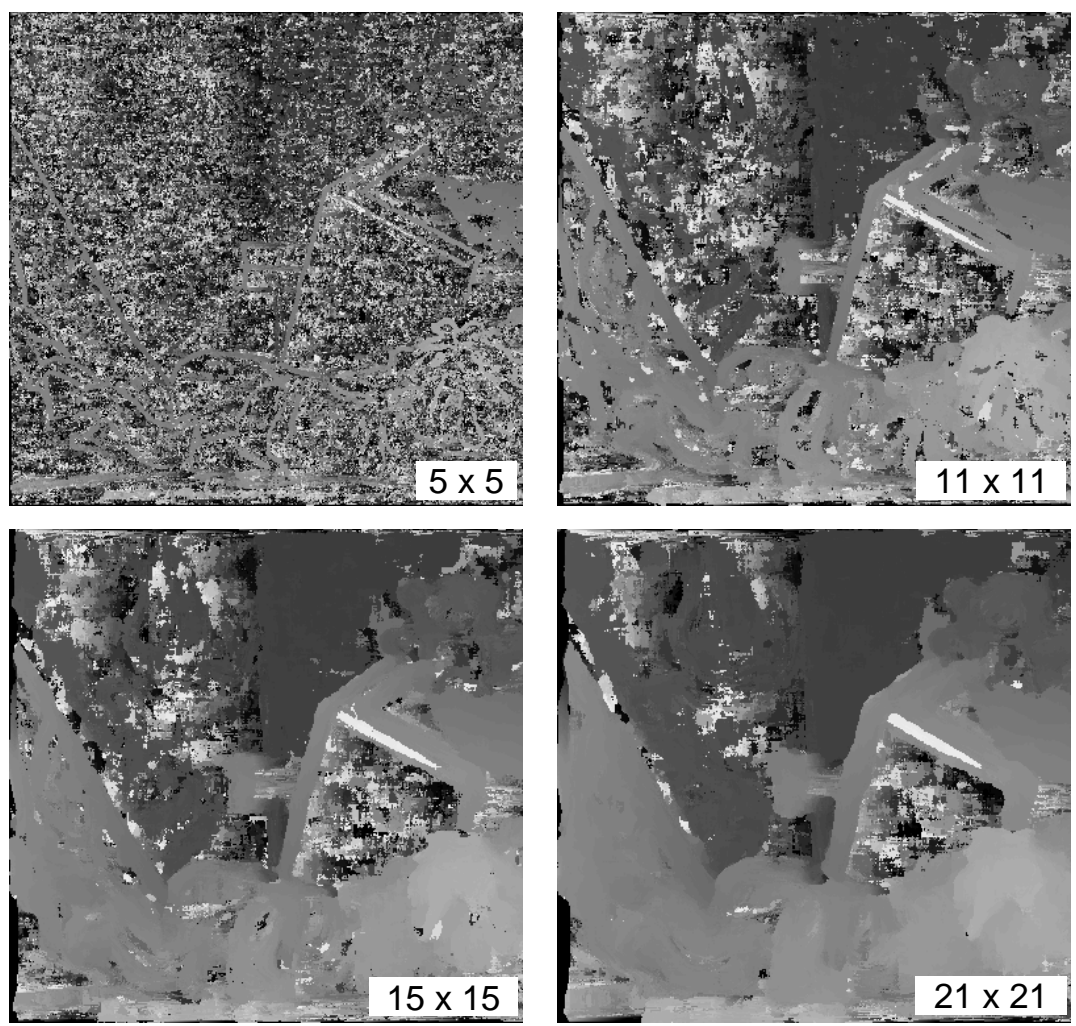

Figura B59: Execução do método Transformada Modificada 4 na imagem com ruído de variância 200 

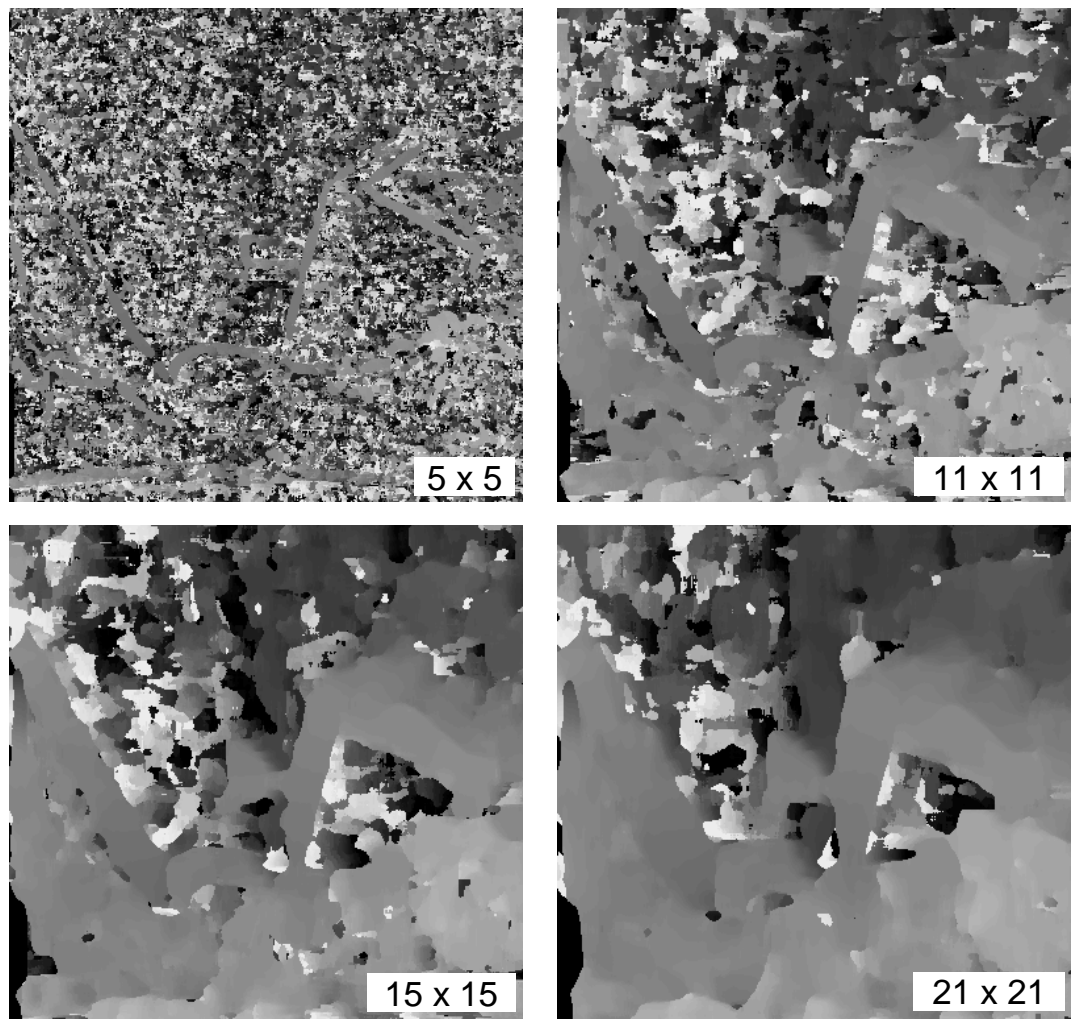

Figura B60: Execução do método Transformada Modificada 5 na imagem com ruído de variância 200 
Imagem Cones

Resultados da execução dos algoritmos com a imagem original
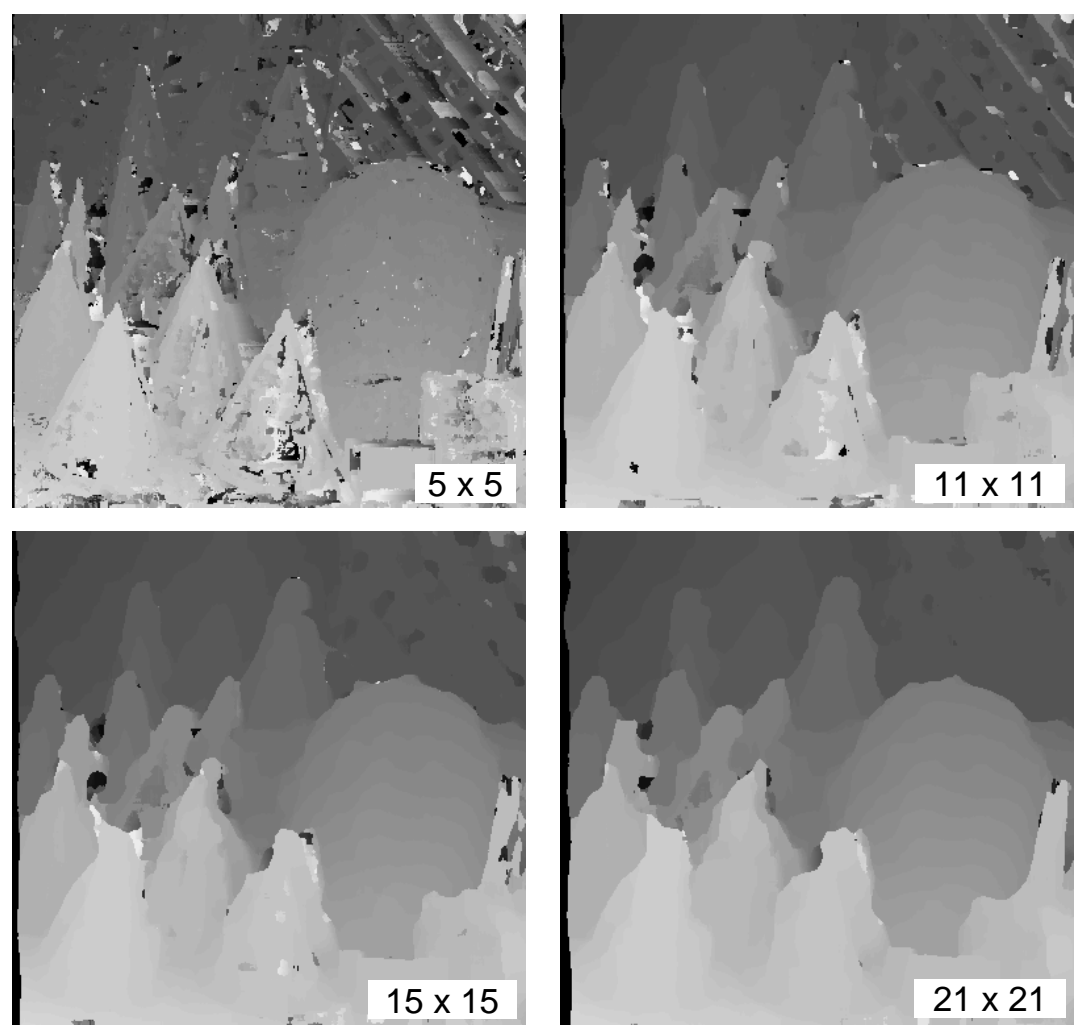

Figura B61: Execução do método Soma das Diferenças Absolutas na imagem original 

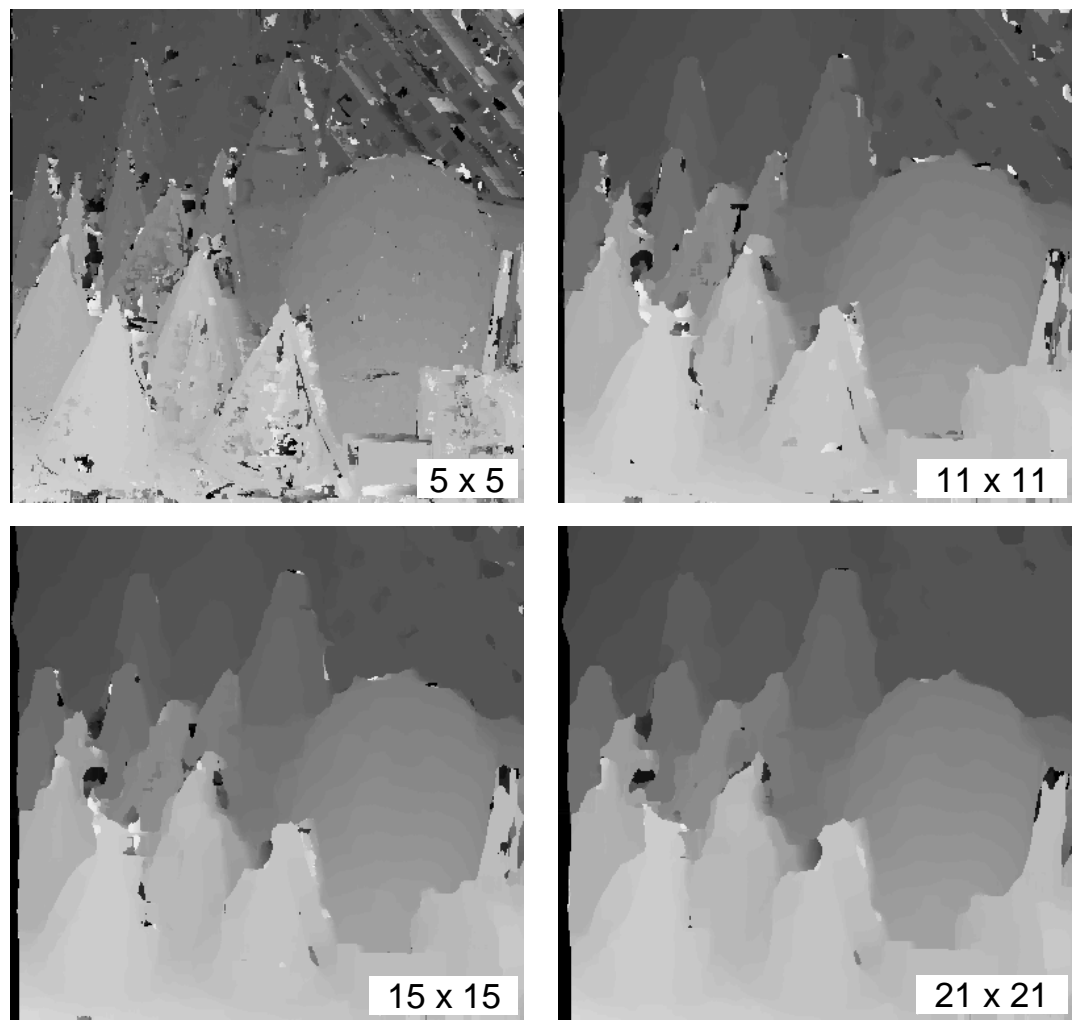

Figura B62: Execução do método Soma do Quadrado das Diferenças na imagem original
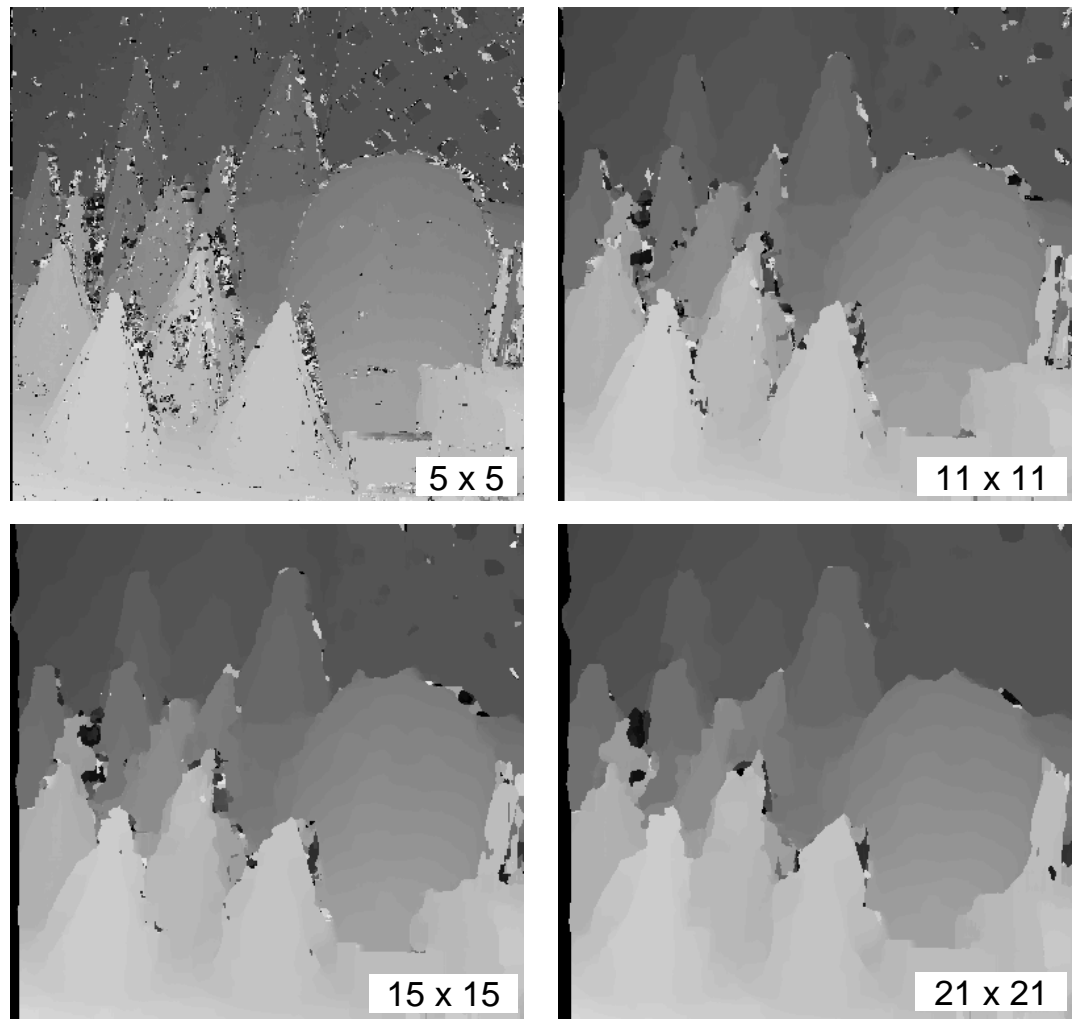

Figura B63: Execução do método Correlação Cruzada Normalizada na imagem original 

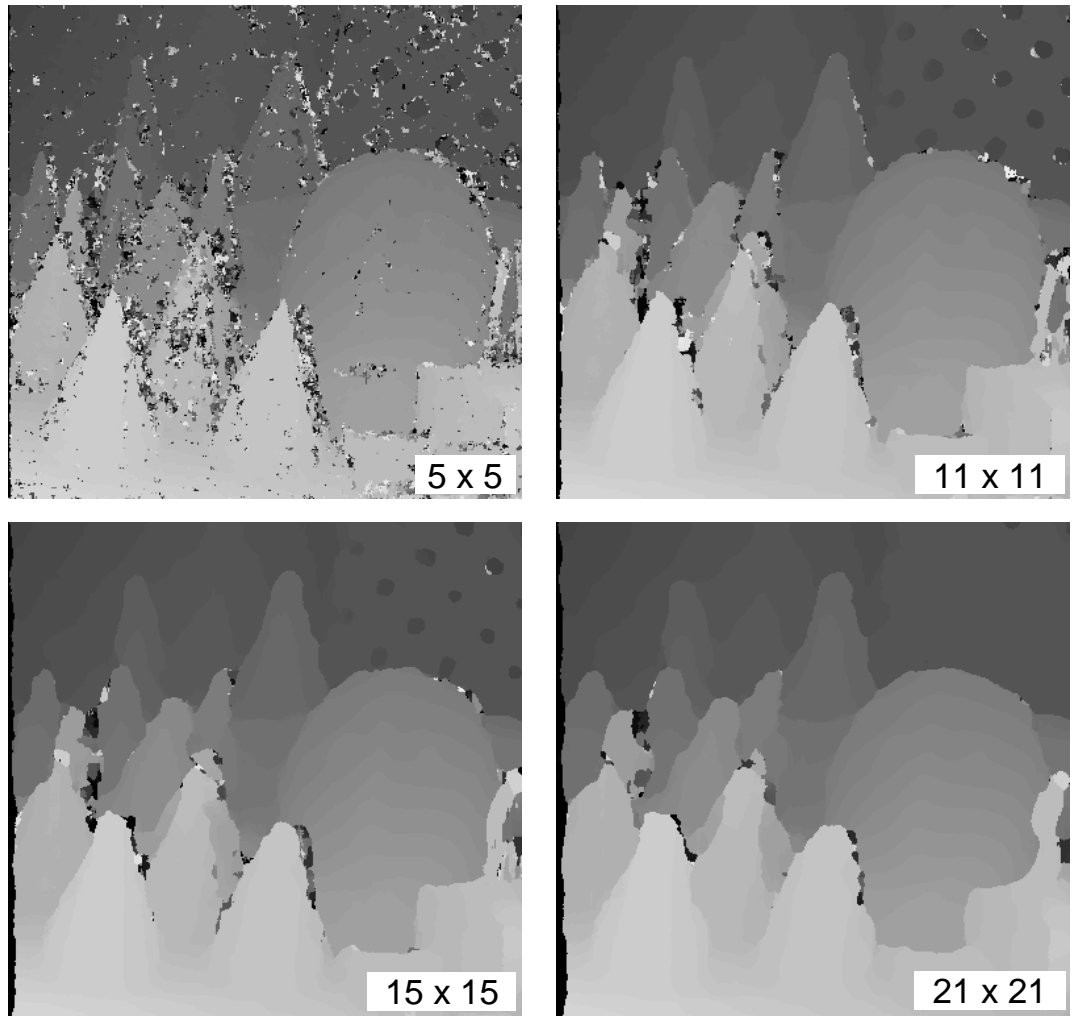

Figura B64: Execução do método Transformada Rank na imagem original
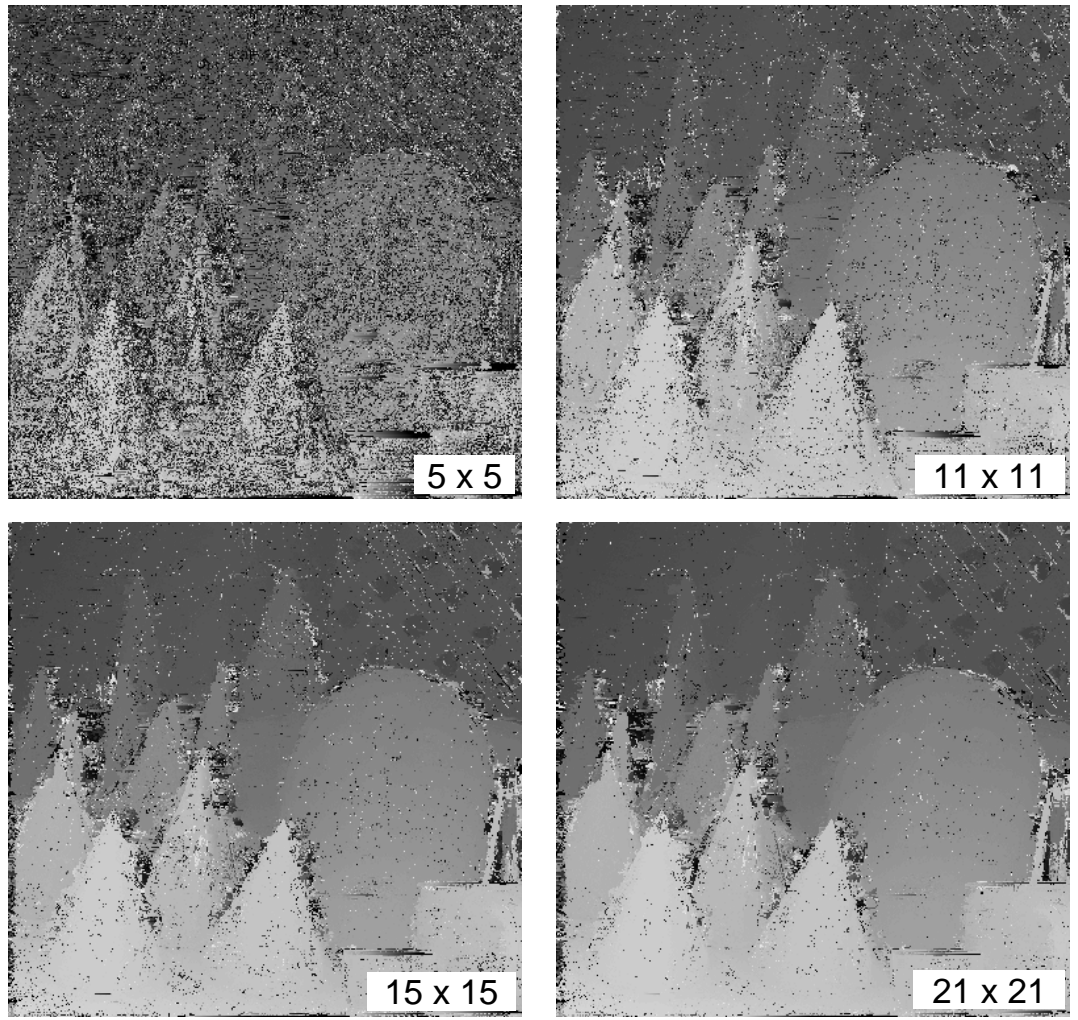

Figura B65: Execução do método Transformada Censo na imagem original 

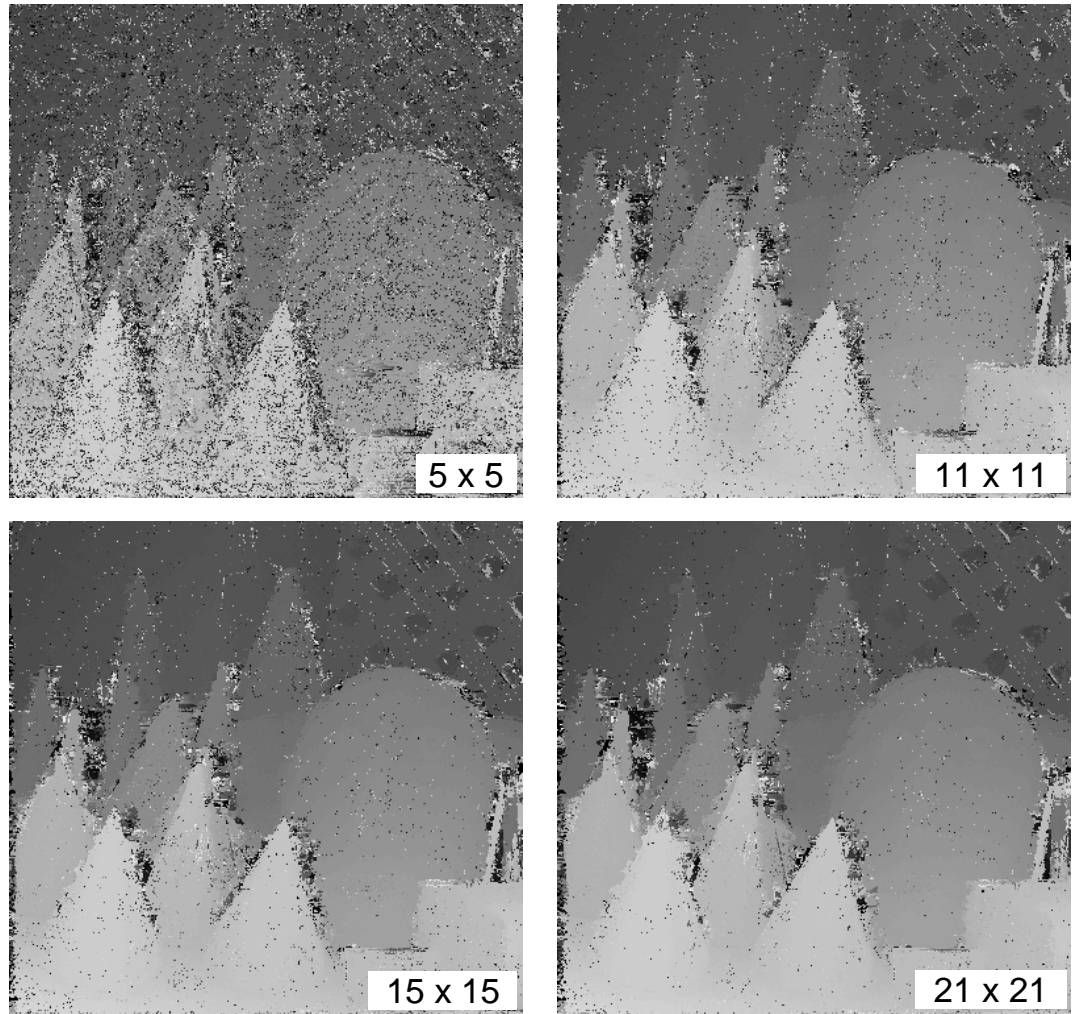

Figura B66: Execução do método Transformada Modificada 1 na imagem original
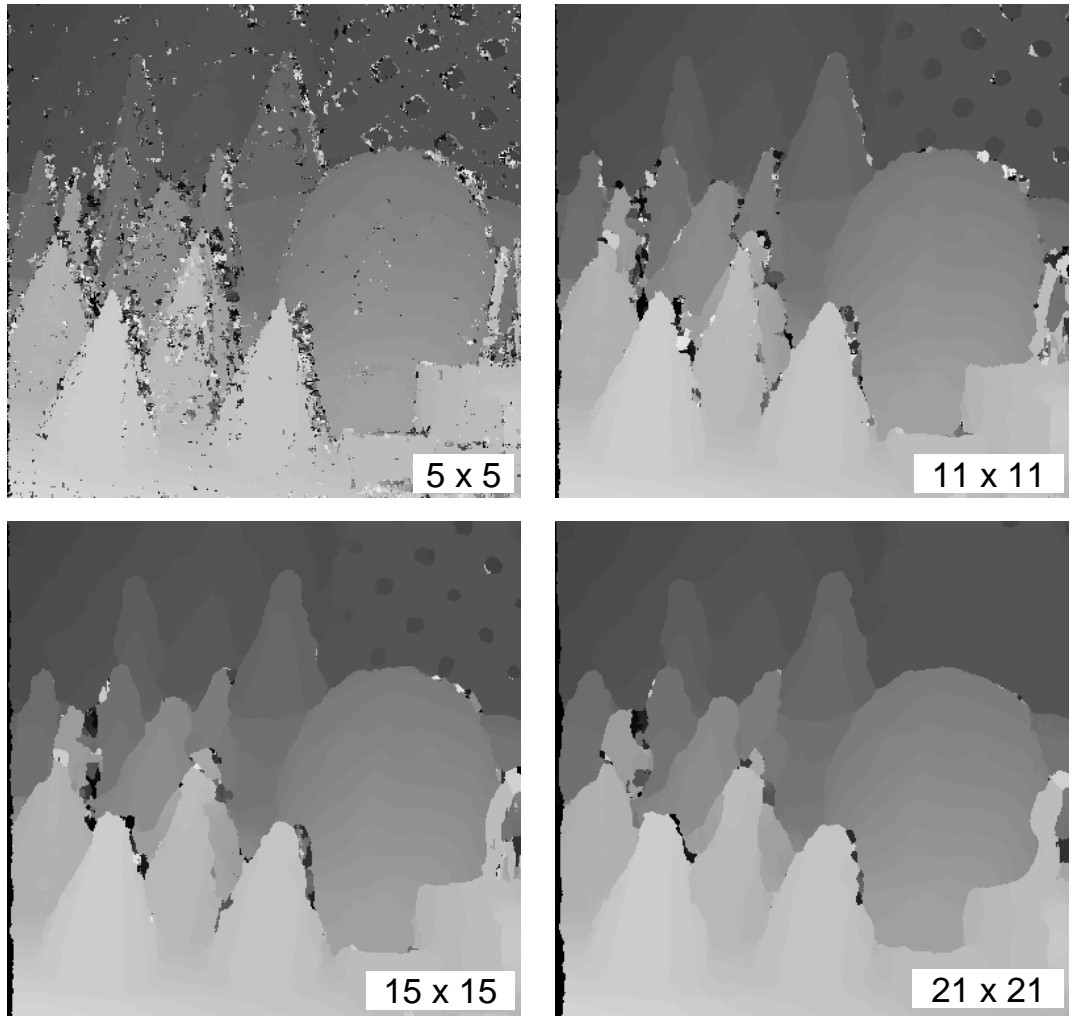

Figura B67: Execução do método Transformada Modificada 2 na imagem original 

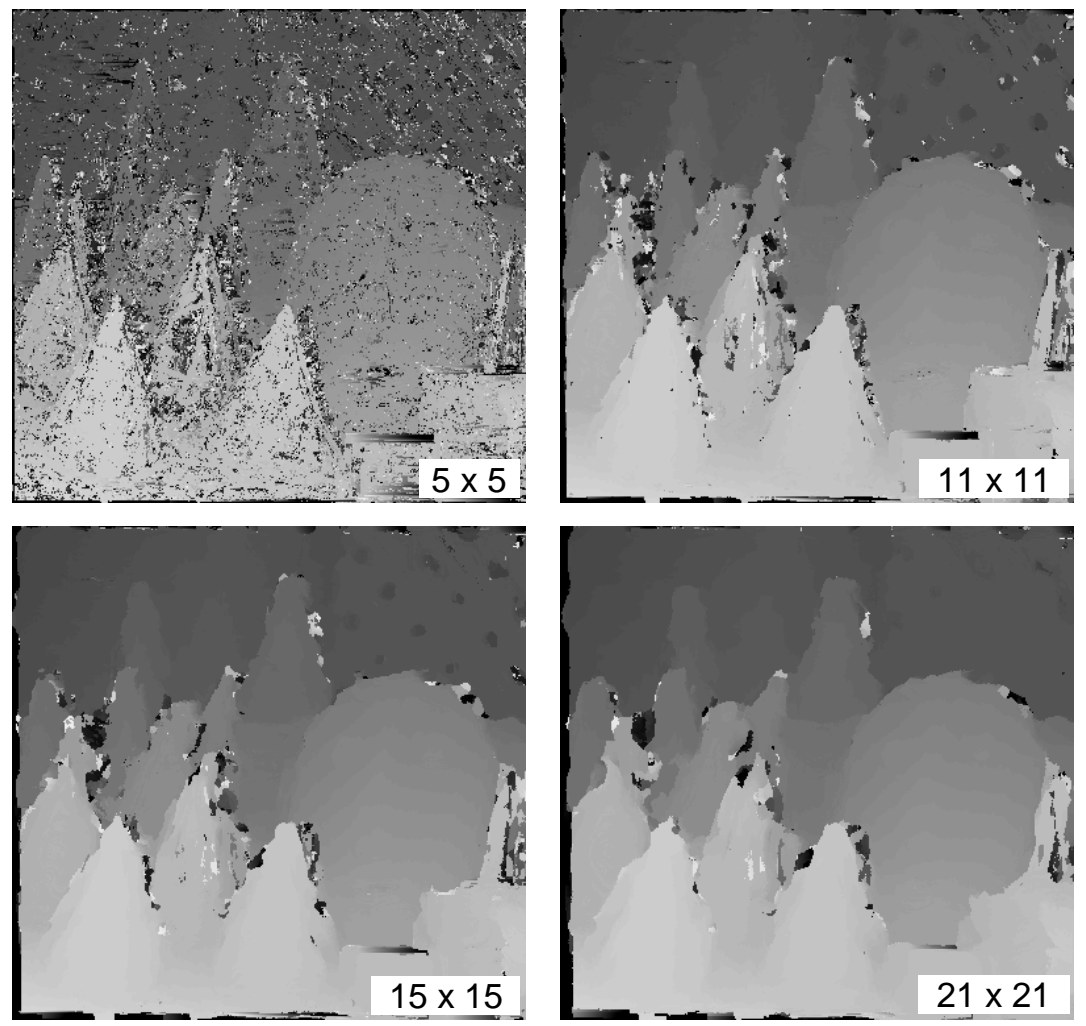

Figura B68: Execução do método Transformada Modificada 3 na imagem original
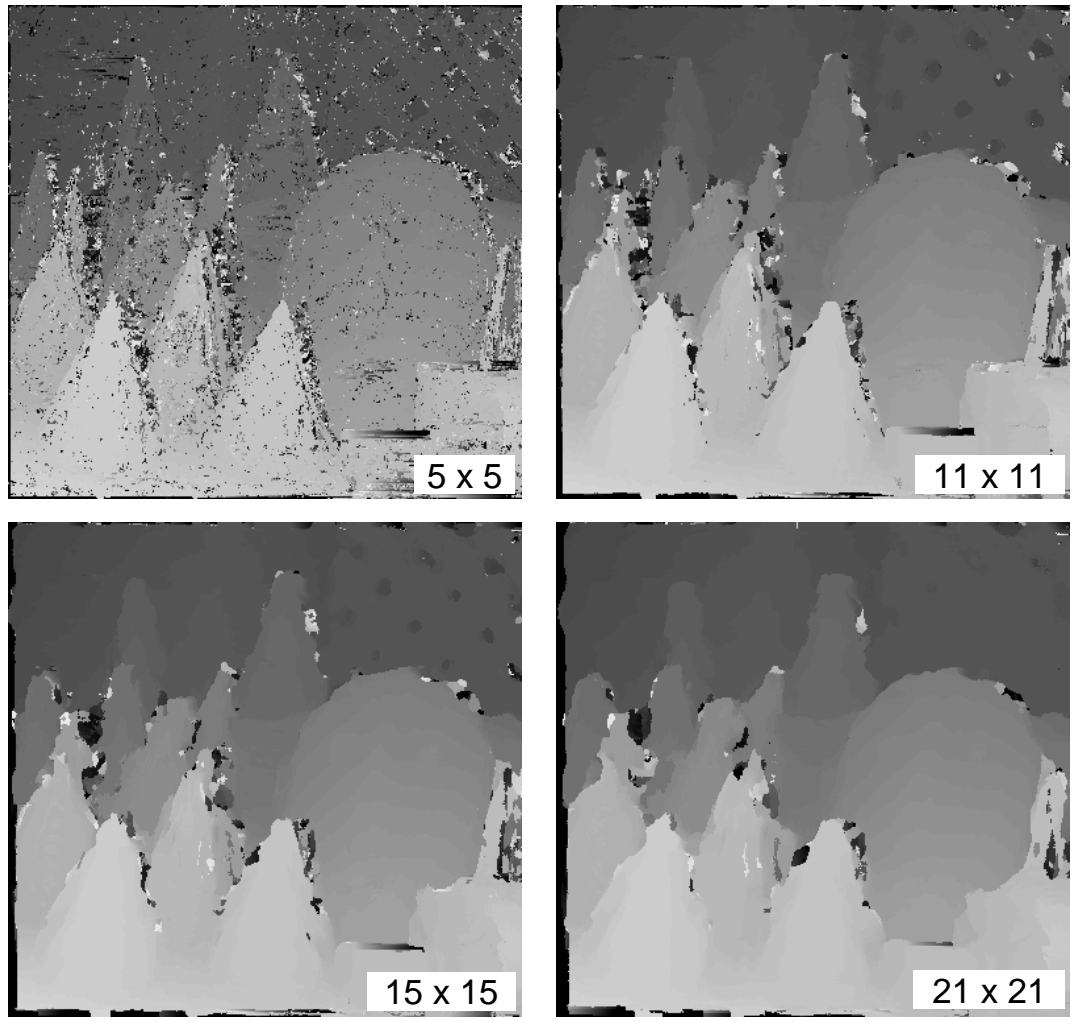

Figura B69: Execução do método Transformada Modificada 4 na imagem original 

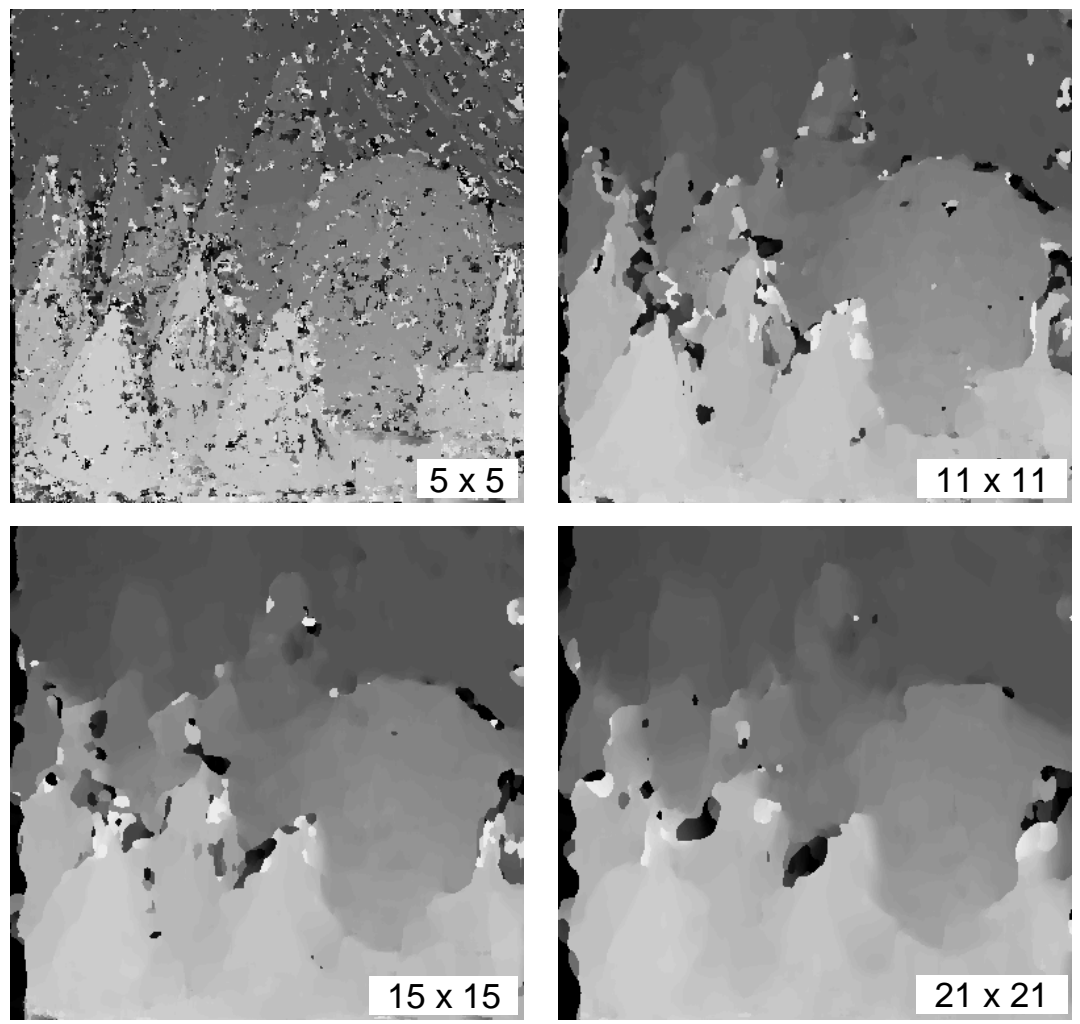

Figura B70: Execução do método Transformada Modificada 5 na imagem original 
Resultados da execução dos algoritmos com a imagem esquerda com $30 \%$ menos luminosidade
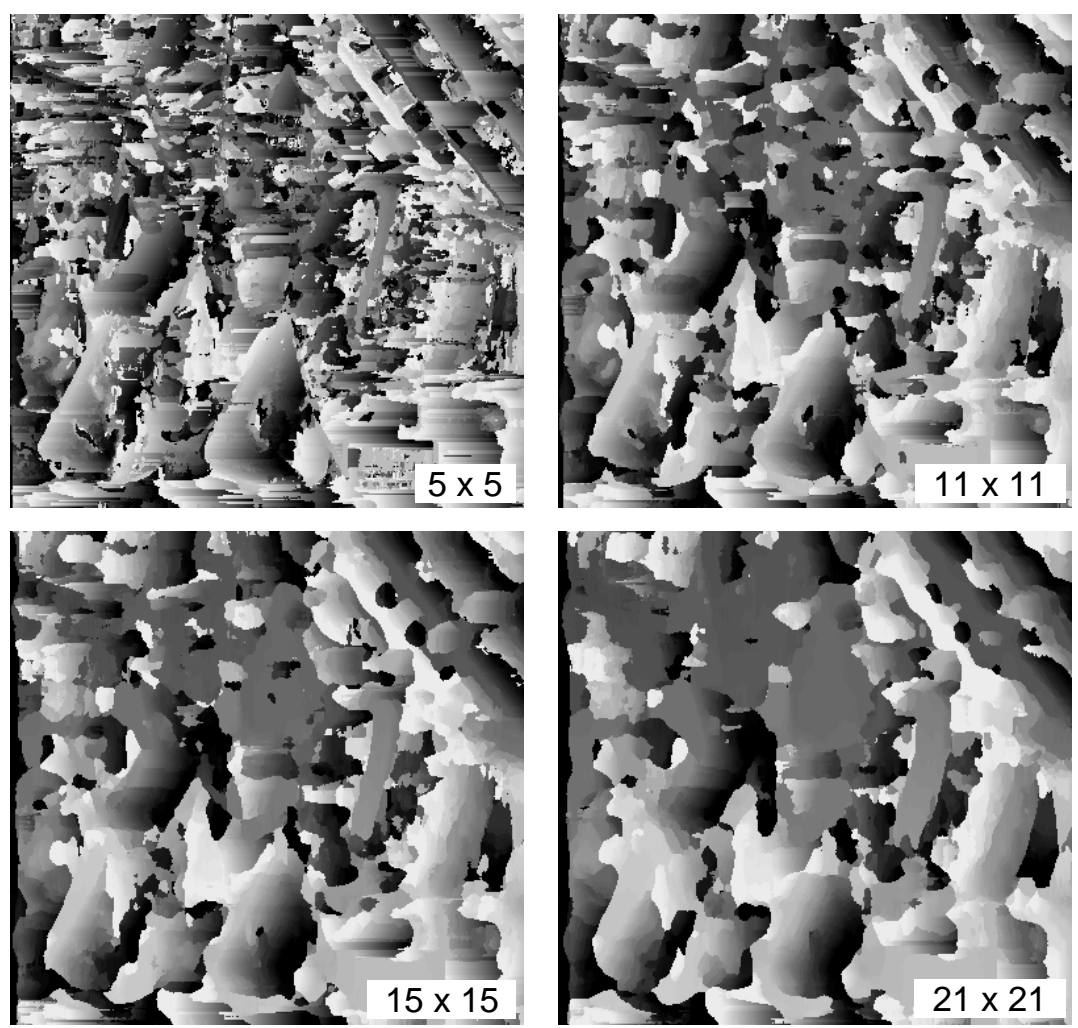

Figura B71: Execução do método Soma das Diferenças Absolutas na imagem com luminosidade $30 \%$ diferente 

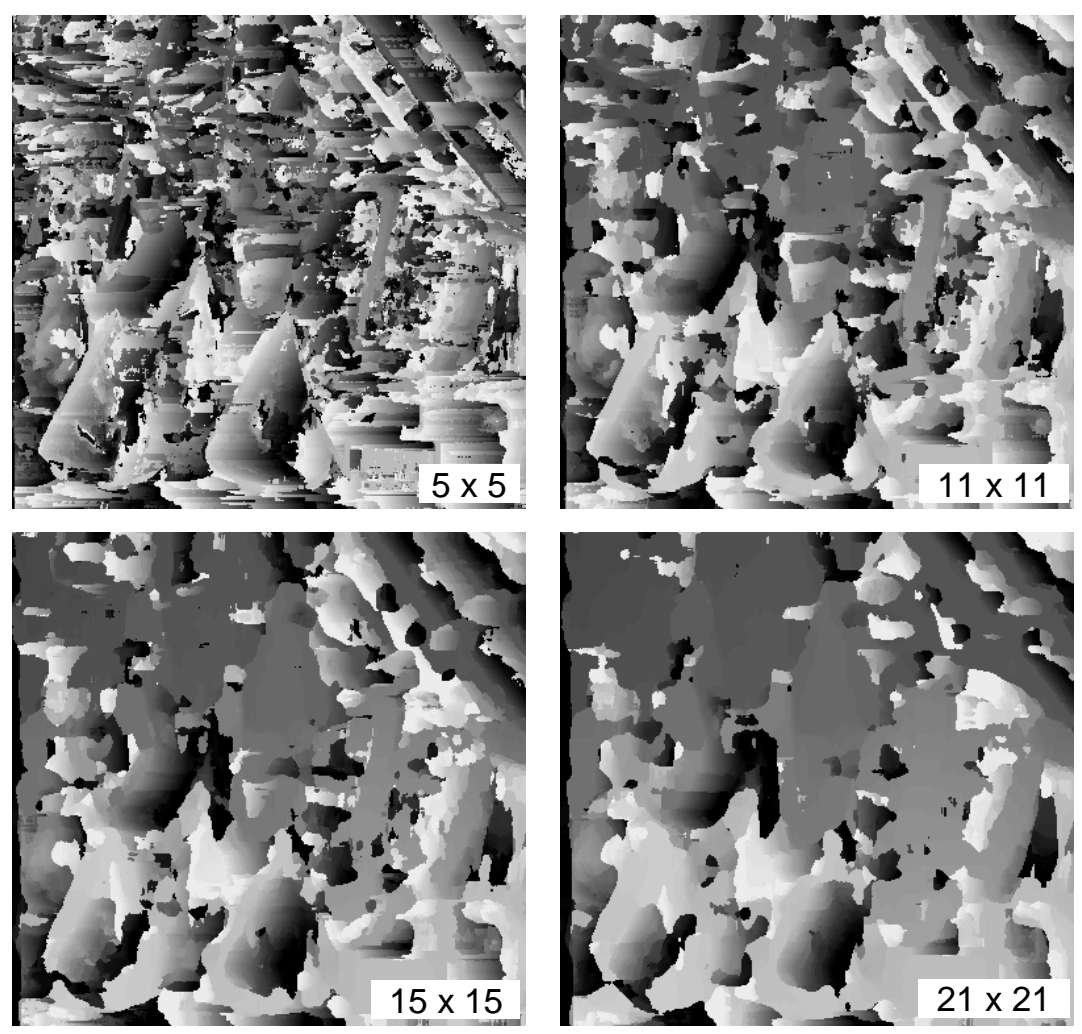

Figura B72: Execução do método Soma do Quadrado das Diferenças na imagem com luminosidade $30 \%$ diferente
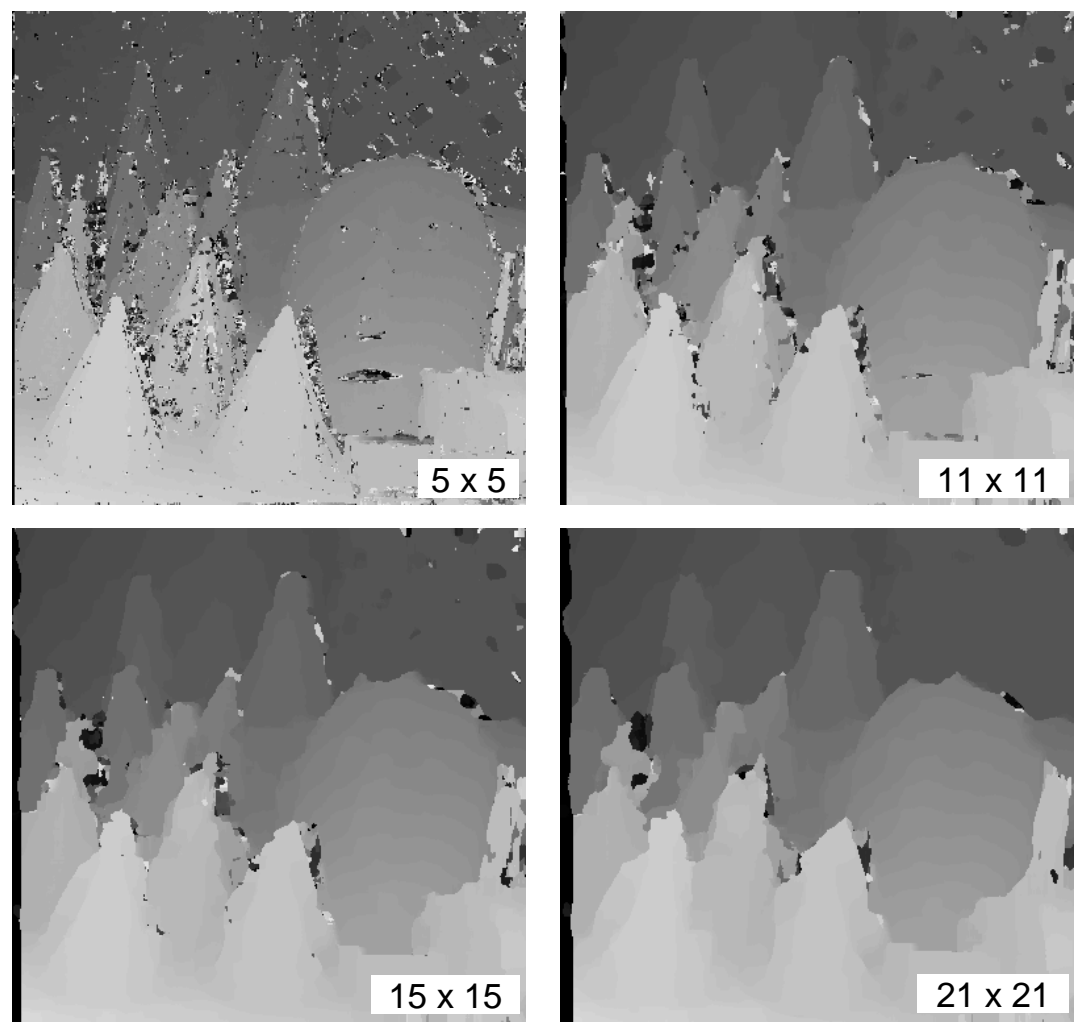

Figura B73: Execução do método Correlação Cruzada Normalizada na imagem com luminosidade $30 \%$ diferente 

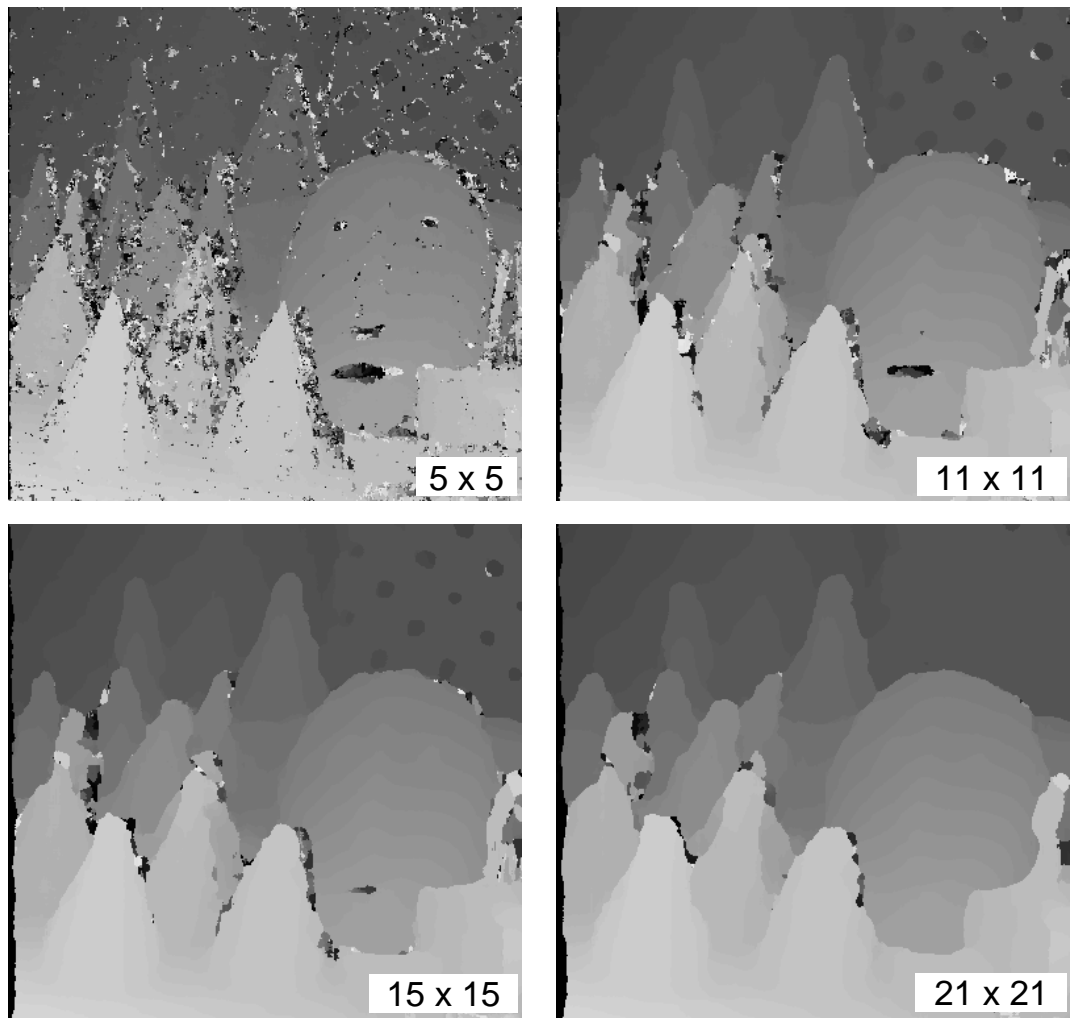

Figura B74: Execução do método Transformada Rank na imagem com luminosidade 30 \% diferente
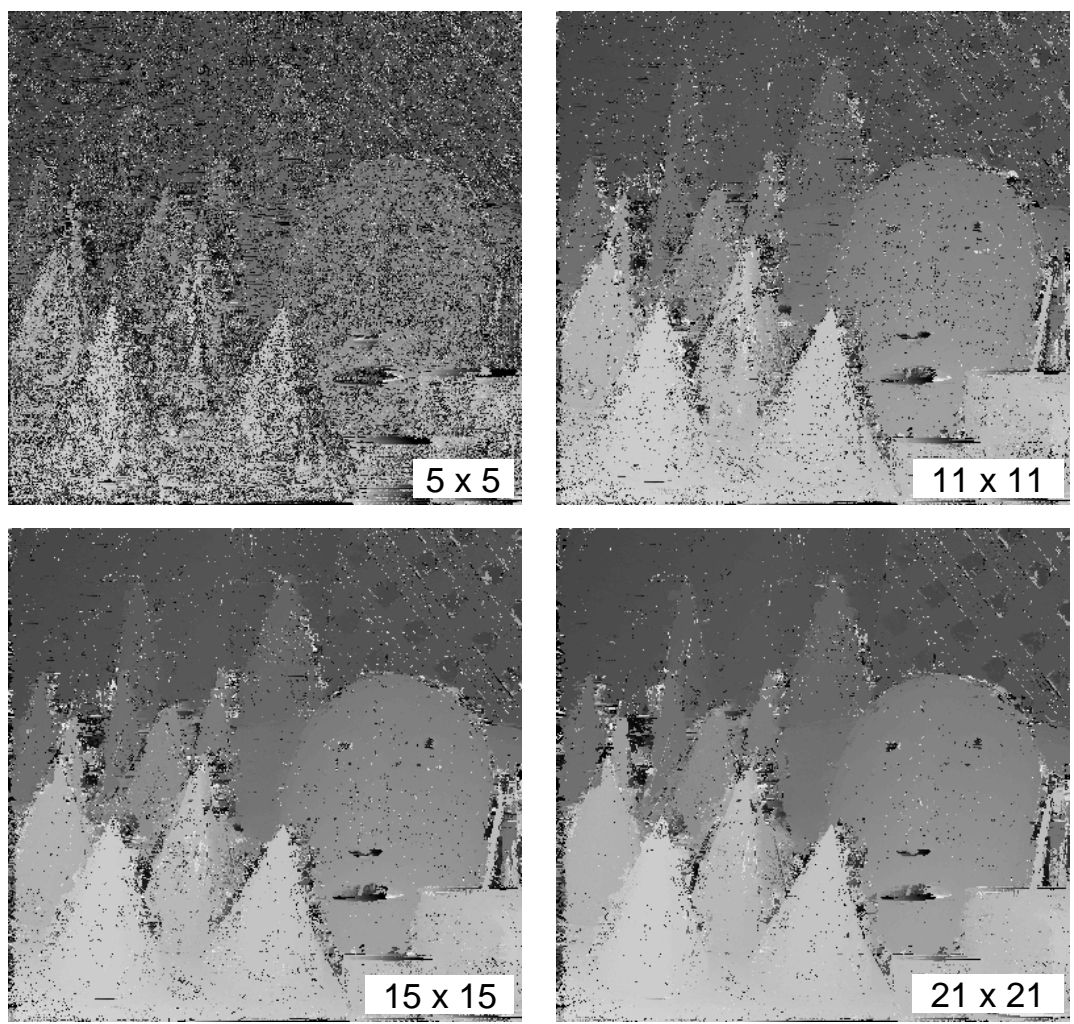

Figura B75: Execução do método Transformada Censo na imagem com luminosidade 30 \% diferente 

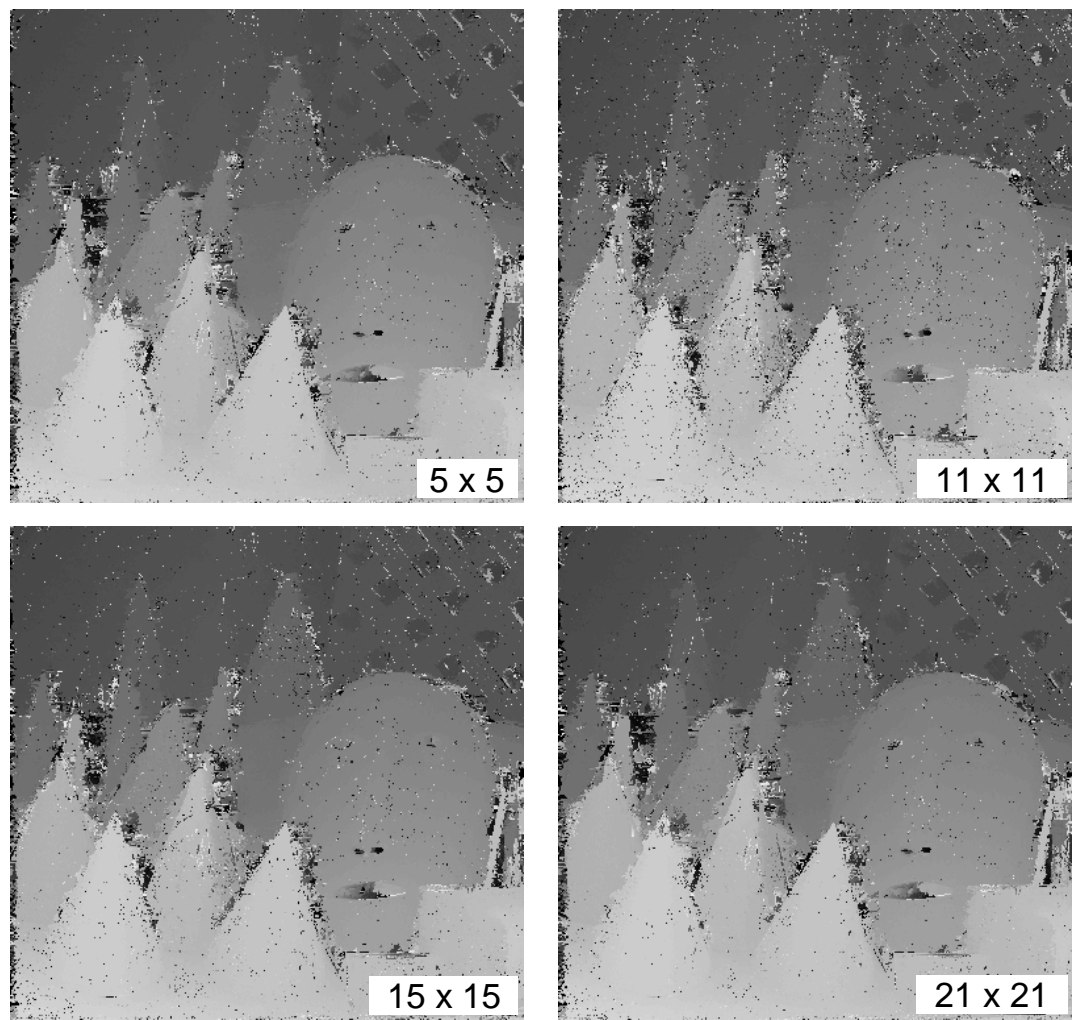

Figura B76: Execução do método Transformada Modificada 1 na imagem com luminosidade $30 \%$ diferente
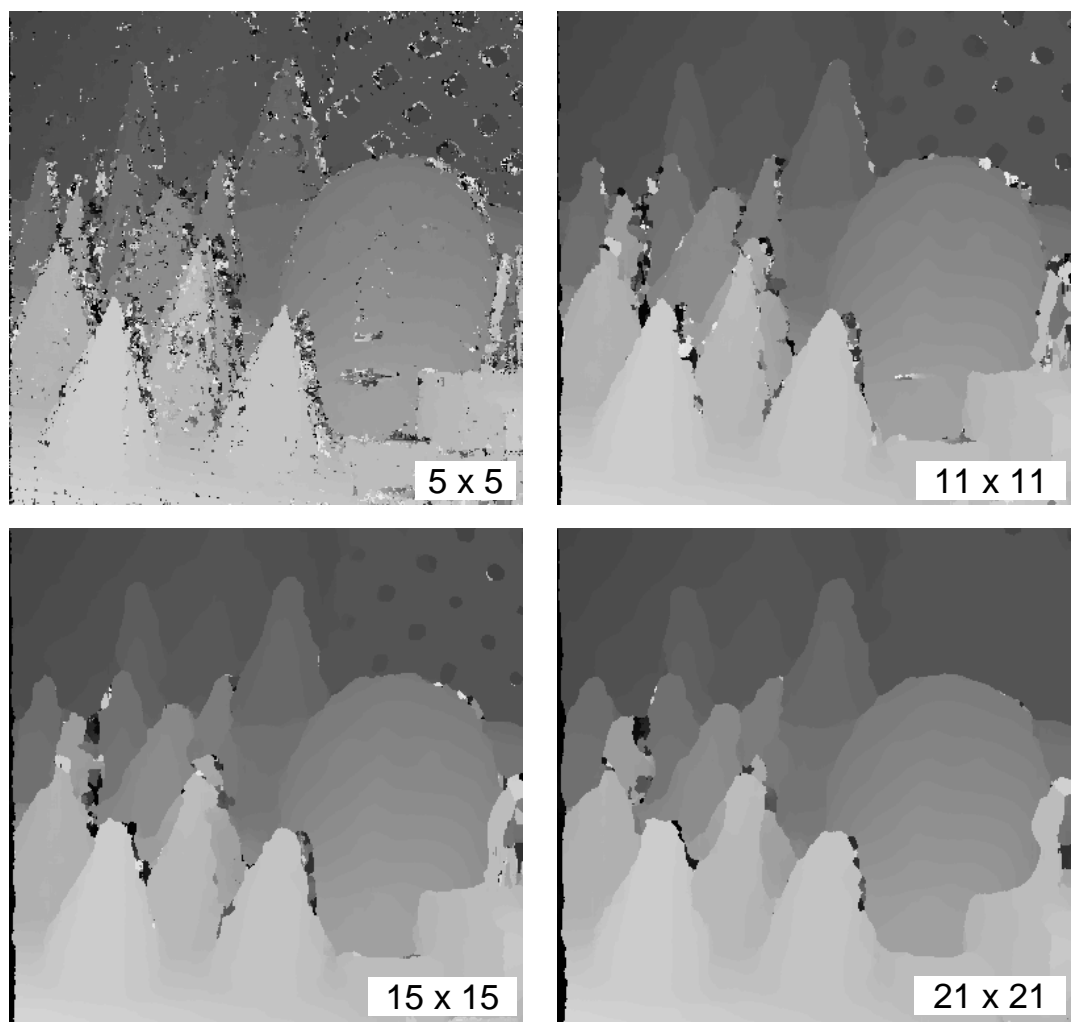

Figura B77: Execução do método Transformada Modificada 2 na imagem com luminosidade $30 \%$ diferente 

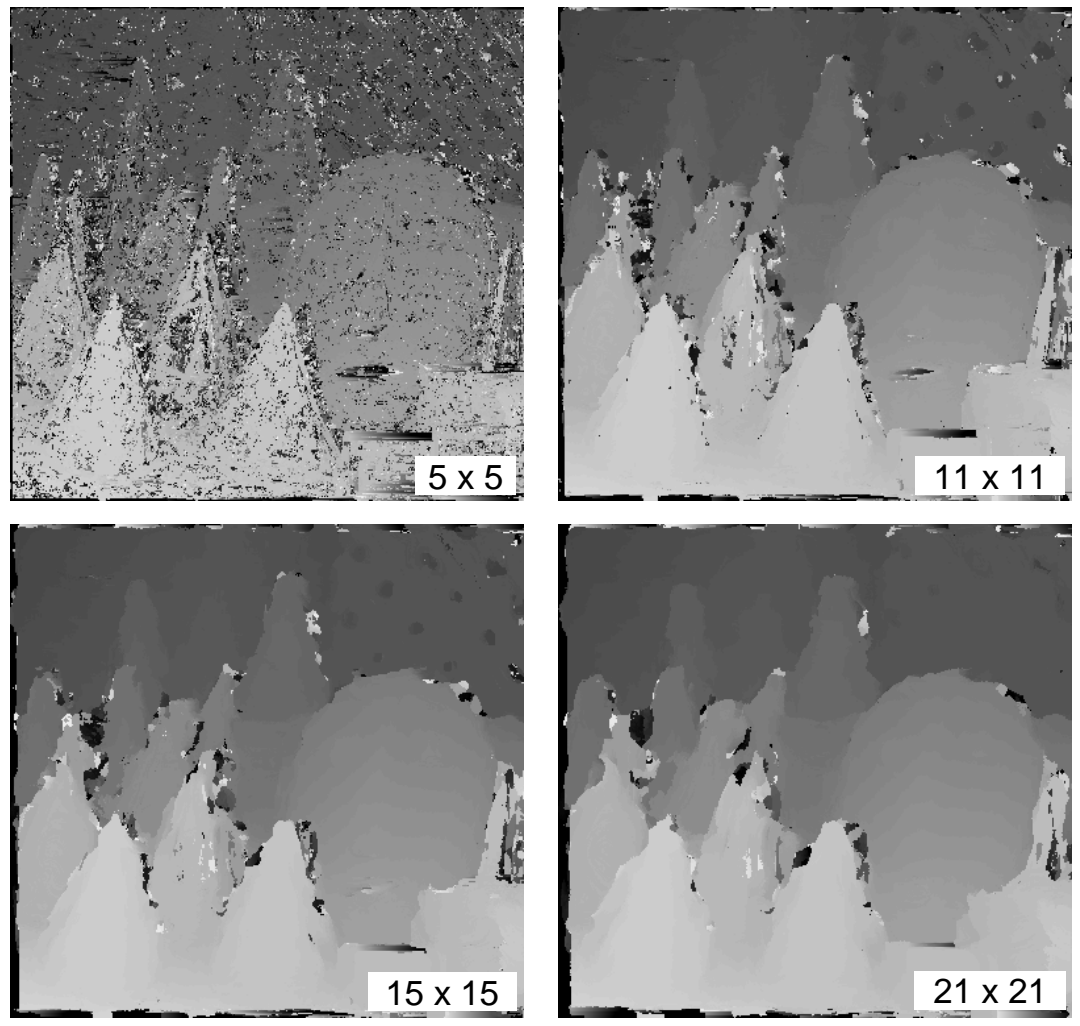

Figura B78: Execução do método Transformada Modificada 3 na imagem com luminosidade $30 \%$ diferente
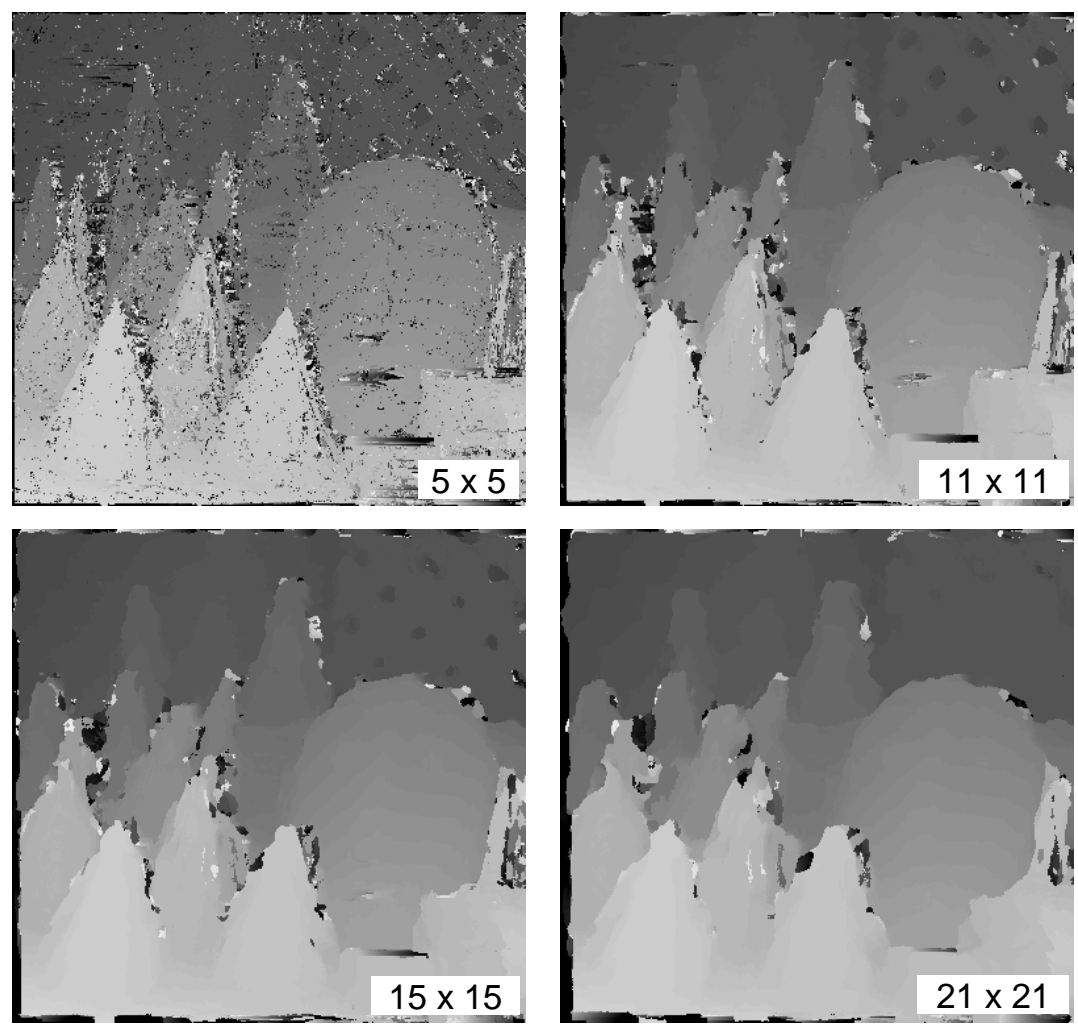

Figura B79: Execução do método Transformada Modificada 4 na imagem com luminosidade $30 \%$ diferente 

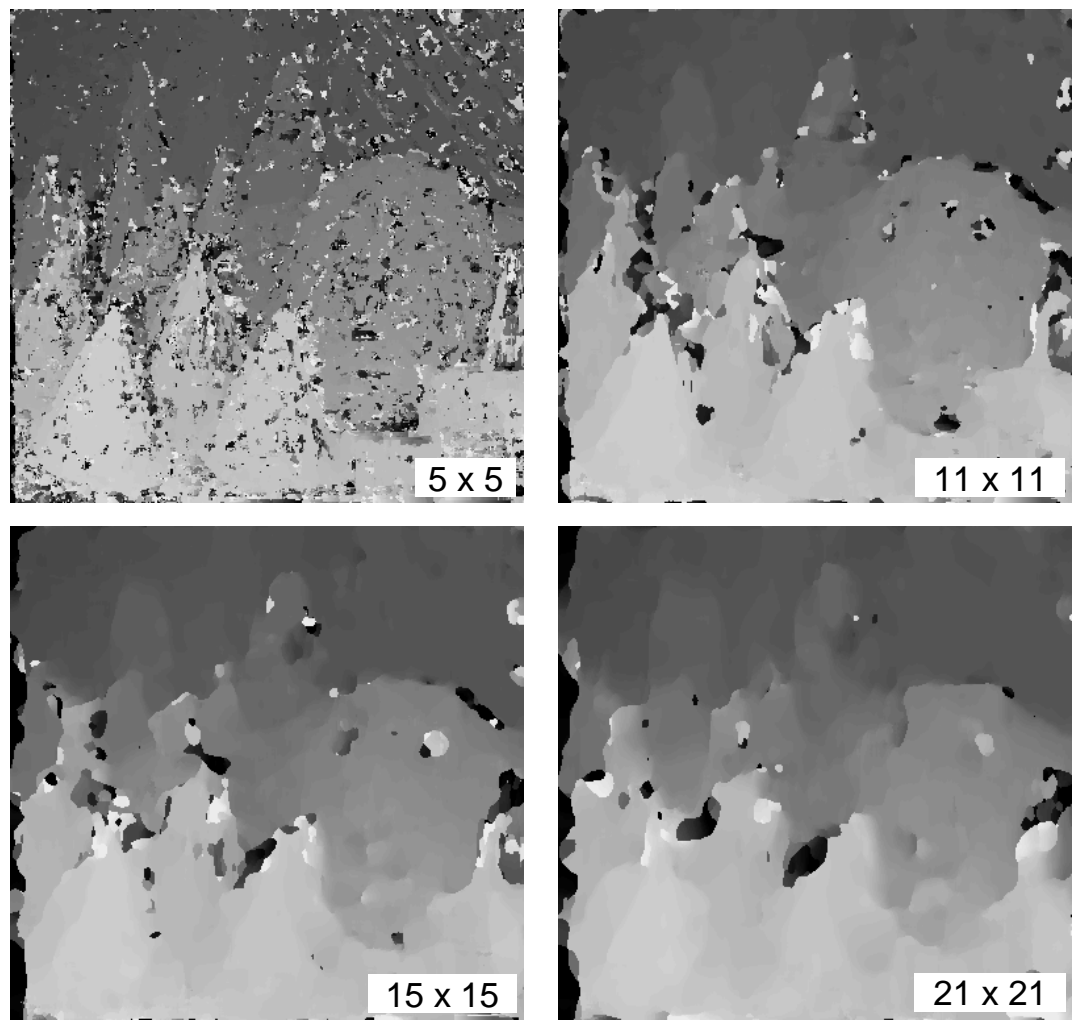

Figura B80: Execução do método Transformada Modificada 5 na imagem com luminosidade $30 \%$ diferente 
Resultados da execução dos algoritmos com a imagem contaminada por ruído de variância 200
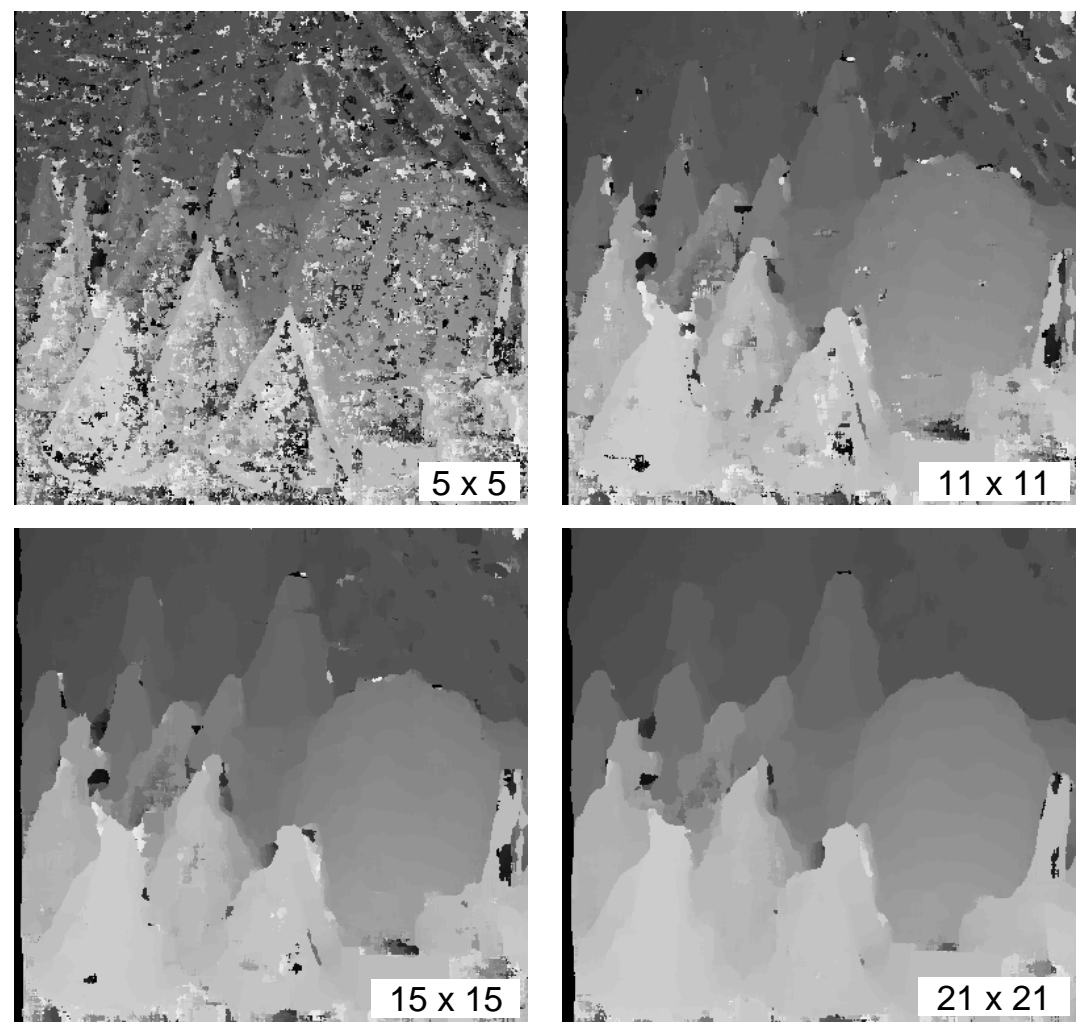

Figura B81: Execução do método Soma das Diferenças Absolutas na imagem com ruído de variância 200 

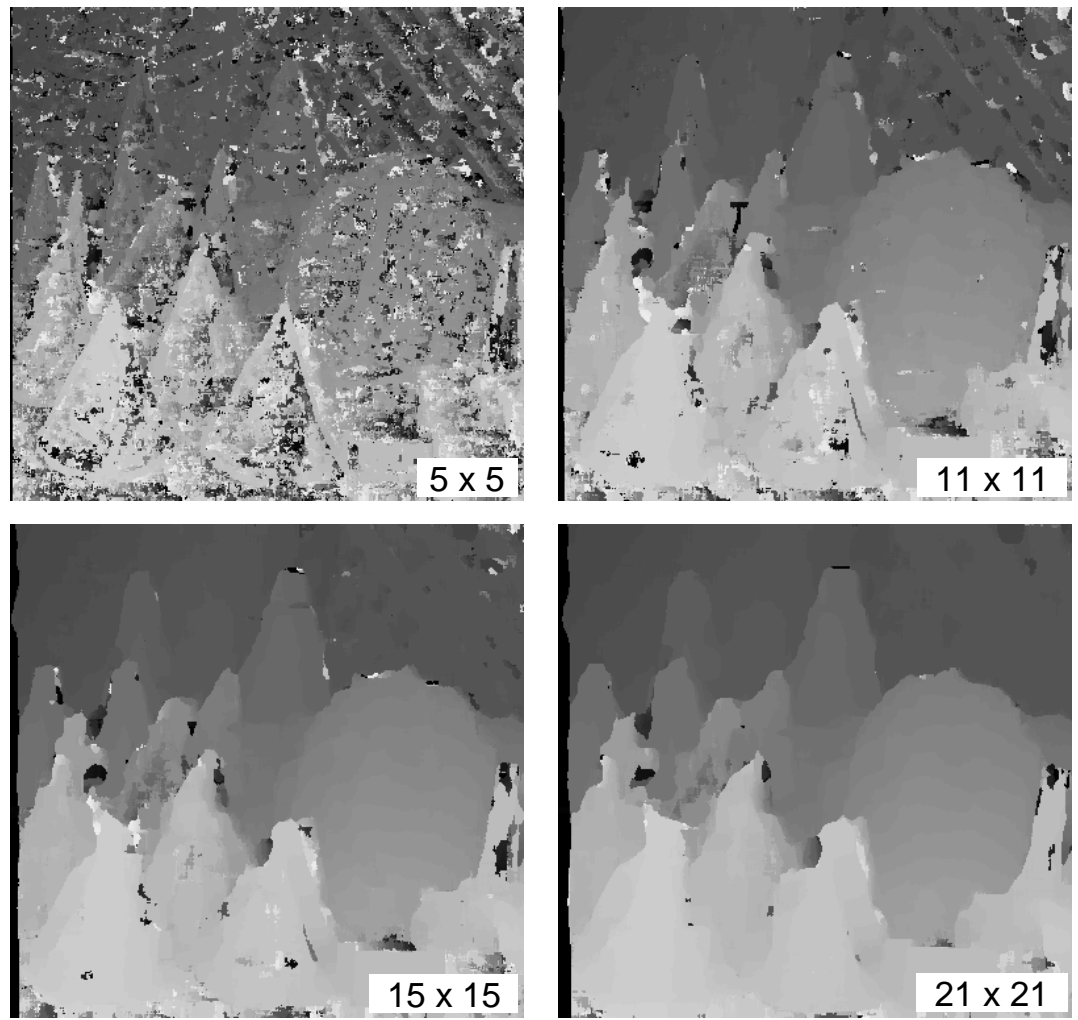

Figura B82: Execução do método Soma do Quadrado das Diferenças na imagem com ruído de variância 200
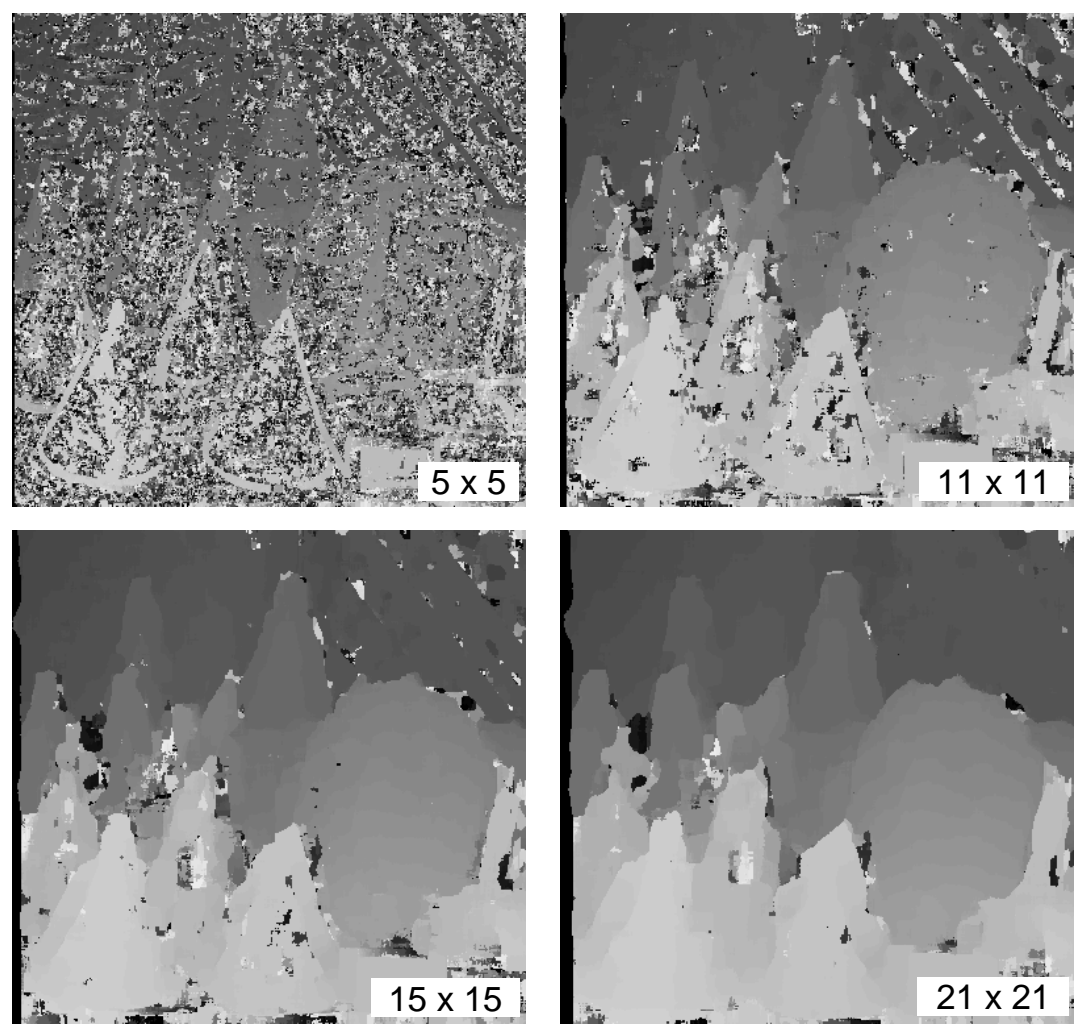

Figura B83: Execução do método Correlação Cruzada Normalizada na imagem com ruído de variância 200 

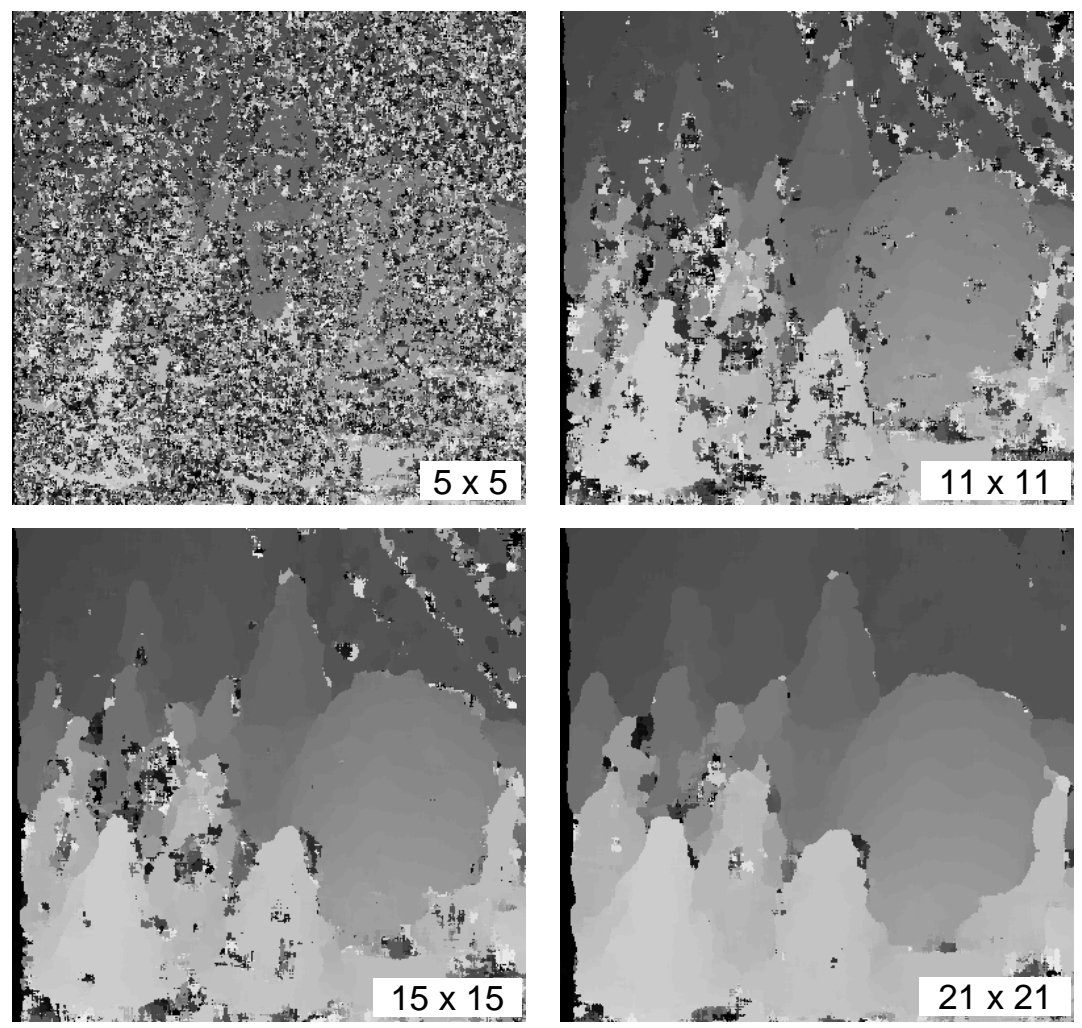

Figura B84: Execução do método Transformada Rank na imagem com ruído de variância 200
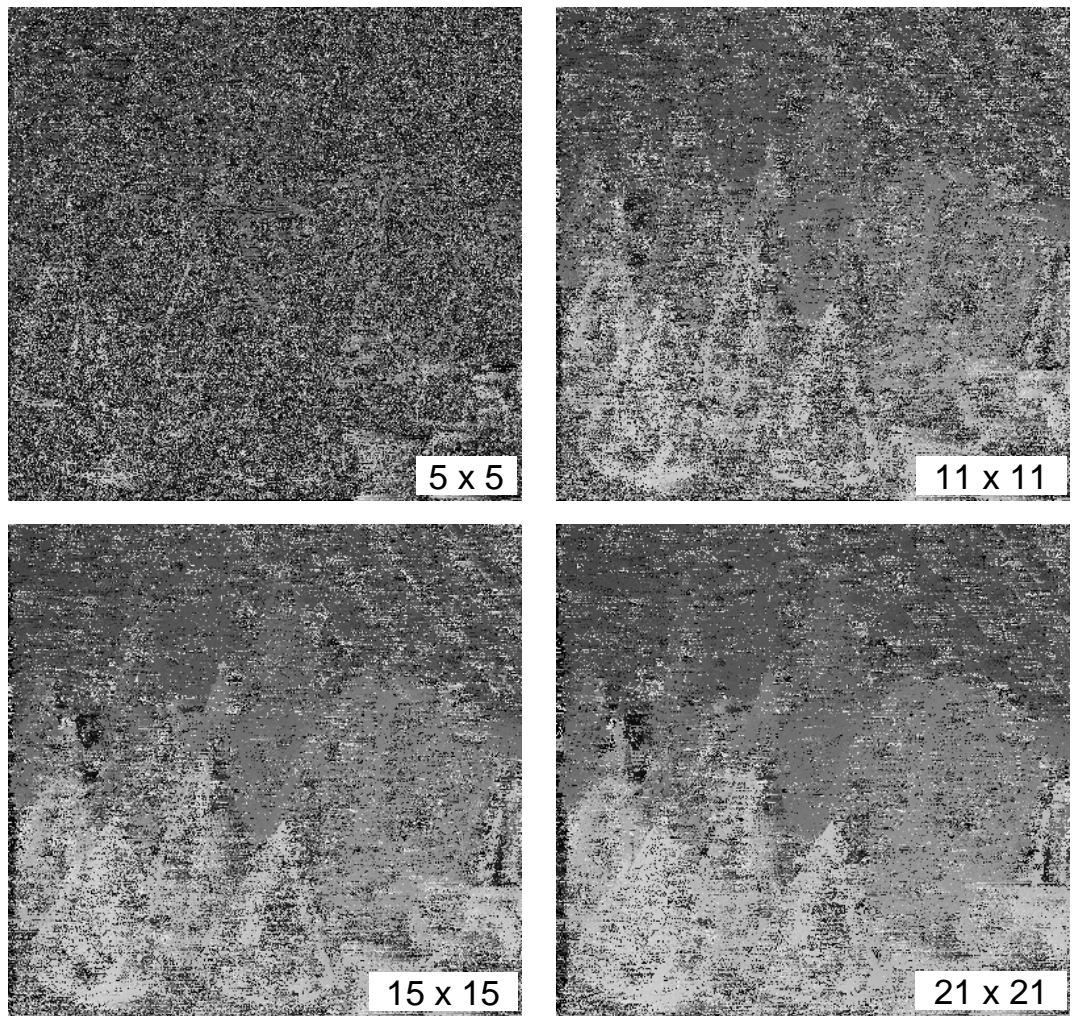

Figura B85: Execução do método Transformada Censo na imagem com ruído de variância 200 

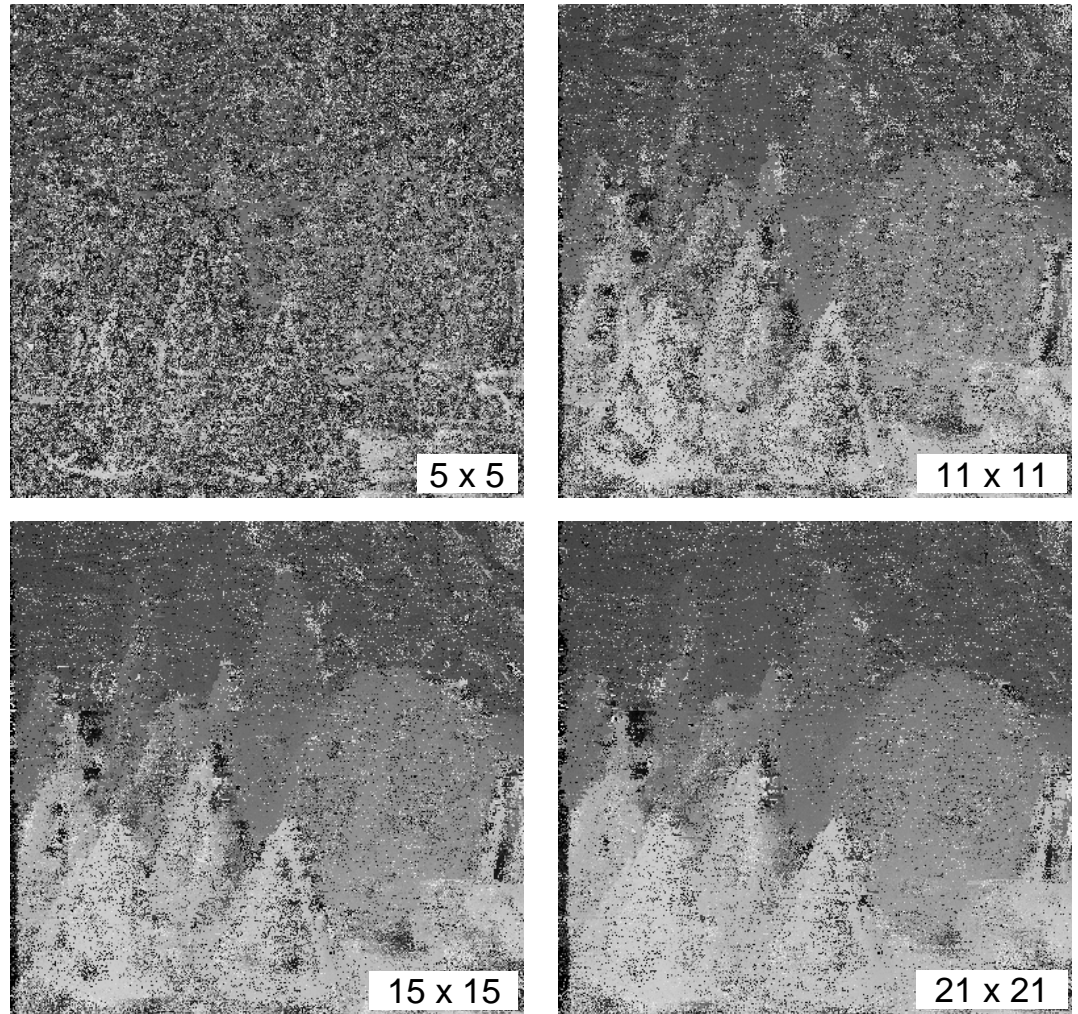

Figura B86: Execução do método Transformada Modificada 1 na imagem com ruído de variância 200
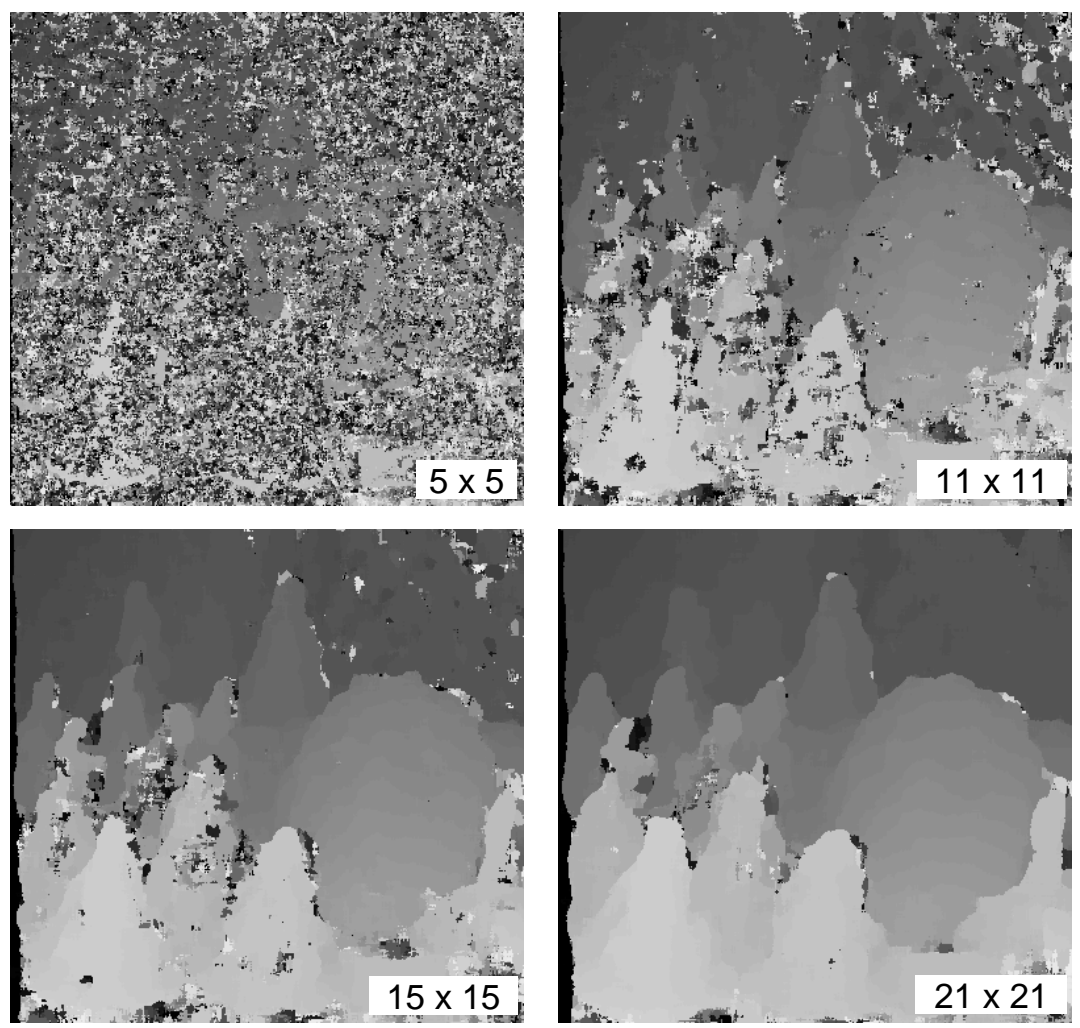

Figura B87: Execução do método Transformada Modificada 2 na imagem com ruído de variância 200 

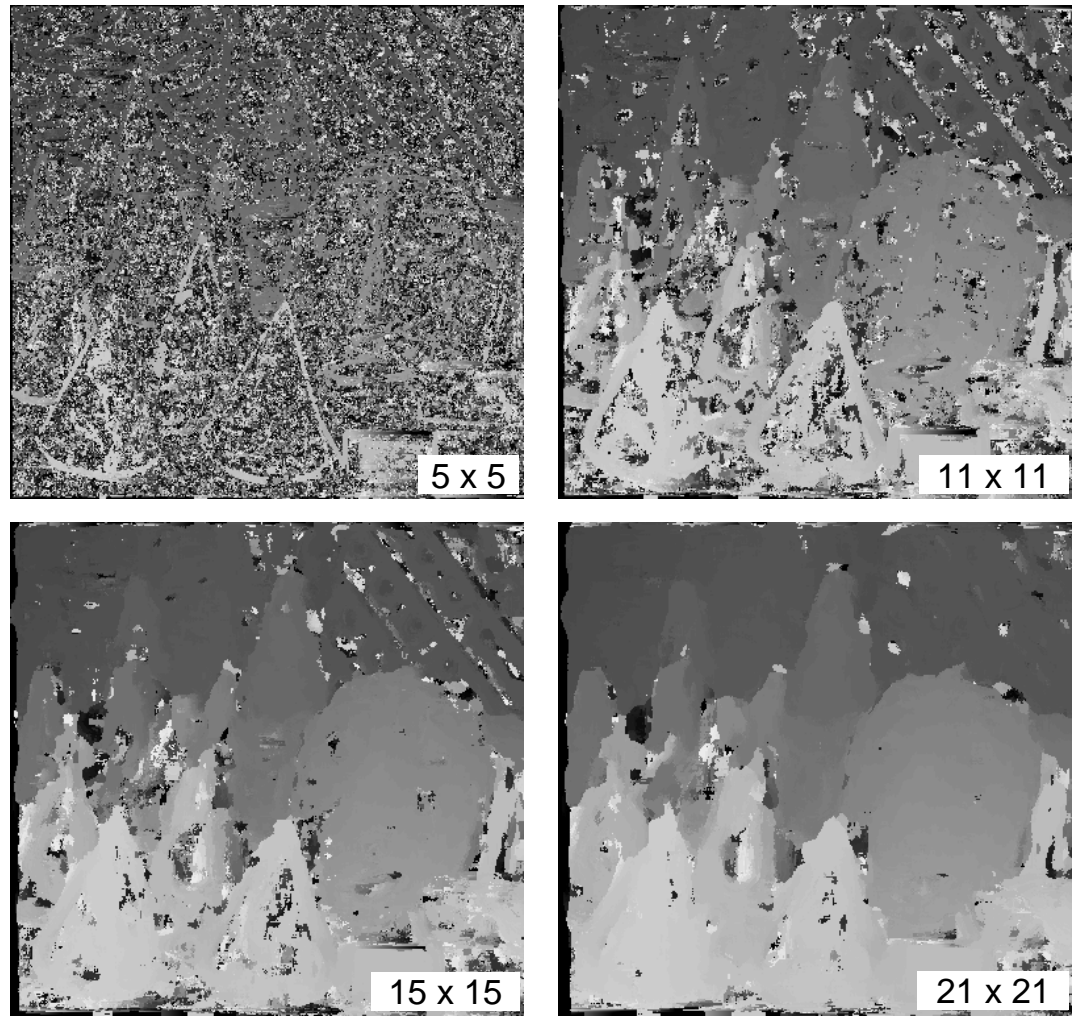

Figura B88: Execução do método Transformada Modificada 3 na imagem com ruído de variância 200
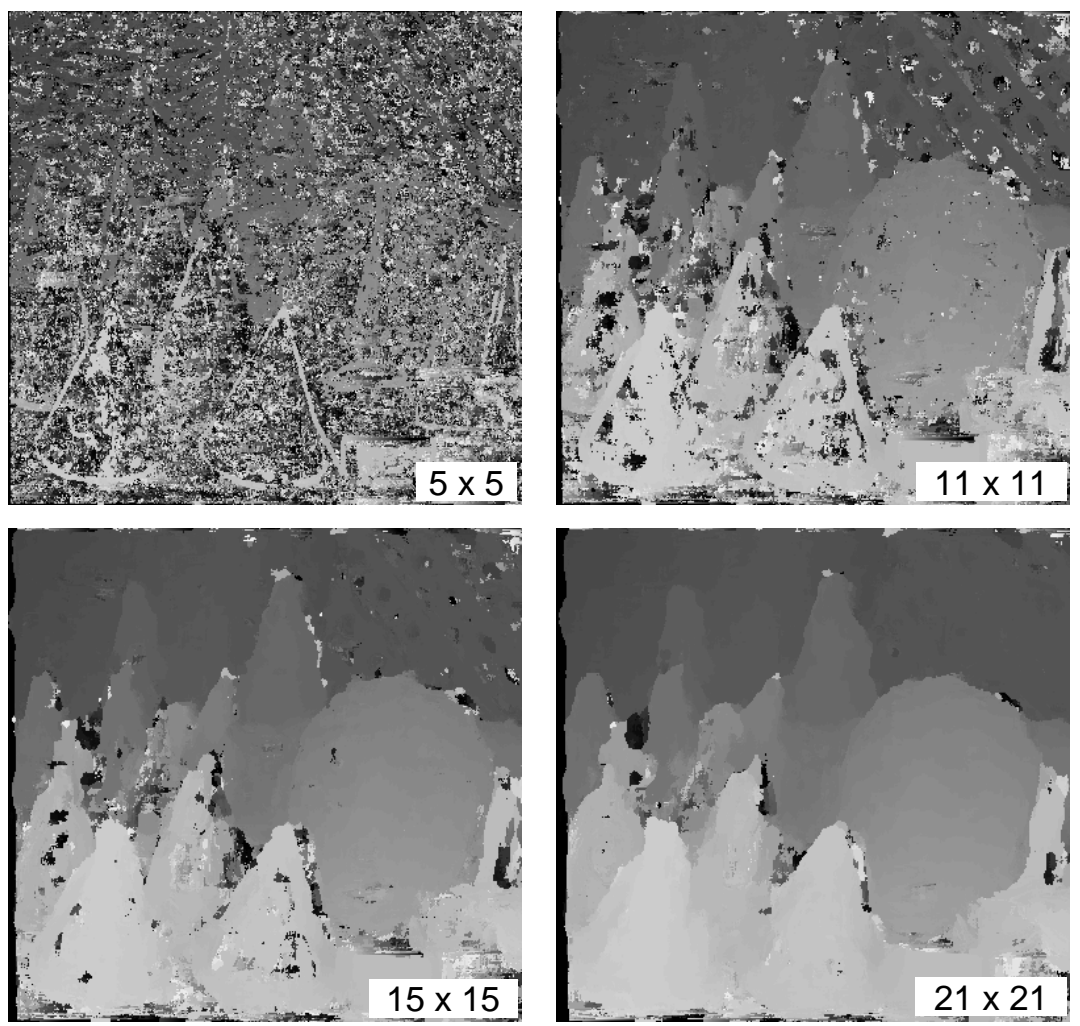

Figura B89: Execução do método Transformada Modificada 4 na imagem com ruído de variância 200 

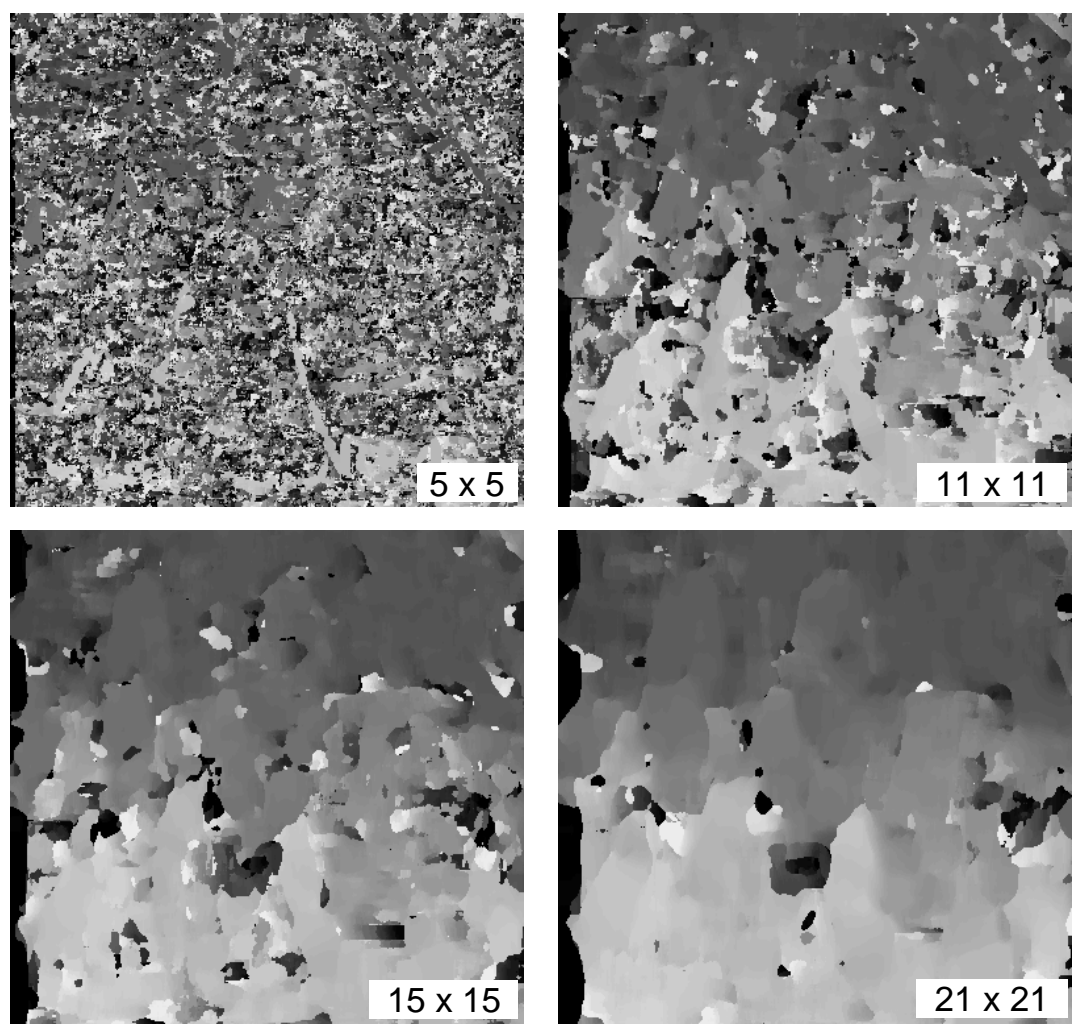

Figura B90: Execução do método Transformada Modificada 5 na imagem com ruído de variância 200 